Portland State University

PDXScholar

Winter 3-14-2019

\title{
Behavior of Non-Ductile Slender Reinforced Concrete Columns Retrofit by CFRP Under Cyclic Loading
}

Wisam Amer Aules

Portland State University

Follow this and additional works at: https://pdxscholar.library.pdx.edu/open_access_etds

Part of the Civil and Environmental Engineering Commons Let us know how access to this document benefits you.

Recommended Citation

Aules, Wisam Amer, "Behavior of Non-Ductile Slender Reinforced Concrete Columns Retrofit by CFRP Under Cyclic Loading" (2019). Dissertations and Theses. Paper 4804.

https://doi.org/10.15760/etd.6688

This Dissertation is brought to you for free and open access. It has been accepted for inclusion in Dissertations and Theses by an authorized administrator of PDXScholar. Please contact us if we can make this document more accessible: pdxscholar@pdx.edu. 
Behavior of Non-Ductile Slender Reinforced Concrete Columns Retrofit by CFRP under Cyclic Loading

by

Wisam Amer Aules

A dissertation submitted in partial fulfillment of the requirements for the degree of

Doctor of Philosophy

in

Civil and Environmental Engineering

Dissertation Committee:

Franz Rad, Chair

Peter Dusicka

Thomas Schumacher

Hormoz Zareh

Portland State University

2019 


\section{(C) 2019 Wisam Amer Aules}




\begin{abstract}
In the Middle East region and many countries in the world, older reinforced concrete (RC) columns are deemed to be weak in seismic resistance because of their low amount of reinforcement, low grades of concrete, and large spacing between the transverse reinforcement. The capacity of older RC columns that are also slender is further reduced due to the secondary moments. Appropriate retrofit techniques can improve the capacity and behavior of concrete members. In this study, externally bonded Carbon Fiber Reinforced Polymer (CFRP) retrofit technique was implemented to improve the behavior of RC columns tested under constant axial load and cyclic lateral load. The study included physical testing of five half-scale slender RC columns, with shear span to depth ratio of 7. Three specimens represented columns in a 2-story, and two specimens represented columns in a 4-story building. All specimens had identical cross sections, reinforcement detail, and concrete strength. Two specimens were control, two specimens were retrofit with CFRP in the lateral direction, and one specimen retrofit in the longitudinal and lateral directions. A computer model was created to predict the lateral load-displacement relations. The experimental results show improvement in the retrofit specimens in strength, ductility, and energy dissipation. The effect of retrofitting technique applied to two full-scale prototype RC buildings, a 2-story and a 4-story building located in two cities in Iraq, Baghdad and Erbil, was determined using SAP2000.
\end{abstract}




\section{Acknowledgments}

First of all, my gratitude is offered to Allah (God) for giving me the faith and capability to complete this research project, and my ongoing education. I would like to express my most sincere gratitude to Dr. Franz Rad for his guidance, support, and encouragement during the course of this research. Also, I extend my thanks Dr. Peter Dusicka, Dr. Thomas Schumacher, and Dr. Hormoz Zareh for serving on my dissertation committee, and for their helpful comments. My deep gratitude goes to my parents, sisters, and brothers for their prayers, and support. Special thanks to my wife for her encouragement, support and patience, and thanks to my wonderful children Maryam, Reem, Samer, and Sofia. Special thanks to my friends of graduate students who helped with the experimental part of this research project, especially Hosam Al-Azzawi, Qabas Hameed, Yasir Saeed, Anas Yosefani, Ali Hafiz, Salih Mahmood, Qusay Aqooly, Anwer Mohammed, Hayder Al-Khafaji, and Ali Al-Zerkani. Furthermore, I extend my thanks to Mr. Tom Bennett, the lab expert and technician, for his efforts in instrumentation set-up and testing. My sincere thanks also go to Mr. Robert Turpin for his help with manufacturing the loading frame.

I would also acknowledge the Higher Committee of Education Development in Iraq (HCED) for sponsoring my PhD program at Portland State University, and my gratitude is extended to my home university in Iraq, Tikrit University, for their support. 


\section{Table of Contents}

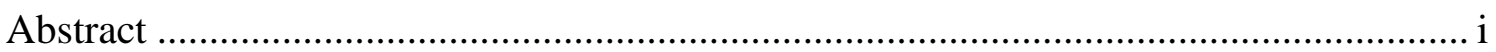

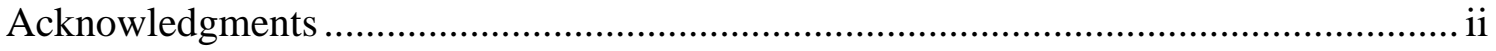

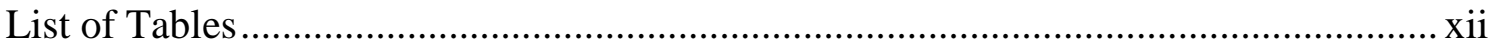

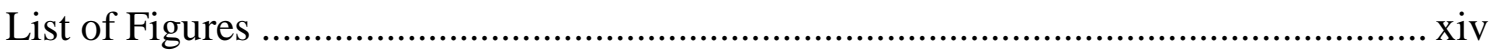

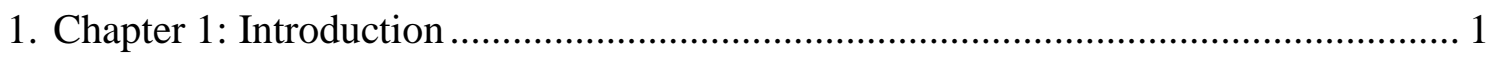

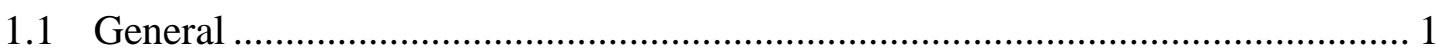

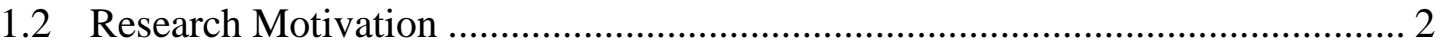

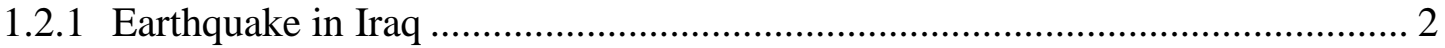

1.2.2 Reinforced Concrete Buildings with Deficient Slender Columns.................... 5

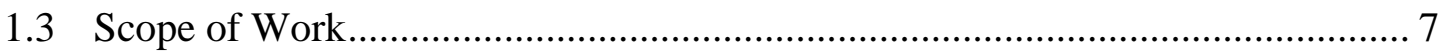

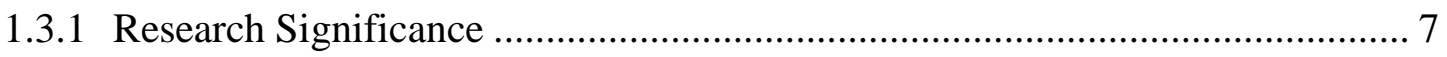

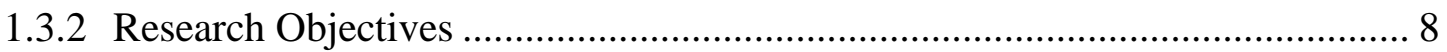

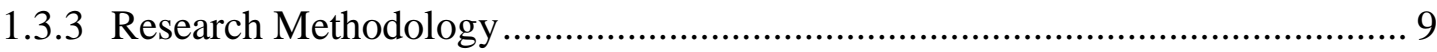

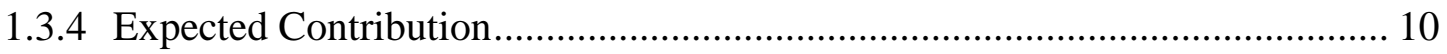

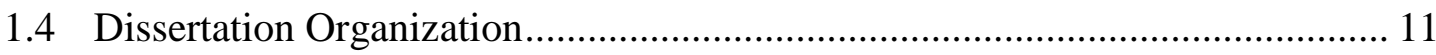

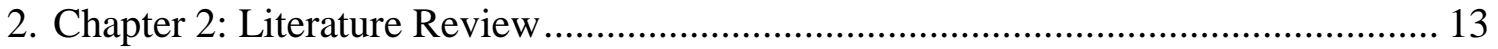

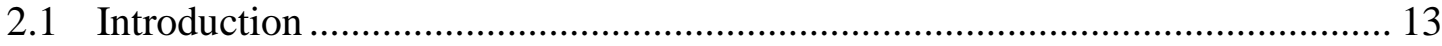


2.2 CFRP Confined Rectangular Concrete

2.3 Axial Stress-Strain Model for CFRP Confined Concrete Columns ..................... 18

2.3.1 Monotonic Stress-Strain Model.............................................................. 19

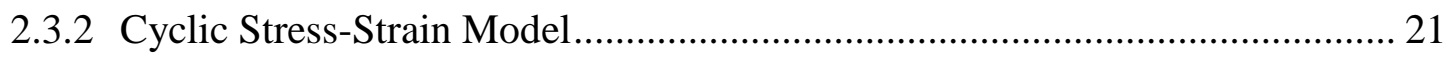

2.4 CFRP-Strengthened Rectangular RC Column Tested under a Combination of

Constant Axial Load and Cyclic Lateral Load ........................................................ 22

2.4.1 Lateral Confinement for Rectangular RC Columns ........................................ 23

2.4.2 Flexural Strengthening of Rectangular RC Columns..................................... 24

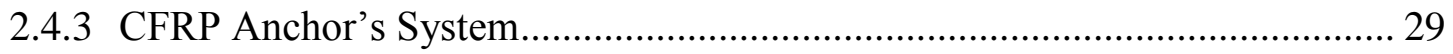

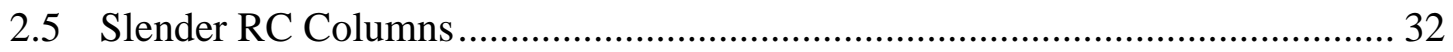

2.5.1 Effect of the Second-Order Moments P- $\Delta$..................................................... 34

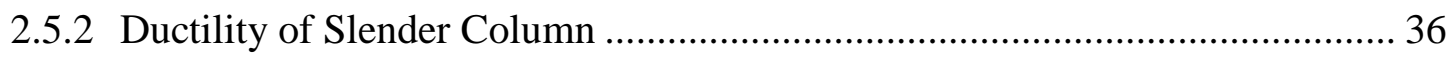

2.5.3 Strengthening RC Slender Columns with CFRP............................................ 38

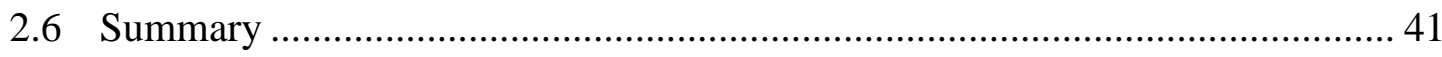

3. Chapter 3: Background …………………………............................................. 42

3.1 Reinforced Concrete Buildings with Deficient Columns.................................... 42

3.2 Slender Reinforced Concrete Columns .............................................................. 44

3.3 Retrofit Objective for Non-Ductile RC Columns ............................................. 45

3.4 CFRP Retrofit for Rectangular Column ........................................................... 47 


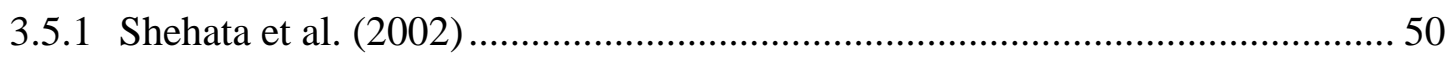

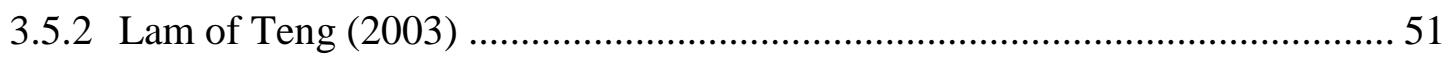

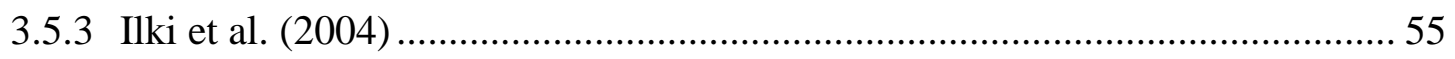

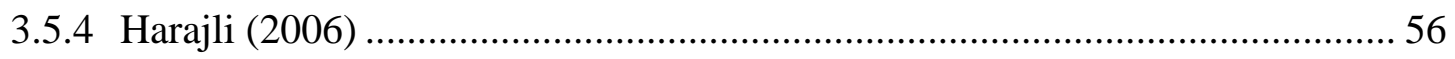

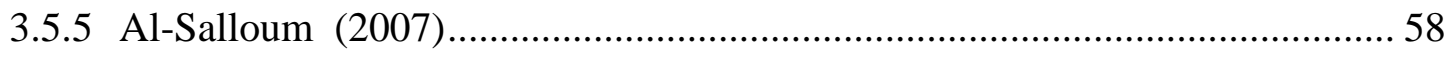

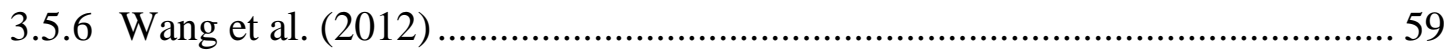

3.6 CFRP Retrofit Design for Seismic Strengthening ...................................... 61

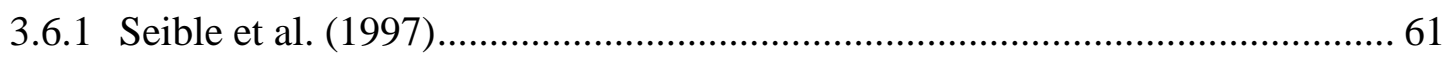

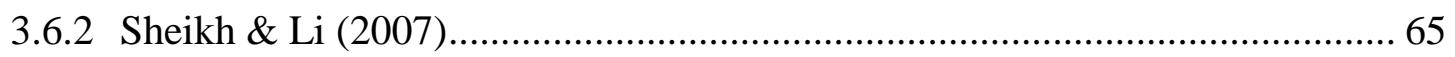

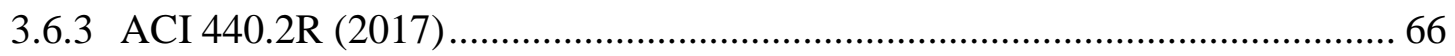

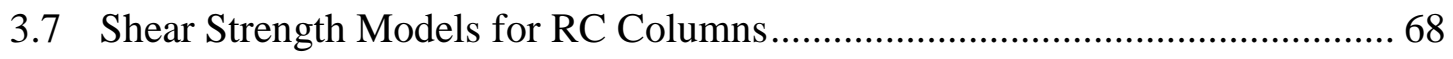

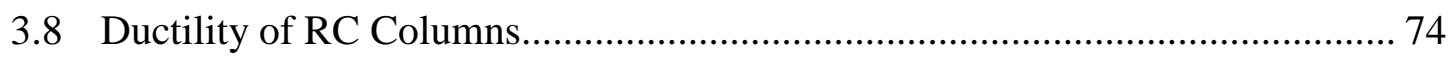

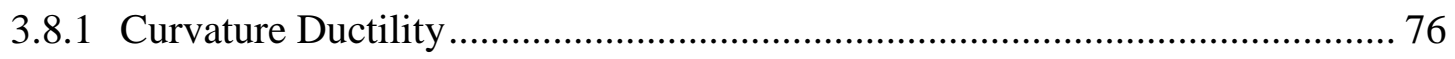

3.8.1.1 Yield, Ultimate, and Plastic Curvature............................................. 76

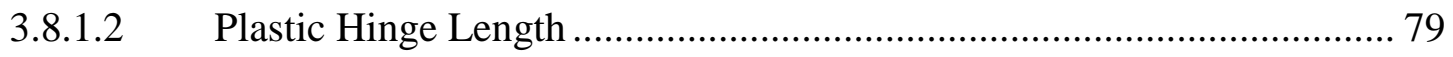

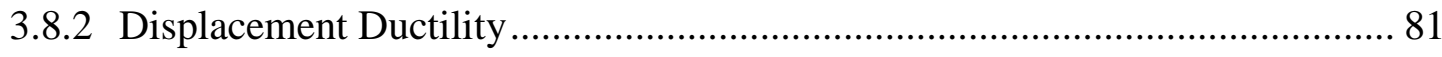

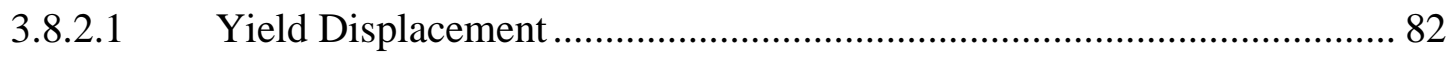

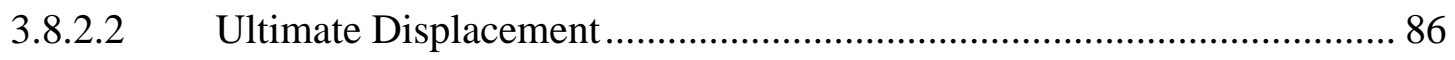




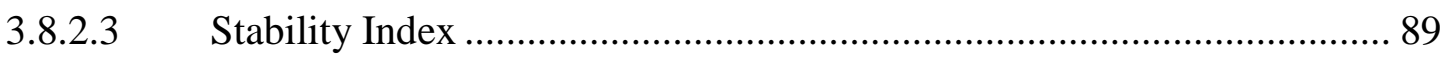

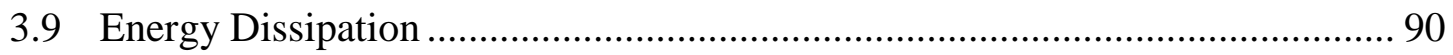

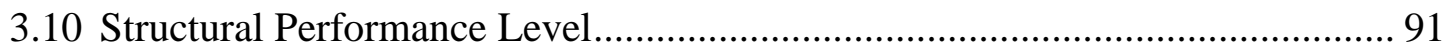

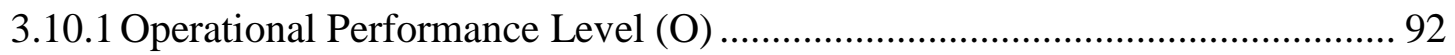

3.10.2 Immediate Occupancy Performance Level (IO) ...................................... 93

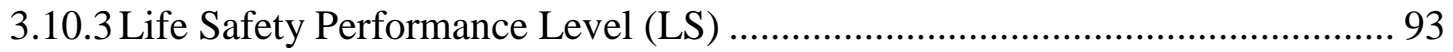

3.10.4 Collapse Prevention Performance Level (CP) ........................................... 93

3.11 Seismic Rehabilitation and Basic Safety Objective ...................................... 94

3.12 Existing Buildings Capacities and Retrofit Philosophy ................................ 94

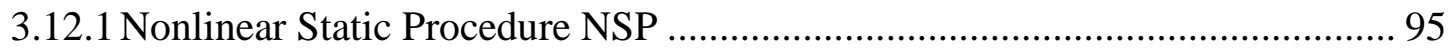

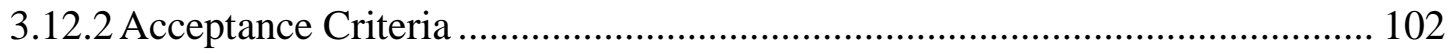

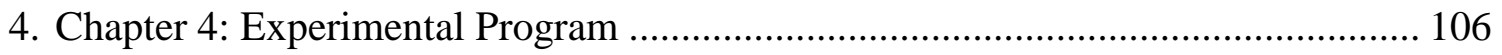

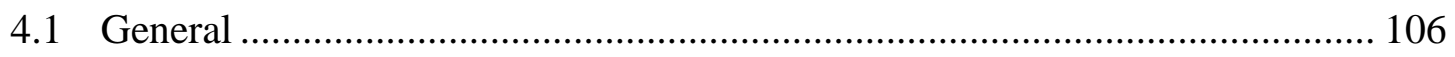

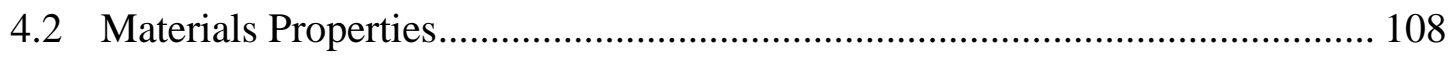

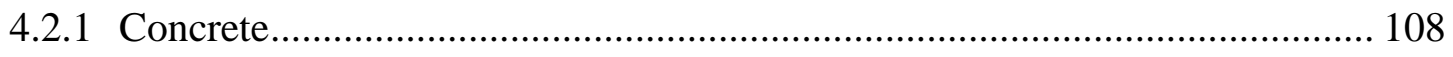

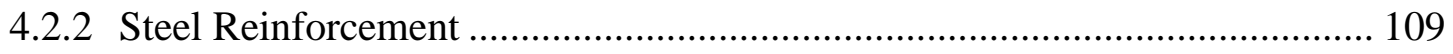

4.2.3 Carbon Fiber Reinforced Polymers (CFRP) …...................................... 111

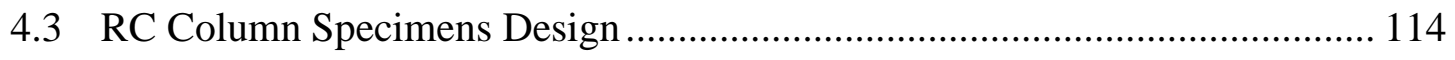

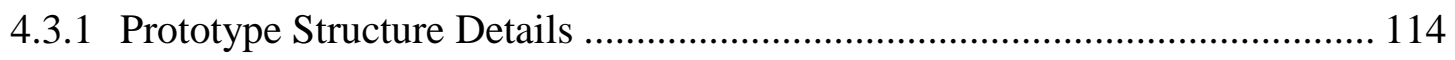




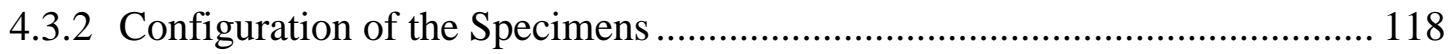

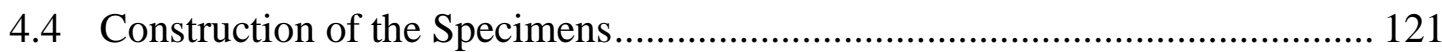

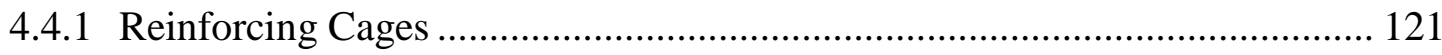

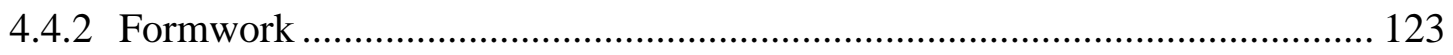

4.4.3 Concrete Casting and Curing ……………………................................ 125

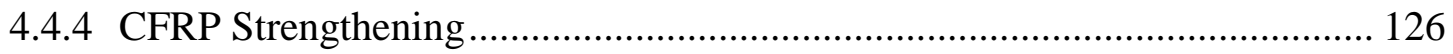

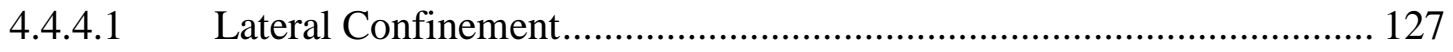

4.4.4.2 Longitudinal CFRP Strengthening ..................................................... 129

4.4.4.2.1 Proposed CFRP Anchor ………………………......................... 130

4.4.4.2.2 Pullout Test for CFRP Anchor ........................................................ 133

4.4.4.2.3 Longitudinal Strengthening of the Specimens ................................ 139

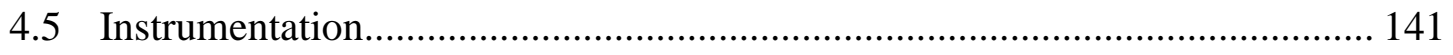

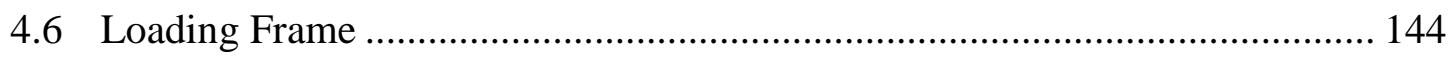

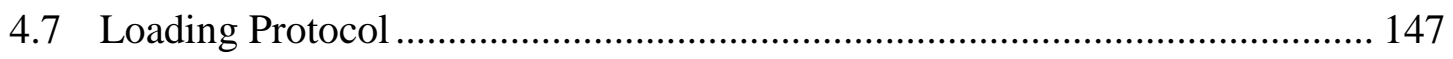

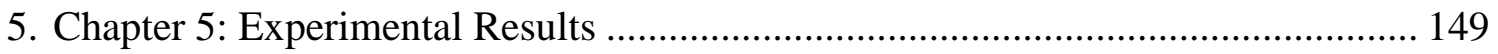

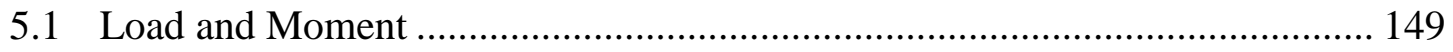

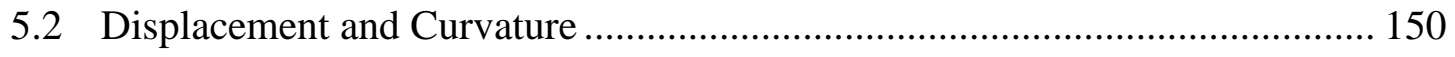

5.3 Test Procedure and Observation ……………………................................ 150

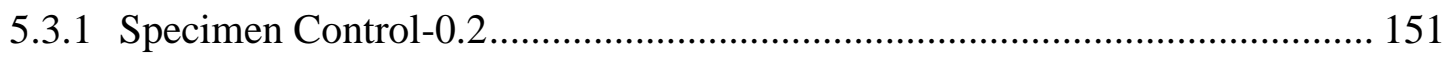




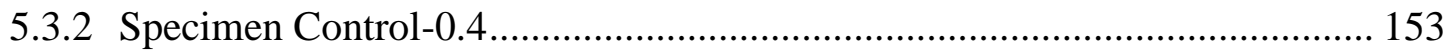

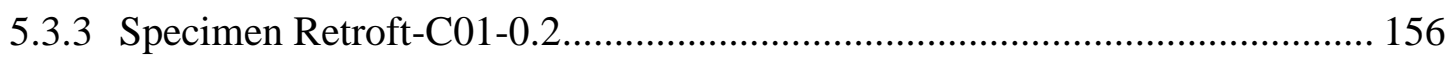

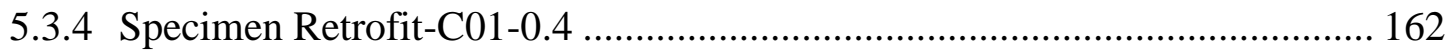

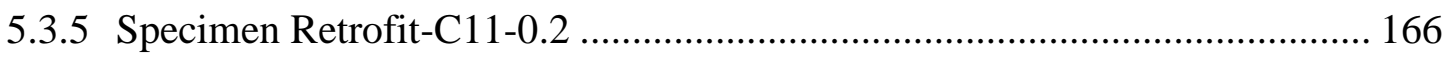

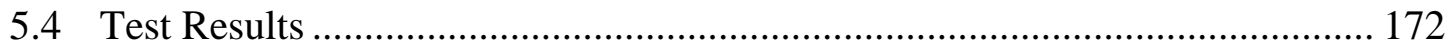

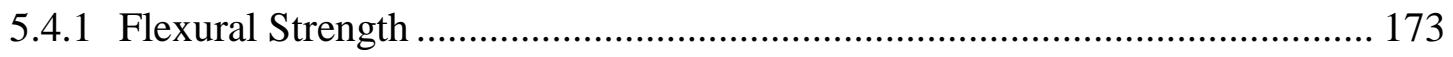

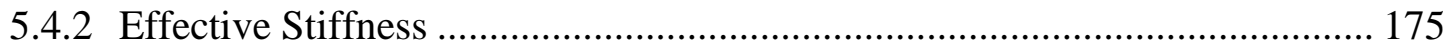

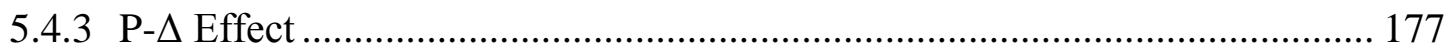

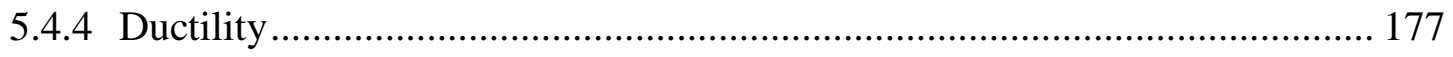

5.4.4.1 Curvature Ductility............................................................................ 177

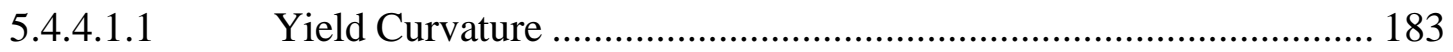

5.4.4.1.2 Plastic Hinge Length .................................................................. 183

5.4.4.1.3 Ultimate Curvature ................................................................... 185

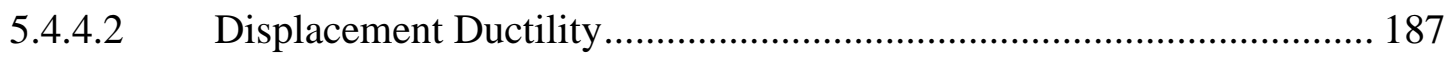

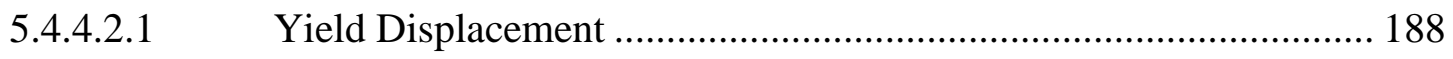

5.4.4.2.2 Ultimate Displacement ………………….................................. 190

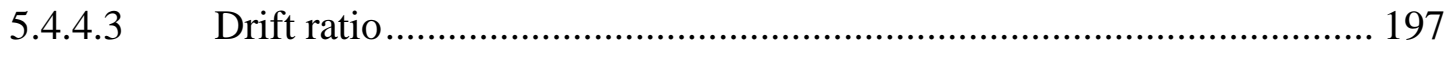

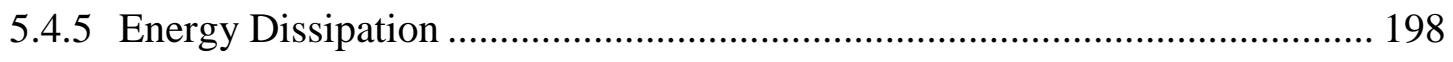

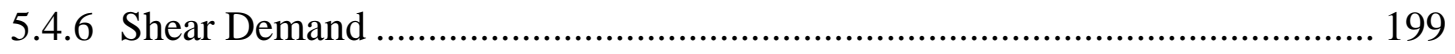


5.5 Discussion of the Experimental Results

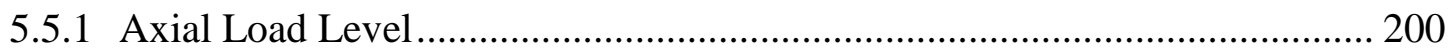

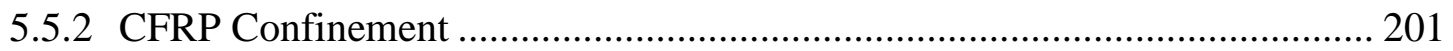

5.5.3 Tensile Strain in Longitudinal CFRP Sheet. ................................................. 203

6. Chapter 6: Study of Buildings' Behavior with Slender RC Columns ...................... 207

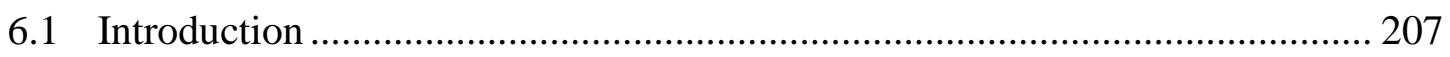

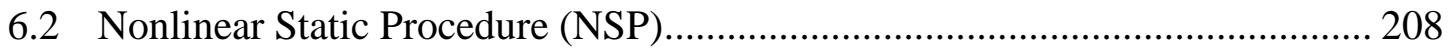

6.2.1 Nonlinear Structural Analysis (Pushover) ...................................................... 211

6.2.2 Displacement Modification Procedure (DMP) ............................................. 212

6.3 Nonlinear Analysis of the Slender RC Columns............................................ 213

6.3.1 Moment-Curvature Relation of RC Column ................................................. 213

6.3.1.1 Stress-Strain Relation of Unconfined Concrete ................................... 214

6.3.1.2 Stress-Strain Relation for Steel Confined Concrete .............................. 215

6.3.1.3 Stress-Strain Relation of the CFRP-Confined Concrete ....................... 218

6.3.1.4 Stress-Strain Relation for Longitudinal Reinforcement Model ............ 218

6.3.1.5 Moment-Curvature Algorithm ………………………………........ 219

6.3.1.6 Verifying the Theoretical Results …………...................................... 220

6.3.2 Lateral Load-Displacement Relation........................................................... 224

6.4 Modeling Parameters and Acceptance Criteria …………………………...... 228 
6.4.1 Modeling Based on ASCE Standards

6.4.2 Modeling Based on the Stress-Strain Relation.......................................... 232

6.4.3 The Acceptance Criteria Limits Proposed for Un-Retrofit Specimens ...........233

6.4.4 The Acceptance Criteria Limits Proposed for Retrofit Specimens ................ 236

6.5 Case Study of Two Prototype Buildings ………………............................... 240

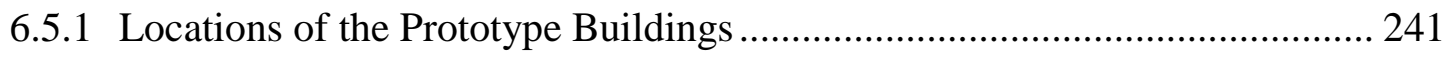

6.5.2 Plastic Hinge Rotation Capacity .............................................................. 242

6.5.2.1 Un-Retrofit Slender Column ......................................................... 242

6.5.2.2 CFRP Retrofit Slender Column ....................................................... 246

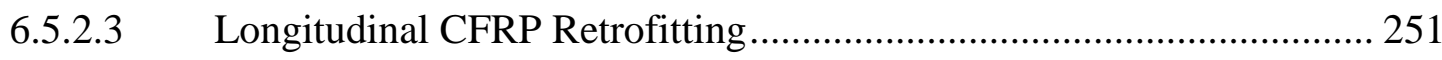

6.5.3 Performance Level of the Buildings................................................................ 255

6.5.3.1 Un-Retrofit Column …………………………………………..... 257

6.5.3.2 CFRP Retrofit Column.................................................................. 261

6.5.3.3 CFRP Longitudinal Strengthening …………………………........... 264

6.5.4 Comparison between the Un-Retrofit and Retrofit Buildings ........................ 269

7. Chapter 7: Conclusions and Recommendations for Future Work ............................ 273

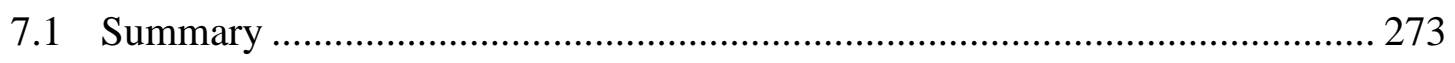

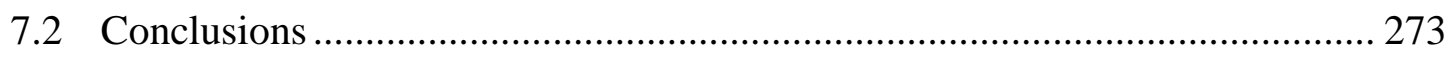

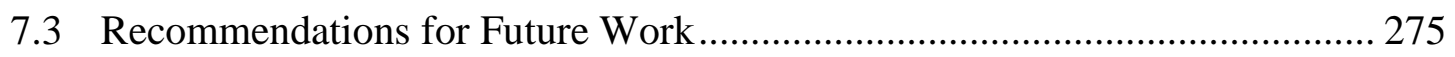


References 


\section{List of Tables}

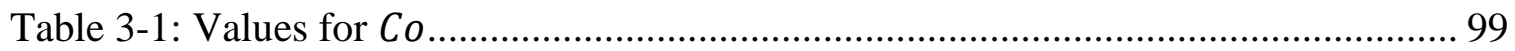

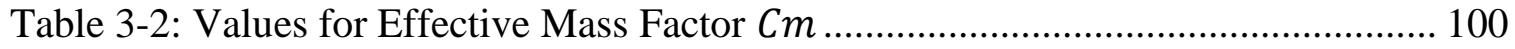

Table 3-3: Nonlinear Modeling Parameter Presented in ASCE 41-13 (2013) ............... 105

Table 4-1: Mechanical Properties of Reinforcing Steel........................................... 110

Table 4-2: Mechanical Properties and Geometric Parameters of CFRP....................... 111

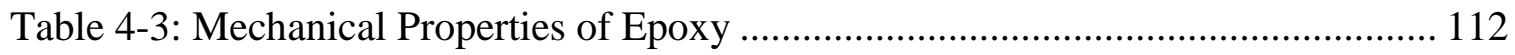

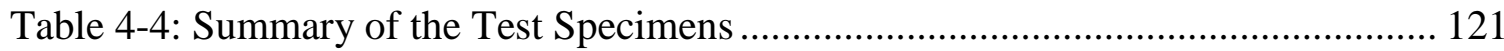

Table 5-1: Effective Stiffness, Experimental and Calculated .................................... 176

Table 5-2: Determined Yield Curvature ................................................................... 183

Table 5-3: Curvature Ductility of the Tested Specimens.......................................... 187

Table 5-4: Yield Displacements of Specimens .................................................... 189

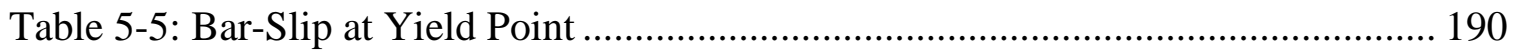

Table 5-6: Displacement Ductility of Tested Specimens ........................................... 196

Table 5-7: Drift Ratio of the Tested Specimens ....................................................... 197

Table 6-1: Comparison between the Acceptance Criteria ........................................ 235

Table 6-2: the Acceptance Criteria of the Retrofit and Un-Retrofit Specimens ............ 240

Table 6-3: Response Acceleration Parameters of 2\% Probability of Exceedance in 50

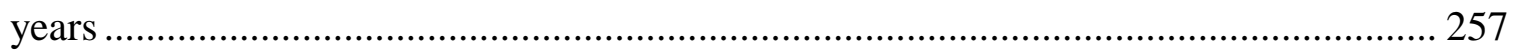

Table 6-4: Target-Displacement of Un-Retrofit RC Buildings. ................................... 259

Table 6-5: Displacement Target of Retrofit RC Buildings........................................ 263

Table 6-6: Displacement Target of Longitudinal CFRP Strengthening ........................ 267 
Table 6-7: Target Displacement and Lateral Displacement Capacities... 


\section{List of Figures}

Figure 1.1: Cenozoic Tectonic Setting of the Arabian Plate (Johnson, 1998).................. 4

Figure 1.2: Three-Story RC Building in Derbendihan, Iraq ...................................... 5

Figure 1.3: Existing Test Results for RC Column with Variable Aspect Ratio ................ 6

Figure 2.1: Distribution of Confinement Stress on Circular and Rectangular Cross-

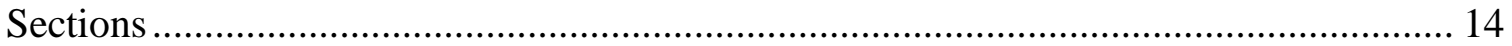

Figure 2.2: Stress-Strain Model (Mander, J. B., Priestley, M. J. N., \& Park, 1988) ........ 19

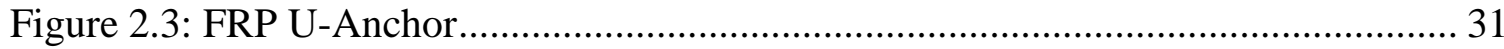

Figure 2.4: Bolted U-anchor with Steel Angle for Shear Strength .............................. 32

Figure 2.5: Bolted U-anchor with Steel Angle Prying Action ..................................... 32

Figure 2.6: the Effect of Slenderness on the Interaction Diagram ............................... 33

Figure 2.7: P- $\Delta$ Effect on the Slender RC Column................................................. 36

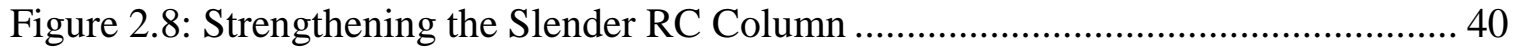

Figure 3.1: (a) Shear Failure, (b) Confinement Failure, (c) Lap Splice Failure .............. 44

Figure 3.2: the Effect of Slenderness on the Interaction Diagram.............................. 45

Figure 3.3: Typical Tensile Stress-Strain Curves for FRP and Mild Steel ..................... 47

Figure 3.4: Equivalent Circular Cross-Section .................................................... 53

Figure 3.5: Stress-Strain Model for CFRP Confined Concrete ..................................... 55

Figure 3.6: Confinement Effectiveness Coefficients: (a) Using CFRP, (b) Using Steel

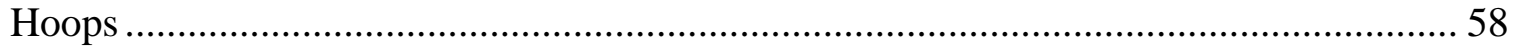

Figure 3.7: Parameters for Confinement Coefficient of CFRP and Hoop Reinforcement 60

Figure 3.8: Shear Strength Capacity based on the Section Curvature Ductility .............. 63 
Figure 3.9: Interaction between Shear Strength and Shear Capacity 69

Figure 3.10: Shear Strength Envelope Proposed by (Ghobarah \& Elmandoohgalal, 2004)

Figure 3.11: Curvature and Displacement of RC Columns ....................................... 75

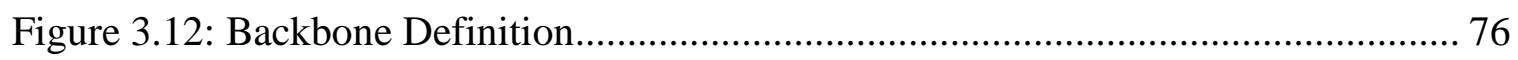

Figure 3.13: Definition of Curvature Parameters (Park, 1988) .................................... 78

Figure 3.14: Definition of Curvature Parameters (FEMA 440, 2005) ........................... 79

Figure 3.15: Definition of the Yield and Ultimate Displacement (Priestley, M. J., 2000)82

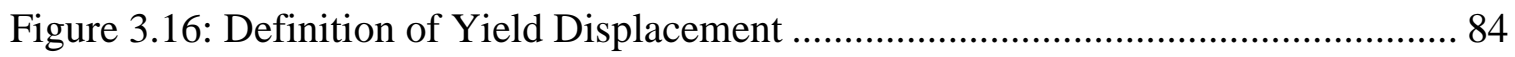

Figure 3.17: Displacement Components of RC Columns........................................ 84

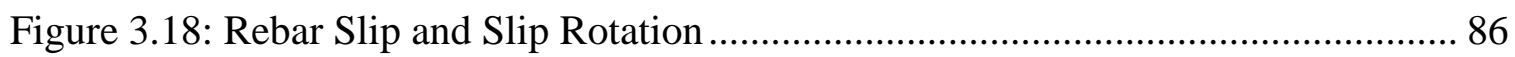

Figure 3.19: Determining the Lateral Displacement for RC Columns .......................... 88

Figure 3.20: Energy Dissipated by Enclosed Cycle................................................ 91

Figure 3.21: RC Structure Performance Level .................................................. 92

Figure 3.22: Flow Chart Simplified Nonlinear Analysis Process (FEMA-440).............. 97

Figure 3.23: Idealized Force-Displacement Curve for NSA (FEMA-440, 2005; FEMA-

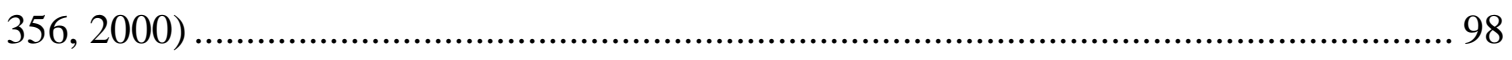

Figure 3.24: Classification of Structural Response (ASCE41-13) .............................. 103

Figure 3.25: Generalized Component Force-Deformation Relation and Accompanied

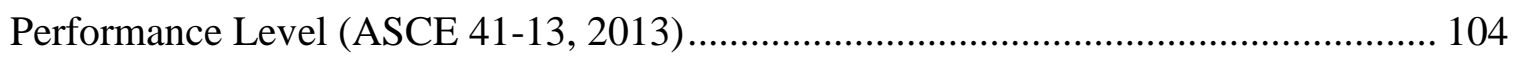

Figure 4.1: the Common Tested Models, (a) Double Curvature Specimens, (b) Double-

ended Specimens, (c) Simple Cantilever ..... 107 


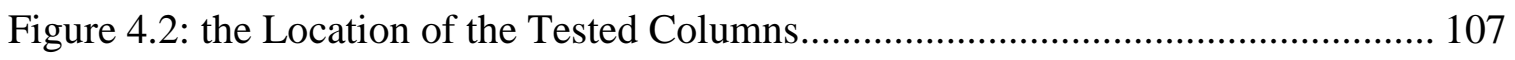

Figure 4.3: Stress-Strain Curves for Concrete ....................................................... 109

Figure 4.4: Stress-Strain Curves for Steel Reinforcement ...................................... 110

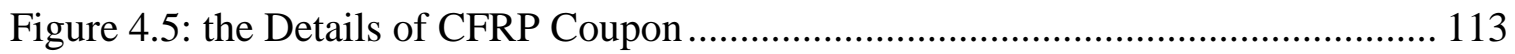

Figure 4.6: Stress-Strain Responses of CFRP Coupons ........................................... 114

Figure 4.7: Details and Configurations of the Prototype RC Buildings ....................... 116

Figure 4.8: Interaction Diagram for Prototype Column.......................................... 117

Figure 4.9: Interaction Diagram for Half-Scale Column ........................................ 117

Figure 4.10: Configuration of the Double-ended Column......................................... 119

Figure 4.11: Details of Test Specimen........................................................... 120

Figure 4.12: Specimens Identification ................................................................ 120

Figure 4.13: Typical Reinforcing Cage ............................................................ 122

Figure 4.14: Finishing Formworks and Placing the Steel Cages ............................... 124

Figure 4.15: Details of the Specimen Ends, (a) Holding the C-channel during Casting,

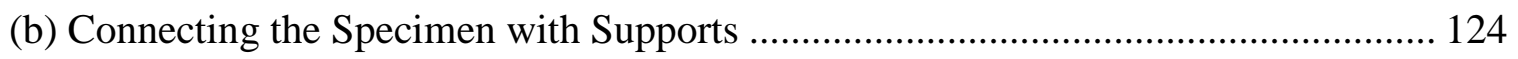

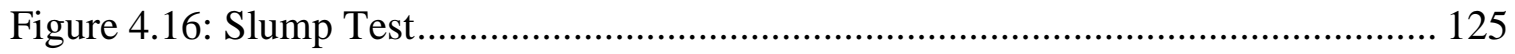

Figure 4.17: After Finishing the Casting Process ................................................. 126

Figure 4.18: Column Preparation: (a) Overview, (b) Rounded Corners, (c) Concrete

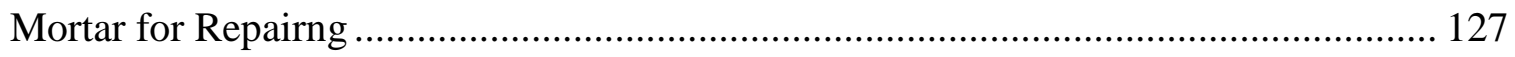

Figure 4.19: CFRP Wrapping Procedure: (a) Primer Layer, (b) Putty Layer, (c) Preparing CFRP Sheet, (d) Saturant Layer with Application, (e) Laminating.............................. 129 
Figure 4.20: Proposed CFRP Anchor System: (a) CFRP Anchor components,

(b) PVC with Stainless Steel Tube, (c) CFRP Rope

131

Figure 4.21: PVC Rod and Stainless Steel Tube: (a) PVC Rod and Stainless Steel Tube,

(b) Cutting the PVC Rod and Stainless Steel Tube

132

Figure 4.22: Manufacture of Novel Anchor: (a) Half PVC Rod, (b) Cutting Groove by

Drill, (c) Final Shape for the PVC Part ............................................................... 132

Figure 4.23: the Geometry of the T-section Concret Block...................................... 133

Figure 4.24: Installation Procedure for Novel CFRP Anchor. (a) Groove Preparation,

(b) First layer of Epoxy, (c) First Layer of CFRP Sheet in Perpendicular Direction with

Epoxy, (d) Placement of longitudinal CFRP Sheet with Epoxy, (e) Second Layer of

CFRP Sheet Placed in Perpendicular Direction, (f) Instal the Anchor Device, (g) Instal

the CFRP Rope around the Anchor Device. ....................................................... 135

Figure 4.25: Concrete Block Groove Preparation: (a) Vertical Cuts, (b) Groove aftere

Removing the Concrete, (c) Inclined Grooves .................................................. 135

Figure 4.26: Filling and Leveling the Grooves with Epoxy: (a) Placing the Anchor,

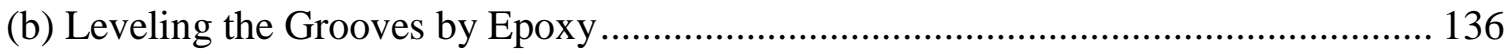

Figure 4.27: Test Setup for Pullout Test ............................................................ 138

Figure 4.28: Comparison between Pullout Test and Average Tensile Strength ............. 138

Figure 4.29: Failure of the Novel Anchor: (a) CFRP Anchor, (b) CFRP Rope Rupture,

(c) Close up of Rope Rupture ........................................................................... 139 
Figure 4.30: Steps to Longitudinally Strengthen the Specimens: (a) Overview,

(b) Preparing the Grooves, (c) Applying Longitudenal CFRP Sheet, (d) Precut CFRP,

(e) CFRP Rope, (f) Placing PVC with Stainless Steel Tupe, (g) Leveling the Grooves 140

Figure 4.31: CFRP Strips to Anchor the Longitudinal CFRP Sheet along the Column. 140

Figure 4.32: Location of the Strain Gauges on Steel Reinforcements.......................... 141

Figure 4.33: Location of the Strain Gauges on Lateral CFRP Confinement ................. 142

Figure 4.34: Location of the Strain Gauges on Longitudinal CFRP Sheet................... 142

Figure 4.35: LVDTs to Measure Specimen Curvature .............................................. 143

Figure 4.36: Two LVDTs to Measure the Lateral Displacement ................................ 144

Figure 4.37: Details of the Loading Frame ...................................................... 146

Figure 4.38: Loading Frame before Modification(Saeed, 2016) ................................ 146

Figure 4.39: Loading Frame after Modification: (a) Slid Support, (b) Slid Support after

Painting, (c) Fixed Support, (d) Final Loading Frame............................................. 147

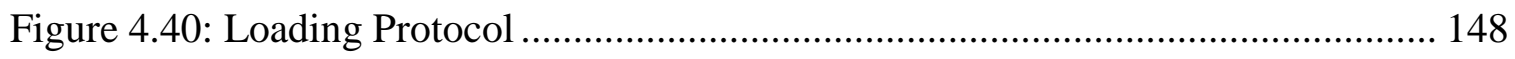

Figure 5.1: Hysteresis Loops, Lateral Load vs. Lateral Displacement for Specimen

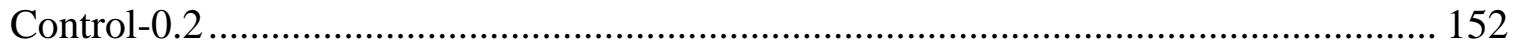

Figure 5.2: Distribution of the Cracks at the First Cycle of Each Increment for Specimen

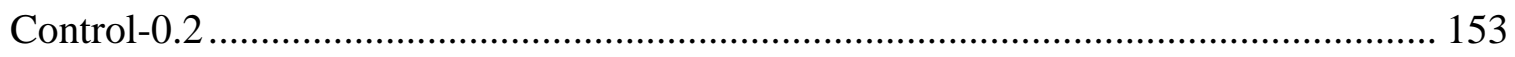

Figure 5.3: Initial Concrete Cover Spalling and Plastic Hinge Damage with Rebar

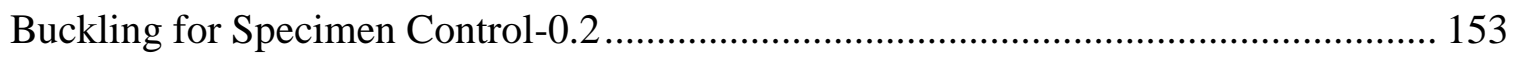

Figure 5.4: the Hysteresis Loops Lateral Load vs. Lateral Displacement for Specimen

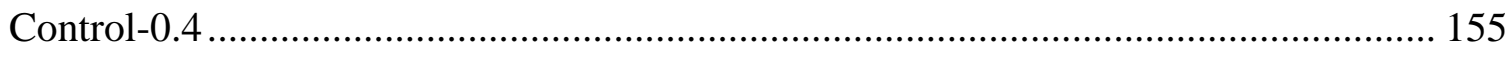

xviii 
Figure 5.5: Distribution of the Cracks at the First Cycle of Each Increment for Specimen Control- 0.4 155

Figure 5.6: Initial Concrete Cover Spalling, and Plastic Hinge Damage with Rebar

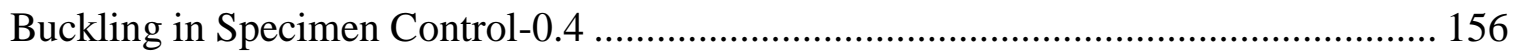

Figure 5.7: One Layer of CFRP Retrofit of Specimen Retrofit-C01-0.2..................... 157

Figure 5.8: the Hysteresis Loops Lateral Load vs. Lateral Displacement for Specimen

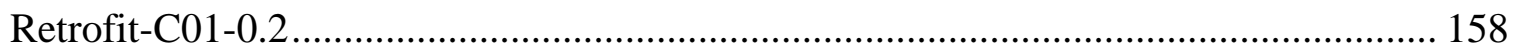

Figure 5.9: Initial Cracks at the Column-Stub Intersection for Retrofit-C01-0.2......... 158 Figure 5.10: Distribution of the Cracks at the End of the Cycle $\varphi$ y for Specimen Retrofit-C01-0.2 159

Figure 5.11: Increasing the Crack Width at Colum-Stub Intersection and CFRP Retrofit

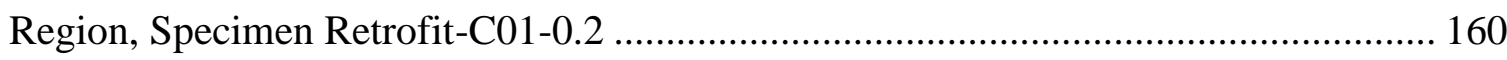

Figure 5.12: the Cracks Width at Fourth Increment of Loading Protocol, Specimen

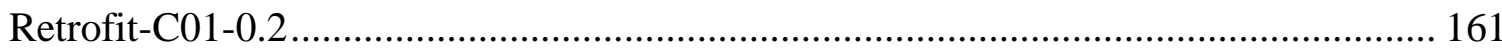

Figure 5.13: CFRP Bulging and Diagonal Shear Cracks, Specimen Retrofit-C01-0.2 .. 161 Figure 5.14: Crushed Concrete Cover after Peeling the CFRP, Specimen Retrofit-C01-0.2 162

Figure 5.15: the Hysteresis Loops Lateral Load vs. Lateral Displacement for Specimen

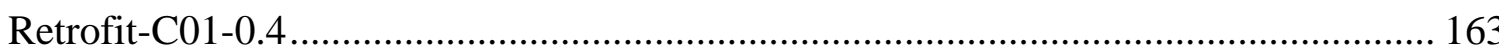

Figure 5.16: Initial Flexural Cracks at the Column-Stub Intersection, Specimen Retrofit-C01-0.4 164 
Figure 5.17: Initial Crack on CFRP Layer and Increasing the Crack Width, Specimen Retrofit-C01-0.4 164

Figure 5.18: Flexural Cracks Distributed Beyond CFRP Retrofit Region, Specimen

Retrofit-C01-0.4 165

Figure 5.19: for Views of Bulging and Flexural Cracks at the CFRP Retrofit Region, Specimen Retrofit-C01-0.4 165

Figure 5.20: Diagonal Cracks and Large Flexural Cracks, Specimen Retrofit-C01-0.4 166 Figure 5.21: Specimen Retrofit-C11-0.2 167

Figure 5.22: the Hysteresis Loops Lateral Load vs. Lateral Displacement for Specimen

Retrofit-C11-0.2 169

Figure 5.23: Cracks at Column-Stub Intersection, Specimen Retrofit-C11-0.2 169

Figure 5.24: Long Cracks at CFRP Retrofit Region, Specimen Retrofit-C11-0.2 ........ 170

Figure 5.25: Cracks at the End of $\pm 4 \varphi \mathrm{y}$, Specimen Retrofit-C11-0.2 ….................... 170

Figure 5.26: Cracks at the End of $\pm 5 \varphi \mathrm{y}$, Specimen Retrofit-C11-0.2 …................... 171

Figure 5.27: Cracks at the End of $\pm 6 \varphi y$, Specimen Retrofit-C11-0.2 ....................... 171

Figure 5.28: Longitudinal CFRP Rupture, Specimen Retrofit-C11-0.2 _.................... 172

Figure 5.29: Hysteresis Loops and Backbone Curves for the Specimens ..................... 173

Figure 5.30: Interaction Diagram for the Specimen .............................................. 174

Figure 5.31: LVDTs and Mid-Point Locations ................................................... 179

Figure 5.32: Curvature Distribution for Specimen Control-0.2 ............................... 179

Figure 5.33: Curvature Distribution for Specimen Retrofit-C01-0.2 ......................... 180

Figure 5.34: Curvature Distribution for Specimen Retrofit-C11-0.2 _....................... 180 
Figure 5.35: Curvature Distribution for Specimen Control-0.4................................ 181

Figure 5.36: Curvature Distribution for Specimen Retrofit-C01-0.4 ......................... 181

Figure 5.37: Backbone Curves for Moment Curvature ........................................... 182

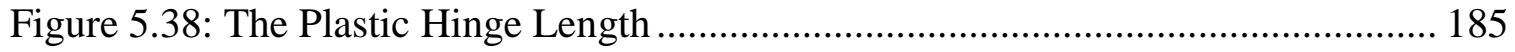

Figure 5.39: Backbone Curves for the Tested Specimens ........................................ 188

Figure 5.40: Displacement Ductility Based on Lateral Strength ............................... 191

Figure 5.41: Displacement Ductility Based on Moment Strength ............................... 194

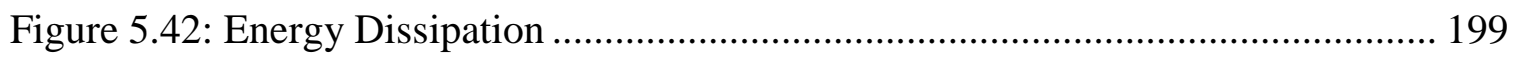

Figure 5.43: CFRP Lateral Strain vs. Lateral Displacement, Retrofit-C01-0.2 ............ 202

Figure 5.44: CFRP Lateral Strain vs. Lateral Displacement, Retrofit-C01-0.4............ 203

Figure 5.45: Distribution of the Tensile Strain of the CFRP Sheet .............................. 204

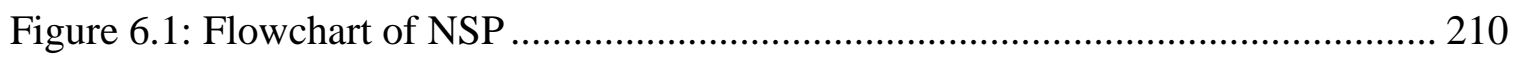

Figure 6.2: Identification of the Performance Level Based on the Target Displacement210 Figure 6.3: Modeling Parameters and Acceptance Criteria ...................................... 212 Figure 6.4: Strain Compatibility and Force Equilibrium for the Block Stress RC Column

Figure 6.5: Stress-Strain Model for Unconfined and Confined Concrete ..................... 216

Figure 6.6: Distribution of Lateral Stress on Rectangular RC Column ........................ 218

Figure 6.7: Raynor Axial Stress-Strain Model ................................................... 219

Figure 6.8: Flowchart for Calculating Moment-Curvature ....................................... 221

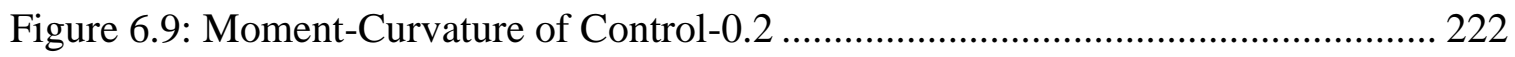

Figure 6.10: Moment-Curvature of Control-0.4 ................................................ 222 


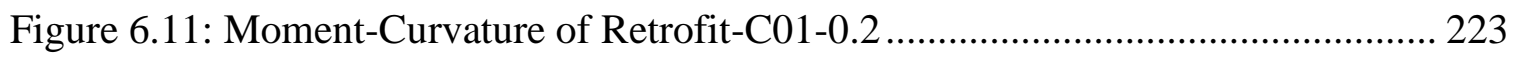

Figure 6.12: Moment-Curvature of Retrofit-C01-0.4 ............................................ 224

Figure 6.13: Flowchart for Calculating Lateral Load-Displacement........................... 226

Figure 6.14: Experimental Results vs. Theoretical Results ..................................... 227

Figure 6.15: Modeling Parameters and Acceptance Criteria Proposed by ASCE 41-13

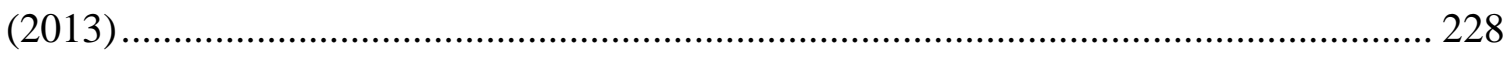

Figure 6.16: Nonlinear Curve of Specimen Control-0.2 ...................................... 230

Figure 6.17: Nonlinear Curve of Specimen Control-0.4 ........................................... 230

Figure 6.18: Nonlinear Curve of Specimen Retrofit-C01-0.2 ................................ 231

Figure 6.19: Nonlinear Curve of Specimen Retrofit-C01-0.4 ............................... 231

Figure 6.20: Modified Acceptance Criteria of Specimen Control-0.2.......................... 234

Figure 6.21: Modified Acceptance Criteria of Specimen Control-0.4 ......................... 235

Figure 6.22: Proposed Acceptance Criteria of Specimen Retrofit-C01-0.2 ................ 238

Figure 6.23: Proposed Acceptance Criteria of Specimen Retrofit-C11-0.2 ................ 239

Figure 6.24: Proposed Acceptance Criteria of Specimen Retrofit-C01-0.4 ................. 239

Figure 6.25: Probabilistic Seismic Hazard in Iraq (2\% in 50 years) .......................... 241

Figure 6.26: Details and Properties of the Un-Retrofit Slender Column...................... 242

Figure 6.27: Moment-Curvature for Full-scale Column, Axial Load 0.2 $f c^{\prime} A g$........... 243

Figure 6.28: Moment-Curvature for Full-scale Column, Axial Load 0.4f $c^{\prime} A g$........... 243

Figure 6.29: Load-Displacement and Acceptance Criteria, Full-scale Column $0.2 f c^{\prime} A g$ 
Figure 6.30: Load-Displacement and Acceptance Criteria, Full-Scale Column, $0.4 f c^{\prime} A g$ 244

Figure 6.31: Rotation Capacity for Axial Load Level $0.2 f c^{\prime} A g$................................. 245

Figure 6.32: Rotation Capacity for Axial Load Level 0.4f $c^{\prime} A g$............................... 246

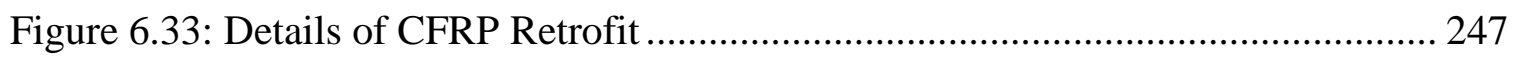

Figure 6.34: Moment-Curvature for Axial Load Level $0.2 f c^{\prime} A g$.............................. 248

Figure 6.35: Moment-Curvature for Axial Load Level $0.4 f c^{\prime} A g$.............................. 248

Figure 6.36: Lateral Load-Displacement for Axial Load Level 0.2f $c^{\prime} A g$................... 249

Figure 6.37: Lateral Load-Displacement for Axial Load Level 0.4f $c^{\prime} A g$.................... 249

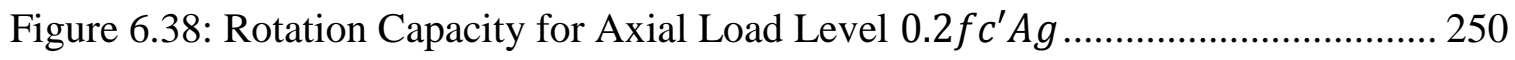

Figure 6.39: Rotation Capacity for Axial Load Level $0.2 f c^{\prime} A g$................................ 250

Figure 6.40: Moment-Curvature for Axial Load Level 0.2 $f c^{\prime} A g$............................. 252

Figure 6.41: Moment-Curvature for Axial Load Level 0.4f $\mathrm{c}^{\prime} \mathrm{Ag}$................................ 253

Figure 6.42: Lateral Load-Displacement for Axial Load Level 0.2f $c^{\prime} A g$................... 253

Figure 6.43: Lateral Load-Displacement for Axial Load Level 0.4f $c^{\prime} A g$.................... 254

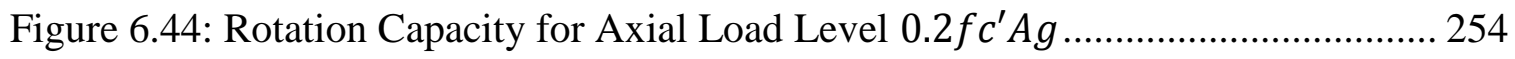

Figure 6.45: Rotation Capacity for Axial Load Level $0.2 f c^{\prime} A g$................................ 255

Figure 6.46: Baghdad and Erbil Locations ....................................................... 256

Figure 6.47: Capacity Curve for Un-Retrofit Two and Four-Story Buildings .............. 258

Figure 6.48: Target-Displacement of Two-Story Buildings at Erbil and Baghdad ........ 258

Figure 6.49: Target-Displacement of the Four-Story Buildings in Erbil and Baghdad.. 259

Figure 6.50: Failure Mechanism of Two- and Four-Story Buildings .......................... 260 
Figure 6.51: Capacity Curve of Two and Four-Story Buildings ................................ 262

Figure 6.52: Target Displacement of Two-Story Buildings in Erbil and Baghdad ........ 262

Figure 6.53: Target Displacement of Four-Story Buildings in Erbil and Baghdad ........ 263

Figure 6.54: Failure Mechanism of the Lateral Retrofit Column ................................ 264

Figure 6.55: Capacity Curve of Two and Four-Story Buildings ................................ 265

Figure 6.56: Target Displacement of Two-Story Buildings in Erbil and Baghdad ........ 266

Figure 6.57: Target Displacement of Four-Story Buildings in Erbil and Baghdad ........ 266

Figure 6.58: Failure Mechanism of the Longitudinal Retrofit Column........................ 268

Figure 6.59: Comparison Between Un-Retrofit and Retrofit Two-story Buildings ....... 270

Figure 6.60: Comparison Between Un-Retrofit and Retrofit Four-story Buildings ....... 271 


\section{Chapter 1: Introduction}

\subsection{General}

In seismically active zones, the occupants' lives depend on the performance level that buildings and bridges can provide during earthquake events. Based on observations and investigations about seismic events that have happened in many countries around the world, it was concluded that the greatest losses in terms of lives and properties occurred due to vulnerable structures, which had been designed without any consideration for earthquake forces. The impact of earthquake events such as San Fernando, CA 1971; Northridge, CA 1994; Kobe, Japan 1995; Izmit, Turkey 1999; Jiji, Taiwan 1999; and Bam, Iran 2003 have encouraged researchers and engineers to find ways to improve vulnerable structures.

Indeed, most buildings constructed worldwide before the 1970's were designed for a combination of gravity and wind loads. In addition, Masters Builders had constructed a large portion of the residents RC buildings in the Mediterranean and Latin American countries without engineering design. Reinforced concrete buildings that have poor structural characteristics, such as inadequate reinforcement in the critical zones, poor reinforcement details, and low-grade concrete strength result in unsafe buildings especially when subjected to earthquake loading (Yalcin, Kaya, \& Sinangil, 2008).

In developing countries, the significant human loss from earthquakes is the consequence of poorly constructed structures (Kenny, 2009). For example, in 2003, a magnitude 6.6 earthquake struck Bam, a city located in southern Iran, ending in the 
deaths of more than 43,000 people and rendering more than 60,000 people homeless. Weak materials and poor construction have been used in reinforced and unreinforced concrete buildings without any consideration for seismic forces (Yalcin et al., 2008). This leads to extensive human casualties and destruction of the region's economy. Tearing down and reconstructing all these buildings is not a feasible option. As a result, looking for practical solutions to strengthen poorly designed buildings is the first step to reduce the impact of earthquakes and save people's lives and properties.

Iraq is a developing country that can expect extremely damaging earthquakes due to its location in the seismically active region of the Arabian and the Eurasian Plates. Moreover, a great majority of reinforced concrete (RC) buildings in Iraq have not been designed to resist seismic forces (Yaseen, Begg, \& Nanos, 2015), so the need to find solutions for improving the seismic structural responses of these buildings is crucial.

\subsection{Research Motivation}

\subsubsection{Earthquake in Iraq}

Large earthquakes throughout the history have affected the Middle East, extending from the Eastern Mediterranean to the Himalayas in the East-West direction, and from the Gulf of Oman to the Greater Caucasus in the North-South direction. The complex interactions among the four major tectonic plates, Africa, Arabia, India, and Eurasia, make these regions one of the most seismically active regions on Earth, as shown in Fig. 1.1. Iraq is one of the countries that is affected by the interaction between 
these plates. Many researchers (Alsinawi, 2002; Salazar, Lyndon, \& Mannette, 2013; Ameer et al., 2004) have investigated the seismicity of Iraq, and concluded that the seismic activity is moderate to high at the northern and northeastern boundaries, and low in the south and southwestern regions. Based on a statistical study executed on earthquake database in Iraq, a relatively large destructive earthquake was expected to happen in the northern and northeastern boundaries of Iraq (Ameer et al., 2005). In 2017, the Iraq-Iran border was struck by a magnitude 7.3 earthquake. The closest cities, Halabja in Iraq and Sarpol-e-Zahab in Iran, suffered significant loss of life and property. Fig. 1.2 shows one of the destroyed three-story RC buildings in Iraq in the 2017 earthquake. Most of the damaged buildings were vulnerable and poorly reinforced for seismic loads even though some of these buildings were built recently. More than 400 people were killed, 2,500 were injured, and 12,000 houses were destroyed in Iran and Iraq. It was considered the deadliest earthquake of the year, transcending the one that hit Mexico City in September 2017. In Iraq, most of the reinforced concrete buildings, especially typical commercial reinforced concrete buildings, have been constructed without any seismic considerations. Moreover, the collapse of the structural buildings in the neighboring countries (Bam earthquake in Iran in 2003 and Van earthquake in Turkey in 2011) has raised many questions regarding how best to retrofit the existing buildings in this region. 


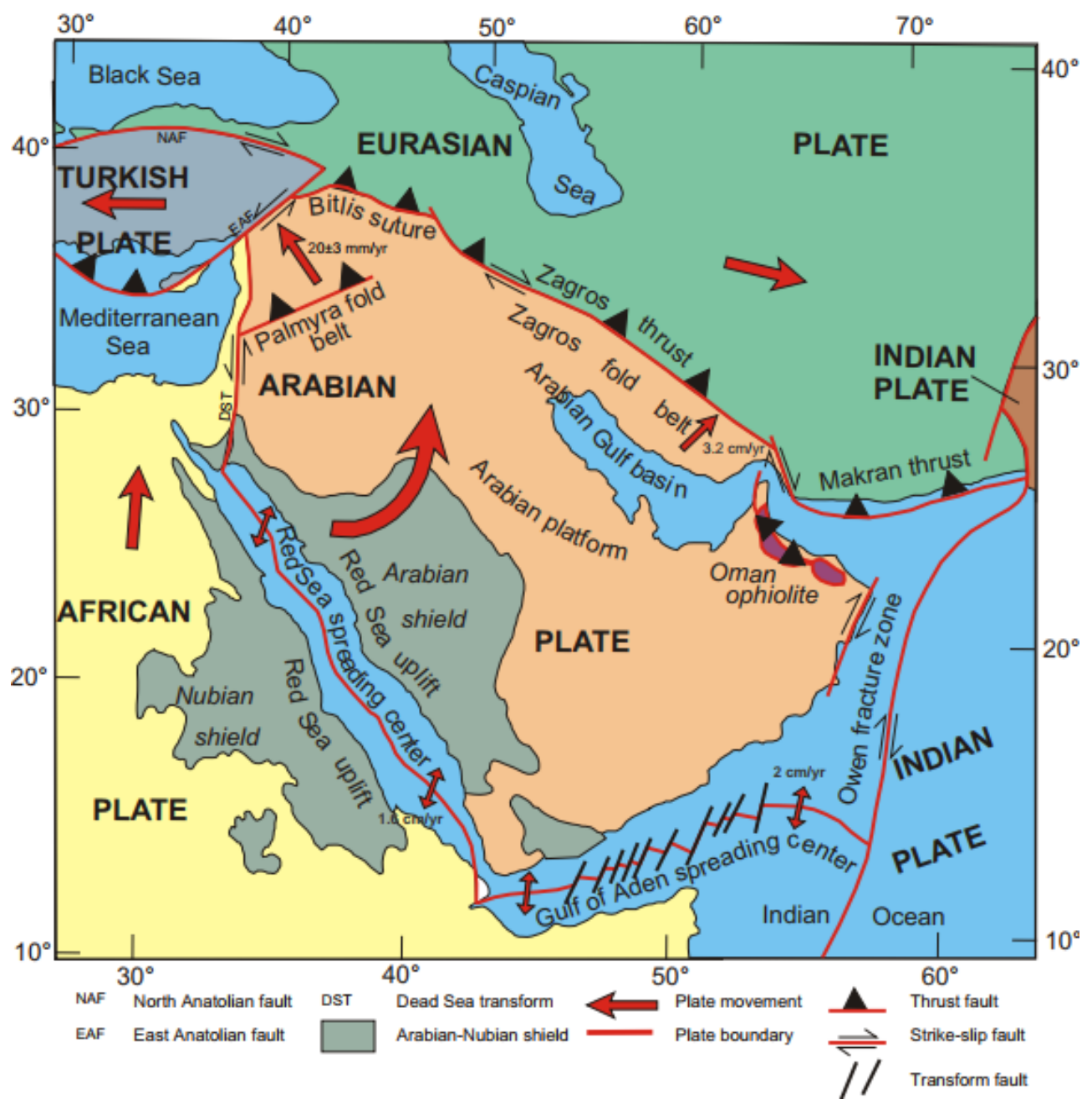

Figure 1.1: Cenozoic Tectonic Setting of the Arabian Plate (Johnson, 1998) 


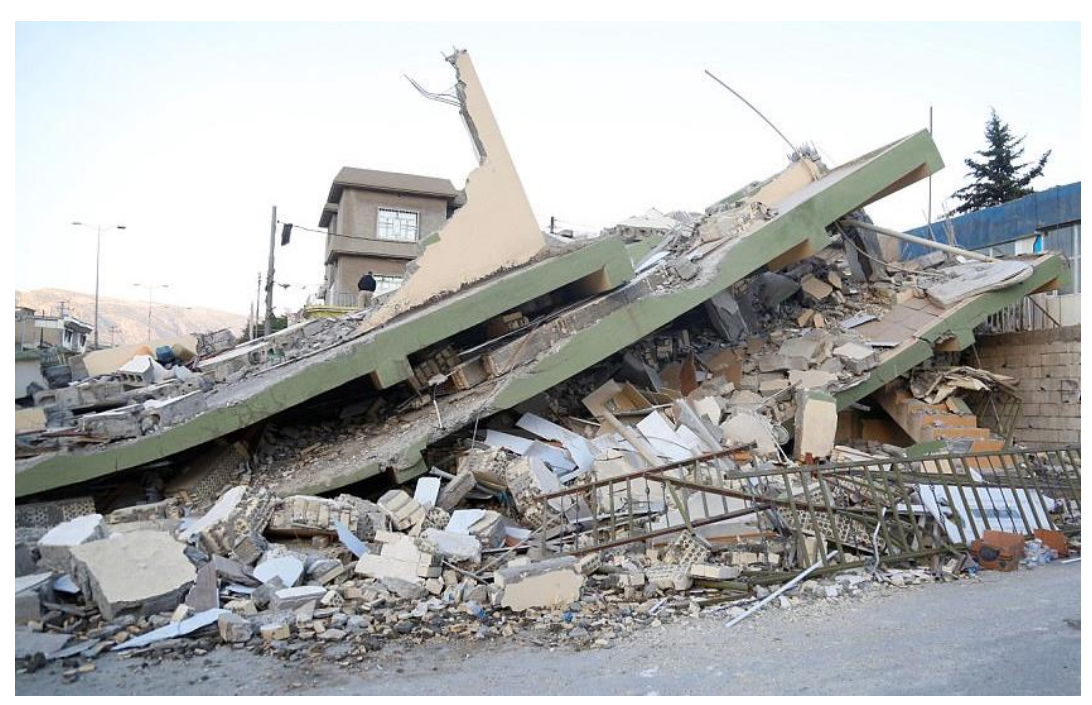

Figure 1.2: Three-Story RC Building in Derbendihan, Iraq

\subsubsection{Reinforced Concrete Buildings with Deficient Slender Columns}

For RC structures, columns are one of the most important structural elements because the endurance of structures to sustain the gravity loads and prevent collapse mainly depends on columns. There are two categories of RC columns: Short and long (or slender). In design, most attention are given to long columns due to the secondary moment effects, $\mathrm{P}-\Delta$. The additional moment resulting from gravity load, $\mathrm{P}$, acting through lateral deflection, $\Delta$, has a major influence on elastic stiffness, inelastic strength, and deformation capacity (Paulay \& Priestley, 1992). Based on a survey of RC building in the US, it was observed that around $60 \%$ and $10 \%$ of columns are considered slender column in unbraced and braced buildings, respectively (MacGregor, et al., 1970). In older RC buildings designed before 1970's, most of the slender RC columns had been designed with insufficient and widely spaced transverse reinforcement with 90-degree end hooks in column's ends which experience the most inelastic rotations that column can provided 
under lateral load. Most of the available experimental research have focused on RC columns that have shear span ratios, $\left(L_{s} / h\right)$, less than 6.5 (Caballero-Morrison et al., 2012; Barrera et al. 2011) as shown in Fig. 1.3, where $L_{s}$ is a distance between the maximum and zero moments and $h$ is the overall depth of the column's cross-section. Frg. 1.3 reveals that information on slender columns with $\left(L_{s} / h\right)$ more than 7 is sparse. Therfore, more experimental tests are needed on slender columns, especially older columns, to be tested under cyclic lateral loads to assess their seismic response.

After determining the seismic response of slender columns, investigating the effectiveness of retrofit methods to improve the strength and ductility of such slender columns is crucial (Ghatte et al., 2016; Seyhan et al., 2015). Therefore, there is a need to propose a retrofit technique that can improve the performance of such columns.

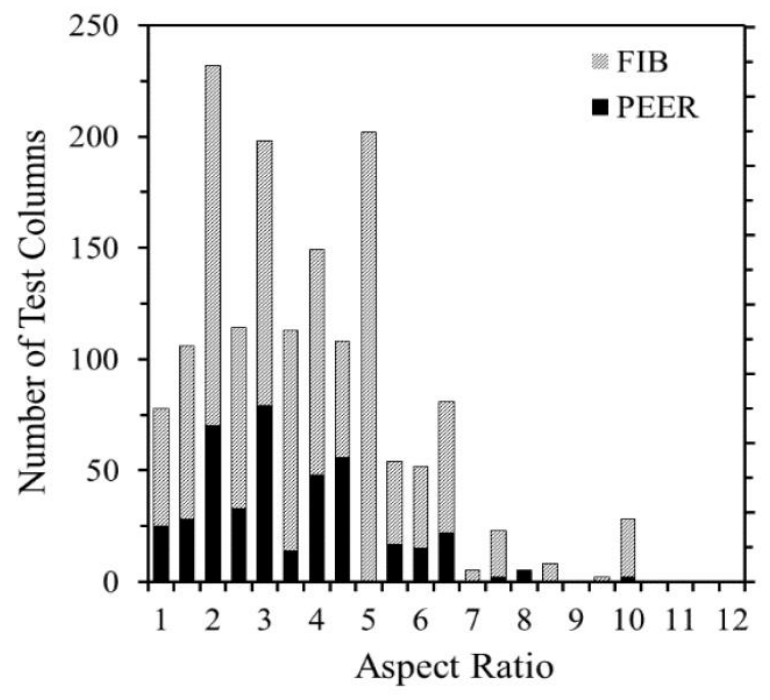

Figure 1.3: Existing Test Results for RC Column with Variable Aspect Ratio 
In Iraq and neighboring countries, slender RC columns that have low-grade concrete, low reinforcement ratio, large spacing between ties, and a shear span ratio above 6.5 are common in existing RC buildings (both commercial and residential). These buildings have traditionally been constructed by "master builders" without any robust engineering principles (Kassaee et al., 2009).

\subsection{Scope of Work}

\subsubsection{Research Significance}

Nowadays, predicting the damage in slender RC columns is commonly done based on experiments on the short columns without fully considering the effect of slenderness and second-order moments on damage (Babazadeh, 2017). A better understanding of the effects of the second-order moment in the inelastic domain and performance level of vulnerable slender RC columns is a highly important issue. Moreover, enhancing the behavior of slender columns by using CFRP can reduce the damaging consequences of seismic forces. This research aims to experimentally assess the behavior of existing vulnerable slender RC columns, and investigate the effects of retrofitting with CFRP on the performance level and controlling failure mechanism for RC buildings in Iraq. 


\subsubsection{Research Objectives}

The main goals of the current study are: 1) create a computer based-program to predict the moment-curvature, moment-rotation and lateral load-displacement responses for CFRP retrofit and un-retrofit RC slender columns, 2) experimentally assess behavior of the existing (as built) slender (RC) columns, using half-scale specimens, under cyclic lateral load and with two levels of axial load, low and moderate, 3 ) experimentally evaluate the effectiveness of the retrofitting technique with CFRP to improve the performance level of such columns, and 4) assess the performance level of two prototype RC building in Iraq with un-retrofit and retrofit slender RC columns by using SAP2000. To achieve these goals, six objectives were established:

1) Evaluate the existing compressive stress-strain models for short square RC columns retrofit with CFRP under monotonically increasing axial load by validating the model results with available experimental results.

2) Write a computer-based program model to predict the behavior of slender RC columns that are un-retrofit, and retrofit with CFRP, under a combination of constant axial load and lateral load.

3) Identify the vulnerabilities of typical slender RC columns in buildings, built in Iraq without considerations for seismic loads, by experimentally testing two columns under cyclic lateral load with constant low and moderate axial load.

4) Experimentally evaluate the behavior of slender rectangular concrete columns, retrofit by CFRP laterally and longitudinally, under cyclic lateral load with constant low and moderate axial load level. 
5) Select prototype RC buildings with square RC slender columns.

6) Implement the theoretical moment-rotation and expected performance level, obtained from computer program model, for retrofit and un-retrofit slender columns using SAP2000 to determine the performance level of prototype buildings, failure mechanism, and the displacement target for each building based on the FEMA 440 provisions.

\subsubsection{Research Methodology}

To achieve the aforementioned objectives, the research project will be divided into five parts.

1. Perform a literature review on the axial stress-strain behavior of short square concrete columns retrofit with CFRP under axial load and the behavior of RC column retrofit with CFRP under the combination of cyclic lateral load and axial load.

2. Perform an experimental program on five half-scale slender RC columns, unretrofit, and retrofit by CFRP. Two modes of retrofit will be investigated; lateral direction, and lateral plus longitudinal direction.

3. Implement a proposed CFRP anchor developed in this study for the longitudinal CFRP direction.

4. Create a computer-based program for non-linear analysis of slender RC square columns under a combination of lateral and constant axial loads that are laterally and longitudinally retrofit with CFRP. 
5. Use SAP 2000 program to evaluate the existing (prototype) RC buildings and investigate the effect of CFRP confinement on the performance level and failure mechanism of the porotype buildings.

\subsubsection{Expected Contribution}

The contributions of the research to the field of knowledge are summarized below:

1. Expand the current knowledge on the behavior of slender RC columns designed with low-grade concrete, low reinforcement steel ratio, and transverse reinforcement with large spacing, and tested under a combination of cyclic lateral load and constant axial load, under two levels of axial load.

2. Present the contribution of strengthening techniques with CFRP on increasing the strength, ductility, and failure mode of slender RC columns.

3. Show the effectiveness of a proposed CFRP U-Anchor for longitudinal strengthening.

4. Present an assessment of older vulnerable RC buildings in Iraq that have been constructed without seismic provisions, by implementing pushover analyses.

5. Present an assessment of older vulnerable RC buildings in Iraq that have been constructed without seismic provisions, but are retrofit with CFRP, by implementing pushover analyses 


\subsection{Dissertation Organization}

Chapter 1: presents the outline of the dissertation, motivation of the study, research significance, research objectives, research methodology, and expected contribution.

Chapter 2: reviews the development in the axial stress-strain models of CFRP confinement, the effect of CFRP confinement on increasing the rotation capacity and shear strength of the rectangular RC columns, the contribution of CFRP sheet in flexural strengthening of the column, and the state of art for the available CFRP anchor system. In last part of chapter 2, the vulnerable issues of RC slender columns are discussed with some strengthening techniques.

Chapter 3: presents a background information on axial stress-strain models for CFRP retrofit columns, rotation and shear capacity of the retrofit columns at the plastic hinge regions, ductility, performance level, and energy dissipation of RC columns. In this chapter, a nonlinear analysis procedure to identify the displacement demand and acceptance criteria for RC building is introduced.

Chapter 4: introduces the newly conducted experiments on five half-scale RC slender columns. In this chapter, properties of materials, prototype RC structures, configuration and construction of loading frame and specimens, and instrumentation are described.

Chapter 5: presents the results of the experimental tests conducted on specimens tested under cyclic lateral load and constant low and moderate axial loads. The 
experimental results are presented in term of flexural strength, effective stiffness, ductility, energy dissipation, and shear demand.

Chapter 6: introduces the development of a computational program, which includes developing MATLAB codes to determine the moment-curvature, momentrotation, and lateral load-displacement and verifying the computer modeling results with experimental results. The results of a pushover analysis conducted on the porotype RC buildings are discussed in term of performance level and failure mechanism of the buildings.

Chapter 7: presents the conclusions and recommendation for further study in the future. 


\section{Chapter 2: Literature Review}

\section{$2.1 \quad$ Introduction}

This section introduces some of the extensive research that has been conducted on using the CFRP material for strengthening existing RC columns. In order to organize the literature review, the review has been divided into four parts: the stress-strain behavior of CFRP retrofit rectangular concrete, the axial stress-strain models for CFRP confined concrete columns, the rectangular RC columns that were strengthened with CFRP and tested under the combination of a constant axial load and a cyclic lateral load, and RC slender columns.

\subsection{CFRP Confined Rectangular Concrete}

To assist the progress of the practical application of FRP composites in column strengthening, the compressive stress-strain relation of FRP confined concrete column requires a good understanding of the modeling. Furthermore, a large body of experimental studies have been conducted on the effects of the FRP confinement in short columns with a circular and rectangular cross-sections under a monotonic axial load (Mirmiran, A., Shahawy, M., Samaan, M., Echary, H., Mastrapa, J., and Pico, 1998; Jiang \& Teng, 2007). It was concluded that a FRP retrofit improved both of the axial strain and strength of the short column, and that these improvements are affected by many parameters such as; concrete strength, types of FRP and resin, the volume ratio and thickness of the fibers, and the shape of cross-section (Mirmiran, A., Shahawy, M., Samaan, M., Echary, H., Mastrapa, J., \& Pico, 1998). Moreover, FRP confinement stress 
that was applied onto the concrete was passive rather than active because the FRP confinement started when the lateral deformation in the concrete core was increased due to axial stress (Jiang \& Teng, 2007). The efficiency of FRP confinement in increasing the axial strain and strength for circular sections is better than on rectangular sections due to the un-regular distribution of confinement stress on the cross-section circumference, as shown in Fig. 2.1. However, the strain ductility for the rectangular sections is larger than for the circular sections (Lam, L. and Teng, 2003; Micelli \& Modarelli, 2013). One of the parameters that reduces FRP confinement efficiency in the rectangular concrete columns is the sharp corners because the sharp angles produced concentrated stress that offered poor confinement in the columns (Mirmiran, A., Shahawy, M., Samaan, M., Echary, H., Mastrapa, J., \& Pico, 1998; L. M. Wang, \& Wu, 2008; D. Y. Wang, Wang, Smith, \& Yu, 2016)).

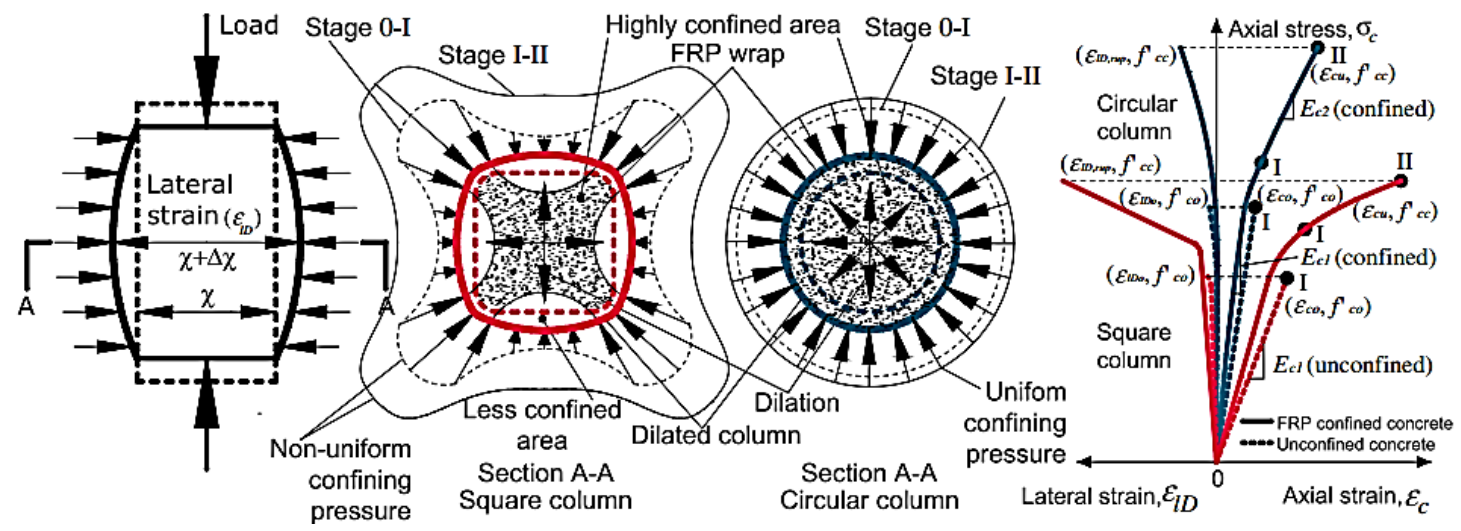

Figure 2.1: Distribution of Confinement Stress on Circular and Rectangular CrossSections 
For rectangular RC columns, many experimental studies attempted to overcome the concentrated stress problem at the corners. Rounding the corner of rectangular concrete columns is one of the best methods that have been proposed and tested to reduce the effects of concentrated stress. Experimental studies on the effect of increasing the corner radius on CFRP retrofit square concrete columns (Mirmiran, A., Shahawy, M., Samaan, M., Echary, H., Mastrapa, J., \& Pico, 1998; Wang \& Wu, 2008). In Wang \& Wu (2008) test, 108 specimens with the dimension (6x6 in with 12 in. in height) were prepared with the following primary variables: the radius of the corners, the thickness of the CFRP, and the concrete grade. The concrete grade was $4350 \mathrm{psi}$ and $7200 \mathrm{psi}$ to identify the effect on concrete grade on CFRP confinement efficiency. The radius of each corner was varied with $0,0.6,1.2,1.77,2.4,3$ in. and each radius was tested for both of concrete grades. One and two CFRP layers were used to confine the specimens. The test results show that the CRFP retrofit column with sharp corners provided an insignificant increase in terms of strength, but a significant improvement in terms of ductility, and increasing the radius of the corners lead to an increase the CFRP retrofit confinement's effect. Moreover, CFRP retrofit improves the strength and ductility of a low-grade concrete more than high-grade concrete.

In spite of the improvement in confinement stress by rounding the sharp corners, the confinement stress on the flat side was much lower than on the round corner, which also concentrated the stress at round corner (Al-Salloum, 2007). In order to alleviate this problem, a few researchers have focused on the effect of modifying the square columns shape to a circular or elliptical cross-section and then wrapping them with CFRP sheets 
(Priestley \& Seible, 1995; Yan et al., 2006; Pham, Doan, \& Hadi, 2013). The experimental results showed a significant improvement in strength and ductility.

The effect of the length to diameter ratio $L / D$ (column height/column width) for plain concrete columns retrofit with FRP has been investigated (Mirmiran, A., Shahawy, M., Samaan, M., Echary, H., Mastrapa, J., \& Pico 1998). Twenty-four specimens with a range of different $L / D$ ratios $(2 / 1,3 / 1,4 / 1$, and $5 / 1)$ were tested under an axial load. The specimens were confined by using FRP with different thicknesses $(0.057,0.087$, and $0.117 \mathrm{in.}$.). The results showed that both the strength and ductility of the tested columns were reduced as the $L / D$ ratio was increased due to the eccentricities and bending curvature that were observed in the long specimens $4 / 1$ and $5 / 1$.

The aspect ratio for the rectangular columns was one of the parameters that was affected by CFRP confinement efficiency. A total of 45 plain concrete columns with a height of $12 \mathrm{in}$., a constant short dimension ( $h=6 \mathrm{in}$.), and a rounded corner radius ( $r=1.2$ in.) were tested by Wu and Wei 2010 to study the effect of the aspect ratio $(b / h)$. The following variable aspect ratios $(1,1.25,1.5,1.75$, and 2$)$ were used in this study. The compressive strength for all specimens was 3500 psi. Experimental results for the axial compressive test indicated that the strength gain in confined concrete columns was reduced by increasing the aspect ratio, and there was insignificant confinement for aspect ratio 2 .

In general, the CFRP retrofit for rectangular columns usually increases the deformation capacity (ductility) significantly compared with strength (L. Lam \& J.G. Teng, 2003; Ilki, Kumbasar, \& Koc, 2004; Y. Wu, Liu, \& Oehlers, 2006). It is important 
to note that most of the experimental results were conducted on small-scale columns. The effect of the scales' size was conducted by few studies (Rocca \& Nanni, 2006; Turgay, Polat, Koksal, Doran, \& Karakoç, 2010; Y. Wang \& Wu, 2011; Liang, Wu, Ueda, Zheng, \& Akogbe, 2012). A total of 22 specimens were tested by Rocca and Nanni 2006. The variables that were investigated were the geometry of the specimens (circular, square, and rectangular), the area aspect ratio, the side aspect ratio, and a height-to-width aspect ratio. A new stress-strain model was proposed based on the results of the specimens in an experimental study (Liang et al., 2012). This study used six cylinders of plain concrete with diameters 4, 6, and 8 inches, each confined with one-ply, two-ply, and three-ply CFRP, and were tested under a compressive axial load. The results showed that size does not affect the strength gain or ultimate axial strain for the specimens that have the same confining lateral stress. This conclusion was confirmed by Elsanadedy et al., 2012 in a study where a total of 37 concrete cylinders with three different sizes that had diameter/height ratios in inches $(2 / 4,4 / 8,6 / 12)$ were retrofit with CFRP, and were tested under compressive axial load. The results showed that the specimen's size did not affect the CFRP retrofit for the columns that had a different size, but the same lateral confinement ratio. This conclusion was not observed with large-scale square columns that were experimentally tested (Rocca, 2007; Wang, Wang, \& Lu 2010; Wang and Smith 2012). In the latter experimental study, a total of 10 square plain concretes with different cross-section were retrofit by CFRP sheet in which the same lateral confinement pressure was provided for all specimens. All specimens were tested under monotonic axial compressive load. The results showed that the improvement in terms of axial stress and 
axial strain for the confined small size specimens was not the same as for the large specimens. The efficiency of the CFRP retrofit on the small size was better than that for the large size. Moreover, it was observed that the slope of the second linear portion of the stress-strain curve was less than that for the small size. It was concluded that the sizeeffect had a significant effect in reducing the CFRP retrofit efficiency on square columns compared to circular columns (Wang et al., 2010). The inability of CFRP retrofit to restrain the dilation of concrete on the straight side of square columns increased as the square columns size was increased.

\subsection{Axial Stress-Strain Model for CFRP Confined Concrete Columns}

The early stress-strain model that was used for CFRP retrofit concrete was the steel confinement stress-strain model developed by Mander, Priestley, \& Park (1988) as shown in Fig. 2.2. This model was developed based on numerical stress-strain relationship for concrete that was proposed by Popovics 1973. However, based on massive experimental tests, this stress-strain relationship was inappropriate to represent the stress-strain behavior for CFRP confined concrete. Moreover, the steel confinement model does not give a close prediction of the peak stress (Teng et al., 2007). Because the steel and CFRP have different mechanical properties, the lateral confinement pressure that is produced by steel confinement is constant after yielding while the confinement pressure of the CFRP-confinement is continually increased. Extensive experimental studies were conducted on CFRP confinement circular concrete columns, and most of the existing stress-strain models have been developed based on these studies (Lam, L. \& 
Teng, 2003). Based on the loading pattern, there are two types of stress-strain models: monotonic stress-strain model, and cyclic stress-strain model.

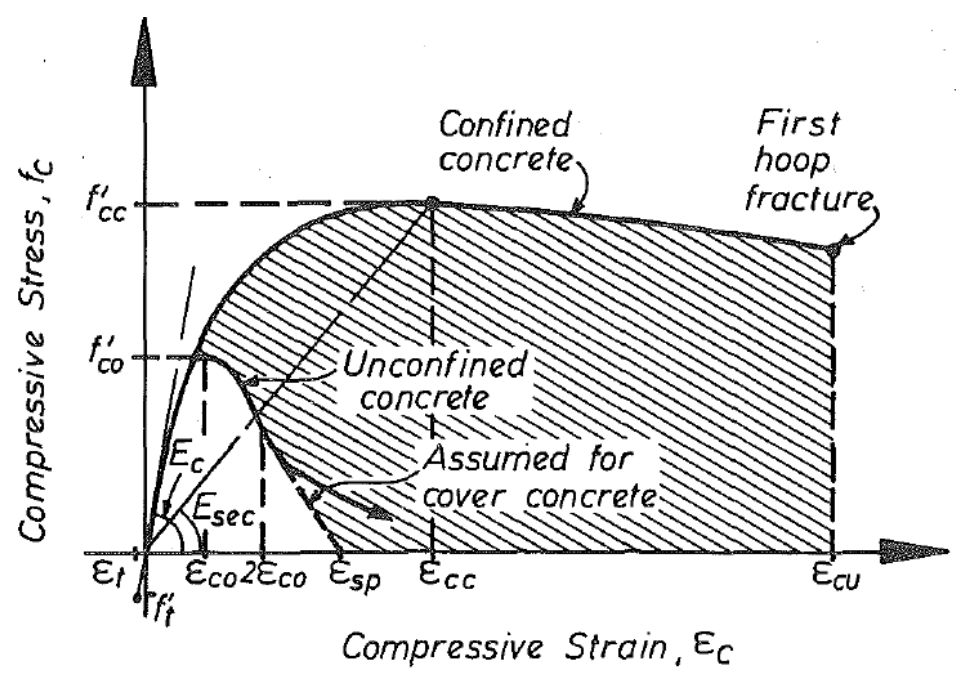

Figure 2.2: Stress-Strain Model (Mander, J. B., Priestley, M. J. N., \& Park, 1988)

\subsubsection{Monotonic Stress-Strain Model}

In general, the stress-strain models proposed for monotonic loading test have been classified into two groups: analysis-oriented models that use an incremental numerical approach that treated the CFRP and concrete core separately, and design-oriented models, which are closed-form equations that are directly developed from the experimental results and treat the CFRP-confined concrete as one composite material (Jiang \& Teng, 2007). Analysis-oriented models require a non-linear finite element analysis program, and are mostly used to obtain more accurate results and a better account of the concrete-fiber interaction behavior. In contrast, the design-oriented models are very simple and easy to use for both design and analysis. Ozbakkaloglu, Lim, \& Vincent (2013) assessed the 
analysis-oriented models and the design-oriented models by comparing the models with the experimental results for 730 tests collected from 92 experimental studies. All of these specimens were tested under monotonic axial load. It was concluded that the designoriented models generally performed better than the analysis-oriented models in predicting the ultimate strength and ultimate strain.

In order to assess the validity of using the design-oriented models, a few researchers (Zafra \& Kawashima, 2008; Liu, He, Luan, Guo, \& Liu, 2013; Teng, Lu, \& Xiao, 2011) have used design-oriented models, and the theoretical results have shown good agreement with experimental results. Moreover, for determining the best model that gives the closet prediction for CFRP-confined concrete behavior (Fahmy, Ismail, \& Wu, 2017) conducted an assessment of 14 design-oriented models. The Lam, L. \& Teng (2003) model adopted by ACI 440.2R-17 is one of the design-oriented models that was used in this study. The numerical results showed that all design-oriented models achieved good agreements with experimental results.

It is important to mention that most of the proposed stress-strain models were derived from test results that were conducted on circular CFRP retrofit concrete. Rectangular shape is one of the most common types of RC columns used in real structures. Therefore, extensive experimental studies have been conducted on the CFRP retrofit rectangular concrete columns to understand their behavior under axial compressive test (Lam, L. \& Teng, 2003; Wang \& Wu, 2008; Turgay, Polat, Koksal, Doran, \& Karakoç, 2010). Many stress-strain models for rectangular CFRP-confined concrete have been proposed (Lam, L. \& Teng, 2003; Youssef, Feng, \& Mosallam, 2007; 
Yu-Fei Wu \& Zhou, 2010). The ACI 440.2R-17 (2017) adopted the design-oriented stress-strain that was proposed by Lam and Teng 2003. This model was originally an extension of the stress-strain model for circular FRP-confined concrete with modifications to the shape factors that also considered the effect of the corners configuration, the cross-section of effectively confined concrete, and the aspect ratio of the cross-section sides on the confinement pressure distribution. This model will be illustrated in details in Chapter 3.

\subsubsection{Cyclic Stress-Strain Model}

One of the most important applications for the CFRP retrofit is to enhance the strength and ductility of the RC members during an earthquake. Therefore, it is very important to understand the behavior of the stress-strain behavior for CFRP retrofit concrete under cyclic axial compression. Only a few studies on the cyclic stress-strain behavior of the confined concrete (Lam, Teng, Cheung, \& Xiao, 2006; Lam \& Teng, 2009; Z. Wang, Wang, Smith, \& Lu, 2012; Yu, Zhang, \& Teng, 2015) have been compared with studies conducted on the monotonic axial compressive tests. The main features for the cyclic stress-strain model are: envelop curve, which is like the monotonic stress-strain curve, and the unloading/reloading loops. Lam et al. (2006) experimentally tested six concrete cylinders where half of them were confined with one-ply and the other half with two-plies of CFRP under cyclic axial compressive test with displacement control with a constant rate $0.6 \mathrm{~mm}$ per minute. In this test, the experimental results were compared with an available monotonic stress-strain model that was developed (Lam \& Teng, 2003). The results showed that the loading and reloading loops had little effect on 
the stress-strain envelope, and that the monotonic stress-strain model can be accurately used to predict the compressive strength and ultimate axial strain. The next study conducted by Lam \& Teng (2009) developed a cyclic stress-strain model that consisted of three parts: the monotonic stress-strain that was developed (Lam \&Teng, 2003), an equation for predicting the loading and unloading path, and another equation for predicting the permanent strain and stress deterioration. Based on the limited previous experimental results that were conducted on the normal compressive strength, the model stress-strain results achieved good agreement with the experimental results. A new cyclic stress-strain model was proposed by Yu et al. (2015). This model was developed based on a large number of experimental results that were conducted on normal and high strength concrete that were retrofit with CFRP. The proposed stress-strain model provided reasonably accurate predictions for normal and high strength CFRP-confined concrete.

\subsection{CFRP-Strengthened Rectangular RC Column Tested under a Combination of Constant Axial Load and Cyclic Lateral Load}

The existence of vulnerable RC columns in buildings located in active earthquake zones leads to severe damage in these building. The use of the CFRP composites materials for increasing the compressive strength and ductility of the RC columns has been successfully developed and experienced all over the world. Many experimental studies have been conducted to investigate and assess the behavior of the RC columns that are retrofit laterally with FRP to improve the shear resistance and deformability (Seible, Priestley, Hegemier, \& Innamorato, 1997; Iacobucci, Sheikh, \& Bayrak, 2003; 
Sause, Harries, Walkup, Pessiki, \& Ricles, 2005; Harajli \& Dagher, 2008; YF Wu, Liu, \& Wang, 2008; Faustino, Frade, \& Chastre, 2016; Al-Khafaji, H. L., 2016; Ouyang, Gao, Zhen, \& Lu, 2017; Truong, Kim, \& Choi, 2017).

On the other hand, some researchers have conducted experimental studies on testing RC columns strengthened longitudinally by using CFRP sheet or stripes (Barros, Sena-cruz, Dias, Ferreira, \& Fortes, 2004; Olivova \& Bilcik, 2009; Bournas \& Triantafillou, 2009; Vrettos, Kefala, \& Triantafillou, 2013). Moreover, some of the experimental studies were conducted using longitudinal CFRP for restoring the strength for a damaged RC column (Belarbi, Silva, \& Bae, 2008; He et al., 2013).

\subsubsection{Lateral Confinement for Rectangular RC Columns}

The efficiency of CFRP retrofit in lateral confinement has been investigated and improved by extensive experimental studies. The use of the CFRP retrofit in the lateral direction helps to improve both the shear capacity and the rotation capacity of the plastic hinge region, where the maximum moment is concentrated. In this section, the results of some experimental tests conducted on the RC columns are discussed.

Eight large-scale RC columns retrofit with CFRP sheets were tested by Iacobucci et al. (2003). In this test, the main variables were the number of CFRP layers applied in the lateral direction, and the axial load level. These columns were tested under constant axial load and lateral cyclic load. The steel reinforcement details were designed based on pre-1971 ACI code. Based on the experimental results, an increase was observed in the displacement ductility and energy dissipation for the CFRP retrofit columns compared 
with the un-retrofit columns. The axial load level affected the CFRP-confinement behavior because the higher axial load increased the degradation rate in the inelastic range. Therefore, it was concluded that with increasing axial load level the number of CFRP layers needed to be increased. The effects of the concrete dilation on the straight side of the CFRP retrofit square column was addressed by Wu et al. (2008). In series of tests, CFRP-anchors were used to increase the confinement of the concrete in the straight side zones. Six half-scale columns were tested under a cyclic lateral load and constant axial load. The results showed that CFRP anchors help to reduce the strength degradation and increase the energy dissipation of the column. The effect of a CFRP retrofit on a slender column was investigated by limited number of researchers. Slender RC columns with a shear span ratio equal to 6.4 were experimentally investigated by D. Bournas et al. (2009). In part of this study, a control and CFRP retrofit column with a square crosssection were tested laterally with a constant axial load $0.275 A_{c} f_{c}^{\prime}$. Two layers of CFRP sheets were used on square column at the plastic hinge regions. The test results showed an improvement in strength degradation and ductility with the ductile failure mode.

\subsubsection{Flexural Strengthening of Rectangular RC Columns}

The use of CFRP material in the flexural strengthening of concrete columns at the potential plastic hinge regions can only be used in a case where the strengthening transfers the inelastic deformation from the columns to other locations (ACI 440.2R-17, 2017). Due to the difficulty of achieving adequate development length for the longitudinal CFRP at column-stub interaction, where the maximum flexural moment is 
concentrated, only a limited amount of studies have been conducted using CFRP sheets in flexural strengthening for columns (Li, Lv, Zhang, Sha, \& Zhou, 2013; del Rey Castillo, Griffith, \& Ingham, 2018; Mahdavi \& Tasnimi, 2018).

One of the most common structural issues in vulnerable RC frames is the unsatisfactory strong-beam/weak-column behavior that during an earthquake leads to concentrate the cracks at the plastic hinges in $\mathrm{RC}$ columns before hinges form in the beams, which reduces the RC frame displacement ductility resulting in sudden collapse. In addition, some RC columns are affected by corrosion, which eventually leads to a reduction in the strength of the RC columns. In order to overcome these problems, a practical solution is to increase flexural strength of RC columns. Few experimental studies have been conducted on improving RC columns strength mainly because most focus have been on the ductility by using different types of materials and techniques. The use of FRP materials for structural strengthening and repairing has increased during the last few decades due to the several advantages of FRP compared with conventional materials like steel. Two techniques have been used for strengthening RC columns: Near Surface Mounted (NSM) technique, and Externally Bonded Reinforcement (EBR). In the NSM method, CFRP material, rebar, or lamina are placed inside a pre-cut groove in the concrete cover of an $\mathrm{RC}$ element and the groove is filled with an appropriate filler such as epoxy or specific mortar. On the other hand, in the EBR method, the CFRP material, sheets mostly, are placed on the prepared surface of the RC element.

A few researchers have implemented the NSM technique for strengthening RC columns. Barros et al, 2004 conducted experimental tests using the NSM technique to 
strengthened rectangular RC columns. In tests, three grooves were first cut into the concrete cover on both sides of the column. Then, CFRP reinforcement in the form of CFRP lamina strips were bonded with an appropriate groove filler. The columns were tested under a constant axial load $0.22 f_{c}^{\prime} A_{g}$ and a lateral cyclic load, three cycles in each increment. The test results show good improvement in the lateral load carrying capacity. The maximum tensile strain measured on the CFRP lamina strips was approximately 0.01. However, in some cases, the CFRP failed with very low tensile strain. Moreover, another analytical and experimental study on strengthening rectangular RC columns by using NSM technique was done by Olivova \& Bilcik, 2008, in which RC columns were strengthened with CFRP lamina strips. The specimens were tested under combination of constant axial load of $0.125,0.225,0.325,0.375$, and $0.425 f_{c}^{\prime} A_{g}$ respectively, and lateral cyclic load. Based on results, an improvement in the lateral capacity was obtained in the strengthened specimens. In this test, it was observed that the maximum measured tensile strains for the CFRP strips ranged between high tensile strain, close to the tensile rupture of the CFRP coupon, and very low strain, where the concrete did not crack. The instability in the tensile strength of the CFRP strips at the failure created a need to find other methods to strengthen the column with CFRP in the longitudinal direction. Bournas and Triantafillou (2009) investigated the effect of a NSM configuration, parallel or perpendicular CFRP strips to strengthened column sides, on the strengthening efficiency for RC rectangular columns. The columns were designed to fail by yielding the longitudinal reinforcement bars. All columns were tested under a combination of the constant axial load of $0.2 f_{c}^{\prime} A_{g}$ and a cyclic lateral load. An improvement in the lateral 
load carrying capacity was observed for all specimens. The contribution of the NSM configuration affected the maximum tensile strength for the specimens. The perpendicular strips achieved a tensile strain about 0.009 with drift ratio of $3 \%$, and the mode of failure was a tensile rupture at the column base. On the other hand, the parallel strips showed poor behavior with 0.005 in tensile strain and a $2 \%$ drift ratio. The CFRP strips buckled where the column was compressed, which led to the early de-bonding of the CFRP strips. However, this premature damage was controlled by adding a layer of CFRP sheet in the lateral direction in the region within $2.4 * h$. The tensile strain was increased to 0.016 , and 0.0085 in push and pull direction respectively. Moreover, the drift ratio was increased to $4 \%$, and the lateral load capacity was increased by $46 \%$ compared with the control column.

Due to the complexity of the anchorage system at the maximum moment zone, a few researchers have experimentally tested RC columns that were longitudinally strengthened by using the EBR technique. Belarbi et al. (2008) tested the effects of CFRP reinforcement on the rehabilitation of a damaged RC circular column. In this study, the CFRP sheet was mounted in the longitudinal direction to restore the lateral strength of the damaged column. A CFRP sheet was also used for lateral confinement at the plastic hinge region. The longitudinal CFRP sheet was anchored to the column base by using a steel expansion bolt and CFRP procured plate. A lateral cyclic load with a constant axial load, $0.07 f_{c}^{\prime} A_{g}$, was applied on the column during the test. It was observed that the anchorage system failed at very low lateral load level due to the pull-out mode of failure. The contribution of the longitudinal CFRP sheet was very small due to the premature 
failure of the anchor system. Lately, He et al. (2013) experimentally investigated the use of longitudinal and transverse CFRP to restore the strength of damaged rectangular RC columns. In order to anchor the longitudinal CFRP sheet to the column base and avoid pulling-out failure mode, a novel CFRP anchor was designed. However, results showed that the maximum tensile strain of 0.00244 that was obtained when the longitudinal CFRP sheet was damaged, which was very low. The premature damage of the longitudinal CFRP was contributed to the anchor's configuration with a sharp edge that cut the CFRP when it touched the end. Increasing the tensile strain in the longitudinal CFRP mostly depended on the anchor system. Vrettos et al. (2013) investigated the use of a CFRP anchor that had a form like spikes. A bundle of fibers soaked in epoxy at one end was inserted inside a pre-drilled hole located in the column's base and the other end was splayed out and glued onto the longitudinal CFRP sheet. Prepared CFRP anchors were used to anchor the longitudinal CFRP to the column base. Different size and number of CFRP anchors were tested under a lateral cyclic load with a constant axial load $0.254 f_{c}^{\prime} A_{g}$. A good improvement in strength was achieved. It was observed that the failure mode in all cases was a tensile rupture of the anchors. The maximum tensile strain, calculated based on strain compatibility of the cross-section for the longitudinal CFRP sheet, was 0.0047. More recently, del Rey Castillo et al. (2018) conducted an experimental test on strengthening RC columns with a longitudinal CFRP sheet anchored to the column base by using a CFRP anchor. Two and three layers of CFRP sheet were used to increase the flexural strength of the columns with different sizes of CFRP anchors. Based on the experimental results, it was concluded that the use of a CFRP sheet 
with a CFRP anchor improved both the effective stiffness and the lateral strength of the $\mathrm{RC}$ columns. Moreover, the effect of the cyclic compression-tension stress on the longitudinal CFRP sheet's capacity was not significant.

\subsubsection{CFRP Anchor's System}

The efficiency of the CFRP anchor is related to the amount of tensile strength capacity that the CFRP can reach before rupture (ACI 440.2R-08, 2008). Using CFRP sheet for flexural strengthening largely depends on the CFRP anchor by preventing or delaying CFRP debonding (Niemitz, James, \& Breña, 2010). The properties of CFRP, brittle and anisotropic, increases the complexity of improving the efficiency of the anchor, so it is highly recommended to investigate any proposed anchor before use in the field (ACI 440.2R-08, 2008). There were many attempts to improve the FRP connection with the concrete surface, and various types of FRP anchors have been implemented (Niemitz et al., 2010). One of the most common types of FRP anchors is U-Anchor. A UAnchor is the bent portion from FRP embedded inside a prepared groove filled with high viscosity epoxy, as shown in Fig. 2.3. A U-Anchor is basically used to transfer tensile strength between the CFRP sheet and column's foundation to develop tensile strength in FRP sheet at the critical section where space is not enough for the development length or close to an abrupt change in FRP direction, such as at the junction of two orthogonal members. In general, the U-Anchor' strength is typically controlled by the shear and tensile strength of the bond between the concrete surface and the epoxy. This type of bond depends on the properties of both the concrete and the epoxy, which may not be 
enough to prevent debonding when the strength demand is high (Grelle \& Sneed, 2013). Many experimental studies have been conducted to improve the U-Anchor capability in the load transfer mechanism. Experimental study was conducted by Khalifa et al. (1999) using a CFRP U-Anchor for FRP shear strengthening an RC T-beam, and it was observed that the U-anchor increased the shear capacity by $30 \%$. No CFRP debonding was observed compared with CFRP strengthening without a U-Anchor. In this test, the role of the U-Anchor was to increase the developed length of the CFRP sheet at a critical section. Using the U-Anchor in strengthening the damaged RC shear walls was studied by T. Nagy-György, M. Moşoarcă, V. Stoian, J. Gergely (2005). In this study, CFRP sheet was used to strengthen the flexural-shear by using the U-Anchor to connect the longitudinal CFRP with foundation. Based on the experimental results, it was found that the major failure mode was controlled by the strength capacity of the CFRP U-Anchor, which is limited. In order to increase the tensile strength of the U-Anchor, a mechanical steel system was proposed that basically consisted of a steel angle placed on top of the UAnchor and bolted to a column's foundation, as shown in Fig. 2.4. In this test, the anchorage system behaved successfully without any degradation. Based on experimental studies conducted by Lombard (1999); and Hiotakis (2004), it was observed that using a bolted steel angle for a CFRP anchor for flexural strengthening produced a prying action that led to the CFRP sheet pulling away from the concrete surface. The eccentricity between the load carried by CFRP, and the centerline of anchored bolts, led to an early failure in CFRP sheet, as shown in Fig. 2.5. Under a cyclic load, repeat loading and unloading generated a lateral deformation that started at the top of steel angle with a 
combination of tensile forces, which led to a break or a cut in the CFRP sheet. However, for shear walls, using the CFRP for shear strengthening meant that the lateral load direction was out-of-plane (only tensile forces were applied on the anchor), while the behavior of the anchor was different if the lateral motion was in plane. Moreover, the use of an external steel anchor device was undesirable due to corrosion (Godat et al., 2017). Therefore, the need for a CFRP anchorage device that provides a sufficient tensile strength without affecting by cyclic lateral load direction and corrosion free is crucial.

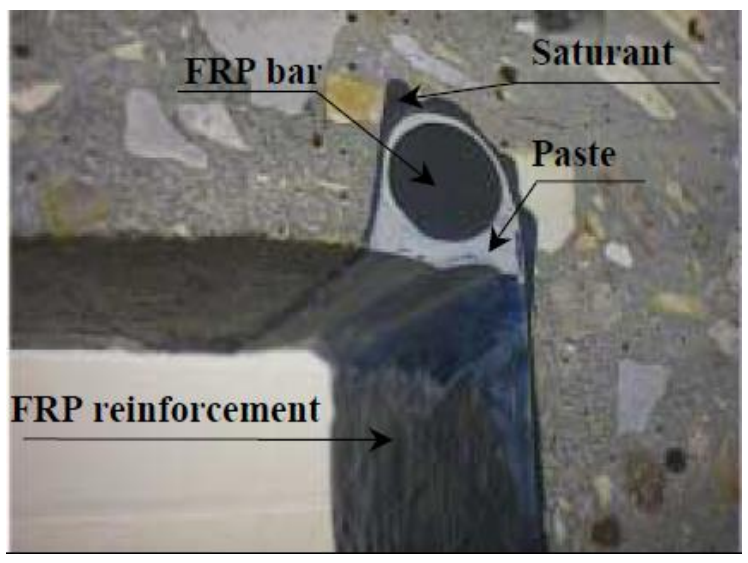

Figure 2.3: FRP U-Anchor 


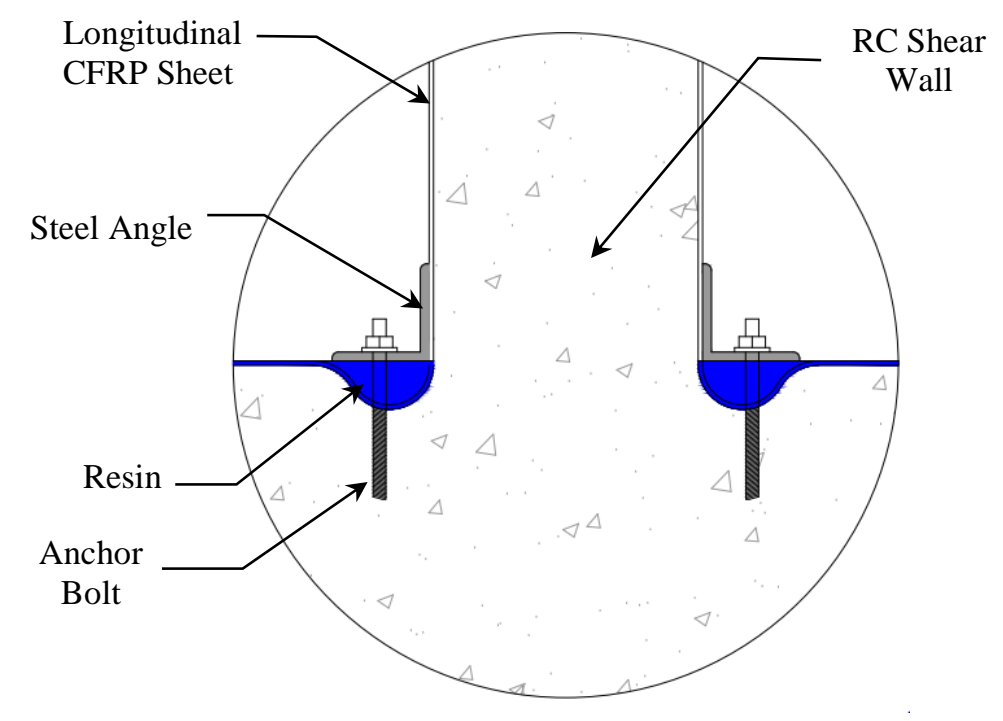

Figure 2.4: Bolted U-anchor with Steel Angle for Shear Strength

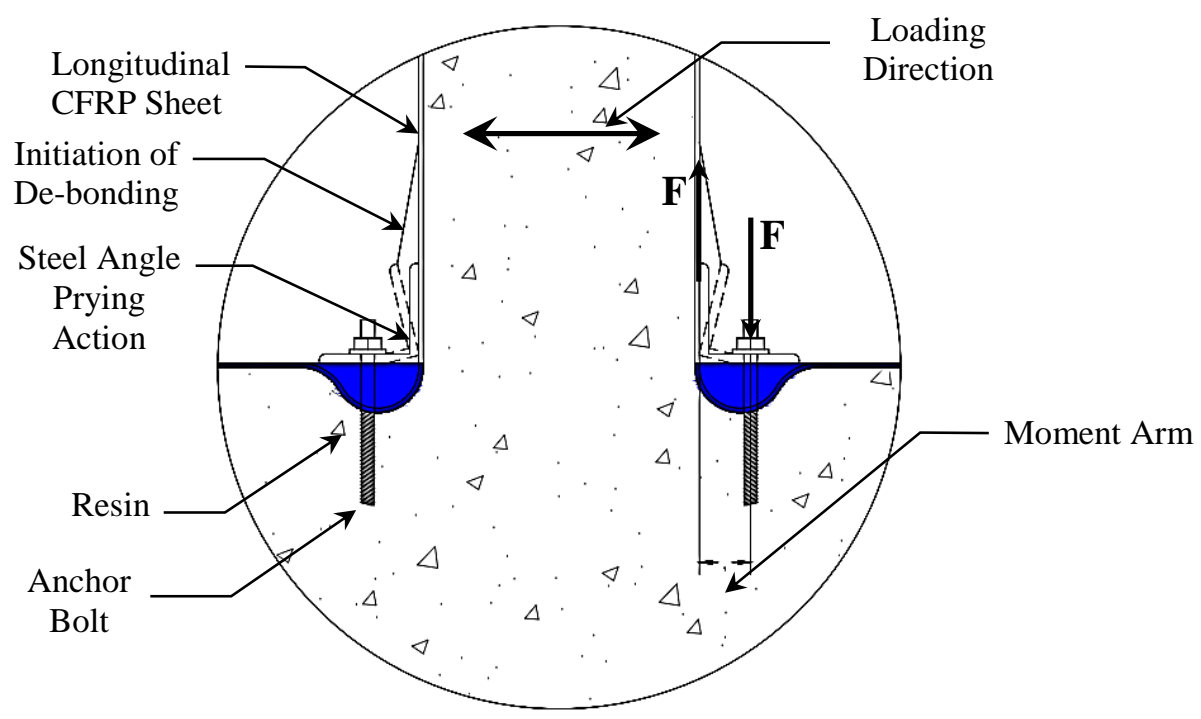

Figure 2.5: Bolted U-anchor with Steel Angle Prying Action

\subsection{Slender RC Columns}

In general, a slender column is a column where the strength is significantly reduced by the effect of the secondary moment. The secondary moment, $\mathrm{P}-\Delta$, develops as 
a result of applying an axial load, $\mathrm{P}$, multiplied by the off-axis displacement, $\Delta$. The effect of $\mathrm{P}-\Delta$ in reducing column strength is increased by increasing the lateral displacement. Fig. 2.6 illustrates the effect of the slenderness of the RC column on the axial load and the bending moment capacities. Although the interaction diagram for the $\mathrm{RC}$ columns is the same for the cross-sections in the three different slenderness ratios: short, slender, and very slender, their failure modes are different. For the first and second case, the mode of failure is controlled by the strength limit of the materials. However, the third case mode of failure is controlled by buckling, which is when the column reaches its buckling load limit before the materials reach their strength limits. Buckling failure is an undesireable type of failure because it happens suddenly without warning, and is brittle. Very slender RC columns under high axial load are vulnerable to instability failure, which is the reason why building codes limit the slenderness of columns.

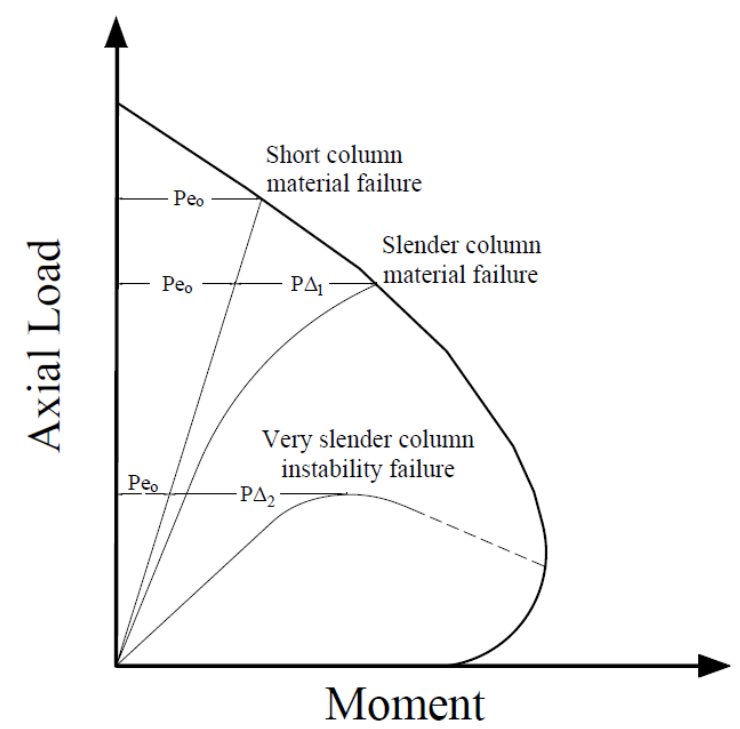

Figure 2.6: the Effect of Slenderness on the Interaction Diagram 


\subsubsection{Effect of the Second-Order Moments P-A}

The result of the lateral displacement of the RC column that is produced by the lateral load with an existing axial load lead to the development of additional moments, P$\Delta$. The added moment is increased as the lateral displacement increases, which adds an extra moment to the primary moment that is produced by a lateral load (Ferguson \& Breen, 1966). With a limited bending capacity provided by a column's cross-section, the lateral strength capacity of the RC columns is reduced, as shown in Fig. 2.6. Many studies have focused on the P- $\Delta$ effect on the RC columns' behavior. The early analytical and experimental studies that investigated the effects of many variables on the slender RC column behavior were conducted by Ferguson, P. M. \& Breen, J. E. (1966); MacGregor, J. G., Breen, J. E., \& Pfrang, E. (1970); and MacGregor, J. G. (1993).

The behavior of the rectangular RC slender column in the frame subjected to a lateral load was conducted by Ferguson \& Breen (1966). The three series of RC slender columns included: an isolated slender column, a slender column as part of the frame subjected to single curvature, and a slender column as part of a frame subjected to reversed curvature. Based on the results, it was concluded that a significant strength reduction was observed when the shear span to depth ratio was $L_{s} / h=5$, and the reduction was increased when the ratio was $L_{S} / h=10$. The failure mode for the column with $L_{s} / h=5$ was essentially developed by reaching the materials capacities before frame failure. However, a primarily frame instability failure mode was observed for the column with $L_{s} / h=10$. 
Burgueño et al. (2016) investigated the P- $\Delta$ effect on reinforced slender columns with a shear span to cross-section ratio of 12 . Two large-scale slender RC columns with a deferent reinforcement ratio of 0.015 and 0.03 were subjected to a constant axial load of $0.05 A_{g} f_{c}^{\prime}$ and a cyclic lateral load. The test results showed that the column with the lower longitudinal reinforcement ratio was more affected by P- $\Delta$. Increasing the member strength is a method that is used to compensate for the P- $\Delta$ effect on the slender columns (Paulay, 1978; Pettinga \& Priestley, 2008).

Under a high axial load, the P- $\Delta$ effect can cause instability and sudden failure in the slender column even with a small lateral displacement. Therefore, many available design codes provide a limit for the acceptable amount of the P- $\Delta$. The stability index is defined as the ratio of the secondary moment to the total moment, secondary moment plus primary moment. MacGregor, E. Hage (1977) conducted an analytical study on a RC frame, and concluded that the probability of stability failure increases rapidly when the P$\Delta$ exceeds 0.2 of the base moment capacity. American Concrete Institute (ACI, 2014) adopted a 1.4 as a maximum limit for the ratio of the total moment to the primary moment. On the other hand, ASCE 7-10, 2010 considers a 0.25 as a limit for the stability index coefficient. Moreover, in different studies (Priestley, Michael J. N; Seible, F; \& Calvi, 1996; Silva \& Sangtarashha, 2012), the stability index was increased to 0.3 and 0.4, respectively. Burgueño et al. (2016) compared these limits with the results of their experimental test for two slender RC columns, $L_{s} / h=12$, and observed that both columns exhibited a stable response beyond the stability limits mentioned above. 


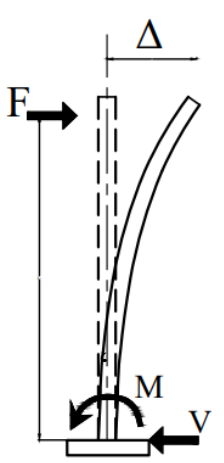

Without P- $\Delta$

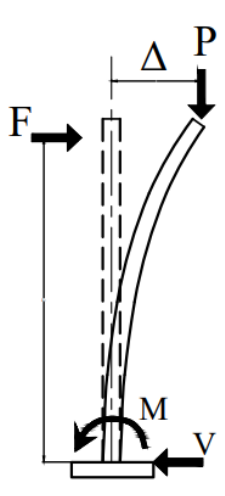

With P- $\Delta$

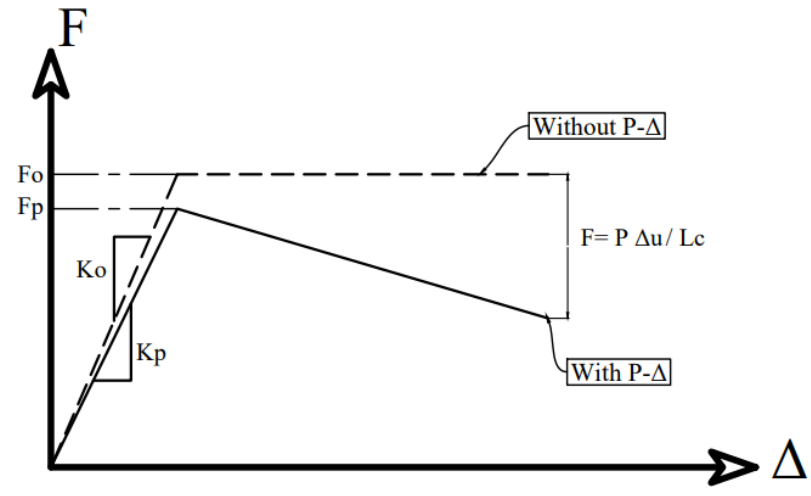

Figure 2.7: P- $\Delta$ Effect on the Slender RC Column

\subsubsection{Ductility of Slender Column}

In order to provide an overall inelastic response in a structure during an earthquake, seismic design provisions require inelastic deformation to develop in plastic hinge regions. The term displacement ductility, which is the ratio of ultimate displacement including inelastic displacement to the yield displacement, is used to define the amount of inelastic ductility that structure can provide during an earthquake while keeping its vertical load-carrying capacity. Therefore, the displacement ductility is an essential property of structures when subjected to an earthquake.

In order to determine the displacement ductility for RC columns, there are some approaches used for calculating the maximum lateral displacement, which basically depend on the shear capacity of the RC column (Ghee, Priestley, \& Paulay, 1989; Wong, Paulay, \& Priestley, 1993; B. M. J. N. Priestley, 1994). In general, determining the maximum displacement corresponding to a strength decay of $20 \%$ of the measured maximum lateral strength is one of the most common approaches. It has been assumed 
that exceeding this limit, as mentioned above, leads to lateral instability. Moreover, this limit has been determined based on a large database of the experimental tests conducted on RC columns mostly considered as non-slender columns. For slender RC columns under a high axial load, considering the $20 \%$ decay in the lateral strength as a limit for displacement ductility is considered severe (Saatcioglu \& Baingo, 1999; M Saatcioglu \& Razvi, 2002). ACI Committee 374 (2013) recommended to identify the deformation corresponding to $20 \%$ decay in the lateral strength. It has also been recommended to continue the test to at least $50 \%$ decay in the lateral strength to evaluate the collapse behavior.

The displacement ductility of slender RC columns is affected by the $\mathrm{P}-\Delta$, which reduces the lateral strength in the inelastic domain, as shown in Fig. 2.6. Also, the lateral load carrying capacity is reduced relative to an increase in the lateral displacement, $\Delta$. The ductility of slender RC columns has been investigated by several studies ( Barrera, Bonet, Romero, \& Fernández, 2012; Silva \& Sangtarashha, 2012; Burgueño et al., 2016). An experimental test (Barrera et al., 2012) was conducted to investigate the effect of the slenderness of RC columns on ductility. Forty slender RC columns were prepared in order to investigate the effect of concrete strength, shear span ratio, axial load level, and transverse and longitudinal reinforcement on the ductility. All specimens were subjected to a constant axial load and a monotonically increasing lateral load. The test results showed that the displacement ductility decreased by increasing the concrete strength and longitudinal reinforcement ratio, and increased by increasing the confinement level. In 
this study, the maximum lateral displacement was determined based on the $20 \%$ drop in the lateral strength.

On the other hand and especially for slender columns, there were attempts to relate the displacement ductility limit with the stability limit instead of the $20 \%$ drop in the lateral strength (Silva \& Sangtarashha, 2012; Barrera, Bonet, Romero; \& Miguel, 2011, Burgueño et al., 2016). In addition to the performance limit states defined by a particular damage state as described by Hose, Silva, \& Seible (2000); and Silva \& Sangtarashha (2012) proposed an additional limit state based on the stability limit for slender RC columns. In this study, the displacement ductility for the slender columns was analytically determined by considering 0.4 as a limit for the stability index. The relationship of the performance level of the RC column to the stability limit was one of the most important outcomes of the study. It was concluded by Burgueño et al. (2016) that the displacement ductility for the slender RC columns with $L_{s} / h=12$ based on the stability limit 1.4 , the ratio of the total moment to the primary momenta, adopted by ACI (2014) is very conservative especially with a slender column that has low reinforcement steel ratio. However, the displacement ductility was significantly improved when the proposed stability limit by Silva and Sangtarashha (2012) was used.

\subsubsection{Strengthening RC Slender Columns with CFRP}

A few experimental studies have been conducted on strengthening a slender RC column with FRP to investigate the ability of strengthening technique to improve the behavior of slender RC column subjected to a combination of a constant axial load and a 
cyclic lateral load (Eshghi, S; \& Zanjanizadeh, 2008; Jaya \& Mathai, 2012; Sadone, R., Quiertant, M., Mercier, J., 2012). In Eshghi, S, \& Zanjanizadeh (2008) study, six halfscale slender RC columns ( shear span to depth ratio $=5.33$ ) were constructed with low reinforcement steel ratio, $\rho=0.0178$, and large spacing between transverse reinforcement. These columns were retrofit with four layers of bidirectional GFRP at the plastic hinge zone with height of 1.6 column's width. All slender columns were tested under a cyclic lateral load and three levels of constant axial loads, $0.05 A_{g} f_{c}^{\prime}, 0.10 A_{g} f_{c}^{\prime}$, and $0.15 A_{g} f_{c}^{\prime}$. Test results showed that the GFRP retrofit improved the flexural strength and ductility. It was also observed that the failure mode of the slender columns was altered from flexural-shear failure to flexural failure. The effect of increasing the axial load affected the ductility of the column because the lateral strength degradation increased as the axial load level was increased. However, there was no specific explanation about the effect of the P- $\Delta$ effects on the strengthening technique with GFRP.

Strengthening the slender column is one of the practical methods used to reduce the effect of P- $\Delta$ (Paulay, 1978, Paulay \& Priestley, 1992; Pettinga \& Priestley, 2008). It was suggested by Paulay (1978) to increase the lateral strength of the slender RC columns to the limit, where the same amount of energy for the column tested without P- $\Delta$ effect can be provided, as shown in Fig. 2.8. An increase in the base moment capacity of the slender RC column by 50\% was recommended by Pettinga \& Priestley (2007). 


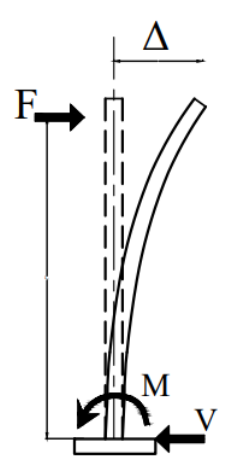

Without P- $\Delta$

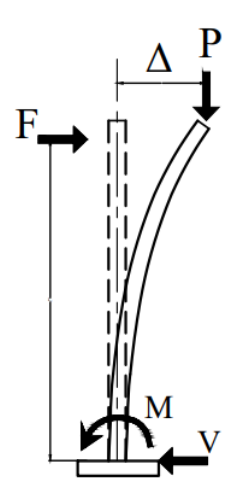

With P- $\Delta$

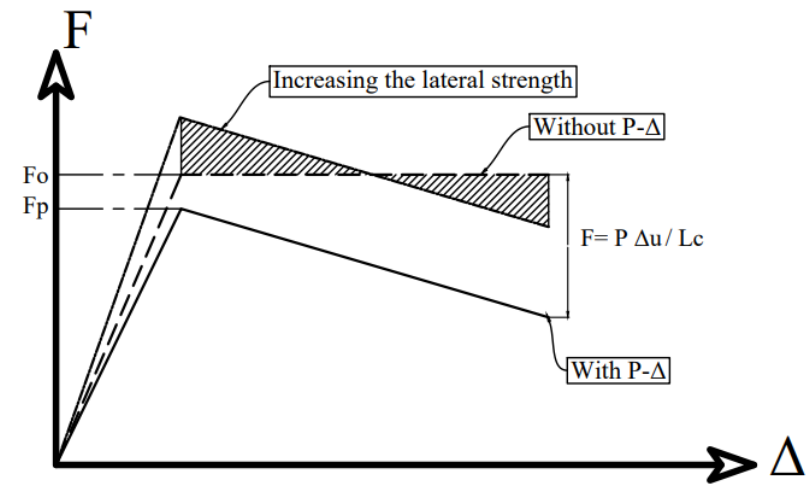

Figure 2.8: Strengthening the Slender RC Column

Several studies increased the lateral strength of the column by adding different types of materials (Realfonzo \& Napoli, 2009; Faustino et al., 2016). Increasing the lateral strength of the columns by using steel angels was conducting by Realfonzo \& Napoli (2009). In this test, the RC columns with $L_{S} / h=5.66$ were tested under a cyclic lateral load with two levels of constant axial loads of 0.14 and $0.4 f_{c}^{\prime} A_{g}$. These columns were strengthened by placing steel angels at the four corners, and by attaching an anchorage system to the foundation using steel bolts. The whole system was laterally confined by using CFRP sheets. It was concluded that using the steel angles provided higher energy dissipation and flexural strength compared with as-built spacemen (control specimen). In this test, the effect of secondary moments was not discussed. In a different study conducted by Faustino et al. (2016) a CFRP lamina was used to increase the lateral strength of RC columns. In this study, the column was tested under a cyclic lateral load and a constant axial load of $0.14 f_{c}^{\prime} A_{g}$. The specimen was confined using 3 layers of CFRP sheets in the lateral direction after the longitudinal CFRP lamina was mounted in 
the longitudinal direction, and anchored into the foundation. Based on the test results, it was concluded that the flexural strength of the columns was increased to approximately $40 \%$ larger than as-built spacemen with good ductility behavior. The mode failure of the specimen was controlled by the longitudinal CFRP's rupture.

\subsection{Summary}

In order to have a better understanding of the topic, a summary of the relevant studies reported in this literature review is presented in this chapter. As illustrated above, several experimental studies have been conducted on strengthening RC columns with CFRP-confinement, and tested under a combination of a constant axial load and a cyclic lateral load. However, most of these studies were focused on columns with a shear span to depth ratio less than 6.5. Moreover, the use of CFRP sheets for longitudinal flexural strengthening is very limited, especially with slender RC columns. The contribution of using the longitudinal flexural strengthening is to increase the slender column strength within he elastic range, which helps to transfer plastic hinges to other locations. In order to use the CFRP in the longitudinal direction, a compatible CFRP anchor is the first challenge that needs to be addressed. Therefore, the need for more experimental studies to investigate the effect of strengthening slender RC columns with CFRP is crucial. 


\section{Chapter 3: Background}

\subsection{Reinforced Concrete Buildings with Deficient Columns}

In older RC buildings designed before 1971, RC structures were designed for either gravity load alone or for a combination of gravity and wind loads without adequate consideration for seismic loads. Therefore, many of these buildings are vulnerable to earthquakes above the moderate scale (Wu, et al., 2006). Older RC columns are one of the main causes for RC structural vulnerability due to inadequate detailing of transverse reinforcement at the plastic hinge regions (Park, 2001). Poor transverse reinforcement at the plastic hinge lead to:

a) Poorly confined concrete that reduce the rotation capacity of the plastic hinges during an earthquake.

b) Large spaces between transverse reinforcements reduce the shear capacity at the plastic hinge regions.

Configuration and spacing of the transverse reinforcements are the most important parameters affecting the ductility and strength of RC columns (Paulay and Priestley, 1992). Assessing the vulnerability of the old RC columns have attracted several researchers who focused on identifying the deficiency and determining the optimum strengthening technique that can be used to overcome the vulnerability. A total of eight full-scale columns were constructed based on the old code design requirements and tested by Lynn, et al., (1996). These columns had widely-spaced transverse reinforcement with a 90-degree end hook and a longitudinal reinforcement with and without short lab- 
splices. The columns were tested under a combination of a constant axial load and a cyclic lateral load. It was observed that the failure mode of all the specimens with poor confinement was a non-ductile failure mode concentrated at the plastic hinge regions. The failure mode included concrete crushing, rebar buckling, and opening or a rupture of the confinement reinforcement.

The failure mode of existing vulnerable RC columns that have poor reinforcement details have been classified into three main types (Murray \& Sasani, 2013; Ying and Jinxin, 2018). The first type is a shear failure, which is one of the most critical failure modes, as shown in Fig. 3.1 (a). In the shear failure mode, failure progresses as follows: an inclined crack develops where the concrete tensile capacity is surpassed causing the concrete cover to spall as the crack widths increase followed by a rupture of the transverse reinforcement. This rupture causes the longitudinal reinforcement to buckle, which fragments the concrete column core. In order to avoid shear failure, the shear capacity needs to be evaluated at both ends of the column or at the expected plastic hinge region in the column. The second failure mode is a confinement failure, which happens due to an opening or a rupture in the confinement reinforcement at the plastic hinge zones, see Fig. 3.1 (b). This type of failure is concentrated at the plastic hinge zone where the flexural cracking, concrete cover spalling, and longitudinal reinforcement buckling occur. The third failure mode is where the lap-splice bond is not strong enough to transfer the tensile forces between the column and foundation, see Fig. 3.1(c). This failure happens at the end of the column where the starter rebar is placed during the foundation construction. The flexural capacity for such a column is dependent on the bonding 
between the starter rebar and the RC column. A shorter lap splice with poor confinement causes a rapid decrease in flexural capacity due to early de-bonding. All of these types of failure have significant effects on RC buildings where failures in the columns lead to partial damage or even total collapse these types of buildings.

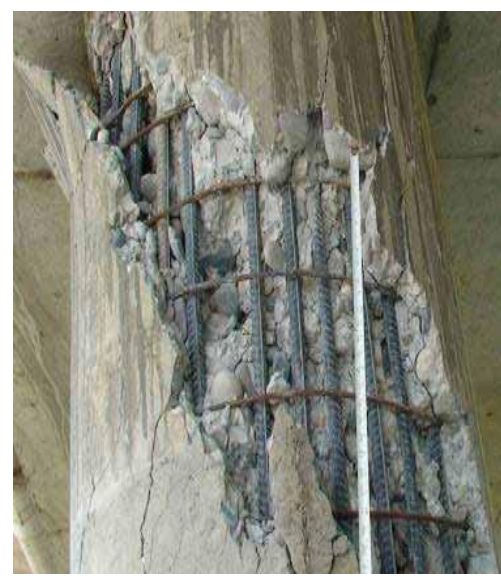

(a)

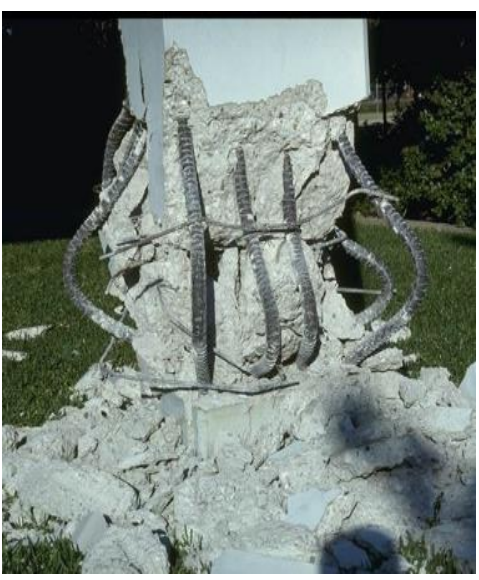

(b)

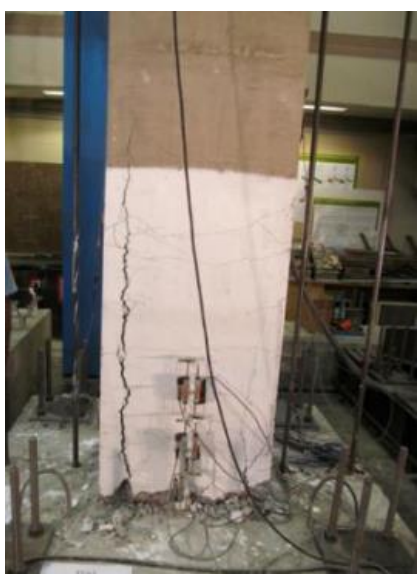

(c)

Figure 3.1: (a) Shear Failure, (b) Confinement Failure, (c) Lap Splice Failure

\subsection{Slender Reinforced Concrete Columns}

In addition to the poor transverse reinforcement, a slender column is a critical case for existing old columns due to the presence of the P- $\Delta$ effects. Under a constant axial load, the primary moment of the RC column is reduced by increasing the shear span to depth ratio up to the limit where an instability failure happens, as shown in Fig. 3.2. For the column under a combination of a constant axial load and a lateral load, the probability of the instability failure increases with an increase in lateral displacement, $\Delta$, due to increasing the P- $\Delta$ effect. This is especially true in an inelastic domain where the lateral strength degradation is increased by increasing lateral displacement. 


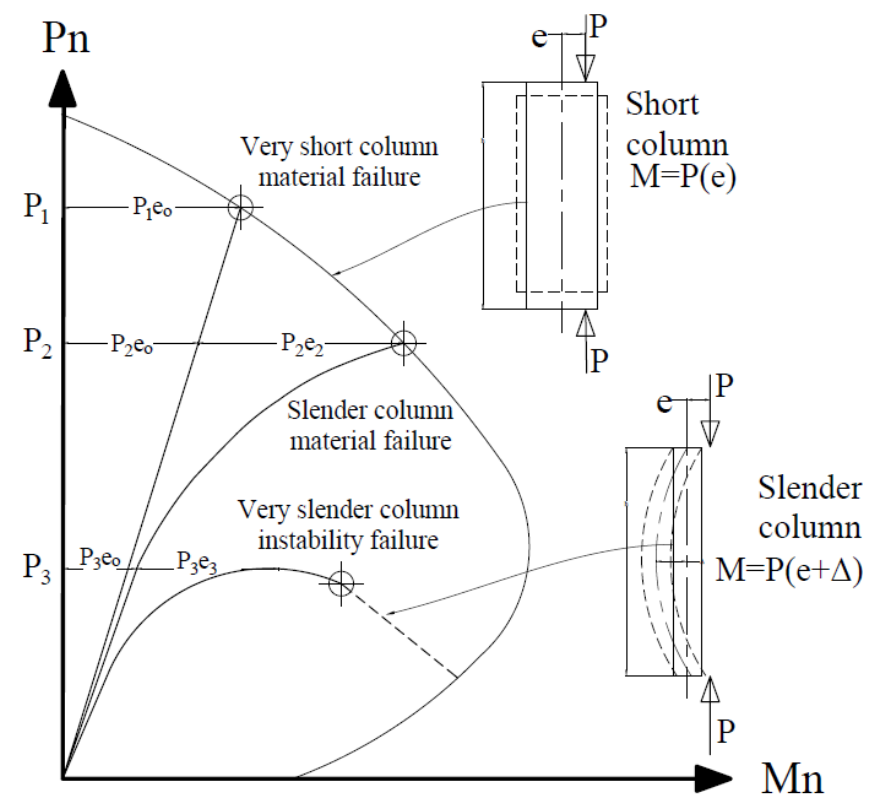

Figure 3.2: the Effect of Slenderness on the Interaction Diagram

\subsection{Retrofit Objective for Non-Ductile RC Columns}

Considering the failure modes described above, is it is necessary to achieve an effective strengthening technique for the columns. An effective strengthening would produce a retrofit column that sustains the gravity load during an earthquake by overcoming these deficiencies. While newer design codes emphasize the contribution of the transverse reinforcement details to improve the ductility and strength for RC columns, strengthening of poorly detailed columns can be done by using an external shear reinforcement techniques. Many studies have involved investigating the contribution of available techniques to improving the behavior of RC columns (Wu et al., 2006; Sichko \& Sezen, n.d., 2017; Truong, Kim, \& Choi, 2017). Wu et al. (2006); and Sichko \& Sezen (2017) conducted an extensive review and assessment to identify the key factors that 
affect the effectiveness and deficiencies of different retrofitting techniques. Based on these studies, it was found that using a CFRP retrofit is one of the most effective retrofitting methods that is used to increase the shear strength and deformation capacity of RC columns.

The CFRP retrofit is currently one of the most popular techniques used to provide sufficient shear strength for concrete structural members. Researchers and engineers have been attracted to the desirable properties of the CFRP such as the high tensile strength to weight ratio, corrosion resistance, and a relatively high fatigue resistance. Fig. 3.3 shows the tensile strength of different materials, including CFRP, in comparison with mild steel. In addition, over the past two decades, implementing the CFRP as a retrofit material for existing RC structures has increased in structural engineering applications, and is now widely accepted (Sadeghian and Fam, 2015; Zerkane, Saeed, \& Rad, 2019).

A CFRP strengthening may be designed to provide one or more of the following:

a) Increased concrete confinement in order to increase the compressive strain, and consequently improve the deformability of the column;

b) Delayed buckling of the longitudinal bars within a plastic hinge regions;

c) Increased shear strength of the column;

d) Improve d flexural strength of the column;

e) Improved bonding strength within a lap-splice length; 


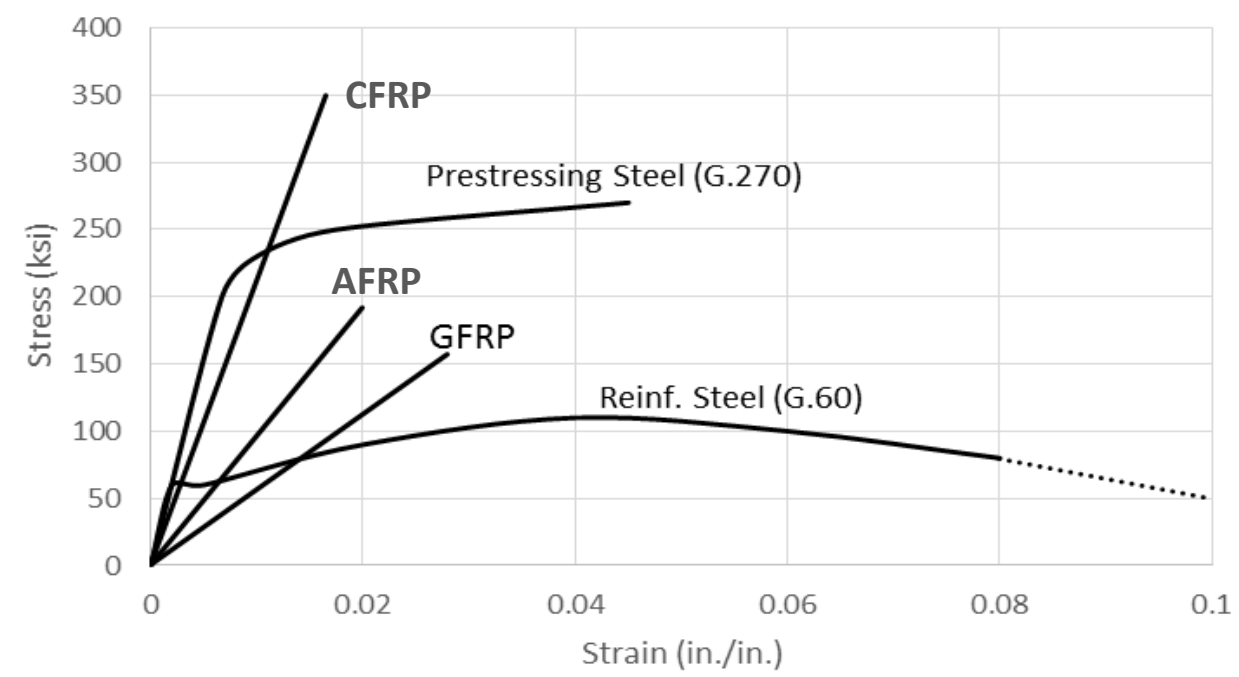

Figure 3.3: Typical Tensile Stress-Strain Curves for FRP and Mild Steel

\subsection{CFRP Retrofit for Rectangular Column}

Testing plain concrete under uniaxial compressive load is the common method that provides an axial compressive stress-strain behavior. The failure mechanism for a plain concrete is controlled by the lateral tensile strain developed as a consequence of increasing the compressive axial strain, this is also known as Poisson's effect. Longitudinal cracks grow when the lateral strain is larger than the tensile cracking strain of the plain concrete. It is well known that concrete has a weak tensile strength, therefore the crack width will increase if it is not controlled through confinement, and the plain concrete will suddenly crush when the longitudinal cracks widen. This type of failure is unstable, brittle, and undesirable. The existence of the lateral confinement for plain concrete will provide a lateral pressure that develops by increasing the tensile strength in the lateral direction. The lateral pressure confines the concrete materials, and increases 
the compressive strength and strain for the concrete. The CFRP retrofit is one of the most common methods used for externally confining RC columns. Using the CFRP composite materials as lateral reinforcement in concrete columns has been of interest to the research community over the past three decades. A large portion of previous efforts has been primarily focused on the enhancement of both the ductility and strength of vulnerable RC columns.

Understanding the CFRP retrofit mechanism in retrofitting concrete columns is important for design. The existence of a lateral CFRP retrofit in an RC column develops a radial compressive pressure in response to the lateral expansion of the concrete material. The lateral pressure increases as the lateral expansion increases until the CFRP material reaches its tensile strain limit in the hoop direction. In circular concrete columns, the lateral pressure is uniformly distributed on the concrete surfaces. In a non-circular crosssection, such as a rectangular column, a non-uniform lateral pressure is developed by the CFRP retrofit in the way that leads to a reduction in the confinement action. CFRP retrofit in rectangular columns has been widely investigated because this type of a crosssection is very common in structures. Because of existing right angled corners in the rectangular cross-section, the tensile stress in the CFRP material at these corners develops rapidly as the confinement pressure increases compare with the CFRP between the corners. Furthermore, concentration of high tensile stress at these corners produce high confinement pressures at the corners. This action leads to a non-uniform confinement pressure distribution around the column and to an early CFRP rupture. Therefore, the efficiency of CFRP confinement in increasing the axial strength for 
rectangular columns is less compared to circular columns. Rounding the corners before applying the CFRP is a practical method used to increase the FRP confinement efficiency (Wang \& Wu, 2008). Despite increasing the radius of the rounded corners to increase the efficiency of the confinement stress, the rounded corner radius is limited by the existing column reinforcement.

In addition, the existing CFRP confinement in RC columns significantly increases the strength and ductility by delaying the concrete cover spalling. This subsequently delays the longitudinal rebar buckling, and upholds the $\mathrm{RC}$ column until a large amount

of displacement occurs, which is where the CFRP sheet fractures (Bournas, Triantafillou, Zygouris, \& Stavropoulos, 2009; Fitzwilliam \& Bisby, 2010). Furthermore, the tensile deformation of the transverse reinforcements is decreased due to the existing lateral CFRP confinement, and subsequently the opening of transverse reinforcements will be avoided.

\subsection{Models for the Concrete CFRP Confined Rectangular Columns}

The CFRP retrofit technique has proved to effectively enhance the axial load capacity and axial deformability of the columns. Several studies have evaluated the ultimate compressive strength and strain enhancement of the CFRP confinement concrete. In the early studies, a stress-strain model proposed by Mander, Priestley, and Park, 1988 for steel confinement, was used to represent the stress-strain behavior of the CFRP confinement concrete. However, it was concluded that the stress-strain relationship of the CFRP confinement behavior is not related to the steel confinement stress-strain 
relation due to the diversity in tensile stress-strain behavior between the CFRP and steel. Therefore, the researchers proposed several CFRP confinement concrete models that were developed based on the large body of experimental results to give a better understanding of the CFRP confinement concrete behavior under an axial compressive stress. Most of the available models were developed based on the CFRP confinement of circular RC columns, and were then modified by "shape factor" or "efficiency factor" to apply to RC columns with a rectangular cross-section. This factor intended to include the non-uniformly lateral confinement pressure distribution for a non-circular cross-section of columns. In the next section, the discussion will focus on the proposed models and the shape factor for the CFRP confinement rectangular columns.

\subsubsection{Shehata et al. (2002)}

Shehata, Carneiro, \& Shehata (2001) proposed equations to calculate the axial strength and strain for the square and rectangular cross-section confined laterally with CFRP. These equations were developed based on the experimental results of the 54 short columns tested under an axil compressive stress. The equations are given as following below:

a) For square cross-section

$$
\begin{aligned}
& \frac{f_{c c}^{\prime}}{f_{c o}^{\prime}}=1+0.85 \frac{f_{l}}{f_{c o}^{\prime}} \\
& \frac{\varepsilon_{c c}}{\varepsilon_{c o}}=1+13.5 \frac{f_{l}}{f_{c o}^{\prime}}
\end{aligned}
$$

b) For rectangular cross-section 


$$
\begin{gathered}
\frac{f_{c c}^{\prime}}{f_{c o}^{\prime}}=1+0.7 \frac{f_{l}}{f_{c o}^{\prime}} \\
\frac{\varepsilon_{c c}}{\varepsilon_{c o}}=1+12.4 \frac{f_{l}}{f_{c o}^{\prime}}
\end{gathered}
$$

Where:

$f_{c c}^{\prime}$ is the compressive strength of confined concrete, $f_{c o}^{\prime}$ is compressive strength of unconfined concrete, $\varepsilon_{c c}$ compressive strain of confined concrete, $\varepsilon_{c o}$ is the compressive strain of unconfined concrete, and $f_{l}$ is lateral confined pressure, which is determined based on the following equation:

$$
f_{l}=\frac{2 f_{f} t_{f}}{D}
$$

Where:

$f_{f}$ is a tensile strength of the CFRP material, $t_{f}$ is a thickness of the CFRP sheet, and $D$ is the confined concrete diameter.

\subsubsection{Lam of Teng (2003)}

Based on the large database from the existing test results conducted on CFRP confined rectangular columns, Lam, L. \& Teng (2003) proposed a new stress-strain model. The proposed stress-strain model was an extension of the recent design-oriented stress-strain model developed for CFRP confined circular columns. In this model, both of the axial stress and strain are determined based on the CFRP confined circular model, and the results are modified by shape factor. The strength equation takes the following form: 


$$
\begin{gathered}
\frac{f_{c c}^{\prime}}{f_{c o}^{\prime}}=1+k_{1} k_{s 1} \frac{f_{l}}{f_{c o}^{\prime}} \\
k_{s l}=\left\{\frac{b}{h}\right\}^{2} \frac{A_{e}}{A_{e}}
\end{gathered}
$$

Where:

$k_{1}$ is a confinement effectiveness coefficient for a stress calculation, $k_{s 1}$ is a shape factor for a strength enhancement, $b$ and $h$ are the width and depth of the column respectively. $A_{e} / A_{c}$ is the ratio of the effective confinement area, $A_{e}$, to the total area of concrete, $A_{c}$, and is expressed as following:

$$
\begin{gathered}
\frac{A_{e}}{A_{c}}=\left\{\frac{1-\left((b / h)\left(h-2 r_{c}\right)^{2}+(h / b)\left(h-2 r_{c}\right)^{2}\right) /\left(3 A_{g}\right)-\rho}{\left(1-\rho_{s}\right)}\right\} \\
A_{g}=b h-(4-\pi) r_{c}^{2}
\end{gathered}
$$

Where:

$r_{c}$ is the corner radius of the column section, $A_{g}$ is the gross area of the column section, and $\rho_{s}$ is the ratio of the longitudinal steel reinforcement area to cross sectional area of the column. The following equation is used to determine the lateral confined pressure:

$$
f_{l}=\frac{2 E_{f} t_{f} \varepsilon_{h, \text { rup }}}{D}
$$

Where: 
$E_{f}$ is the modulus of elasticity of CFRP, $t_{f}$ is thickness of the CFRP confinement, and $\varepsilon_{h, \text { rup }}$ is the hoop rupture strain of CFRP. The $\varepsilon_{h, \text { rup }}$ is calculated based on the following equation:

$$
\varepsilon_{h, r u p}=k_{\varepsilon} \varepsilon_{f u}
$$

Where:

$k_{\varepsilon}$ is a CFRP strain efficiency factor. Based on the large database of CFRP confined circular concrete columns, an average 0.586 for $k_{\varepsilon}$ found to be more acceptable (Lam, L. $\&$ Teng, 2003). $\varepsilon_{f u}$ is an ultimate tensile strain of the CFRP sheet.

The confined concrete diameter, $D$, is equal to the diagonal of the rectangular cross-section. As shown in Fig. 3.4.

$$
D=\sqrt{h^{2}+b^{2}}
$$

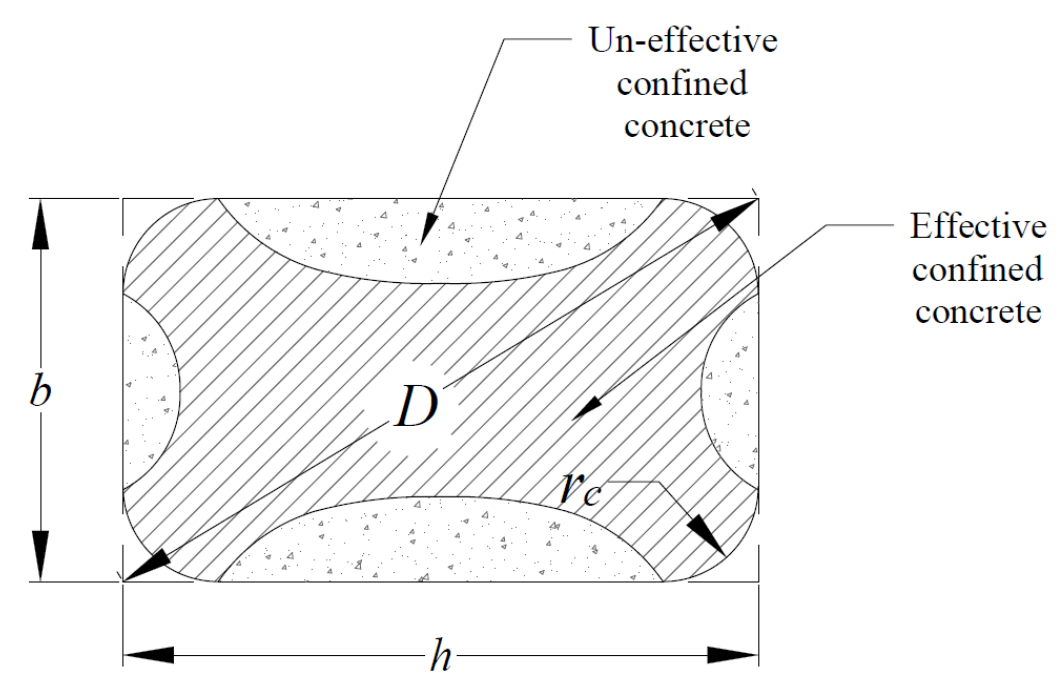

Figure 3.4: Equivalent Circular Cross-Section 
To determine the ultimate axial strain, $\varepsilon_{c c u}$, of the CFRP confined rectangular concrete columns, Lam, L. \& Teng (2003) proposed the following equation:

$$
\frac{\varepsilon_{c c u}}{\varepsilon_{c o}}=1.75+12 \frac{A_{e}}{A_{c}}\left(\frac{b}{h}\right)^{0.5}\left(\frac{f_{l}}{f_{c o}^{\prime}}\right)\left(\frac{\varepsilon_{h, r u p}}{\varepsilon_{c o}}\right)^{0.45}
$$

The stress-strain relation for the confined concrete is shown in Fig. 3.5, and is defined based on the following equations:

$$
f_{c}=\left[\begin{array}{cc}
E_{c} \varepsilon_{c}-\frac{\left(E_{c}-E_{2}\right)^{2}}{4 f_{c}^{\prime}} & 0 \leq \varepsilon_{c} \leq \varepsilon_{t}^{\prime} \\
f_{c}^{\prime}+E_{2} \varepsilon_{c} & \varepsilon_{t}^{\prime} \leq \varepsilon_{c} \leq \varepsilon_{c, \max }
\end{array}\right.
$$

Where:

$$
\begin{gathered}
\varepsilon_{c, \max } \leq \varepsilon_{c c u} \leq 0.01 \\
E_{2}=\frac{f_{c c}^{\prime}-f_{c}^{\prime}}{\varepsilon_{c c u}}
\end{gathered}
$$

In order to prevent excessive cracking, the maximum compressive axial strain, $\varepsilon_{c c u}$ of CFRP confined concrete should be limited to 0.01 (ACI 440.2R-17, 2017). $\varepsilon_{t}^{\prime}$ is a transition strain in the stress-strain curve of the CFRP confined concrete.

$$
\varepsilon_{t}^{\prime}=\frac{2 f_{c}^{\prime}}{E_{c}-E_{2}}
$$




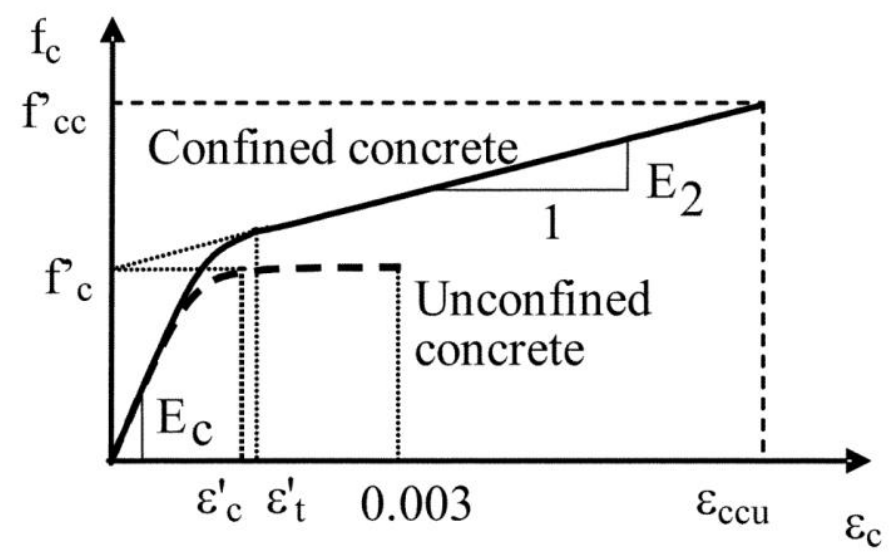

Figure 3.5: Stress-Strain Model for CFRP Confined Concrete

This model has been adopted by both ACI 440.2R-08 (2008), and ACI 440.2R-17 (2017) to define the compressive axial stress-strain behavior for both circular and rectangular cross-section of CFRP confined concrete.

\subsubsection{Ilki et al. (2004)}

In another experimental study conducted by Ilki et al. (2004), 32 CFRP retrofit rectangular short columns were tested under axial load, and based on the results a new model for CFRP confined concrete was proposed. A low-grade concrete strength with 850 and 1500 psi was used in this study. The following equation represents the proposed model:

$$
\begin{gathered}
\frac{f_{c c}^{\prime}}{f_{c o}^{\prime}}=1+2.4\left(\frac{f_{l, \max }}{f_{c o}^{\prime}}\right)^{1.2} \\
f_{l, \text { max }}=\frac{k_{a} \rho_{f} E_{f} \varepsilon_{h, \text { rup }}}{2}
\end{gathered}
$$


Where:

$f_{l, \max }$ is a maximum effective transverse confinement stress, $k_{a}$ is an area efficiency factor, which calculated by using the following equation:

$$
k_{a}=1-\frac{\left(h-2 r_{c}\right)^{2}+\left(h-2 r_{c}\right)^{2}}{3 b h} \tan \theta-\frac{(4-\pi) r_{c}^{2}}{b h}-\rho_{f}
$$

Where:

$\theta$ is an arching angle, which is assumed to be $45^{\circ}$ based on the observation of the damaged specimens, and $\rho_{f}$ is a confinement ratio, which calculated as following:

$$
\rho_{f}=\frac{2(h+b) t_{f}}{b h-(4-\pi) r_{c}^{2}}
$$

A new expression for determining the ultimate axial strain of the CFRP confined concrete, is proposed as the following:

$$
\frac{\varepsilon_{c c}}{\varepsilon_{c o}}=1+20\left(\frac{h}{b}\right)\left(\frac{f_{l, \max }}{f_{c o}^{\prime}}\right)^{1.2}
$$

\subsubsection{Harajli (2006)}

Most of the available stress-strain models ignored the confinement effect of the internal transverse reinforcement. Therefore some researchers attempted to include the effect of the internal transverse reinforcement in their models. Harajli (2006) proposed a stress-strain relationship based on the available database for rectangular RC columns 
confined externally with CFRP and internally with transverse reinforcement. The stressstrain model is expressed below:

$$
f_{c}=\left[\begin{array}{cc}
f_{c o}\left(\frac{2 \varepsilon_{c}}{\varepsilon_{c o}}-\left(\frac{2 \varepsilon_{c}}{\varepsilon_{c o}}\right)^{2}\right) & 0 \leq \varepsilon_{c} \leq \varepsilon_{c o} \\
f_{c}^{\prime}+k_{1} f_{l f}+k_{1} f_{l s} \frac{A_{c c}}{A_{g}} & \varepsilon_{c o} \leq \varepsilon_{c} \leq \varepsilon_{c, \max }
\end{array}\right.
$$

Where:

$k_{1}=4.1, A_{c c}$ is the area of the concrete core, and $f_{c o}, \varepsilon_{c o}$ are the stress and strain values at the intersection point between the first and second stage, and calculated by the next expression:

$$
\begin{aligned}
& f_{c o}=f_{c}^{\prime}+k_{1} \varepsilon_{l o}\left(\frac{k_{e f} \rho_{f} E_{f}}{2}+\frac{k_{e s} \rho_{s t} E_{s}}{2}\left(\frac{A_{c c}}{A_{g}}\right)\right) \\
& \varepsilon_{c o}=\varepsilon_{o}\left(1+\left(310.57 \varepsilon_{l o}+1.9\left(\frac{f_{c c}}{f_{c}^{\prime}}-1\right)\right)\right.
\end{aligned}
$$

The $f_{l f}$ and $f_{l s}$ are the lateral confinement pressure exerted by the CFRP and transverse steel reinforcement, and are determined by the following equations:

$$
\begin{gathered}
f_{l f}=\left(\frac{k_{e f} \rho_{f} E_{f}}{2}\right) \varepsilon_{l} \\
f_{l s}=\left(\frac{k_{e s} k_{v} \rho_{s t} E_{s}}{2}\right) \varepsilon_{l} \leq\left(\frac{k_{e s} k_{v} \rho_{s t}}{2}\right) f_{y t} \\
\rho_{f}=\frac{4 n_{f} t_{f}(b+h)}{b h} \\
\rho_{s t}=\frac{2 A_{s t}}{b s}
\end{gathered}
$$

Where: 
$\rho_{f}$ and $\rho_{s t}$ are a volumetric ratio of CFRP sheet and steel respectively. $A_{s t}$ is the crosssection area of the transverse reinforcement. Fig. 3.6 illustrates the procedure for calculating each of the parameters $k_{e f}, k_{v}$, and $k_{e s}$.

a

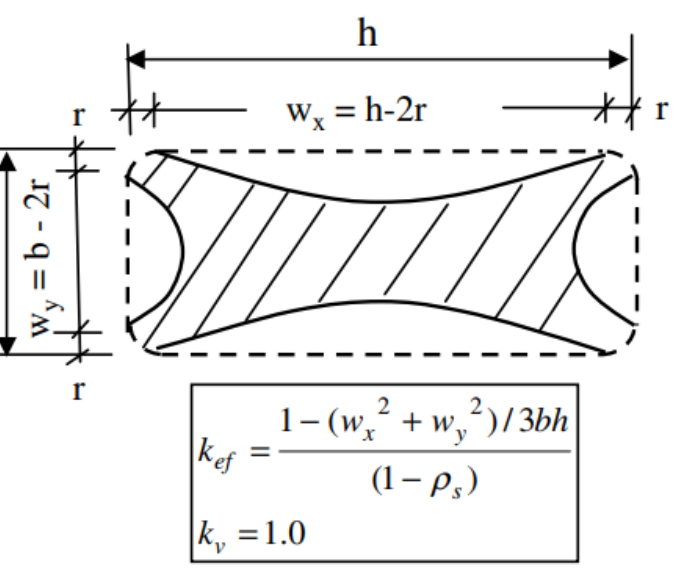

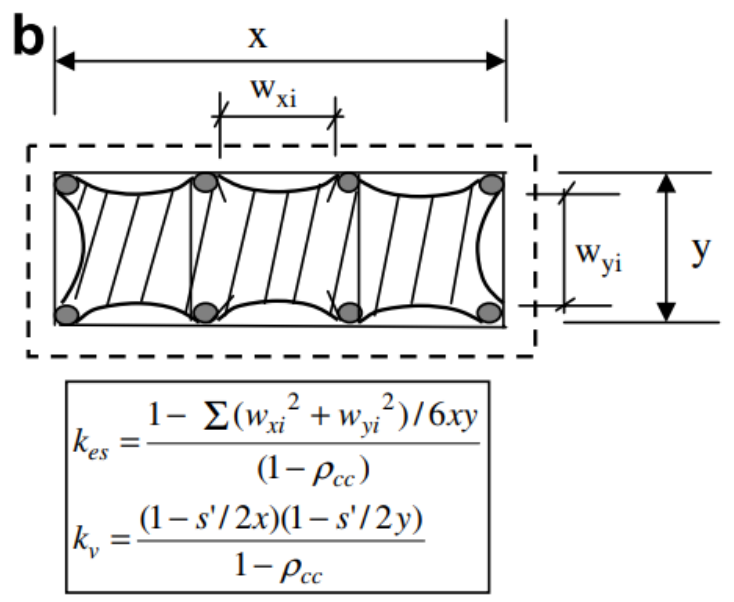

Figure 3.6: Confinement Effectiveness Coefficients: (a) Using CFRP, (b) Using Steel Hoops

\subsubsection{Al-Salloum (2007)}

In order to study the effect of a corner radius on the CFRP confined square columns, 20- CFRP confined concrete specimens with square section were prepared and tested by Al-Salloum (2007). The main variable in this test was the radius of the corners. These specimens were constructed with a corner radius that increased to transform the cross-section from square to circular. Based on the results of the compressive strength, a new stress-strain confinement model was proposed.

$$
\frac{f_{c c}^{\prime}}{f_{c o}^{\prime}}=1+3.14\left(\frac{b}{D}\right)\left(\frac{f_{1}}{f_{c o}^{\prime}}\right)
$$


Where:

$D$ is a shape factor that is calculated by the following equation:

$$
D=\sqrt{2} b+2 r_{c}(\sqrt{2}-1)
$$

and

$$
f_{1}=\frac{2 f_{f} t_{f}}{D} k_{e}
$$

Where:

$k_{e}$ is calculated based on the next equation:

$$
k_{e}=1-\frac{2}{3}\left[\frac{\left(1-2 \frac{r_{C}}{b}\right)^{2}}{1-(4-\pi)\left(\frac{r_{C}}{b}\right)^{2}}\right]
$$

The value $k_{e}$ is affected by the ratio of $r_{c} / b$, and the maximum value for $k_{e}$ is 1.0 when $r_{c} / b$ equal $1 / 2$, which is the case for circular section.

\subsubsection{Wang et al. (2012)}

Most of the available models that define the applied lateral CFRP confinement pressure were conducted on small scale columns. Limited attempts have been conducted on the large scale column with square section. Wang et al. (2012a) tested large scale square RC columns under a monotonic and cyclic axial loading, and based on the results a modified lateral confinement pressure model was proposed as following: 


$$
\begin{gathered}
f_{l m}=f_{l f}+f_{l s} \\
f_{l f}=0.5 k_{a} \rho_{f} E_{f} \varepsilon_{f e} \\
f_{l s}=0.5 k_{e s} k_{v} \rho_{s t} f_{y t}
\end{gathered}
$$

Where:

$f_{l m}$ is the modified lateral confinement pressure, $\varepsilon_{f e}$ is the effective tensile strain of CFRP confinement, which is equal to $0.4 \varepsilon_{f u}$ for a large-sized column, and $0.6 \varepsilon_{f u}$ for medium-sized column. $k_{a}$ is a shape factor for the rectangular cross-section and is determined by the next equation:

$$
k_{a}=\frac{A_{c c}}{A_{g}}=\frac{1-\frac{2\left(B-2 r_{C}\right)^{2}}{3 A_{g}}-\rho_{g}}{1-\rho_{g}}
$$

Where:

$\rho_{g}$ is the ratio of the longitudinal steel ratio; and $A_{g}$ is the gross cross-sectional area of a square-sectioned column. Fig. 3.7 illustrates the values of the $k_{e s}$ and $k_{v}$ respectively.

$$
A_{g}=B^{2}-(4-\pi) r_{C}{ }^{2}
$$
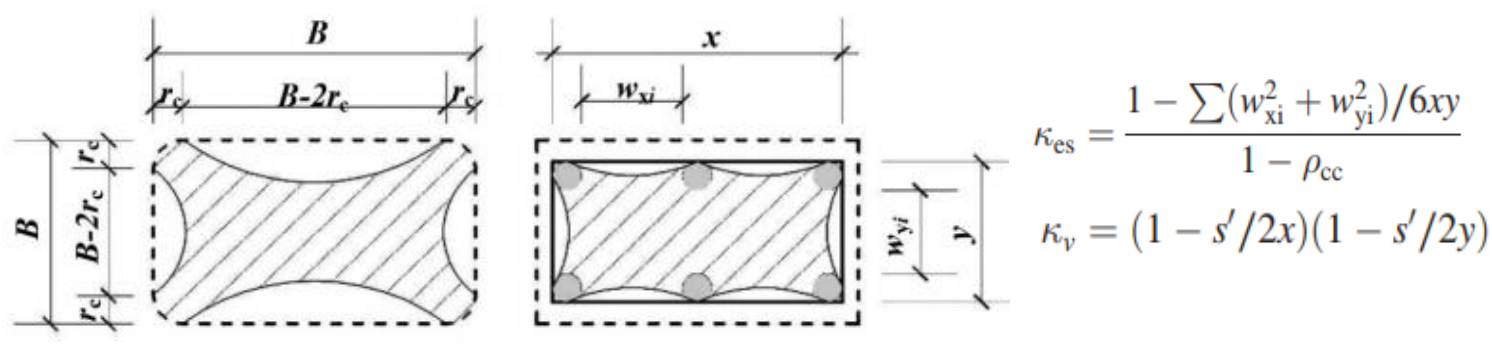

Figure 3.7: Parameters for Confinement Coefficient of CFRP and Hoop Reinforcement 


\subsection{CFRP Retrofit Design for Seismic Strengthening}

Experimental studies proved that using CFRP retrofit enhances the flexural ductility of RC columns subjected to a combination of axial load and cyclic lateral loads (Seible, Priestley, Hegemier, \& Innamorato, 1997; Iacobucci, Sheikh, \& Bayrak, 2003; Wu, Liu, \& Wang, 2008; Truong et al., 2017). Increased strength and ductility for an RC building is required to meet seismic demand, changes in the facility, construction errors, or revisions of code requirements. Confining the plastic hinge regions of $\mathrm{RC}$ columns is the most recommended method used to increase the inelastic rotation of the plastic hinges. This is achieved through increasing the concrete compressive strain, which prevents concrete cover spalling and consequently prevents rebar buckling (ACI 440.2R17, 2017). In order to design the CFRP retrofit to achieve inelastic rotation at the plastic hinge regions, several researchers proposed different design procedures, such as designing the CFRP retrofit based on the moment-curvature capacity.

\subsubsection{Seible et al. (1997)}

Seible et al. (1997) proposed a procedure for the design of the CFRP jacket based on the shear strength demand of the RC columns. The following equation was proposed to determine the requirements for the CFRP jacket's thickness, where $t_{j}$, of rectangular columns is based on the shear demand.

$$
t_{j}=\frac{\frac{V_{o}}{\phi_{v}}-\left(V_{c}+V_{S}+V_{p}\right)}{2 * 0.004 E_{j} * D}
$$


Where:

$V_{o}$ is the shear demand when a full flexural strength is developed at the potential plastic hinge; $\phi_{v}$ is the shear reduction factor, which is equal to $0.85 . V_{c}, V_{s}$, and $V_{p}$ are the contributions of the concrete, transverse steel reinforcement, and axial load on shear strength, respectively. $E_{j}$ is the elastic module of the CFRP jacket. D is the column dimension parallel to the loading direction. The values of the $V_{c}, V_{s}$, and $V_{p}$ are calculated based on equations that proposed by Priestley, M. J., Verma, Ravindra, Xiao \& Priestley, B. M. (1994). The shear strength of the concrete, $V_{c}$, is calculated based on the curvature ductility demand of the concrete columns as follows:

$$
V_{c}=k \sqrt{f_{c}^{\prime}} A_{e}
$$

Where:

$k$ is a factor that is used for including the effect of the increase in the section curvature on the shear strength capacity, as shown in the Fig. 3.8. $A_{e}$ is an effective area of the cross-section of column, which is equal to $0.8 \mathrm{Ag}_{\mathrm{g}}$. 


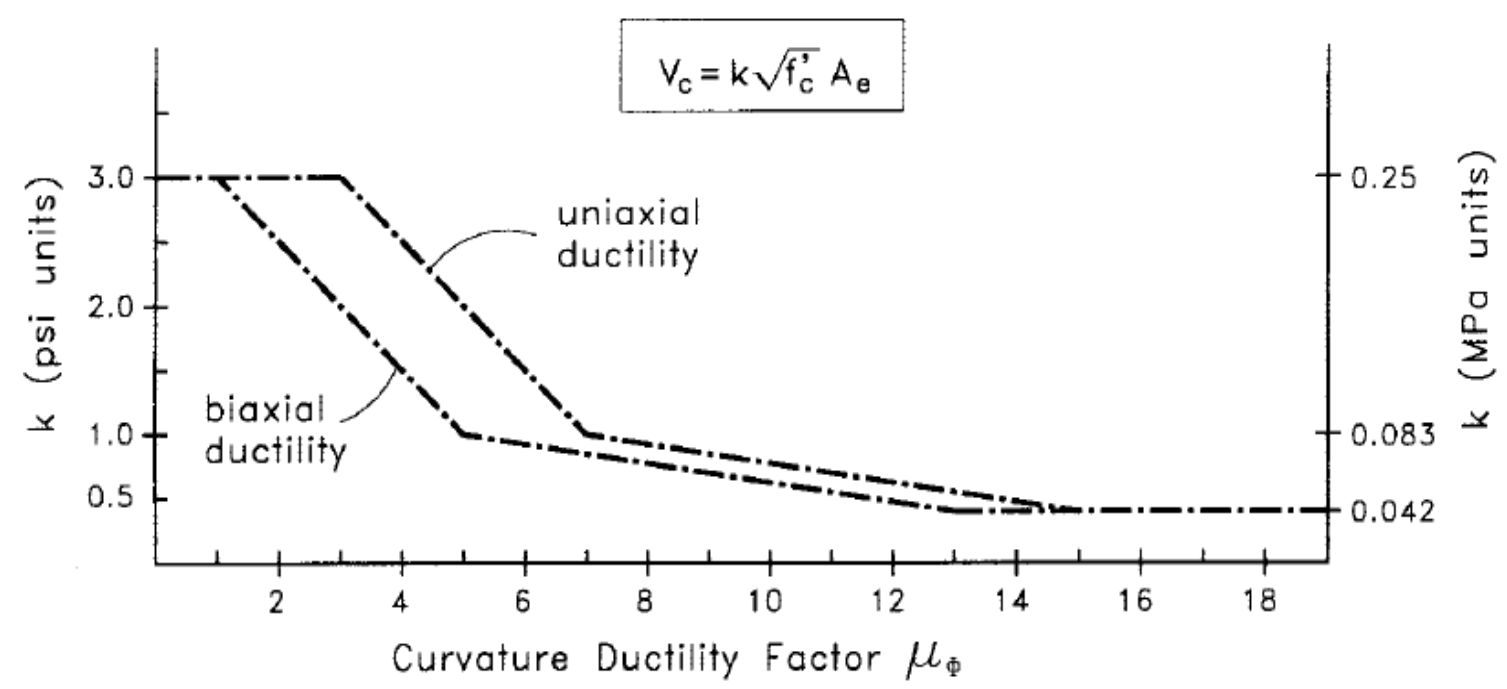

Figure 3.8: Shear Strength Capacity based on the Section Curvature Ductility

$V_{S}$ is the shear strength that provides by the transverse reinforcement, and is calculated based on the following expression:

$$
V_{s}=\frac{A_{v} f_{y} d}{s}
$$

Where:

$A_{v}$ is the total transverse reinforcement area, $s$ is the spacing between stirrups, and $d$ is the effective depth of the cross-section.

Increasing the axial load level of the concrete column enhances the shear strength (Priestley, B. M., 1995). The contribution of increasing the axial load level on shear strength is determined by using the following expression:

$$
V_{p}=\frac{D-c}{2 a} P
$$


Where:

$D$ is the overall section depth or diameter, $C$ is the depth of the compression zone, and $a$ is the shear span length, which equal to total high, $\mathrm{H}$, for a cantilever column and $\mathrm{H} / 2$ for a column in reversed bending.

On the other hand, based on the curvature ductility demand, the thickness of the CFRP jacket was determined according to the following expression:

$$
t_{j}=0.09 \frac{D\left(\varepsilon_{c u}-0.004\right) f_{c c}^{\prime}}{\Phi_{f} f_{j u} \varepsilon_{j u}} * 2
$$

Where:

$f_{j u}$ and $\varepsilon_{j u}$ are the strength and strain capacity of the CFRP jacket in the hoop direction, $\Phi_{f}$ is a flexural reduction factor, which equal to 0.9 , and $\varepsilon_{c u}$, is the ultimate axial strain determined by using the following equation:

$$
\varepsilon_{c u}=0.004+\frac{2.8 \rho_{j} f_{j u} \varepsilon_{j u}}{f_{c c}^{\prime}}
$$

Where:

$\rho_{j}$ is the volumetric jacket reinforcement ratio. Based on the curvature ductility demand, the ultimate strain can be calculated from the next equation:

$$
\varepsilon_{c u}=\Phi_{u} c_{u}
$$


The ultimate section curvature, $\Phi_{u}$, and the corresponding neutral axis depth, $c_{u}$, are calculated based on the moment-curvature analysis and the member displacement ductility, which calculates based on the following expression:

$$
\mu_{\Delta}=1+3\left(\frac{\Phi_{u}}{\Phi_{y}}-1\right) \frac{L_{p}}{L}\left(1-0.5 \frac{L_{p}}{L}\right)
$$

Where:

$L_{p}$ is the plastic hinge length, which is calculated based on following equation:

$$
L_{p}=0.08 L+0.022 f_{s y} d_{b}
$$

Where:

$L$ is a shear span of the column; $\Phi_{y}$ section yield curvature; and $f_{s y}$ and $d_{b}$ are the yield strength and bar diameter for longitudinal reinforcement (Priestley and Park, 1987).

\subsubsection{Sheikh \& Li (2007)}

A design procedure for a lateral CFRP retrofit of RC square columns was proposed by Sheikh and Li (2007). This procedure was developed based on the experimental test results conducted on ten square RC columns retrofit by CFRP and GFRP. In this study, the effect of the axial load level, the amount of the CFRP materials, and the type of the FRP confinement were considered in the design equations.

$$
n \cdot f_{u}=0.25 \cdot h \cdot f_{c}^{\prime} \cdot\left(1+13\left(\frac{P}{P_{o}}\right)^{5}\right) \frac{\mu_{\Phi 80, i n}^{1.15}}{29}
$$


Where:

$n$ is the number of the FRP layers, $f_{u}$ is the ultimate tensile strength of the FRP, $h$ is a cross-sectional dimension of column, $\left(\frac{P}{P_{O}}\right)$ is the axial load level, and $\mu_{\Phi 80, i n}^{1.15}$ is the increase in the curvature ductility due to the FRP confinement determined based on the following expression:

$$
\mu_{\Phi 80, \text { in }}=\mu_{\Phi 80}-\mu_{\Phi 80, c o n}
$$

Where:

$\mu_{\Phi 80}$ is the demand curvature ductility of the FRP confined columns; and $\mu_{\Phi 80, c o n}$ is the curvature ductility of the column without FRP retrofit.

\subsubsection{ACI 440.2R (2017)}

The ACI 440.2R-17 (2017) provides a design FRP retrofit procedure for the plastic hinge region for $\mathrm{RC}$ columns. In this procedure, the plastic hinge curvature demand is calculated by using the following equation:

$$
\Phi_{D}=\Phi_{y, f r p}+\frac{\theta_{p}}{L_{P}} \leq \Phi_{u, f r p}
$$

Where:

$\theta_{p}$ is the plastic rotation demand, $\Phi_{y, f r p}$ is the curvature of the CFRP confined column where the longitudinal reinforcement steel yields, and $\Phi_{u, f r p}$ is the ultimate curvature capacity. $\Phi_{y, f r p}$, and $\Phi_{u, f r p}$ are calculated by the following equations: 


$$
\Phi_{y, f r p}=\frac{\varepsilon_{y}}{d-C_{y, f r p}}
$$

Where:

$\varepsilon_{y}$ and $C_{y, f r p}$ are the steel strain and depth of the neutral axis at steel yielding respectively, and $d$ is the effective depth of the column.

$$
\Phi_{u, f r p}=\frac{\varepsilon_{c c u}}{C_{u, f r p}}
$$

Where:

$\varepsilon_{c c u}$ and $C_{u, f r p}$ are the extreme compression fiber strain and the depth of the neutral axis at the ultimate condition respectively.

In order to apply the CFRP confinement onto the RC columns, the height of the CFRP confined needs to be determined. ACI 440.2R-17 (2017) recommends using the larger plastic length, $L_{p}$, or the distance between the joint's face to the end of special transvers reinforcement. $l_{o}$, is recommended by American Concrete Institute (ACI-318, 2014). The plastic hinge length is calculated by using following equation proposed by Priestley, Michael J. N; Seible, F; \& Calvi (1996):

$$
L_{p}=g+0.0003 f_{s y} d_{b}
$$

Where:

$g$ is the clear gap between the CFRP jacket and the adjacent member. The gap should not be larger than 2 in. 
The height of the provided special transvers reinforcement is the larger of the following expressions:

$$
l_{o}=\left[\begin{array}{c}
\text { One }- \text { sixth of the clear span of the column } \\
\text { Max.cross }- \text { sectional dimension of the column } \\
18 \mathrm{in}
\end{array}\right.
$$

The demand axial strain, $\varepsilon_{c c u}$, is based on the design curvature, and $\phi_{D}$, is determined based on the following expression:

$$
\varepsilon_{c c u}=\Phi_{D} C_{u} \leq 0.01
$$

Where:

$C_{u}$ is the depth of the neutral axis at the ultimate design limit. In order to insure the shear strength integrity of the CFRP confined concrete, the value of axial strain, $\varepsilon_{c c u}$, should be limited to 0.01 . The required CFRP jacket's thickness can be calculated based on Lam \&Teng (2003) equations illustrated previously.

\subsection{Shear Strength Models for RC Columns}

Based on the post-earthquake observations and experimental studies, it was concluded that the shear failure of the RC columns may strongly limit the displacement ductility of the existing RC structural system during an earthquake (Del Vecchio et al., 2017). The conceptual model that illustrates the interaction between the shear strength capacity and shear strength demand based on the displacement ductility demand was proposed by Applied Technology Council (ATC-6) (Seismic Design, 1981), as shown in 
Fig 3.9. In this equation, the dashed line represents the shear capacity of the RC column while the sold line represents the shear demand. The brittle failure mode, Case \#1, happens when the shear demand is larger than the initial shear strength. In Case \#2, a flexural-shear failure happens where there is shear demand between the initial and residual shear strength, causing a displacement ductility corresponding to the intersection point between shear demand curve and shear strength curve. A ductile failure mode, Case \#3, is ensured when the maximum shear demand is less than the residual shear strength. In order to determine the mode failure of the RC columns correctly, many researchers (Priestley, M J Nigel, Verma, Ravindra, \& Xiao, 1994; Kowalsky \& Priestley, B. M., 2000; Biskinis, Roupakias, \& Fardis, 2004; Sezen \& Moehle, 2004; Ghobarah \& Elmandoohgalal, 2004) have focused on proposing models for determining the degradation of shear strength in RC columns with inelastic cyclic displacement.

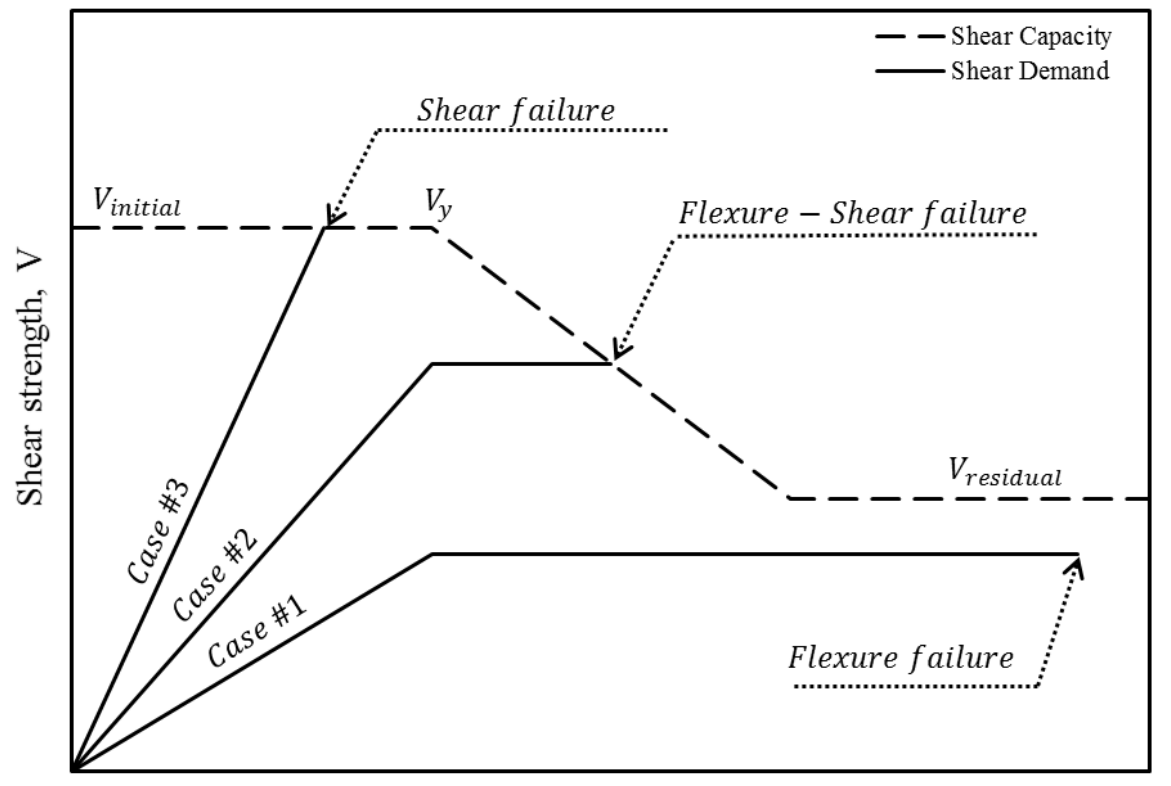

Displacement ductility, $\mu \Delta$

Figure 3.9: Interaction between Shear Strength and Shear Capacity 
Priestley, Michael J. N; Seible, F; \& Calvi (1996) proposed a shear strength model for RC columns that considers the effect of curvature ductility and axial load level. The proposed equation is defined in following expression:

$$
V_{n}=V_{c}+V_{p}+V_{s}
$$

The values of $V_{c}, V_{s}$, and $V_{p}$ are calculated by using equations 3.40 through 3.42. In this model, the concrete shear strength capacity, $V_{c}$, was calculated based on the gradual reduction of the aggregate interlock along the flexural cracks.

In order to include the effect of the longitudinal reinforcement ratio and the column aspect ratio, the concrete shear strength capacity, $V_{c}$ in the previous model was revised by Kowalsky \& Priestley (2000):

$$
V_{c}=\alpha \beta k \sqrt{f_{c}^{\prime}} A_{e}
$$

Where:

$\alpha$ and $\beta$ are factors that account for the column aspect ratio and the longitudinal steel ratio, respectively, and are calculated by using the following equation:

$$
\begin{gathered}
1 \leq \alpha=3-\frac{L_{S}}{h} \leq 1.5 \\
\beta=0.5+20 \rho_{l} \leq 1
\end{gathered}
$$

Based on a large database of experimental tests on RC columns and RC beams with rectangular and circular sections, a new shear strength model was proposed by Biskinis et al. (2004). In this model, the effect of the cyclic degradation on the concrete 
and transvers reinforcement was included. Based on the proposed model, the shear strength is computed by using the following equation:

$$
V_{n}=k\left(\mu_{\Delta}\right)\left(V_{c}+V_{s}\right)+V_{p}
$$

Where;

$k\left(\mu_{\Delta}\right)$ is the coefficient of the shear strength degradation with ductility demand, and is equal to:

$$
0.75 \leq 1.05-0.05 \mu_{\Delta} \leq 1
$$

$V_{c}, V_{s}$, and, $V_{p}$, are calculated by using the following equations:

$$
\begin{gathered}
V_{c}=\left[0.16 \max \left(0.5,100 \rho_{\text {tot }}\right)\left(1-0.16 \min \left(5, \frac{L_{s}}{h}\right)\right) \sqrt{f_{c}^{\prime}} A_{g}+V_{s}\right] \\
V_{s}=\frac{A_{s}}{s} 0.9 d f_{y w} \\
V_{p}=\frac{H-x}{2 L_{s}} \min \left(P, 0.55 A_{g} f_{c}\right)
\end{gathered}
$$

For rectangular RC columns with light transverse reinforcement, a shear strength model was proposed by Sezen \& Moehle (2004). This model was developed based on the large database of numerous column tests, and the model's results showed improved accuracy in predicting the shear strength compared with available models. The proposed model included the contribution of the concrete and transvers reinforcement to the shear strength as shown in following equation:

$$
V_{n}=V_{c}+V_{s}
$$




$$
\begin{gathered}
V_{s}=k \frac{A_{v} f_{y} d}{s} \\
V_{c}=k\left(\frac{6 \sqrt{f_{c}^{\prime}}}{L_{s} / d} \sqrt{1+\frac{P}{6 \sqrt{f_{c}^{\prime}} A_{g}}}\right) 0.8 A_{g}
\end{gathered}
$$

Where:

$k$ is the factor that accounts for displacement ductility. The $k$ factor value is calculated by using the following expression:

$$
0.7 \leq 1.15-0.075 \mu_{\Delta} \leq 1
$$

Furthermore, the last model was adopted by ACI 369R-11 (2011); and ASCE/SEI41-13 (2013) to determine the shear strength for RC columns based on the required displacement ductility.

Ghobarah \& Elmandoohgalal (2004) proposed a shear capacity model for RC columns that includes the effect of the CFRP retrofit. The following equations illustrates the shear capacity envelope based on displacement ductility limit, as shown in Fig. 3.10.

$$
V_{\mu}=\left[\begin{array}{ll}
V_{c}+V_{p}+V_{s}+V_{f} & 0 \leq \mu_{\Delta} \leq 2 \\
\frac{1}{3} *\left(V_{c}+V_{p}\right)+V_{s}+V_{f} & \text { at } \mu_{\Delta}=4 \\
V_{s}+V_{f} & \text { at } \mu_{\Delta}=6
\end{array}\right.
$$

Where: 
$V_{c}$ is the shear strength of the confinement concrete, and the compressive strength of the confinement concrete, $f_{c c}^{\prime}$, will be used instead of the unconfined compressive strength, $f_{c}$, as shown in following equation:

$$
V_{c}=0.3 \sqrt{f_{c c}^{\prime}} A_{e}
$$

The equations that were used to calculate each of the $V_{s}, V_{f}$ and $V_{p}$ are illustrated below:

$$
\begin{gathered}
V_{s}=\frac{A_{v} f_{y} d}{s} \\
V_{f}=0.95\left(2 t_{f}\right)\left(\varepsilon_{f e} E_{f}\right) d_{f} \\
V_{p}=k_{p} \frac{P t / 2}{H}
\end{gathered}
$$

Where:

$k_{p}$ is the factor that equals 1 in a double curvature column, and 0.5 in a single curvature column. $P, t, H$ are the axial load level, the total depth of the column, and the height of the column, respectively. In this model, the contribution of the CFRP retrofit on the shear strength is not effected by increasing the displacement ductility up to $\mu_{\Delta}=6$. 


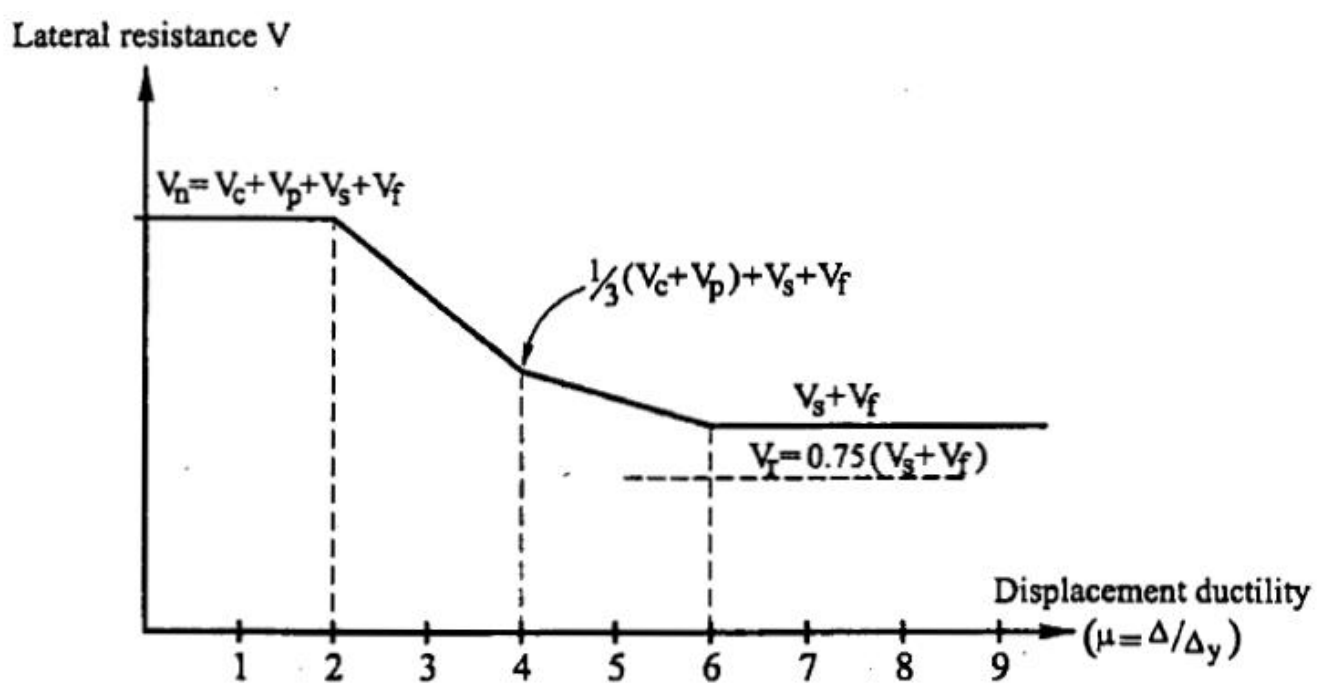

Figure 3.10: Shear Strength Envelope Proposed by (Ghobarah \& Elmandoohgalal, 2004)

\subsection{Ductility of RC Columns}

Improving the ability of the structure to achieve an adequate ductility increases

the probability that structural failure will be prevented in seismic events. Ductility of the structure plays a significant role in dissipating more energy during an earthquake. In general, the ductility of RC columns is commonly referred to as curvature ductility $\mu_{\emptyset}$, section ductility, and a displacement ductility, $\mu_{\Delta}$, member ductility. The relationship between the curvature ductility and displacement ductility was investigated by Park R \& Paulay T (1975); and Bae, Bayrak, \& Williamson (2004) and it was concluded that a column with high curvature ductility may not provide a high displacement ductility. Fig. 3.11 illustrates the relationship between curvature and displacement ductility. Based on ASCE/SEI41-13 (2013), the procedure to determine each curvature ductility and displacement ductility of a structural element tested under a cyclic lateral load starts by 
constructing backbone curves, which are a series of linear segments drawn through each point of the peak curvature or displacement during the first cycle of each increment of loading or deformation, as shown in Fig. 3.12. By considering either a positive force vs. positive deformation or a negative force vs negative deformation, the curvature ductility and displacement ductility is calculated.

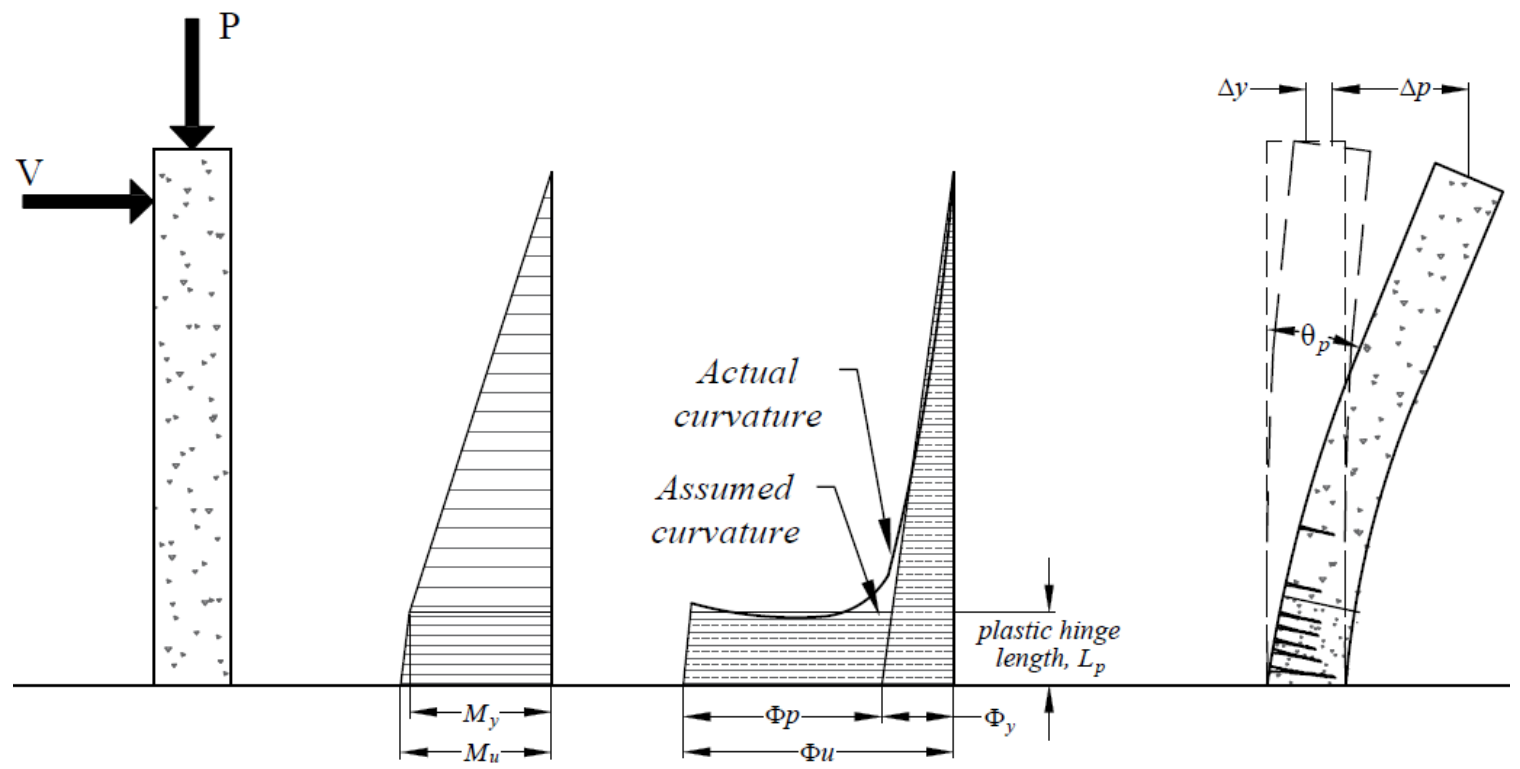

Figure 3.11: Curvature and Displacement of RC Columns 


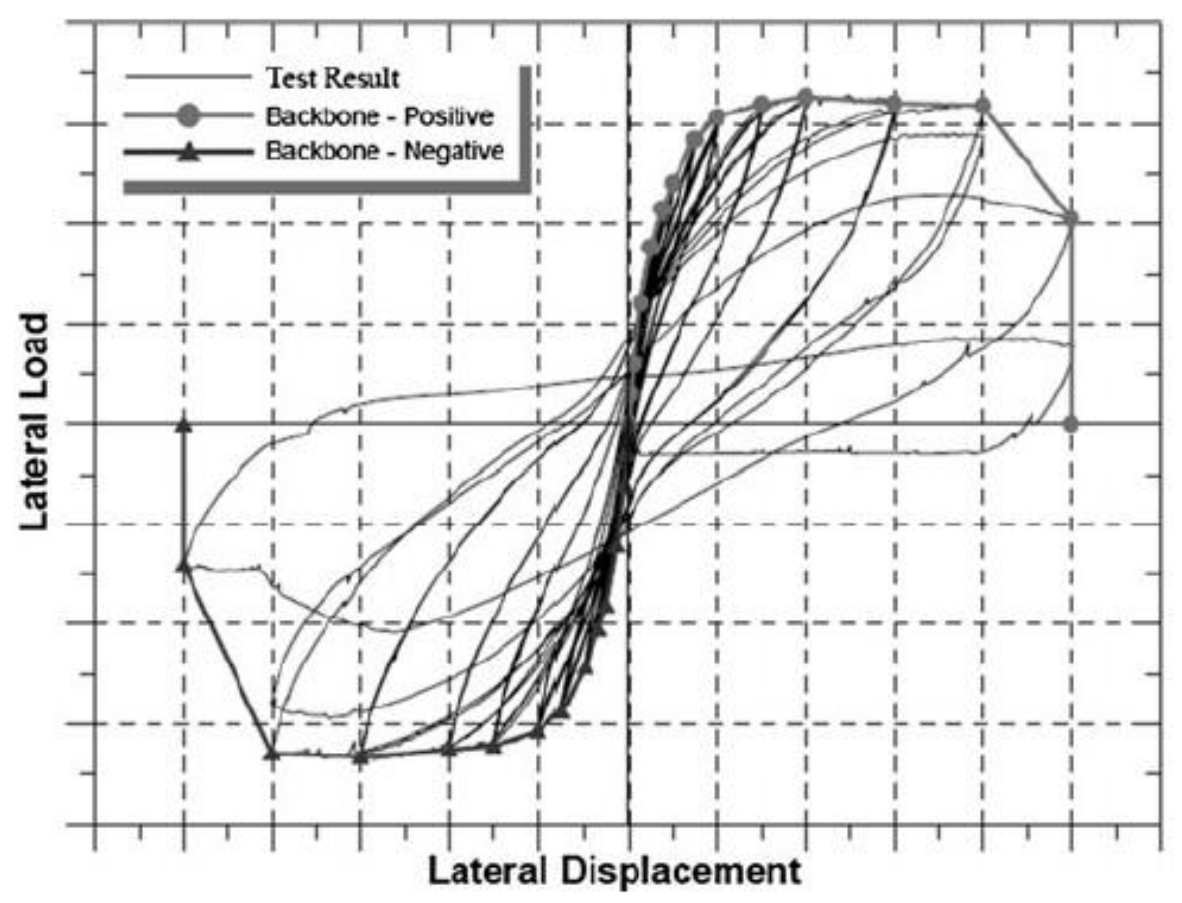

Figure 3.12: Backbone Definition

\subsubsection{Curvature Ductility}

Curvature ductility is defined as a ratio of the ultimate curvature of the section, $\Phi_{u}$, to the yield curvature, $\Phi_{y}$. In general, the rotation capacity of the structural element is completely dependent on the curvature that is provided during cyclic action and the plastic hinge length where the inelastic curvature is concentrated, as shown in Fig. 3.11.

\subsubsection{Yield, Ultimate, and Plastic Curvature}

In general, under a lateral cyclic load the behavior of the RC sections are not elastic-perfectly plastic, therefore several definitions for yield curvature, $\Phi_{y}$, and ultimate curvature, $\Phi_{u}$, are proposed in the literature review. Park (1989) presented several methods that were used to determine the $\Phi_{y}$. The most two common methods are 
illustrated in Figs. 3.13 and 3.14. In Fig. 3.13, the $\Phi_{y}$ is defined as the curvature corresponding to the intersection point of two lines. The first line is a straight inclined line drawn from the origin point through the intersection point of the straight horizontal line of $0.75 M_{\max }$. on the moment-curvature curve. The second line is a horizontal line drawn from the maximum moment $M_{\max }$. This procedure was adopted by ACI Committee 374 (2013) with consideration for the axial load level. Fig. 3.14, illustrates the second procedure in which the slope of the second line is modified by equating the areas between the line and the envelope of the experimental test above, and under the line to ensure equal energy criteria, as shown in Fig. 3.14. This approach was adopted by FEMA-440 (2005).

The ultimate limit of the curvature, $\Phi_{u}$, is determined based on the damaged limits which include: the maximum compressive strength of the concrete, the longitudinal and transverse reinforcement steel strain limits, etc. However, the most common determination for the ultimate curvature was the curvature corresponding to $20 \%$ decay in the moment capacity (Saatcioglu \& Baingo, 1999; Iacobucci et al., 2003; FEMA, 2005), is shown in Fig. 3.13.

The inelastic curvature provided by the RC section is defined as a plastic curvature, $\Phi_{p}$. The plastic curvature is an important factor to determine a plastic rotation, $\theta_{p}$, developed by a plastic hinge region. The amount of plastic curvature is calculated as the difference between the ultimate curvature and the yield curvature:

$$
\Phi_{p}=\Phi_{u}-\Phi_{y}
$$


The plastic curvature is assumed to be a constant along the plastic hinge length, $L_{p}$, and the rotation capacity, $\theta_{p}$, of the plastic hinge is a result of multiplying the average plastic curvature within the plastic hinge region by the length of the plastic hinge, $L_{p}$, as illustrated below:

$$
\theta_{p}=\Phi_{p} * L_{p}
$$

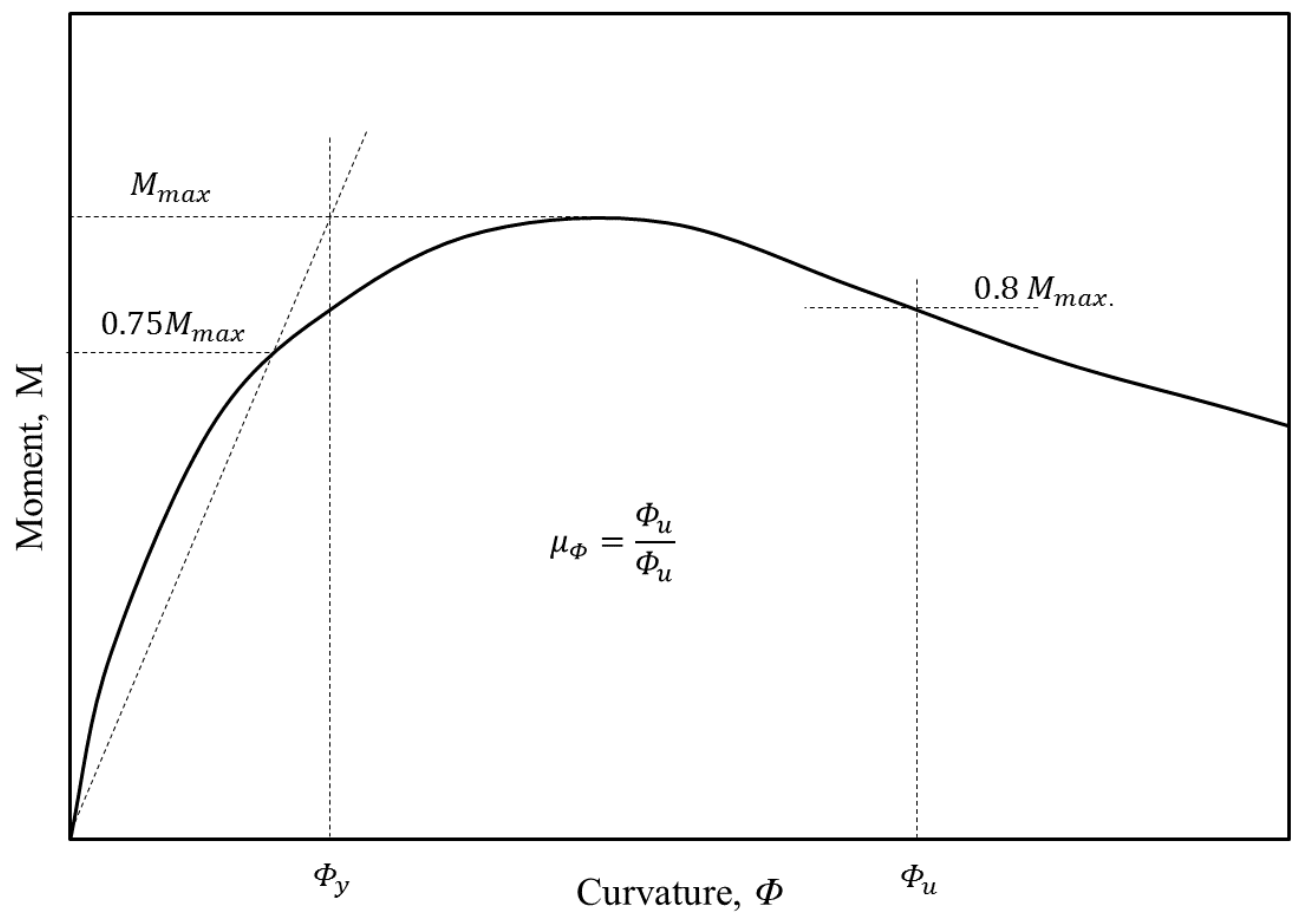

Figure 3.13: Definition of Curvature Parameters (Park, 1988) 


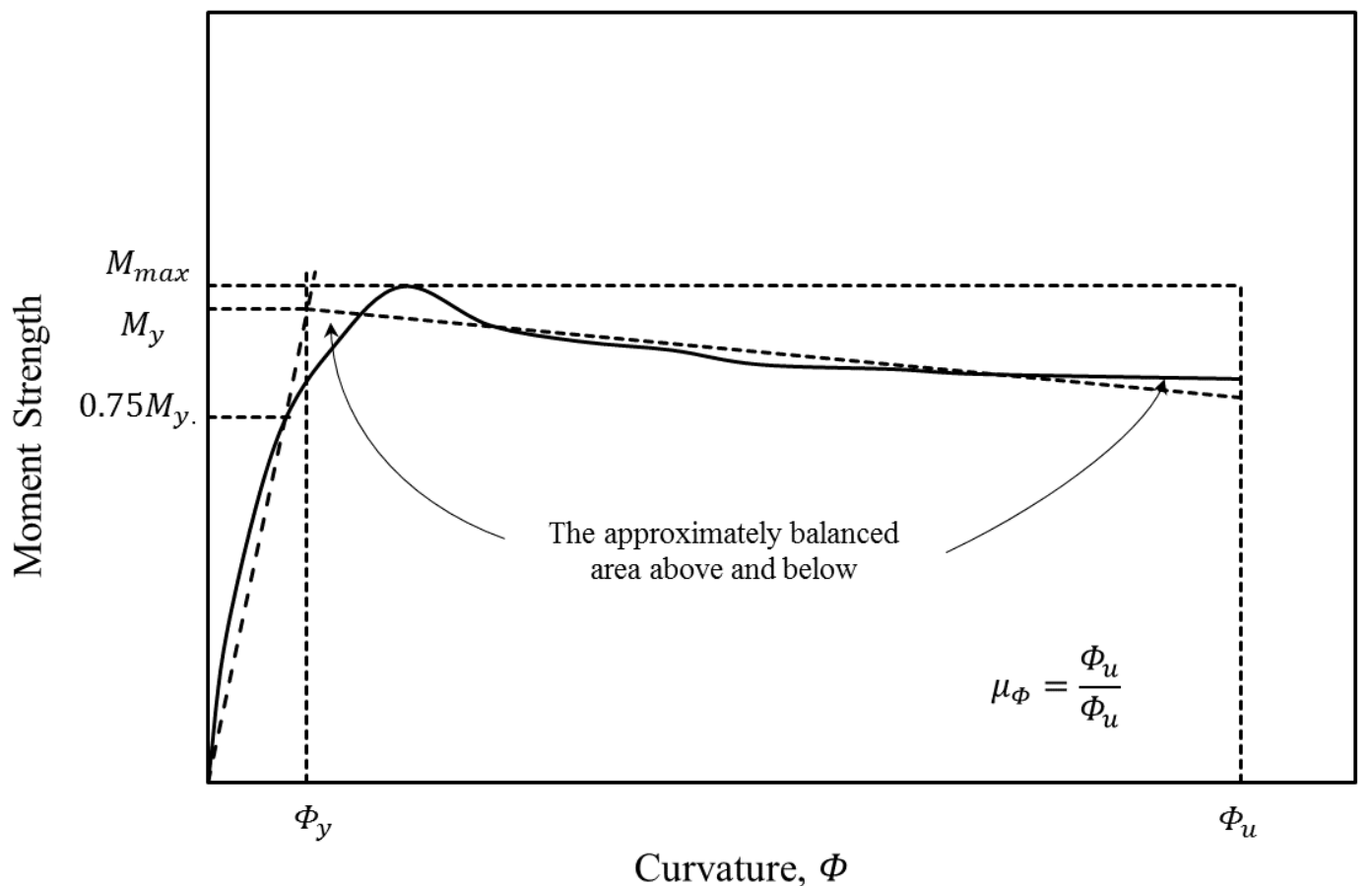

Figure 3.14: Definition of Curvature Parameters (FEMA 440, 2005)

\subsubsection{Plastic Hinge Length}

Several models have been proposed to determine the plastic hinge length of RC columns. Paulay \& Priestley (1992) proposed a simple approach that considers the effects of column bending and rebar slip of the longitudinal reinforcement, as illustrated below:

$$
L_{p}=0.08 L+0.15 f_{y} d_{b}
$$

Where, $L$ is the length of the cantilever column (the distance between the critical section of the plastic hinge to the point of the contra-flexure), and $d_{b}$ is the diameter of the longitudinal rebar. This model has been the focus of attention for several researchers who proposed models for determining the plastic hinge length, (Bae \& Bayrak, 2008; Jiang, Wu, \& Wu, 2014; Babazadeh, Burgueño, \& Silva, 2016). The slenderness effect on the 
plastic hinge length was investigated by Bae \& Bayrak (2008a), and was based on the experimental results for four RC columns. It was observed that the plastic hinge length increased as the slenderness ratio and the axial load level were increased. Therefore, a new model that includes the effect of both the slenderness and axial load level was proposed as illustrates below:

$$
L_{p}=h\left(\left(0.3\left(\frac{P}{A_{g} f_{c}^{\prime}}\right)+3\left(\frac{A_{s}}{A_{g}}\right)-0.1\right)\left(\frac{L_{s}}{h}\right)+0.25\right)
$$

The effect of the CFRP confinement on the plastic hinge length was investigated by few researchers $(\mathrm{Gu}, \mathrm{Wu}, \mathrm{Wu}, \& \mathrm{Wu}, 2012$; Jiang et al., 2014; Yuan, Wu, \& Li, 2017). It was concluded that the CFRP confinement led to an increase of the plastic hinge length at first, but then reduced it based on the confinement ratio. Gu et al. (2012) proposed a model to determine the plastic hinge length for RC columns retrofit with CFRP, and the confinement effect was included in this model, as shown below:

$$
L_{p}=0.08 L+0.15 f_{y} d_{b}\left[\begin{array}{ll}
3.028 \lambda_{f} L & 0 \leq \lambda_{f}<0.1 \\
\left(0.51-2.3 \lambda_{f}+\lambda_{f}^{2}\right) L & 0.1 \leq \lambda_{f}<0.5
\end{array}\right.
$$

$\lambda_{f}$, is the ratio of lateral confinement, $f_{l}$, to the concrete strength, $f_{c}^{\prime}$. The first part of this model is the same model proposed by Paulay and Priestley (1992) and the second part considers the confinement ratio effect. 


\subsubsection{Displacement Ductility}

Displacement ductility is defined as the ratio of the ultimate displacement of the RC member, $\Delta_{u}$, to the yield displacement, $\Delta_{y}$. The displacement ductility is a very important factor for a seismic design that needs to be identified locally for the RC member and globally for the whole structure. The ability of the member and structure to dissipate seismic forces mainly depends on the amount of the displacement ductility developed during an earthquake. Several definitions for the yield displacement and ultimate displacement have been proposed, which creates a difficulty in reaching a consensus in determining the exact value for the yield and ultimate displacement of the structures (Priestley, 2000). Fig. 3.15 illustrates three values considered as yield displacement: 1) the intersection of the initial tangent with a nominal strength;2) the displacement at the first yield in the longitudinal steel; and 3) the intersection of the secant stiffness through the first yield with nominal strength. While the definition of the ultimate displacement includes: 1) the displacement at ultimate strength; 2) the displacement at $20 \%$ or $50 \%$ drop in lateral strength; 3 ) the displacement at the initial fracture in the transverse reinforcement. 


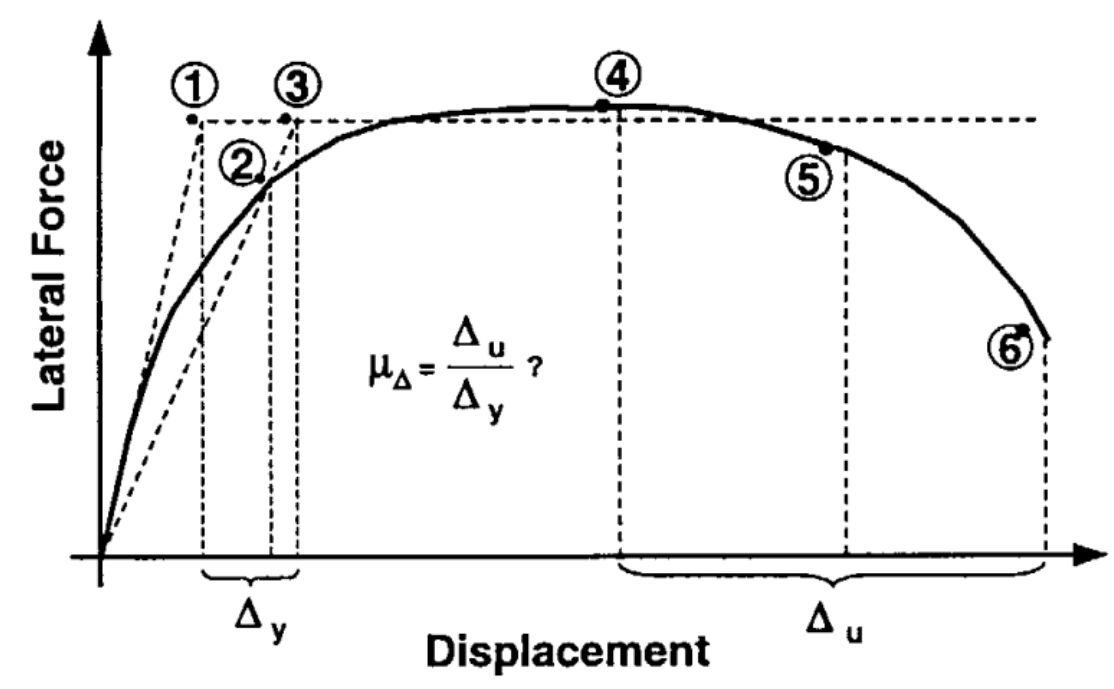

Figure 3.15: Definition of the Yield and Ultimate Displacement (Priestley, M. J., 2000)

\subsubsection{Yield Displacement}

The yield displacement is defined as the point where there is a significant change in the rate of deformation with little change in the load. For RC columns tested under a cyclic lateral load, ACI Committee 374 (2013) provides a procedure that determines the yield displacement of RC columns. Fig. 3.16 illustrates the bilinear load-displacement relation that used to determine the yield displacement. The bilinear load-displacement relationship consists of two straight lines. The first straight line joins the origin and the point of $\alpha V_{\max }$ on the envelope curve where $\alpha$ varies between 0.65 and 0.75 depending on the axial load level, the reinforcement pattern, and predominant stress, flexural, or shear. The second straight line is a horizontal line that passes through the $V_{\operatorname{Max}}$. The lateral displacement of the intersection point between the extension of the first line and the horizontal line is the yield displacement. This definition of yielding displacement was recommended by Park (1988), and was considered as the most realistic definition for the 
yield displacement for RC structures. In order to determine the equivalent stiffness of RC columns, the slope of the first straight line has to be considered as the equivalent stiffness, $K_{e}$, of the RC column (ACI 369R-11, 2011).

On the other hand, the procedure of the equal energy criteria as shown in Fig. 3.14 is an acceptable method for determining the yield displacement (Park, 1988). The second procedure was adopted by FEMA-440 (2005).

It is important to mention that the value of the theoretical yield displacement of the RC column represents the total effect of flexural, shear, and reinforcement slip from stub, as shown in the following equation:

$$
\Delta_{y}=\Delta_{y \text { flex }}+\Delta_{y \text { shear }}+\Delta_{y \text { slip }}
$$

Where $\Delta_{\text {flex }}, \Delta_{\text {shear }}$, and $\Delta_{\text {slip }}$ are the flexural, shear, and rebar slip displacement, respectively, at yield, as shown in Fig. 3.17. 


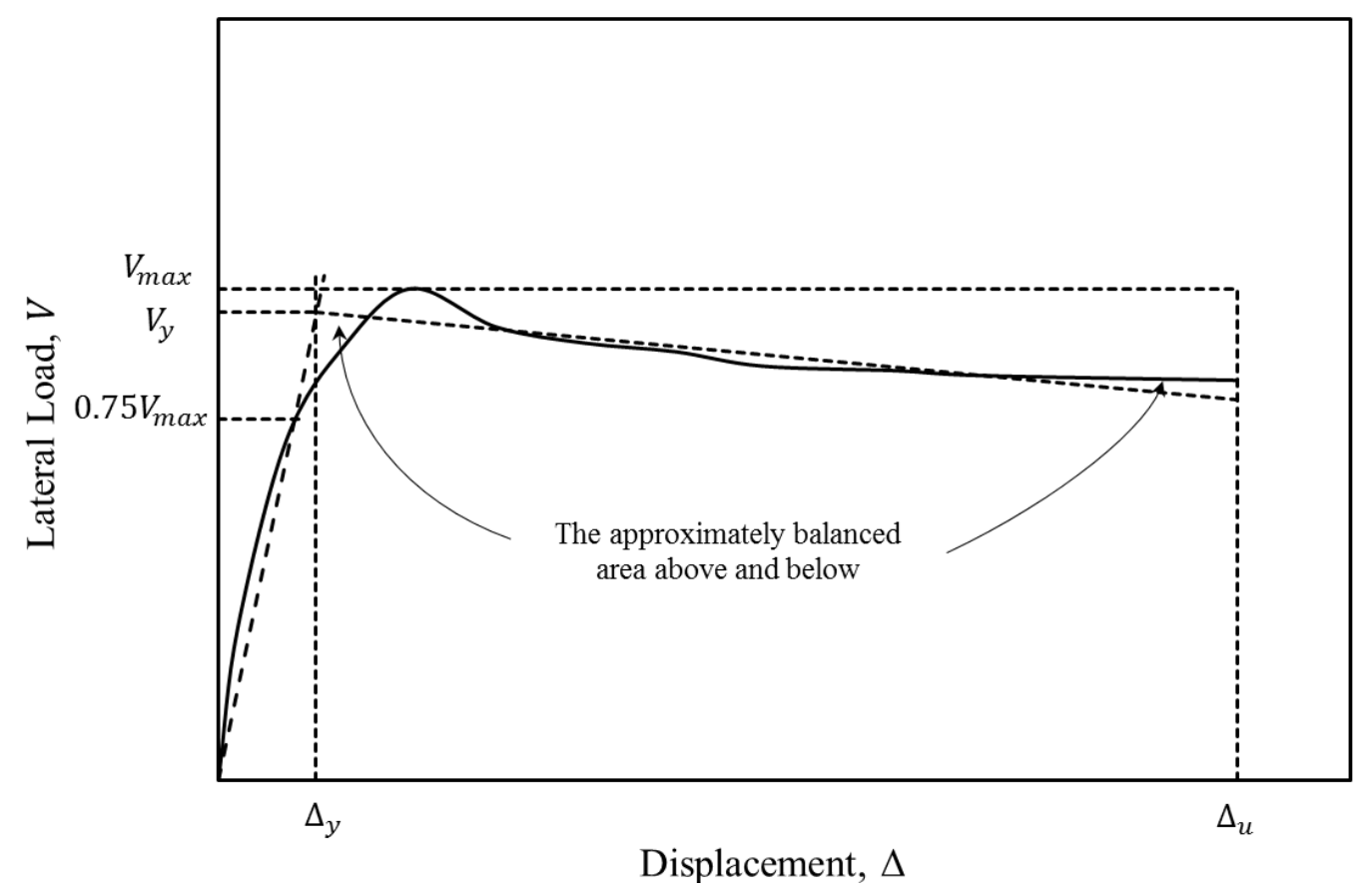

Figure 3.16: Definition of Yield Displacement

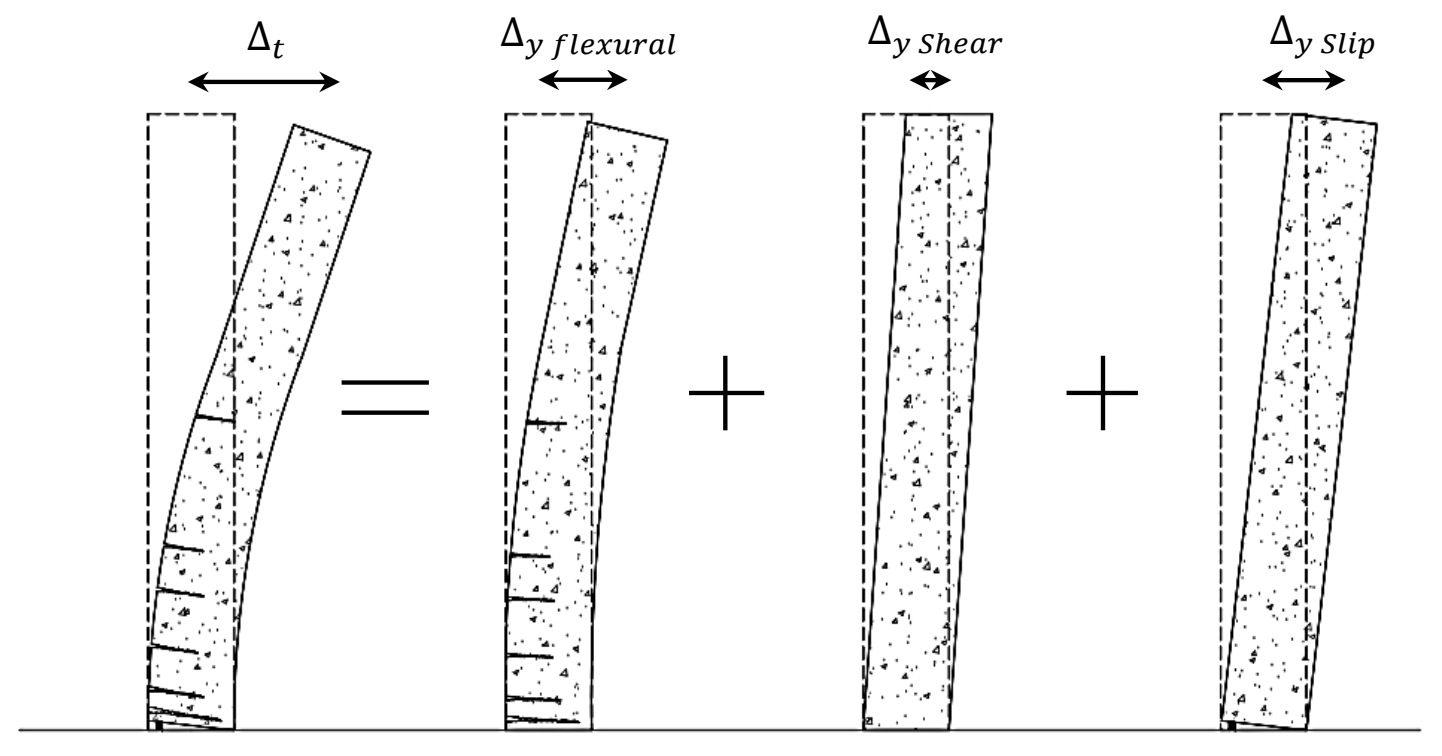

Figure 3.17: Displacement Components of RC Columns 
The flexural contribution to the yield displacement can be determined by integrating the column yielding curvature using the following expression:

$$
\Delta_{\text {flex }}=\int_{0}^{L} \Phi_{y}(x) x d x
$$

The contribution of the shear displacement is very small and therefore is often neglected during the displacement calculation (Elwood et al., 2007). The following equation is used to calculate the shear displacement:

$$
\Delta_{\text {shear }}=\frac{M_{y}}{A_{v} G_{\text {eff }}}
$$

Where, $A_{v}$ is the effective shear area of the column cross-section proposed to be $5 / 6$ of the gross-section area of a rectangular column (Popov, 1990), and $G_{e f f}$ is the effective shear modulus. It can be assumed that the cracked section as one-half of the elastic value, $G_{e}$ with Poisson's Ratio, $\gamma=0.2$.

$$
G_{e}=\frac{E_{c}}{2(1+\gamma)}
$$

The lateral displacement of the column is further increased due to the slip of the longitudinal bar within the foundation or the beam-column joint, as shown in Fig. 3.18. The length of the slip, $\delta_{\text {slip }}$ can determine by using the following expression:

$$
\delta_{\text {slip }}=\frac{\varepsilon_{S} d_{b} f_{S}}{8 u}
$$

Where $\varepsilon_{s}, d_{b}$, and $f_{s}$ are the steel tensile strain, bar diameter, and tensile stress of the steel reinforcement respectively. $u$ is a bond stress between the bar and the concrete, 
and the value of the bond stress ranges between $6 \sqrt{f_{c}^{\prime}}$ to $12 \sqrt{f_{c}^{\prime}}$ psi (Sezen \& Moehle, 2004 , Sezen \& Setzler, 2008; Kenneth J. Elwood and Marc O. Eberhard, 2009). The rotation of the column end, $\theta_{\text {slip }}$ is calculated by dividing the $\delta_{\text {slip }}$ by the depth of the neutral axis, $c$, as shown in Fig. 3.18. To determine the lateral displacement associated with rebar-slip at any distance, $L$, from the column base, the following equation is used:

$$
\Delta_{\text {slip }}=\theta_{\text {slip }} L
$$

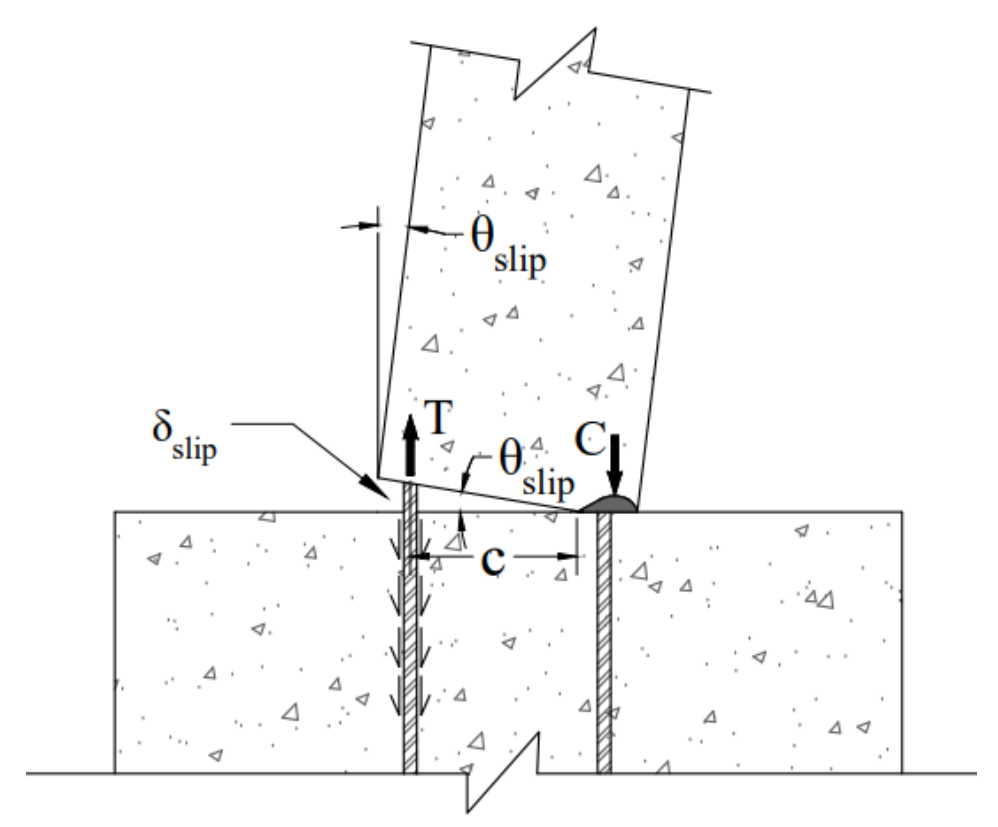

Figure 3.18: Rebar Slip and Slip Rotation

\subsubsection{Ultimate Displacement}

The ultimate displacement for RC columns tested under a combination of a constant axil load and a cyclic lateral load is determined at the post-peak where the RC member reaches the ultimate conditions. In earthquake research and design, it is common 
to define the ultimate lateral displacement at the point where the lateral load is reduced to $80 \%$ of the maximum lateral load. Based on the study conducted by Brachmann, I., Browning, J., \& Matamoros (2002), two reasons were expressed for considering this approach. The first reason is due to a conservative approximation made by considering the displacement ductility at the $20 \%$ decay in the lateral load, Fig. 3.19. The second reason is that determining the lateral displacement at this point is relatively easier than determining lateral displacement with further shear strength decay in columns.

Furthermore, for many years this approach was used for calculating the ultimate lateral displacement by many researchers, and it was assumed that exceeding the displacement beyond $80 \%$ of maximum lateral load leads to lateral instability (ACI Committee 374, 2013). For a column that was expected to be controlled by flexural failure, the $20 \%$ decay in lateral strength might be a consequence of concrete cover crushing or bar buckling while a severe diagonal cracking or shear-compression failure might happen for a column expected to experience shear failures due to $20 \%$ decay. However, without sever damage, the $20 \%$ decay in lateral strength for slender columns tested under high axial load might be a results of the $P-\Delta$ effect. Considering the lateral displacement corresponded to $20 \%$ decay as a limit for the ultimate condition may be conservative for slender RC column (Saatcioglu, 1991; Saatcioglu \& Baingo, 1999). Moment strength decay is one of the methods that is used to define the limit state of columns especially for columns governed by flexural stress. Saatcioglu (1991); and Saatcioglu \& Baingo (1999) suggested that considering a $20 \%$ decay in the moment capacity of the plastic hinge as a limit state for the displacement ductility is related more to the cross-section rotation capacity for 
columns controlled by flexural failure mode. In addition, RC columns with a slenderness ratio over 6.5 have not been investigated adequately (Barrera et al., 2011) to identify a clear definition for the ultimate displacement for slender columns.

For the slender RC columns, the flexural stress and the instability effects caused by gravity loads and lateral inelastic displacement mostly govern the failure mode.

Therefore, there is a need to determine the displacement ductility for the slender columns with consistent approach or a requirement that includes the effects of the secondary moment on the stability of the columns (Silva \& Sangtarashha, 2012; Burgueño et al., 2016). Furthermore, the limit state for RC columns confined with CFRP needs more investigation and clear guidance to identify the limit state of damage (Jean et al., 2012). In addition to the decay in lateral strength, the stability limit of slender columns is one of the most important indexes that limits the displacement ductility of the slender columns.

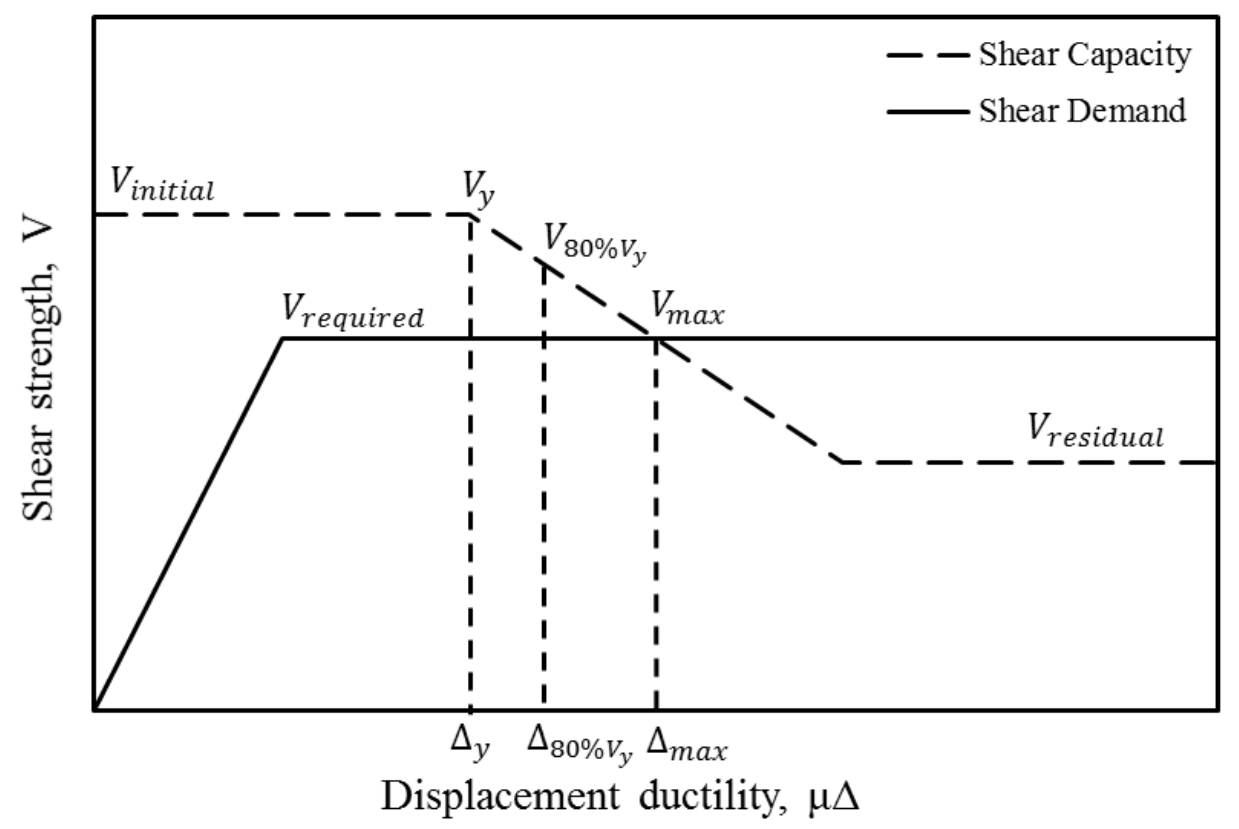

Figure 3.19: Determining the Lateral Displacement for RC Columns 


\subsubsection{Stability Index}

Under a constant gravity load, increasing the lateral displacement of slender RC columns leads to increase in the secondary moment, $\mathrm{P}-\Delta$, which consumes the moment capacity at the plastic hinge region and reduces the lateral resistance capacity of the columns. The significant effect of the secondary moment in reducing the lateral resistance capacity of the columns is measured by the stability index, $\mathcal{Q}$, as defined in the following equation:

$$
\mathcal{Q}=\frac{P \Delta_{o}}{F_{o} L_{c}}
$$

Where $F_{o} L_{c}$ represents the total moment capacity of the RC column base. Increasing the stability index beyond a specific limit leads to an instability failure, when buckling failure happens prior to the cross-section failure (MacGregor, J. G., \& Hage, 1977). Many experimental and analytical studies have been conducted to investigate the stability limit for the RC structures (Priestley, Michael J. N; Seible, F; and Calvi, 1996; Pettinga \& Priestley, 2008; Silva \& Sangtarashha, 2012; Barrera, Bonet, Romero, \& Fernández, 2012). It was recommended by Priestley, Michael J. N; Seible, F; and Calvi (1996) that using $\mathcal{Q} \leq 0.3$ would be a conservative limit for achieving a stable cyclic response. By relating the stability limit with the critical buckling load, Silva and Sangtarashha (2012) proposed an increase in the stability limit to $\mathcal{Q} \leq 0.4$. In American Concrete Institute (ACI, 2014), the limit of the ratio of total moment (primary moment plus secondary moment) to the primary moment is set as $\leq 1.4$. However, ASCE (2010) adopted a more conservative stability limit with $\mathcal{Q} \leq 0.25$. Some researchers considered 
these stability limits as damage limits for RC slender columns, and the available displacement ductility was determined based on these limits (Silva \& Sangtarashha, 2012; Burgueño et al., 2016).

\subsection{Energy Dissipation}

Energy dissipation is defined as the amount of energy that the member can absorb during an earthquake up to the ultimate condition. Using the energy dissipation for defining the structure response and safety against earthquake is the most suitable physical index (Ohno \& Nishioka, 1984; Park, HG., Eom, 2006; Eom \& Park, 2010). The energy dissipation is calculated by adding up the area enclosed by the load cycles at each level of the displacement increment, as shown in Fig 3.20. In general, the energy dissipation for $\mathrm{RC}$ columns is affected by many factors such as the longitudinal reinforcement ratio, the transverse reinforcement configuration, and the axial load level. The distribution of absorbed energy along RC columns is mostly concentrated at the plastic hinge regions, which can sustain a large amount of the inelastic rotation. Therefore, the amount of energy dissipated by RC columns is controlled by the plastic hinge behavior during an earthquake (Ohno \& Nishioka, 1984). 


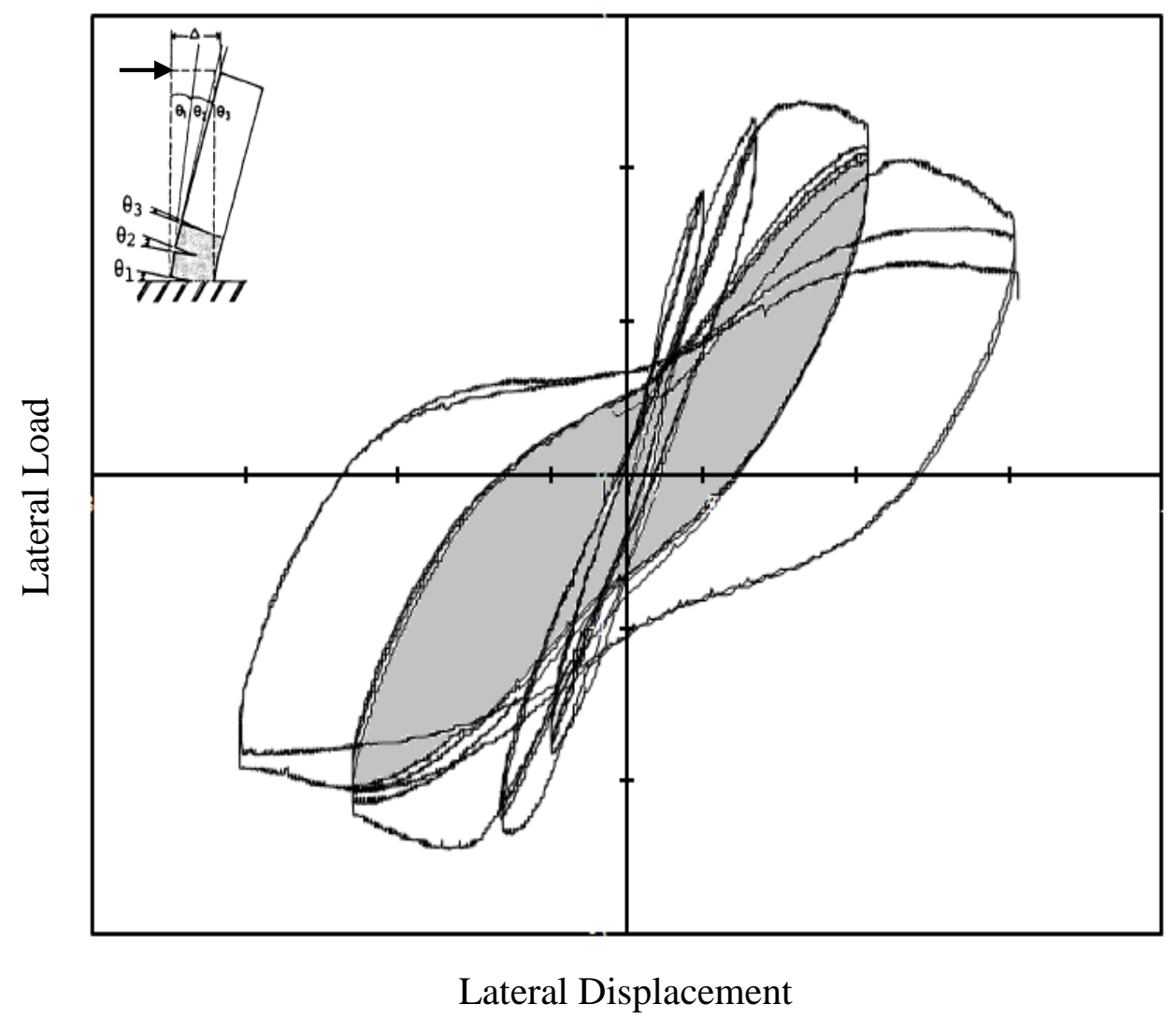

Figure 3.20: Energy Dissipated by Enclosed Cycle

\subsection{Structural Performance Level}

Any experimental result for testing an RC structural member should be compared with predetermined structural performance levels that set the qualification of the member to sustain a specific level of earthquake hazard based on the RC member behavior during the test (FEMA-356, 2000; ACI Committee 374, 2013). These performance levels are defined as acceptable levels of damage that need to be achieved under different levels of seismic hazards. Based on ACI 369R-11 (2011), and ASCE/SEI41-13 (2013), the performance levels are categorized into four major levels: 1) operational, 2) immediate 
occupancy, 3) life safety, and 4) collapse prevention. Fig. 3.21 illustrates the performance level limit for RC structures based on the lateral drift ratio. A description of a postearthquake damage in an RC building for each level is briefly explained in the next sections (ASCE/SEI 41-13, 2013).

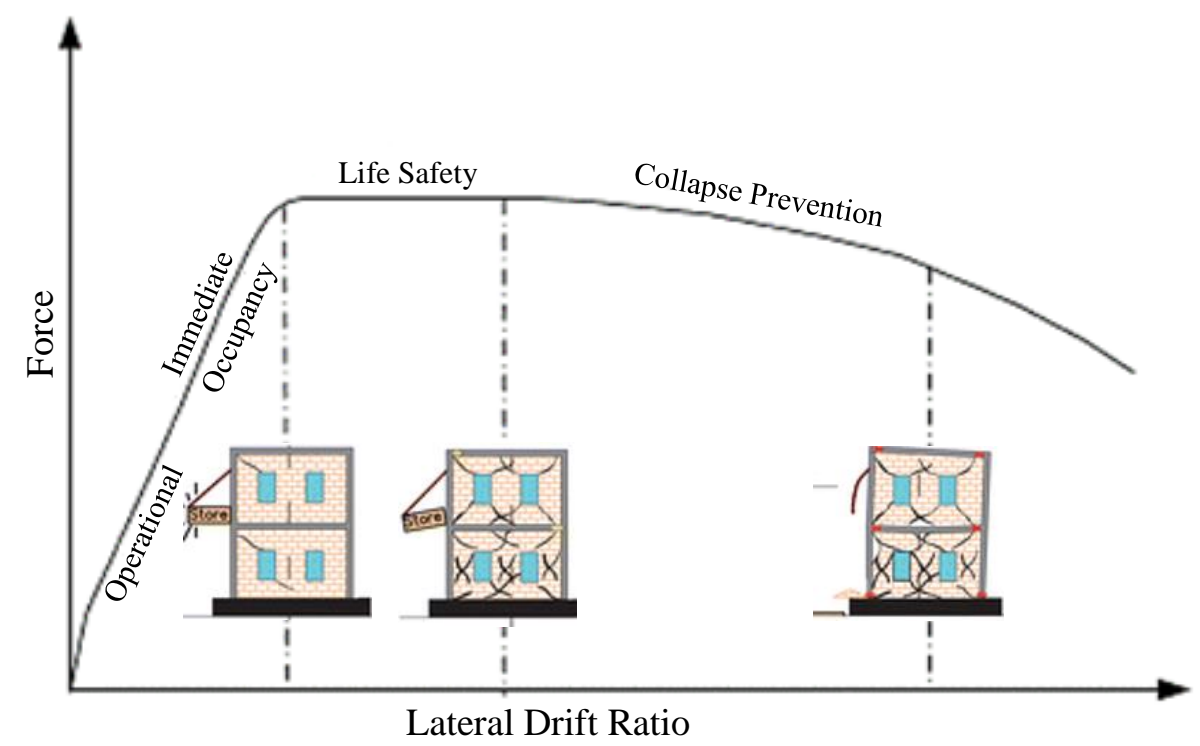

Figure 3.21: RC Structure Performance Level

\subsubsection{Operational Performance Level (O)}

The damage state in this level is very light with minor hairline cracking in the structural elements and no permanent drift ratio. Furthermore, the structure can continue to operate during and after an earthquake, and retains to its original strength and stiffness without degradation. 


\subsubsection{Immediate Occupancy Performance Level (IO)}

This level is accompanied by light damage that includes small cracks and limited yielding strain at some locations in the structural elements with no concrete crushing. After an earthquake, the building retains most of its strength and stiffness without permanent deformation and can be reoccupied.

\subsubsection{Life Safety Performance Level (LS)}

In this level, there is a moderate amount of damage that is accompanied by extensive damage in the beams, cover spalling in the columns, and shear cracks less than $1 / 8$ in. wide. Occasionally, this damage results in injuries but the overall risk to life is expected to be low. Some residual strength and stiffness are left in RC structure to sustain the gravity loads.

\subsubsection{Collapse Prevention Performance Level (CP)}

Severe damage is expected at this level where the RC building is near collapse. The damage is accompanied by extensive spalling in the concrete cover of the beams and columns, and extensive cracking at the plastic hinge regions with the buckling of some of the longitudinal reinforcement steel. This damage level includes a significant reduction in the strength and stiffness of the RC structure, but limited degradation in sustaining the gravity loads. In this case, the building is not safe to reoccupy and is not repairable. 


\subsection{Seismic Rehabilitation and Basic Safety Objective}

Seismic rehabilitation is defined as improving the seismic response of the existing buildings that are not retrofit to withstand earthquakes by replacing the deficiencies in the structural components with new technology to achieve rehabilitation objectives (ASCE/SEI41-13, 2013). According to FEMA-356 (2000); and ASCE/SEI41-13 (2013), the Basic Safety Objective (BSO) is the performance level required for a building to behave during an earthquake. The building must achieve a seismic hazard life safety performance level of $10 \%$ in 50-years, and have a collapse prevention performance level of $2 \%$ in 50 -years. Seismic hazard is defined as the relation between the probability that a ground-motion intensity will occur in a specific area and their annual probabilities of

exceedance (or return period). The type of seismic rehabilitation will be selected based on the seismic evaluation that identifies the deficiencies in a building that prevent the building from achieving BSO during an earthquake.

\subsection{Existing Buildings Capacities and Retrofit Philosophy}

Most of the existing pre-1971 RC buildings around the world are not strong enough to withstand a moderate or strong earthquake level. Previous research studies and observations have shown that the main reason for earthquake damage in most of the older $\mathrm{RC}$ buildings was due to insufficient confinement reinforcement and inadequate reinforcement detail in columns and beam-column joints (Park, 2001). Due to these deficiencies, the pre-1971 RC buildings are at risk of partial or even complete failure by brittle failure mechanisms when exposed to an earthquake. Therefore, the need for 
improving the performance level of these buildings during an earthquake is crucial to saving lives and properties. Retrofitting is a common strengthening method to improve the deficiencies in the older buildings. ASCE/SEI41-13 (2013); and ACI 369R-11 (2011) adopted a guide for seismic rehabilitation of existing vulnerable RC buildings by correcting the deficiencies that are identified in a seismic evaluation, thereby achieving a selected rehabilitation objective. In order to give a more realistic picture of a building performance level during an earthquake and the effect of the retrofit technique on the building response, four analysis procedures are illustrated in these standards; 1) Linear Static Procedure (LSP); 2) Linear Dynamic Procedure (LDP); 3) Nonlinear Static Procedure (NSP); 4) Nonlinear Dynamic Procedures(NDP). Using the linear analysis procedure for seismic analysis is not always accurate, and provides a more conservative estimation with unnecessary seismic rehabilitation. Therefore, a nonlinear analysis procedure is recommended to obtain more accurate results (ASCE/SEI41-13, 2013). In this project, a Nonlinear Static Procedure (NSP) will be used to analyze because this procedure is reliable and can be applied to a wide-range of existing RC building and potential earthquakes.

\subsubsection{Nonlinear Static Procedure NSP}

Several approaches for the NSP have been developed and presented by different standards. Fig. 3.22 illustrated the flow chart for any NSP approach used for analyzing buildings. In the NSP method, a pushover analysis, which is an incremental static analysis implemented to determine the capacity curve for a structure, is constructed. 
Based on the capacity curve, the effective stiffness of the structure is determined. In order to simplify the analysis, a structural system with a multi-degrees of freedom is modeled by an equivalent single-degree of freedom with the same effective stiffness value determined from the capacity curve. Based on an elastic spectrum curve, a linear elastic structure response of varying natural frequencies, the displacement demand of the singledegree of the freedom system is determined by using one of available approaches. This will be illustrated later. The value of the displacement demand distributed along the structural height is based on the available methods (FEMA-356, 2000). The performance level of the structure is determined based on the location of the displacement demand on the capacity curve, as shown in Fig. 3.21. There are two approaches that are commonly used to determine the demand curve: 1) the Capacity-Spectrum Method (CSM), which was developed and introduced by ATC-40 (1996); and 2) the Coefficient Method (CM), which was developed and introduced by FEMA-356 (2000). The advantages and drawbacks of each method are illustrated elsewhere (FEMA-440, 2005). Both of these procedures were improved and modified by FEMA-440 (2005) to present two new procedures: the Equivalent Linearization Procedure (ELP) and the Displacement Modification Procedure (DMP). In this project, the DMP will be used to determine the demand curve. The first step in applying NSP includes determining the fundamental period of the building. The fundamental period should be calculated for the direction under consideration by using the following empirical expression:

$$
T=C_{t} h_{n}^{\beta}
$$

Where 
$C_{t}=0.035$ for steel moment-resisting frame system

$=0.018$ for concrete moment-resisting frame system

$=0.030$ for steel eccentrically-braced frame system

$=0.020$ for wood buildings

$=0.020$ for all other framing system

$h_{n}=$ height, in $\mathrm{ft}$, above the base to the roof level

$\beta=0.80$ for steel moment-resisting frame system

$=0.90$ for concrete moment-resisting frame system

$=0.75$ for all other framing system

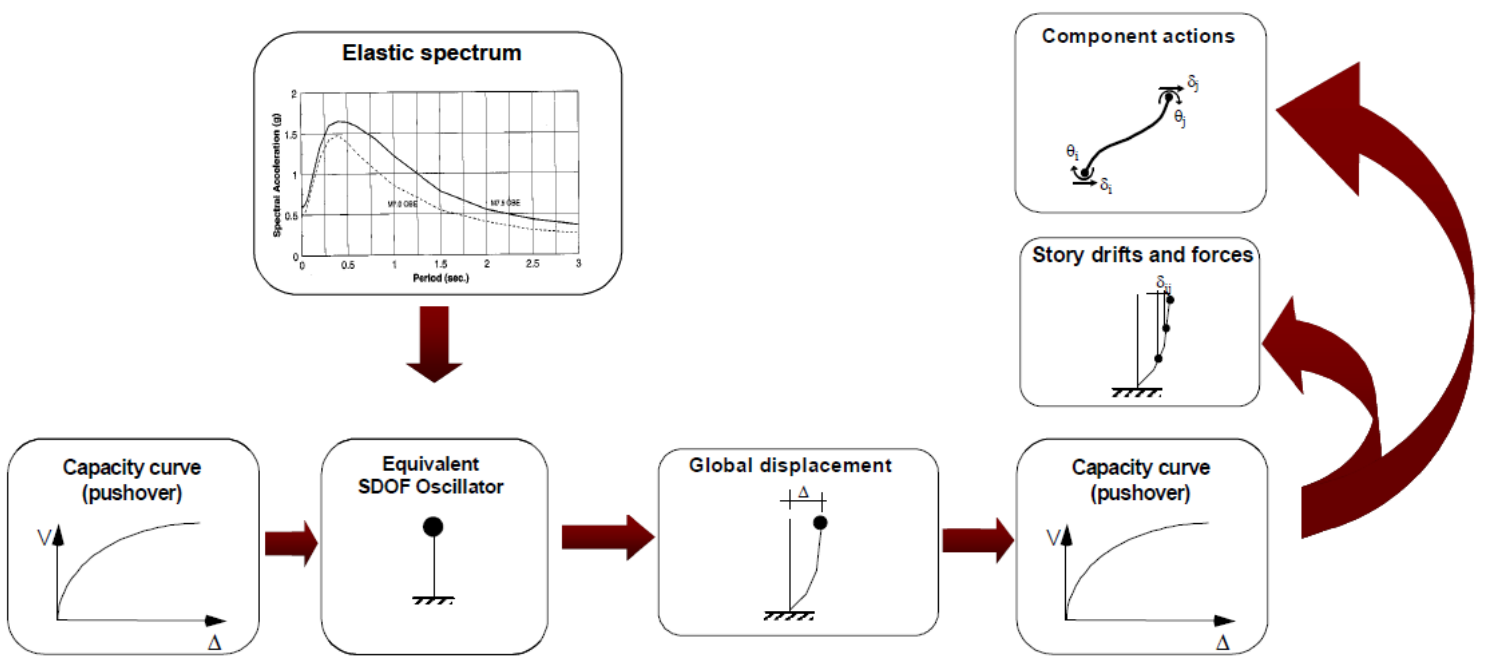

Figure 3.22: Flow Chart Simplified Nonlinear Analysis Process (FEMA-440) 
The second step is to conduct the pushover analysis and determine the capacity curve of the building. Based on the capacity curve, the effective stiffness, $K_{e}$, effective yield strength, $V_{e}$, and post-yield stiffness, $\alpha_{1} K_{e}$, can be determined, as shown in Fig.

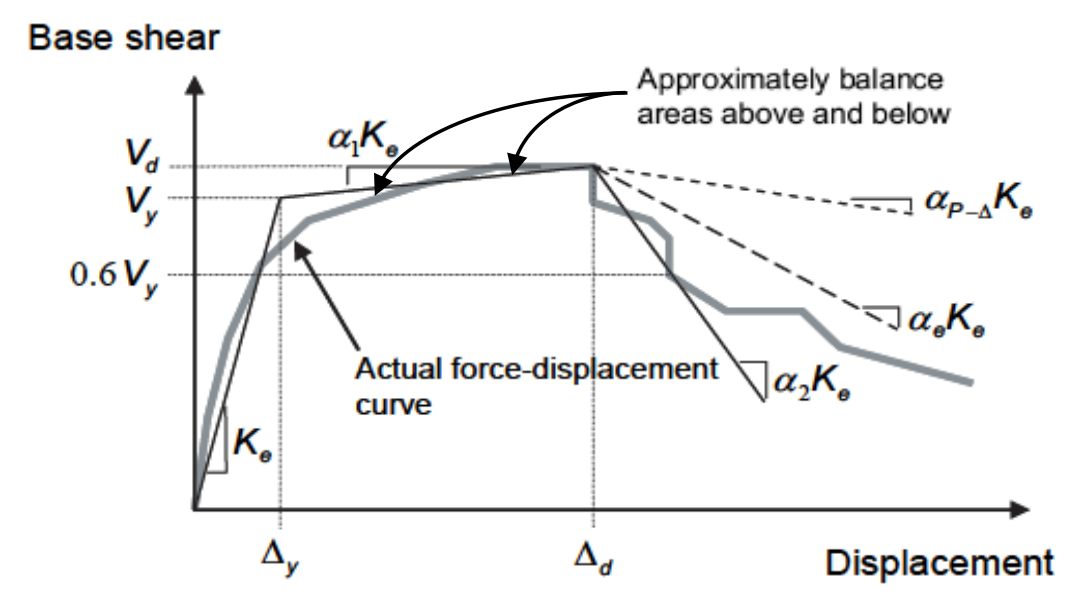

Figure 3.23: Idealized Force-Displacement Curve for NSA (FEMA-440, 2005; FEMA$356,2000)$

The final step in NSP is to calculate the displacement demand, a target displacement of $\delta_{t}$, by using DMP, which is intended to represent the maximum displacement likely to be experienced during an earthquake. The following expression is used to calculate the target displacement:

$$
\delta_{t}=C_{o} C_{1} C_{2} S_{a} \frac{T_{e}^{2}}{4 \pi^{2}} \mathrm{~g}
$$

Where: 
$C_{o}=$ the modification factor related to the spectral displacement of an equivalent single- degree of freedom system to the roof displacement of the building multi-degree of freedom system. The simplest method to calculate $C_{o}$ is illustrated in Table 3-1.

Table 3-1: Values for $C_{o}$

\begin{tabular}{||c||c|c||c||}
\hline \hline \multirow{2}{*}{ Number of Stories } & \multicolumn{2}{c||}{ Shear Buildings } & Other Buildings \\
\cline { 2 - 4 } & $\begin{array}{c}\text { Triangular Load } \\
\text { Pattern }\end{array}$ & $\begin{array}{c}\text { Uniform Load } \\
\text { Pattern }\end{array}$ & Any Load Pattern \\
\hline \hline 1 & 1.0 & 1.0 & 1.0 \\
\hline 2 & 1.2 & 1.15 & 1.2 \\
\hline 3 & 1.2 & 1.2 & 1.3 \\
\hline 5 & 1.3 & 1.2 & 1.5 \\
\hline+10 & 1.3 & 1.2 & 1.4 \\
\hline \hline
\end{tabular}

$C_{1}=$ the modification factor related to the expected maximum inelastic displacement to displacement calculated for a linear elastic response. A simplified expression is used to calculate $C_{1}$.

$$
C_{1}=1+\frac{\mu_{\text {strength }}-1}{a T_{e}^{2}}
$$

Where:

$a=$ the site class factor, which is equal to: 130 for class $\mathrm{A}$ and $\mathrm{B}, 90$ for class C, 60 for class D, E, and F. 
$T_{e}=$ the effective fundamental period of the building in direction under consideration, in seconds.

$\mu_{\text {strength }}=$ the ratio of the elastic strength demand to yield strength coefficient, and is calculated using the following expression:

$$
\mu_{\text {strength }}=\frac{S_{a}}{V_{y} / W} C_{m}
$$

Where:

$S_{a}=$ the response spectrum acceleration, at the effective fundamental period and damping ratio (ASCE/SEI41-13, 2013).

$V_{y}=$ the yield strength calculated using the results of the NSP for the idealized force-displacement curve developed for building, Fig. 3.16.

$W=$ the effective seismic weight.

$C_{m}=$ the effective mass factor from Table 3-2.

Table 3-2: Values for Effective Mass Factor $C_{m}$

\begin{tabular}{||c||c||c||c||}
\hline $\begin{array}{c}\text { No. of } \\
\text { Stories }\end{array}$ & $\begin{array}{c}\text { Concrete Moment } \\
\text { Frame }\end{array}$ & $\begin{array}{c}\text { Concrete Shear } \\
\text { Wall }\end{array}$ & $\begin{array}{c}\text { Concrete Pier- } \\
\text { Spandrel }\end{array}$ \\
\hline \hline $1-2$ & 1.0 & 1.0 & 1.0 \\
\hline 3 or more & 0.9 & 0.8 & 0.8 \\
\hline
\end{tabular}


For buildings with negative post-yield stiffness, the maximum strength ratio $\mu_{\max }$ shall be calculated by using the following expression:

$$
\mu_{\max }=\frac{\Delta_{d}}{\Delta_{y}}+\frac{\left|\alpha_{e}\right|^{-h}}{4}
$$

Where

$\Delta_{d}=$ the lesser of target displacement, $\delta_{t}$, or displacement at maximum base shear as shown in Fig. 3.23

$\Delta_{y}=$ the displacement at the effective yield strength as defined in Fig. 3.23

$h=1+0.15 \ln T_{e}$

$\alpha_{e}=$ the effective negative post-yield ratio defined in the following equation:

$$
\alpha_{e}=\alpha_{p-\Delta}+\lambda\left(\alpha_{2}-\alpha_{p-\Delta}\right)
$$

Where

$\alpha_{2}=$ the negative post-yield slope ratio defined in Fig. 3.23

$\alpha_{p-\Delta}=$ the negative slope ratio caused by $P-\Delta$ effects, in cyclic degradation.

$\lambda=$ the near field effect factor:

$=0.8$ if $S_{a} \geq 0.6$ (Maximum Considered Earthquake, MCE)

$=0.2$ if $S_{a}<0.6(\mathrm{MCE})$ 
$C_{2}=$ the modification factor representing the effect of a pinched hysteresis shape, cyclic stiffness degradation, and strength deterioration on a maximum displacement response. A simplified expression is used to calculate $C_{2}$

$$
C_{2}=1+\frac{1}{800}\left(\frac{\mu_{\text {strength }}-1}{T_{e}}\right)^{2}
$$

For a period greater than $0.7 \mathrm{sec}, C_{2}=1$.

$\mathrm{g}=$ the acceleration of gravity

\subsubsection{Acceptance Criteria}

Acceptance criteria are defined as the acceptable performance levels that all primary and secondary structural elements shall be capable of providing while resisting the force and deformation actions during an earthquake. According to ASCE/SEI41-13 (2013), the structural component response must be classified as deformation controlled, ductile, or force controlled, non-ductile. Fig. 3.24 illustrated three types of structural response curves that most of the structure systems were classified based on these types. The first type of curve represents the ductile behavior with plastic range starting from 1 to 3 with a losing seismic resistance capacity at point 3 and the gravity load support at point 4 . The second type of curve represents the ductile behavior with a plastic range from 1 to 2 , and the ability to support the gravity load vanishes at point 4 . The behavior of the third type is completely brittle without plastic range and a gravity load support after point 2 up to point 4 . 


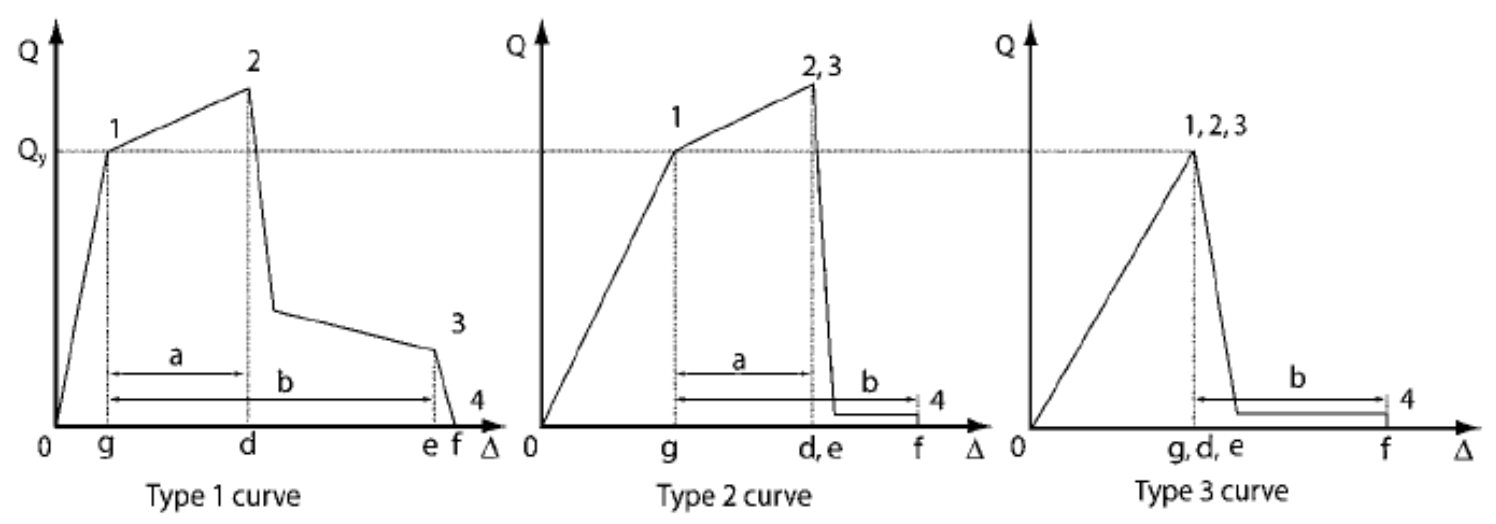

Figure 3.24: Classification of Structural Response (ASCE41-13)

Based on these types of responses, ASCE/SEI41-13 (2013) provides a generalized nonlinear modeling curve, force versus deformation curves are shown in Fig. 3.25. This curve defines the component's response based on modeling parameters $\boldsymbol{a}, \boldsymbol{b}$, and $\boldsymbol{c}$. Based on these values, the performance level of structure during an earthquake is identified. The elastic and plastic response of the component are defined by line $\mathrm{AB}$ and $\mathrm{BC}$, respectively. The slope of line $\mathrm{AB}$ depends on the effective elastic stiffness, and point $\mathrm{B}$ represents the yield strength of the component. Points $\mathrm{C}$ and $\mathrm{E}$ represent the limits where the component was considered to have lost its lateral strength and axil load capacity, respectively. The value of rotation (deformation) corresponding to the point $\mathrm{B}$ and $\mathrm{C}$ represents the yield and the ultimate rotation, respectively. Parameter $\boldsymbol{a}$ is the difference between the ultimate rotation and the yield rotation of the component. Parameter $\boldsymbol{b}$ is a difference between the rotation at point $\mathrm{E}$ and the yield rotation at point B. Parameter $\boldsymbol{c}$ is the amount of residual lateral strength at point E. ASCE/SEI41-13 (2013) provides the tables used to identify the values of the modelling parameters $\boldsymbol{a}, \boldsymbol{b}$, and $\boldsymbol{c}$, illustrated in 
Table 3-3. For RC columns, the value of parameter $\boldsymbol{a}$ is based on an appropriate level of safety based on the following principles: (1) For an RC column expected to experience shear failure, the probability of failure is less than 15\%. (2) For an RC column expected to experience flexural failure, the probability of failure is less than $35 \%$. These modeling parameters are defined based on the axial load level $\left(P / A_{g} f_{c}^{\prime}\right)$, transverse reinforcement ratio $\left(\rho_{v}\right)$, and normalized design shear force $\left(V / b d \sqrt{f_{c}^{\prime}}\right)$. Further discussion about using this table can be found in ASCE/SEI41-13 (2013).
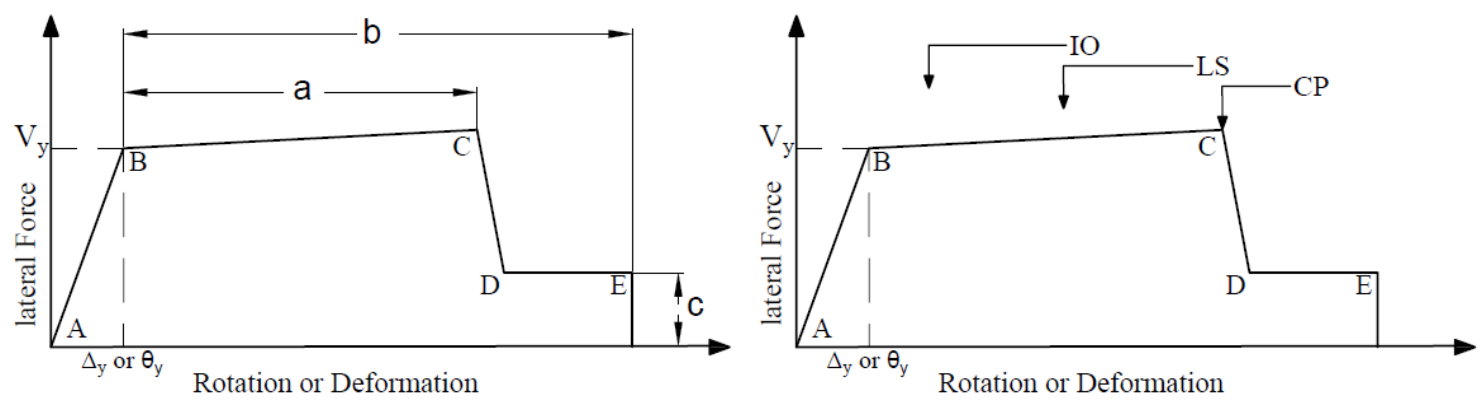

Figure 3.25: Generalized Component Force-Deformation Relation and Accompanied Performance Level (ASCE 41-13, 2013) 
Table 3-3: Nonlinear Modeling Parameter Presented in ASCE 41-13 (2013)

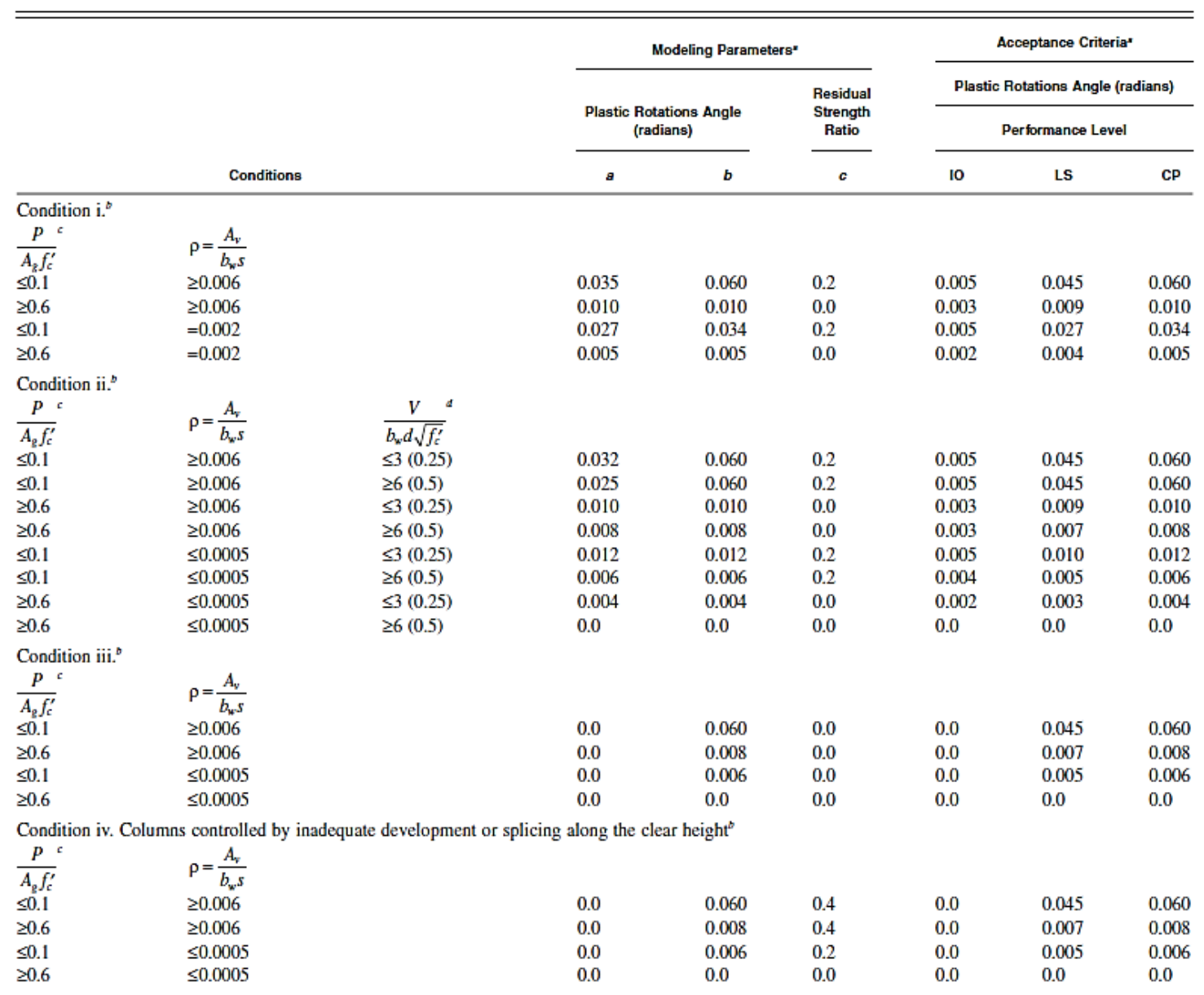




\section{Chapter 4: Experimental Program}

\subsection{General}

Generally, the purpose of testing a specimen is to simulate the behavior of a component or portion of a structure. Therefore, it is very important that the materials, design, and boundary conditions are simulated properly. Most of the experimental studies conducted on RC columns have utilized one of the following models: (1) a double curvature specimen, as in Fig. 4.1a, (2) double-ended specimens, as in Fig. 4.1b, or (3) simple cantilever, shown in Fig. 4.1c. In this project, the double-ended specimen (4.1b) is used, because the loading frame available in the lab on our campus is best suited to test this type of testing arrangement. The proposed specimen to be tested is a slender RC column, located between the first and second floor, where two columns connect to a rigid element, or stub (Fig. 4.2).

In the lab, five half-scale slender RC columns were prepared, with a square six by six inch cross-section and a shear span to depth ratio equal to 7 . The main variables of this experimental study are the axial load level and strengthening technique used with CFRP sheet. This chapter details the current experimental program, including material properties, specimen configuration and construction, instrumentation, test setup, and cyclic loading protocol. 


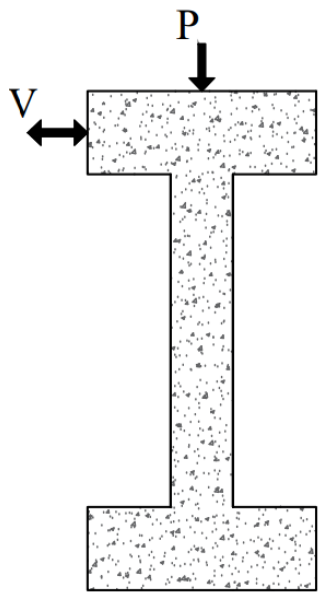

(a)

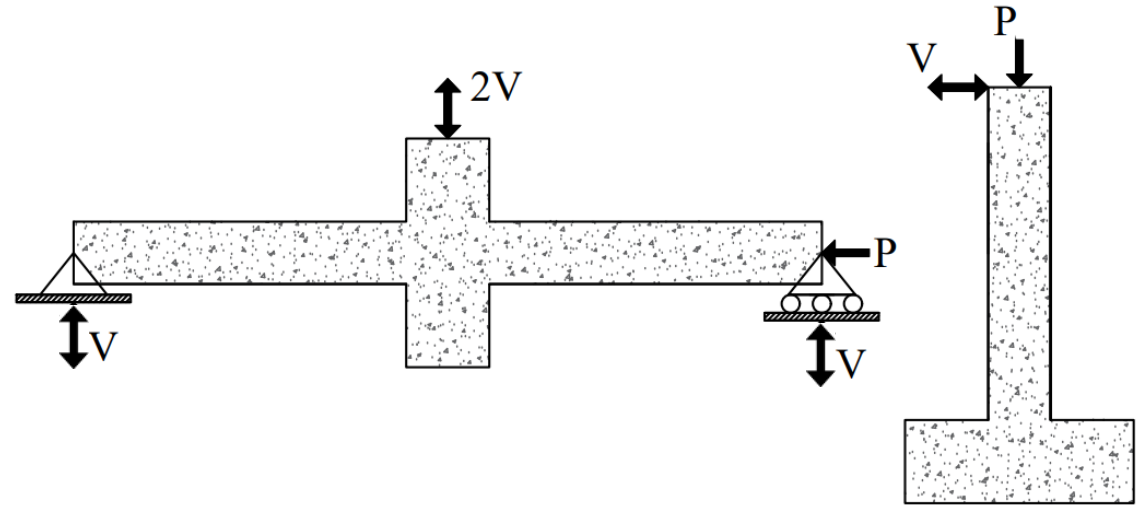

(b)

(c)

Figure 4.1: the Common Tested Models, (a) Double Curvature Specimens, (b) Doubleended Specimens, (c) Simple Cantilever

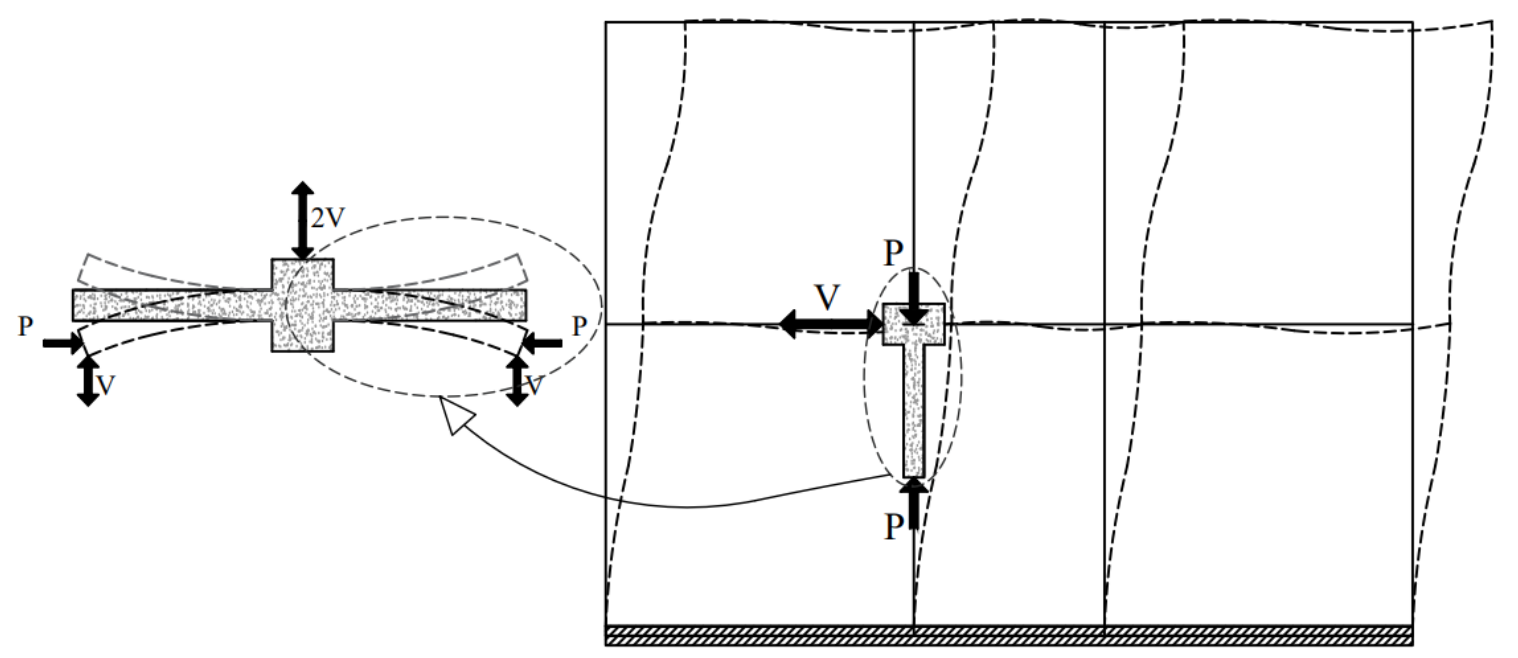

Figure 4.2: the Location of the Tested Columns 


\subsection{Materials Properties}

\subsubsection{Concrete}

Concrete was prepared using a semi-automatic concrete mixture with two cubicfoot capacity, and the coarse and fine aggregate used to prepare the concrete mix were saturated surface dry. The maximum size for the coarse aggregate was $3 / 8$-inch. The concrete mix was designed for a compressive strength of 3000 psi in 28 days using Portland Cement Association (PCA) guidelines (Kosmatka \& Wilson, 2011). In this mix design, the water-cement ratio was selected as 0.67 , and the weight of materials to produce a cubic foot of concrete using cement, coarse aggregate, and fine aggregate were 18,46 , and 65 pounds, respectively. In order to investigate the compressive strength $\left(f_{c}^{\prime}\right)$ of concrete mix at 28 days, three standard size ( 6 inx 12 in) plastic cylinder molds were prepared. The cylinders were filled with the fresh concrete in three layers, and rodded according to ASTM C143, and sealed with a plastic cover. After 28 days of curing, the specimens were tested using a Forney Compressive Machine F-250 with a 250-kip capacity. The results of compressive strength testing on the specimens are shown in Fig. 4.3. The average compressive strength of the three specimens was $3255 \mathrm{psi}$, and the range of values for compression tests was 3050 to 3450 psi. However, the number of specimens tested was too small for calculating the standard deviation and the coefficient of variation. 

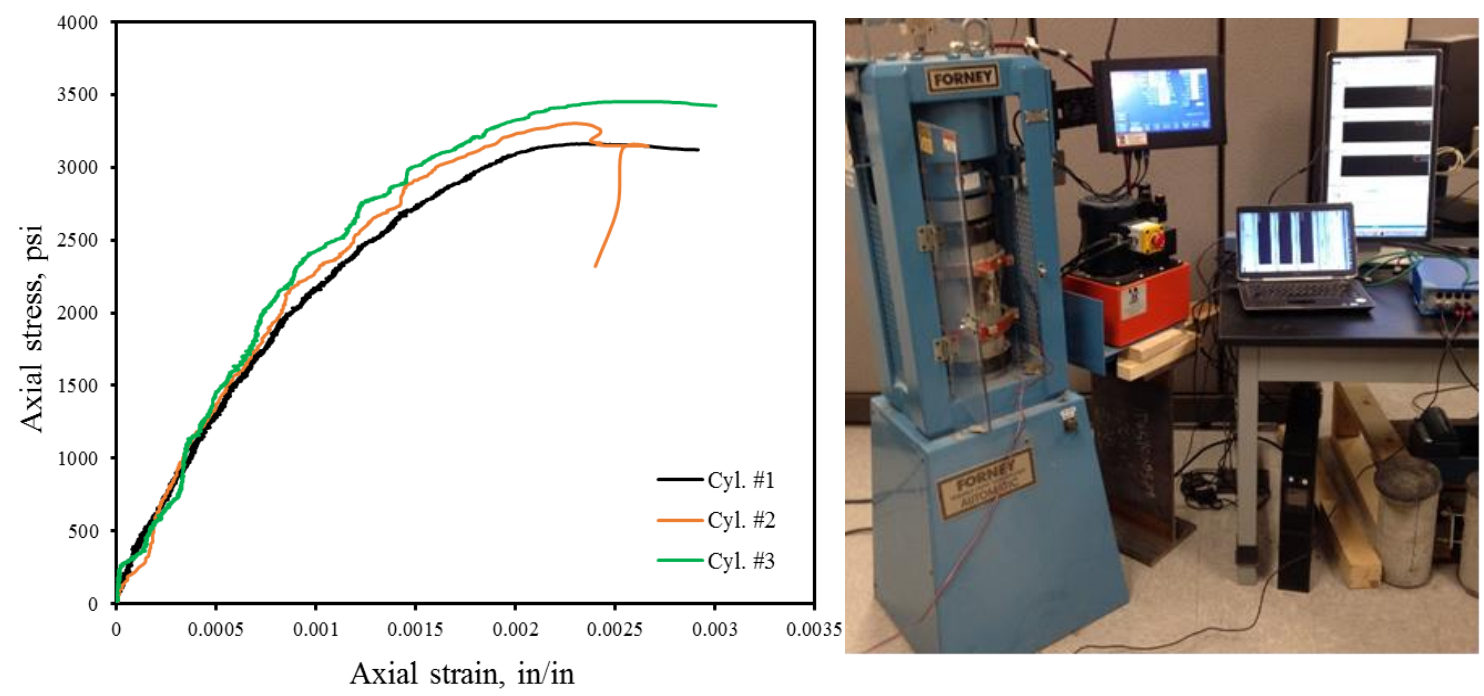

Figure 4.3: Stress-Strain Curves for Concrete

\subsubsection{Steel Reinforcement}

Three types of steel reinforcement were used in this project: deformed steel \#3 bars were used for longitudinal reinforcement, plain (smooth) steel \#2 bars for transversal reinforcement, and \#3 and \#4 steel bars for the steel cage for the stub. The mean values of mechanical properties were gleaned from a previous tensile strength tests (Yosefani, 2018) using a minimum of three samples of each size. The mechanical properties are illustrated in table 4-1, while the tensile stress-strain behavior for \#2 and \#3 bars are shown in Fig. 4.4. 
Table 4-1: Mechanical Properties of Reinforcing Steel

\begin{tabular}{||c|c|c|c|c|c|c||}
\hline \hline $\begin{array}{c}\text { Rebar } \\
\text { Type }\end{array}$ & $\begin{array}{c}\text { Area } \\
\boldsymbol{A}_{\boldsymbol{s}} \\
\left(\boldsymbol{i n}^{2}\right)\end{array}$ & $\begin{array}{c}\text { Yield } \\
\text { Strength } \boldsymbol{f}_{\boldsymbol{y}}\end{array}$ & $\begin{array}{c}\text { Yield Strain } \\
\boldsymbol{\varepsilon}_{\boldsymbol{y}}\end{array}$ & $\begin{array}{c}\text { Elastic } \\
\text { Modulus, } \boldsymbol{E}_{\boldsymbol{s}} \\
(\mathrm{ksi})\end{array}$ & $\begin{array}{c}\text { Ultimate } \\
\text { Strength, } \boldsymbol{f}_{\boldsymbol{u}} \\
(\mathrm{ksi})\end{array}$ & $\begin{array}{c}\text { Strain at } \\
\text { strength } \boldsymbol{f}_{\boldsymbol{u}}, \\
\boldsymbol{\varepsilon}_{\boldsymbol{u}}\end{array}$ \\
\hline \hline$\# 3$ & 0.11 & 72 & 0.0024 & 30000 & 105 & 0.05 \\
\hline$\# 2$ & 0.049 & 57 & 0.00218 & 26150 & 68 & 0.05 \\
\hline \hline
\end{tabular}

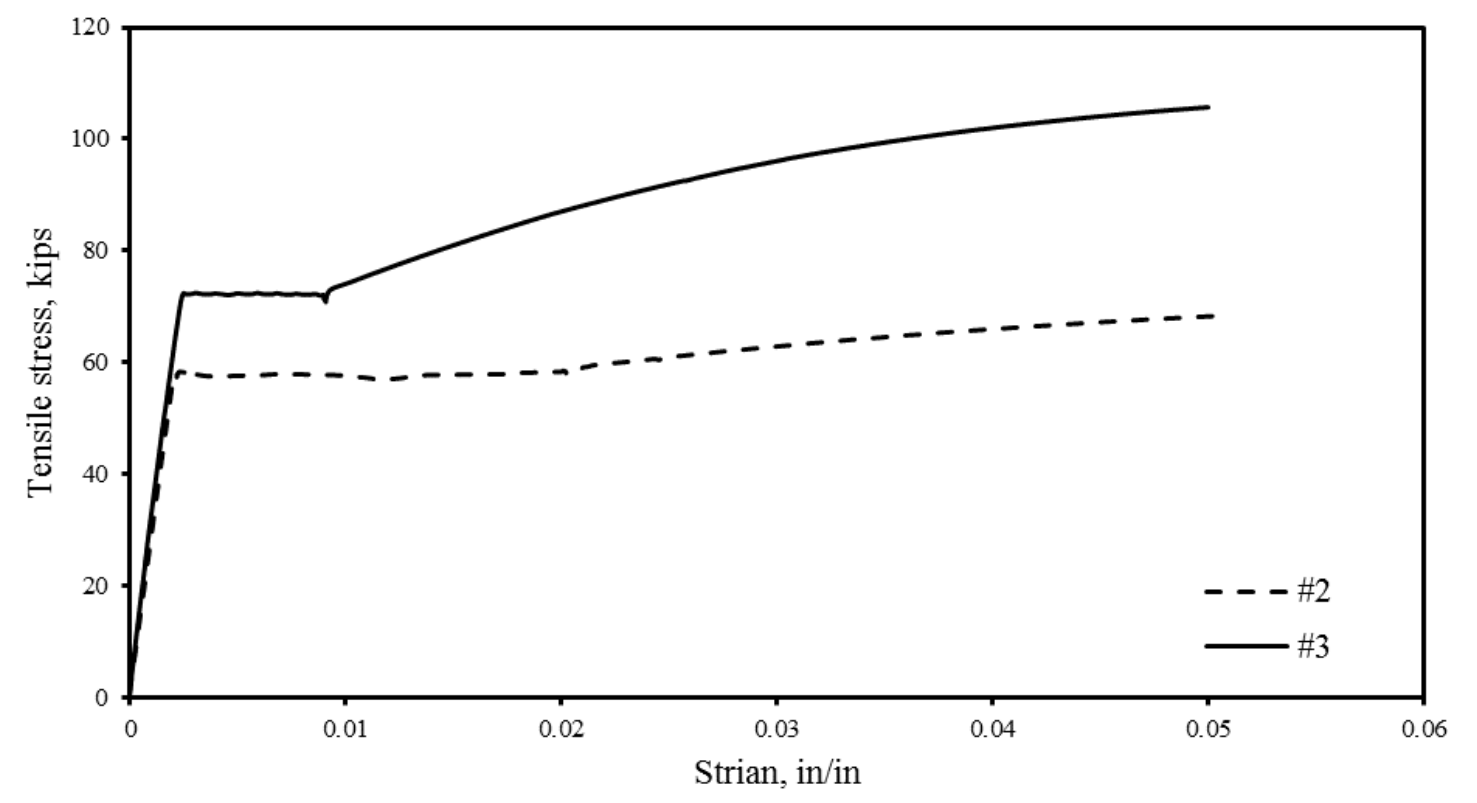

Figure 4.4: Stress-Strain Curves for Steel Reinforcement 


\subsubsection{Carbon Fiber Reinforced Polymers (CFRP)}

For experimental tests, Toray carbon fiber (T300, 12k), a unidirectional high strength carbon fabric, was used. The properties of the fiber yarns according to the manufacturer are listed in Table 4-2. The fiber sheet was a single-layer unidirectional fabric 30 feet in length and 1-foot wide, delivered as a roll. Table 4-3 illustrates the mechanical properties of the epoxy used with CFRP sheet.

Table 4-2: Mechanical Properties and Geometric Parameters of CFRP

\begin{tabular}{||l||l||}
\hline \hline Parameter & Value \\
\hline Number of filaments per yarn & $12 \mathrm{k}$ \\
\hline Tensile Strength $(\mathrm{ksi})$ & 512 \\
\hline Elastic Modulus $(\mathrm{ksi})$ & 34000 \\
\hline Ultimate Strain $(\%)$ & $1.5 \%$ \\
\hline Weight $\left(\mathrm{oz} / \mathrm{yd} \mathrm{d}^{2}\right)$ & 8.85 \\
\hline Thickness (in) & 0.00657 \\
\hline \hline
\end{tabular}


Table 4-3: Mechanical Properties of Epoxy

\begin{tabular}{||l||l|l||}
\hline Parameter & Tensile Properties & Compressive Properties \\
\hline \hline Yield Strength & $7900 \mathrm{psi}$ & $12500 \mathrm{psi}$ \\
\hline Strain at Yield & $2.5 \%$ & $5.0 \%$ \\
\hline Elastic Modulus & $440000 \mathrm{psi}$ & $380000 \mathrm{psi}$ \\
\hline Ultimate Strength & $8000 \mathrm{psi}$ & $12500 \mathrm{psi}$ \\
\hline Rupture Strain & $3.5 \%$ & $5 \%$ \\
\hline Poisson's Ratio & 0.40 & \\
\hline \hline
\end{tabular}

In order to verify the mechanical properties of the materials provided by the manufacturer, four CFRP composite coupons were prepared according to the ASTM D3039/D3039-08 standard for a tensile test. The CFRP laminate was fabricated according to a wet lay-up technique. After 48 hours of curing, four 10 -inch by 0.6 inch strips were tested at the University of Portland. In order to provide an appropriate anchor for both ends of the coupons, two rectangular aluminum tabs, configured according to ASTM D3039/D3039-08 (2008) standard, were glued to the CFRP coupon at the ends, as shown in Fig. 4.5. To measure the tensile strain of the coupons, a strain gage was mounted in the middle of each CFRP coupon. In this test, the Instron tensile test machine located at Mechanical Engineering Department of Portland State University was used to apply tensile force with displacement control. Before applying the load, the coupons' ends were firmly clamped by the machine's grips. Coupons were tested under a constant deformation rate of 0.02 inch per minute. Fig. 4.6 the tensile stress-strain reported by 
manufacturer and results of the four coupons tested. The average values of tested coupons were:

Ultimate tensile strength $=453 \mathrm{ksi}$,

Rupture strain $=1.34 \%$,

Modulus of elasticity $=33806 \mathrm{ksi}$.
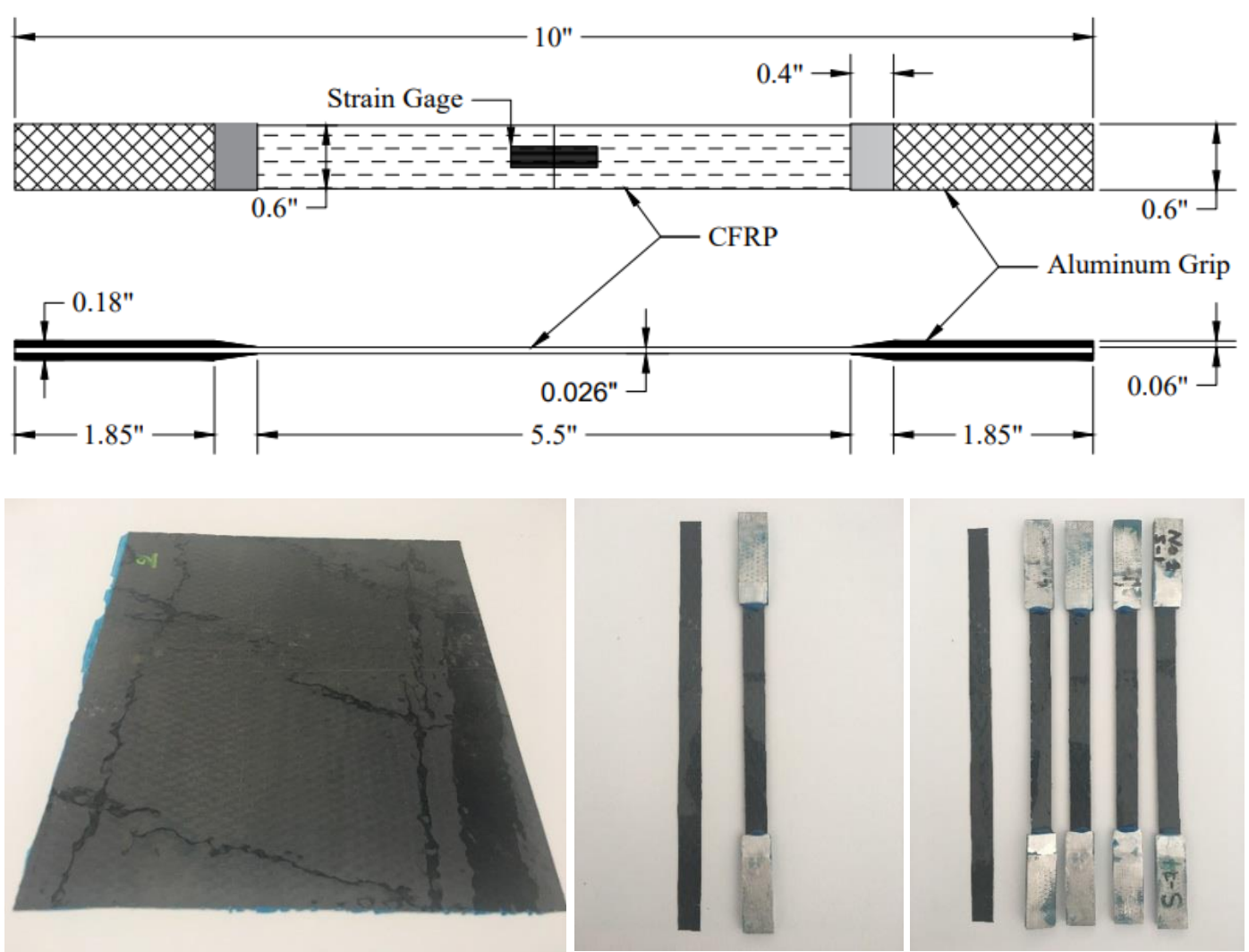

Figure 4.5: the Details of CFRP Coupon 


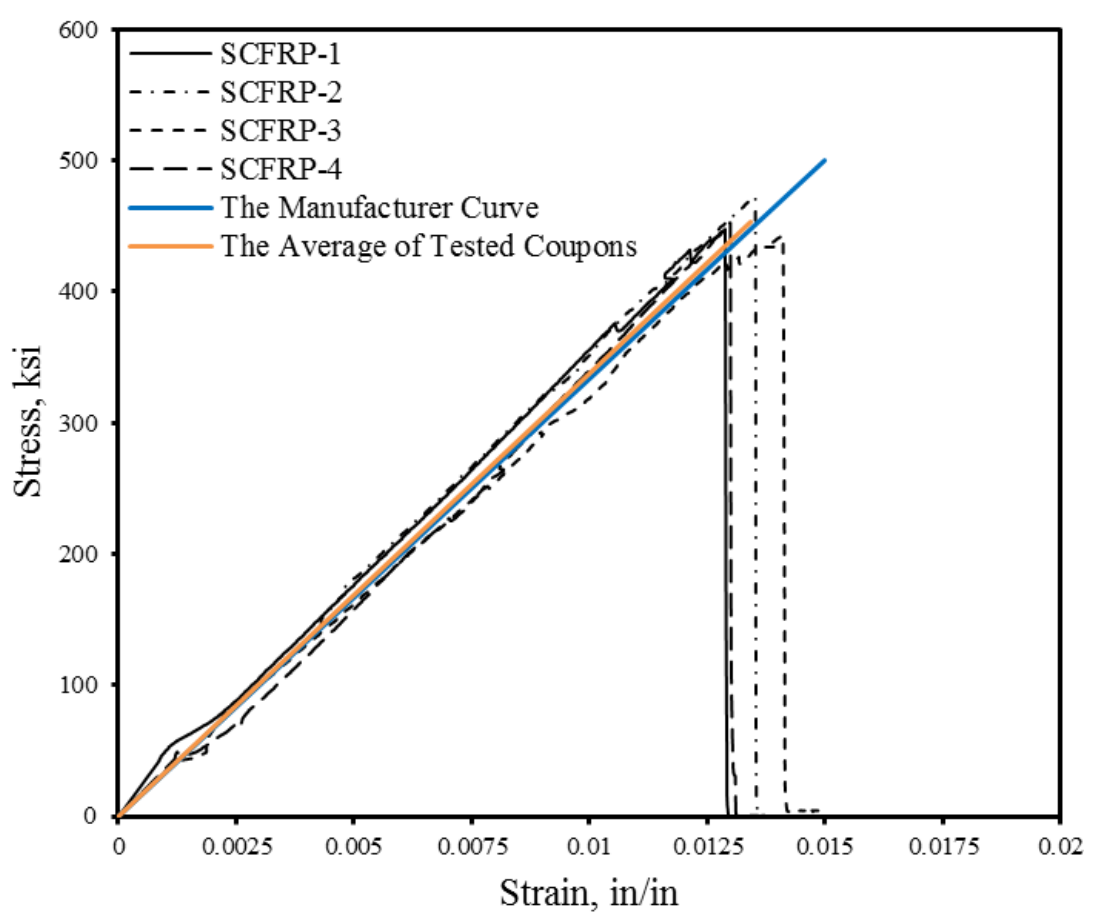

Figure 4.6: Stress-Strain Responses of CFRP Coupons

\subsection{RC Column Specimens Design}

The specimens were designed to represent older columns that exist in RC buildings in Iraq. In this study, two RC building frames were selected to represent twoand four-story buildings in Iraq built without seismic consideration. In Iraq, buildings that are two- to four-stories high are very common in residential and commercial RC construction, commonly built with low reinforcement ratio and low grade concrete.

\subsubsection{Prototype Structure Details}

Fig. 4.7 illustrates the plan and elevation views of an interior frame of prototype buildings, with a cross-section for the interior column and slab-beam section. Each building has a 14-ft clear column length on the first floor and 12-foot column length in 
the remaining floors, with 14 foot bay widths. The structural skeleton consists of a seven inch thick RC slab supported by beams and columns. Both prototype buildings shared identical RC column cross-section and reinforcement details on the first floors. The prototype buildings were also designed for gravity load only, without consideration for wind or seismic loads. The gravity load considered in design are given below.

Floor dead loads: $\quad$ structural weight plus 15 psf. for interior finishes

Floor live loads: $\quad 40$ psf. (residential)

Roof dead loads: $\quad$ structural weight plus 15 psf. for roofing

Roof live loads: $\quad 30$ psf

To ensure the prototype and the subsequent models are realistic, the level of applied axial load and the interaction diagrams should be checked for both the prototype RC columns and the half-scale model. This procedure begins with determining the applied axial load on RC columns on the first floor of the two- and four-story of prototype buildings. The amount of applied axial load (service load only) for an interior column on the first floor were 85 kips $\left(\sim 20 \% f^{\prime}{ }_{c} A_{g}\right)$ for the two-story building and 172 kips $\left(\sim 40 \% f^{\prime}{ }_{c} A_{g}\right)$ for the four-story building. The column thrust loads were calculated based on Dead Load only when the building is subjected to Seismic Loads. The interaction diagram of the prototype RC columns is shown in Fig. 4.8, including the axial load level for both prototype RC columns. Clearly, the level of axial loads are located above and below the balance condition for the prototype RC column. This situation must be emulated with the amount of axial load applied on the half-scale columns. As such, 
Fig. 4.9 reflects the interaction diagram for the half-scale column. The axial load applied on the half-scale column is $25 \%$ of the prototype axial load level. As shown in Fig. 4.9, the location of the axial load level for the half-scale is approximately compatible with that of the prototype $\mathrm{RC}$ columns.

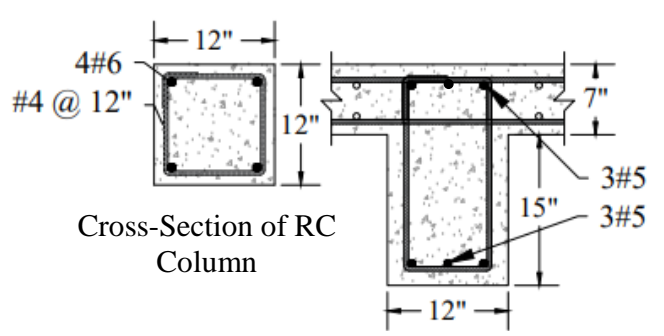

Cross-Section of Beam

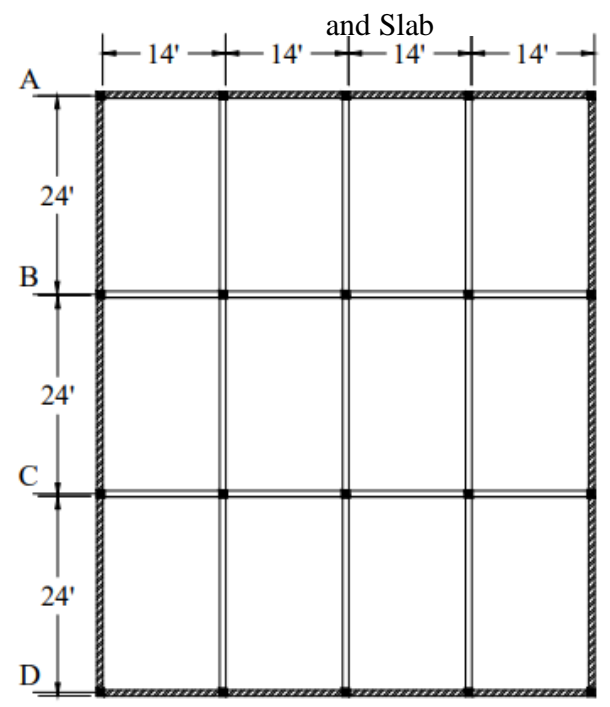

Plan View for Two and Four-Story

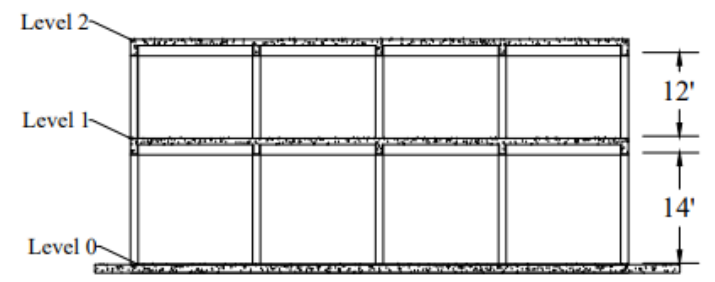

Two-Story's Elevation of Interior Frame

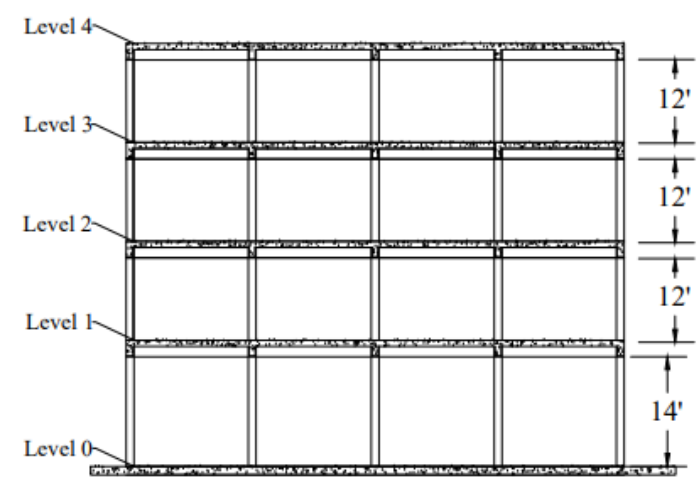

Four-Story’s Elevation of Interior Frame

Figure 4.7: Details and Configurations of the Prototype RC Buildings 


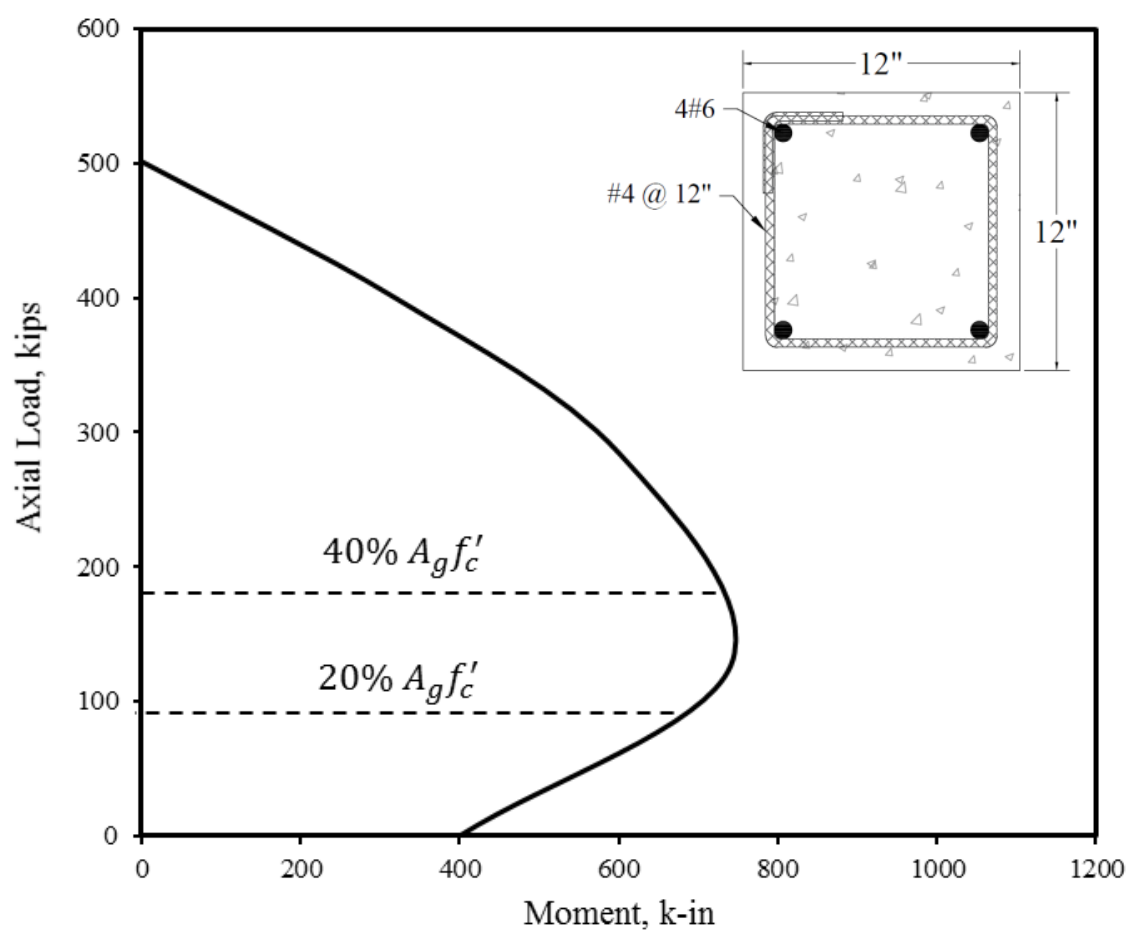

Figure 4.8: Interaction Diagram for Prototype Column

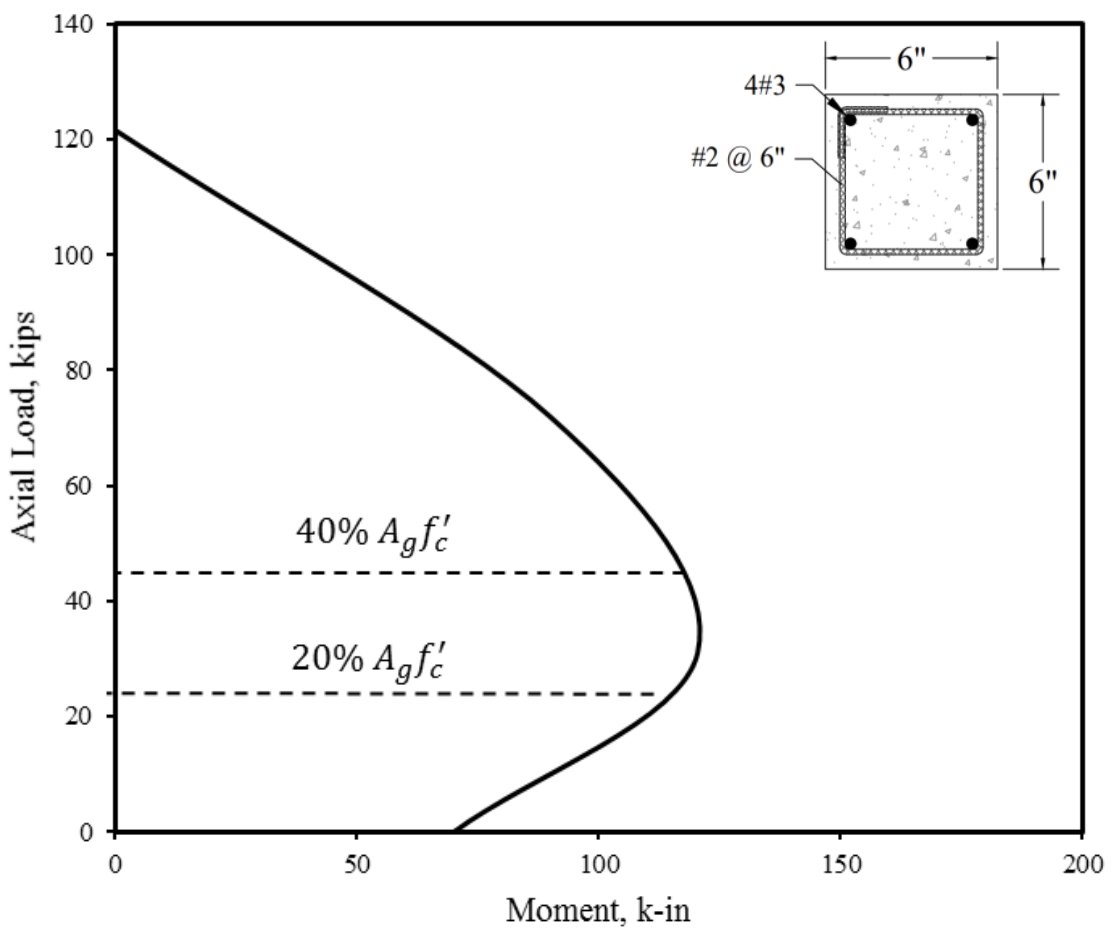

Figure 4.9: Interaction Diagram for Half-Scale Column 


\subsubsection{Configuration of the Specimens}

The overall configuration of each specimen is shown in Fig. 4.10. This illustration shows two cantilever-columns, connected by a stiffer central element, or stub, measuring $12 \mathrm{x}$ $18 \times 6$ inches. This represents one-half of a long column $\left(L_{s} / \mathrm{h}=7\right)$ connected to a very stiff beam, in conjunction with a very stiff foundation. Moreover, each specimen may also represent a column connected to a very stiff beam in conjunction with a flexible foundation, or a column connected to a flexible beam in conjunction with a very stiff foundation. For the last two cases, the slenderness would be $\left(L_{S} / \mathrm{h}=14\right)$.

For the specimen shown in Fig. 4.10, the length of each cantilever-column is 42 inches, which includes 38 inches of distance between the end of the specimen and stub face, and an additional four inches between the end of the specimen and the center of the hinge support (Fig. 4.11). The specimens were designed based on old, pre-1970 code , using poor tie reinforcement details in potential plastic hinge regions, low-grade concrete $(\sim 3000 \mathrm{psi})$, and a low reinforcement ratio $\left(\mathrm{A}_{\mathrm{st}} / \mathrm{A}_{\mathrm{g}}\right.$, equal to $\left.1.2 \%\right)$. All specimens were reinforced using four \#3 Grade 60 rebars for the longitudinal direction, and \#2 Grade 40 smooth (plain) bars for the transverse direction. Fig. 4.12 shows the columns' identification tags for the test specimens. In each, the first letter, C, represents the type of fiber reinforced polymers used (CFRP). Next, the first two digits after the letter C represent the number of CFRP layers in the longitudinal and lateral direction respectively. Finally, the last two digits represent the axial load level $\left(P / f^{\prime}{ }_{c} A_{g}\right)$. 
The specimens were classified into two categories according to the axial load level, as shown in Table 4-4. In this study, a low axial load (0.2Ag f'c) was used to simulate the gravity load for the first-floor column in the two-story RC building, and a moderate axial load $\left(0.4 \mathrm{Ag} \mathrm{f}^{\prime} \mathrm{c}\right)$ was used to simulate the gravity load for the first-floor column in the four-story RC building.

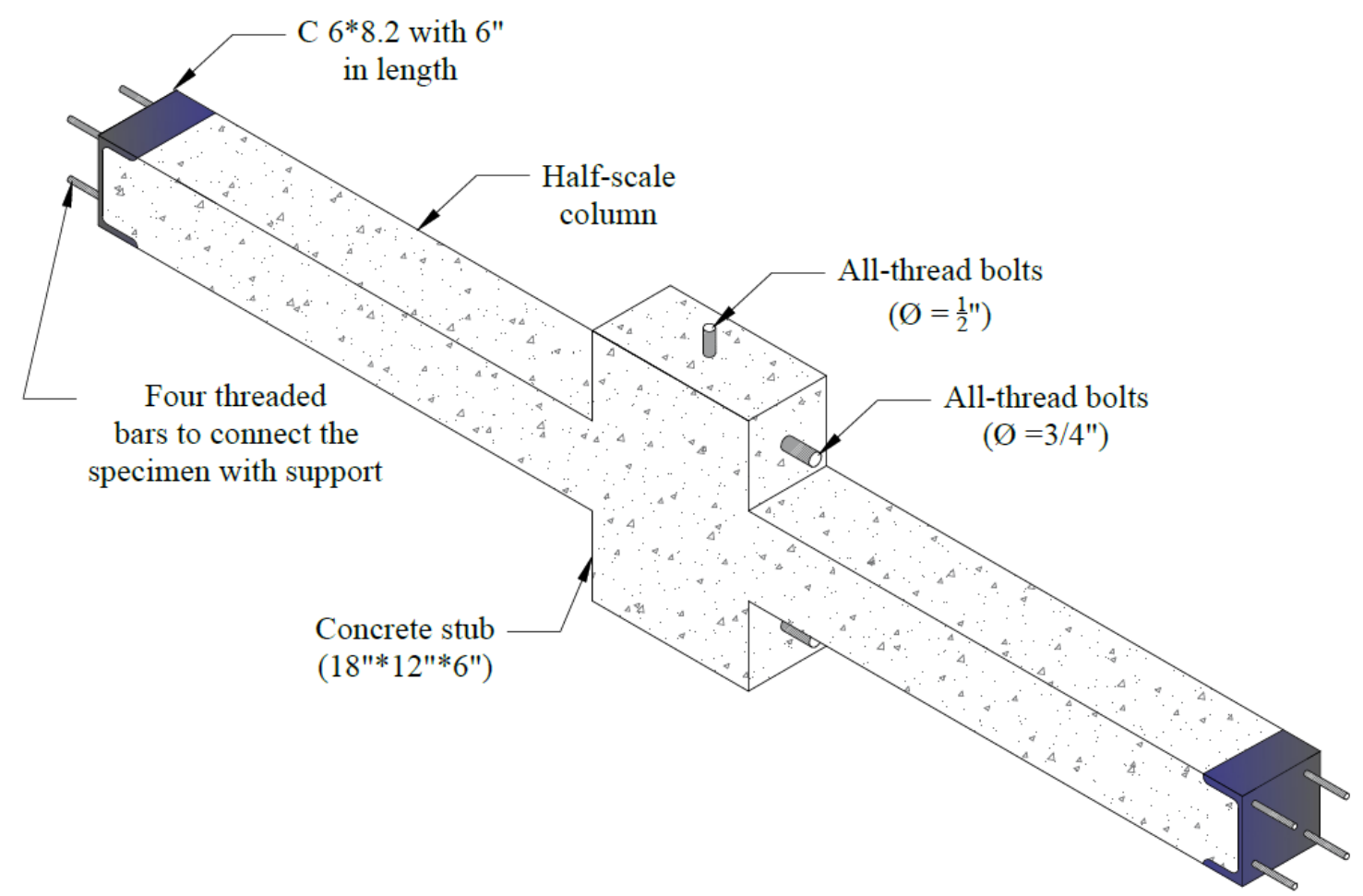

Figure 4.10: Configuration of the Double-ended Column 


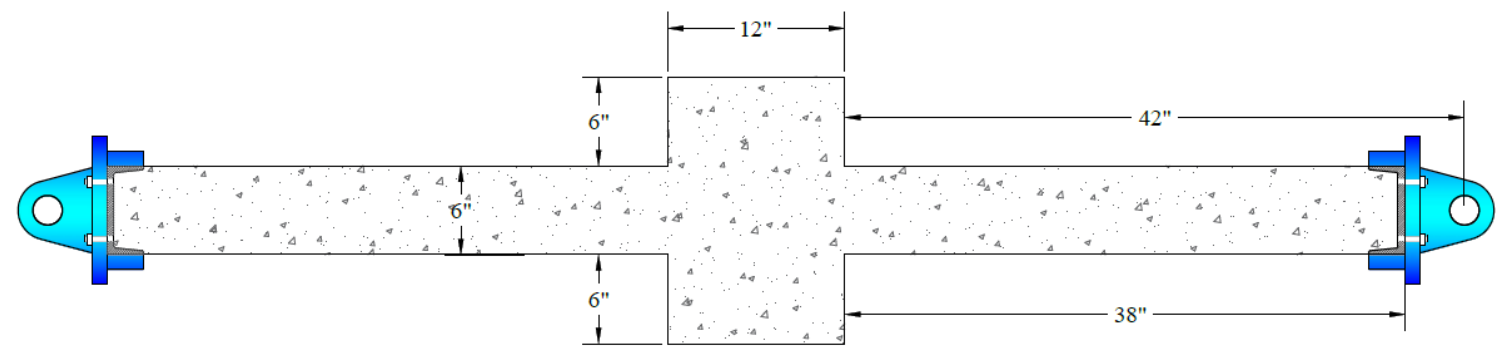

Figure 4.11: Details of Test Specimen

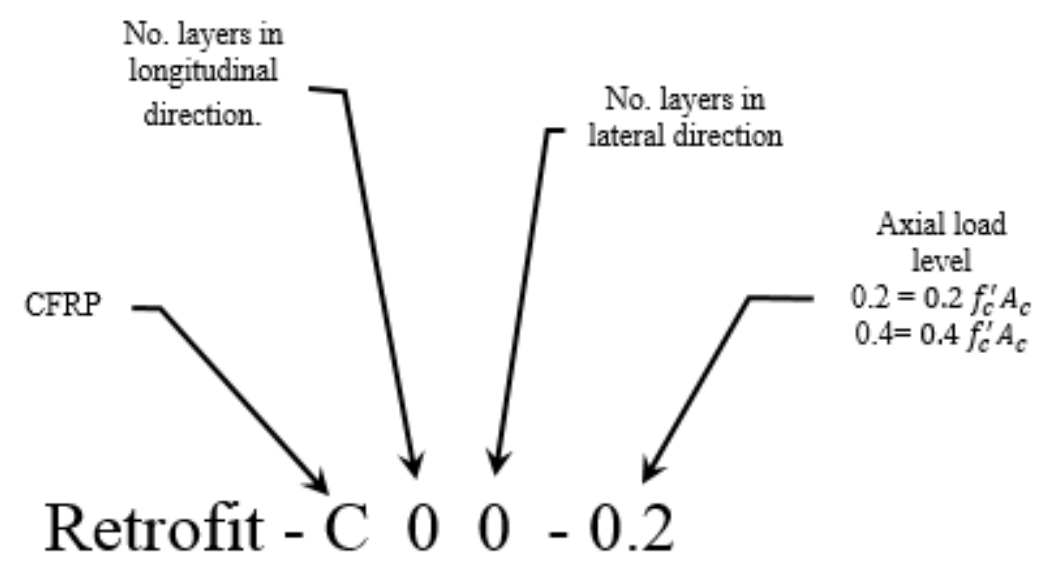

Figure 4.12: Specimens Identification 
Table 4-4: Summary of the Test Specimens

\begin{tabular}{||c||c||c||c||}
\hline \hline Specimen & Test Parameter & Axial load & Retrofit \\
\hline \hline Control-0.2 & Control & $0.2 \mathrm{Ag} \mathrm{f'c}$ & None \\
\hline Retrofit-C01-0.2 & CFRP-Lateral & $0.2 \mathrm{Ag}$ f'c $^{\prime}$ & One-layer CFRP- at plastic hinge zone \\
\hline Retrofit-C11-0.2 & $\begin{array}{l}\text { CFRP-Lateral } \\
\& \text { longitudinal }\end{array}$ & $0.2 \mathrm{Ag} \mathrm{f'c}$ & $\begin{array}{l}\text { One-layer CFRP- at plastic hinge zone } \\
\text { and one layer in longitudinal direction }\end{array}$ \\
\hline Control-0.4 & Control & $0.4 \mathrm{Ag} \mathrm{f'c}$ & None \\
\hline Retrofit-C01-0.4 & CFRP-Lateral & $0.4 \mathrm{Ag} \mathrm{f'c}$ & One layer CFRP- at plastic hinge zone \\
\hline \hline
\end{tabular}

\subsection{Construction of the Specimens}

\subsubsection{Reinforcing Cages}

The reinforcement of columns was designed in accordance with a low reinforcement ratio of $1.2 \%$, and wide spacing between the transversal reinforcements. The transverse reinforcement ratio is equal to $0.33 \%$, with $90^{\circ}$ hook end. The structural skeleton of each specimen consists of two components, a column cage and a stub cage, as shown in Fig. 4.13. Four \#3 deformed rebars with threaded ends were extended along the total length of the specimen, with a clear cover of 0.75 inches. This threaded end was then used to connect the specimen with the supports of the loading frame. In addition, \#2 plain bar was used for transverse reinforcement (ties), spaced six inches apart. The behavior of the specimens with smooth bar ties can be expected to be close to the fullscale members that have deformed rebar ties. This is because the effectiveness of ties in 
providing confinement and shear capacity are primarily due to the tension capacity of the bars utilized as ties. Moreover, the deformed bar ties can be expected to be somewhat more effective than smooth bars because of the added bond strength. So, the experimental behavior of specimens with smooth tie bars may be considered as the "lower bound" capacity of the members with deformed bars that are used in real columns.

In order to avoid a shear or flexural failure in the stub during the test, the steel cage for the stub was reinforced with four \#4 deformed rebar bars, arranged vertically with hooks at the ends, and \#3 deformed rebar for horizontal ties, with 2 inches spacing.

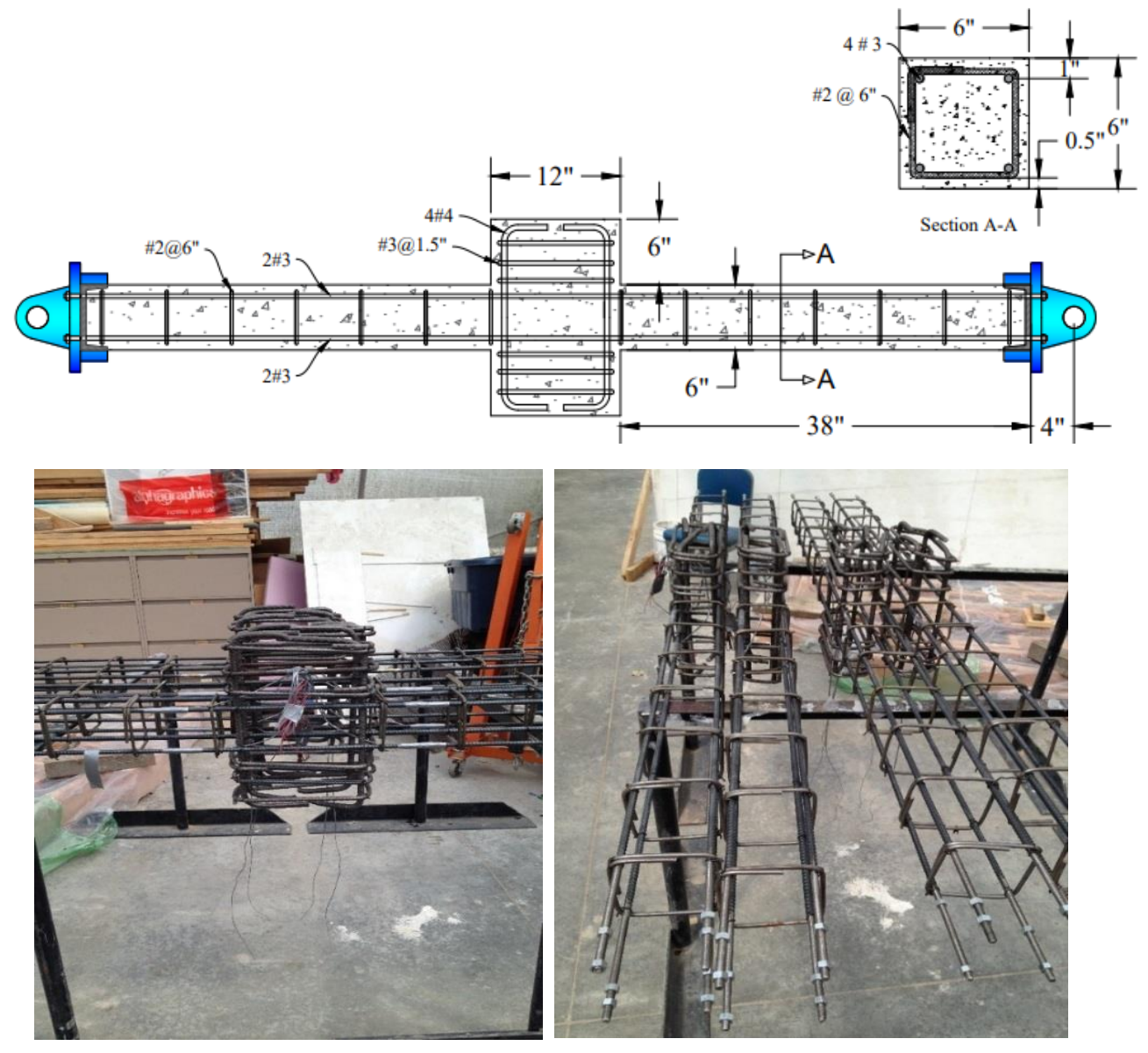

Figure 4.13: Typical Reinforcing Cage 


\subsubsection{Formwork}

Fig. 4.14 illustrates the formwork for the five specimens. The formworks were constructed using 2x10 lumber. Threaded anchors of 3/4-inch diameter were installed through pre-drilled holes on the sides of the stub. These anchors connected the stub with a lateral load system that prevented the rotation of the stub during test. After assembling the formwork, all screw holes and corners were filled with silicone caulking to prevent water seepage from the fresh concrete. Before placing the steel cage inside, the interior surfaces of the formwork were brushed with a thin layer of oil in order to prevent the wood from absorbing water from the fresh concrete, as well as for easy removal of the form. The steel cages were placed correctly in the formworks, and plastic spacers were placed between the steel cage and the formwork to provide a clear cover and hold the steel cage during casting. In order to protect the ends of the specimen during the test, two C6x8.2 channels, each with four holes 1/2-inch in diameter, were vertically placed at the ends of the specimens. The C-channel was held in place during casting with threaded ends on the longitudinal bares and a tying nut on each. Moreover, the threaded ends were used to connect the specimen with the pin supports at the ends during the test setup (Fig. 4.15). 


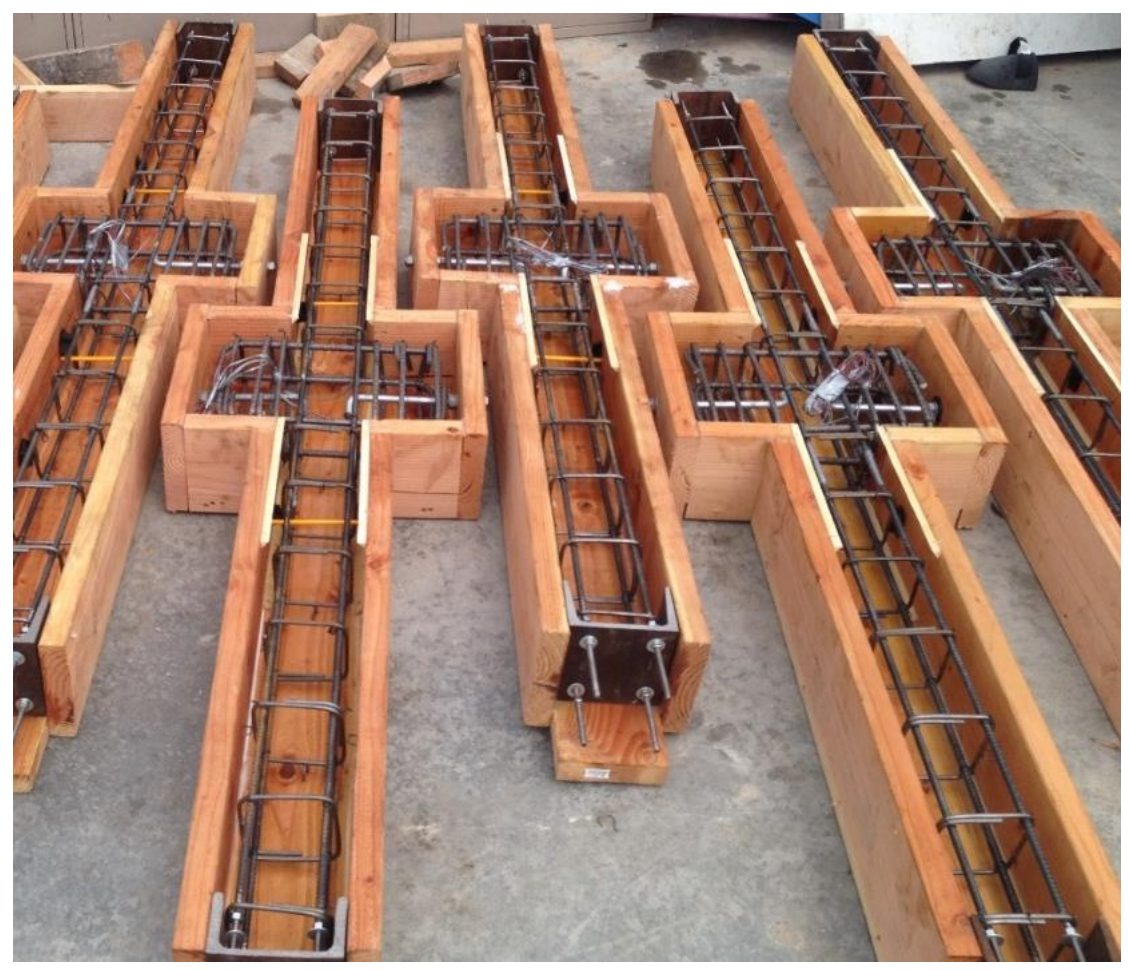

Figure 4.14: Finishing Formworks and Placing the Steel Cages

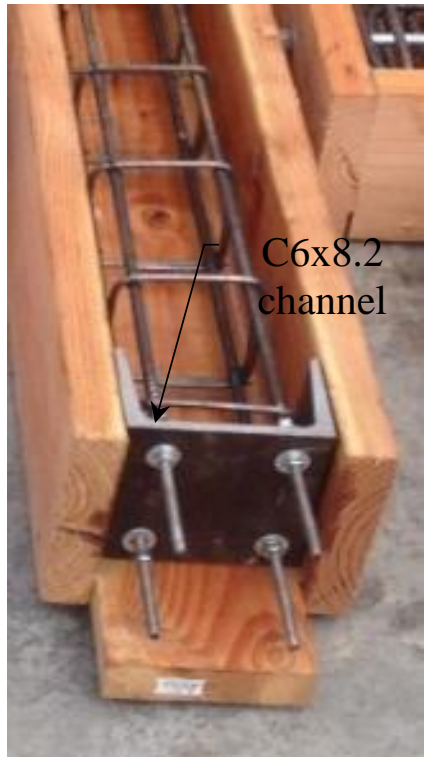

(a)

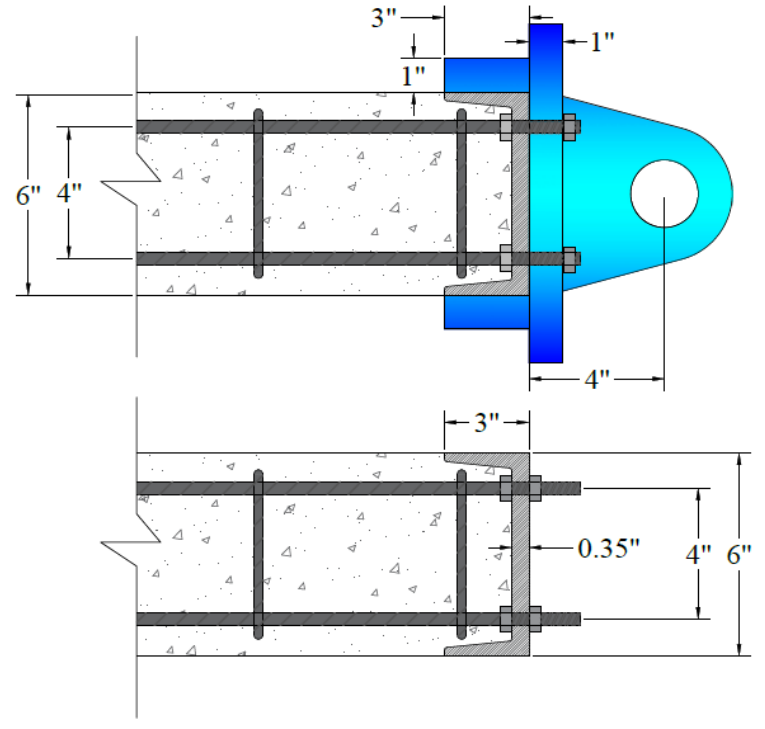

(b)

Figure 4.15: Details of the Specimen Ends, (a) Holding the C-channel during Casting,

(b) Connecting the Specimen with Supports 


\subsubsection{Concrete Casting and Curing}

The concrete materials were scaled according to the mix design and mixed using a mechanical mixer, allowing three to five minutes of mixing to obtain a homogenous blending of the materials. To check the workability of the fresh concrete, the slump test was conducted and the results showed that the slump was between eight and nine inches, as shown in Fig. 4.16- Two concrete batches were made for each specimen. In order to test the compressive strength of specimens, two concrete cylinders were prepared from each concrete batch on the day of the test. During casting, a vibrator was used to consolidate the concrete. After casting, all specimens and cylinders were covered with wet burlap and polyethylene sheeting to provide a moist environment for curing. After seven days of casting, all specimens and cylinders were demolded and placed in the laboratory for air-curing, as shown in Fig 4.17.
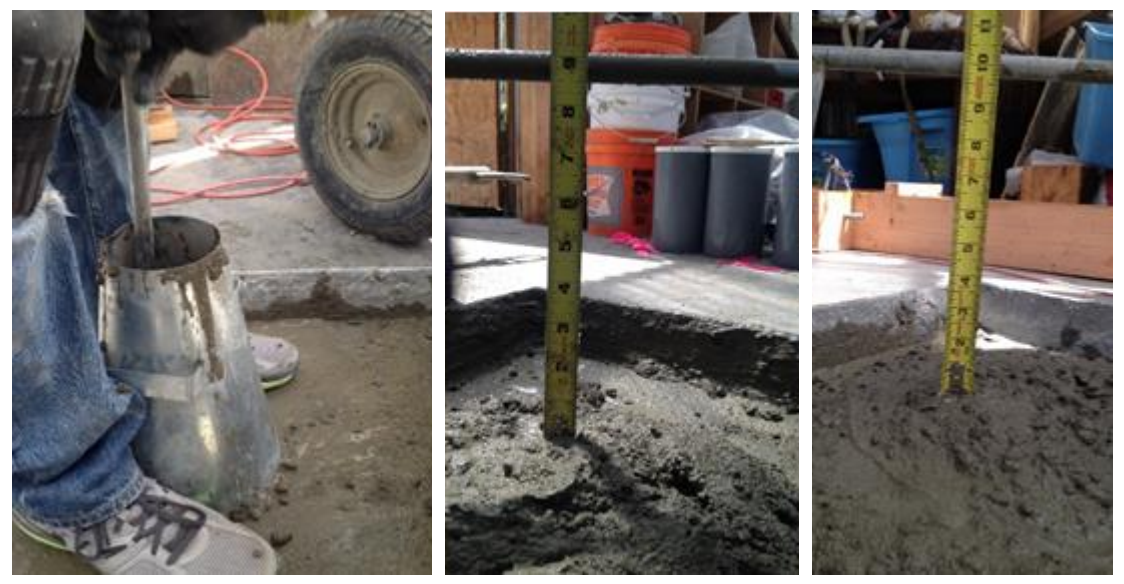

Figure 4.16: Slump Test 


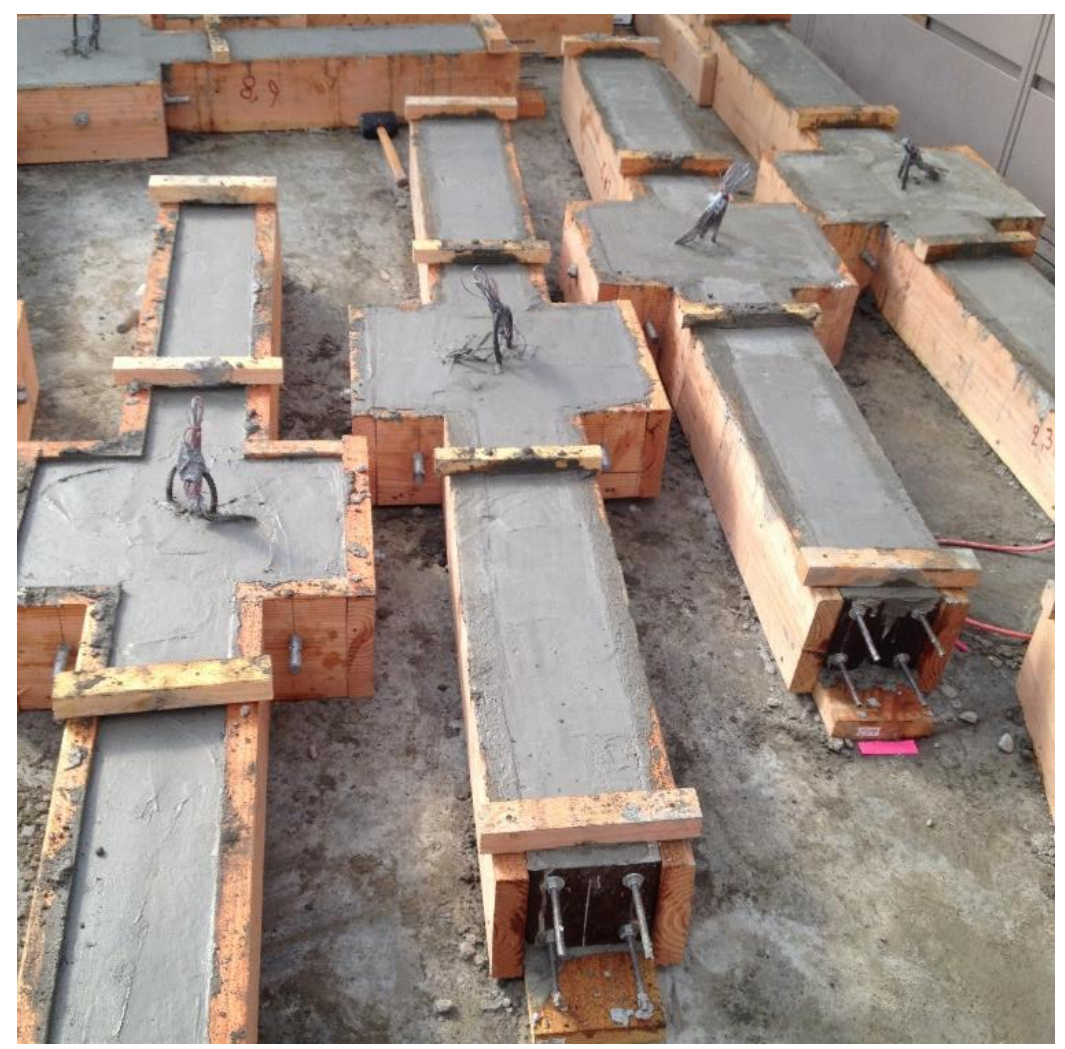

Figure 4.17: After Finishing the Casting Process

\subsubsection{CFRP Strengthening}

In this experimental study, two strengthening schemes were utilized based on the literature review. In the first scheme, CFRP lateral confinement was used to increase shear strength and deformability of deficient columns at the plastic hinge regions. In the second scheme, in addition to the lateral CFRP confinement, longitudinal CFRP was used to increase flexural strength and eliminate a potential strong-beam, weak-column situation. In this section, the CFRP wrapping procedure and preparation of the specimens are described in greater detail. 


\subsubsection{Lateral Confinement}

After 28 days of casting the specimens, the CFRP wrapping was applied by rounding the corners of the column at plastic hinge regions fourteen inches from the column base (ACI 440.2R-17, 2017). The target for the corners' radii was one inch. The corners were ground to the desired radius with a grinder and masonry disk, as shown in Fig. 4.18. The concrete surface was ground as well to remove loose particles. Pressured air was used to clean the surface of remaining dust. After cleaning, the concrete surface was repaired with cement-mortar to fill any large- to moderate-sized craters, as shown in Fig. 4.18.

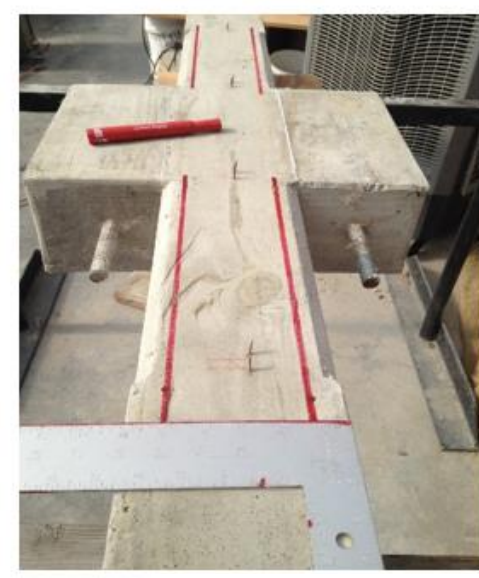

(a)

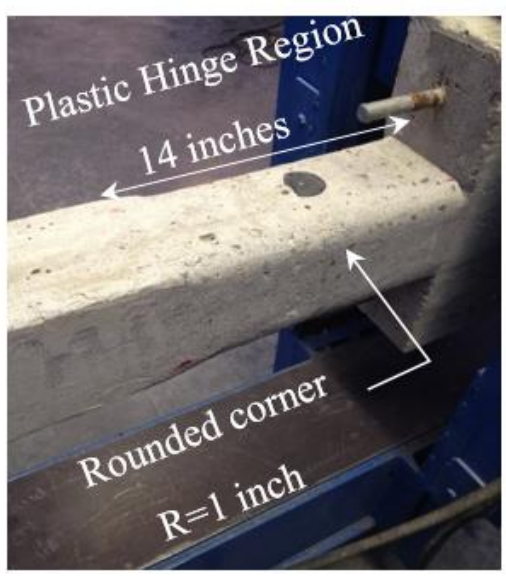

(b)

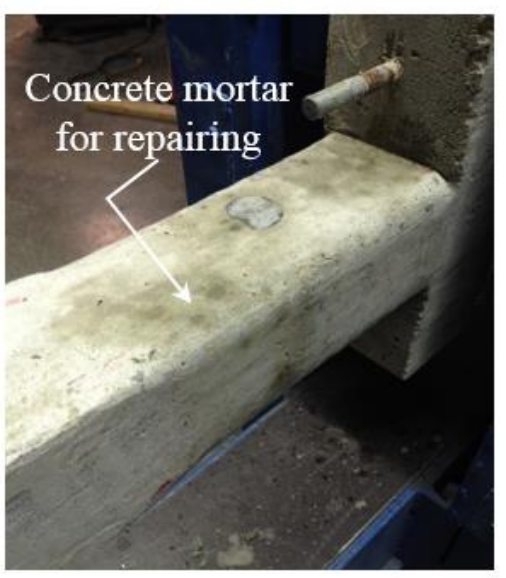

(c)

Figure 4.18: Column Preparation: (a) Overview, (b) Rounded Corners, (c) Concrete Mortar for Repairng

After three days of curing the cement-mortar, the first layer of epoxy was applied with a paint brush as primer, to increase adhesion between the surface and the confinement system. It was important to ensure that the epoxy was spread evenly while 
applying the primer. After 48 hours of curing, the second layer of epoxy, or putty, was applied. This layer leveled all small surface defects. The putty was cured for 48 hours, as recommended by the manufacturer. The unidirectional CFRP sheet was cut to the desired dimensions and prepared for installation. The CFRP fabric was installed following the dry lay-up procedure. Initially, the first layer of the resin to glue the CFRP sheet on the column (saturant), was applied on the whole surface of the confinement area with paint brush. Immediately after that, the CFRP sheet was installed starting from the mid-width of the column faces, as shown in Fig. 4.19. The CFRP was wrapped in the hoop direction of the column and any air pockets were squeezed out with gentle hand pressure. A proper laminating roller was used to firmly roll the CFRP sheet in the direction of the fibers and force the resin through the fiber yarns. At the end of the CFRP, six inches of overlap was left. Finally, the second layer of saturant was applied on the outer surface of the CFRP sheet, and after 48 hours of curing the specimen was ready for testing. 


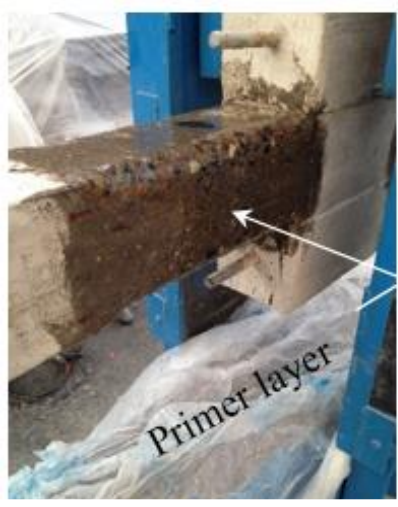

(a)

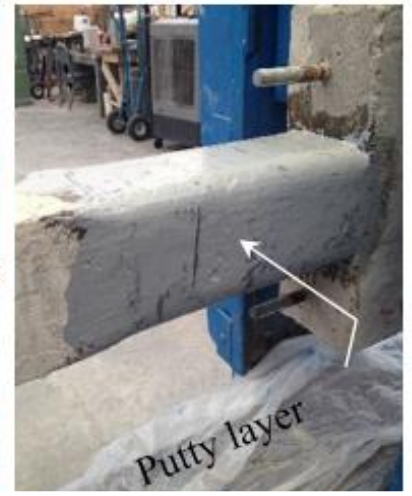

(b)

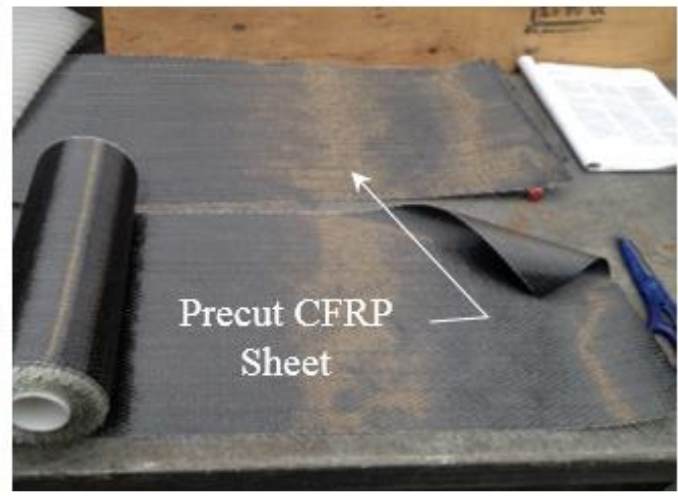

(c)

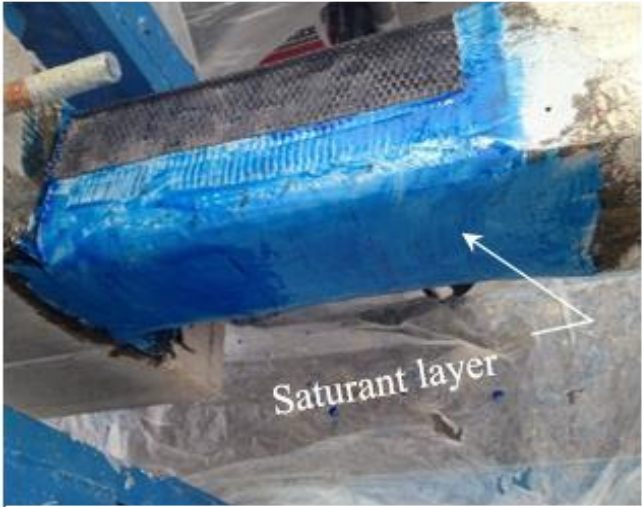

(d)

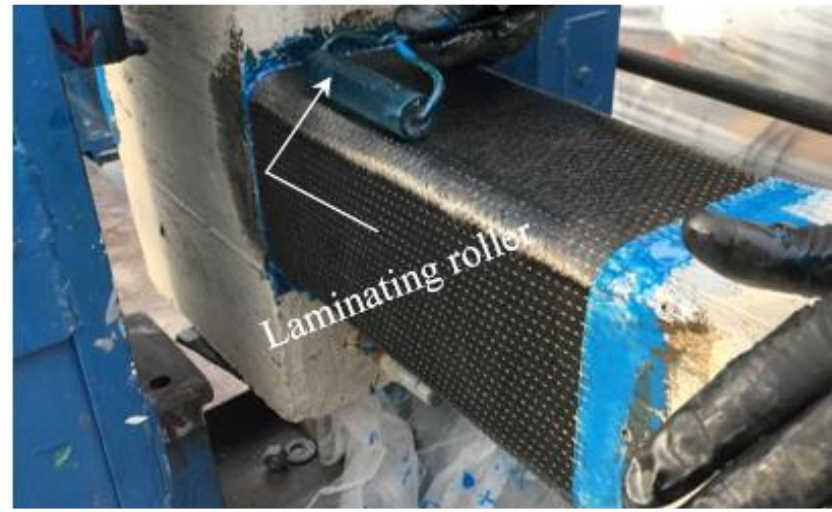

(e)

Figure 4.19: CFRP Wrapping Procedure: (a) Primer Layer, (b) Putty Layer, (c) Preparing CFRP Sheet, (d) Saturant Layer with Application, (e) Laminating

\subsubsection{Longitudinal CFRP Strengthening}

One method to eliminate inelastic deformation at the plastic hinge region and transfer inelastic deformation to other locations while enhancing the flexural strengthening of slender RC columns is to use CFRP (ACI 440.2R-17, 2017). The greatest potential problem in using the CFRP sheet in flexural strengthening for the RC column is a lack of development length at critical locations, such as the column-stub intersection (ACI 440.2R17, 2017). In order to address this problem, a CFRP anchorage system was devised to clamp 
the sheet at the column-stub intersection. The tensile strength capacity of this anchor was limited, however, and depended on the anchor capacity. Several types of CFRP anchors have been discussed in recent studies (Kalfat, Al-Mahaidi, \& Smith, 2011; Grelle \& Sneed, 2013), but no anchorage design guidelines have been proposed. Therefore, in this study a novel anchorage system for CFRP sheet was developed, as presented in the following section.

\subsection{Proposed CFRP Anchor}

Fig. 4.20 illustrates the details of the CFRP anchor system used in this study. This system consisted of an anchor device and a CFRP rope. The anchor device was constructed from a solid, rounded PVC rod type \#1 two inches in diameter, and a stainless steel tube with an inside diameter of two inches and a thickness of $3 / 32$ inch. Both the PVC rod and stainless steel tube were cut to four inches in length. The steel tubes were then cut lengthwise to make two equal halves, as shown in Fig. 4.21. A semi-circular longitudinal groove with a diameter of 0.75 inches was then cut into the PVC rod using a drill bit, as shown in Fig. 4.22. These groves were rounded at the ends with the same diameter. The stainless steel and PVC pieces were then glued together using epoxy, and cured for two days.

The CFRP rope used to connect the anchor device with the footing stub was constructed by rolling a CFRP sheet with epoxy and using small plastic cable zip ties to firmly tie the rope in place. Orton (2007) recommended that the amount of the CFRP material in the rope should be 1.3 to 1.5 times the amount of material in the CFRP sheet. In this project, one four-inch wide layer was used for the CFRP sheet in the longitudinal 
direction. Therefore, six inches, or 1.5 times the CFRP sheet, was used to construct the rope. The diameter of the resulting rope was approximately $0.5 \mathrm{inch}$. The length of the rope was 17 inches, including at least five inches of length inserted in a pre-drilled hole on each side of the stub
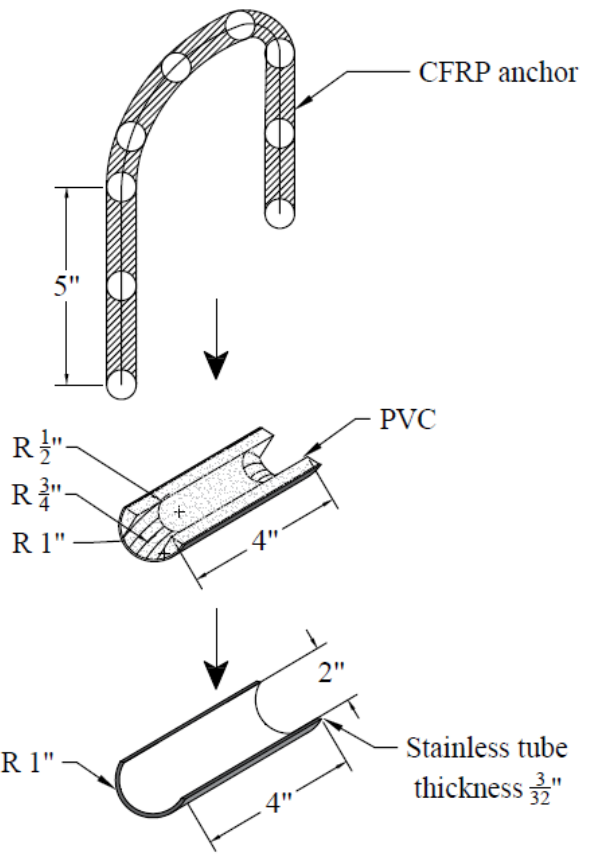

(a)

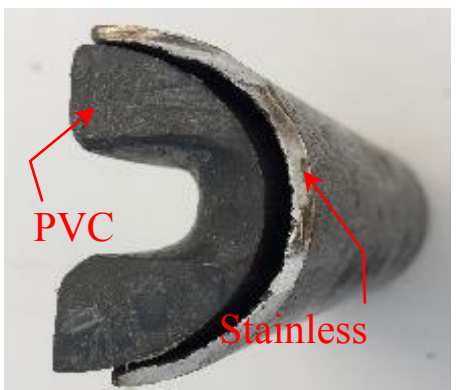

(b)

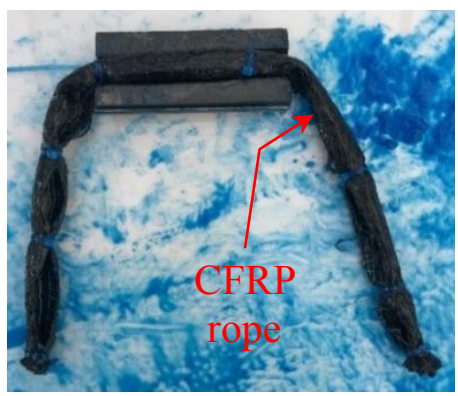

(c)

Figure 4.20: Proposed CFRP Anchor System: (a) CFRP Anchor components, (b) PVC with Stainless Steel Tube, (c) CFRP Rope 


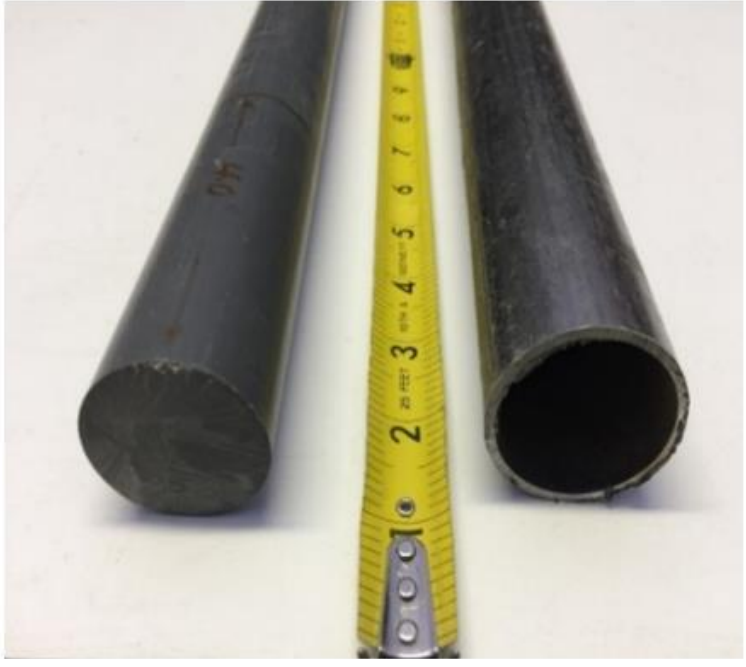

(a)

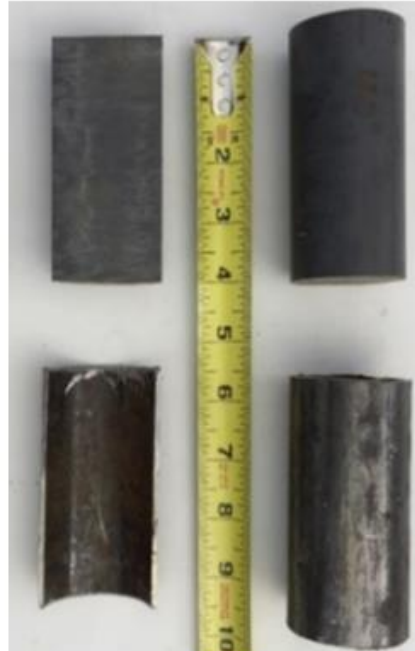

(b)

Figure 4.21: PVC Rod and Stainless Steel Tube: (a) PVC Rod and Stainless Steel Tube, (b) Cutting the PVC Rod and Stainless Steel Tube

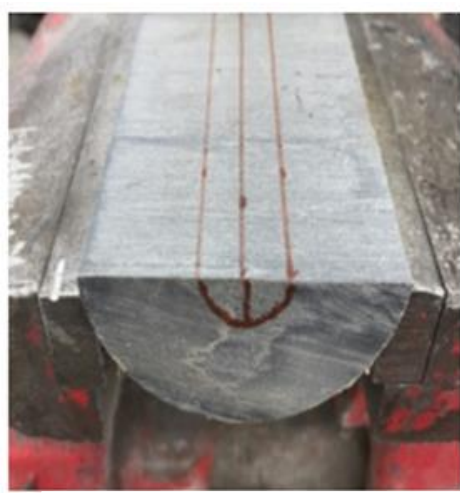

(a)

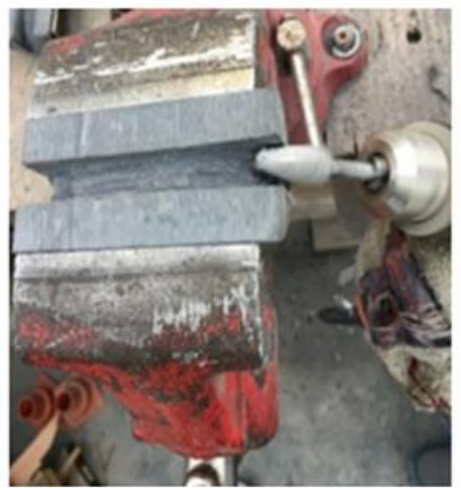

(b)

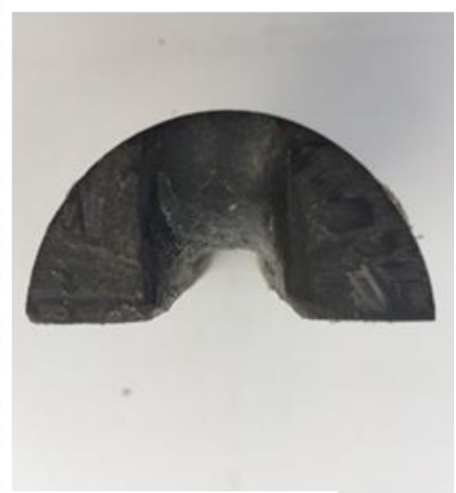

(c)

Figure 4.22: Manufacture of Novel Anchor: (a) Half PVC Rod, (b) Cutting Groove by Drill, (c) Final Shape for the PVC Part 


\subsection{Pullout Test for CFRP Anchor}

Before applying this anchor for longitudinal CFRP sheet in the column, sources in the literature suggested that the performance of any anchor should be substantiated by physical testing (ACI 440.2R-17, 2017). Therefore, a pullout test was conducted on the anchor to investigate its tensile capacity. In order to conduct this test, a T-shaped plain concrete block, simulating the column-footing connection, was constructed, as shown in Fig. 4.23.

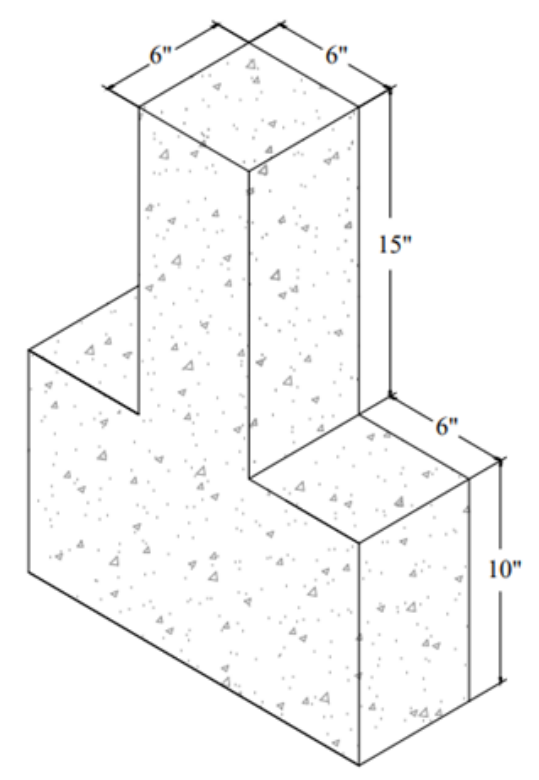

Figure 4.23: the Geometry of the T-section Concret Block

Fig. 4.24 illustrates the steps followed to install the anchor in the concrete block.

First, a rounded groove 2 inches long and 1 inch wide was cut next to the column footing intersection on two opposite sides, using a grinder with a suitable cutting and grinding disk. Next, two inclined grooves were created at a $45^{\circ}$ angle on the footing's sides, five 
inches in length and with a 0.75 inch square cross-section (Ozbakkaloglu, \& Saatcioglu, 2009), as shown in Fig. 4.25. After cleaning out the grooves with pressurized air, two layers of primer and putty were applied on the top rounded grooves. Then, a layer of epoxy was applied on the top rounded grooves and one layer of CFRP, six inches in width and four inches in length, was placed perpendicular to the longitudinal CFRP layer. The four-inch wide longitudinal CFRP layer was placed above the first CFRP layer with a layer of epoxy in between. The last CFRP layer, six inches in width and four inches in length, was placed in opposite direction, with epoxy above the longitudinal CFRP. The reason for applying the top and bottom CFRP layers in the perpendicular direction is to provide lateral strength to the longitudinal CFRP at the anchor zone and to hold the fiber in place. Once the anchor device was placed on top of CFRP layers with a layer of epoxy on the side grooves, the rope was saturated with epoxy and bent around the anchor device and inside the PVC groove, inserting the rope ends in the side groove. Finally, all the grooves were filled with epoxy and leveled, as shown in Fig. 4.26. 


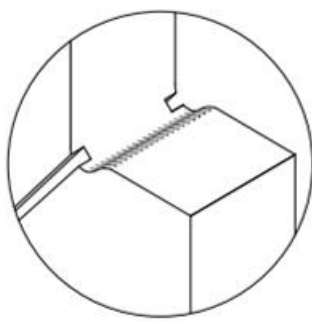

(a)

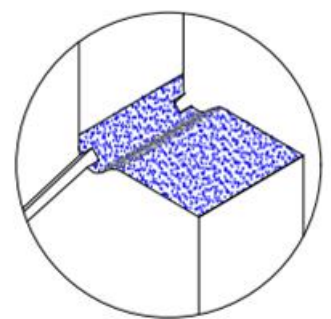

(b)

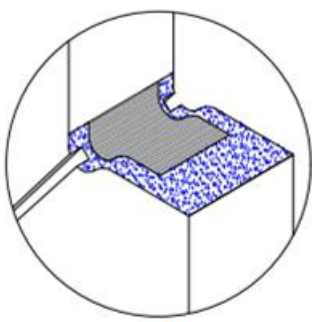

(c)

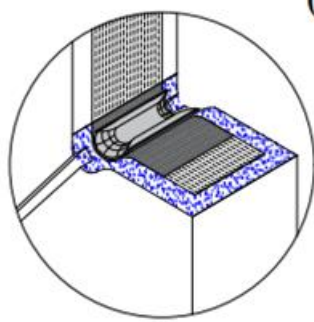

(f)

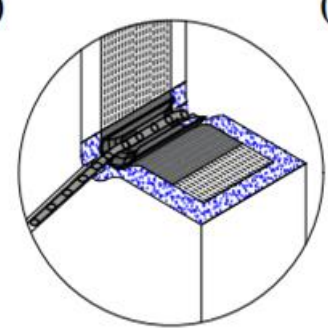

(g)

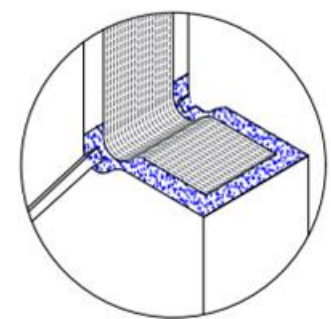

(d)

(e)

Figure 4.24: Installation Procedure for Novel CFRP Anchor. (a) Groove Preparation, (b) First layer of Epoxy, (c) First Layer of CFRP Sheet in Perpendicular Direction with Epoxy, (d) Placement of longitudinal CFRP Sheet with Epoxy, (e) Second Layer of CFRP Sheet Placed in Perpendicular Direction, (f) Instal the Anchor Device, (g) Instal the CFRP Rope around the Anchor Device.

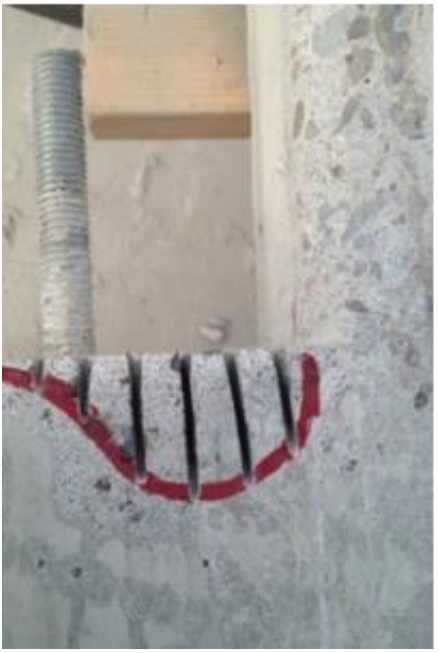

(a)

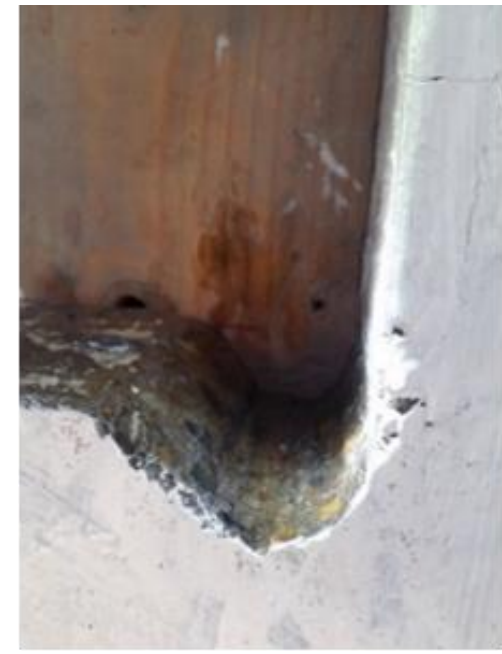

(b)

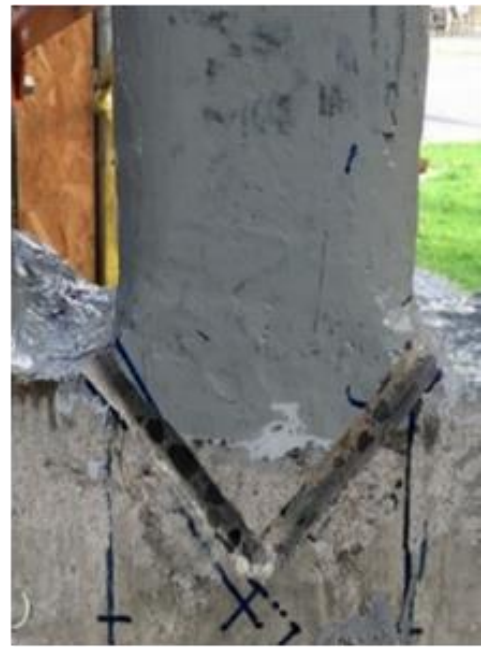

(c)

Figure 4.25: Concrete Block Groove Preparation: (a) Vertical Cuts, (b) Groove aftere Removing the Concrete, (c) Inclined Grooves 


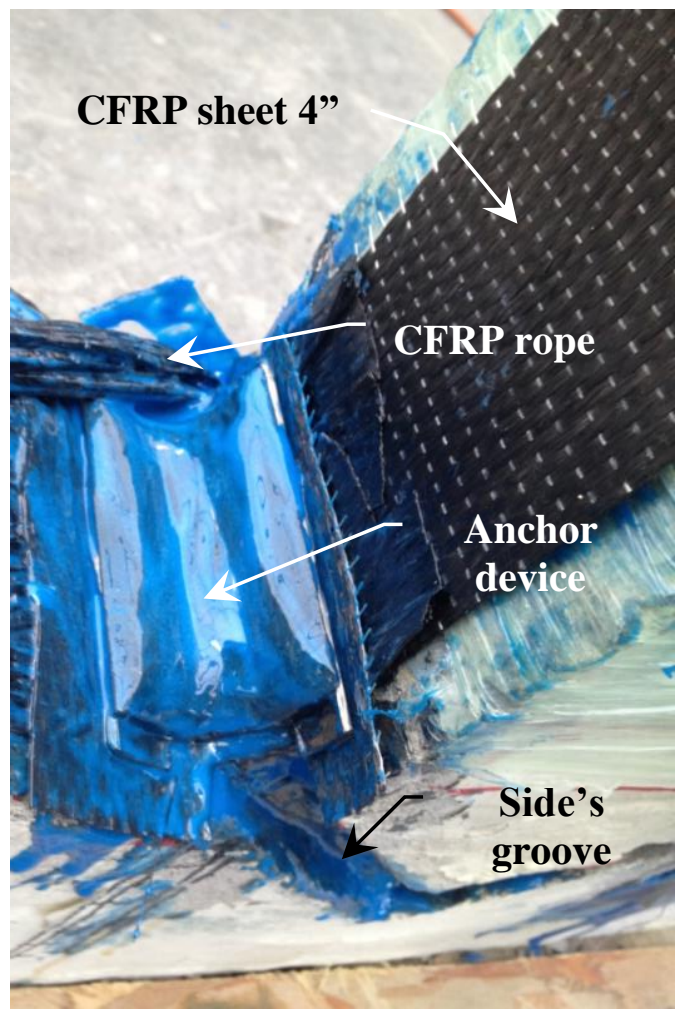

(a)

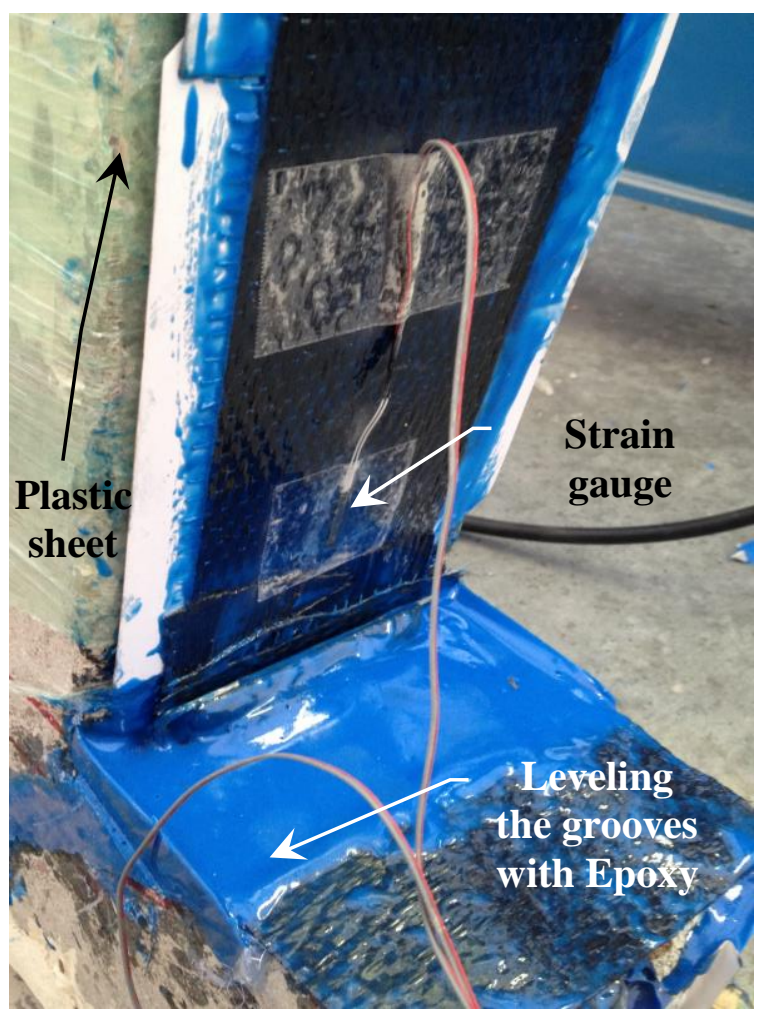

(b)

Figure 4.26: Filling and Leveling the Grooves with Epoxy: (a) Placing the Anchor, (b) Leveling the Grooves by Epoxy

Fig. 4.27 illustrates the setup for a pullout test of the proposed anchor. The loading system consisted of an HSS of $6 \times 3 \times 0.5$ inches with a rounded corner 1 inch in diameter, a load cell, and a hydraulic ram with a 60 kips capacity. The load cell and hydraulic ram were placed between the concrete block and the HSS steel section. The external CFRP sheet, four inches in width, was a wet lay-up system, saturated with epoxy. The CFRP sheet was placed along two opposing sides of the concrete block and wrapped around the HSS section with epoxy. In order to prevent any connection between the CFRP and the concrete block outside the anchor zone, a plastic sheet was wrapped 
around the concrete block before applying the longitudinal CFRP sheet. The loading system transferred the tensile load to the CFRP sheet by applying a compression load on both the HSS and the concrete block. The loading system was conducted with displacement control of 0.2 millimeters per minute. Two strain gages were mounted on the CFRP sheet just on each side of the anchor zone. In order to determine the anchor efficiency, the test results were compared with the average tensile strength test results of the CFRP coupons. As shown in Fig. 4.28, the proposed anchor sustained a load which was about $88 \%$ of the average tensile strength of the coupons. The failure happened suddenly and a simultaneous rupture took place in both the CFRP rope and longitudinal CFRP, as shown in Fig. 4.27. Based on observation of this failure, the anchor device may need more CFRP material in the rope to avoid anchor device failure before the CFRP sheet ultimate strength is achieved.

It should be mentioned that for other conditions, e.g., for larger columns, scaling of the proposed anchor system must be computed based on the thickness (capacity) of the CFRP and the concrete capacity holding the "rope". The capacity of the CFRP sheet that is to be used in practice, or in a future experimental test, along with the concrete capacity that provides the holding power will dictate the size and the epoxy specifications for the rope. 

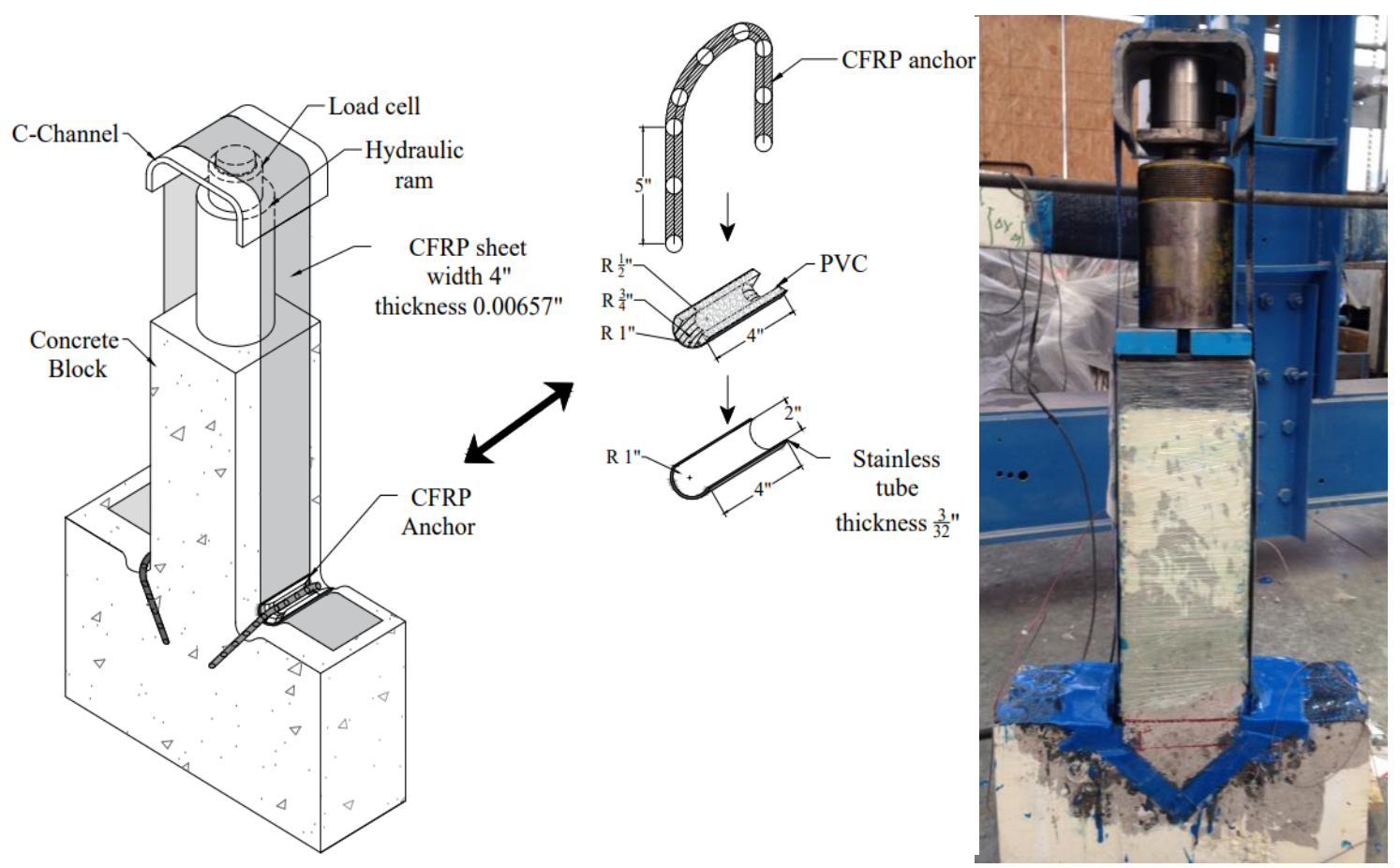

Figure 4.27: Test Setup for Pullout Test

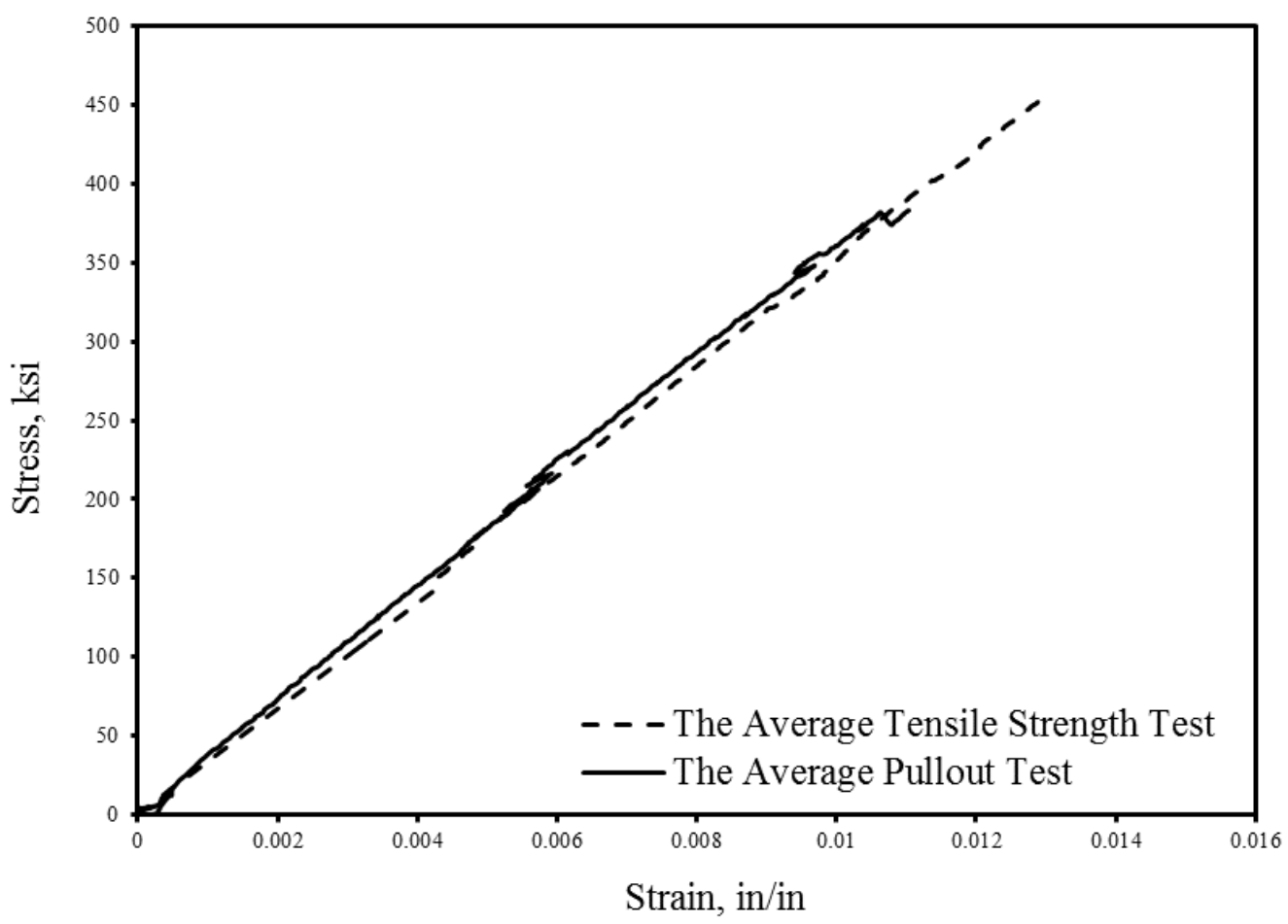

Figure 4.28: Comparison between Pullout Test and Average Tensile Strength 


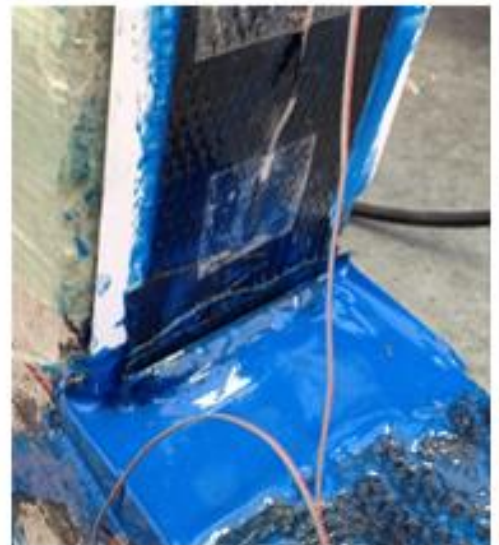

(a)

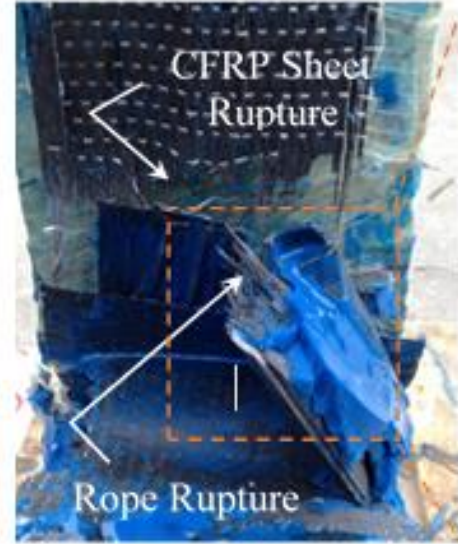

(b)

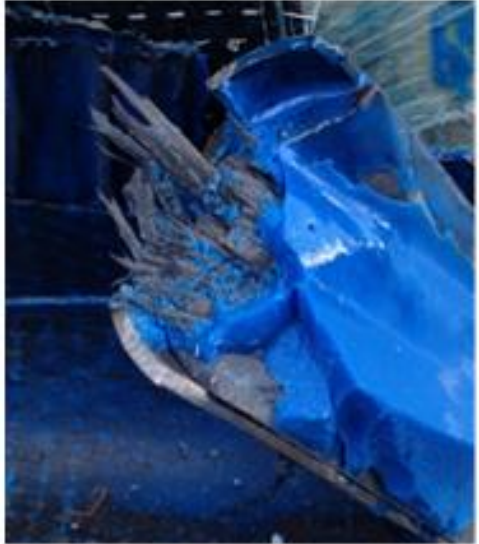

(c)

Figure 4.29: Failure of the Novel Anchor: (a) CFRP Anchor, (b) CFRP Rope Rupture, (c) Close up of Rope Rupture

\subsection{Longitudinal Strengthening of the Specimens}

The same installation of the longitudinal CFRP sheet in the pullout test was followed again, with one change: this time the CFRP rope material thickness was increased to 1.75 times the CFRP sheet material. This is illustrated in Fig. 4.30. Research suggests that for longitudinal CFRP strengthening of RC columns, the plastic hinge regions should be laterally confined by CFRP sheet for providing a good confinement and bonding for the longitudinal CFRP sheet and the region beyond the plastic hinge should be confined laterally with CFRP strips (ACI 440.2R-17, 2017). Therefore, one fourteen-inch layer of the CFRP sheet was applied above the longitudinal CFRP sheet in the lateral direction at the plastic hinge region. In addition, two-inch CFRP strips were added beyond the plastic hinge, along the CFRP sheet, with four inches of spacing between the strips. These stripes were used to anchor the long CFRP sheet, as shown in Fig. 4.31. 


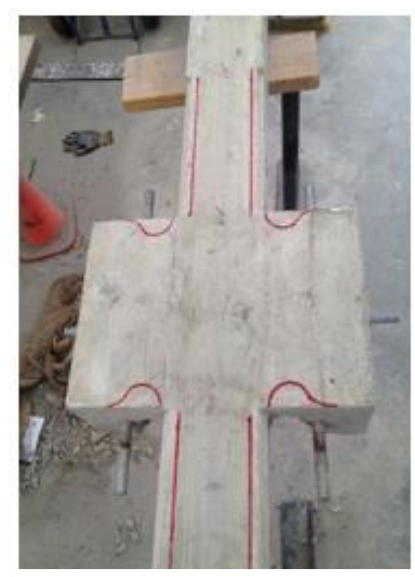

(a)

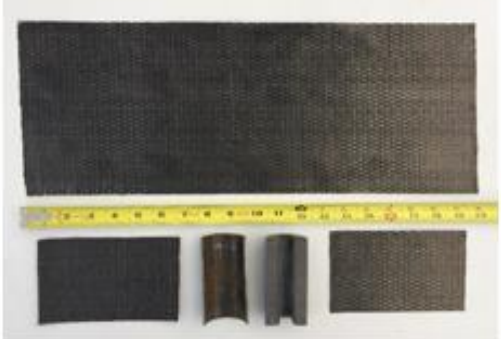

(d)

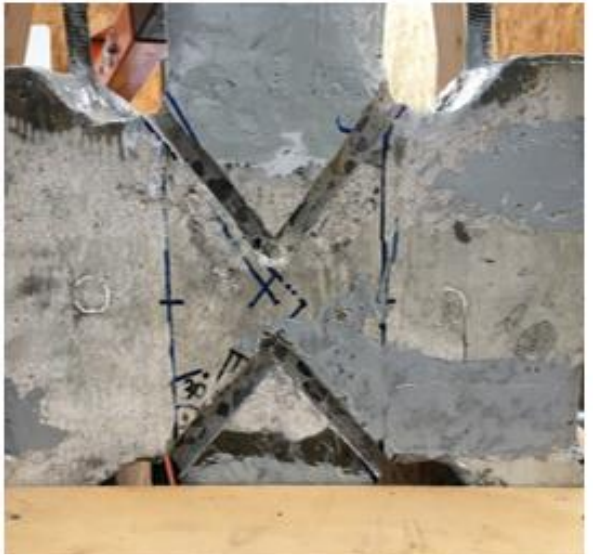

(b)

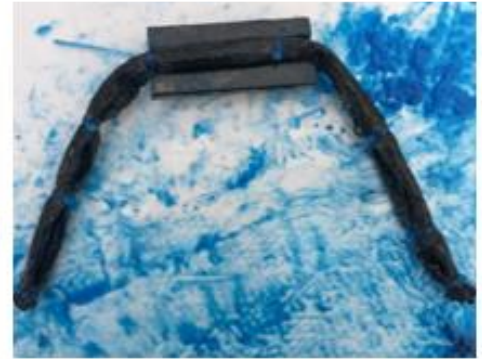

(e)

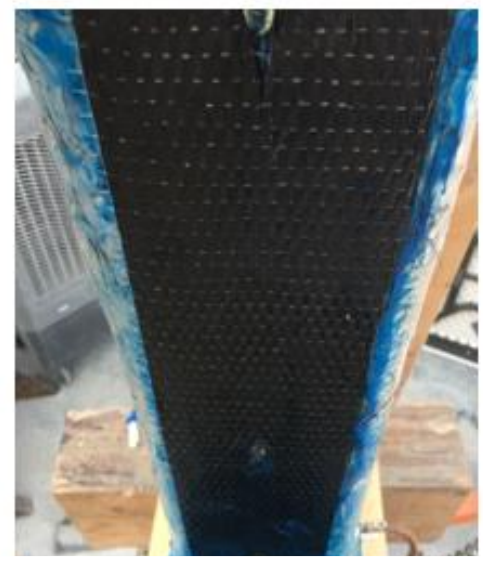

(c)

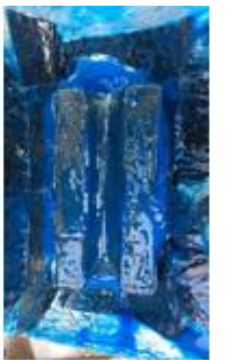

(f)

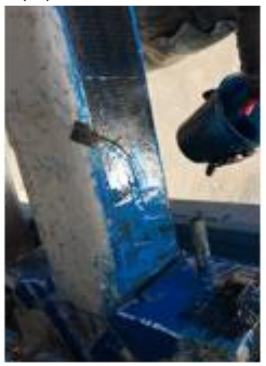

(g)

Figure 4.30: Steps to Longitudinally Strengthen the Specimens: (a) Overview, (b) Preparing the Grooves, (c) Applying Longitudenal CFRP Sheet, (d) Precut CFRP, (e) CFRP Rope, (f) Placing PVC with Stainless Steel Tupe, (g) Leveling the Grooves

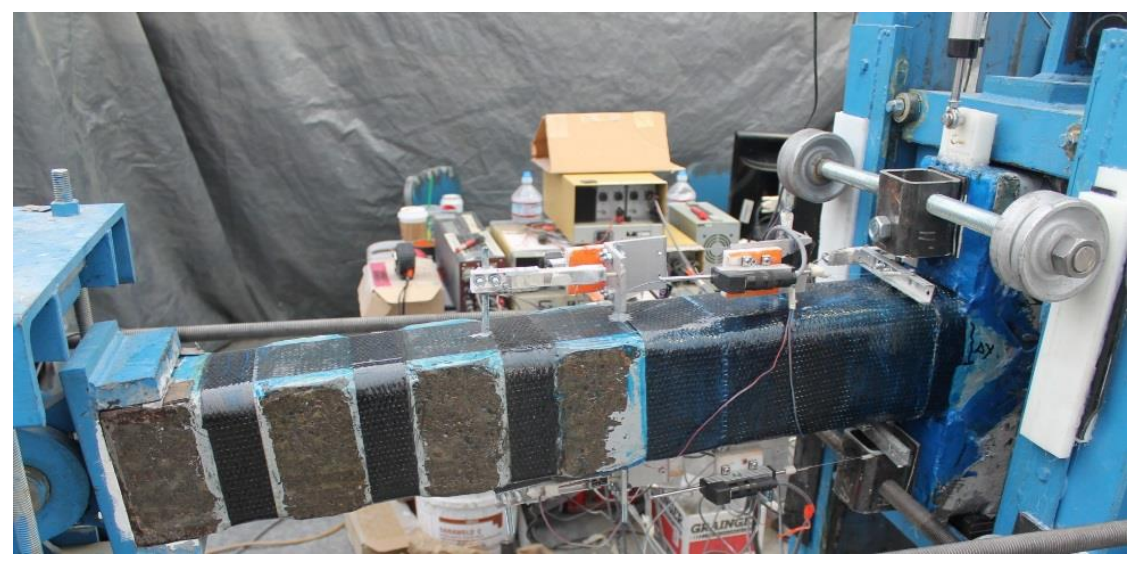

Figure 4.31: CFRP Strips to Anchor the Longitudinal CFRP Sheet along the Column 


\subsection{Instrumentation}

Instrumentation was used to collect data for each specimen during the test. In each column, four strain gauges were mounted on the longitudinal steel rebar at the mid-point of the expected plastic hinge regions. The gauges were placed three inches from the column-footing intersection in each side of the specimen for both columns. This was done to capture the first yield in longitudinal steel rebar, as shown in Fig. 4.32. Fig. 4.32 illustrates the distribution of strain gauges on the longitudinal CFRP sheet. Strain gauges to capture the tensile strain in the CFRP sheet were placed on one cantilever column, top and bottom. To measure the lateral strain in the CFRP retrofit, four strain gauges were mounted on the outer surface of the CFRP, three and six inches from the column-stub intersection on the top and bottom, as shown in Fig. 4.33. In the case of longitudinal CFRP strengthening, six strain gauges were installed along the top and bottom face of the CFRP sheet three, four, and nine inches from the column-stub intersection.

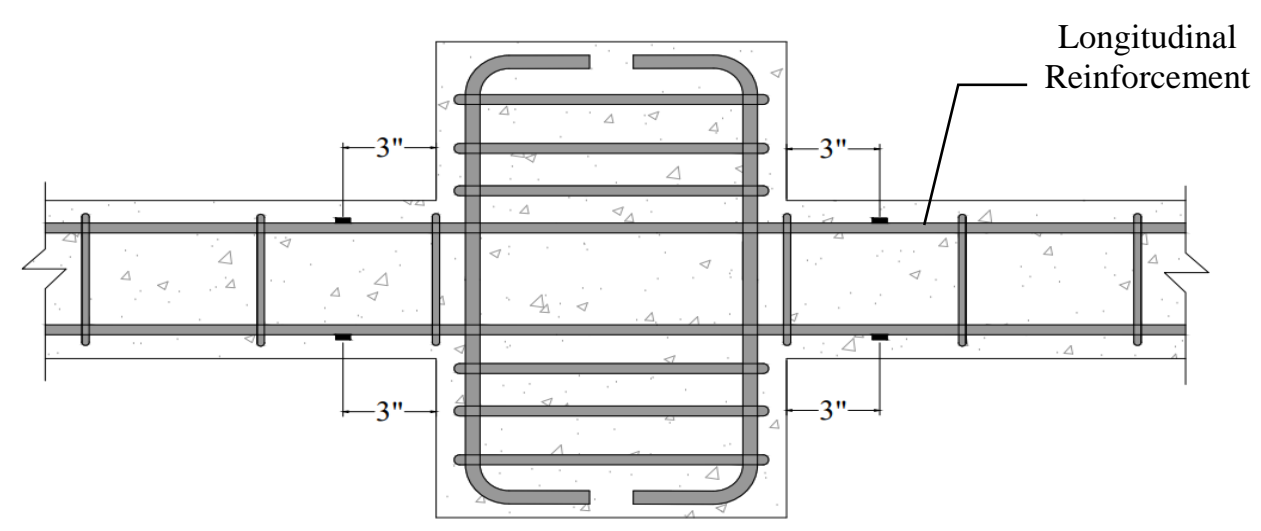

Figure 4.32: Location of the Strain Gauges on Steel Reinforcements 


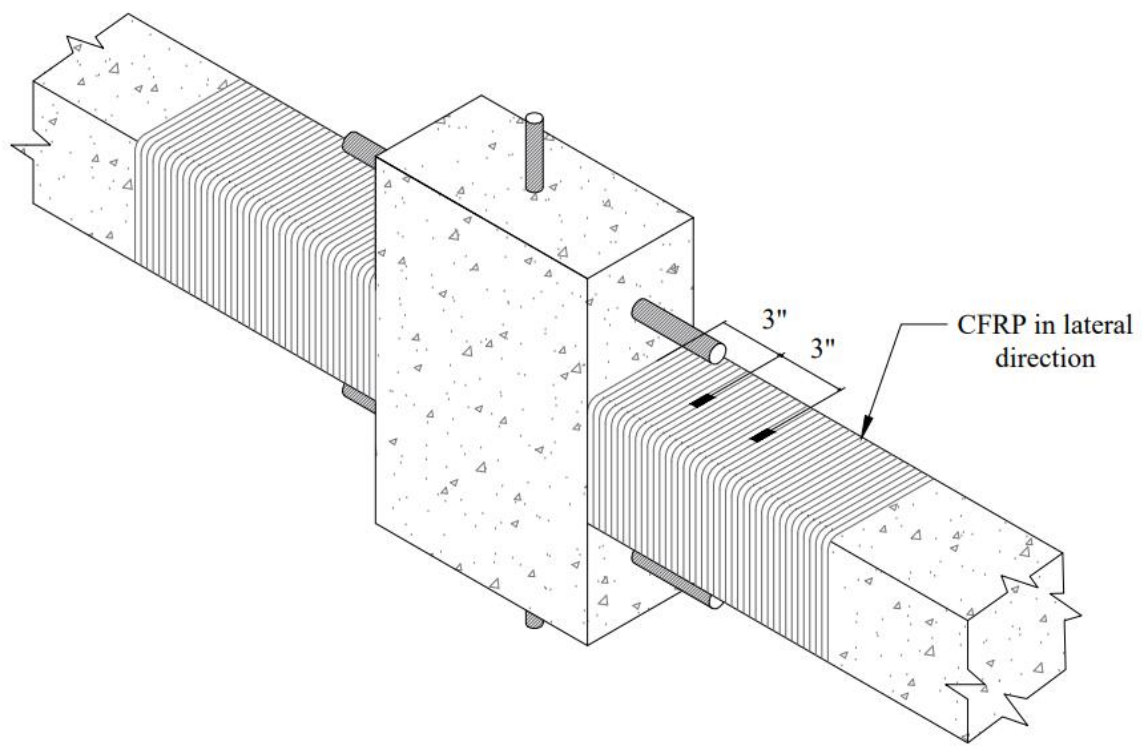

Figure 4.33: Location of the Strain Gauges on Lateral CFRP Confinement

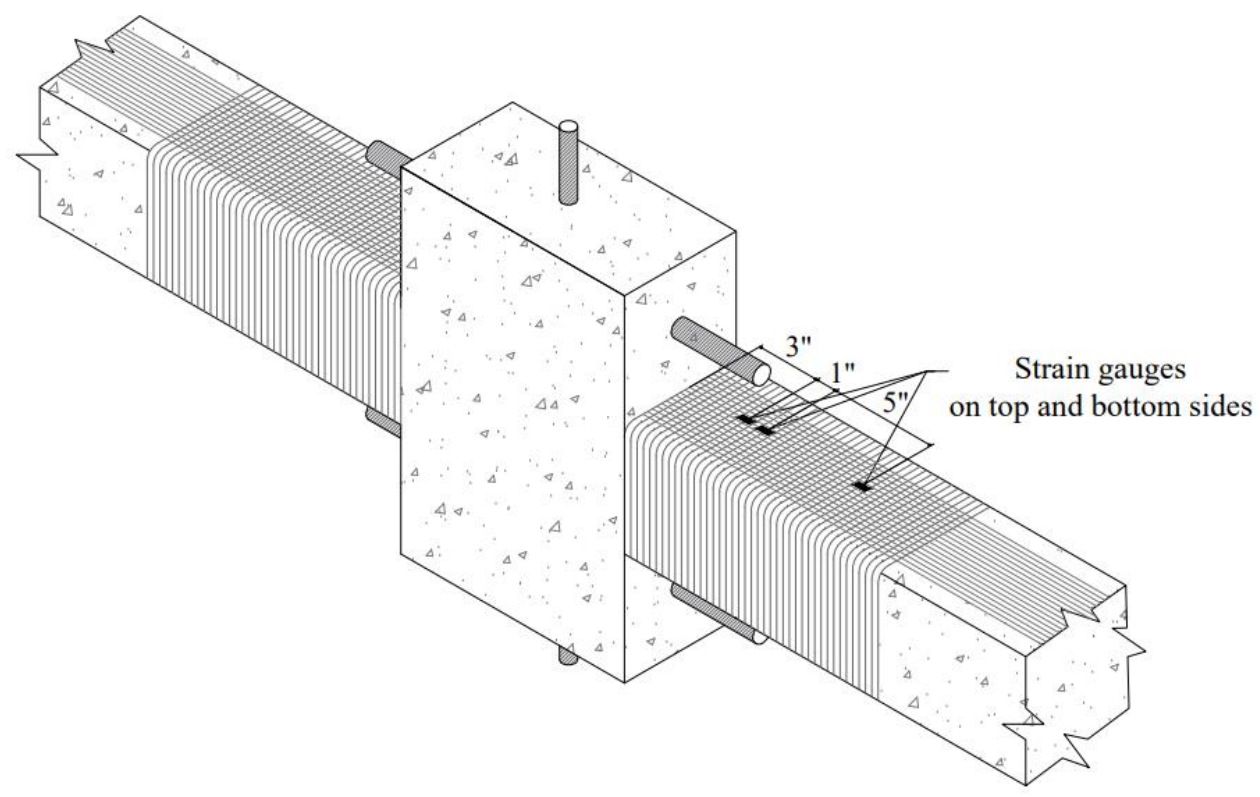

Figure 4.34: Location of the Strain Gauges on Longitudinal CFRP Sheet 
Eight linear variable differential transformers (LVDT) were used to capture the curvature twenty inches from the column-stub interaction. Fig. 4.35 illustrates the locations of the LVDTs along the column. Two long LVDTs were mounted vertically on both sides of the stub to measure the lateral displacement of the specimen during the test, as shown in Fig. 4.36. Two LVDTs were used to capture any rotation in the stub during the test and correct for the lateral displacement. The total lateral displacement, $\Delta$, will be calculated based on the following equation:

$$
\Delta=\delta \pm \theta L
$$

Where $\delta$, is the LVDT reading at the column's base, $\theta$ is the rotation angle, and $L$ is the length of the column.
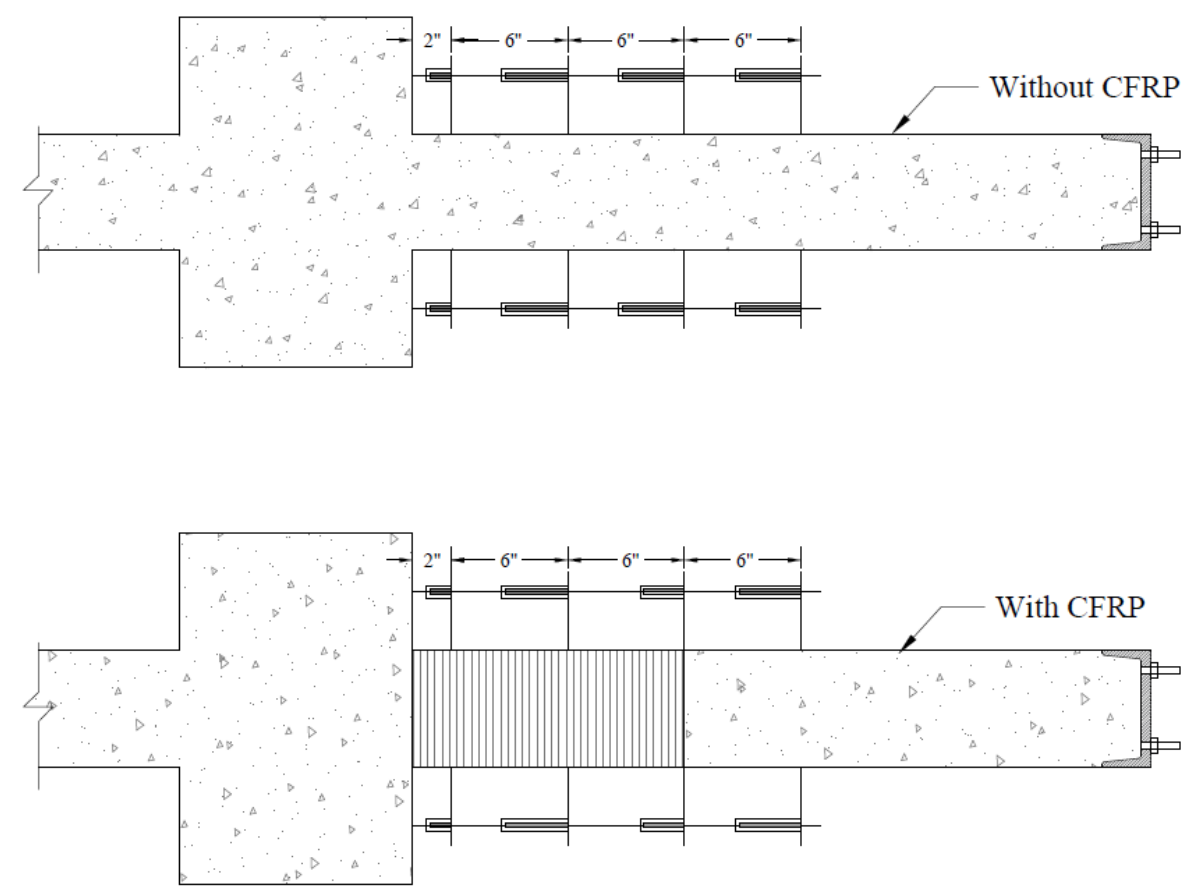

Figure 4.35: LVDTs to Measure Specimen Curvature 


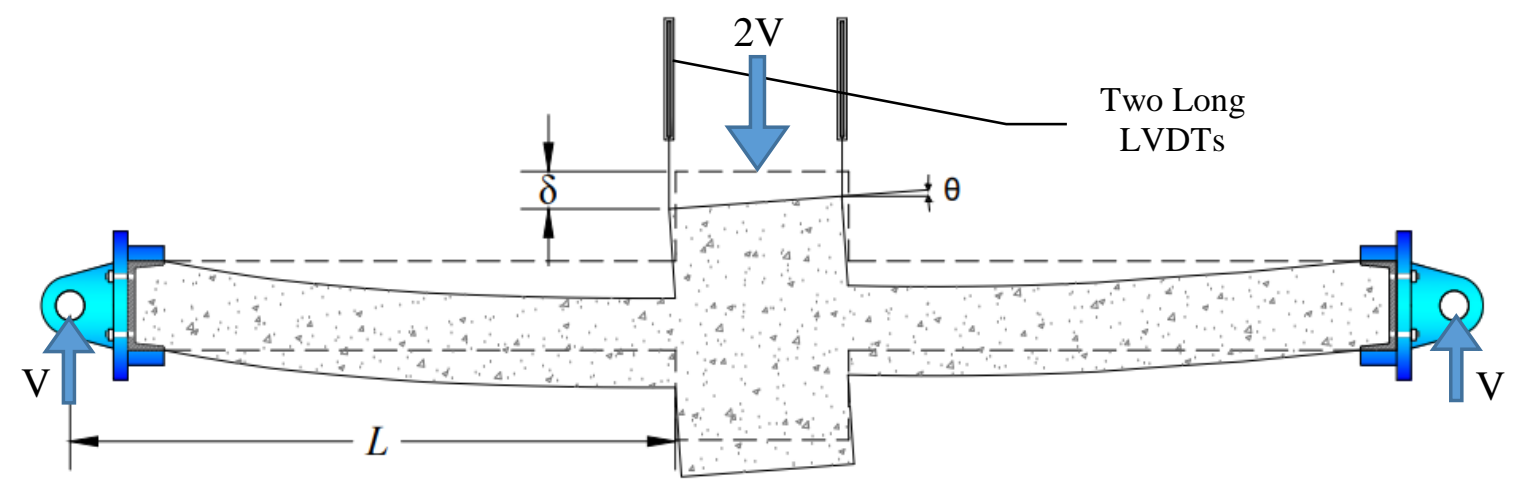

Figure 4.36: Two LVDTs to Measure the Lateral Displacement

\subsection{Loading Frame}

A loading frame was designed to test the slender RC columns horizontally under a combination of constant axial load at the ends of the specimen and lateral cyclic load at the center of the stub. This loading frame, designed and manufactured in the Civil and Environmental Engineering Department at Portland State University, is illustrated in Fig. 4.37. An existing loading frame was modified and reconstructed to perform the test, as shown in Fig. 4.38. Two pin supports, A and B, were designed to clump the ends of the specimen. Support A was a movable support on top and bottom slide rails, which allowed the applied axial load to push the support without friction. Meanwhile, support B was fixed in place, as shown in Fig. 4.39. The axial loading system consisted of two longitudinal bars anchored to C-channels at supports A and B and a 60-kip hydraulic actuator, positioned between the sliding support, A, and the C-channel. When oil was pumped to the 60-kip hydraulic actuator, the load was applied to both the sliding support and C-channel and then traversed to the other end, support B, by two longitudinal bars. 
While the axial load is being applied, the stub is free to move horizontally until the desired axial load is achieved. The stub has a nest of steel rollers on top and on each side of it to allow horizontal movement but to restrict the rotation in the stub. When the vertical load (lateral load on the columns) is applied, the axial loads on the columns are maintained as constant by slight adjustments of hydraulic pump that controls the axial load.

A 150-kip load cell was positioned in front of support A, to control the axial load during the test. The reverse cyclic lateral load was applied with a 50-kip double acting hydraulic actuator, which connected with a 20-kip S-beam load cell to record lateral load values during the test. In order to clamp the stub and prevent unwanted rotation, eight steel rollers were connected on the sides by threaded rods and allowed to roll up and down on the loading tower. The loading frame was designed with a maximum lateral displacement of up to approximately five inches. Therefore, a test would be terminated when the lateral displacement reached five inches. 


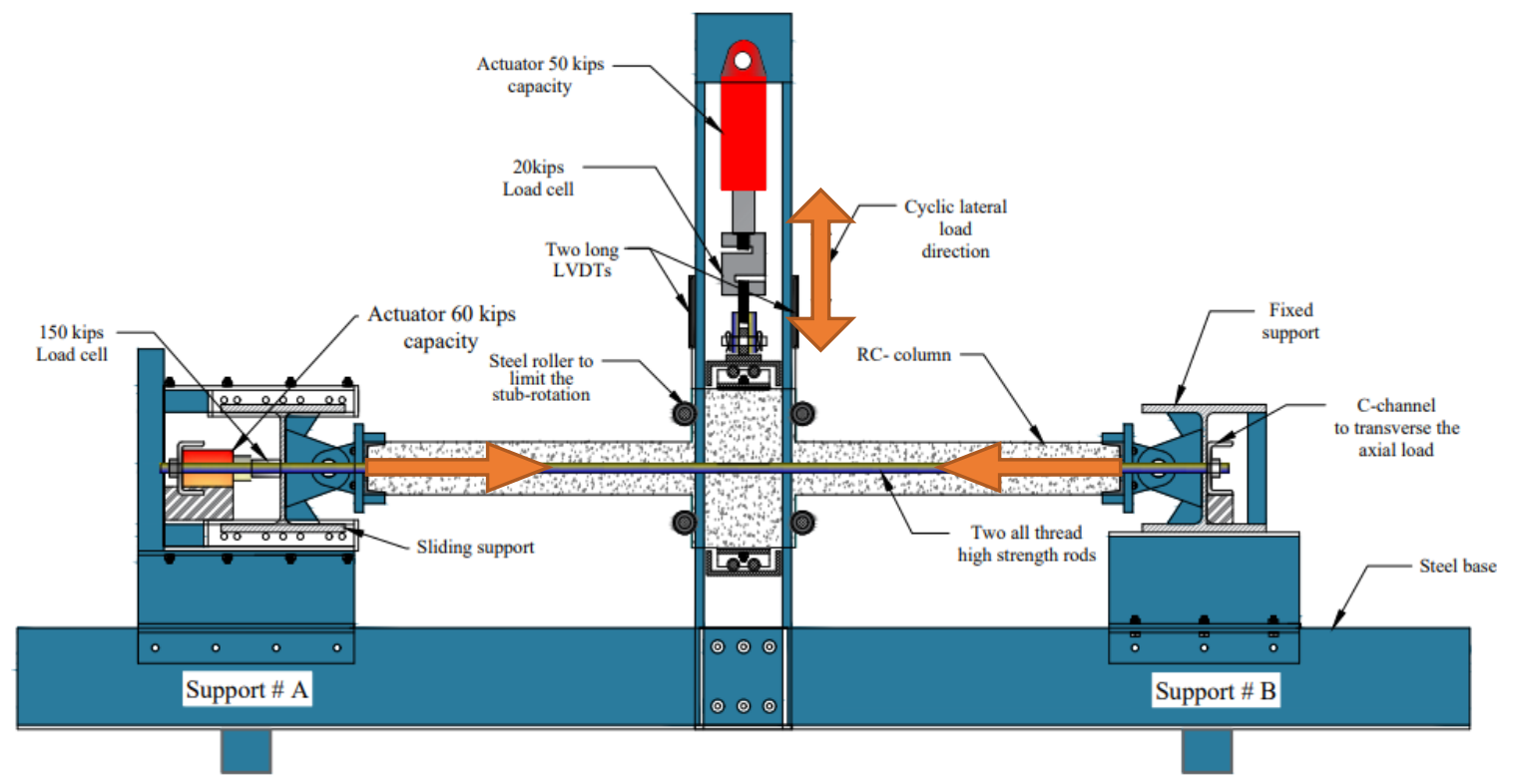

Figure 4.37: Details of the Loading Frame

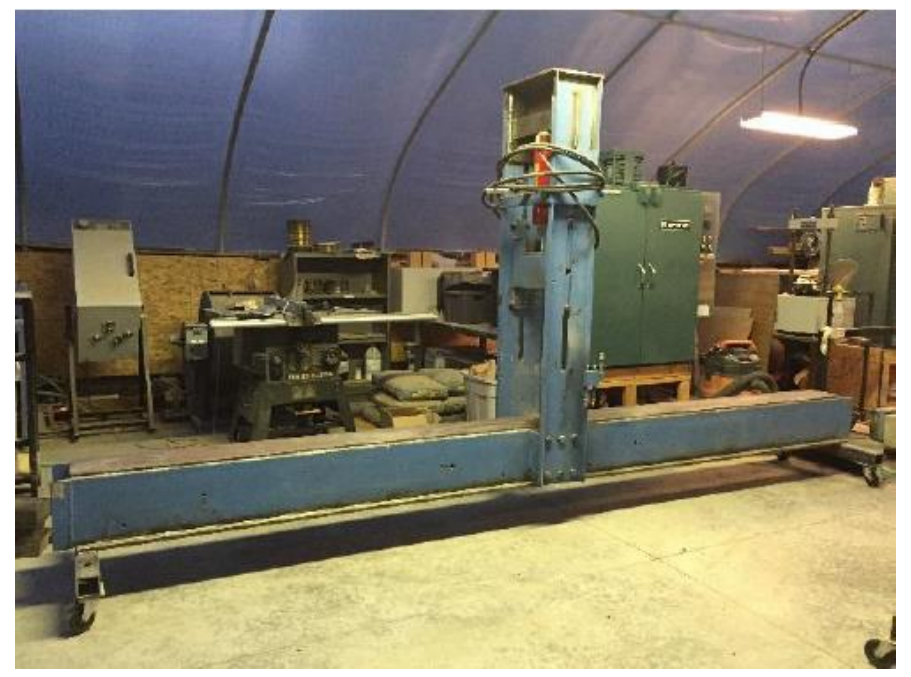

Figure 4.38: Loading Frame before Modification(Saeed, 2016) 


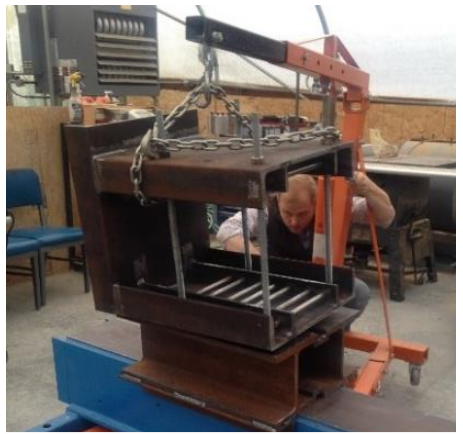

(a)

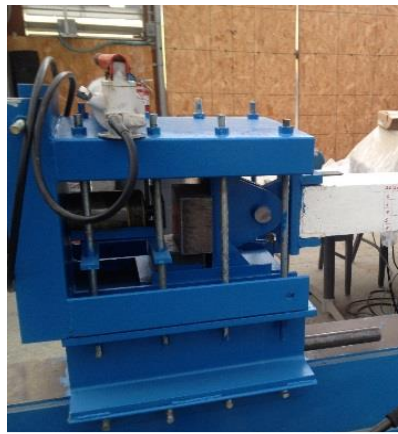

(b)

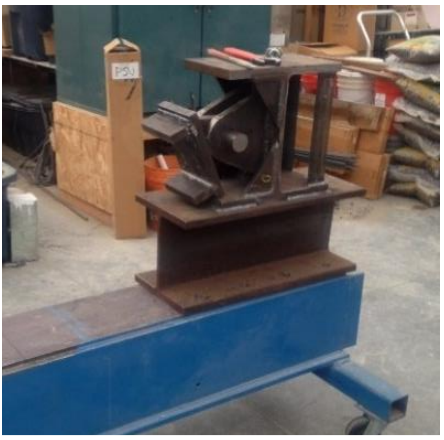

(c)

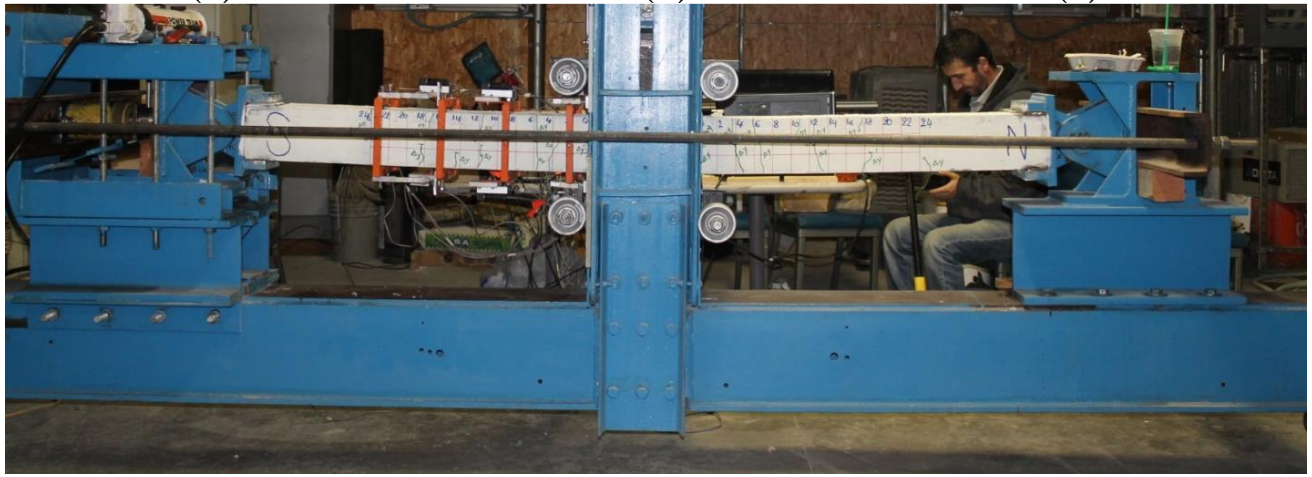

(d)

Figure 4.39: Loading Frame after Modification: (a) Slide Support, (b) Slide Support after Painting, (c) Fixed Support, (d) Final Loading Frame

\subsection{Loading Protocol}

This project utilized the ACI loading protocol with drift ratio increments designed to capture the significant changes in specimen behavior and to relate these changes to performance levels (ACI Committee 374, 2013). This protocol is controlled by the number of cycles and yielding drift ratio $\left(\varphi_{y}\right)$ determined by dividing the lateral yielding displacement $\left(\Delta_{y}\right)$ by the length of the column $(L)$. Two is the minimum number of cycles for each drift ratio level. The cycles can be increased based on the judgment of the 
researcher and degradation characteristics of the specimens being tested. In this research, four cycles were selected at each increment for the loading protocol, as shown in figure 4.40. The first two increments, $\mathrm{Vy} / 2$ and $\mathrm{Vy}$, are controlled by the loading increment. A computer-based program has been developed to provide a yielding lateral load (Vy) and define the first loading increment $(\mathrm{Vy} / 2)$ and the second loading increment $(\mathrm{Vy})$. The lateral deflection $(\Delta y)$ at $\mathrm{Vy}$ was recorded during the test and used for calculating the yielding drift ratio $(\varphi y)$. Moreover, for each drift ratio increment, four cycles were applied to the column and the increment was increased by adding $\varphi_{y}$ up to the column failure or the loading frame displacement limit, \pm 5 inches.

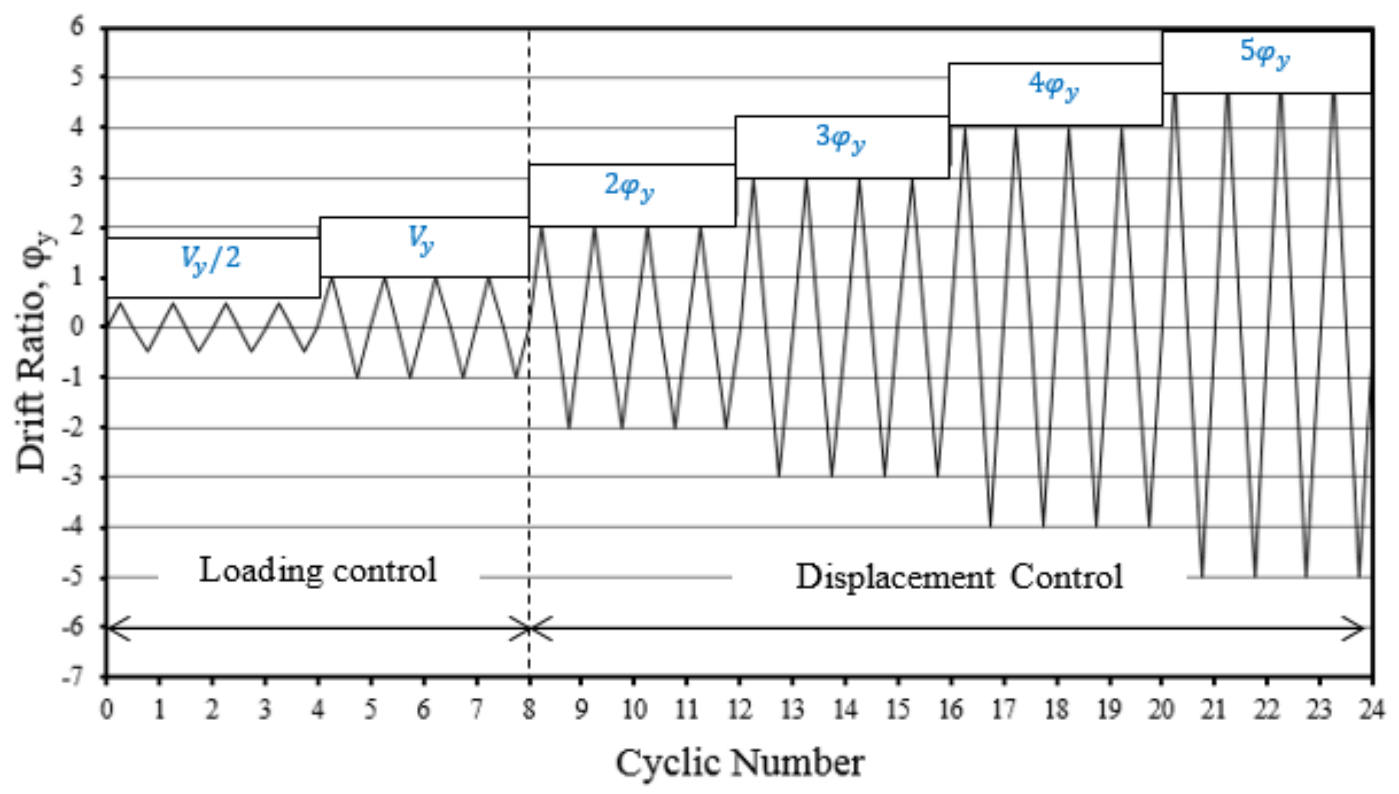

Figure 4.40: Loading Protocol 


\section{Chapter 5: Experimental Results}

In this chapter, the experimental observation and test results for the five $\mathrm{RC}$ slender columns are reported. All of the specimens were tested under a combination of cyclic lateral load and constant axial load. The test results are presented in terms of the hysteresis loops of the lateral load vs. the lateral displacement $(V-\Delta)$ relationship, the moment vs. curvature $(M-\Phi)$ relationship at the critical sections, and energy dissipation. Displacement and curvature ductility for all specimens are discussed based on the various ductility standards.

\subsection{Load and Moment}

The horizontal actuator at support A, Fig. 4.37, applied the axial load gradually up to a predetermined amount, and the load cell placed at the center of support A measured the axial load level. The vertical actuator was used to apply the lateral load measured directly by using a load cell and this load divided by two to represent the amount of the applied lateral load for each column.

Moments were calculated at various critical sections by measuring the primary moments. This was done by multiplying the measured lateral load on the column by the appropriate moment arm distance, and then summating a secondary moment by multiplying the column axial load by the lateral displacement. As mentioned before, the lateral load on each column is one-half of the applied vertical load on the stub. 


\subsection{Displacement and Curvature}

Two long LVDTs, mounted on stub ends, were used to measure the lateral displacement of the specimens and stub rotation if any Fig. 4.36. The measured rotation was used to correct the lateral displacement of the specimen. Furthermore, the existing rotation resistance at the stub ends helped guide the stub move up and down with minimum rotation. The curvatures at the critical section along the column were measured by using LVDTs distributed along the columns. The first row of LVDTs was placed very close to the stub to measure the curvature and bar-slip at the column-stub intersection. Measuring the bar-slip was used to identify its contribution to the lateral displacement. The second row of LVDTs was placed within an expected plastic hinge zone to measure the plastic hinge rotation. The other rows of LVDT were used to measure the curvature beyond the plastic hinge region as shown in Fig. 4.35.

\subsection{Test Procedure and Observation}

In order to apply the loading protocol, a theoretical calculation was made to determine the yielding lateral strength $V_{y}$ by using MATLAB program, which is described in details in Chapter 6. Based on this value, $V_{y}$, the first and second loading increment, $V_{y} / 2$, and $V_{y}$ were defined. However, during the test, the yielding condition was monitored by the strain gauges mounted on the extreme face of the longitudinal steel reinforcement. Once the steel bar yielded, the corresponding lateral displacement at yield $\Delta \mathrm{y}^{\prime}$ and moment strength $\mathrm{My}^{\prime}$ were recorded. The ideal lateral yield displacement is

equals to $\Delta \mathrm{y}=\Delta \mathrm{y}^{\prime} * M_{n} / \mathrm{My}^{\prime}$, where $M_{n}$ is the moment strength of the column when the 
concrete strain at the extreme layer reaches $\varepsilon_{c u}=-0.004$ or the strain in longitudinal steel reinforcement reaches $\varepsilon_{s}=0.015$, whichever comes first (Powell, 2008). The test observations for each specimen are discussed in details in the following sections.

\subsubsection{Specimen Control-0.2}

The hysteresis loops of the lateral load vs. the lateral displacement $(V-\Delta)$ for the specimen Control-0.2 is illustrated in Fig. 5.1. After applying a constant axial load, $0.2 A_{g} f_{c}^{\prime}$, the loading protocol of lateral load was followed. The first loading increment was $\pm V_{y} / 2=1.2$ kips. At the end of the first cycle, initial tiny flexural cracks were observed at top and bottom of the column next to the column-stub intersection. The second loading increment was started by increasing the lateral load up to the first yield in a longitudinal rebar. The recorded lateral load at the steel yield was $+V^{\prime}{ }_{y}=2.43$ kips, and the lateral displacement was $\Delta \mathrm{y}^{\prime}=0.85 \mathrm{inch}$. At this point, the yield displacement was calculated as $\Delta y=0.84$ inch. The $\Delta y$ was used to determine the yield drift ratio, $\varphi y=0.02$. At the yield limit, cracks increased, and were distributed at the top and bottom of the specimen approximately $18 \mathrm{in.}$ from the stub, as shown in Fig. 5.2. At the third level of the displacement increment, $\pm 2 \varphi y=0.04$, the width of the flexural cracks increased at the end of the first cycle of this increment, and several diagonal cracks formed at the plastic hinge region at top and bottom of the column, as shown in 5.2. The concrete cover spalled at the end of the first cycle in the fourth increment, $\pm 3 \varphi y=0.06$. The behavior of the column during this fourth increment was sensitive to repeated cyclic action, and the lateral load strength was degraded as number of cycles increased. During 
the cyclic action, tension-compression cycles were applied $\mathbf{f}$, which led to an increase in the spalling action, and consequently the longitudinal reinforcement steel buckled. At the end of the third cycle of this increment, the lateral load dropped to $+V=1.25 \mathrm{kips}$, and the specimen gradually lost its axial load capacity and was damaged at the plastic hinge zone. This was due to the complete spalling of the concrete cover followed by rebar buckling, (flexural failure), as shown in Fig. 5.3. An increase in the width of the diagonal cracks was expected due to a reduction in the concrete cross-section and the poor steel confinement.

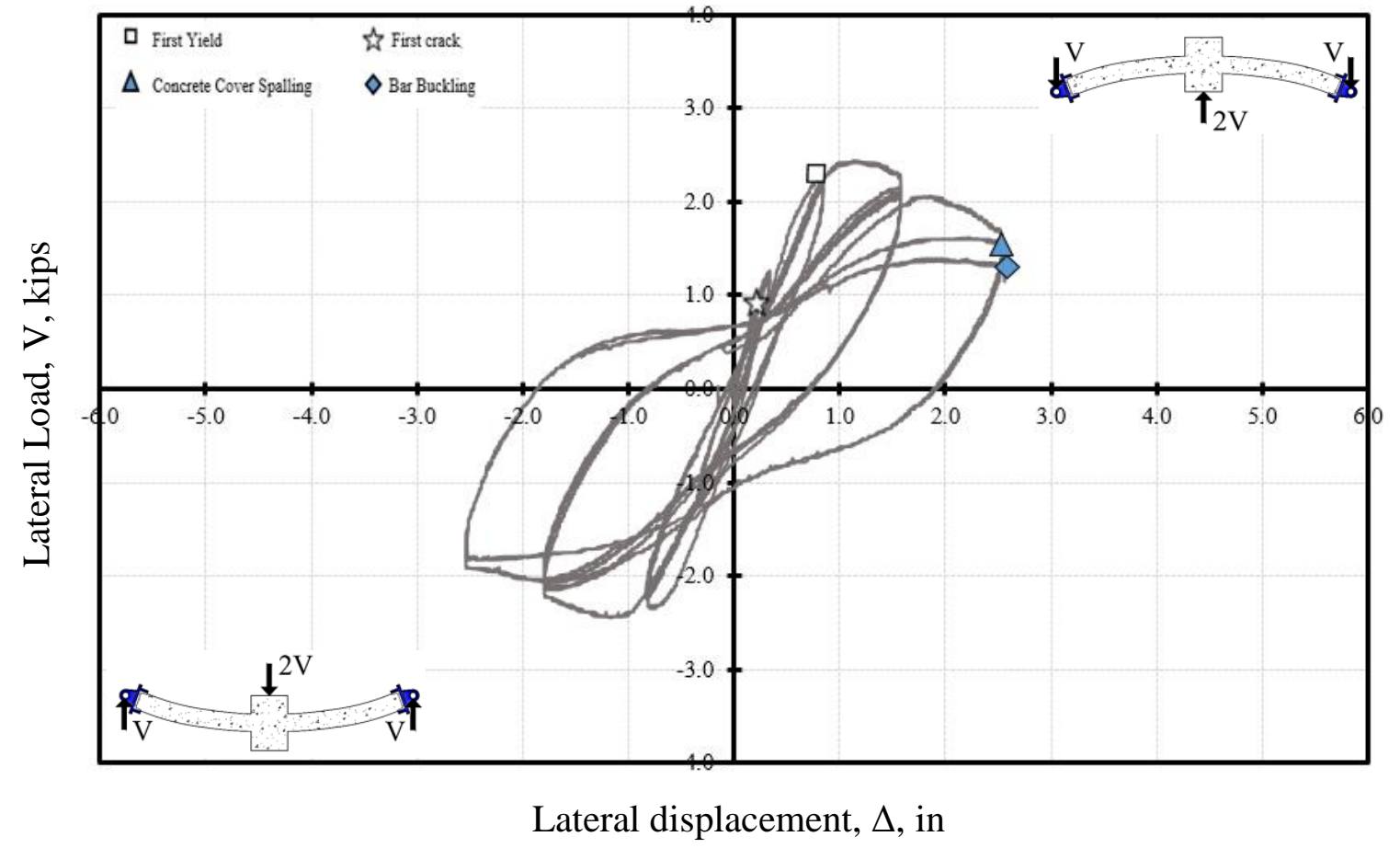

Figure 5.1: Hysteresis Loops, Lateral Load vs. Lateral Displacement for Specimen Control-0.2 

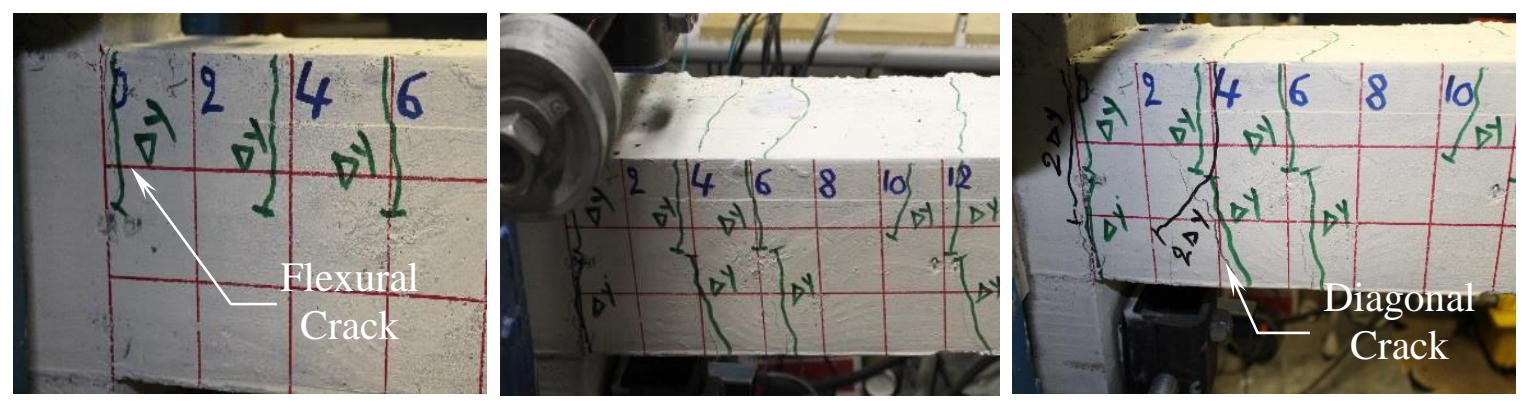

Figure 5.2: Distribution of the Cracks at the First Cycle of Each Increment for Specimen Control-0.2
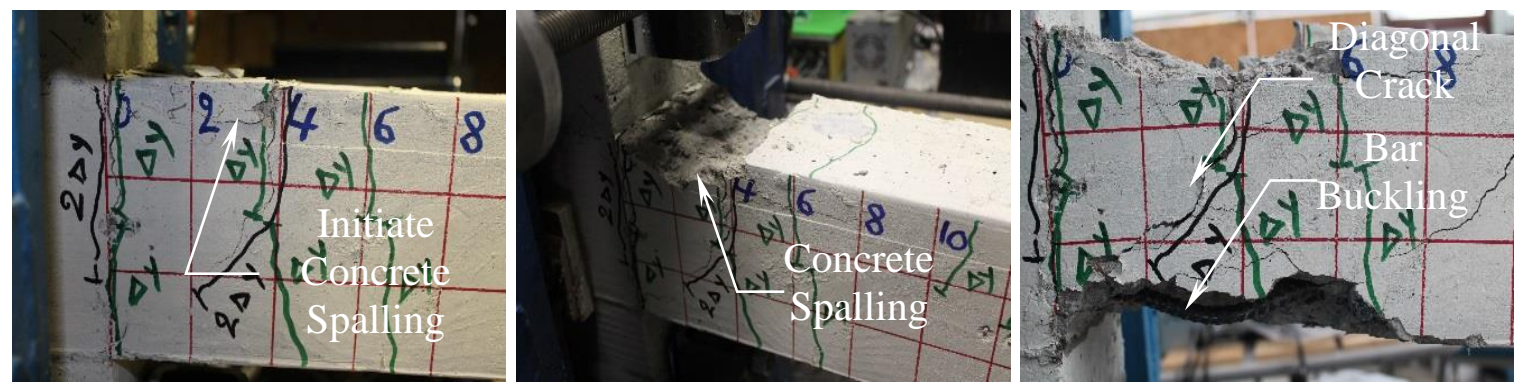

Figure 5.3: Initial Concrete Cover Spalling and Plastic Hinge Damage with Rebar Buckling for Specimen Control-0.2

\subsubsection{Specimen Control-0.4}

Fig. 5.4 illustrates the hysteresis loops in terms of lateral load vs. lateral displacement $(V-\Delta)$ for specimen Control-0.4. After gradually applying the axial level, $0.4 A_{g} f_{c}^{\prime}$, the cyclic lateral load was applied according to the loading protocol. Based on the theoretical calculation, the expected lateral load at yielding was $\pm V_{y}=2.58$ kips. Therefore, the first loading increment was $\pm V_{y} / 2=1.29$ kips. At the end of the last cycle of this increment, an initial small flexural cracking was observed in the columnstub intersection where the maximum flexural stress was concentrated. At the first cycle 
of the second loading increment $\pm V_{y}$, the lateral load was increased up to the first yield in the longitudinal steel. The recorded lateral load at the steel yield was $+V^{\prime}{ }_{y}=2.66$ kips, and the lateral displacement was $\Delta \mathrm{y}^{\prime}=0.87$ inches. At this point, the yield displacement was calculated as $\Delta y=0.84$ inches. Based on the yield displacement of $\Delta y=0.84$ inches and a yield drift ratio of $\varphi y=0.02$, the loading protocol was constructed. At the end of the first cycle, cracks were distributed at the top and bottom of the specimen approximately 9 inches in length from the stub, as shown in Fig. 5.5. The width of the flexural cracks increased at the end of the first cycle of this increment. In the second cycle, it was observed that the concrete cover started to spall with an accompanying of degradation in the lateral strength, which increased as the cyclic action increased. The lateral load dropped from 2.66 kips during the first cycle to 2.05 kips at the fourth cycle at this same displacement increment, $\varphi y=0.02$. When the third level of cyclic protocol $\pm 2 \varphi \mathrm{y}=0.04$, was applied, the lateral load dropped to $1.82 \mathrm{kips}$, and the specimen suddenly lost its axial load capacity, which was accompanied by damage at the plastic hinge zone. At this point, the rebar buckled, the transverse reinforcement opened, and the concrete core crashed, as shown in Fig. 5.6. For an RC column to have an axial load above the balance point, it is expected that it will experience a non-ductile, compressionflexural mode failure, which occurs when inadequate confinement is provided in the plastic hinge region. This results in the spalling of the concrete cover followed by longitudinal reinforcement buckling. ACI 369R-11 (2011) suggests that sudden loss in the axial load carrying capacity occurs for columns with axial loads above $0.6 A_{c} f_{c}^{\prime}$. However, test observations for this specimen provide evidence that effect of slenderness 
reduces the axial load limit that causes sudden loss in load carrying capacity to around $0.4 A_{c} f_{c}^{\prime}$.

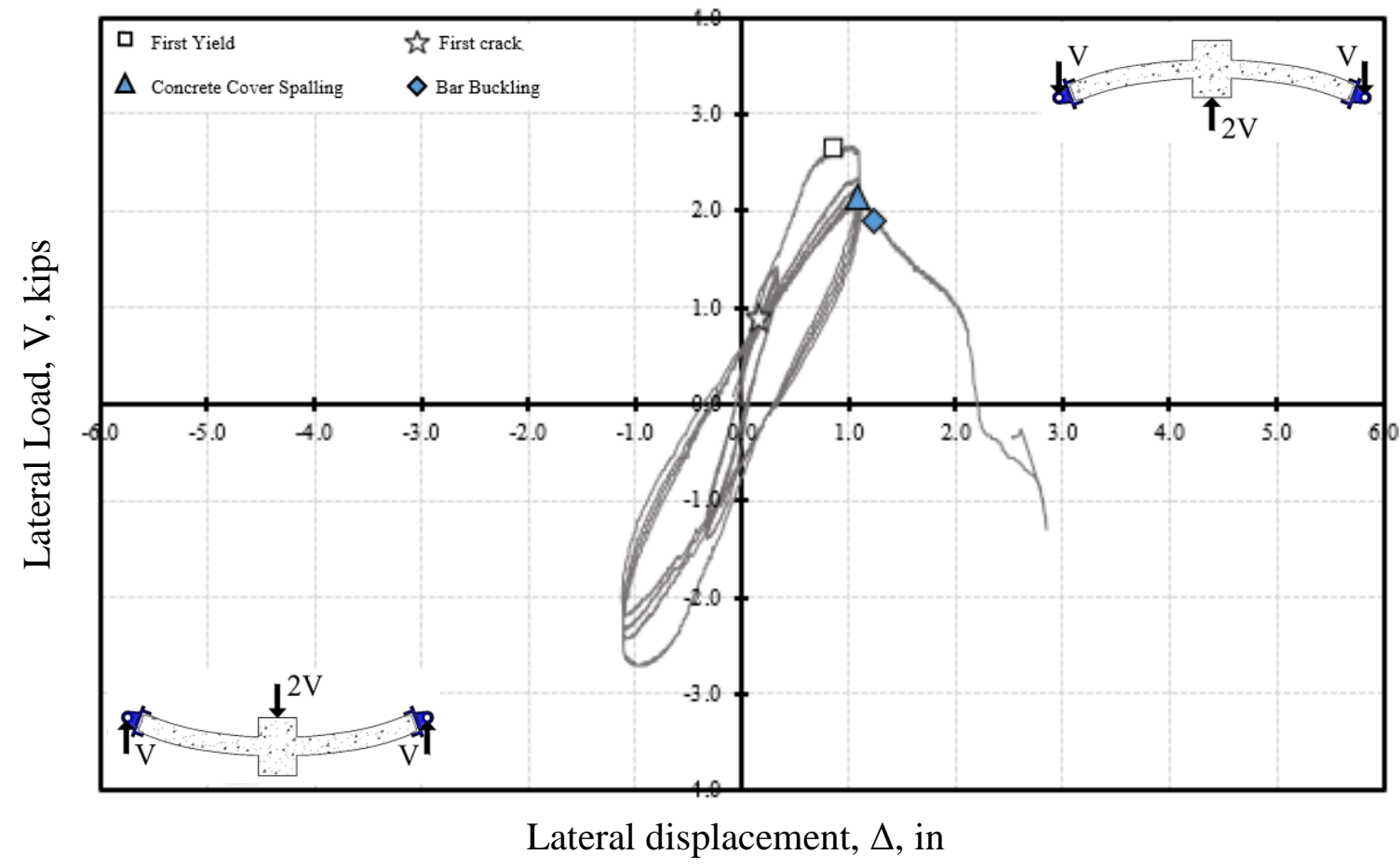

Figure 5.4: the Hysteresis Loops Lateral Load vs. Lateral Displacement for Specimen Control-0.4
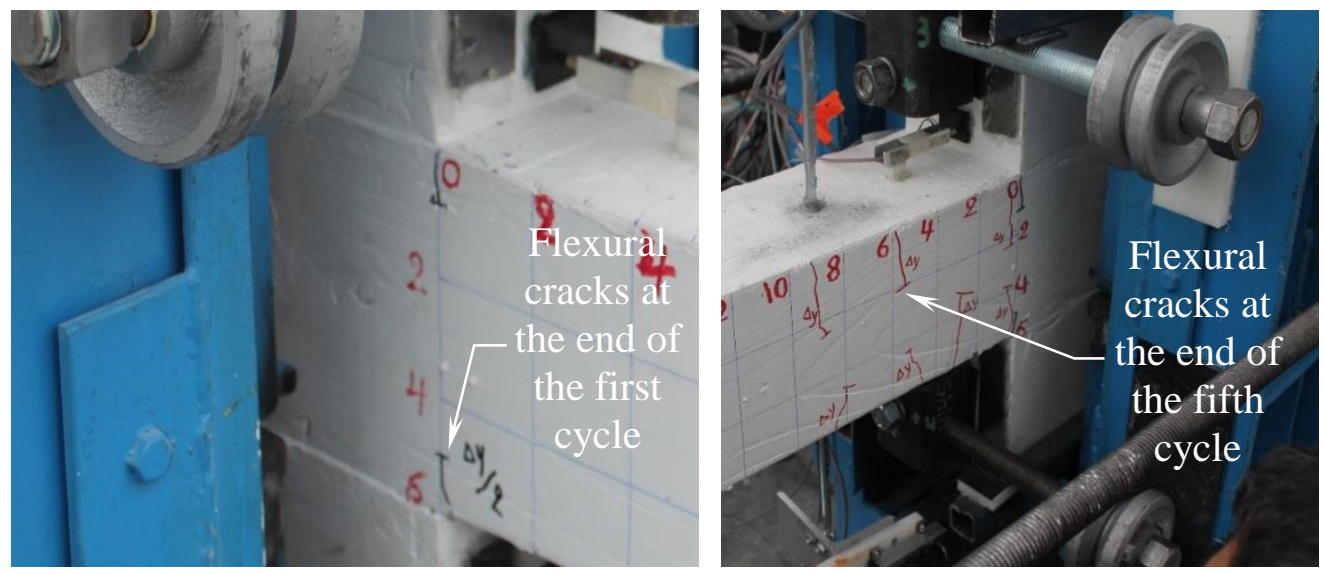

Figure 5.5: Distribution of the Cracks at the First Cycle of Each Increment for Specimen Control-0.4 

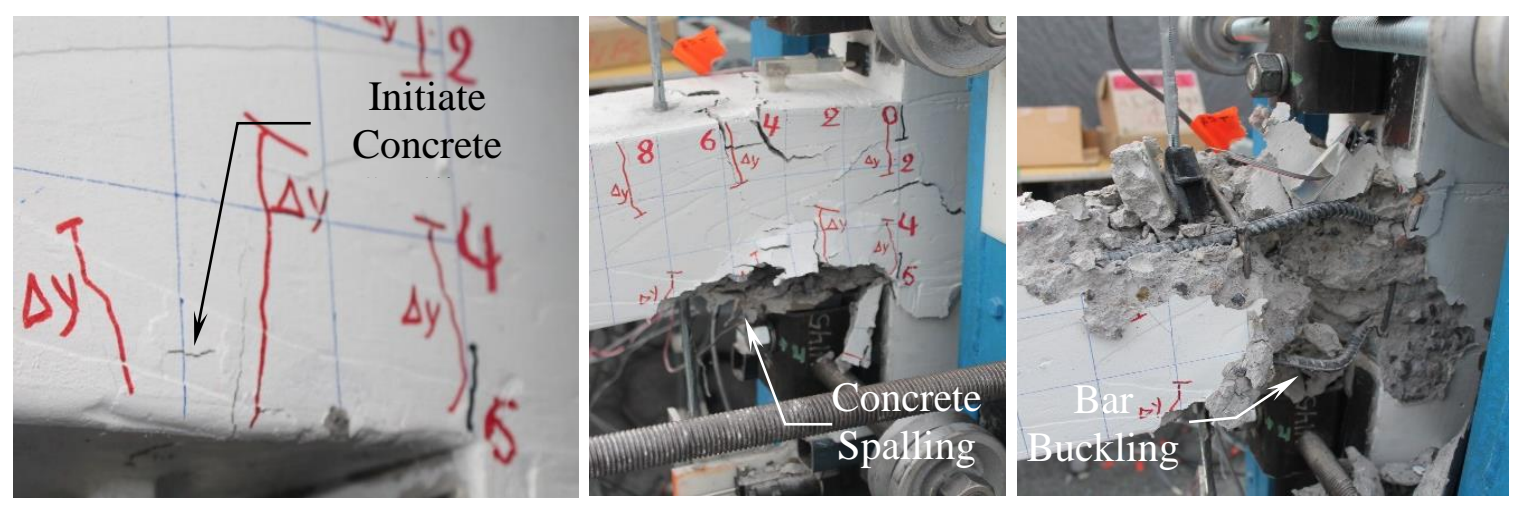

Figure 5.6: Initial Concrete Cover Spalling, and Plastic Hinge Damage with Rebar Buckling in Specimen Control-0.4

\subsubsection{Specimen Retroft-C01-0.2}

One layer of CFRP was wrapped at the plastic hinge region with a height of 14 inches, as shown in Fig. 5.7. A constant axial load, $0.2 A_{g} f_{c}^{\prime}$, was applied gradually at the slide support A. The hysteresis loops of the lateral load vs. lateral displacement $(V-\Delta)$ for the specimen Retrofit-C01-0.2 is illustrated in Fig. 5.8. The first increment of the cyclic protocol was $\pm V_{y} / 2=1.2$ kips. At the end of the first cycle, a small crack was observed at the column-stub intersection next to the CFRP retrofit end on the top and bottom of the specimen, as shown in Fig. 5.9. The second level of loading protocol was obtained by applying the lateral load up to yielding of the steel rebar with $+V^{\prime}{ }_{y}=$ 2.52 kips and $\Delta \mathrm{y}^{\prime}=0.81$ inches. Based on these results, the yield displacement of the column was determined as $\Delta y=0.78$ inch. Based on the yielding displacement $\Delta y=$ 0.78 inch, the yielding drift ratio was determined as $\varphi y=0.019$. At this level, a popping sound was heard at the CFRP retrofit regions. At the fourth cycle of this increment, a few 
cracks were distributed at the CFRP retrofit region and beyond this region, as shown in Fig. 5.10. Most of these cracks were concentrated around the middle of the CFRP confinement at $\sim 6.5$ inches from the stub.

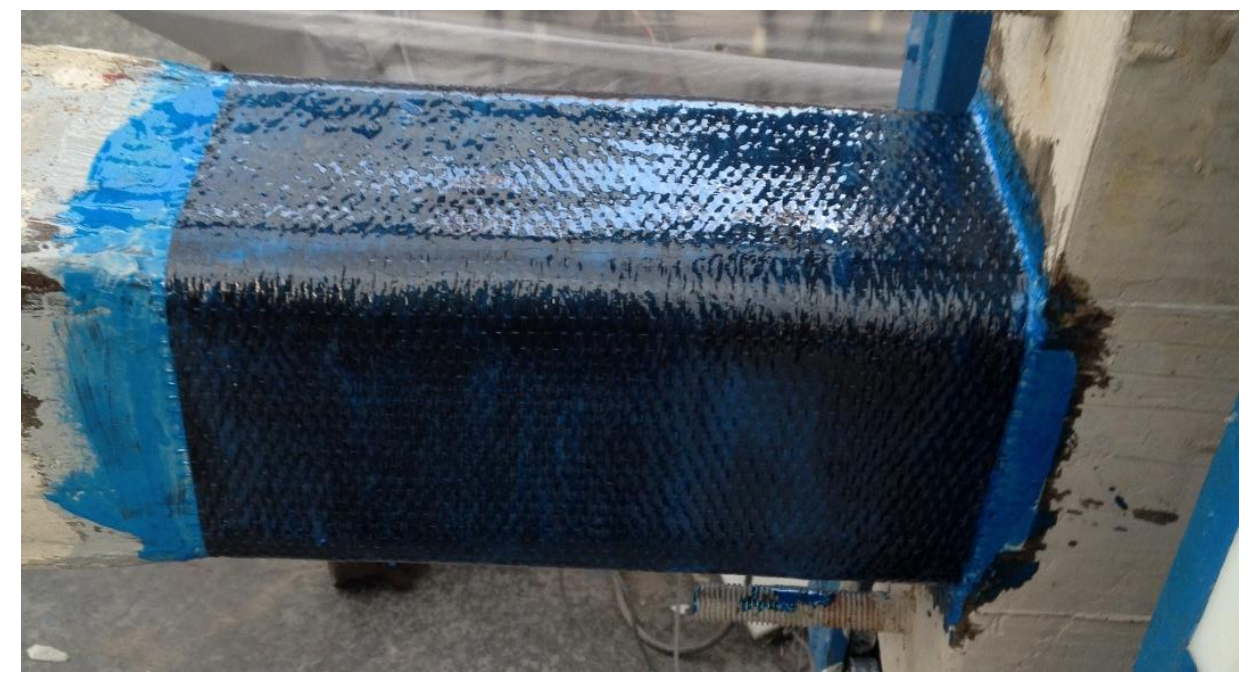

Figure 5.7: One Layer of CFRP Retrofit of Specimen Retrofit-C01-0.2 


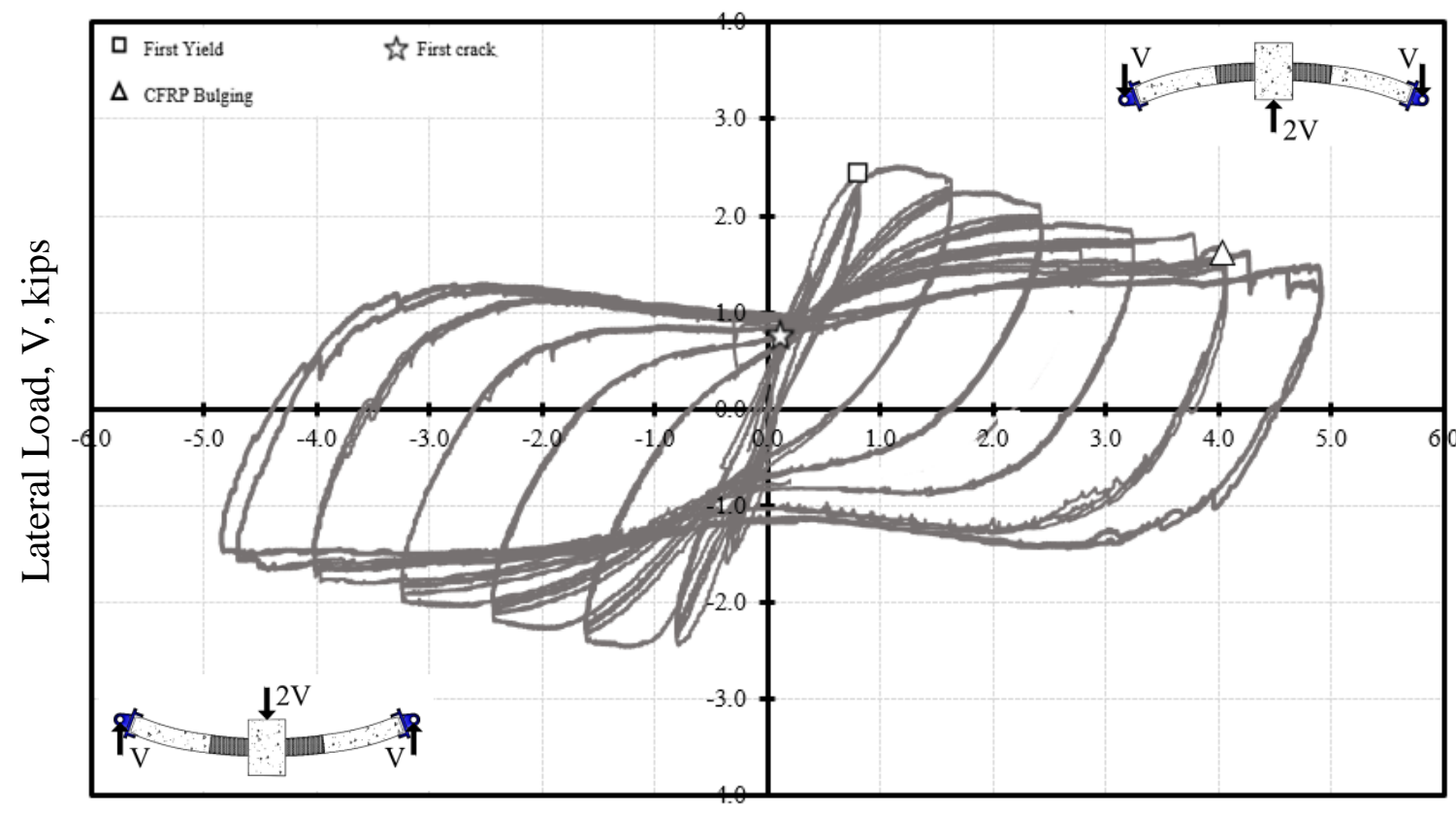

Lateral displacement, $\Delta$, in

Figure 5.8: the Hysteresis Loops Lateral Load vs. Lateral Displacement for Specimen Retrofit-C01-0.2

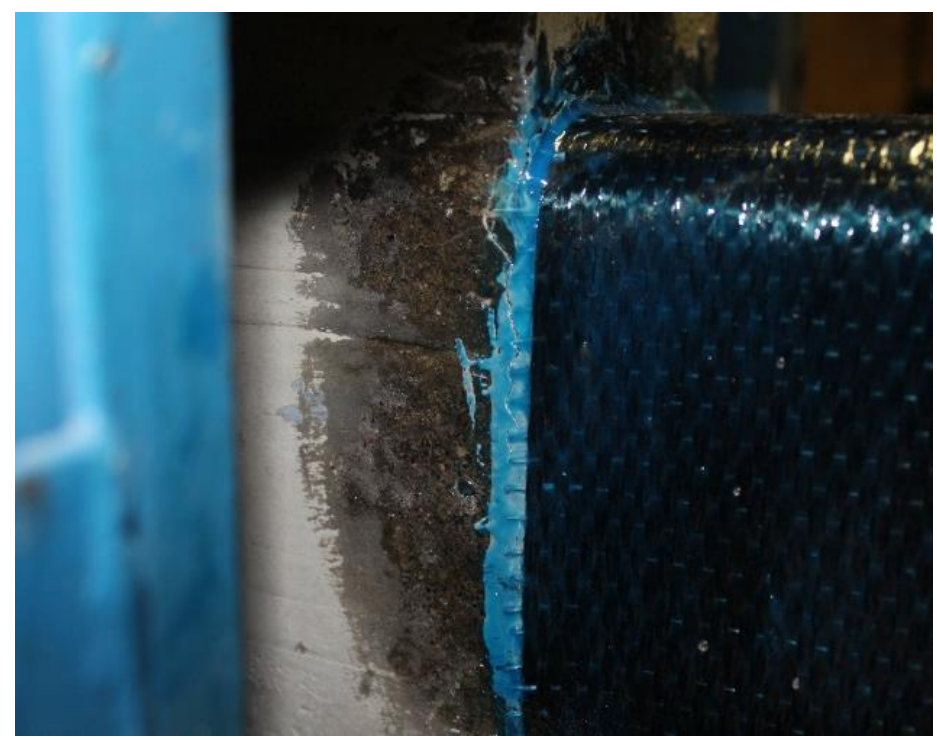

Figure 5.9: Initial Cracks at the Column-Stub Intersection for Retrofit-C01-0.2 

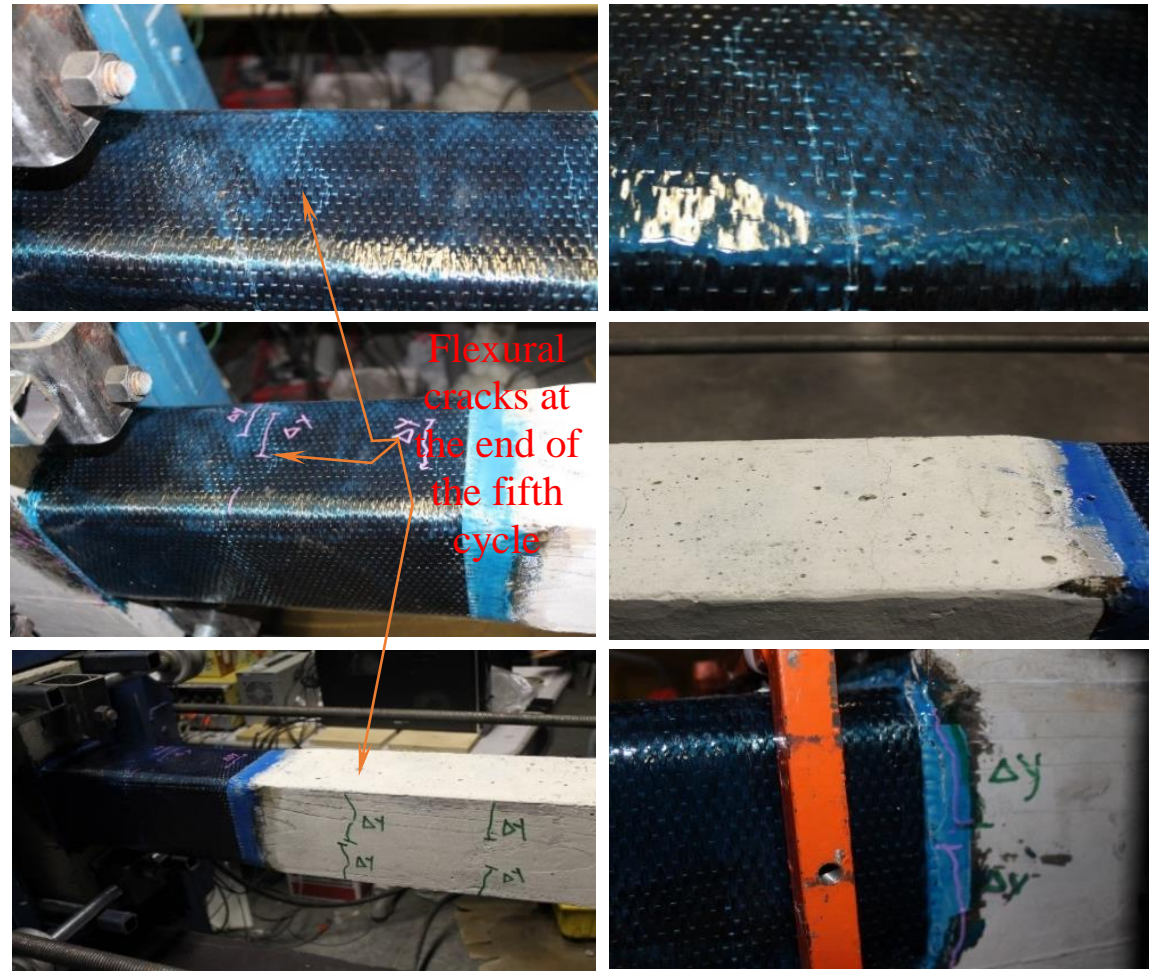

Figure 5.10: Distribution of the Cracks at the End of the Cycle $\varphi y$ for Specimen Retrofit-C01-0.2

At the third increment of the loading protocol, $\pm 2 \varphi y=0.038$, the width of the cracks inside the CFRP retrofit region increased with continuing cyclic action, as shown in Fig. 5.11. The width of the crack at the column-stub intersection and CFRP retrofit region increased as the loading protocol reached the peak of $\pm 3 \varphi y=0.057$, as shown in Fig. 5.12. As the loading protocol increased, the crack width of the flexural cracks increased with each increment level. At the displacement increment, $\pm 5 \varphi y=0.095$, the CFRP layer bulged at the top and bottom of the specimen, and several diagonal cracks formed next to the CFRP retrofit ends, as shown in Fig. 5.13. 


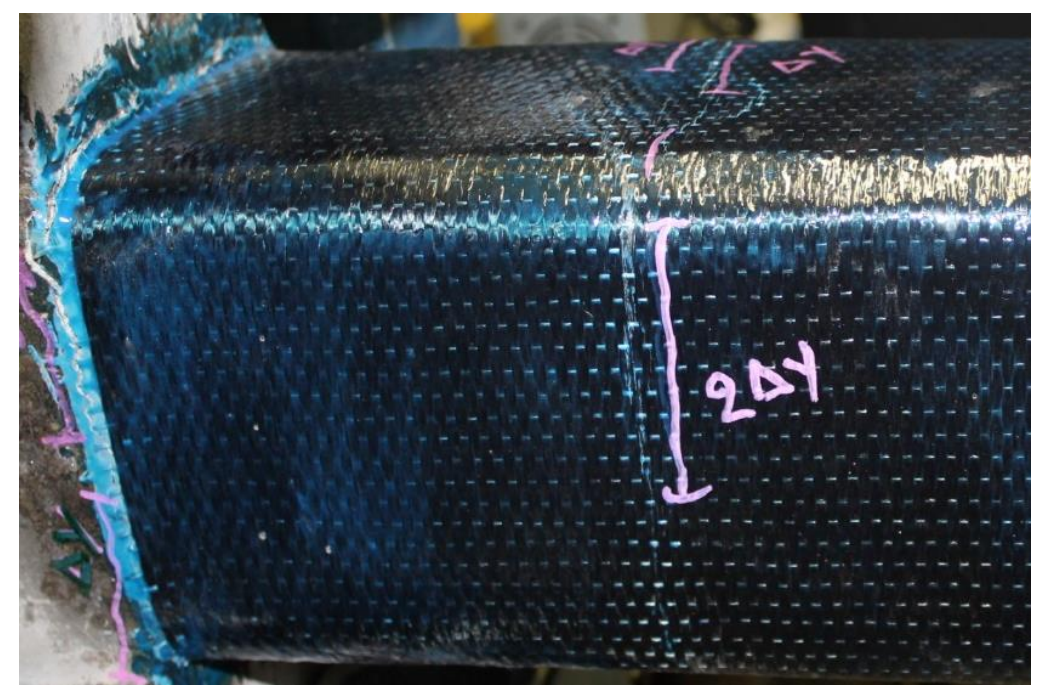

Figure 5.11: Increasing the Crack Width at Colum-Stub Intersection and CFRP Retrofit Region, Specimen Retrofit-C01-0.2

Up until the end of the last loading protocol increment, $\pm 6 \varphi y=0.114$, the specimen supported the axial load without any degradation, and there were no signs of CFRP rupture along the plastic hinge region. At the end of this increment, the test was terminated due to loading frame displacement capacity, \pm 5 in.

In general, the crack width at the column-stub intersection increased after the drift ratio was increased to $\pm 3 \varphi y=0.057$. This might have contributed to increasing the flexural rigidity of the plastic hinge region due to CFRP confinement, and led to increasing the deformation at the column-stub intersection, where the ultimate bending moment was applied. After removing all the instrumentations from the specimen, the CFRP was pealing from the column and it was observed that the concrete cover was completely crushed at the region $\sim 4$ inches from the column-stub intersection. However, 
after removing the crushed concrete, there was no sign of buckling in the longitudinal steel, as shown in Fig. 5.14.
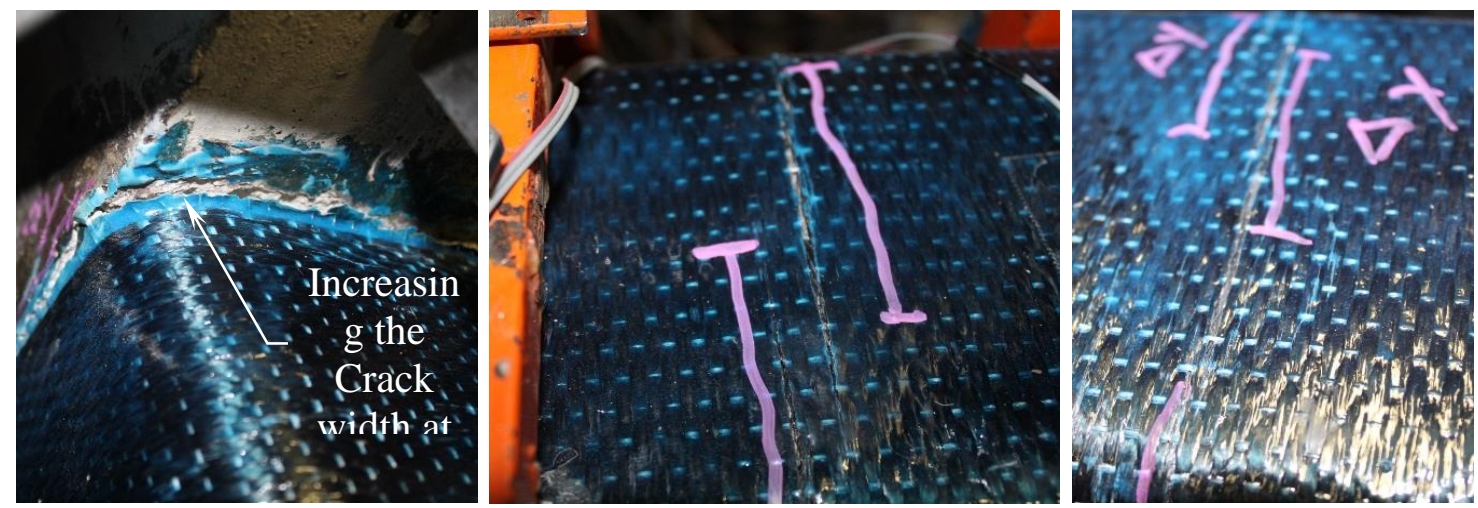

Figure 5.12: the Cracks Width at Fourth Increment of Loading Protocol, Specimen Retrofit-C01-0.2
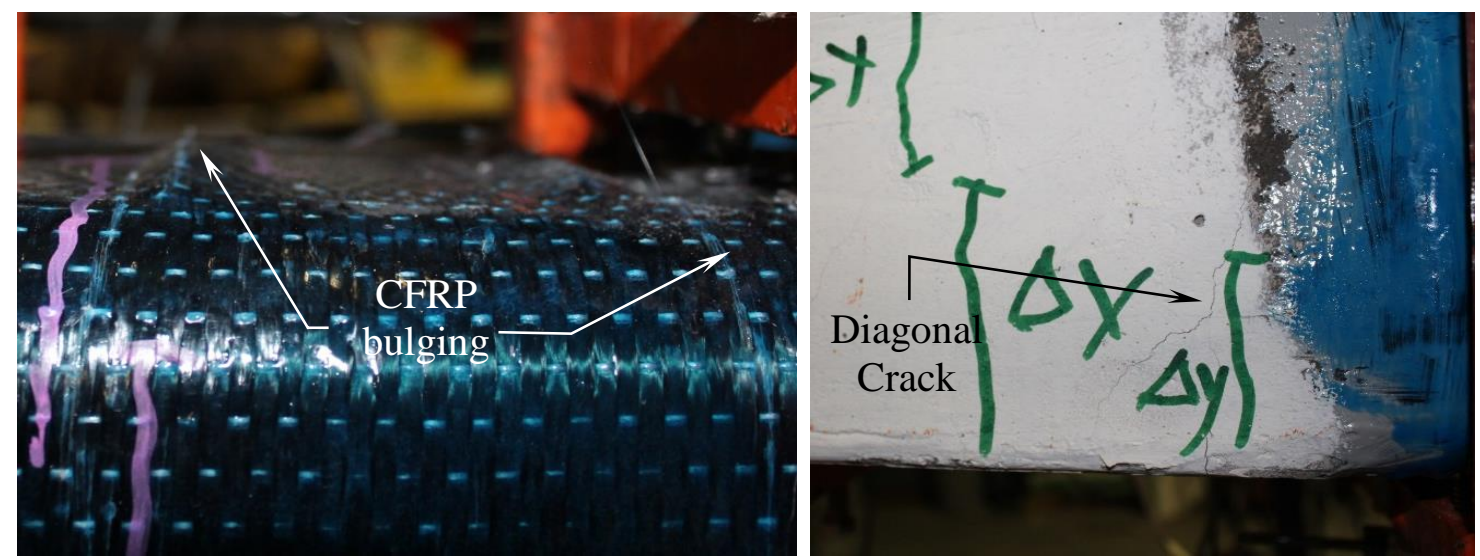

Figure 5.13: CFRP Bulging and Diagonal Shear Cracks, Specimen Retrofit-C01-0.2 

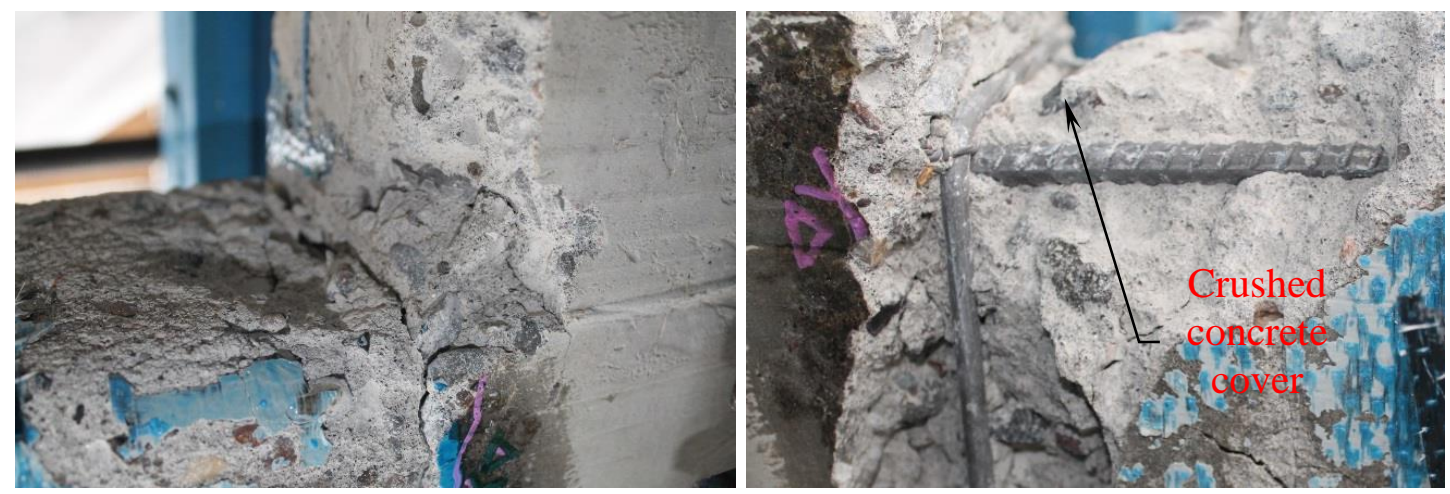

Figure 5.14: Crushed Concrete Cover after Peeling the CFRP, Specimen Retrofit-C01-0.2

\subsubsection{Specimen Retrofit-C01-0.4}

Fig. 5.15 illustrates the hysteresis loops of the lateral load vs. the lateral displacement $(V-\Delta)$ for the specimen Retrofit-C01-0.4. The axial load level was, $0.4 A_{g} f_{c}^{\prime}$. After applying the first increment of the cyclic loading protocol, $\pm V_{y} / 2=$ 1.3 kips, an initial small flexural crack was observed in the column-stub intersection at the end of the first cycle, as shown in Fig. 5.16. It increased along the lateral rebar up to the longitudinal rebar yielding, $+V^{\prime}{ }_{y}=2.68$ kips and $\Delta \mathrm{y}^{\prime}=0.9$ inches. Based on these results, the yielding displacement and the drift ratio were calculated, $\Delta y=0.87$ inches, $\varphi y=0.0207$, respectively. During the first cycle of this level, a popping sound was heard and small cracks were observed on the CFRP layer, $\sim 6$ inches from the columnstub intersection where there was an increase in the width of the flexural cracks, as shown in Fig. 5.17. Fig. 5.18 shows that there were few flexural cracks distributed beyond the CFRP retrofit region after applying the first cycle of the third increment, $\pm 2 \varphi y=$ 
0.0414. The CFRP bulging at the end of the first cycle of the fourth increment, $\pm 3 \varphi y=$ 0.062, as shown in Fig. 5.19. As the cycling action increased, the width of the flexural cracks increased especially at the column-stub intersection, which was where the largest flexural crack width was concentrated. Fig. 5.20 illustrates several of the diagonal cracks that were observed beyond the CFRP retrofit at the end of the first cycle of the sixth increment, $\pm 5 \varphi \mathrm{y}=0.104$, and the width of the flexural cracks at the CFRP retrofit region. The test was terminated due to reaching the loading frame displacement capacity. Furthermore, the specimen sustained the axial load during the last cycles with a stable cyclic action.

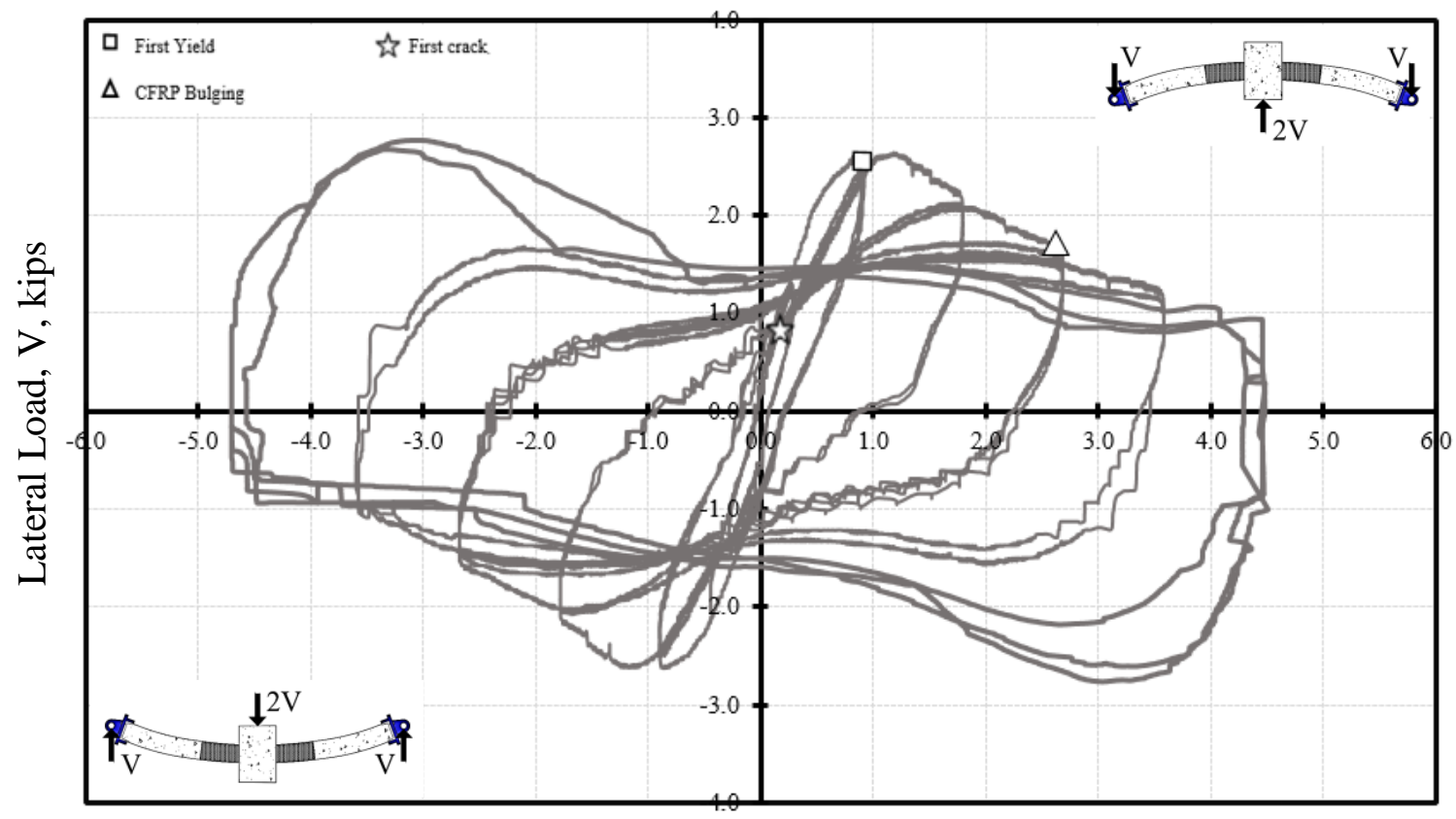

Lateral displacement, $\Delta$, in

Figure 5.15: the Hysteresis Loops Lateral Load vs. Lateral Displacement for Specimen Retrofit-C01-0.4 

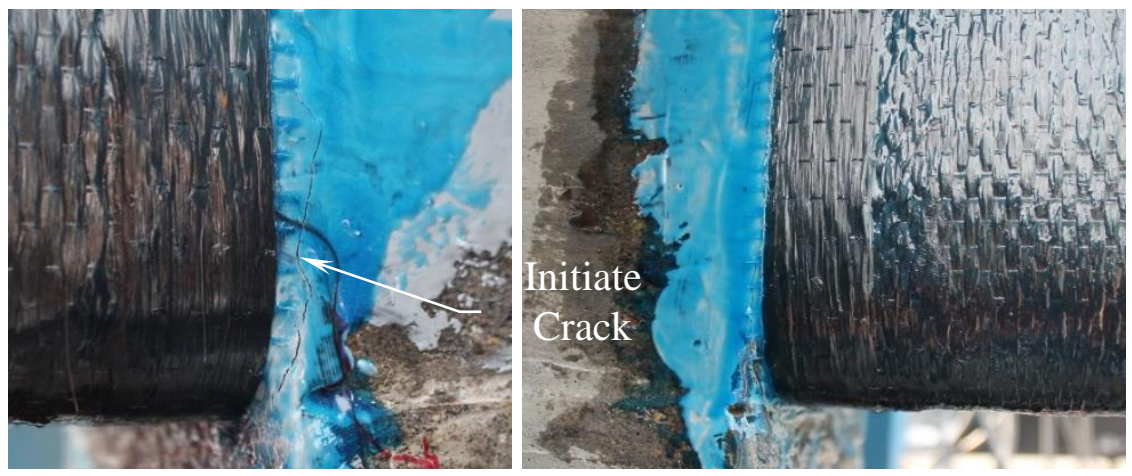

Figure 5.16: Initial Flexural Cracks at the Column-Stub Intersection, Specimen Retrofit-C01-0.4
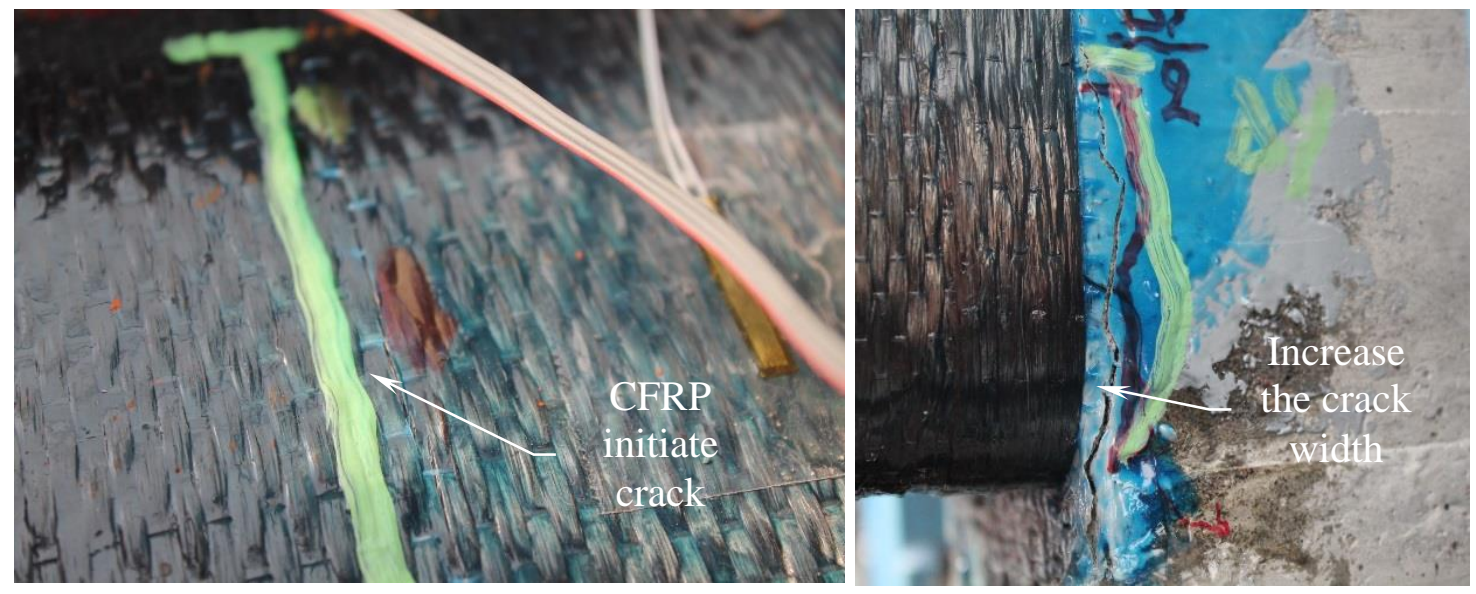

Figure 5.17: Initial Crack on CFRP Layer and Increasing the Crack Width, Specimen Retrofit-C01-0.4 

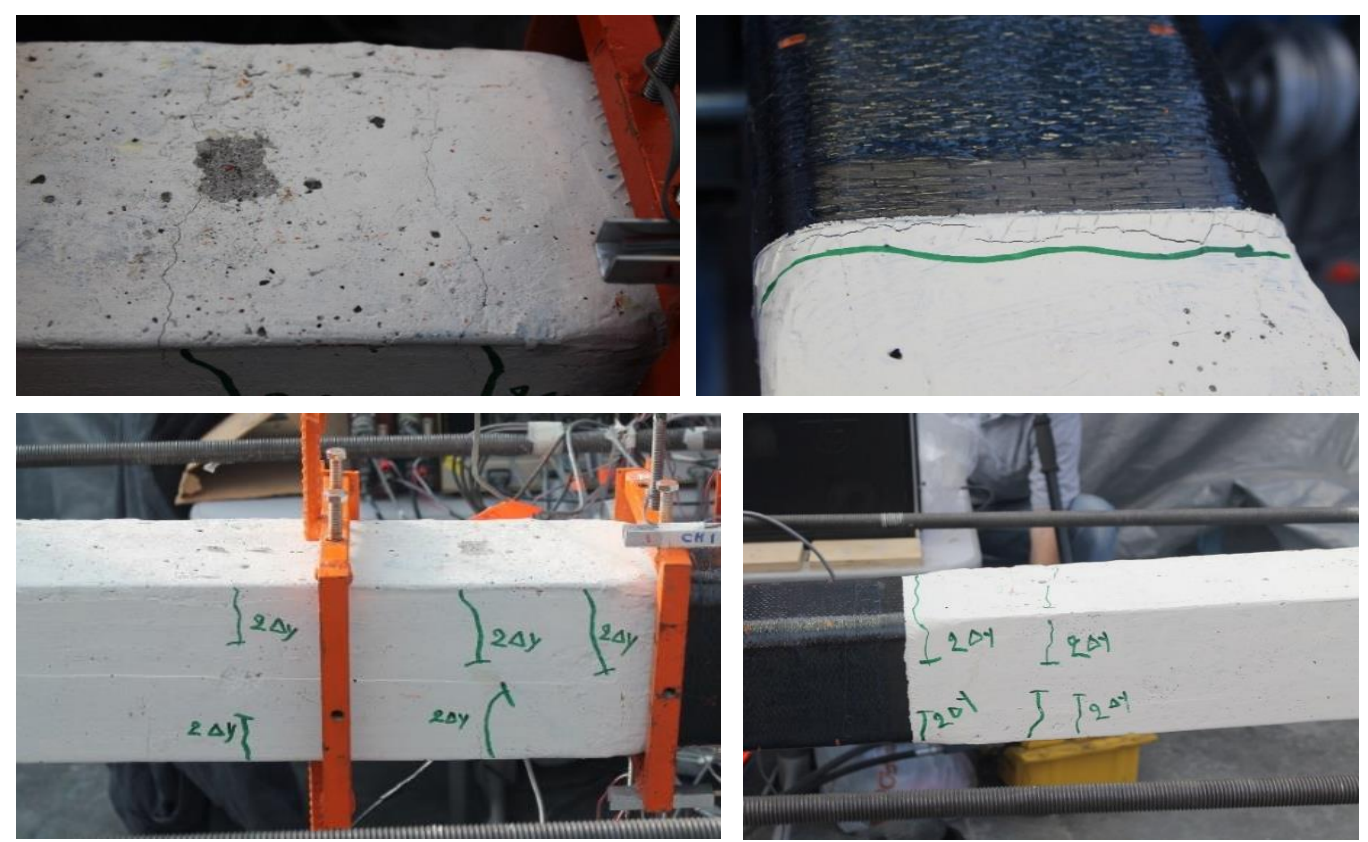

Figure 5.18: Flexural Cracks Distributed Beyond CFRP Retrofit Region, Specimen Retrofit-C01-0.4
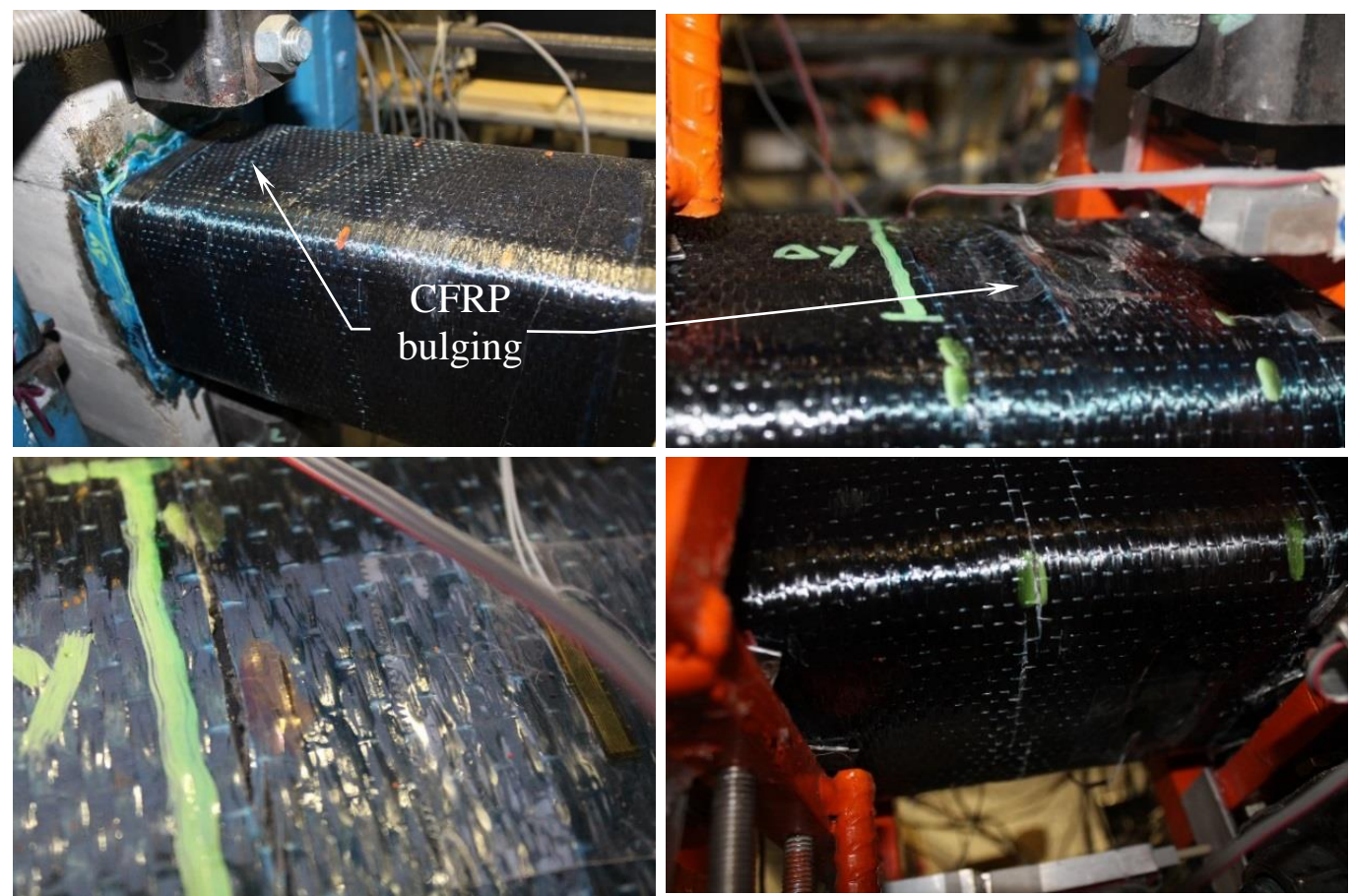

Figure 5.19: for Views of Bulging and Flexural Cracks at the CFRP Retrofit Region, Specimen Retrofit-C01-0.4 

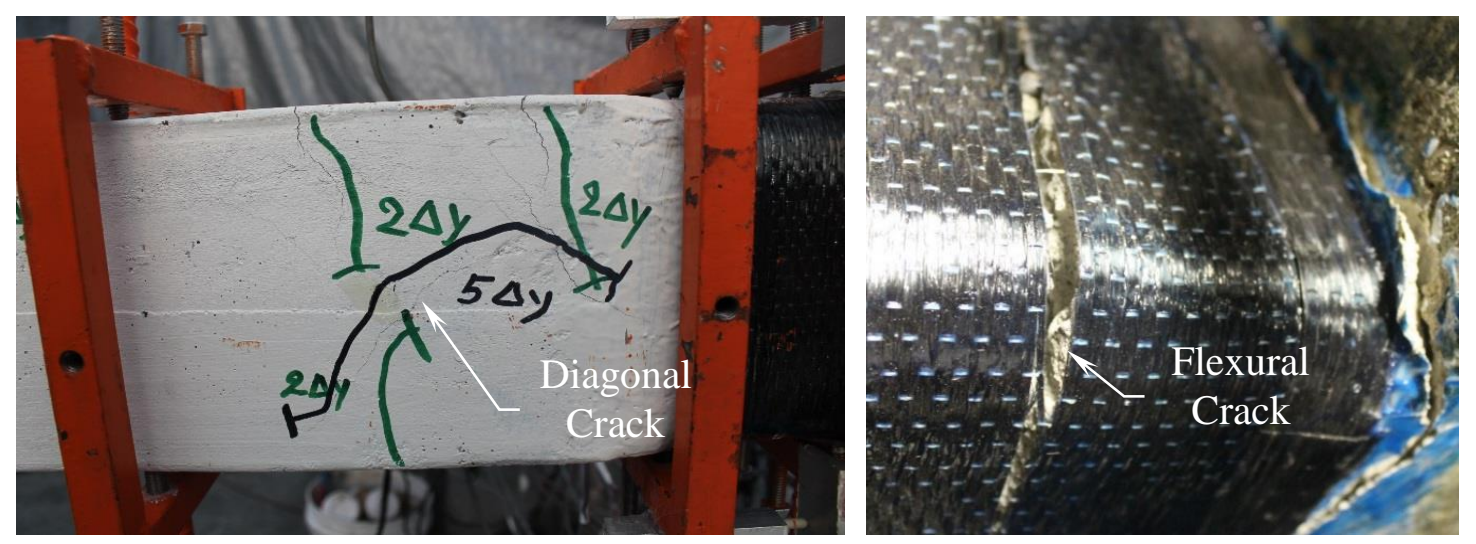

Figure 5.20: Diagonal Cracks and Large Flexural Cracks, Specimen Retrofit-C01-0.4

\subsubsection{Specimen Retrofit-C11-0.2}

In addition to the lateral CFRP retrofit, a 4-inches longitudinal CFRP strip was mounted along the column, and a proposed CFRP anchor was used to anchor the CFRP to the stub, as shown in Fig. 5.21. A low axial load level, $0.2 A_{g} f_{c}^{\prime}$, was gradually applied to the column. Fig. 5.22, illustrates the hysteresis loops of $(V-\Delta)$ for the Specimen Retrofit-C11-0.2. At the end of the last cycle of the first increment, $\pm V_{y} / 2=1.45$ kips, very tiny cracks were observed at the column-stub intersection. 

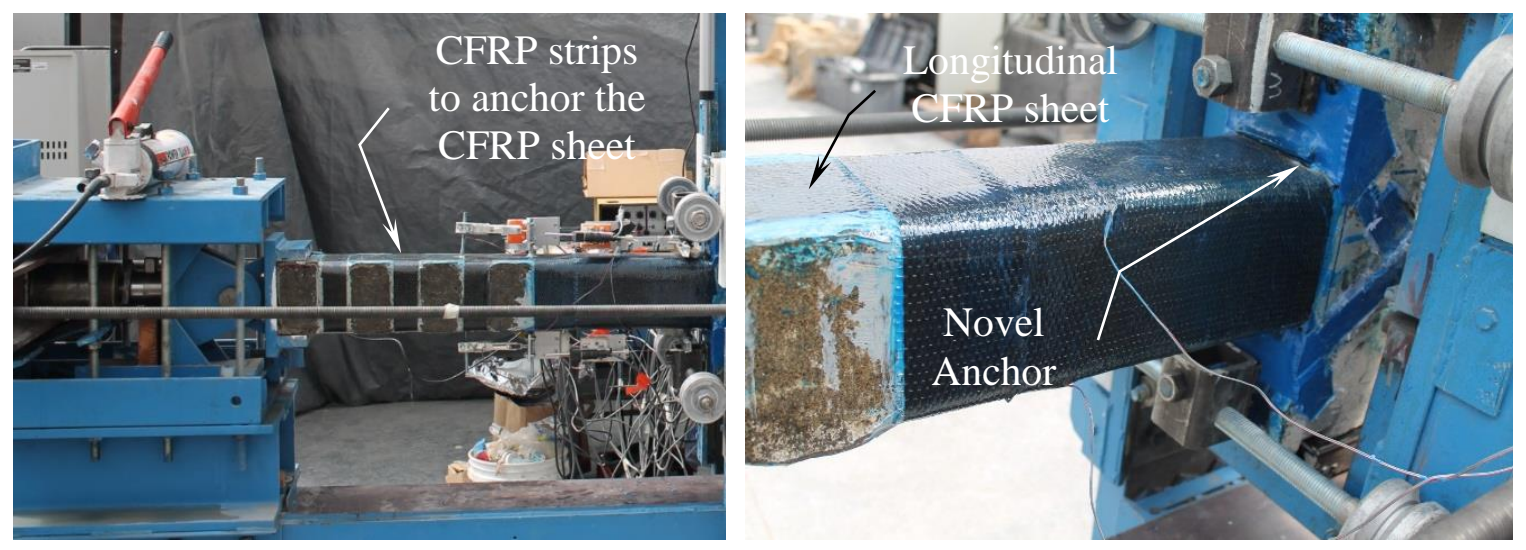

Figure 5.21: Specimen Retrofit-C11-0.2

To obtain the second level of the cyclic protocol, the lateral load was increased up to the limit when the longitudinal steel rebar yielded, $+V^{\prime}{ }_{y}=2.94$ kips and $\Delta y^{\prime}=0.72$ inch. In this case, $M_{n}$ was calculated at the limit where the longitudinal CFRP ruptured, therefore, the ideal yielding displacement was calculated as $\Delta y=0.71$ inches and $\varphi y=$ 0.017. Fig. 5.23 illustrates a few small flexural cracks that were concentrated at the column-stub intersection at the end of the last cycle of this level. Up to this point, the longitudinal CFRP sheet and the CFRP anchor performed well with a stable cyclic tension-compression action without any sign of degradation or damage. For the third increment, the first cycle was loaded up to the longitudinal CFRP rupture in tension side, $+V_{\max }=3.36 \mathrm{kips}$. At this point, the CFRP ruptured with very a loud noise. After it was unloaded, the specimen was reloaded in the opposite direction up to the CFRP rupture on the other side, $-V_{\max }=3.25 \mathrm{kips}$, and was then unloaded again. The reason for following this process was to investigate the maximum strength and strain for the longitudinal CFRP strip on both sides. After this cycle, four cycles were loaded up 
to $\pm 2 \varphi y=0.034$. At this limit, a long crack, $\sim 2$ inches from the column-stub intersection, was observed on the CFRP retrofit region. It was found later that the longitudinal CFRP strip was ruptured at the same location as the long cracks. As the increment level was increased, the flexural cracks were concentrated at the location where the longitudinal CFRP strip ruptured, as shown in Fig. 5.25 through 5.27. The test was terminated at the end of the seventh increment, $\pm 6 \varphi \mathrm{y}=0.102$, and the specimen supported the axial load with stable cycles during the last 4-cycles. Moreover, up to the end of the test, the proposed CFRP anchor described in Chapter 4, performed well during the test without any sign of dislocation or damage. In order to investigate the damage in the longitudinal CFRP strip, the lateral CFRP confinement was removed. It was observed that the large flexural crack was concentrated just above the base stub approximately 2 inches from the column-stub intersection where the longitudinal CFRP ruptured, as shown in Fig. 5.28. The concentration of the damage just above the stub was attributed to the confinement provided by the stub (Paultre, Légeron, \& Mongeau, 2001; Sungjin Bae \& Bayrak, 2008b). 


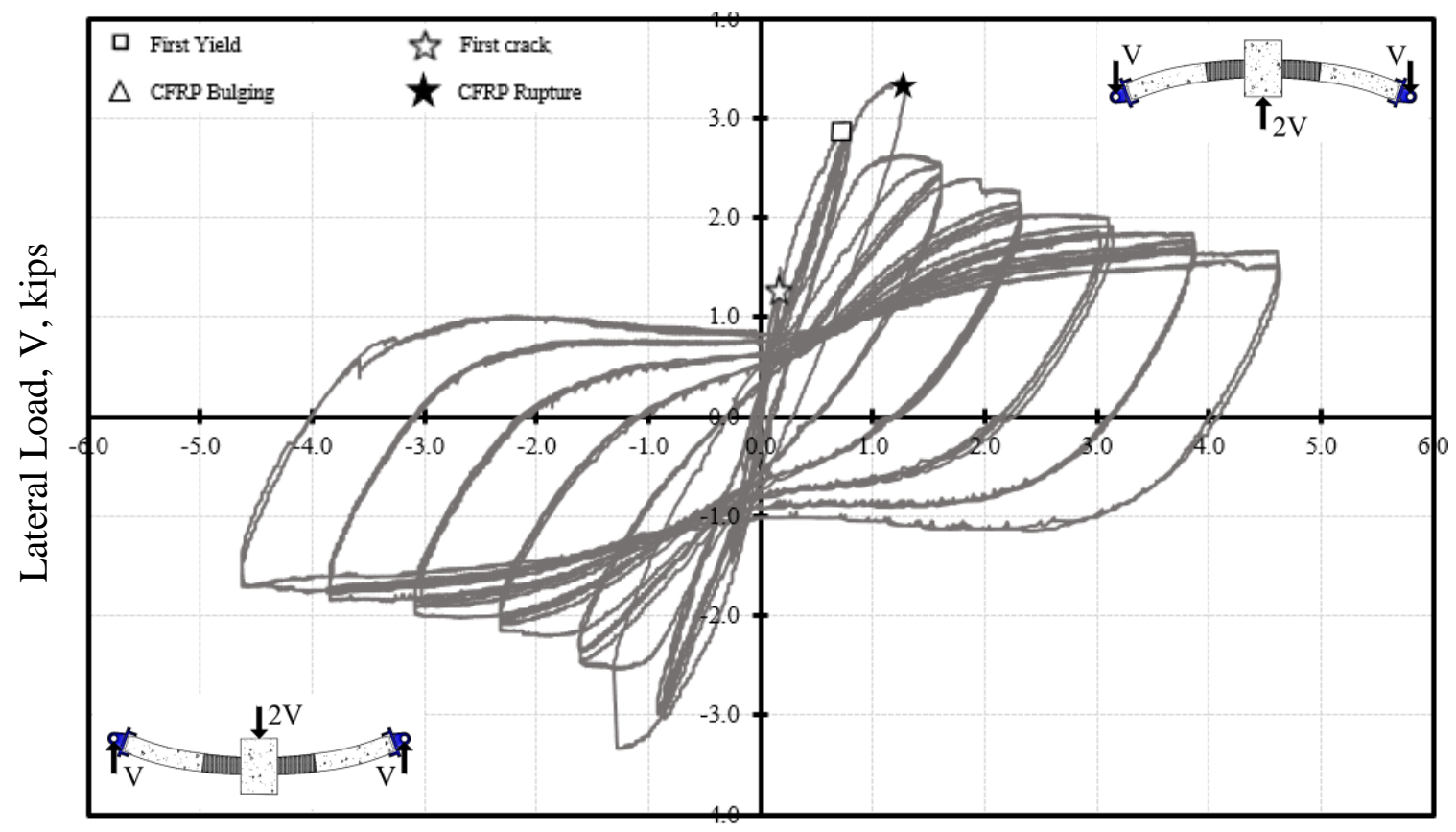

Lateral displacement, $\Delta$, in

Figure 5.22: the Hysteresis Loops Lateral Load vs. Lateral Displacement for Specimen Retrofit-C11-0.2
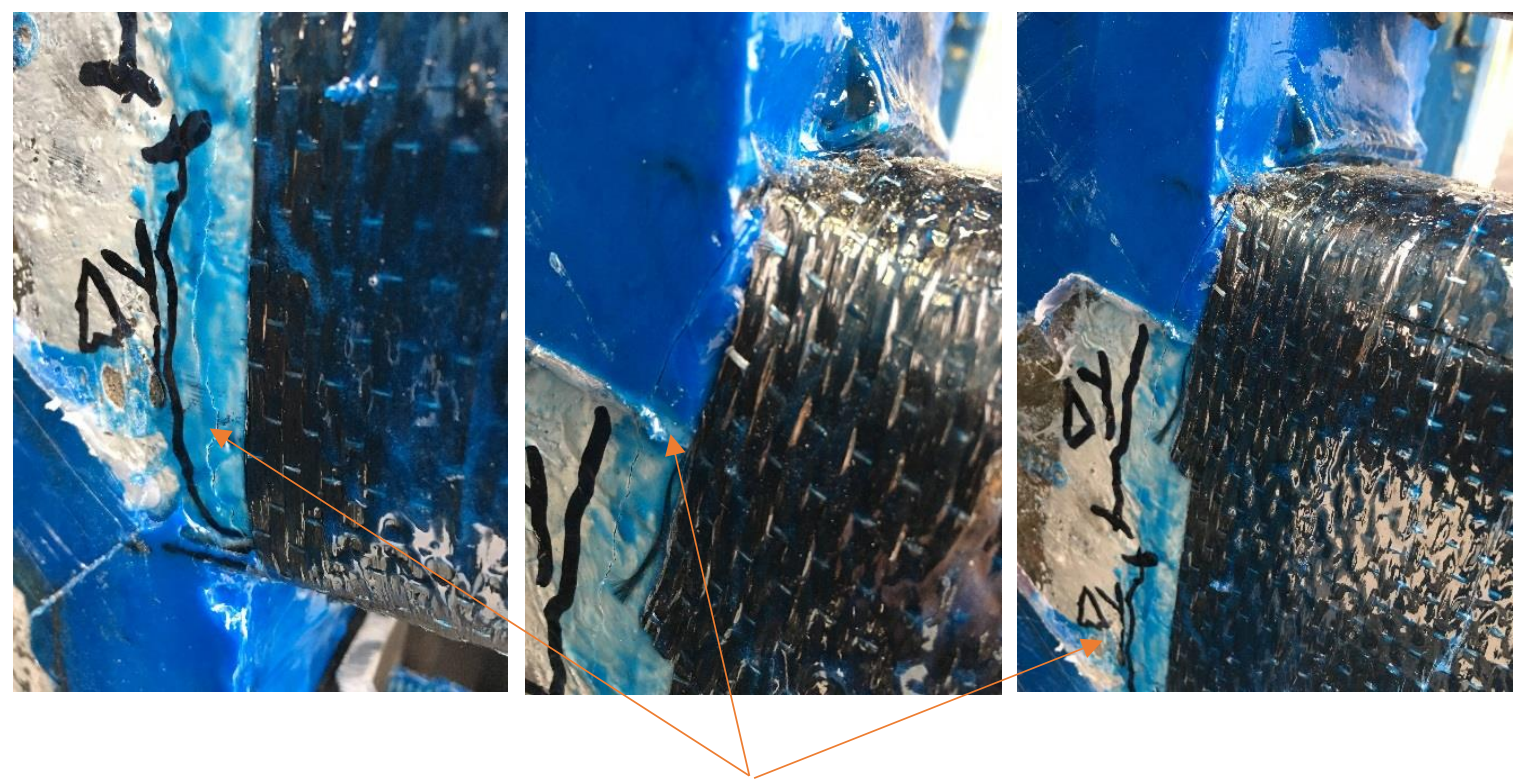

Figure 5.23: Cracks at Column-Stub Intersection, Specimen Retrofit-C11-0.2 


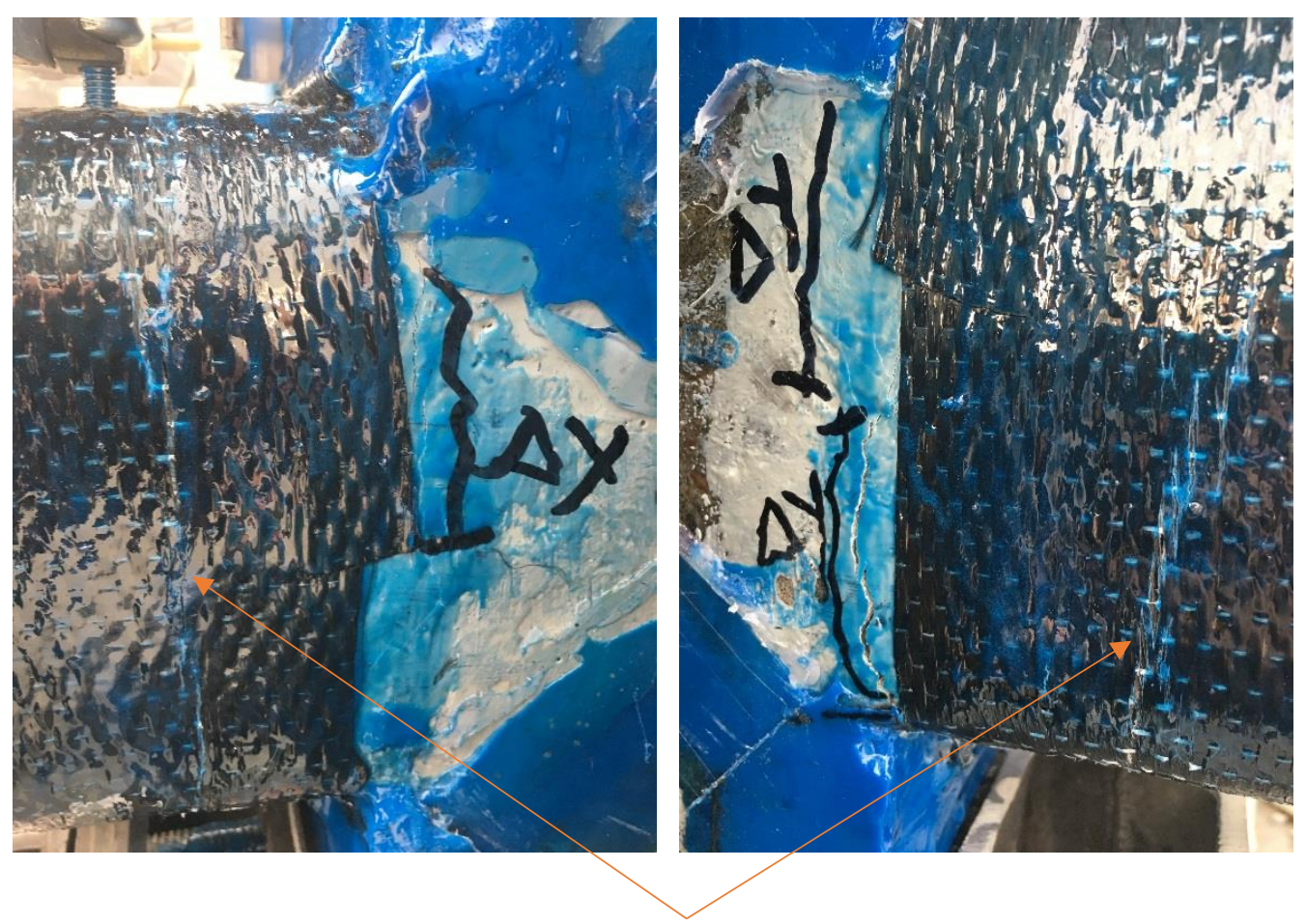

Figure 5.24: Long Cracks at CFRP Retrofit Region, Specimen Retrofit-C11-0.2
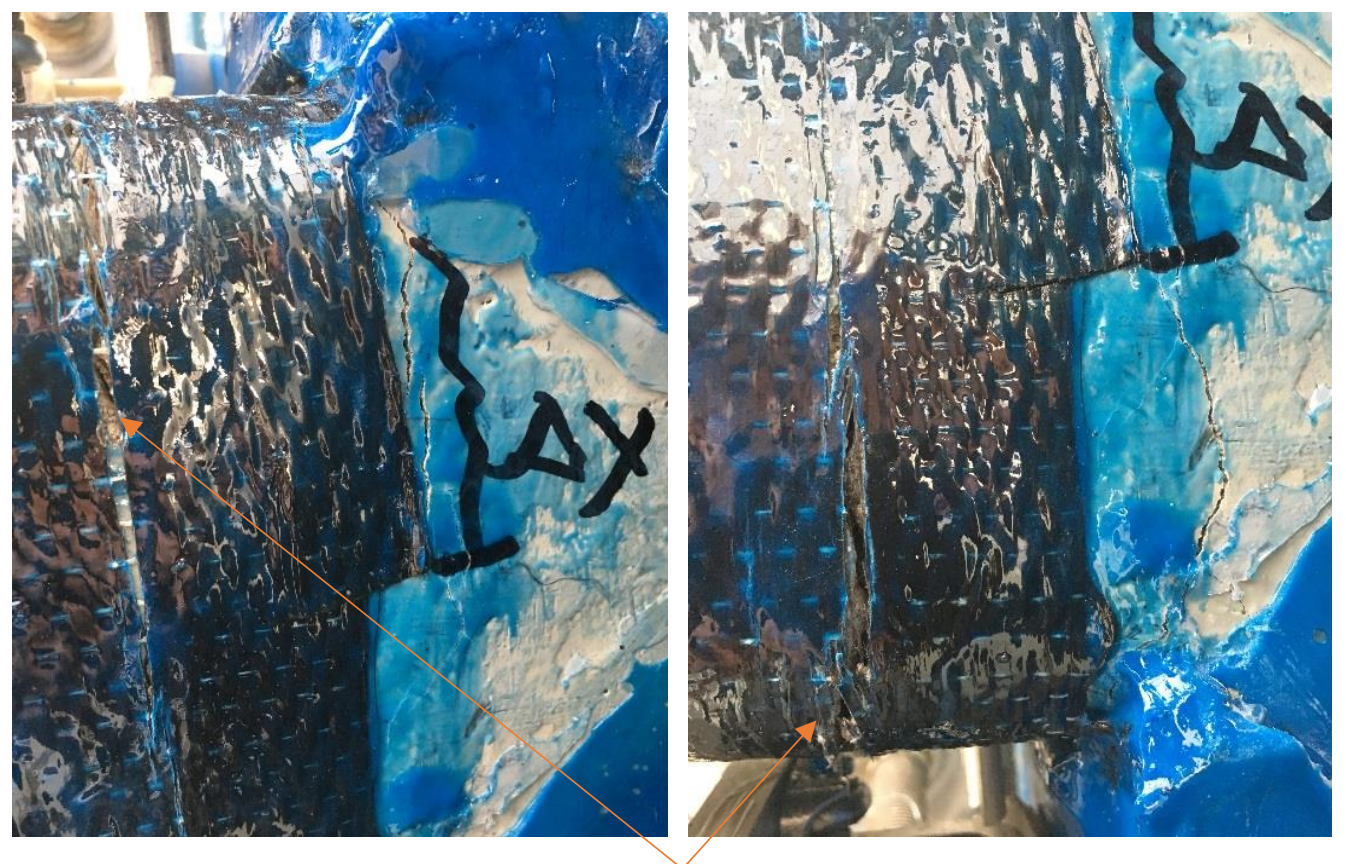

Figure 5.25: Cracks at the End of $\pm 4 \varphi y$, Specimen Retrofit-C11-0.2 

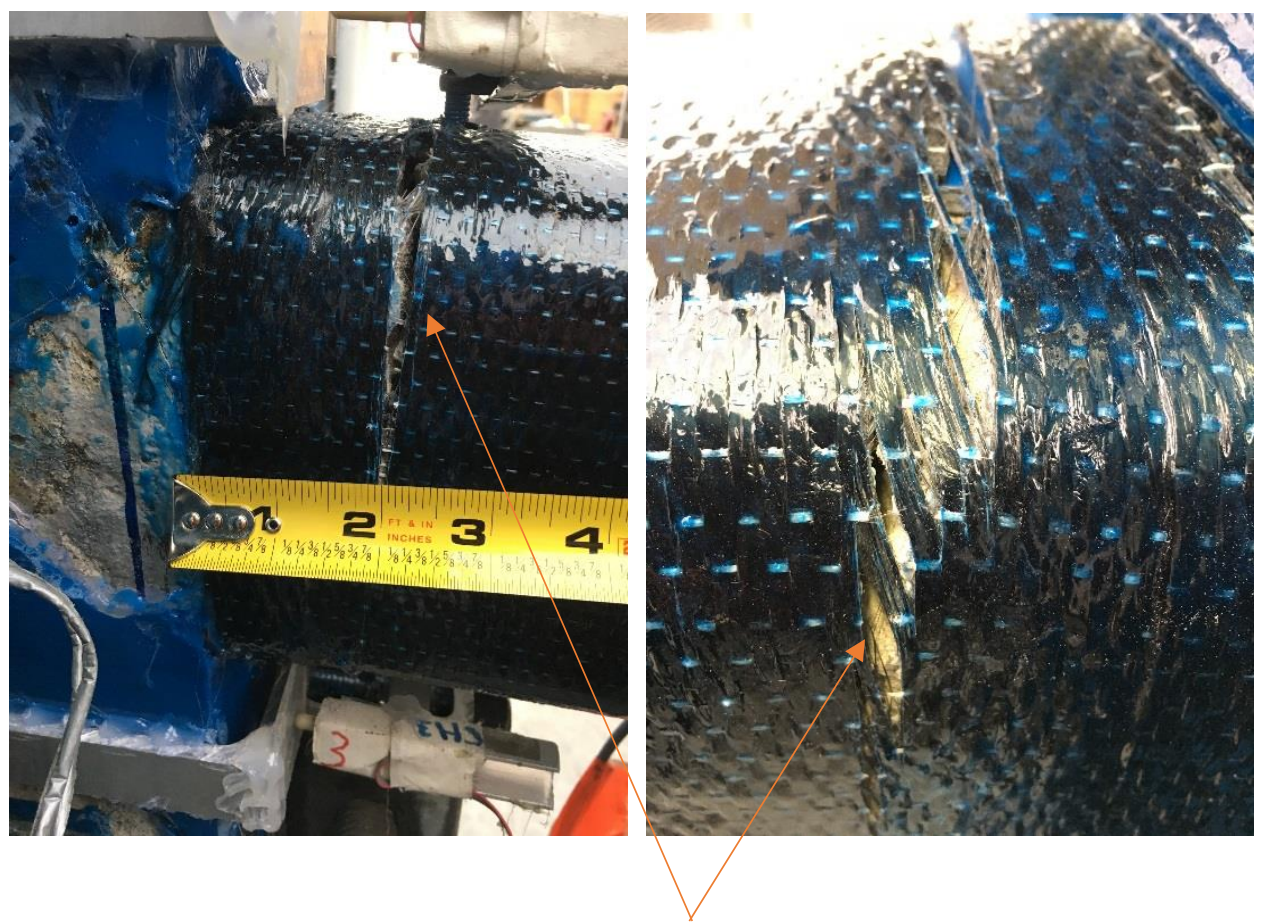

Figure 5.26: Cracks at the End of $\pm 5 \varphi \mathrm{y}$, Specimen Retrofit-C11-0.2
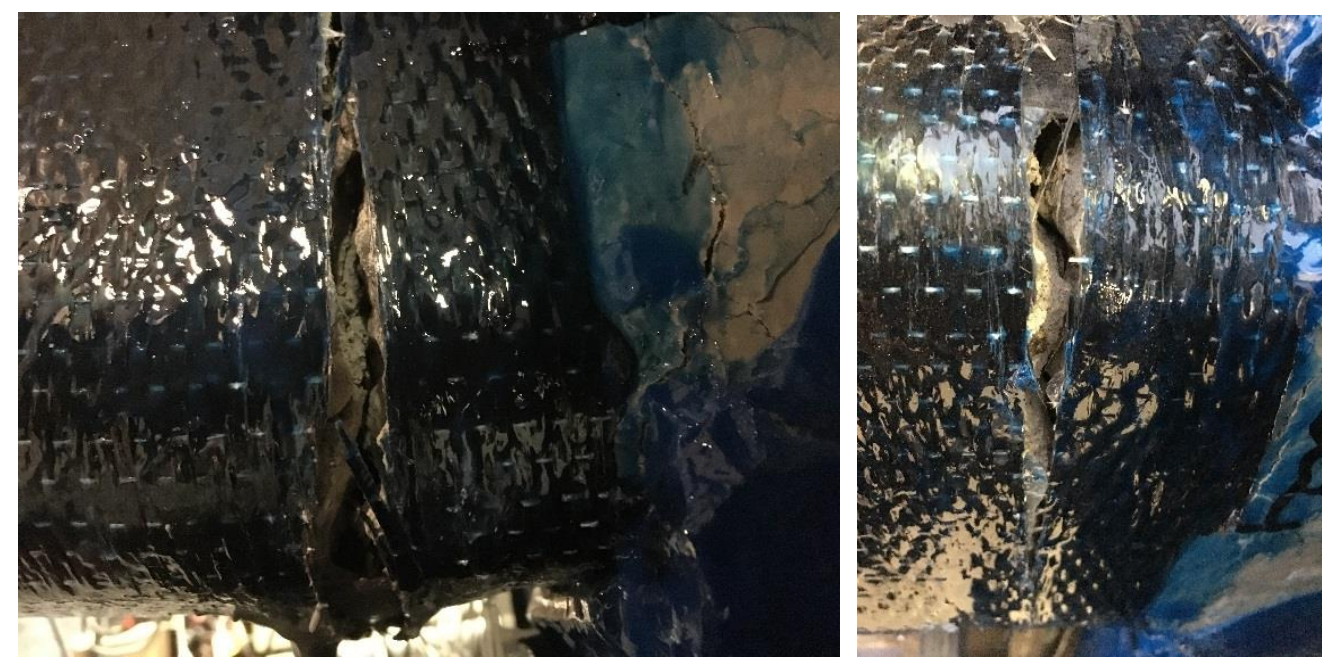

Figure 5.27: Cracks at the End of $\pm 6 \varphi y$, Specimen Retrofit-C11-0.2 

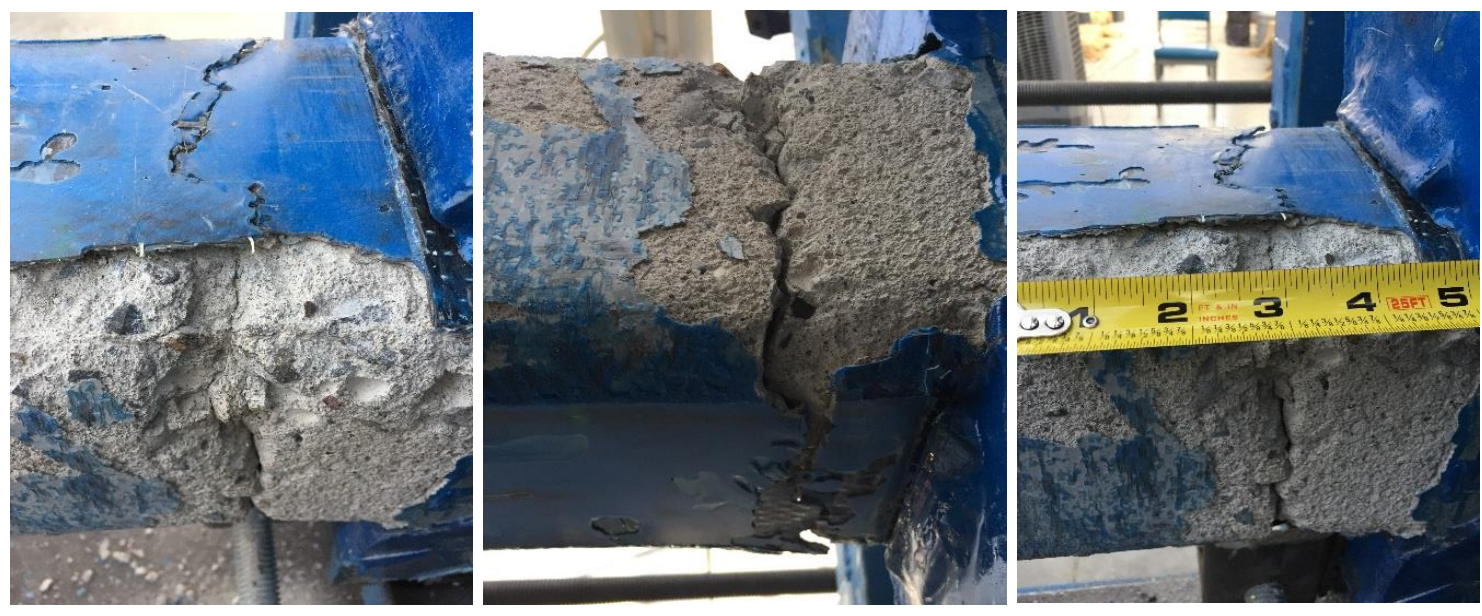

Figure 5.28: Longitudinal CFRP Rupture, Specimen Retrofit-C11-0.2

\section{$5.4 \quad$ Test Results}

This section discusses the overall experimental results of the retrofit and unretrofit specimens. Comparisons were made between the retrofit and un-retrofit specimens to quantify the effect of the retrofitting technique on improving the behavior of the specimens. Fig. 5.29 illustrates the backbone curves of the hysteresis loops lateral load vs. the lateral displacement for all tested specimens. The results will be discussed and compared in terms of flexural strength, elastic effective stiffness, $\mathrm{P}-\Delta$ effect, ductility, energy dissipation, and shear demand. 


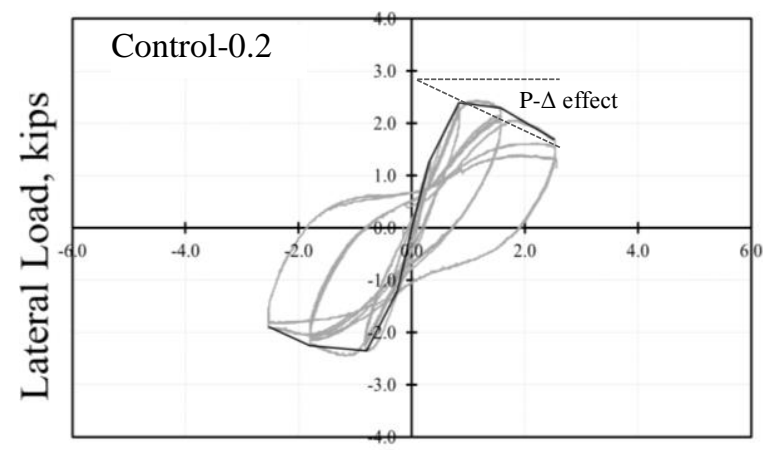

Lateral Displacement, in

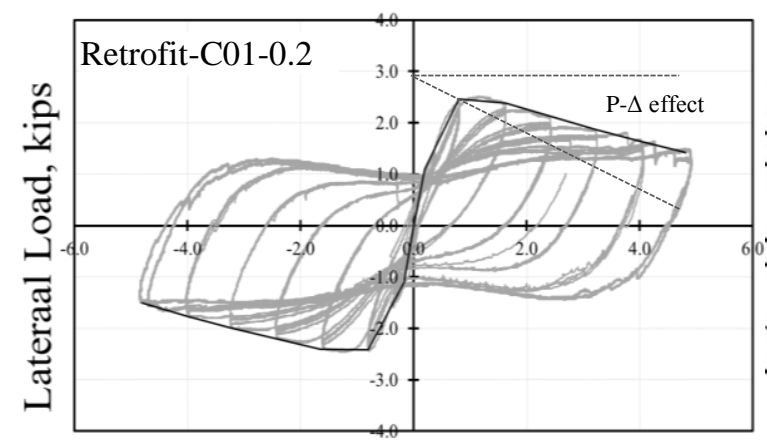

Lateral Displacement, in

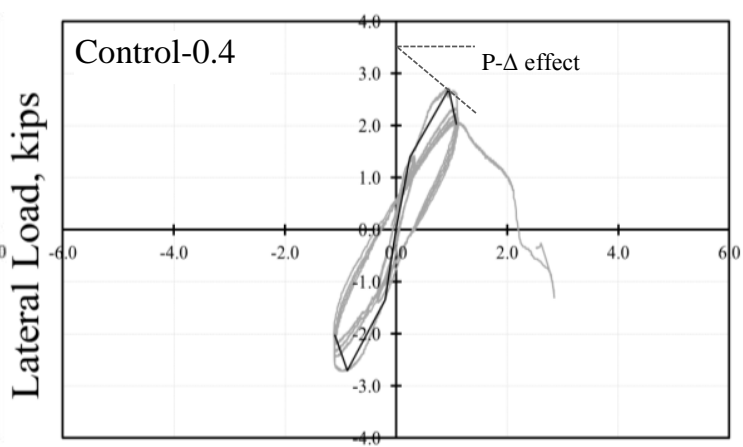

Lateral Displacement, in

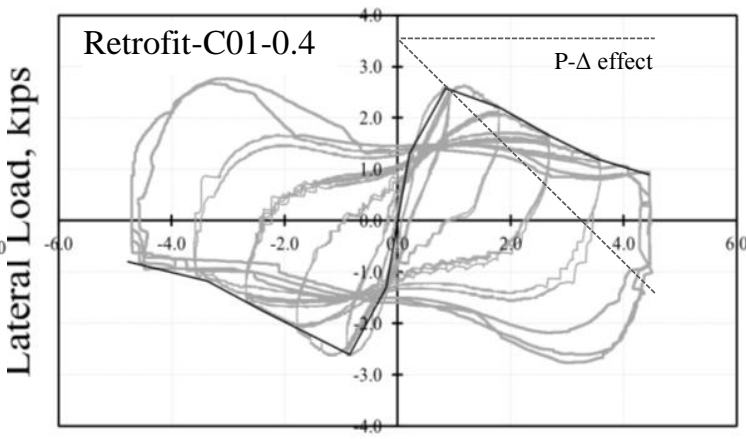

Lateral Displacement, in

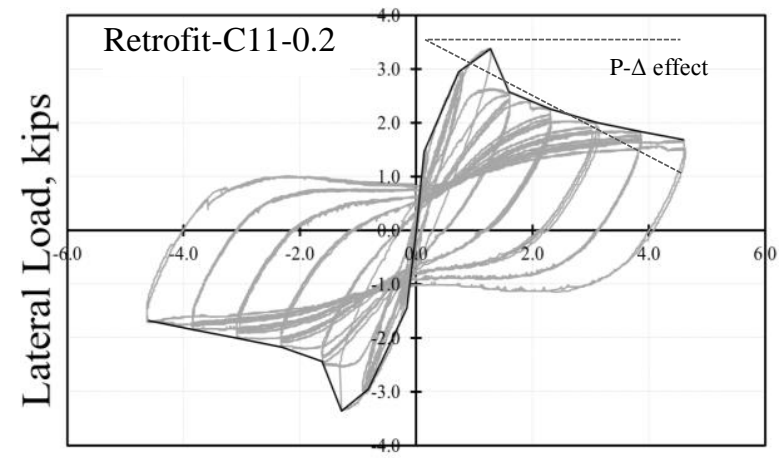

Lateral Displacement, in

Figure 5.29: Hysteresis Loops and Backbone Curves for the Specimens

\subsubsection{Flexural Strength}

For the tested specimens, except Rerofit-C11-0.2, it was observed that the flexural strength increased as the axial load increased from $0.2 A_{g} f_{c}^{\prime}$ to $0.4 A_{g} f_{c}^{\prime}$. Based on the cross-section analysis of the RC column, it is well known that increasing the axial load 
level up to the balance condition increases the moment capacity, as shown in Fig. 5.30. For the un-retrofit specimens, increasing the axial load level from $0.2 A_{g} f_{c}^{\prime}$ to $0.4 A_{g} f_{c}^{\prime}$ increased the flexural strength $10 \%$. For the retrofit specimens confined in the lateral direction only, no considerable effect was observed on the flexural strength compared with the un-retrofit specimens. Moreover, for the specimen that was retrofit in the longitudinal direction, the flexural strength was controlled by the amount of the CFRP material provided in the longitudinal direction. For the specimen Retrofit-C11-0.2, using the 4 - inchs CFRP strip increased the flexural strength 37\% compared with the control specimen Retrofit-C00-0.2.

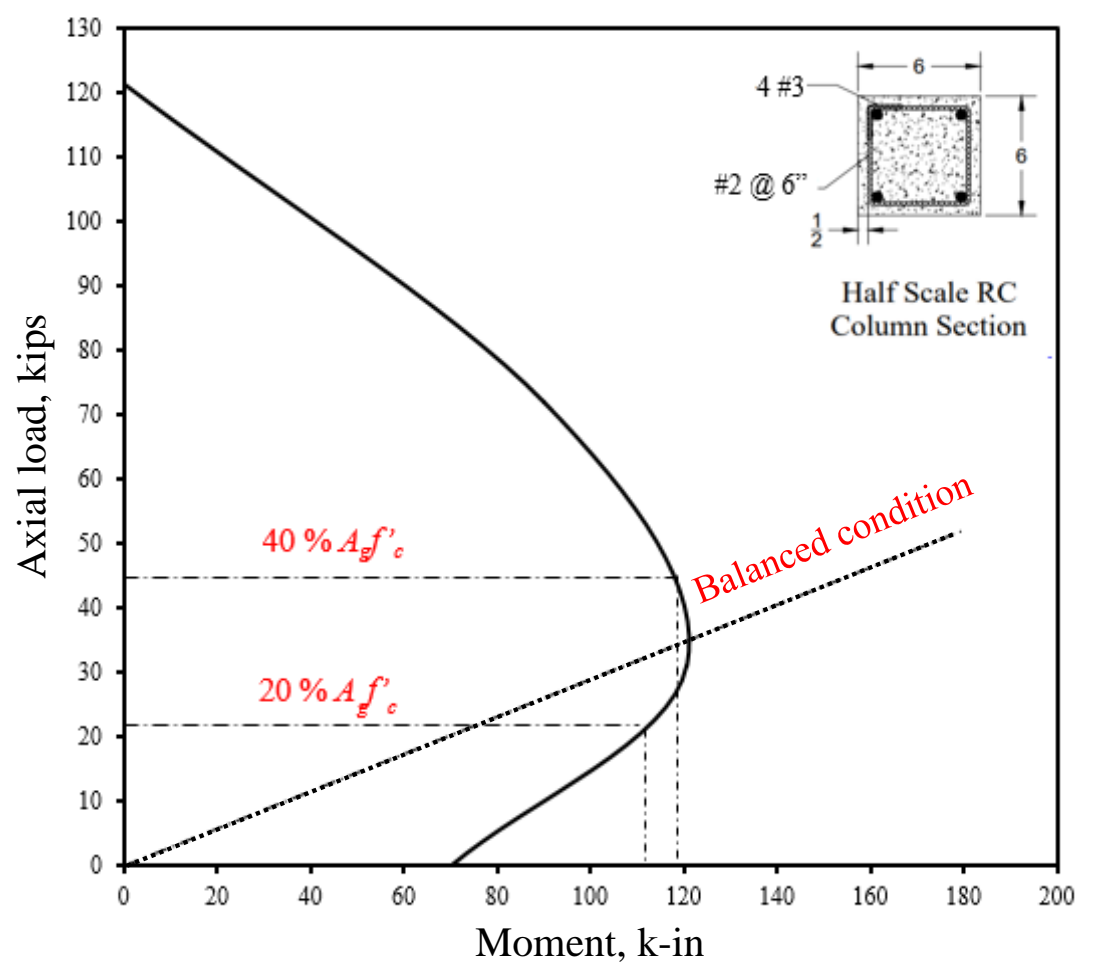

Figure 5.30: Interaction Diagram for the Specimen 


\subsubsection{Effective Stiffness}

The effective stiffness of the RC columns is an important parameter in the seismic analyses. The effective stiffness of the tested specimens was determined according to ACI Committee 374 (2013). Following the procedure described in Chapter 3, backbone curves of the moment-curvature were used to determine the $\mathrm{RC}$ column effective stiffness, $E I_{e f f}$. The experimental results for the effective stiffness were compared with a simple method that directly gives an estimation for the effective stiffness as proposed by Elwood et al. (2007) and adopted by ACI 369R-11 (2011); and ASCE/SEI41-13 (2013). For an RC column, this method completely depends on the axial load level. In order to apply this method, both the moment of inertia, $I_{g}$, of the cross-section and an approximation of the modulus of elasticity, $E_{c}$, for the RC column need to be calculated. The effective flexural stiffness of the RC column is calculated based on the following expression:

$$
E I_{e f f} / E_{c} I_{g}=\left[\begin{array}{cl}
0.3 & P / A_{g} f_{c}^{\prime} \leq 0.1 \\
P / A_{g} f_{c}^{\prime}+1 / 5 & 0.1<P / A_{g} f_{c}^{\prime}<0.5 \\
0.7 & P / A_{g} f_{c}^{\prime} \geq 0.5
\end{array}\right.
$$

Where $I_{g}$ and $E_{c}$ are calculated by using the following expression:

$$
\begin{gathered}
E_{c}=57000 \sqrt{f_{c}^{\prime}} \\
I_{g}=\frac{b h^{3}}{12}
\end{gathered}
$$


Table 5-1 shows the comparison between the experimental and predicted effective stiffness of the tested specimens. It is very important to note that Eq. 5.2 does not take into account the effect of retrofit on stiffness, hence marked as "NA", i.e., not applicable.

Table 5-1: Effective Stiffness, Experimental and Calculated

\begin{tabular}{||c||c||c||}
\hline $\begin{array}{c}\text { Specimen } \\
\text { Identification }\end{array}$ & $\begin{array}{c}\text { Effective Stiffness } \\
\text { (Experimental) kips-in }\end{array}$ & $\begin{array}{c}\text { Effective Stiffness } \\
\text { (ACI/ASCE) kips-in }{ }^{2}\end{array}$ \\
\hline \hline Control-0.2 & 148073 & 139295 \\
\hline Retrofit-C01-0.2 & 150317 & NA \\
\hline Retrofit-C11-0.2 & 276227 & NA \\
\hline Control-0.4 & 220233 & NA \\
\hline Retrofit-C01-0.4 & 223431 & 208942 \\
\hline \hline
\end{tabular}

Based on the experimental results, it was observed that the elastic stiffness for the specimens that were laterally retrofit with CFRP was somewhat larger than the un-retrofit (control) specimens. The contribution of the lateral CFRP in increasing the lateral stiffness compared with the un-retrofit specimens may have led to a small increase in the effective stiffness. The experimental results were slightly higher than the computed values based on ACI 369R-11 (2011). For the moment-resisting frame, the stiffness underestimation may lead to a high estimate for the displacement demand (Elwood et al., 2009). A more refined estimation of the effective stiffness was determined by including the contribution of the flexure, bar-slip, and shear on the lateral displacement (Kenneth J. Elwood; \& Marc O. Eberhard, 2009). 


\subsubsection{P- $\Delta$ Effect}

Fig. 5.29 illustrates the effect of the P- $\Delta$ on the inelastic response of the tested specimens. The oblique $\mathrm{P}-\Delta$ dotted line represents the decrease in the lateral strength due to $\mathrm{P}-\Delta$ effect, which increased as the lateral displacement was increased. Moreover, a strength loss due to critical events such as concrete spalling, the yielding or opening of the transverse reinforcement, or rebar buckling occurred when the response curve was under the $\mathrm{P}-\Delta$ line. However, a strength gain occurred when the response curve is above the P- $\Delta$ line. It is very clear that the CFRP retrofit technique increases the slender column strength in the inelastic range, which consequently helps to improve both the displacement ductility and stability limit, as discussed in $\mathrm{CH} 3$.

\subsubsection{Ductility}

The ductility of the tested specimens is discussed in the following sections in terms of curvature ductility and displacement ductility. In order to measure the curvature of the column during the cyclic test, eight LVDTs were mounted on both sides of the column as discussed previously. Two long LVDTs were mounted on the sides of the stub to measure the lateral displacement of the column, and to correct the stub rotation if any.

\subsubsection{Curvature Ductility}

Curvature ductility is the ratio of the ultimate curvature of a specific cross-section section to its yield curvature. LVDTs were used to capture the cross-section curvature. Fig. 5.31 illustrates the distribution of the LVDTs and the location of the mid-points 
where the average curvature was determined. The curvature was determined as the difference between two LVDT readings that were placed along the same gauge length on opposite faces of the column. The value of curvature thus determined was considered as the curvature at mid-point of the gauge length. Moreover, the variation of the curvature between two consecutive gauge lengths was assumed to be linear. The distribution of the average curvatures at the specific loading history along 20 "from the column-stub intersection is illustrated in Fig. 5.32 through 5.36. However, it is very important to mention that the accuracy of the curvature results was affected by large cracks at the LVDT's pin-supports when the specimen was close to failure. The curvature results for specimen Retrofit-C11-0.2 were discarded after the longitudinal CFRP ruptured, which caused a movement in the first row of the LVDT pin-supports and disturbed the LVDT readings. As expected for slender columns, the flexural response was dominated in the specimen throughout the test and the maximum curvature was concentrated at the plastic hinge regions. Furthermore, the large curvature close to the column-stub interface was affected by longitudinal reinforcement, bar-slip (pull out), and was captured by the first row of LVDTs. This curvature's reading was used to determine the amount of bar-slip length and bar-slip rotation. 


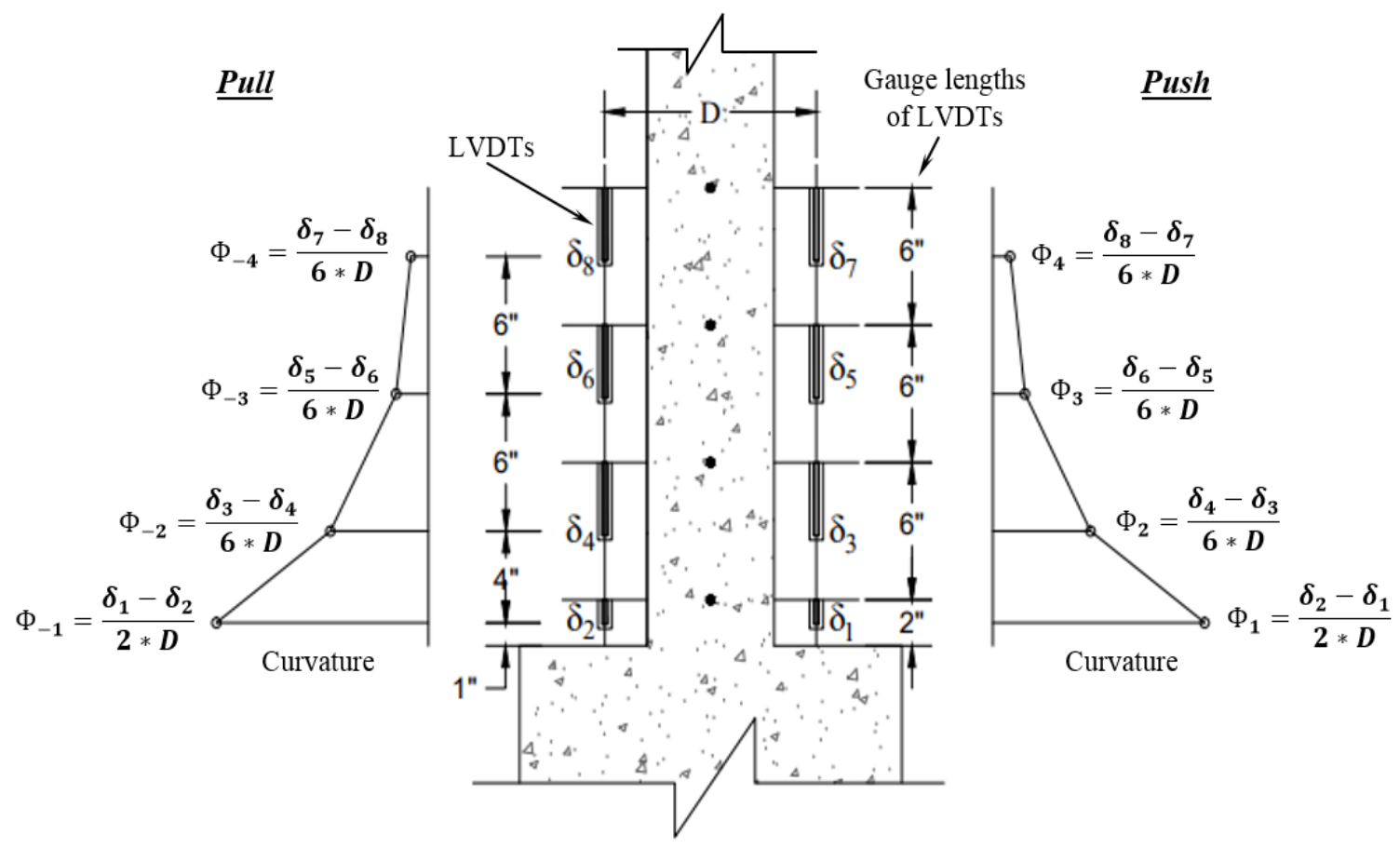

Figure 5.31: LVDTs and Mid-Point Locations

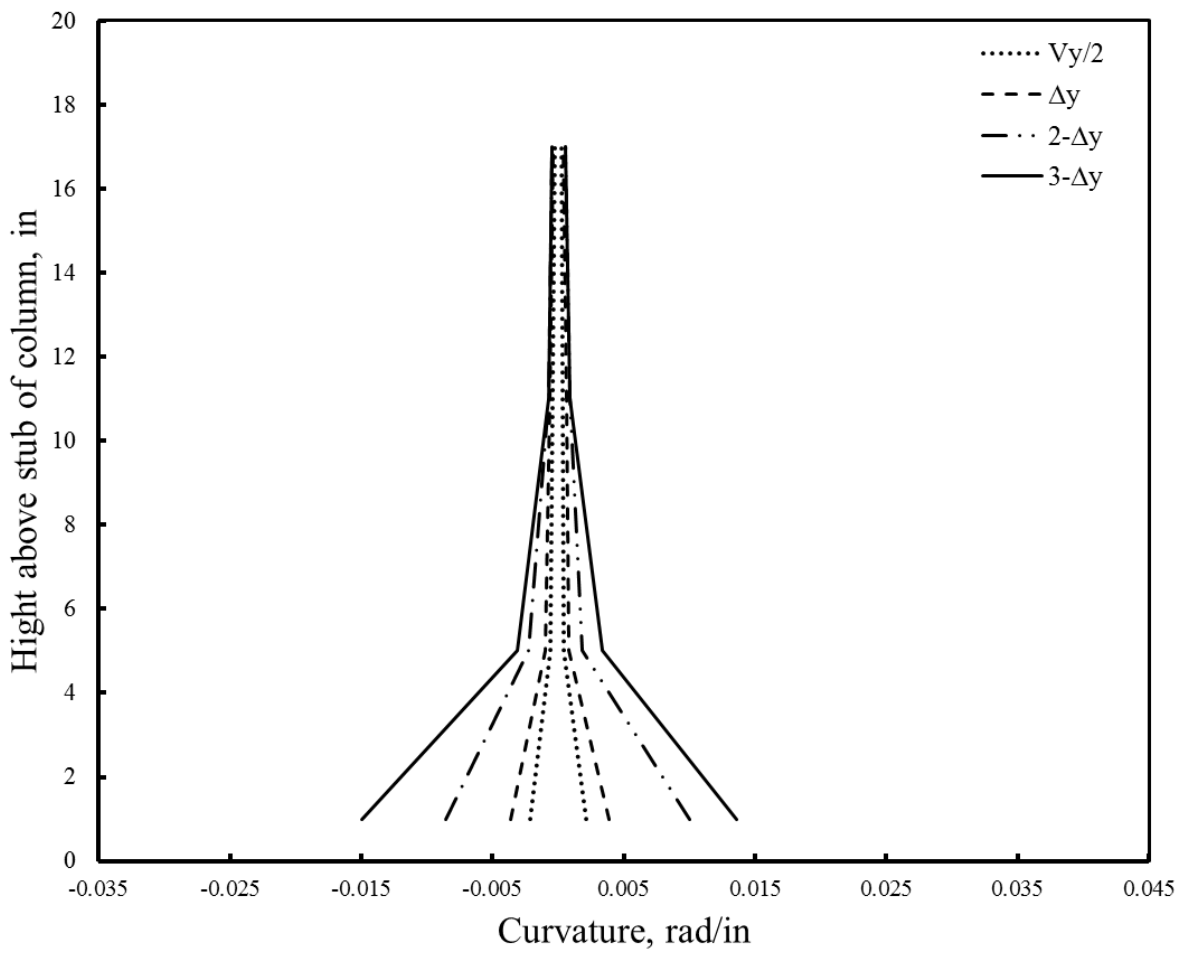

Figure 5.32: Curvature Distribution for Specimen Control-0.2 


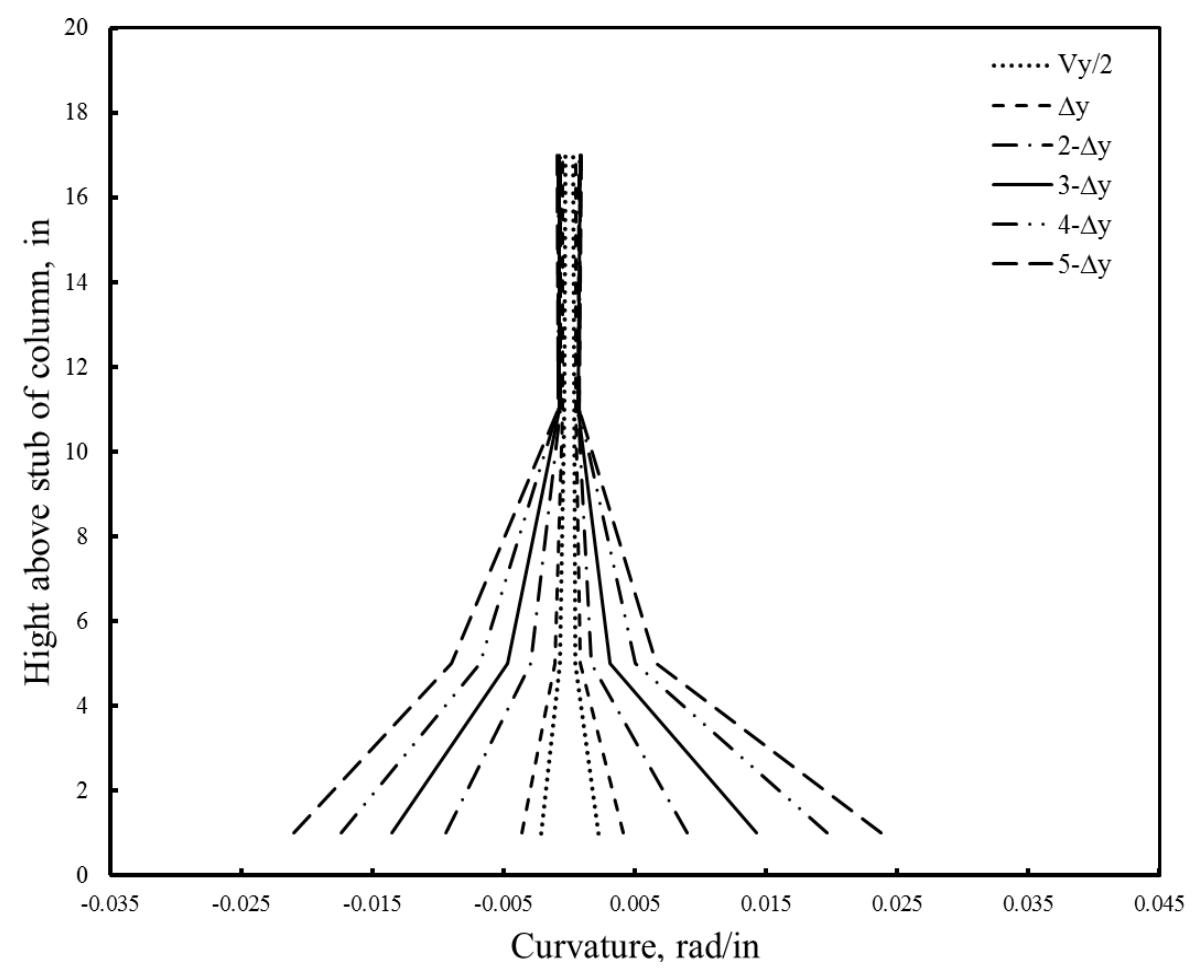

Figure 5.33: Curvature Distribution for Specimen Retrofit-C01-0.2

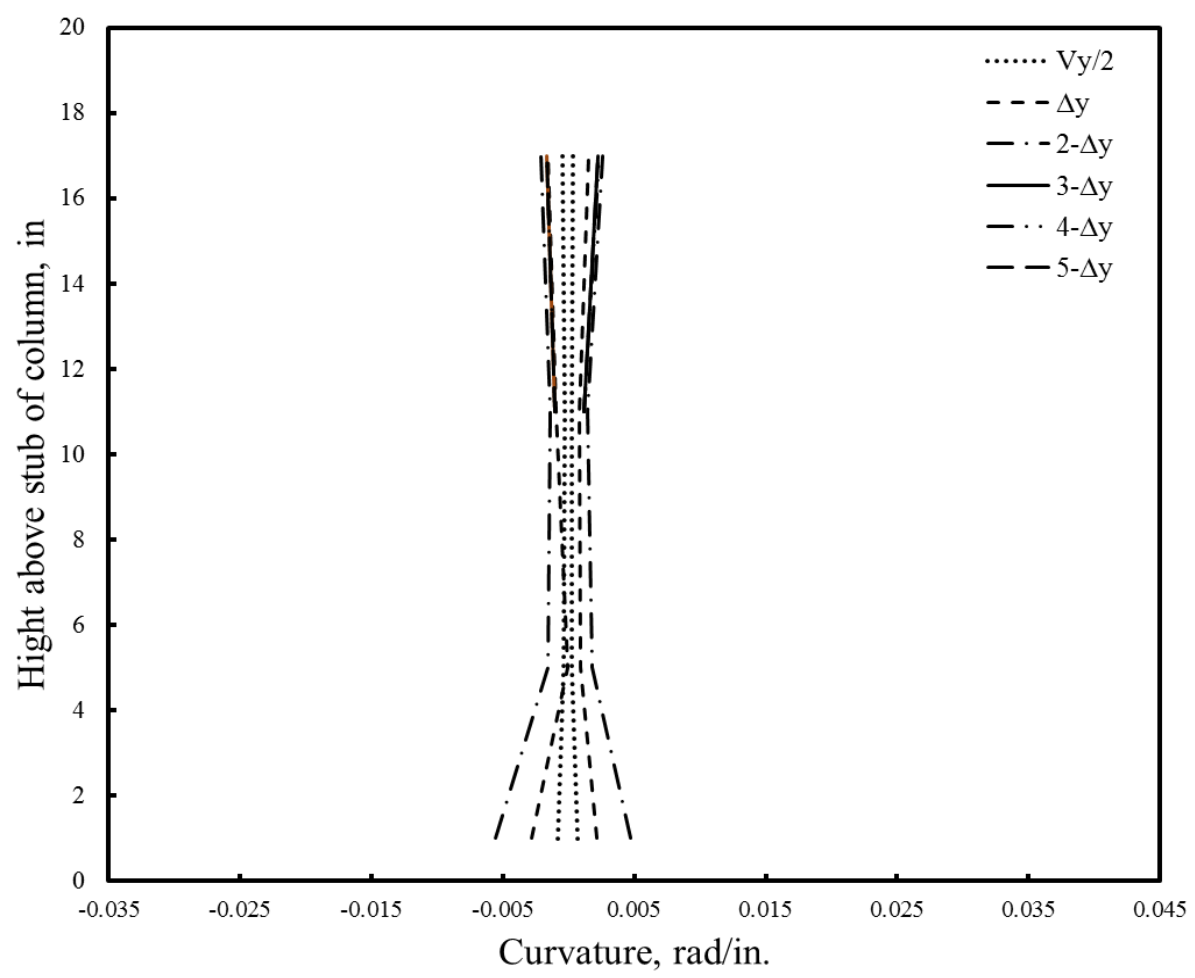

Figure 5.34: Curvature Distribution for Specimen Retrofit-C11-0.2 


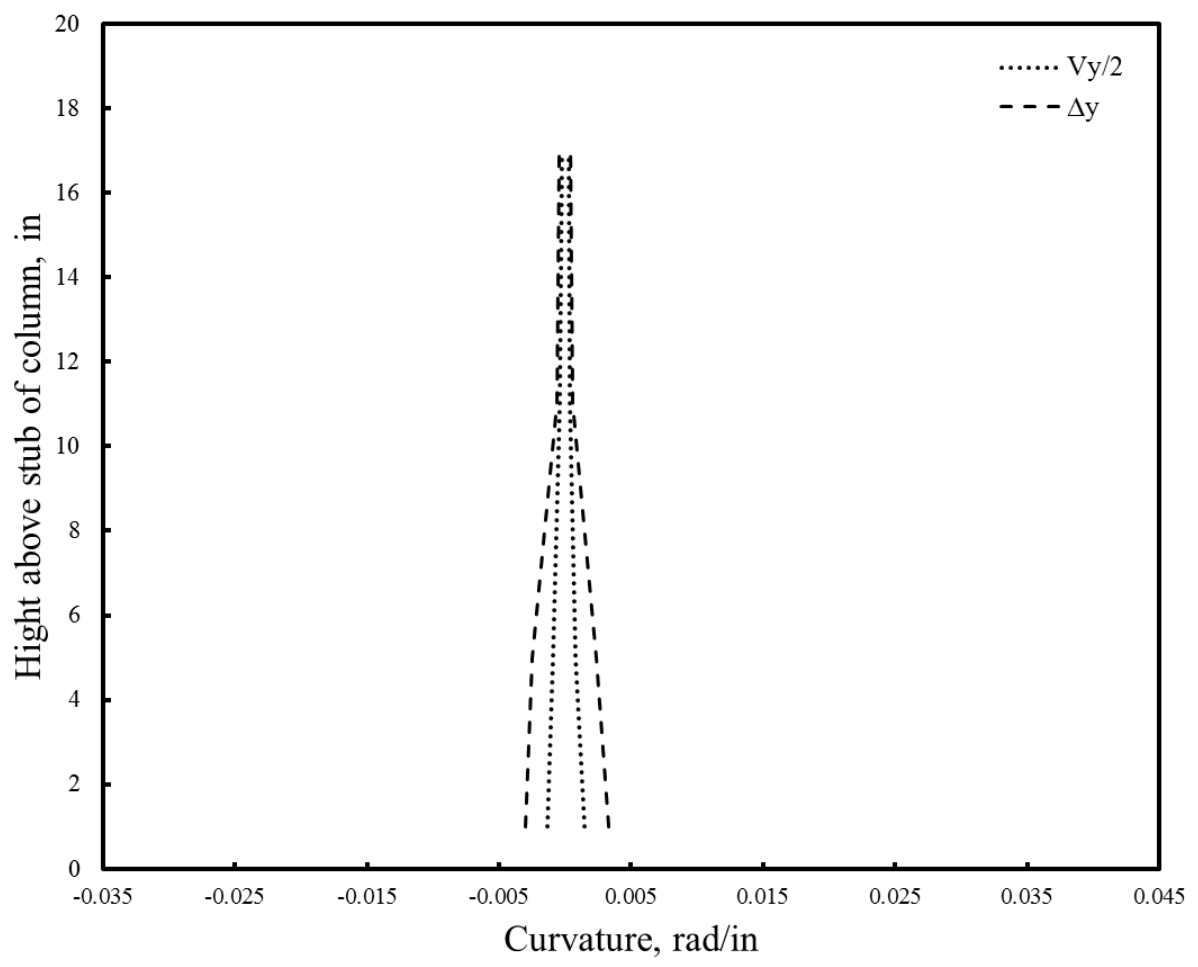

Figure 5.35: Curvature Distribution for Specimen Control-0.4

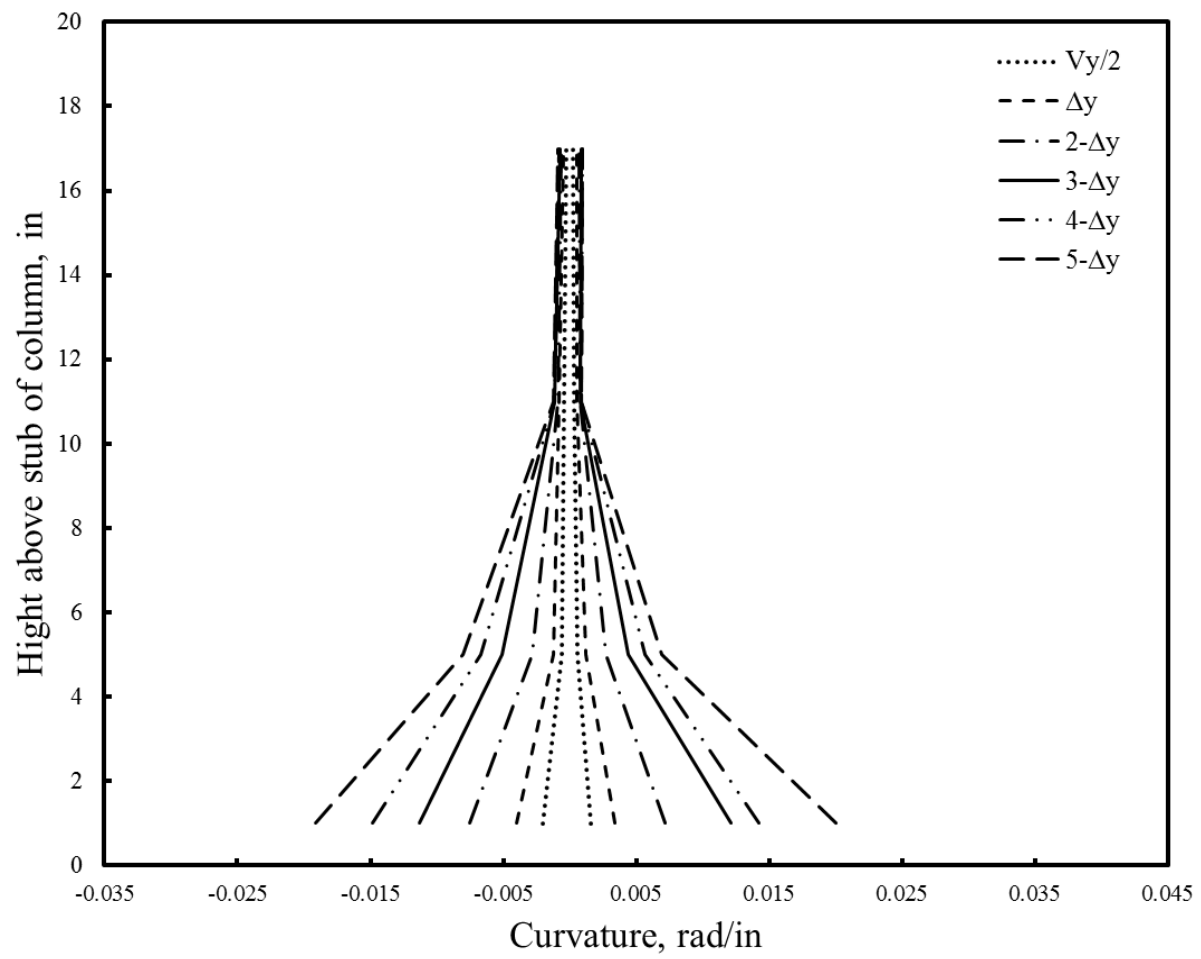

Figure 5.36: Curvature Distribution for Specimen Retrofit-C01-0.4 


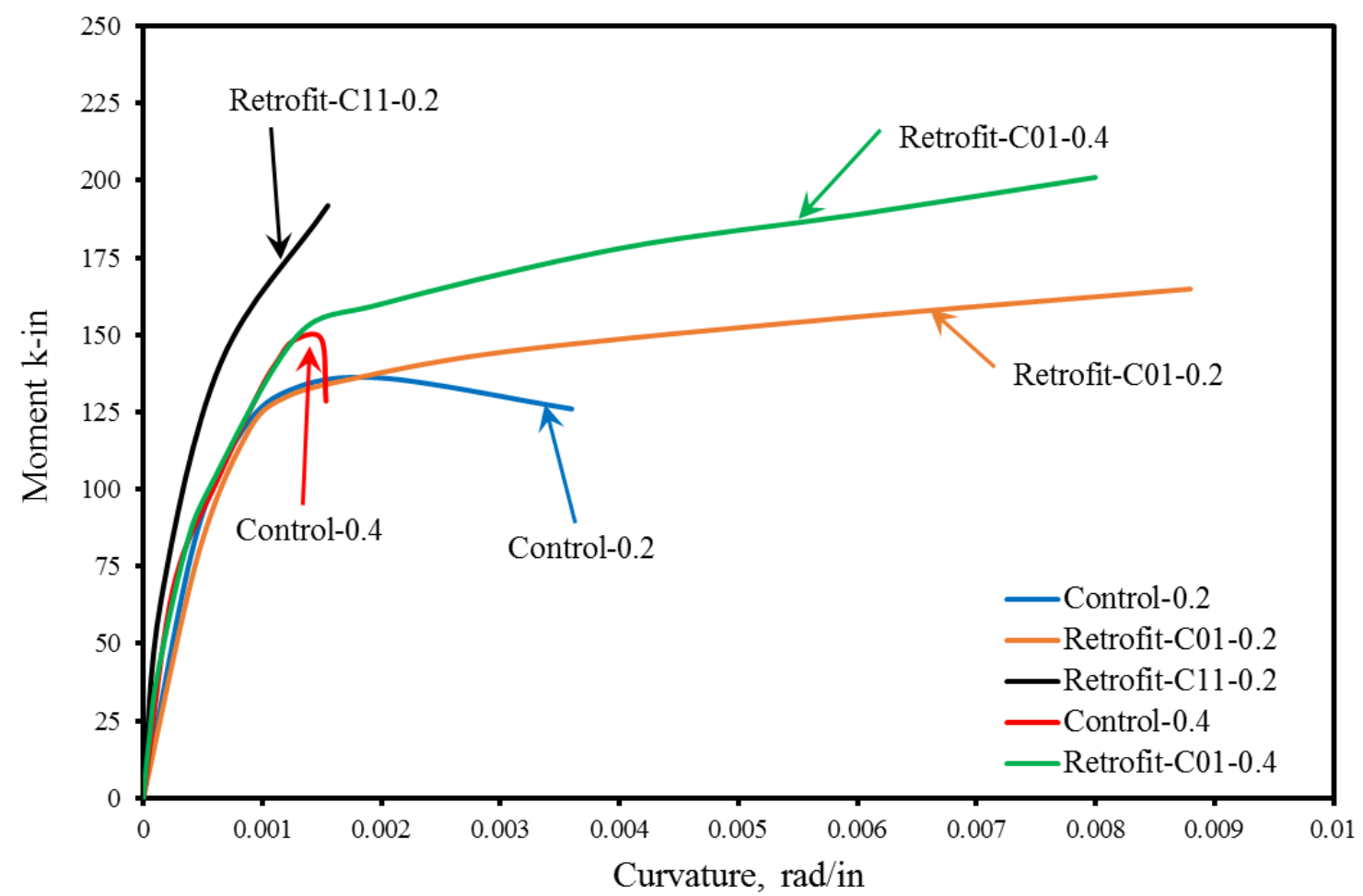

Figure 5.37: Backbone Curves for Moment Curvature

It is clear that in all cases, most of the flexural curvature was concentrated at the plastic hinge region where the maximum bending moment was affected. Fig. 5.37 illustrates a comparison between the backbone curves of the moment-curvature relationship of the specimens. To avoid the effect of the bar-slip at the column-stub intersection on flexural curvature, the yield curvature values for the specimens were determined based on the results of the second row of the LVDTs, $\delta_{3}$ and $\delta_{4}$, Fig. 5.31. For the un-retrofit specimens, Control-0.2 and Control-0.4, the ultimate curvature at failure was very small compared with the CFRP confined specimens. Confinement led to an increase in the compressive strain of the concrete, prevented the early concrete cover 
spalling, and delayed rebar buckle. The improvement in curvature capacity of the retrofit specimens was the direct result of increasing the confinement level.

\subsection{Yield Curvature}

Following the procedure previously described in Chapter 3, the yield curvature was calculated from the backbone curve, Fig 5.37. Table 5-2 shows the values of the yield curvature for all specimens, except Retrofit-C11-0.2. Based on the results, it was observed that the yield curvature increased as the axial load level was increased.

Increasing the axial load level led to an increase the depth of the compression zone at yield point, and consequently a larger curvature was required to yield the longitudinal steel in a specimen under moderate axial load compared with a specimen tested under low axial load.

Table 5-2: Determined Yield Curvature

\begin{tabular}{||c||c||}
\hline \hline $\begin{array}{c}\text { Specimen } \\
\text { Identification }\end{array}$ & $\begin{array}{c}\text { Yield Curvature } \\
\text { (Experimental) } \boldsymbol{\Phi}_{\boldsymbol{y}}\end{array}$ \\
\hline \hline Control-0.2 & 0.0008 \\
\hline Retrofit-C01-0.2 & 0.00088 \\
\hline Control-0.4 & 0.001 \\
\hline Retrofit-C01-0.4 & 0.00116 \\
\hline \hline
\end{tabular}

\subsection{Plastic Hinge Length}

During the test, the distribution of the moment varied along the length of the column and the maximum moment was concentrated at the region close to the column's base. Therefore, most of the damage occurred at this critical region, the plastic hinge region. Measuring the length of the plastic hinge region is important to connect the 
section behavior and curvature with overall behavior of the structural element and lateral displacement. The plastic hinge length depends on measuring the length of the region where the concrete experiences severe damage (Bae and Bayrak, 2008a). The existence of CFRP confinement prevents severe damage to the concrete. Moreover, some researchers (Hines, Restrepo, \& Seible, 2004; Pam \& Ho, 2009; Babazadeh, Burgueño, \& Silva, 2017) have observed that regions where the curvature was larger than the yield curvature fell inside the plastic hinge region, $l_{p}$. In this study, the plastic hinge length was measured based on the curvature profile of the specimens, as shown in Fig. 5.38. For all specimens, the values of the plastic hinge lengths are a little less than $2 \mathrm{~h}$ (12 inches) as specified for design (ACI 318, 2014).

According to the plastic hinge results, the effect of CFRP confinement on the plastic hinge region was small. This is consistent with Monti \& Nistico, 2001 and Binici, 2008. However, the effect of the CFRP confinement might be increased by increasing the thickness of the CFRP jacket. In this study, one layer of CFRP was used to retrofit the plastic hinge region, 14 inches from the column-stub intersection, therefore the data are not sufficient to judge the effect of CFRP on the plastic hinge region. The effect of increasing the axial load level was small, which is consistent with Paulay \& Priestley (1992) observations. 

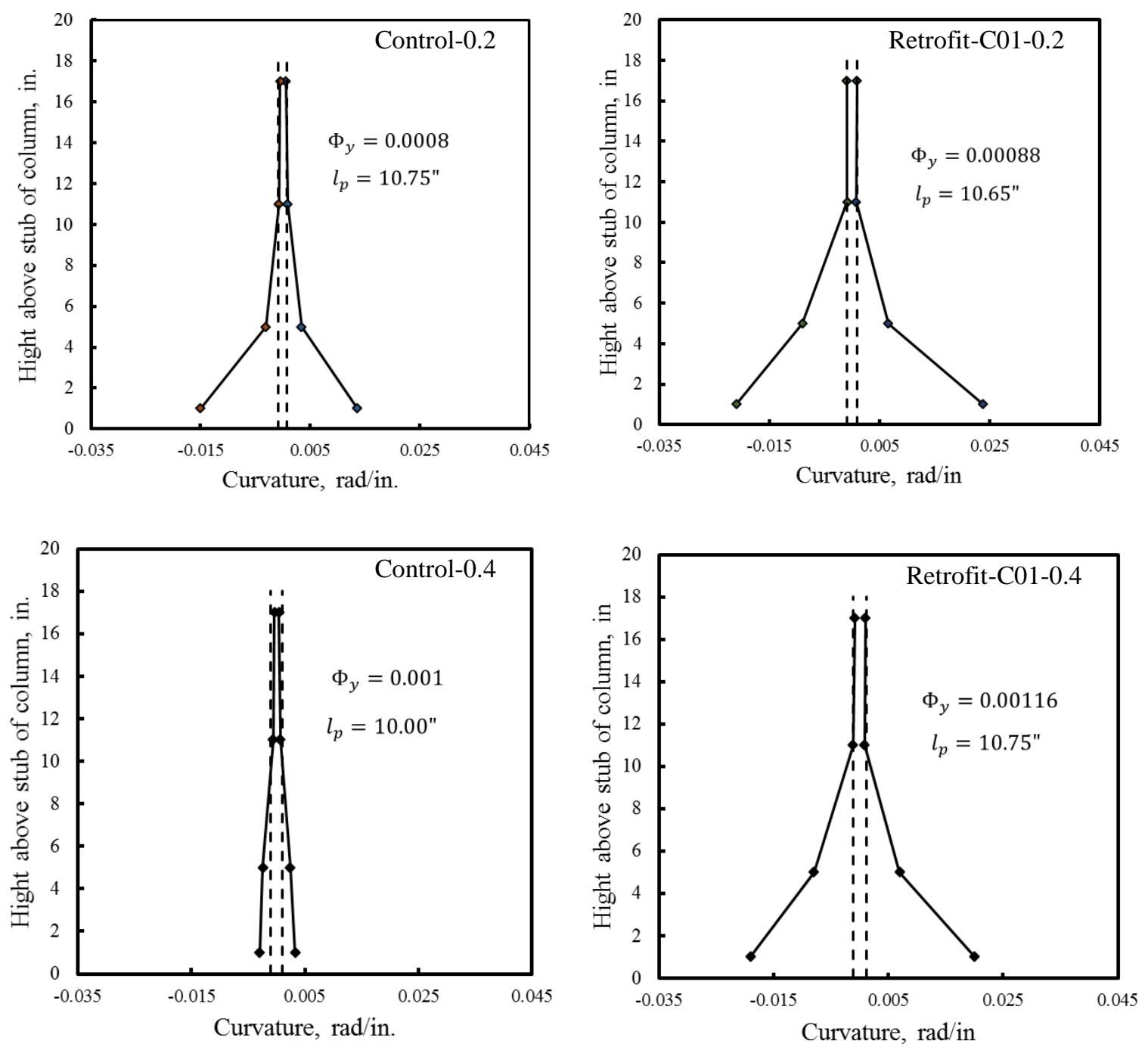

Figure 5.38: The Plastic Hinge Length

\subsection{Ultimate Curvature}

In this project, the ultimate curvature was determined based on the material strength limit or the loading frame capacity. Table 5-3 shows the ultimate curvature and the curvature ductility of the specimens at the plastic hinge regions. For the un-retrofit specimens Control-0.2 and Control-0.4, increasing the axial load level from $0.2 A_{g} f_{c}^{\prime}$ to 
$0.4 A_{g} f_{c}^{\prime}$ led to a reduction in the curvature ductility of the concrete section by $71 \%$. Under a moderate axial load, concrete cover of the column experienced high axial compressive stress under a low curvature compared with specimens tested under a low axial load. Moreover, the early damage of the concrete cover and large spacing between the transverse reinforcement of the specimen Control-0.4 caused the buckling of the longitudinal reinforcement at the plastic hinge region and a drop in the axial load capacity. However, CFRP confinement overcame the crushing of the concrete cover and the longitudinal reinforcement buckling, and consequently improved the concrete section ductility. It is important to mention that the curvature ductility of the specimens RetrofitC01-0.2 and Retrofit-C01-0.4 were determined up to the termination of the test, which was when the loading frame reached its capacity. The curvature ductility of the retrofit specimens Retrofit-C01-0.2 and Retrofit-C01-0.4 were improved by $47 \%$ and $77 \%$ respectively, as compared to the control specimens. For the Retrofit-C11-0.2, the LVDT at the second row was moved after the longitudinal CFRP rupture. Therefore, the results was not discussed at this section. 
Table 5-3: Curvature Ductility of the Tested Specimens

\begin{tabular}{||c||c||c||c||}
\hline $\begin{array}{c}\text { Specimen } \\
\text { Identification }\end{array}$ & $\begin{array}{c}\text { Yield Curvature } \\
\text { (Experimental) } \boldsymbol{\Phi}_{\boldsymbol{y}}\end{array}$ & $\begin{array}{c}\text { Ultimate } \\
\text { Curvature } \boldsymbol{\Phi}_{\boldsymbol{u}}\end{array}$ & $\begin{array}{c}\text { Curvature } \\
\text { Ductility } \boldsymbol{\mu}_{\boldsymbol{\Phi}}\end{array}$ \\
\hline \hline Control-0.2 & 0.0008 & 0.0034 & 4.25 \\
\hline Retrofit-C01-0.2 & 0.00088 & $0.007^{*}$ & $7.95^{*}$ \\
\hline Retrofit-C11-0.2 & $\mathrm{NA}$ & $\mathrm{NA}$ & $\mathrm{NA}$ \\
\hline Control-0.4 & 0.001 & 0.00137 & 1.37 \\
\hline Retrofit-C01-0.4 & 0.00116 & $0.0068^{*}$ & $5.86^{*}$ \\
\hline \hline
\end{tabular}

* The ultimate curvature and curvature ductility were determined based on the limit of the loading frame capacity. NA= Not Available.

\subsubsection{Displacement Ductility}

Displacement ductility is defined as the ratio of the ultimate displacement to yield displacement. Fig. 5.39 illustrated the backbone curves for the lateral load versus lateral displacement of the tested specimens. The relation between the curvature ductility and displacement ductility depends on many factors including the level of axial load, shear span ratio, amount and details of the transverse reinforcement, and reinforcement ratio. Moreover, under high axial load, the secondary moment, $P-\Delta$, controls the available displacement ductility regardless of the large curvature ductility (Bae \& Bayrak, 2005). 


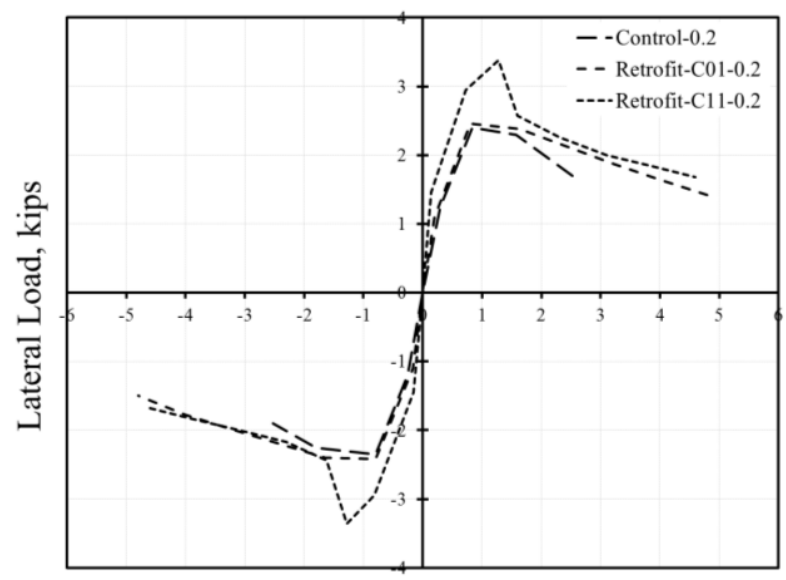

Lateral Displacement, in

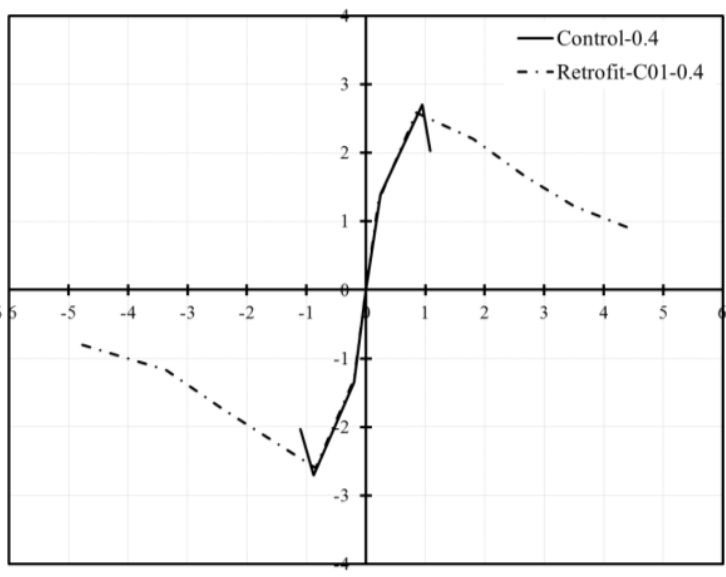

Lateral Displacement, in

Figure 5.39: Backbone Curves for the Tested Specimens

\subsection{Yield Displacement}

The yield displacement of the tested specimens was calculated based on the procedure described in Chapter 3. The backbone curves for the tested specimens were plotted for the positive forces vs. positive deformation as shown in Fig. 5.39. Following the procedure previously illustrated in Chapter 3, the values of the yield displacement were calculated. Table 5-4 shows the yield displacements from the experimental results. The effective stiffness of the laterally retrofit specimens are approximately the same as the control specimens, hence, retrofitting the column in the lateral direction did not affect the yield displacement. However, the specimen retrofit in lateral and longitudinal directions had a lager stiffness, hence a smaller yield displacement. 
Table 5-4: Yield Displacements of Specimens

\begin{tabular}{|c|c||}
\hline $\begin{array}{c}\text { Specimen } \\
\text { Identification }\end{array}$ & $\begin{array}{c}\text { Yield Displacement } \\
\text { (Experimental) } \Delta_{\boldsymbol{y}}, \text { in }\end{array}$ \\
\hline \hline Control-0.2 & 0.71 \\
\hline Retrofit-C01-0.2 & 0.69 \\
\hline Retrofit-C11-0.2 & 0.62 \\
\hline Control-0.4 & 0.75 \\
\hline Retrofit-C01-0.4 & 0.76 \\
\hline
\end{tabular}

The contribution of the bar-slip on the yielding displacement was determined based on the procedure illustrated in Chapter 3 . The length of the slip, $\delta_{\text {slip }}$ and slip rotation, $\theta_{\text {slip }}$ was measured during the test using two small LVDTs mounted 2 inches from the column-stub intersection, which was the first row of the LVDTs, $\delta_{1}$ and $\delta_{2}$. The experimental results of the bar-slip at the yield condition of the specimens was compared with the theoretical results obtained from Eq. 3.78 using $6 \sqrt{f_{c}^{\prime}}$ psi as a value for the expected bond stress, as recommended by Sozen, M.A.; Monteiro, P.; Moehle, J.P. \& Tang (1992). Table 5-5 illustrates the comparison between the theoretical and the measured results. Good agreement was observed for the measured and calculated results except for the results of the specimen Retrofit-C11-0.2, which had a slip length of $\sim 40 \%$ less than the other specimens. The longitudinal CFRP sheet was connected to the stub by embedding it with a CFRP rope anchor. This increased the integrity between the column and stub, which prevented development of a wide crack next to the column-stub intersection. It did this by distributing the increase in length due to bar-slip over a large distance. The contribution of the bar-slip on the yield displacement for the tested 
specimens, except Retrofit-C11-0.2, ranged between $43 \%$ to $51 \%$. This trend was consistent with the conclusion presented by Kwak; Kim; \& Kim (2004).

Table 5-5: Bar-Slip at Yield Point

\begin{tabular}{||l||c||c||c||c||c||c||}
\hline \hline $\begin{array}{c}\text { Specimens } \\
\text { Identification }\end{array}$ & $\begin{array}{c}\text { Exp. Length } \\
\text { of Slip, in }\end{array}$ & $\begin{array}{c}\text { Theo. Length of } \\
\text { Slip Eq. 3.78, in }\end{array}$ & $\begin{array}{c}\boldsymbol{\delta}_{\text {slip-exp. }} \\
\boldsymbol{\delta}_{\text {slip-theo. }}\end{array}$ & $\begin{array}{c}\boldsymbol{\theta}_{\text {slip }}, \text { rad } \\
\text { (At yield) } \\
\text { Exp. }\end{array}$ & $\begin{array}{c}\Delta_{\text {y.slip }}, \text { in } \\
\text { At yield) } \\
\text { Exp. }\end{array}$ & $\frac{\Delta_{\text {y.slip }}}{\Delta_{\boldsymbol{y}}}$ \\
\hline \hline Control-0.2 & 0.0275 & 0.0231 & 1.19 & 0.00744 & 0.32 & 43.2 \\
\hline Retrofit-C01-0.2 & 0.0255 & 0.0241 & 1.05 & 0.00785 & 0.33 & 45.8 \\
\hline Retrofit-C11-0.2 & 0.0146 & 0.0235 & 0.6213 & 0.004485 & 0.19 & 30 \\
\hline Control-0.4 & 0.0261 & 0.0232 & 1.125 & 0.0083 & 0.35 & 48.6 \\
\hline Retrofit-C01-0.4 & 0.0243 & 0.0235 & 0.91 & 0.0092 & 0.38 & 51 \\
\hline \hline
\end{tabular}

\subsection{Ultimate Displacement}

The ultimate displacement for the tested specimens was assessed based on limits provided in the literature to define the limit state of damage for the RC columns. In this study, the limit states include a $20 \%$ and $30 \%$ decay in the lateral strength and stability limit, as shown in Figs. 5.40, and 5.41, respectively. First, the results of Fig. 5.40 that shows displacement ductility based on lateral strength will be discussed. 

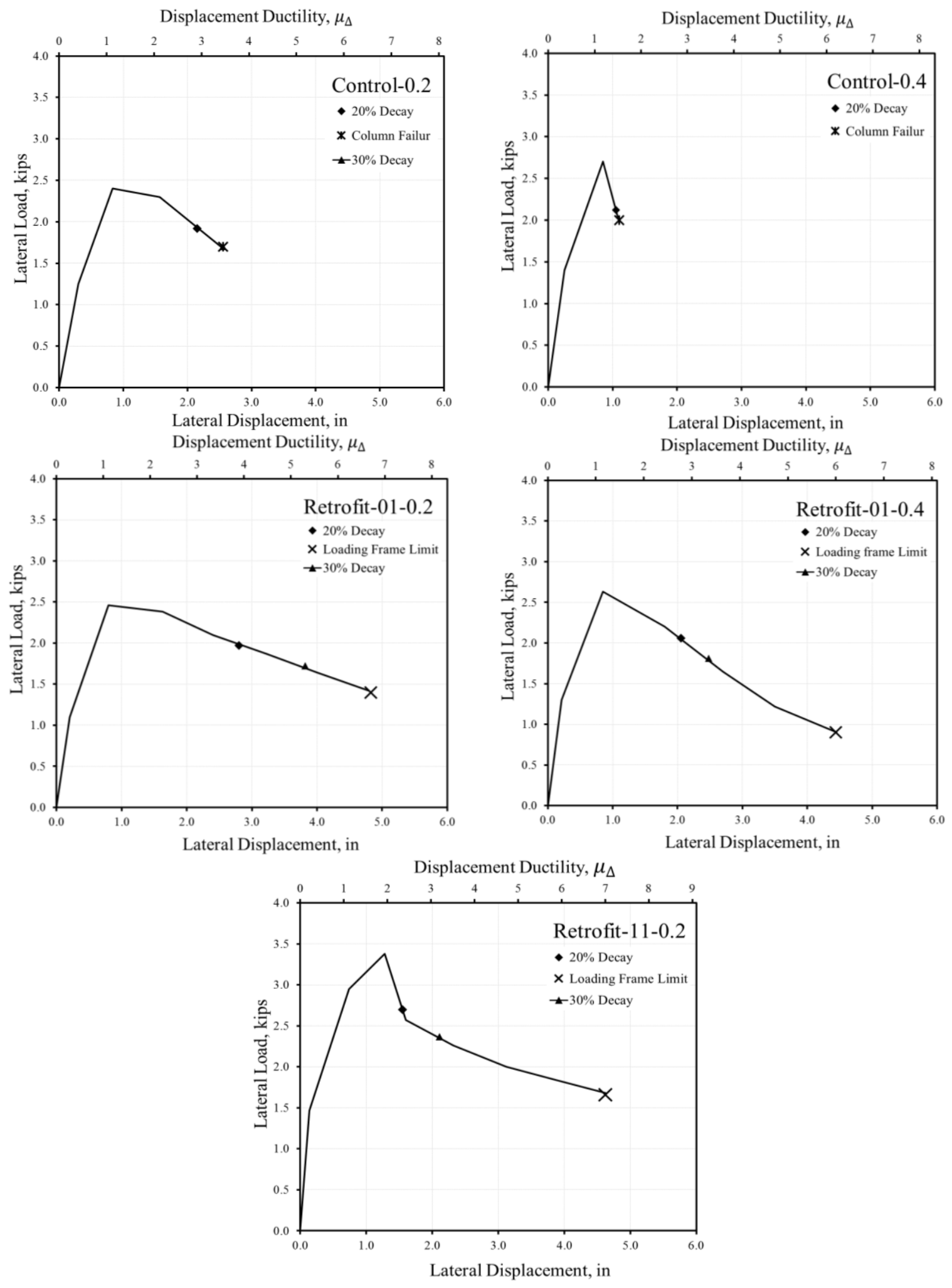

Figure 5.40: Displacement Ductility Based on Lateral Strength 
The ultimate displacement is commonly defined as a displacement corresponding to a $20 \%$ decay in the lateral strength. For an RC column expected to experience a flexural failure, a 20\% loss in lateral strength might result in the concrete crushing and the rebar buckling. For an RC column expected to experience shear failure, a severe diagonal cracking or shear-compression failure might be the consequence of such a loss in the lateral strength (Elwood et al., 2007). Both un-retrofit specimens, Control-0.2, and Control-0.4, experienced a flexural mode failure. Determining the ultimate displacement at $20 \%$ decay in the lateral strength was conservative for Control-0.2, and critical for Control-0.4. However, determining the ultimate displacement based on the stability index provided a more conservative limit for both Control-0.2, and Control-0.4 as compared to a 20\% decay in the lateral strength. For the RC column retrofit with CFRP, these types of failures were controlled by the confinement stress provided by CFRP up to the limit where the CFRP sheet ruptured. Moreover, in many retrofit-concrete columns, the $20 \%$ decay in lateral strength was not observed up to the CFRP rupture or the end of the test (Li \& Harries, 2018). Therefore, in most cases where the retrofit RC column was tested under a combination of lateral load with constant axial load, the ultimate displacement was determined at the point where the CFRP sheet ruptured (Fahmy, Wu, \& Wu, 2009; Li \& Harries, 2018; Alvarez, Breña, \& Arwade, 2018). In this study, no flexure damage, shear damage, or CFRP rupture was observed in both Retrofit-C01-0.2 and Retrofit-C010.4 up to the loading frame limit when the test was terminated. Due to the P- $\Delta$ effect, the lateral strength of the specimens consumed up to $44 \%$ and $68 \%$ of the peak lateral strength for Retrofit-C01-0.2 and Retrofit-C01-0.4, respectively. Moreover, both retrofit 
columns performed well with satisfactory cyclic stability, as shown in Fig. 5.40. Fig. 5.41 shows the stability limits considered in this study: (1) the ACI-318-14 (2014) stability limit, total moment to primary moment ratio $\leq 1.4$, (2) the Pettinga \& Priestley (2008) limit $\mathcal{Q}=0.3$, and (3) the Silva \& Sangtarashha (2012) limit $\mathcal{Q}=0.4$. 

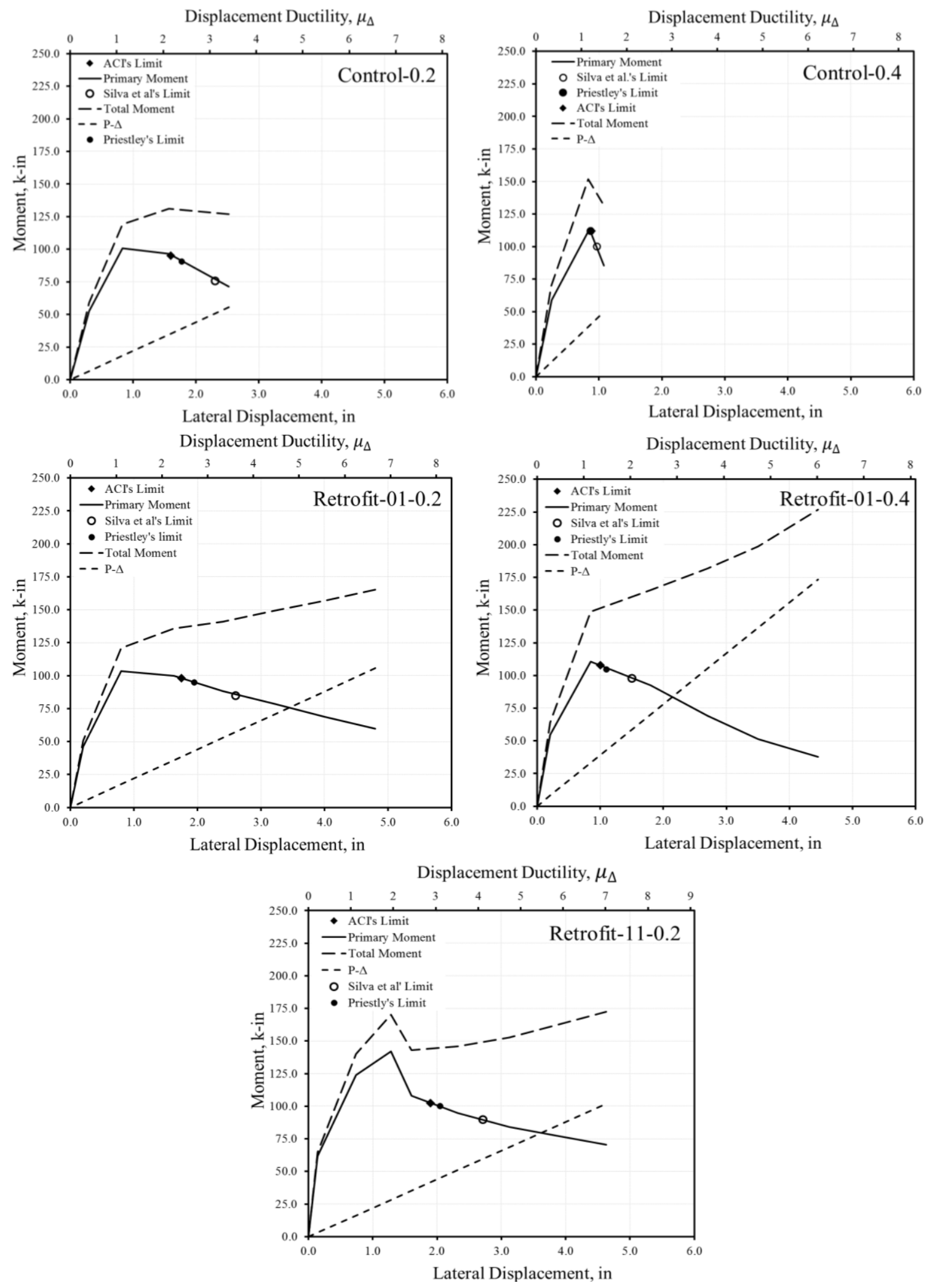

Figure 5.41: Displacement Ductility Based on Moment Strength 
In order to account for the effect of the stability limit on the displacement ductility, the relationship between the moment strength, $M_{T}$, and displacement ductility were constructed as shown in Fig. 5.41. The following relationships were used to calculate the values of the primary moment, $M_{p}$, the secondary moment, $M_{p-\Delta}$, and total moment, $M_{T}$ :

$$
\begin{aligned}
& M_{p}=F * L \\
& M_{p-\Delta}=P * \Delta \\
& M_{T}=M_{p}+M_{p-\Delta}
\end{aligned}
$$

In Figure 5.41 the values of the stability limits are plotted as "points" on the primary moment curves. The displacement ductility increased as the stability limit was increased. Therefore, Silva, \&Sangtarashha (2012), $Q=0.4$, gives the largest displacement ductility compared with others limits. It is important to mention that the retrofit column performed well with stable cyclic response after these limits up to the end of the test, and no sign of instability was observed during the test. Therefore, there is a need for more investigation to provide a stability limit that represents a more realistic limit for the retrofit slender RC columns.

Table 5-6 illustrates the comparison between the results of all limits that were used to define the ultimate displacement ductility in this study. For the specimens under moderate axial load, $0.4 A_{g} f_{c}^{\prime}$, the $20 \%$ decay in the lateral strength provided a displacement ductility larger than the displacement ductility corresponding to the stability 
index. However, for the specimens under a low axial load, $0.2 A_{g} f_{c}^{\prime}$, the displacement ductility corresponding to $20 \%$ decay in the lateral load provided a conservative limit compared with the stability index. For the retrofit specimens, it is evident that the displacement ductility at the end of the test was about two times the displacement ductility corresponding to the $20 \%$ decay. Moreover, up to the end of the test, all of the retrofit specimens provided stable cycles during the test without any sign of unstable behavior. For the retrofit specimens, determining the lateral displacement based on $20 \%$ decay in the lateral strength or stability limits provided a conservative limit that ignored the available lateral displacement beyond these limits. Therefore, in this study, the ultimate displacement for the retrofit specimens corresponded to a $30 \%$ decay in the lateral strength is proposed as limit for the ultimate displacement ductility for the retrofit RC columns.

Table 5-6: Displacement Ductility of Tested Specimens

\begin{tabular}{|c|c|c|c|c|c|c|}
\hline \multirow{3}{*}{$\begin{array}{c}\text { Specimens } \\
\text { Identification }\end{array}$} & \multicolumn{6}{|c|}{ Displacement Ductility, $\mu_{\Delta}$} \\
\hline & \multirow{2}{*}{$\begin{array}{c}20 \% \text { Decay } \\
\text { in Lateral } \\
\text { strength }\end{array}$} & \multirow{2}{*}{$\begin{array}{c}30 \% \text { Decay } \\
\text { in Lateral } \\
\text { strength }\end{array}$} & \multirow{2}{*}{$\begin{array}{c}\text { at failure } \\
\text { or loading } \\
\text { frame } \\
\text { capacity }\end{array}$} & \multicolumn{3}{|c|}{ Stability Limit } \\
\hline & & & & ACI-318 & $\begin{array}{c}\text { Priestly } \\
2008\end{array}$ & $\begin{array}{c}\text { Silva et al. } \\
2012\end{array}$ \\
\hline Control-0.2 & 2.1 & 2.8 & 3.4 & 2.2 & 2.4 & 2.8 \\
\hline Retrofit-C01-0.2 & 3.3 & 5.0 & 6.7 & 2.5 & 2.6 & 3.6 \\
\hline Retrofit-C11-0.2 & 2.4 & 3.5 & 7.1 & 2.8 & 3.0 & 4.1 \\
\hline Control-0.4 & 1.5 & NA & 1.6 & 0.9 & 0.9 & 1.4 \\
\hline Retrofit-C01-0.4 & 2.6 & 3.2 & 6.1 & 1.4 & 1.5 & 2.0 \\
\hline
\end{tabular}

$\mathrm{NA}=$ Not Available 


\subsubsection{Drift ratio}

Drift ratio, $\delta$, is one of the methods used to describe the amount of ductility provided by the structural element. The lateral drift ratio is defined as the ratio of the ultimate displacement to the length of the column. Table 5-7 illustrates the drift ratio (as a percentage) based on the measured ultimate displacement values as discussed previously in this chapter. It was observed that the drift capacity of the columns was improved by CFRP retrofit for the specimens tested under a low and moderate axial load. For example, based on the ultimate displacement at $20 \%$ decay in lateral strength, the drift ratio of the specimens Retrofit-C01-0.2 and Retrofit-C01-0.4 was improved by 56\% and 79\%, respectively. The increase in the drift ratio is attributed to the lateral confinement that increase the flexural ductility of the RC columns in the inelastic range.

Table 5-7: Drift Ratio of the Tested Specimens

\begin{tabular}{|c|c|c|c|c|c|c|}
\hline \multirow{3}{*}{$\begin{array}{l}\text { Specimens } \\
\text { Identification }\end{array}$} & \multicolumn{6}{|c|}{ Drift Ratio, $\varphi \%$} \\
\hline & \multirow{2}{*}{$\begin{array}{l}20 \% \text { Decay } \\
\text { in Lateral } \\
\text { strength }\end{array}$} & \multirow{2}{*}{$\begin{array}{l}30 \% \text { Decay } \\
\text { in Lateral } \\
\text { strength }\end{array}$} & \multirow{2}{*}{$\begin{array}{c}\text { at failure or } \\
\text { loading } \\
\text { frame } \\
\text { capacity }\end{array}$} & \multicolumn{3}{|c|}{ STability Limit } \\
\hline & & & & ACI-318 & $\begin{array}{c}\text { Priestly } \\
2008\end{array}$ & $\begin{array}{c}\text { Silva et al } \\
2012\end{array}$ \\
\hline Control- 0.2 & 4.1 & 5.2 & 6.1 & 3.8 & 4.1 & 5.02 \\
\hline Retrofit-C01-0.2 & 6.43 & 8.45 & 11.54 & 4.28 & 4.57 & 6.17 \\
\hline Retrofit-C11-0.2 & 3.8 & 5.36 & 11.19 & 4.4 & 4.7 & 6.44 \\
\hline Control-0.4 & 2.57 & NA & 2.63 & 1.5 & 1.57 & 2.4 \\
\hline Retrofit-C01-0.4 & 4.6 & 5.476 & 10.7 & 2.46 & 2.64 & 3.5 \\
\hline
\end{tabular}

$\mathrm{NA}=$ Not Available 


\subsubsection{Energy Dissipation}

Energy dissipation is one of the most important factors used to describe the behavior of structural elements under a cyclic lateral load, and to measure the effect of repeating cycles on the structural element at each loading cycle. In order to include the effect of the repeating cycles, the energy dissipation is calculated as the area enclosed by the last cycle of each loading or displacement increment. In this study, a MATLAB code was created and used to determine the area of the last cyclic response for the tested specimens. A comparison between the specimens for the quantitated energy dissipation at each level of drift ratio is illustrated in Fig. 5.42.

In general, the energy dissipation increased as the drift ratio increased up to the ultimate conditions. However, CFRP retrofit increased the amount of the energy dissipated by the columns due to the confinement action that provided more ductility to plastic hinge regions. It was observed that the level of the axial load affected the amount of energy dissipation. Increasing the level of the axial load led to a variation in the slopes of the loading and unloading branches for the cycle, which increased the enclosed area within a cycle. 


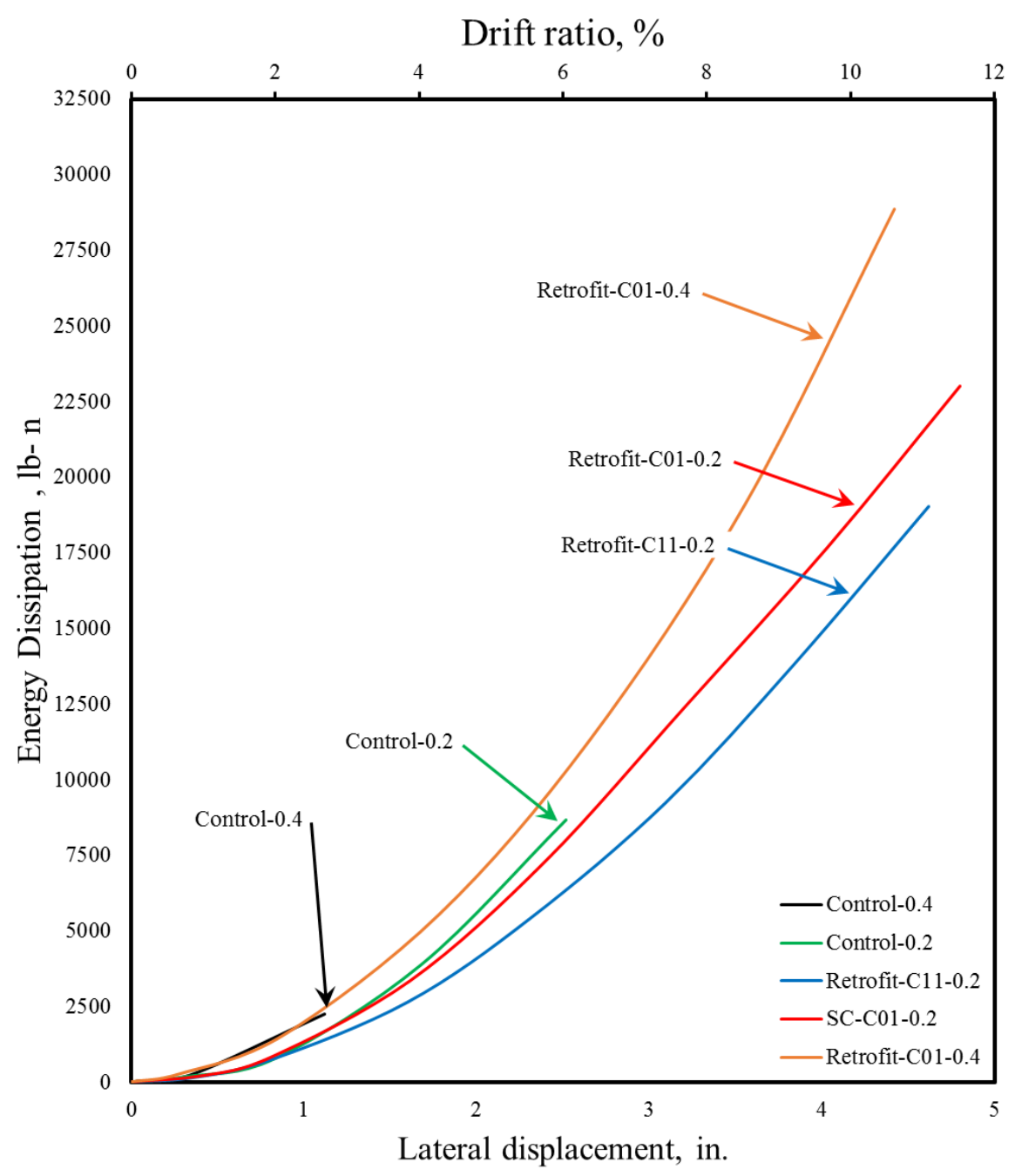

Figure 5.42: Energy Dissipation

\subsubsection{Shear Demand}

During a cyclic test, it is important for the member to maintain its shear strength such that it be larger than shear demand in the plastic hinge region, where the most inelastic rotation is concentrated. Otherwise the brittle shear failure will govern the failure mode. The CFRP retrofit at the plastic hinge region improved the shear strength at this region, therefore shear failure was avoided. In testing the specimens, shear demand 
was measured using a load cell that recorded the lateral load applied to the column stub. The shear capacity of the tested columns was computed to be more than twice the shear demand of the applied cyclic loads.

\subsection{Discussion of the Experimental Results}

\subsubsection{Axial Load Level}

The experimental results show that the behavior of slender RC columns was sensitive to the level of applied axial load. For the un-retrofit specimens, increasing the axial load level reduced the curvature ductility. For example, the curvature ductility of the specimen Control-0.2 was reduced by $67.6 \%$ by increasing the axial load level from $0.2 A_{g} f_{c}^{\prime}$ to $0.4 A_{g} f_{c}^{\prime}$. This affected the amount of the deformability that the plastic hinge region provided, as shown in Table 5-3. It is important to mention that even though the failure mode for both specimens was controlled by a flexural-compression failure mode that the visible damage in Control-0.4 was more severe than in Control-0.2, and the drop in carrying capacity happened instantaneously. During the cyclic action, the increase in the axial load level led to an increase in the depth of the compression region and the compression stress level at the extreme layer of the concrete. Therefore, the concrete cover experienced a crushing failure followed by rebar buckle with a low level of curvature compare with the columns tested under a low axial load level.

For the retrofit specimens, the CFRP lateral confinement controlled the concrete crushing of the concrete cover and rebar buckling up to the limit where the CFRP 
ruptured, which improved the ultimate curvature of the retrofit specimen compare with the un-retrofit specimens. However, increasing the axial load level led to an increased degradation of the lateral strength due to an increase in the effect of the secondary moment, which consumed the moment strength of the column. Moreover, both specimens provided a high curvature ductility up to frame displacement limit with stable cycles.

\subsubsection{CFRP Confinement}

The confinement action provided by the CFRP retrofit improved both of the rotation deformability and shear strength of the plastic hinge region of the columns during the cyclic action. The lateral strain of the CFRP confinement was measured using strain gauges mounted at a certain distance from the column-stub intersection. The results for the strain gauge mounted 6 inches from the column-stub intersection versus the lateral displacement of specimens Retrofit-C01-0.2 and Retrofit-C01-0.4 are illustrated in Fig. 5.43 and 5.44, respectively.

The lateral strain in the CFRP confinement was increased by increasing the lateral displacement. However, the lateral strain did not return to zero when the lateral load was removed or moved in the opposite direction. This was due to concrete dilation under the CFRP layer that led to an increase in the cross section of column. It was observed that the largest recorded CFRP strain was less than 0.005 for both specimens, which was $39 \%$ of the CFRP tensile strength capacity with no damage in the CFRP retrofit. Based on (ACI 440.2R-17, 2017) the limit for the allowable lateral strain for CFRP retrofit is set at 0.004. However, at the high level of lateral displacement, the CFRP layer bulged in some 
regions about 4 to 5 inches from the column-stub intersection without considerable effect on the lateral strength.

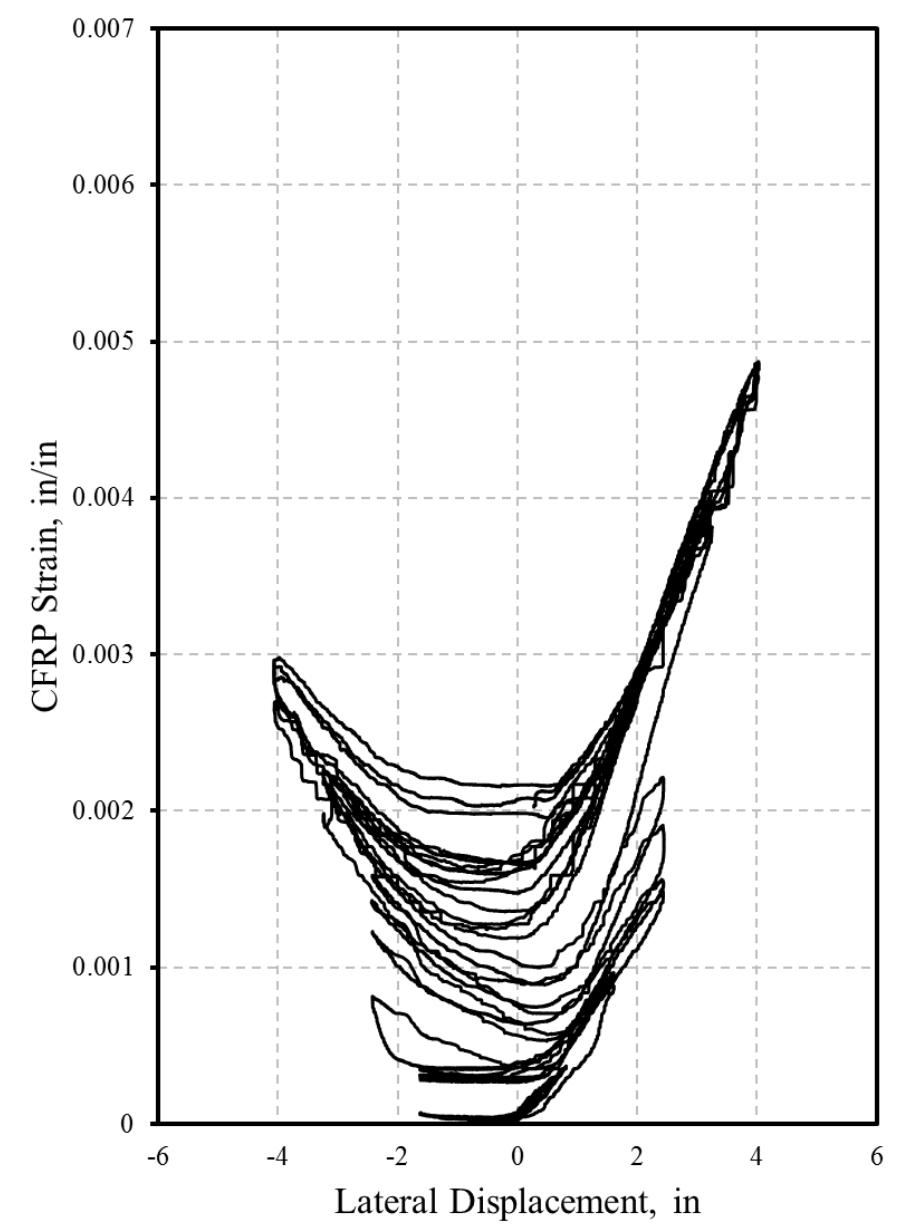

Figure 5.43: CFRP Lateral Strain vs. Lateral Displacement, Retrofit-C01-0.2 


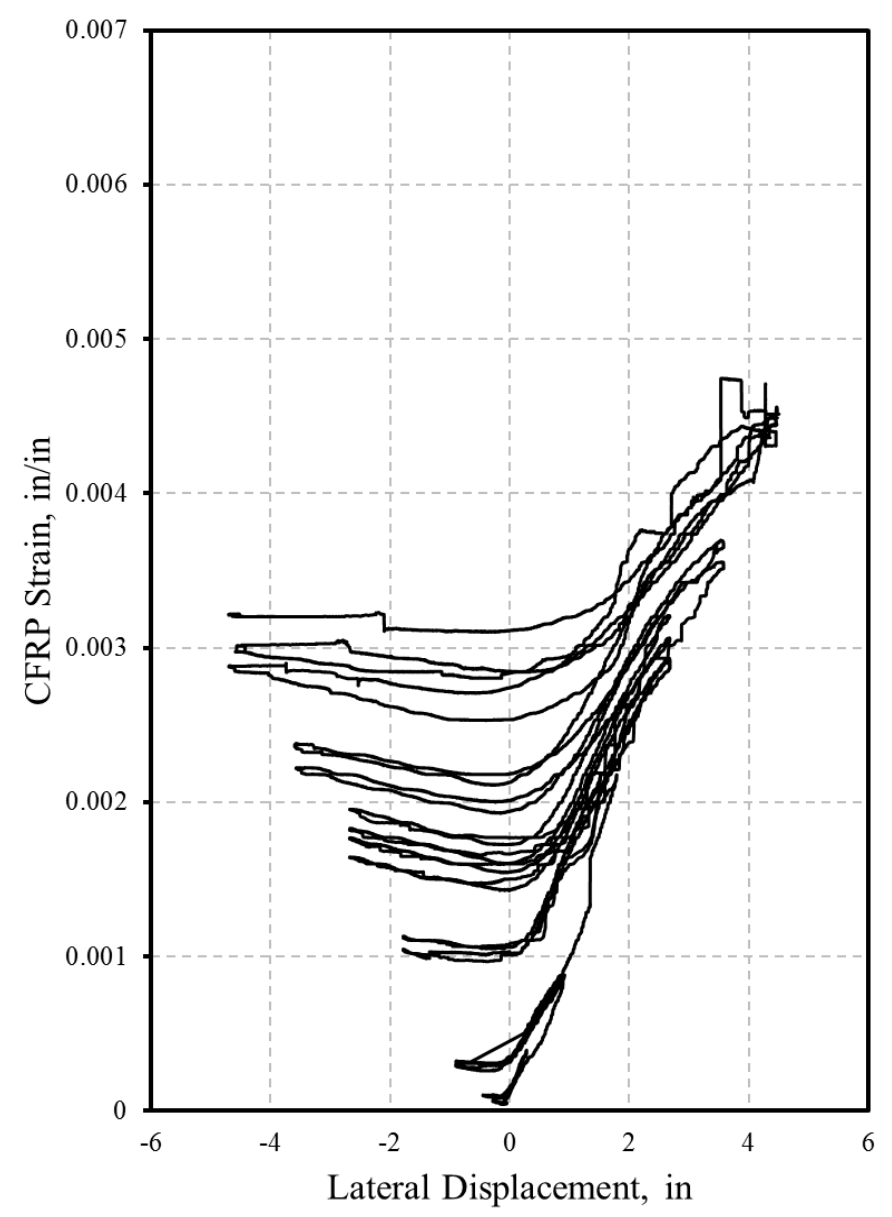

Figure 5.44: CFRP Lateral Strain vs. Lateral Displacement, Retrofit-C01-0.4

\subsubsection{Tensile Strain in Longitudinal CFRP Sheet.}

Using the longitudinal CFRP sheet to increase the lateral stiffness of the slender column is desired to reduce the weak-column-strong-beam effect. Therefore, it is recommended by ACI 440.2R-17 (2017) that the use of CFRP for flexural strengthening should only be used in a case where the inelastic deformation will be eliminated in the strengthened region and transferred to other locations. The use of CFRP for flexural strengthening has been more commonly used with RC beams than with RC columns due to the difficulty of anchoring the CFRP sheet at the column-stub intersection (Grelle \& 
Sneed 2013). Therefore, in this study, a new anchorage system is proposed to provide a more sufficient anchorage system for CFRP sheets. This proposed system was discussed in Chapter 3. In order to measure the strain along the longitudinal CFRP sheet, six strain gauges were mounted on the top and the bottom of the Retrofit-C11-.2 column specimen at 3, 4, and 9 inches from the column-stub intersection. The distribution of the strain gage for the eight strain gauges during the cyclic action is illustrated in Fig. 5.45.

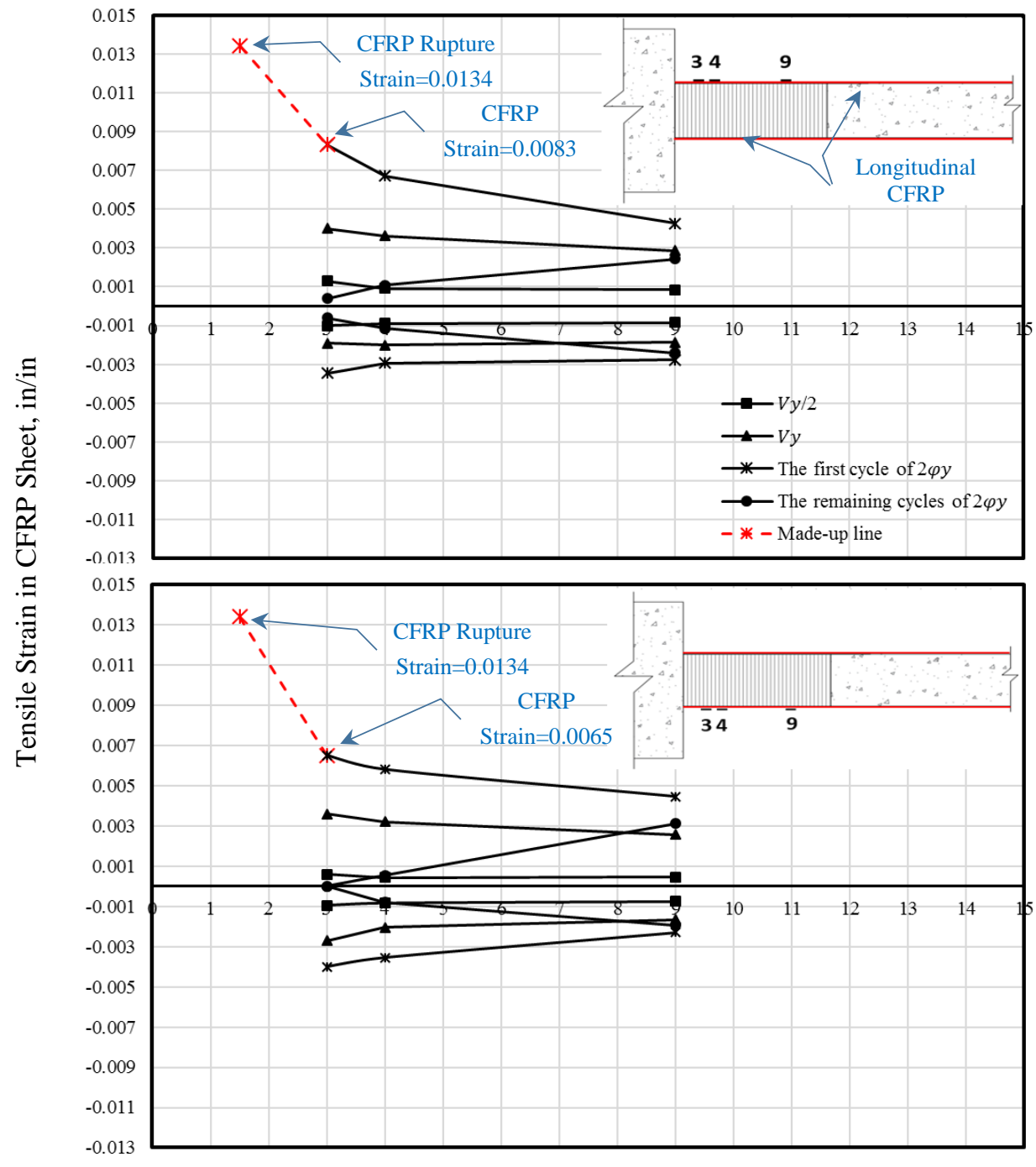

Distance from the Column-Stub Intersection, in

Figure 5.45: Distribution of the Tensile Strain of the CFRP Sheet 
The maximum recorded tensile strain was 0.0083 at the top strain gauge that located at 3 inches from the column-stub intersection. However, CFRP is expected to experience higher strains at the location of the maximum moment (column base) or at the location of CFRP rupture. The CFRP sheet in the longitudinal direction ruptured about 1.5 inches away from the anchor (column base) due to combination of tensile and shear stresses. Therefore, it is reasonable to assume that the strain reached a maximum value of 0.0134 at the location where CFRP ruptured. The anchor did not experience any sign of damage or failure until the column test was terminated. The bottom CFRP sheet ruptured with less tensile strain, 0.0068 . When the top layer of the CFRP sheet reached the maximum tensile strain, 0.0083, the compressive strain on the bottom layer of CFRP reached 0.004 . With 0.004 compressive strain, a local buckle was expected and did occur in the bottom layer of the CFRP. This local buckle led to a reduction in the tensile strength of the longitudinal CFRP when the reverse cycle was applied, (Grelle and Sneed 2013). Therefore, the bottom CFRP layer ruptured with a lower level of tensile strain, 0.0068, compared with the top layer.

After peeling all the lateral CFRP from the column, it was found that the location where the CFRP ruptured ranged between 1.5 to 2.0 inches from the column-stub intersection. The performance of the proposed anchor in supporting the longitudinal CFRP was accomplished without any sign of damage or distortion. The contribution of the longitudinal CFRP sheet in providing tensile strength was continued after the rupture reached 9 inches, as shown in Fig. 5.45. However, this contribution was decreased to $\approx$ 
$50 \%$ after the CFRP rupture because the damage was concentrated at the region where the CFRP ruptured. 


\section{Chapter 6: Study of Buildings' Behavior with Slender RC Columns}

\subsection{Introduction}

In order to illustrate an overall process for the seismic evaluation of older RC buildings that contain slender RC columns, two RC buildings with designs based on the older codes and located in Iraq were analyzed and evaluated using Nonlinear Static Procedure (NSP). The evaluation included a rehabilitation technique that used a CFRP sheet for confinement and strengthening of the vulnerable, slender RC columns. Two software programs, MATLAB and SAP2000, were used to evaluate the performance of these two buildings. Based on the available models used to define the axial stress-strain behavior of the un-retrofit and retrofit RC columns, the theoretical model using MATLAB coding was implemented to predict the moment-curvature and lateral loadlateral displacement relations of the slender RC columns. In order to verify the theoretical results, a comparison was made between them and the experimental results. SAP2000 software was implemented to perform the NSP on the RC buildings. The performance level of a building is dependent on the modeling parameters and acceptance criteria. The American Society of Civil Engineers (ASCE) has provided guides, adopted by SAP2000, to determine the modeling parameters and acceptance criteria for the un-retrofit RC columns. For the retrofit specimens, there is no specific guide to define the acceptance criteria. Therefore, in this chapter, a guide is proposed to define the acceptance criteria. This guide is developed based on the literature review and the experimental results in this study. 
After the theoretical results were verified and the acceptance criteria had been defined, the results were implemented in SAP2000 to define the plastic hinge deformability and perform the NSP on the prototype buildings.

\subsection{Nonlinear Static Procedure (NSP)}

Nonlinear Static Procedure (NSP) is considered to be a reliable approach to estimate the maximum global demand (i.e. lateral displacement of a roof) associated with a specific response spectrum, which represents a ground-motion record (FEMA 356, 2000; FEMA-440, 2005; ASCE/SEI41-13, 2013). Basically, the NSP procedure is designed to identify the performance level of a building based on a structural capacity curve and response spectrum. The NSP process includes: (1) performing the nonlinear static analysis of the structure, pushover analysis, and determining the capacity curve of the structure, and (2) determining the displacement demand (target displacement) for a given response spectrum using one of the available methods (e.g., Equivalent Linearization Procedure (ELP) or Displacement Modification Procedure (DMP)). A flowchart of NSP is shown in Fig. 6.1. In this study, DMP was adopted to determine the target displacement of the buildings. The procedure for determining the target displacement included: (1) converting the structure from a multi-degree of freedom (MDOF) system to a single degree of freedom (SDOF), which has the same effective elastic stiffness of the building, and (2) based on a given response spectrum the target displacement, $\delta_{t}$, for the SDOF was determined.

$$
\delta_{t}=C_{o} C_{1} C_{2} S_{a} \frac{T_{e}^{2}}{4 \pi^{2}} \mathrm{~g}
$$


Where:

$C_{o}=$ the modification factor related to the spectral displacement of an equivalent singledegree of freedom system to the roof displacement of the building multi-degree of freedom system.

$C_{1}=$ the modification factor related to the expected maximum inelastic displacement to displacement calculated for a linear elastic response.

$C_{2}=$ the modification factor representing the effect of a pinched hysteresis shape, cyclic stiffness degradation, and strength deterioration on a maximum displacement response.

$S_{a}=$ the response spectrum acceleration, at the effective fundamental period and damping ratio

$T_{e}=$ the effective fundamental period of the building in direction under consideration, in seconds.

$\mathrm{g}=$ the acceleration of gravity

Based on the value of the target displacement and the capacity curve of the system, the performance level of the structure could be identified, as shown in Fig. 6.2. 


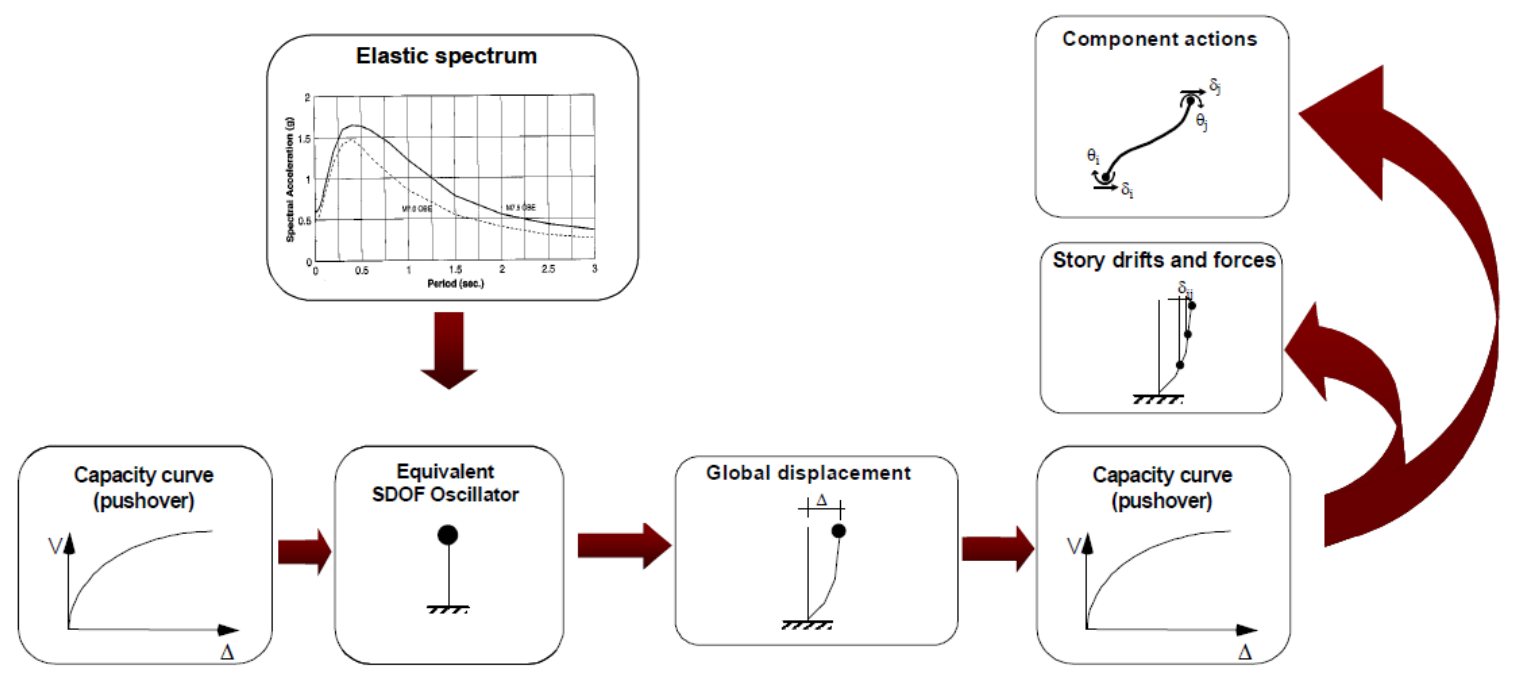

Figure 6.1: Flowchart of NSP

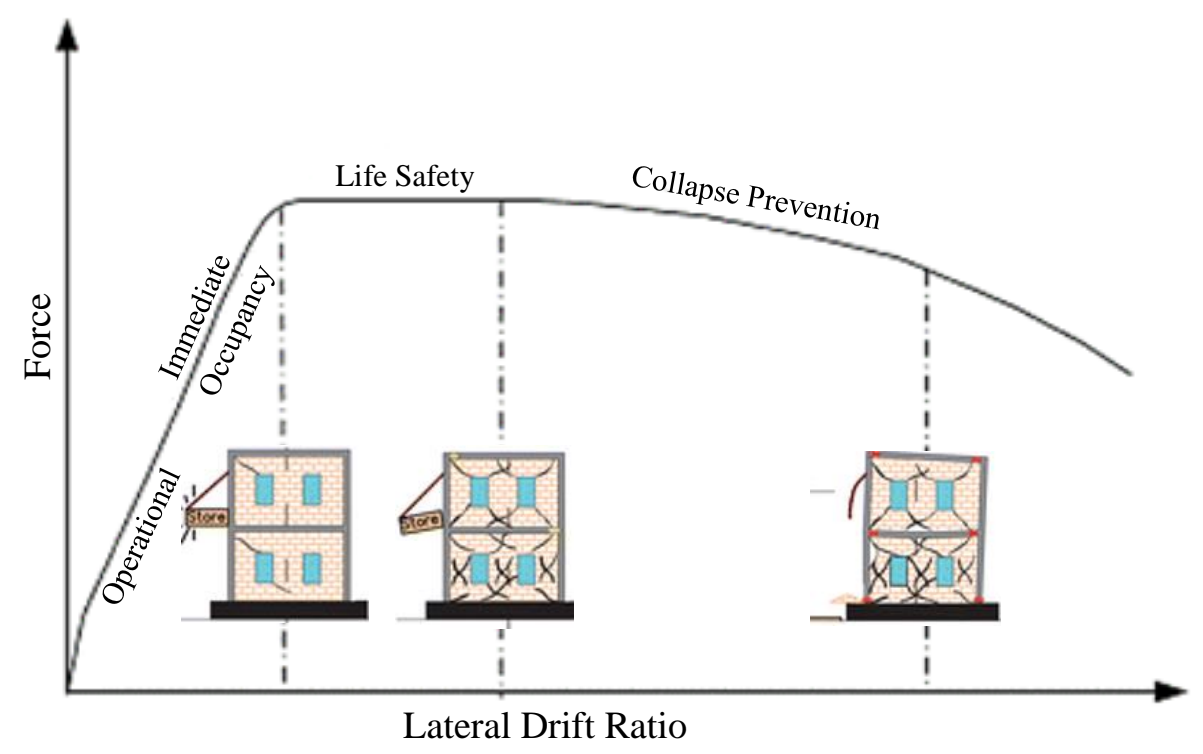

Figure 6.2: Identification of the Performance Level Based on the Target Displacement 


\subsubsection{Nonlinear Structural Analysis (Pushover)}

Pushover analysis is a static nonlinear analysis procedure in which the magnitude of the lateral strength is determined based on applying lateral displacement, increased monotonically through the elastic and inelastic behavior of the structure, up to the ultimate condition. Generally, the output of the pushover analysis represents lateral strength (base shear) versus lateral displacement (roof displacement). Many programs are designed to perform the nonlinear analysis on the structure, such as ABAQUS, ANSYS, ETABS and SAP2000. However, in SAP2000 the pushover analysis is connected directly with methods that predict the target displacement of the structure (Inel \& Ozmen, 2006). Moreover, a high percentage of practical users perform the NSA for structures using SAP2000 (FEMA-440, 2005).

In SAP2000, the nonlinearity response of pushover analysis depends on lumpedplasticity models that define the deformation capacity of the structural member based on the rotation capacity curve of the plastic hinges (Berry, Lehman, \& Lowes, 2008). The deformation capacity of the plastic hinge is defined in terms of normalized moment strength, $\left(M / M_{y}\right)$ versus rotation, $(\theta)$. In SAP2000, there are two options to define the plastic hinge response: (1) default-hinge properties, defined based on the ASCE/SEI4113 (2013)- Table (10-8), (2) user-defined nonlinear hinge properties, based on the nonlinear analysis of the plastic hinge rotation capacity. In ether method, the modeling parameters (a, b, and $\mathbf{c})$, and the acceptance criteria (IO, LS, and CP) need to be determined, as shown in Fig. 6.3. Nonlinear analysis accounting for the effect of shear span ratio and bar-slip deformation to predict the plastic hinge response provides more 
refined results, compared with default results (ACI 369R-11, 2011; Grammatikou, Biskinis, \& Fardis, 2018). Therefore, the nonlinear analysis results for the plastic hinge rotation was implanted in SAP2000 in this study.

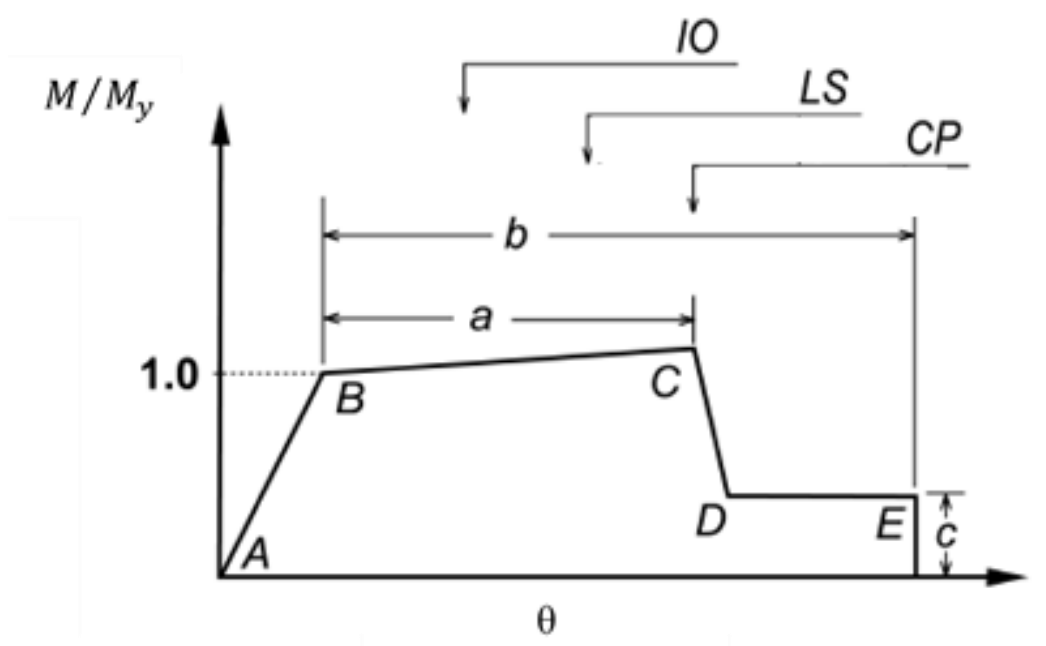

Figure 6.3: Modeling Parameters and Acceptance Criteria

\subsubsection{Displacement Modification Procedure (DMP)}

The Displacement Modification Procedure (DMP) is an NSP developed by FEMA-356 (2000); and FEMA-440 (2005). Basically, this approach determines the lateral displacement demand of the MDOF, based on the SDOF. This can be modified by multiplying the results by a series of coefficients $\left(C_{o}\right.$ through $\left.C_{2}\right)$, as described in Chapter 3, to predict the lateral displacement demand of the MDOF. This process increases the level of uncertainty. However, this level of uncertainty is low compared with the linear static analysis procedure. 


\subsection{Nonlinear Analysis of the Slender RC Columns}

A theoretical model was implemented to predict the moment-curvature, and lateral load-displacement relation, including nonlinear response of RC slender columns when un-retrofit and retrofit with CFRP, tested under a combination of lateral and constant axial loads. These theoretical results would then be used to define the plastic hinge rotation response of the slender column. This approach to predict the structural element rotation capacity has been discussed in more details elsewhere (Park, R \& Paulay, T., 1975; Paulay \& Priestley, 1992).

\subsubsection{Moment-Curvature Relation of RC Column}

In order to perform the nonlinear analysis of the RC column, the momentcurvature behavior of the RC cross-section needed to be defined. A computer program was created to generate moment-curvature relations, briefly described in the following, and shown in Fig. 6.4. Under a constant axial load, each increment in the flexural bending moment was associated with a certain amount of curvature, which satisfied the strain compatibility and force equilibrium of the block stress (Fig. 6.4). In order to determine the moment-curvature relation for an $\mathrm{RC}$ column, the axial stress-strain model for the concrete and steel reinforcement needed to be defined. In this study, monotonic axial stress-strain relations were used to define the stress-strain behavior of concrete. Based on the experimental studies (Mander, Priestley, \& Park, 1988; Lam, Teng, Cheung, \& Xiao, 2006; Wang, Wang, Smith, \& Lu, 2012), it was found that the monotonic axial stress-strain response for the confined and non-confined concrete can be assumed to be identical to the cyclic axial stress-strain response. The stress-strain models used for the 
concrete were (1) a non-confined concrete model for concrete clear cover, (2) a transverse steel confinement model for concrete core, and (3) a CFRP-confinement model for concrete wrapped with CFRP.
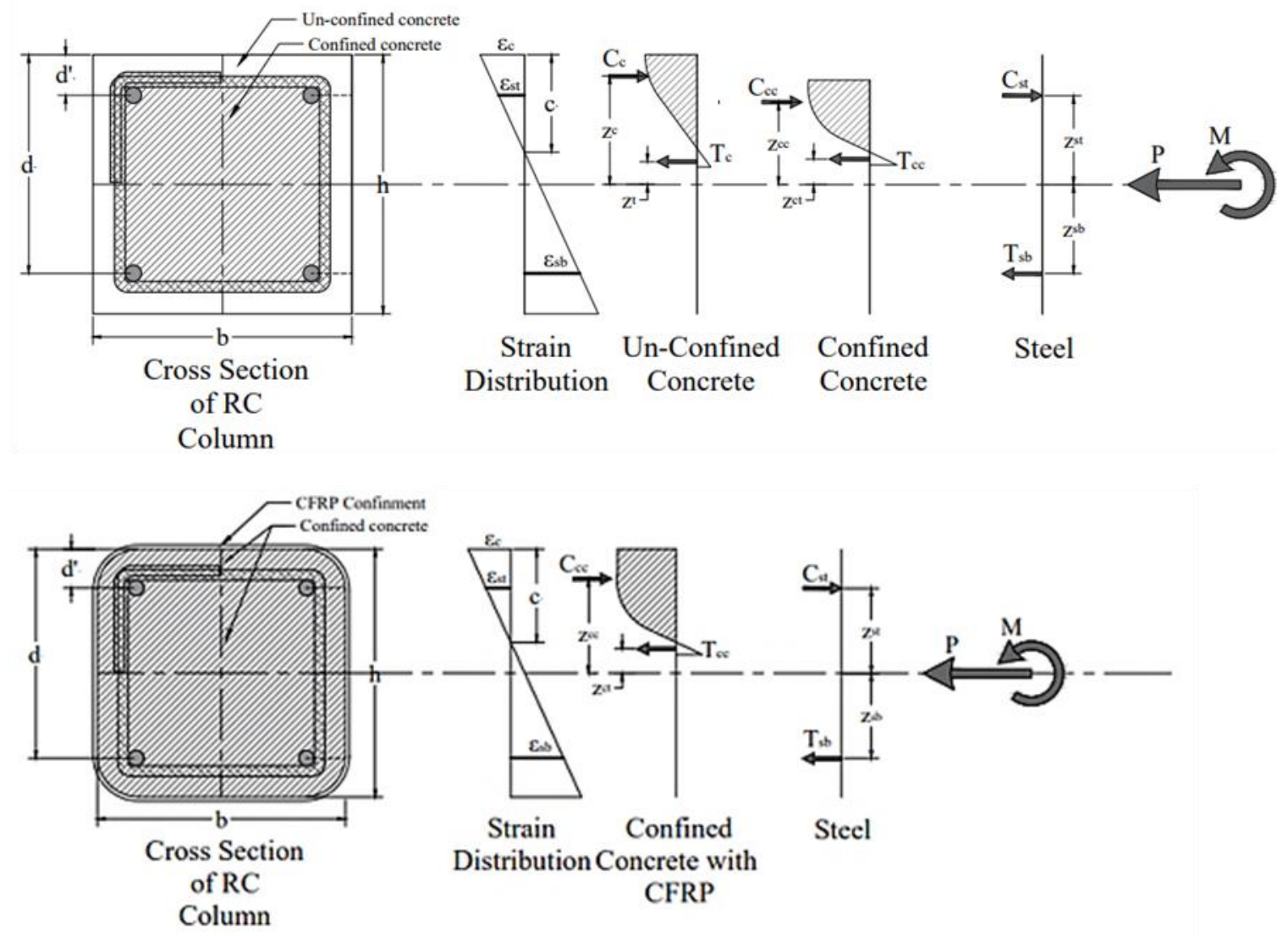

Figure 6.4: Strain Compatibility and Force Equilibrium for the Block Stress RC Column

\subsubsection{Stress-Strain Relation of Unconfined Concrete}

In this study, the model proposed by Mander et al. (1988) was adopted to define the axial stress-strain behavior of the concrete cover of the $\mathrm{RC}$ columns, as shown in Fig.6.5. The unconfined concrete stress-strain model is defined in the following equation: 


$$
f_{c}=\left[\begin{array}{cl}
\frac{f_{c}^{\prime} x r}{r-1+x^{r}} & \varepsilon \leq 2 \varepsilon_{c o} \\
\left(\frac{2 f_{c}^{\prime} r}{r-1+2^{r}}\right)\left(\frac{\varepsilon_{u}-\varepsilon}{\varepsilon_{u}-2 \varepsilon_{c o}}\right) & 2 \varepsilon_{c o} \leq \varepsilon_{c} \leq \varepsilon_{u}
\end{array}\right.
$$

Where,

$$
\begin{gathered}
r=\frac{E_{c}}{E_{c}-\left(f_{c}^{\prime} / 2 \varepsilon_{c o}\right)} \\
x=\frac{\varepsilon}{2 \varepsilon_{c o}}
\end{gathered}
$$

\subsubsection{Stress-Strain Relation for Steel Confined Concrete}

For the concrete portion surrounded by transverse reinforcement steel, the stressstrain relation was defined by using steel-confined stress-strain model proposed by Mander et al. (1988), as shown in Fig. 6.5. The following equation defines the confinement stress-strain model:

$$
f_{c}=\frac{f_{c c}^{\prime} \times r}{r-1+x^{r}}
$$

Where,

$$
\begin{gathered}
r=\frac{E_{c}}{E_{c}-E_{s e c}} \\
x=\frac{\varepsilon}{\varepsilon_{c c}} \\
E_{c}=\frac{f_{c c}^{\prime}}{\varepsilon_{c c}} \\
f_{c c}^{\prime}=f_{c}^{\prime}\left(2.254 * \sqrt{1+\frac{7.94 f_{l}^{\prime}}{f_{c}^{\prime}}}-2 \frac{f_{l}^{\prime}}{f_{c}^{\prime}}-1.254\right) \\
f_{l}^{\prime}=k_{e} f_{l}
\end{gathered}
$$

Where $f_{l}^{\prime}$, is the effective lateral confinement, $f_{l}$ is the lateral confinement pressure of the transverse reinforcement, and $k_{e}$ is the confinement effectiveness coefficient. 


$$
k_{e}=\frac{A_{e}}{A_{c c}}
$$

Where, $A_{e}$ is the effective confinement area of the concrete, and $A_{c c}$ is the concrete core area excluding longitudinal bars. For a rectangular concrete column, the value of both $A_{e}$ and $A_{c c}$ are calculated according to the following procedure:

$$
\begin{gathered}
A_{e}=\left(b_{c} d_{c}-\sum_{i-1}^{n} \frac{\left(w_{i}^{\prime}\right)^{2}}{6}\right)\left(1-\frac{s^{\prime}}{2 b_{c}}\right)\left(1-\frac{s^{\prime}}{2 d_{c}}\right) \\
A_{c c}=d_{c} b_{c}
\end{gathered}
$$

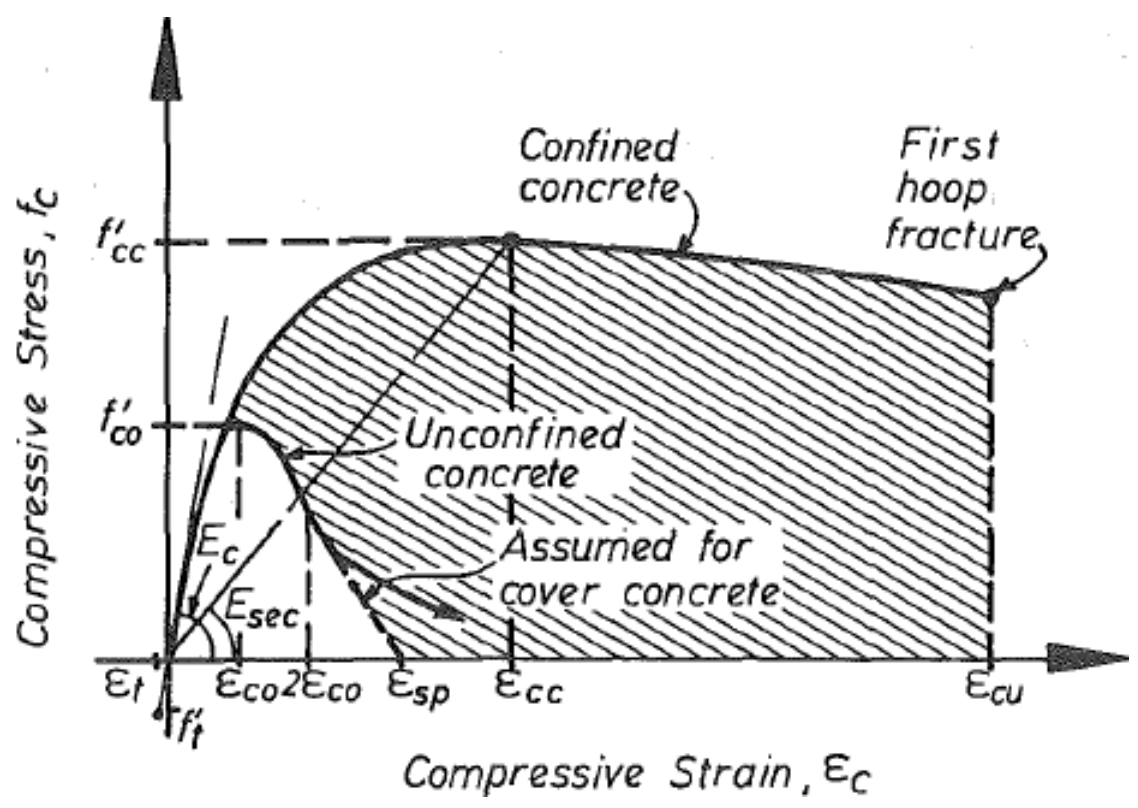

Figure 6.5: Stress-Strain Model for Unconfined and Confined Concrete

The lateral stress applied by the transverse reinforcement is determined in both $\boldsymbol{x}$ and $\boldsymbol{y}$ direction, as shown in Fig. 6.6. The lateral stress equation in each direction is illustrated below:

In the $\boldsymbol{x}$ direction:

$$
\begin{gathered}
f_{l x}=\rho_{x} f_{y h} \\
216
\end{gathered}
$$




$$
\begin{aligned}
& \rho_{x}=\frac{A_{s x}}{s d_{c}} \\
& f_{l x}^{\prime}=k_{e} \rho_{x} f_{l x}
\end{aligned}
$$

In the $\boldsymbol{y}$ direction:

$$
\begin{aligned}
& f_{l y}=\rho_{y} f_{y h} \\
& \rho_{y}=\frac{A_{s y}}{s b_{c}} \\
& f_{l y}^{\prime}=k_{e} \rho_{y} f_{l y}
\end{aligned}
$$

For a square column, when the lateral reinforcement is identical in both directions, $f_{l y}^{\prime}$ is equal to $f_{l x}^{\prime}$.

The ultimate compressive strain, $\varepsilon_{c u}$, was estimated to be at the first transverse confining steel fractures. However, at the first fracture of the transverse steel, a sudden failure happens in the column accommodated with longitudinal steel buckling (Mander et al., 1988). In this study a limit suggested by Paulay \& Priestley (1992) was adopted to calculate the ultimate compressive strain, $\varepsilon_{c u}$.

$$
\varepsilon_{c u}=0.004+1.4\left(\rho_{x}+\rho_{y}\right) f_{y h} \frac{\varepsilon_{s m}}{f_{c c}^{\prime}}
$$

Where $\varepsilon_{s m}$ is the steel strain at maximum tensile stress, and $f_{y h}$ is the yield strain of the hoop. 

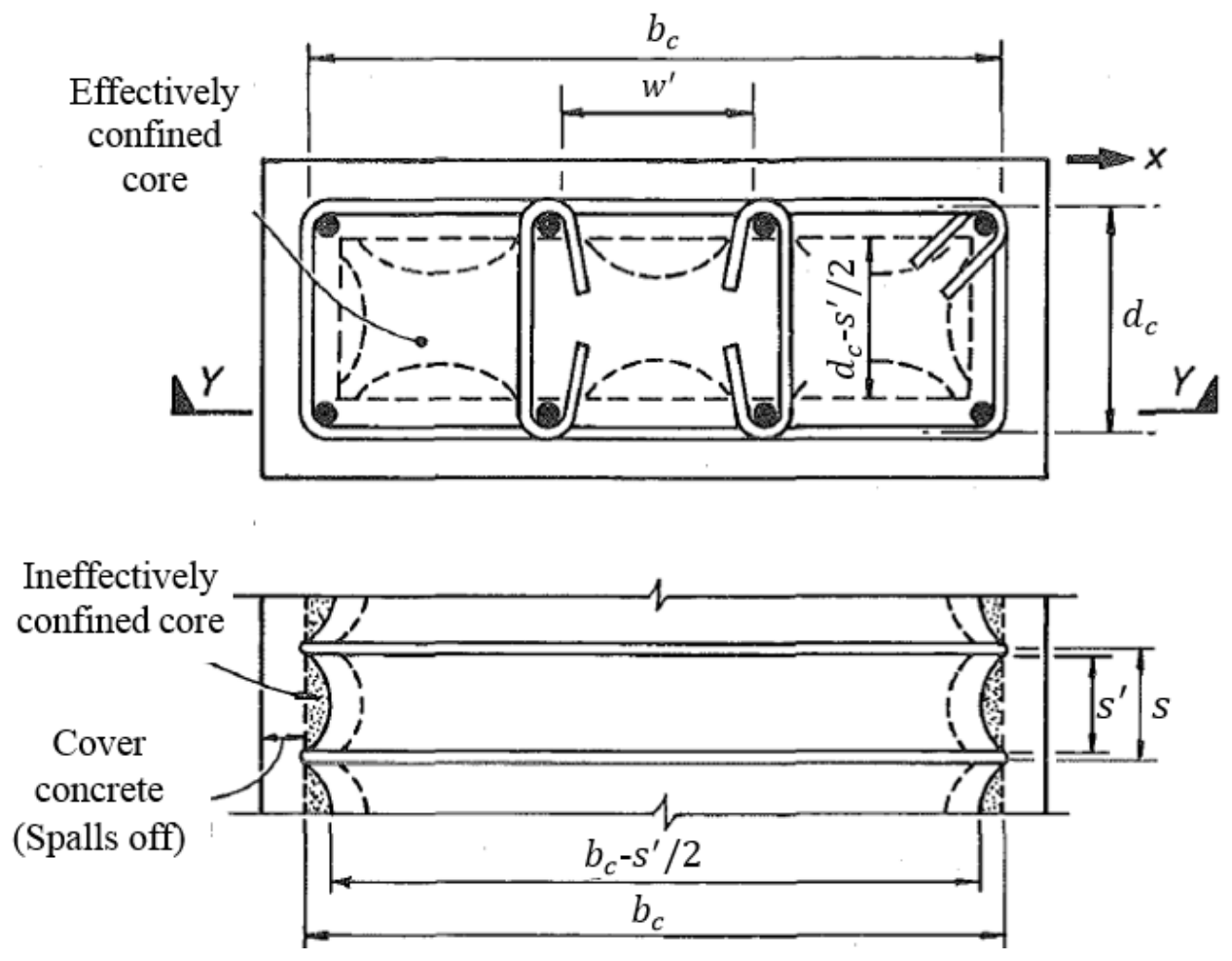

Figure 6.6: Distribution of Lateral Stress on Rectangular RC Column

\subsubsection{Stress-Strain Relation of the CFRP-Confined Concrete}

In this study, the stress-strain relation proposed by Lam \& Teng (2003) and adopted by ACI 440.2R-08 (2008); \& ACI 440.2R-17 (2017) was used to define the behavior of the CFRP-confined concrete. This model was previously described in Chapter 3.

\subsubsection{Stress-Strain Relation for Longitudinal Reinforcement Model}

For longitudinal steel reinforcement, a stress-strain model suggested by Raynor, Lehman, \& Stanton (2002) was used to represent the tensile stress-strain. The following equations were used to define the steel stress-strain behavior: 


$$
\begin{aligned}
f_{s}=E \varepsilon & \text { For } \varepsilon \leq \varepsilon_{y} \\
f_{s}=f_{y}+\left(f_{s h}-f_{y}\right) \frac{\left(\varepsilon-\varepsilon_{y}\right)}{\left(\varepsilon_{s h}-\varepsilon_{y}\right)} & \text { For } \varepsilon_{y} \leq \varepsilon \leq \varepsilon_{s h} \\
f_{s}=f_{u}-\left(f_{u}-f_{s h}\right) \frac{\left(\varepsilon_{u}-\varepsilon\right)^{c}}{\left(\varepsilon_{u}-\varepsilon_{s h}\right)^{c}} & \text { For } \varepsilon_{s h} \leq \varepsilon
\end{aligned}
$$

Where $c$ is the parameter that defined the curvature of the strain hardening portion. Raynor's model was verified by comparing the theoretical results with experimental tensile stress-strain behavior of the rebar \#3, as shown in Fig. 6.7.

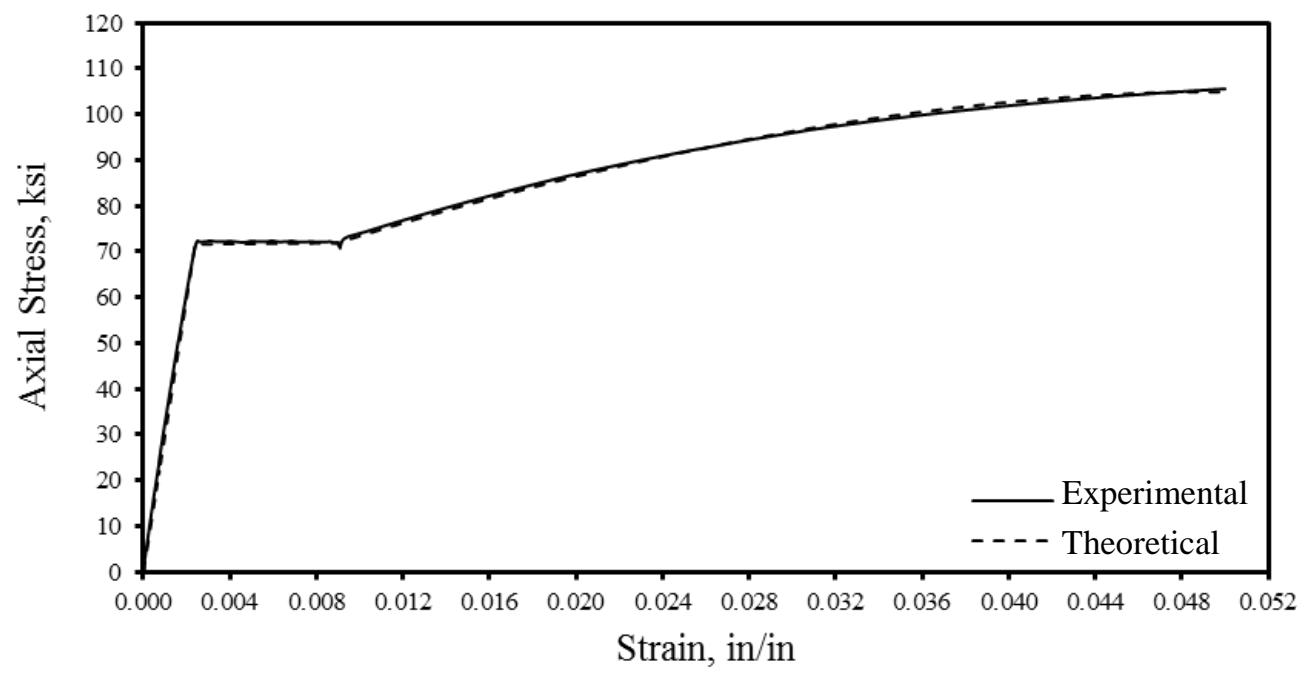

Figure 6.7: Raynor Axial Stress-Strain Model

\subsubsection{Moment-Curvature Algorithm}

In order to determine the moment-curvature behavior of the column section, the block-stress approach with stress-strain relations for concrete and steel were defined in MATLAB scribe, as illustrated in Fig. 6.4. The MATLAB scribe started by increasing the axial strain increment on the extreme compression layer of the concrete cross-section and 
determining the associated curvature and moment that achieved strain compatibility and force equilibrium. The values of the internal tensile and compressive forces were calculated based on the stress-strain models at each increment. The scribe is designed to repeat this step for each axial strain increment up to the ultimate condition. Fig. 6.8 describes the algorithm of the moment-curvature program.

\subsubsection{Verifying the Theoretical Results}

In order to verify the theoretical results, the moment-curvature results obtained from the experimental test were compared with the theoretical moment-curvature. Fig. 6.9 and 6.10 illustrate the comparison between the envelope-curve of the experimental results for specimens Control-0.2 and Control-0.4 and the theoretical results. Based on this comparison, both specimens lost their axial load carrying capacity before reaching the ultimate axial strain proposed by Paulay \& Priestley (1992) and no fracture was observed in the transverse reinforcement. The large spacing between the transverse reinforcement and opening of the transverse reinforcement in the plastic hinge region caused early failure in the RC column under cyclic action. Therefore, it might be that the predicted ultimate compressive axial strain for the concrete confined with light transverse steel is not valid for the slender RC column. Thus, there is a need for further investigation to determine a reliable axial strain limit for slender columns. 


\section{Input}

Start with known axial force $(\mathrm{P})$, geometrical details of the cross section, stress- strain relationship for concrete and reinforcement steel

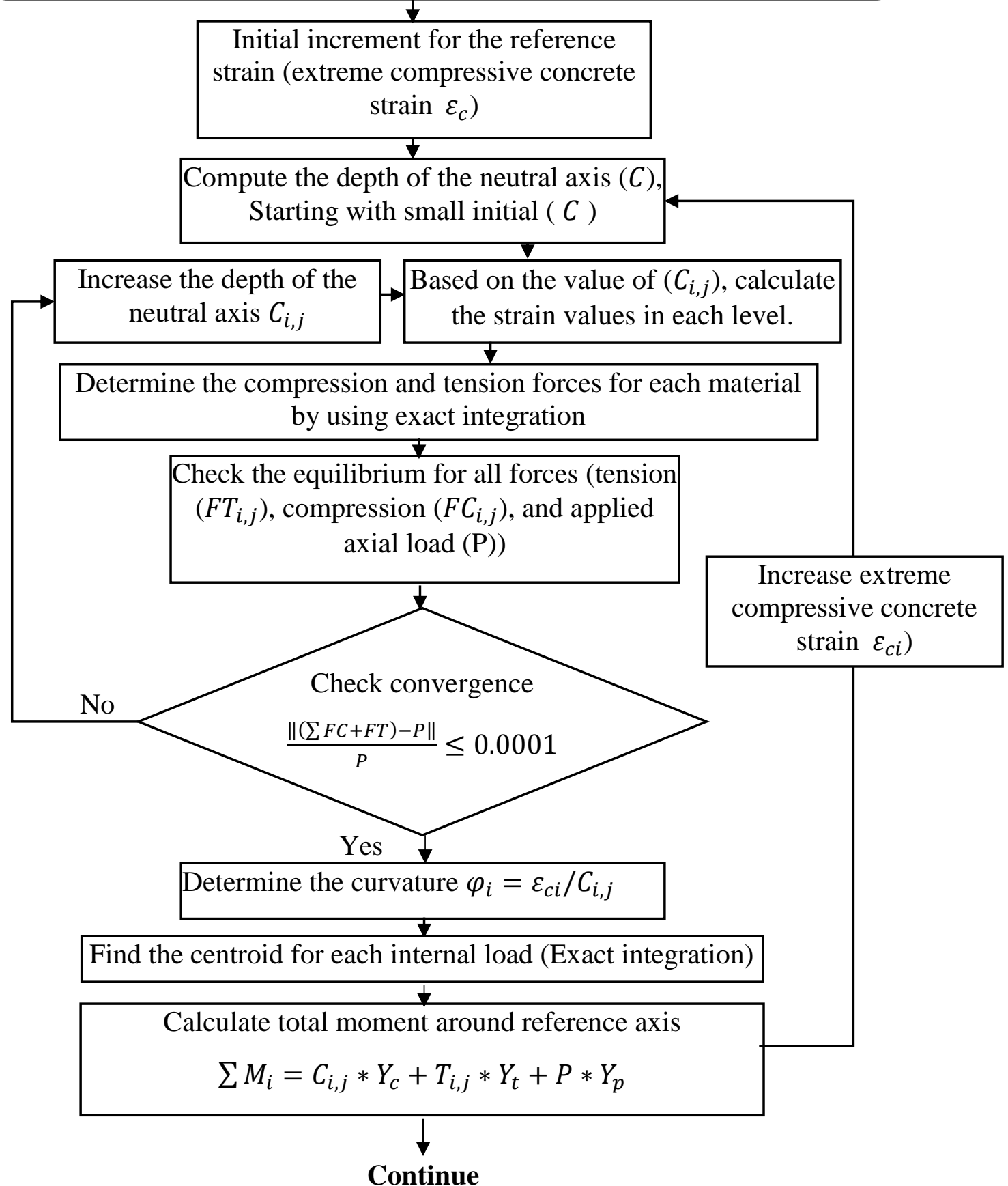

Figure 6.8: Flowchart for Calculating Moment-Curvature 


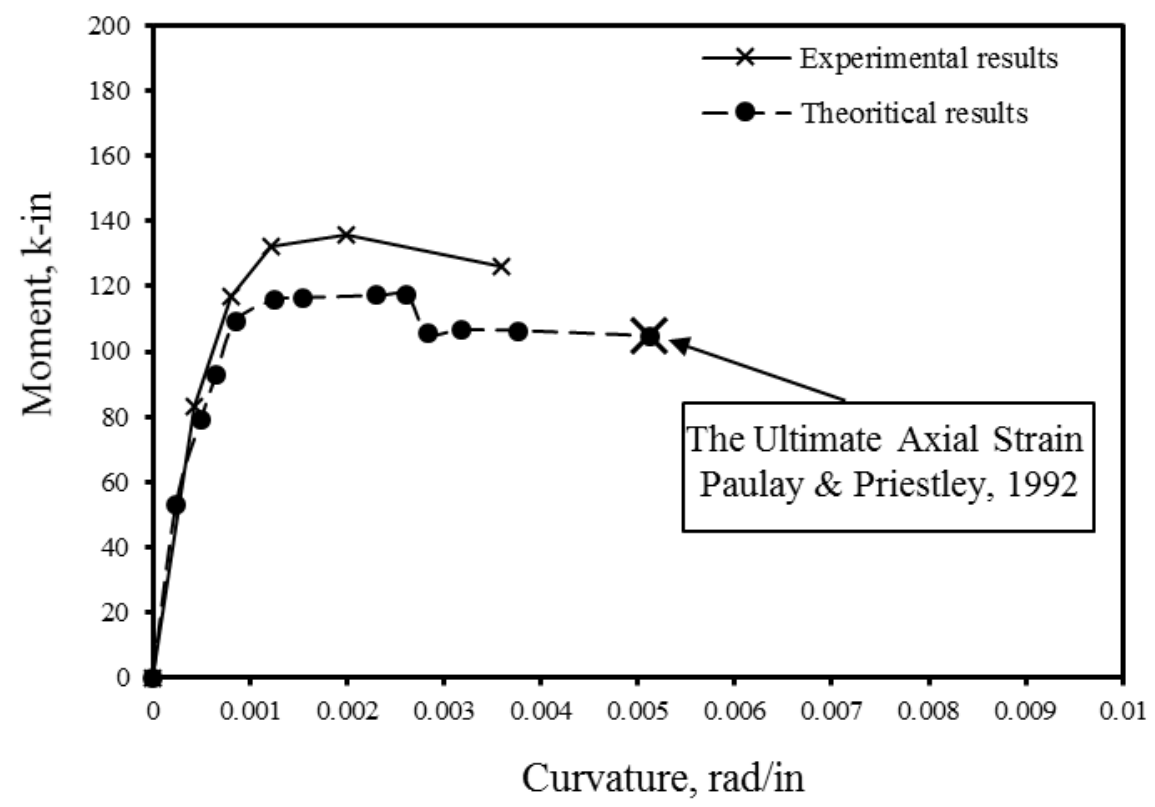

Figure 6.9: Moment-Curvature of Control-0.2

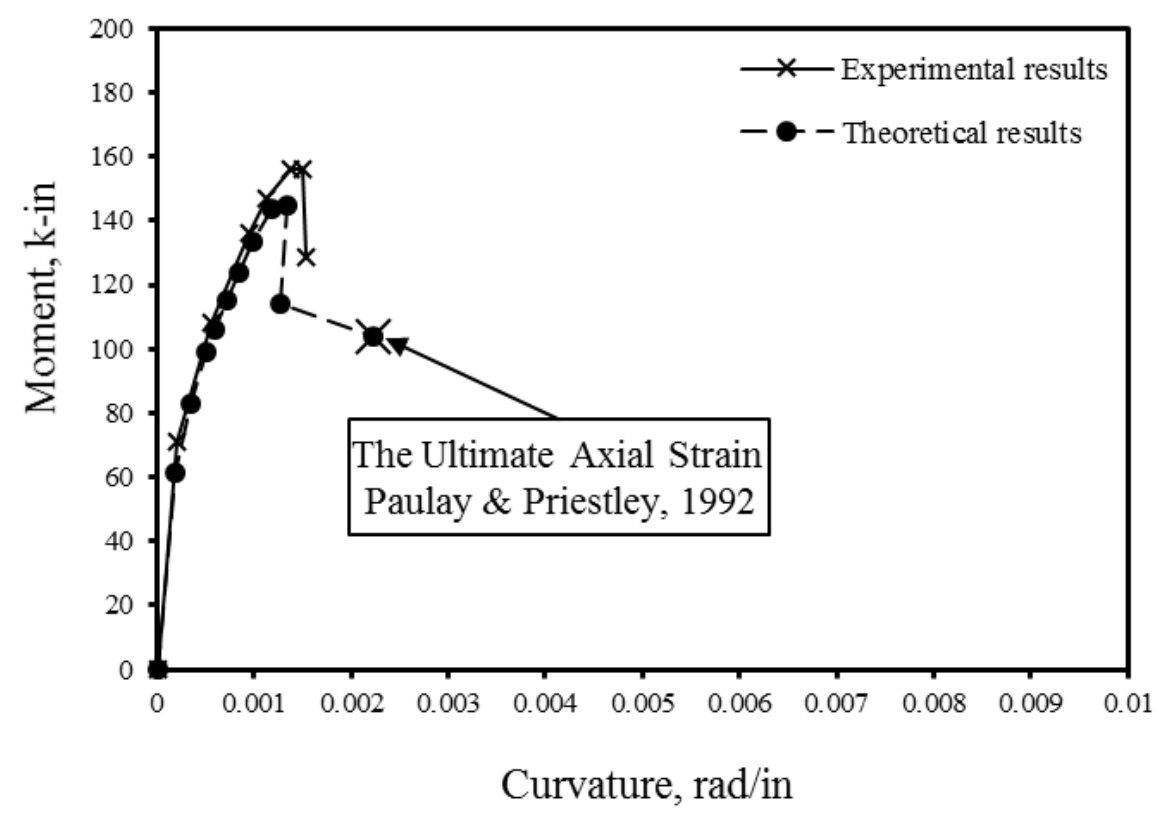

Figure 6.10: Moment-Curvature of Control-0.4

Figs. 6.11 and 6.12 illustrate the comparison between the envelop-curve for experimental results of the CFRP retrofit specimens Retrofit-C01-0.2 and Retrofit-C01- 
0.4 and theoretical results. The theoretical model for CFRP confined concrete predicted a lower value for the ultimate curvature for the CFRP retrofit slender columns tested under a cyclic action.

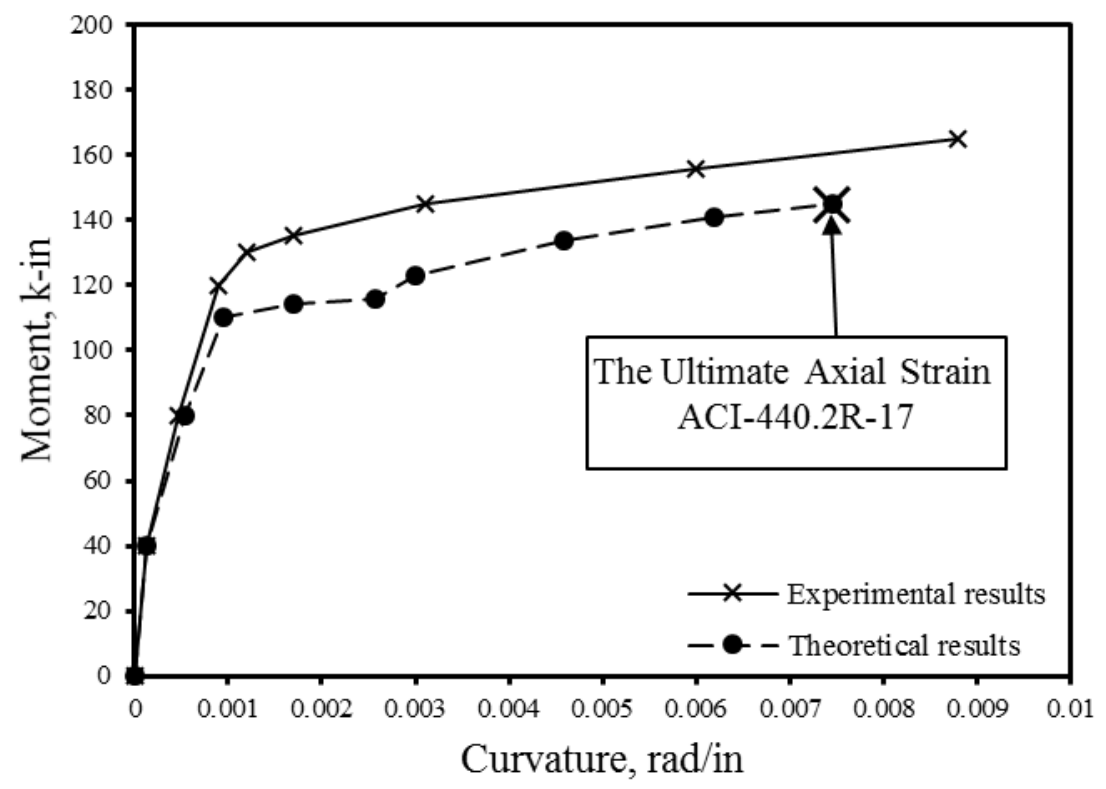

Figure 6.11: Moment-Curvature of Retrofit-C01-0.2

It should be stressed that determination of limit states based on only a few experimental results does not provide a high level of confidence. Most probably, significant statistical variations of the response can be expected if and when similar experiments are repeated in the future. If and when more data are available, it should be feasible to generate confidence limits for the results shown in figures 6.9 through 6.12 . 


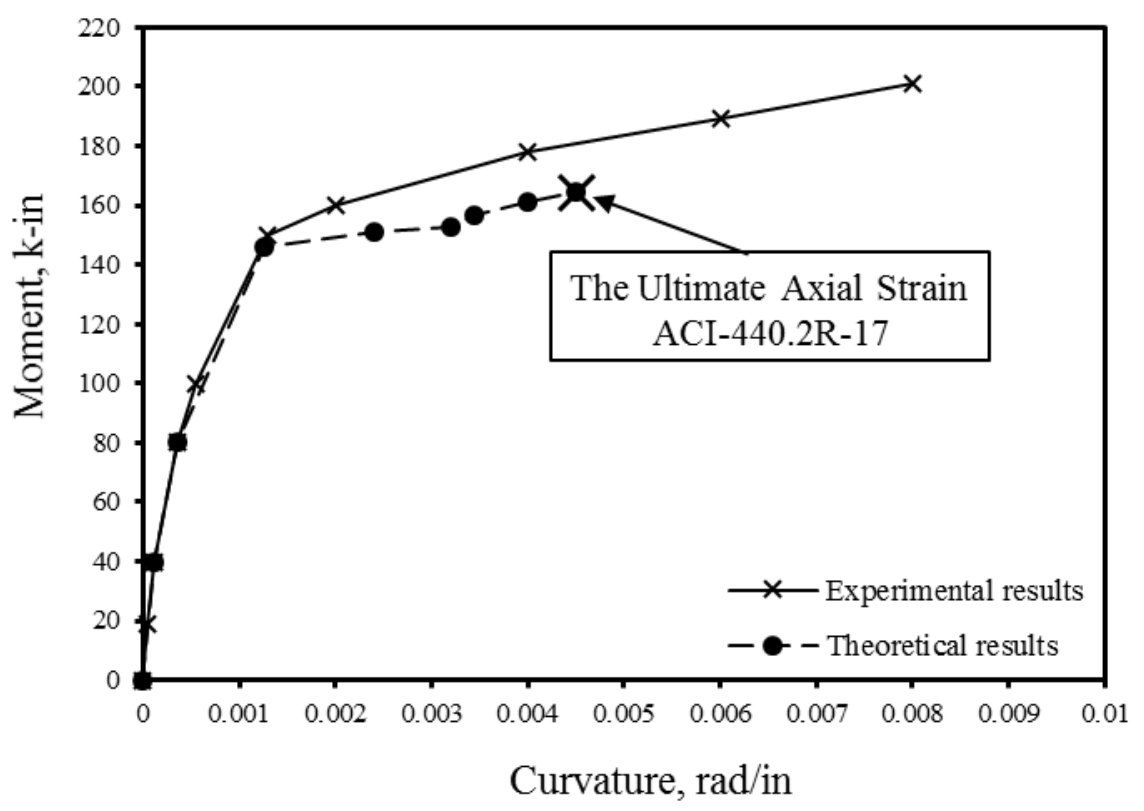

Figure 6.12: Moment-Curvature of Retrofit-C01-0.4

\subsubsection{Lateral Load-Displacement Relation}

Fig. 6.13 illustrates the algorithm of MATLAB scribe used to determine the lateral load-displacement relationship. The program starts with a small lateral load increment, $V_{i}$, and lateral displacement, $\Delta_{i, j}=0$, and calculates the total moment that is equal to the summation of the primary moment plus secondary moment $\left(V_{i}{ }^{*} \mathrm{~L}+\mathrm{P}^{*} \Delta_{i, j}\right)$. The distribution of the curvature along the height of the column is determined based on moment-curvature relation. The flexural displacement, $\Delta_{\text {flexural }}$, is calculated by using the second moment-area method of the curvature curve. Both bar-slip, $\Delta_{\text {bar-slip }}$, and shear deformation, $\Delta_{\text {shear }}$, effects discussed in Chapter 3 are added to the flexural displacement in each step. In order to include the effect of the secondary moment, P- $\Delta$, the program calculates the $\Delta_{i, j+1}$, adds the secondary moment, $\mathrm{P} * \Delta_{i, j+1}$, to the primary 
moment, recalculates the total displacement at $\Delta_{i, j+2}$, and makes a comparison between $\Delta_{i, j+2}$, and $\Delta_{i, j+1}$. These steps are repeated several times until the convergence limit is achieved. When convergence is achieved, the program prints the value of the lateral load, $V_{i}$, versus the displacement, $\Delta_{i, j+n}$, and moves to the next lateral load increment, $V_{i+1}$, up to the ultimate conditions.

The comparison between the theoretical results and the backbone curves of the experimental results of the tested specimens are illustrated in Fig. 6.14. Good agreement was observed between the theoretical and experimental results. 


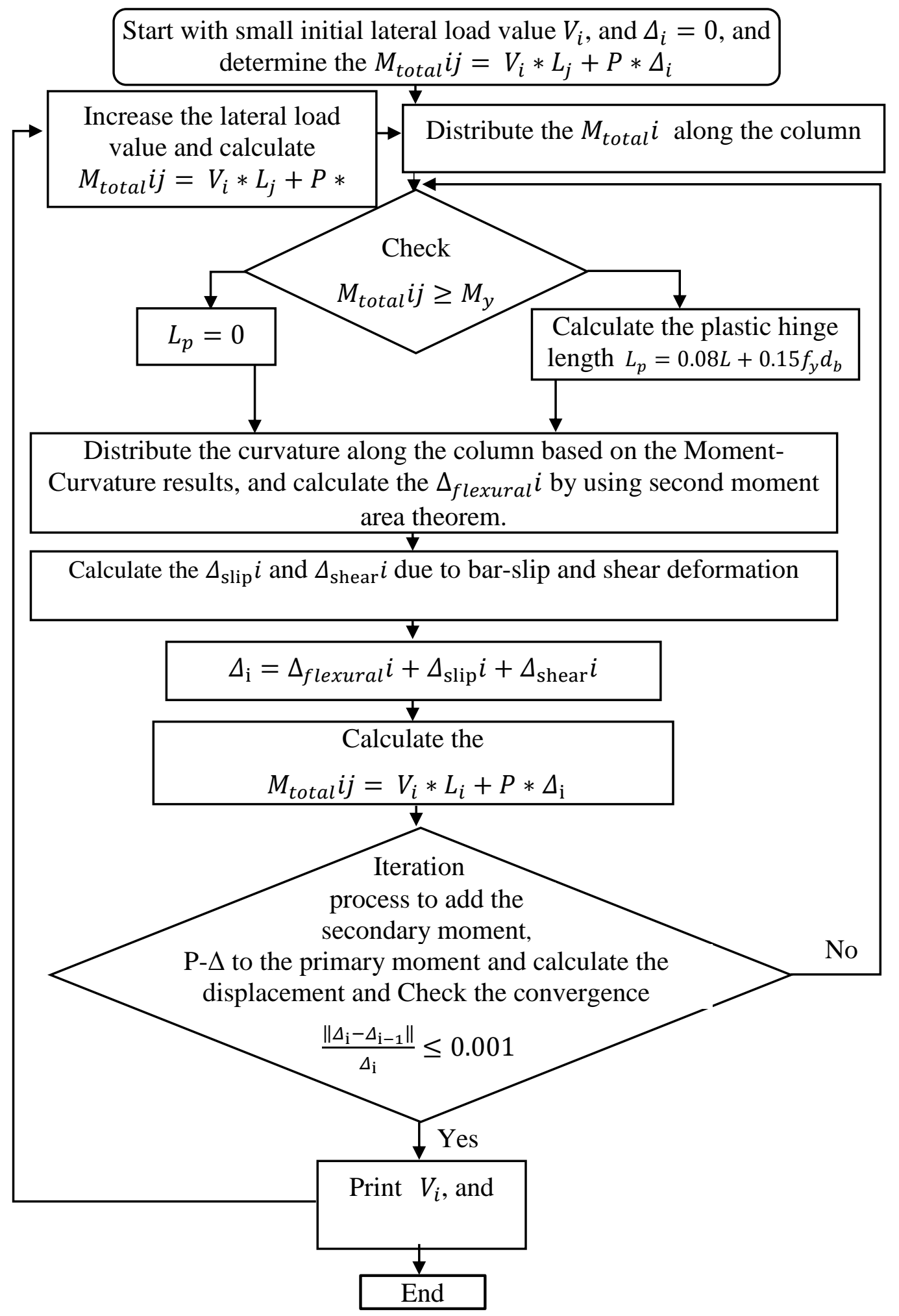

Figure 6.13: Flowchart for Calculating Lateral Load-Displacement 

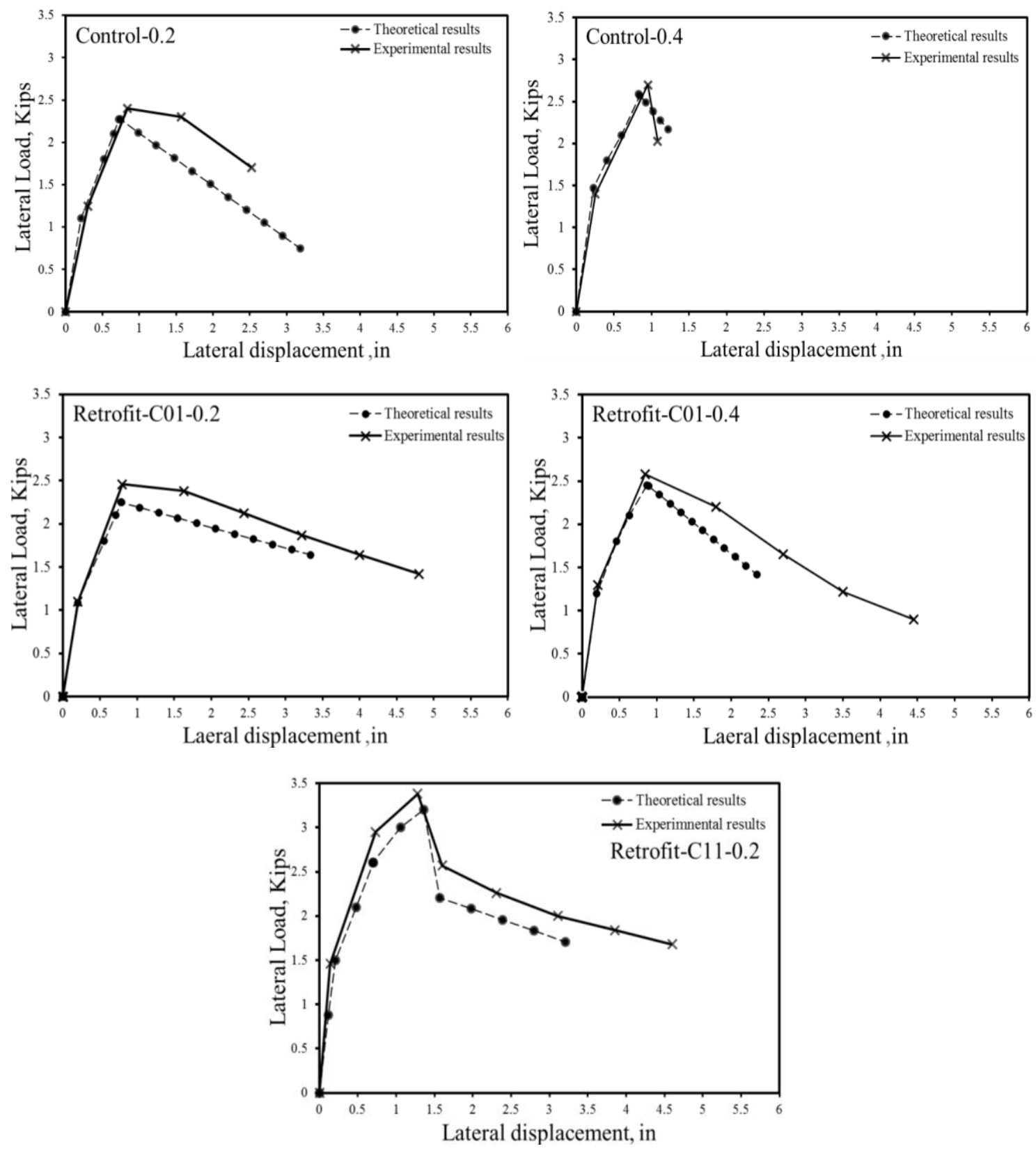

Figure 6.14: Experimental Results vs. Theoretical Results 


\subsection{Modeling Parameters and Acceptance Criteria}

\subsubsection{Modeling Based on ASCE Standards}

Fig. 6.15 illustrates the generalize force-deformation relation proposed by FEMA 356 (2000) and adopted by ASCE/SEI41-13 (2013). In SAP2000, the same relation was implemented to define the modeling parameters and acceptance criteria for the plastic rotation of the concrete element in terms of normalized moment strength versus plastic rotation.

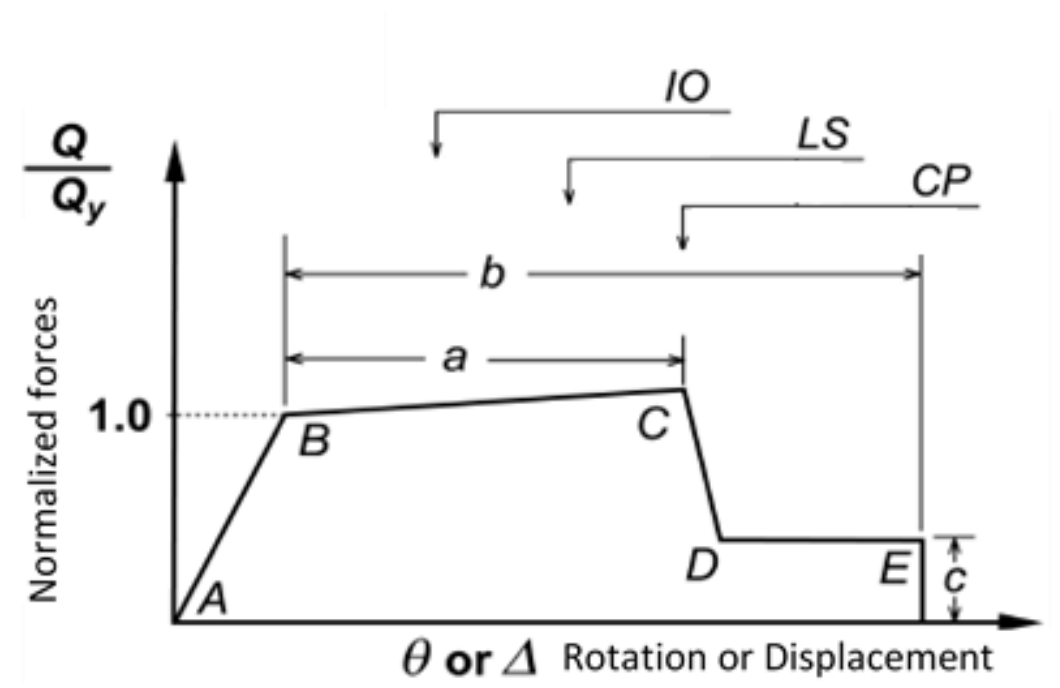

Figure 6.15: Modeling Parameters and Acceptance Criteria Proposed by ASCE 41-13 (2013)

The first portion of the curve, line $\mathrm{AB}$, represents the elastic portion determined based on the elastic stiffness of the structural element. Table 10-5 of ASCE/SEI41-13, (2013) provides values for calculating the effective elastic stiffness for a wide range of structural elements. However, the effect of the shear span to depth ratio is not considered in determining the effective elastic stiffness (ACI 369R-11, 2011). The value of modeling 
parameter $\boldsymbol{a}$ refers to the deformation or plastic rotation that occurs after yield, point B. A sudden drop in the lateral strength, point $\mathrm{C}$, is assumed to be at $20 \%$ (or greater) reduction in the lateral strength (ACI 369R-11, 2011). Parameter $\boldsymbol{b}$ represents the deformation portion or plastic rotation between the yields until the drop in axial load carrying capacity, point $\mathrm{E}$. The residual strength after a sudden drop in lateral load is defined by parameter $\mathbf{c}$.

The values of the modeling parameters $\mathbf{a}$ and $\mathbf{b}$ are calculated based on the table discussed in Chapter 3 (ASCE/SEI41-13, 2013, Table (10-8)). For conventional RC columns, the value of the parameter $\mathbf{a}$ is determined based on the values of axial load ratio, transverse reinforcement ratio, and shear capacity of RC column, and a linear interpolation is allowed for the in-between values. In Table 10-5 of ASCE/SEI41-13 (2013), there is no consideration given to the effect of increasing the shear span to depth ratio related to the secondary moment effect. Figs. 6.16 and 6.17 illustrate the comparison between the calculated modeling parameters and acceptance criteria determined based on Table 10-8 of ASCE/SEI41-13 (2013) and the experimental results of the un-retrofit specimens Control-0.2 and Control-0.4, respectively. For the retrofit specimens, there is no specific guide to define the modeling parameters and acceptance criteria. However, for comparison purposes only, the experimental results for Retrofit-C01-0.2 and RetrofitC01-0.4 are shown along with ASCE/SEI41-13 (2013), Table (10-8), in Figs. 6.18 and 6.19. 


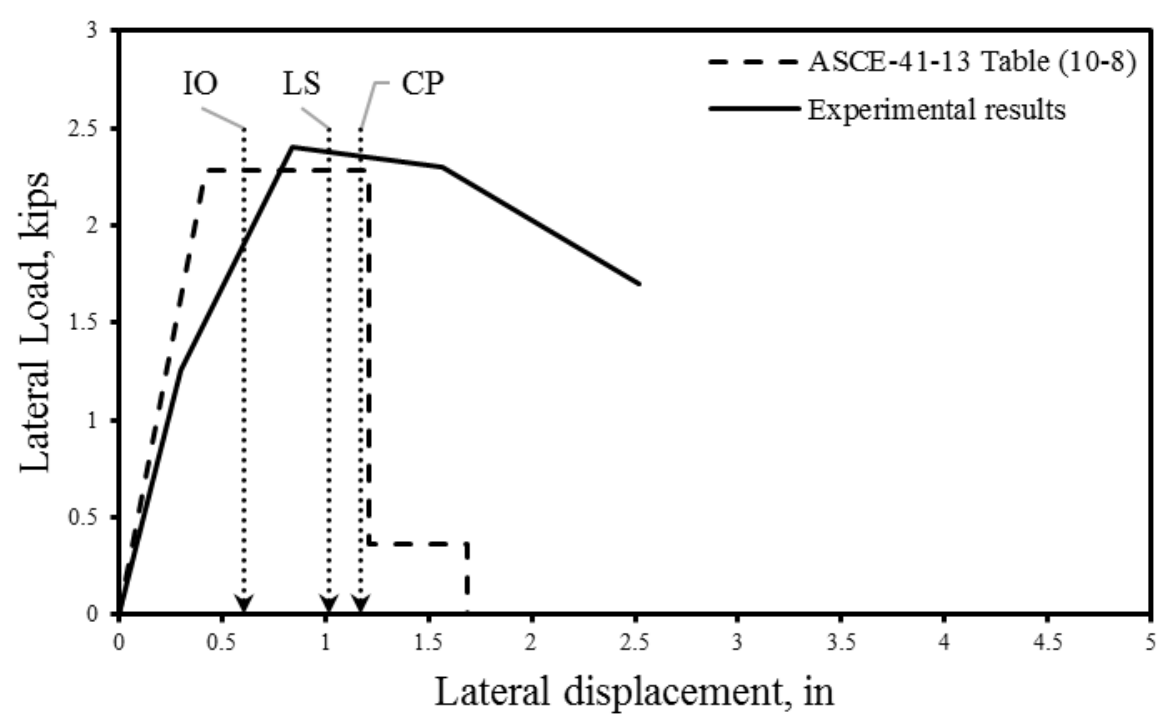

Figure 6.16: Nonlinear Curve of Specimen Control-0.2

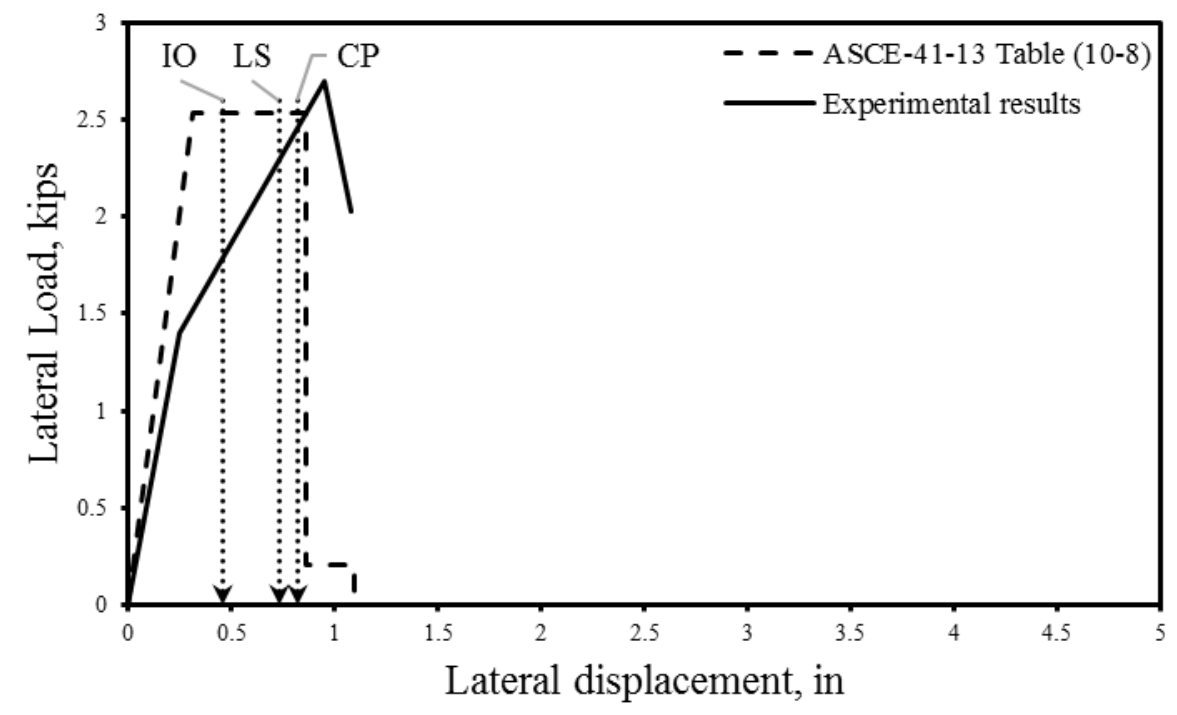

Figure 6.17: Nonlinear Curve of Specimen Control-0.4 


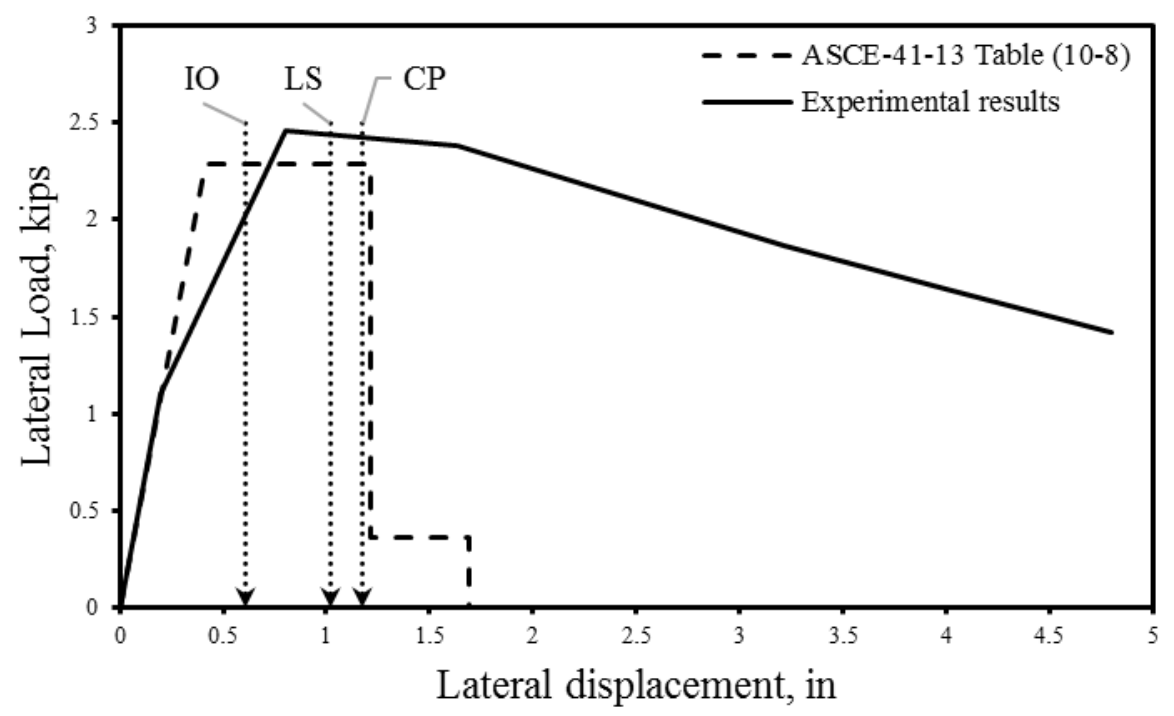

Figure 6.18: Nonlinear Curve of Specimen Retrofit-C01-0.2

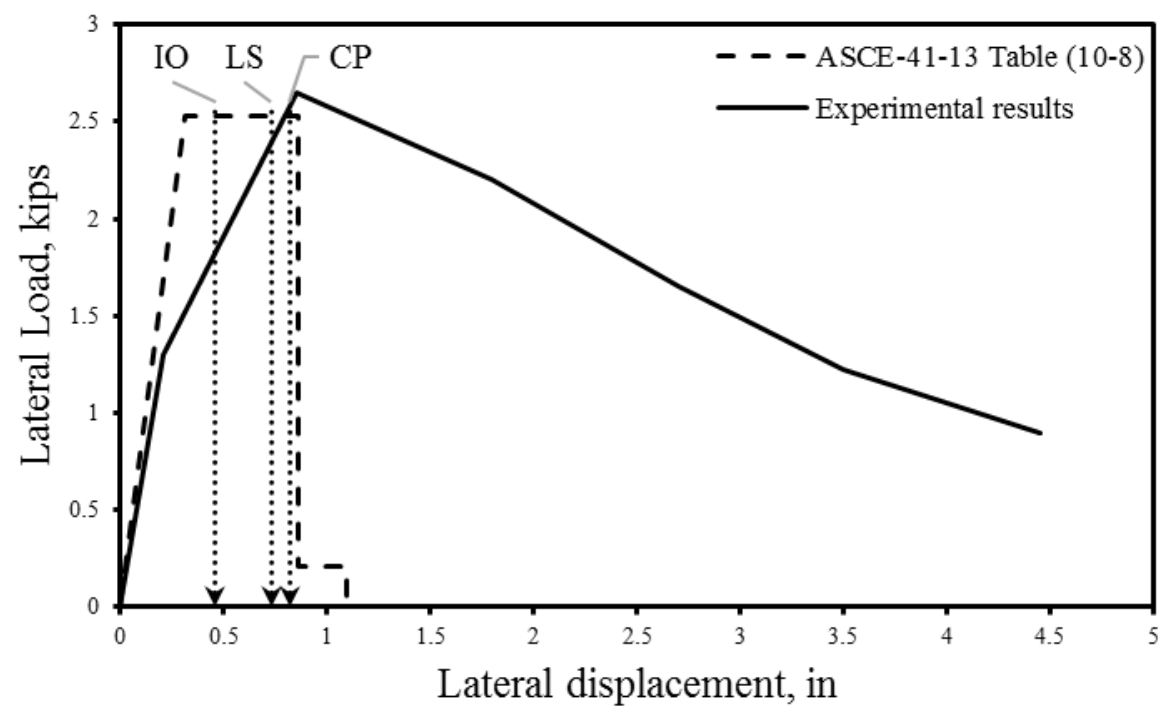

Figure 6.19: Nonlinear Curve of Specimen Retrofit-C01-0.4

Estimating the effective elastic stiffness based on the ASCE/SEI41-13 (2013)

Table (10-5) provides larger values compared with the experimental results, especially for the specimens tested under a high axial load level. As described by (Wu et al., 2006) 
the effect of the secondary moment is increased by increasing the shear-span to depth ratio and axial load level and consequently, the effective elastic stiffness is affected. Determining the elastic stiffness of the member needs to include the effect of the shearspan to depth ratio to refine the elastic effective stiffness value. Moreover, it is recommended that the effect of each flexural bar-slip shear deformation be included in determining the effective elastic stiffness (Elwood \& Eberhard, 2009). In this study the effect of the shear-span to depth ratio, flexural deformation, bar-slip rotation, and shear deformation were considered, and the effective elastic stiffness determined based on the theoretical results provided good agreement with the experimental results.

In order to evaluate the behavior of the tested specimens, the ASCE/SEI41-13 (2013) provides guideline to determine the acceptance criteria, Immediate Occupancy (IO), Life Safety (LS), and Collapse Prevention (CP). In this procedure, the collapse prevention level, $\mathrm{CP}$, is defined as the deformation corresponding to the considerable drop in the lateral strength, and the life safety level, LS, is at $75 \%$ of the deformation at the collapse prevention. While the immediate occupancy level is defined as the deformation corresponding to the permanent, visible damage occurring in the specimen, but no more than 0.67 times the deformation at the life safety level.

\subsubsection{Modeling Based on the Stress-Strain Relation}

A few studies propose the acceptance criteria of the RC member in terms of the stress-strain relation that defined the behavior of the concrete and steel under axial load. As proposed by Sharifi, Banan, \& Banan (2012); Yue, Qian, \& Beskos (2016); and Saleemuddin \& Sangle (2017) the IO limit is defined as the deformation corresponding to 
axial strain $\varepsilon_{c}^{\prime}=0.002$ in concrete, or 0.25 of the ultimate tensile strain in the steel, $\varepsilon_{s u}$; LS limit is defined as the deformation corresponding to $20 \%$ decay in the concrete stress $0.58 \varepsilon_{s u}$, and CP limit at the deformation corresponding to $50 \%$ decay in the concrete strength or $\varepsilon_{s u}$.

However, for slender RC columns, the P- $\Delta$ effect leads to increasing degradation of lateral strength in the inelastic range. Moreover, keeping the lateral strength degradation within a specific limit helps to avoid the lateral instability that leads to a partial or total collapse in the structure ACI 374.2R-13 (2013). Therefore, in this study, a combination of criteria available in the literature was adopted to define the acceptance criteria to evaluate the responses of the tested specimens.

\subsubsection{The Acceptance Criteria Limits Proposed for Un-Retrofit Specimens}

For the un-retrofit specimens, Control-0.2, and Control-0.4, the following parameters were selected:

1. The IO limit is set at concrete axial strain, $\varepsilon_{c}^{\prime}=0.002$, or $0.25 \varepsilon_{s u}$, (Sharifi, Banan, \& Banan, 2012; Yue, Qian, \& Beskos, 2016; Saleemuddin \& Sangle, 2017).

2. The maximum limit for the IO is set at 0.67 of the LS limit, per ASCE/SEI41-13 (2013).

3. The $\mathrm{CP}$ limit is set as the deformation corresponding to $20 \%$ decay in the lateral strength, per ACI 369R-11 (2011).

4. The LS limit is set as a 75\% of the deformation at CP limit, per ASCE/SEI41-13 (2013). 
Based on this definitions, the acceptance criteria for the tested specimens was determined, as shown in Fig. 6.20 through 6.21. Table 6-1 presents the comparison between the acceptance criteria calculated based on ASCE/SEI41-13 (2013), Table (10-8) and the acceptance criteria proposed in this study to evaluate the response of the experimental results of the un-retrofit specimens. Based on this comparison, it appears that increasing the effect of the P- $\Delta$ leads to increased uncertainty in using the results of ASCE/SEI41-13 (2013), Table (10-8). Therefore, seems prudent to include the effect of the shear span to depth ratio in addition to axial load level to predict the acceptance criteria.

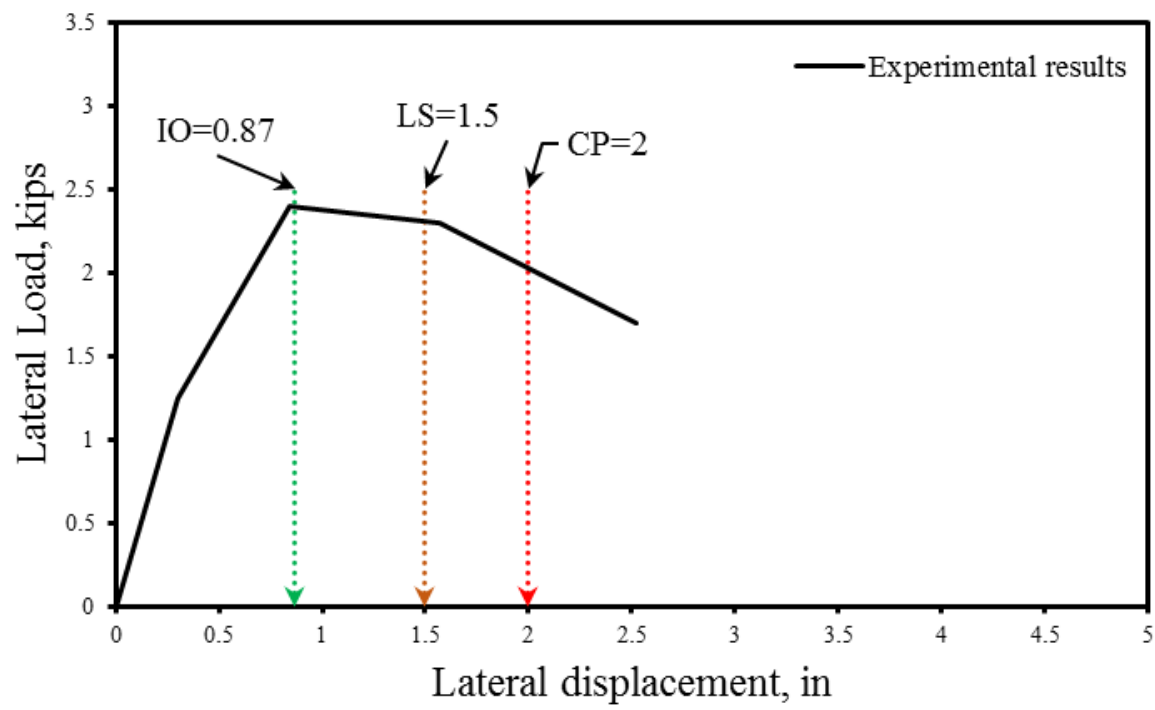

Figure 6.20: Modified Acceptance Criteria of Specimen Control-0.2 


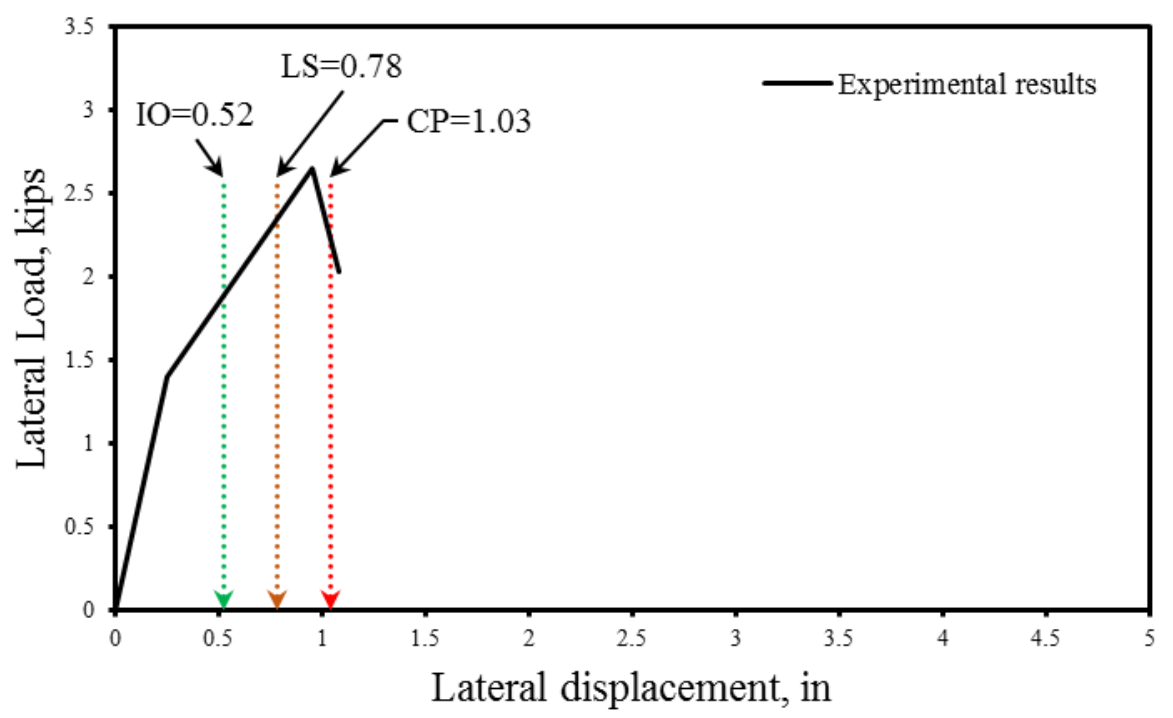

Figure 6.21: Modified Acceptance Criteria of Specimen Control-0.4

Table 6-1: Comparison between the Acceptance Criteria

\begin{tabular}{|c||c|c|c||c|c|c||c|c|c||}
\hline \hline \multirow{2}{*||}{ Specimen } & \multicolumn{3}{|c||}{$\begin{array}{c}\text { ASCE 41-13 Table } \\
\mathbf{( 1 0 - 8 )}, \text { in }\end{array}$} & \multicolumn{3}{c||}{$\begin{array}{c}\text { Proposed Acceptance } \\
\text { Criteria, in }\end{array}$} & \multicolumn{3}{c||}{ Proposed AC } \\
\cline { 2 - 9 } & IO & LS & CP & IO & LS & CP & IO & LS & CP \\
\hline \hline $\begin{array}{c}\text { Control- } \\
0.2\end{array}$ & 0.60 & 1.08 & 1.17 & 0.87 & 1.50 & 2.00 & 1.45 & 1.40 & 1.7 \\
\hline $\begin{array}{c}\text { Control- } \\
0.4\end{array}$ & 0.45 & 0.73 & 0.82 & 0.52 & 0.78 & 1.03 & 1.16 & 1.10 & 1.30 \\
\hline \hline
\end{tabular}

AC: Acceptance Criteria 


\subsubsection{The Acceptance Criteria Limits Proposed for Retrofit Specimens}

For retrofit specimens Retrofit-C01-0.2 and Retrofit-C01-0.4, there was no specific guide to define the acceptance criteria. A few studies attempt to define the ultimate condition of the retrofit $\mathrm{RC}$ member based on the plastic hinge rotation and considered the ultimate tensile strain of the CFRP as a limit for the ultimate plastic rotation (Biskinis \& Fardis, 2013; \& Li \& Harries, 2018). However, ACI 440.2R-17 (2017) adopted 0.01 as the ultimate limit for the axial strain of CFRP-confinement concrete specimens. In this study, the ultimate plastic rotation was defined as the limit at which the axial strain at the extreme confined concrete layer was equal to 0.01 .

Based on experimental results, it was observed that the lateral strength of the retrofit specimens reduced with increasing lateral displacement and the main reason for this reduction is the P- $\Delta$ effect. Considering the $20 \%$ decay in the lateral strength as a limit for the $\mathrm{CP}$ is conservative for the CFRP retrofit specimens, and a large portion of available lateral displacement would be neglected. Moreover, the degradation in the lateral strength during the test was not a result of gradual damage in the column, but was attributed to the existence of $\mathrm{P}-\Delta$. The behavior of the retrofit specimens was stable up to the end of the test. Therefore, in this study, the $30 \%$ decay in lateral strength was adopted as a limit for the CP. Moreover, $30 \%$ decay in lateral strength was considered as a limit for the ultimate lateral displacement, even for the un-retrofit RC columns (Priestley, 2000; Wu, Yu-Fei et al., 2006).

Based on the experimental results of Mirmiran \& Shahawy (1997) tests of confined concrete cylinders, axial strain corresponding to $f_{c}^{\prime}$, i.e., $\varepsilon_{c}^{\prime}=0.002$, was 
proposed as a limit for the point where the FRP fully supports the lateral dilation of the concrete. Recent studies by Jiang \& Teng (2007) proposed that this point approximately corresponds to the axial strain equal to $2 \varepsilon_{c}^{\prime}$ (i.e., 0.004). It seems reasonable to set the IO limit for the retrofit specimens as the axial strain of the confined concrete at which the CFRP-confined system fully suppresses lateral dilation. In order to be on the conservative side, in this study the IO limit is proposed as when concrete strain reaches $\varepsilon_{c}^{\prime}=0.002$.

In this study, the following parameters were selected to define acceptance criteria for the retrofit specimens, Retrofit-C01-0.2, Retrofit-C11-0.2, and Retrofit-C01-0.4:

1. The IO limit is set when concrete axial strain, $\varepsilon_{c}^{\prime}=0.002$, per Mirmiran \& Shahawy (1997) or steel tensile strain $0.25 \varepsilon_{s u}$ per Sharifi, Banan, \& Banan (2012)

2. The maximum limit for the IO is set at 0.67 of the LS limit, per ASCE/SEI41-13(2013)

3. The CP limit is set as the deformation corresponding to $30 \%$ decay in the lateral strength, per Priestley (2000); and Wu, Yu-Fei et al. (2006).

4. The LS limit is set as a 0.75 the deformation at CP limit, per ASCE/SEI41-13 (2013), concrete compression axial strain 0.01 (ACI 440.2R-17, 2017), or steel tensile strain $\varepsilon_{u}$.

Based on these limits, the acceptance criteria for the retrofit specimens RetrofitC01-02, Retrofit-C11-0.2, and Retrofit-C01-0.4 were calculated as shown in Figs. 6.22 through 6.24.

The proposed acceptance criteria provided reasonable limits for the performance level of the retrofit specimens, because these limits considered stress-strain relation, and 
lateral strength degradation. Table 6-2 presents the acceptance criteria for the CFRP retrofit as well as un-retrofit specimens.

For the retrofit specimens tested under low axial load $0.2 f_{c}^{\prime} A_{g}$, the acceptance criteria improved $74 \%$ for LS and CP. Meanwhile, acceptance criteria LS and CP for the retrofit specimens tested under moderate axial load $0.4 f_{c}^{\prime} A_{g}$, improved by $115 \%$. Based on this comparison, the acceptance criteria of the specimen Retrofit-C01-0.4 significantly improved compared with Retrofit-C01-0.2. This improvement was attributed to the difference between the behavior of the retrofit and un-retrofit specimens under moderate axial load levels. For specimen Retrofit-C11-0.2, increasing the lateral strength of the specimen up to $38 \%$ instigated a rapid drop in the lateral strength, leading to a decreased CP limit based on $30 \%$ decay of lateral strength. However, the specimen behaved well with stable cyclic action up to the end of the test.

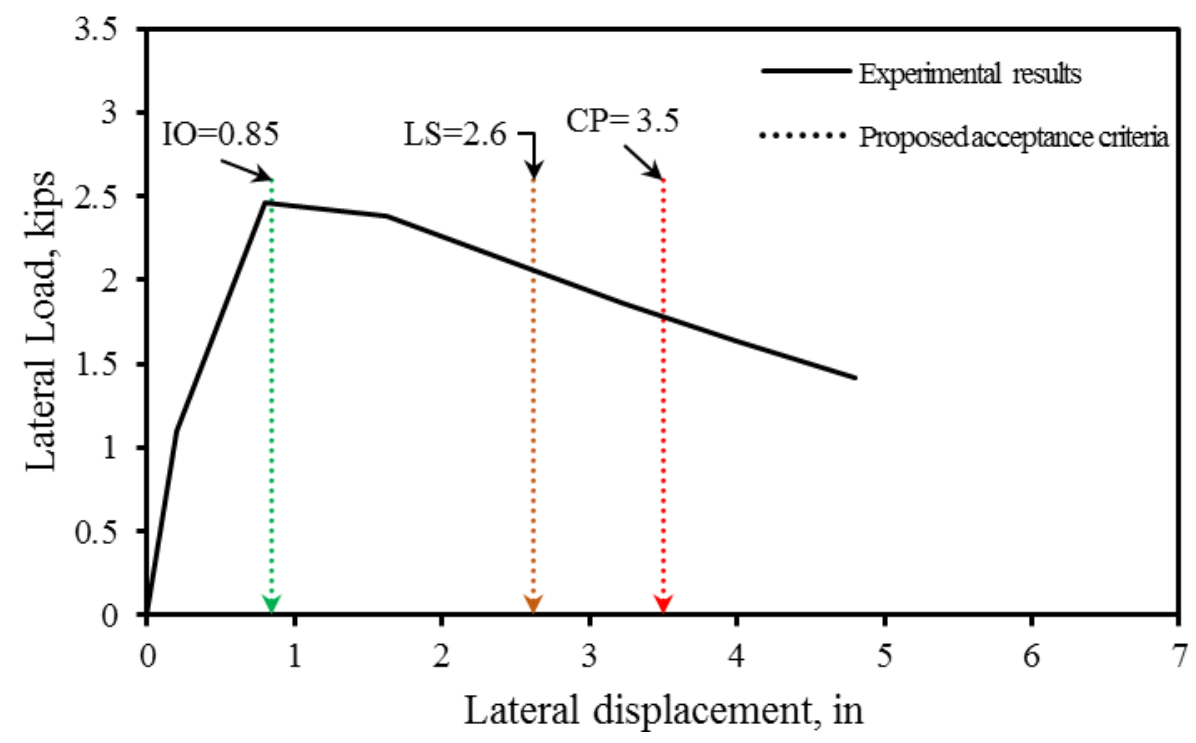

Figure 6.22: Proposed Acceptance Criteria of Specimen Retrofit-C01-0.2 


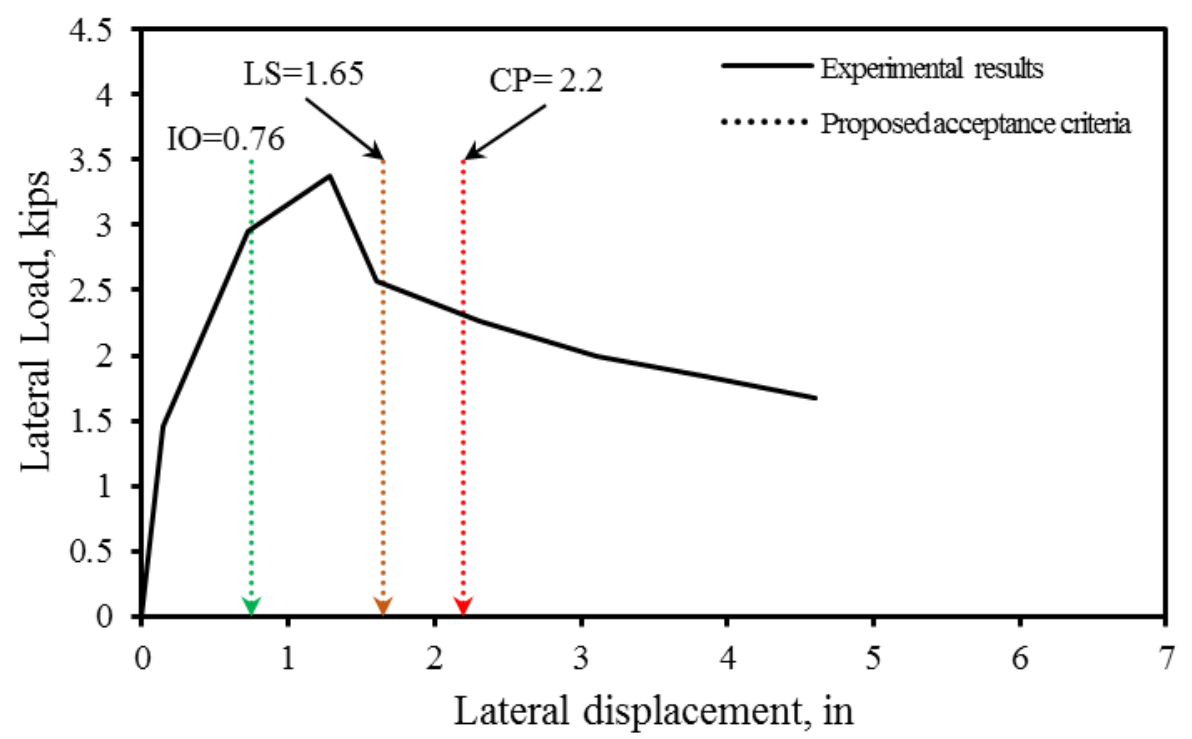

Figure 6.23: Proposed Acceptance Criteria of Specimen Retrofit-C11-0.2

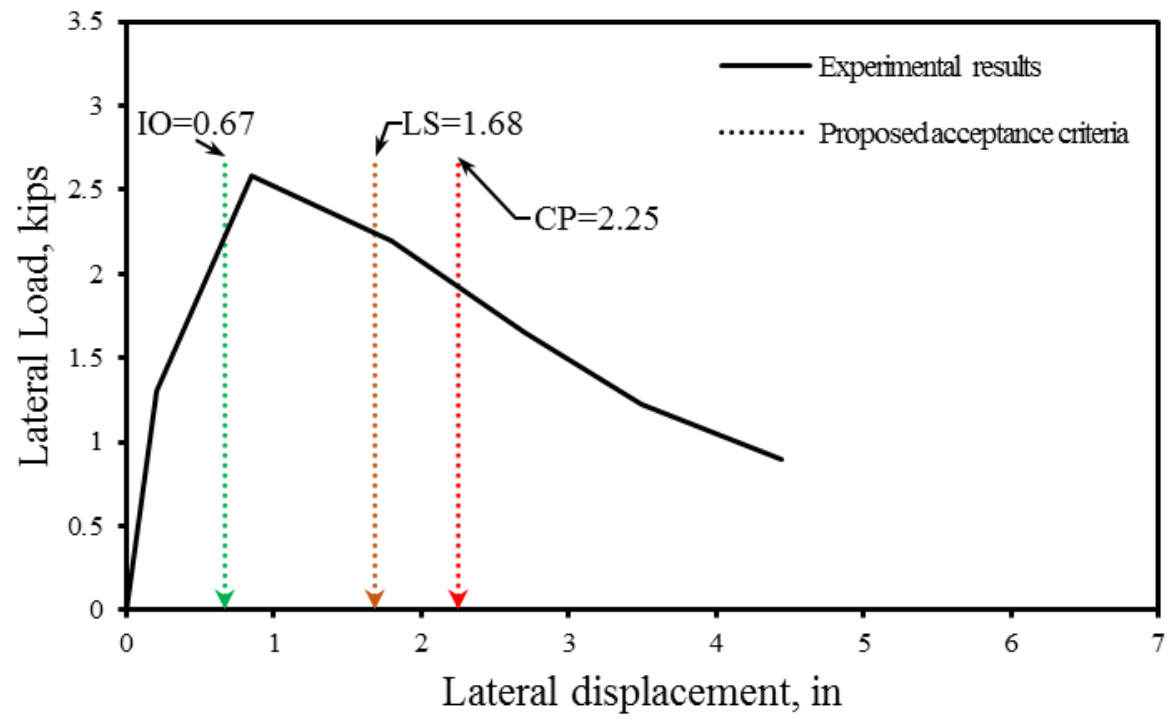

Figure 6.24: Proposed Acceptance Criteria of Specimen Retrofit-C01-0.4 
Table 6-2: the Acceptance Criteria of the Retrofit and Un-Retrofit Specimens

\begin{tabular}{|c|c|c|c|}
\hline \multirow[t]{2}{*}{ Specimen } & \multicolumn{3}{|c|}{$\begin{array}{l}\text { Proposed acceptance criteria for the retrofit and un- } \\
\text { retrofit specimens }\end{array}$} \\
\hline & IO & $\mathbf{L S}$ & $\mathbf{C P}$ \\
\hline Control-0.2 & 0.87 & 1.5 & 2 \\
\hline Retrofit-C01-0.2 & 0.98 & 2.6 & 3.5 \\
\hline Retrofit-C11-0.2 & 0.76 & 1.65 & 2.2 \\
\hline Control-0.4 & 0.52 & 0.78 & 1.03 \\
\hline Retrofit-C01-0.4 & 0.85 & 1.68 & 2.25 \\
\hline
\end{tabular}

\subsection{Case Study of Two Prototype Buildings}

In this study, two- and four-story buildings were selected to perform NSP analysis and investigate their response to specific response spectra. Furthermore, the effect of CFRP retrofitting technique on improving the performance level of the buildings was investigated. The main goal of writing a MATLAB script was to predict the rotation capacity of a full-scale RC slender column, retrofit or un-retrofit with CFRP, and to implement these results in SAP2000 software to define acceptance criteria for such columns. To perform the NSP analysis on the full-scale RC column, several steps need to be followed:

1) Define the prototype buildings in term of structural design and types of loading

2) Define the plastic hinge rotation behavior of the full-scale RC columns by using MATLAB scripts

3) Perform the pushover analysis

4) Implement the CMP to determine the target displacement

5) Identify the performance level of the RC buildings based on the target displacement 


\subsubsection{Locations of the Prototype Buildings}

The configuration and details of the two RC buildings, two-story and four-story respectively, which were constructed with slender RC columns in first-floor level, are illustrated in Chapter 4. The design and reinforcement details for the columns and beams of the RC frames represent the existing $\mathrm{RC}$ buildings designed based on the older codes. These types of buildings are very common around the world. In this study, buildings were selected in Iraq. Iraq is regularly affected by earthquakes and the earthquake intensity is moderate to high at the northern and northeastern boundaries, and low in the south and southwestern regions. Figure 6.25 illustrates the probabilistic seismic hazard in Iraq for a $2 \%$ chance of exceedance in 50 years (Ameer et al., 2005).
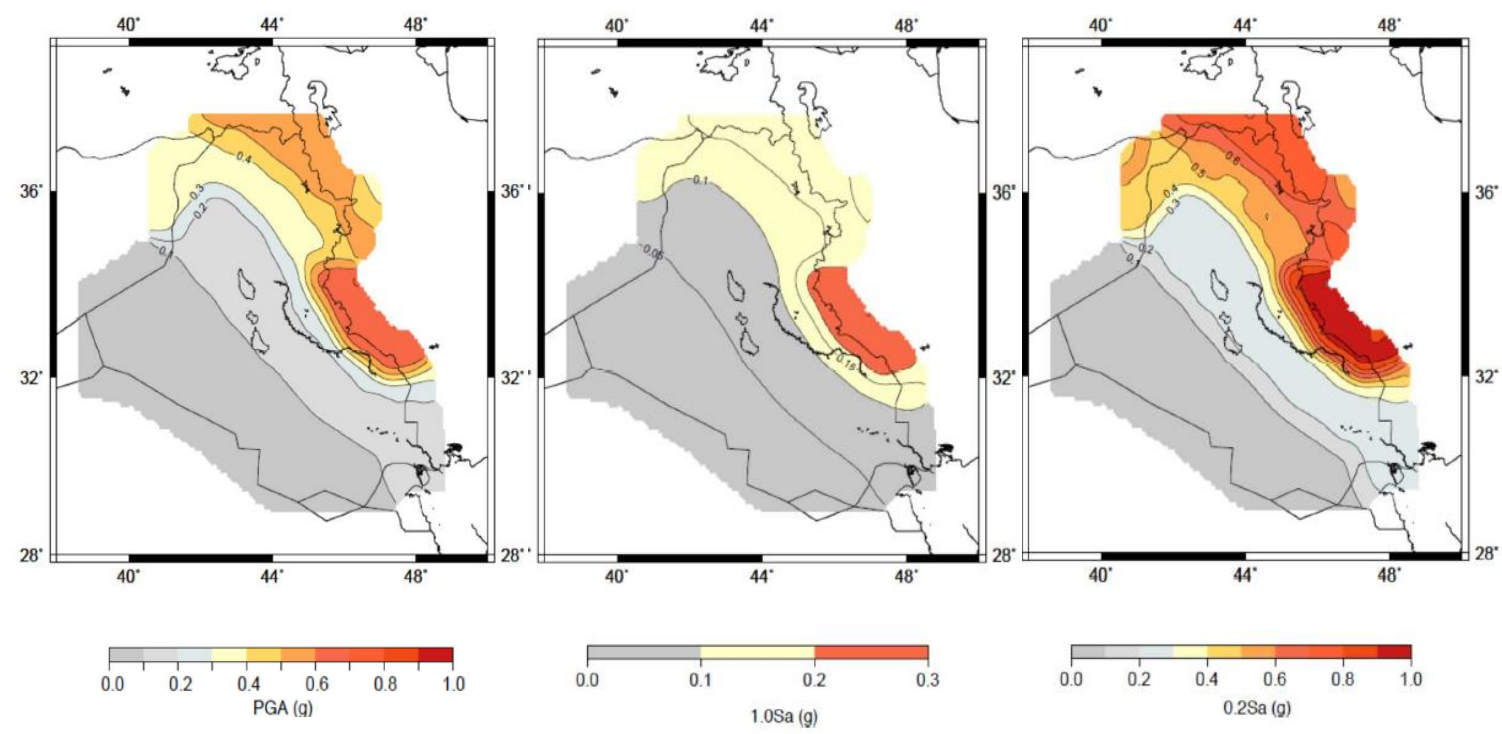

Figure 6.25: Probabilistic Seismic Hazard in Iraq (2\% in 50 years) 


\subsubsection{Plastic Hinge Rotation Capacity}

\subsubsection{Un-Retrofit Slender Column}

The rotation capacity of the plastic hinge of the full-scale RC slender column was determined by using MATLAB scripts. Figure 6.26 illustrates the details and properties of the full-scale slender column used in the first floors of both two- and four-story buildings. Figures 6.27 and 6.28 illustrate the moment-curvature for the un-retrofit fullscale RC columns under axial load levels of $0.2 f_{c}^{\prime} A_{g}$ and $0.4 f_{c}^{\prime} A_{g}$, respectively. In order to simplify the complexity of the inelastic portion, a trilinear moment-curvature relationship was used to determine the lateral load displacement ratios for the columns. With the effect of the P- $\Delta$, the lateral load-displacement relation and the proposed acceptance criteria for the un-retrofit columns were determined as shown in Figs. 6.29 and 6.30 .

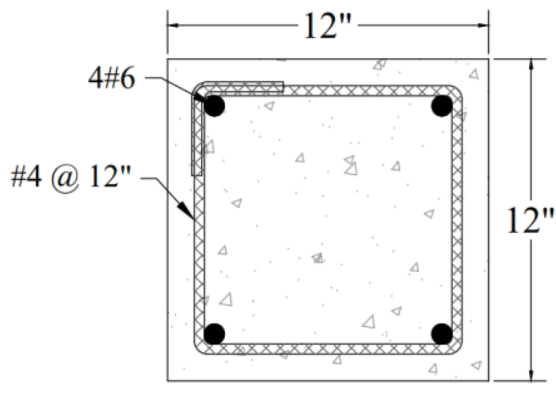

\begin{tabular}{|c|c|c|}
\hline Material & Properties & Quantity \\
\hline \multirow{3}{*}{ Concrete } & Compressive Strength, $f_{c}^{\prime}$ & $3000 \mathrm{psi}$ \\
\hline & Compressive Strain, $\varepsilon_{c}^{\prime}$ & 0.0022 \\
\hline & Ultimate Strain, $\varepsilon_{u}$ & 0.0035 \\
\hline \multirow{5}{*}{ Steel } & Modulus of Elasticity, $E_{y}$ & $29000000 \mathrm{psi}$ \\
\hline & Yield Stress, $f_{y}$ & $72000 \mathrm{psi}$ \\
\hline & Yield Strain, $\varepsilon_{y}$ & 0.00248 \\
\hline & Ultimate stress, $f_{u}$ & $110000 \mathrm{psi}$ \\
\hline & Ultimate Strain, $\varepsilon_{s u}$ & 0.05 \\
\hline
\end{tabular}

Figure 6.26: Details and Properties of the Un-Retrofit Slender Column 


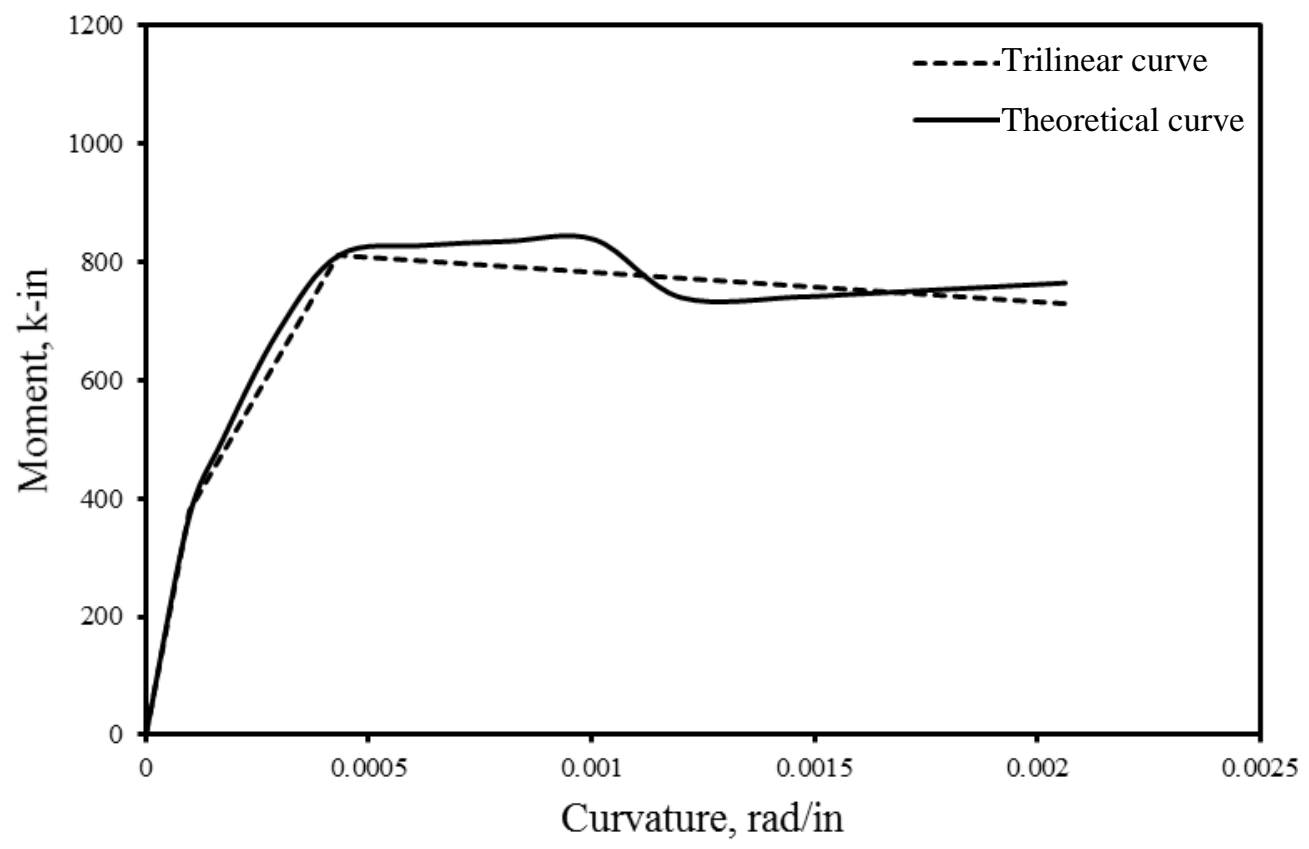

Figure 6.27: Moment-Curvature for Full-scale Column, Axial Load 0.2 $f_{c}^{\prime} A_{g}$

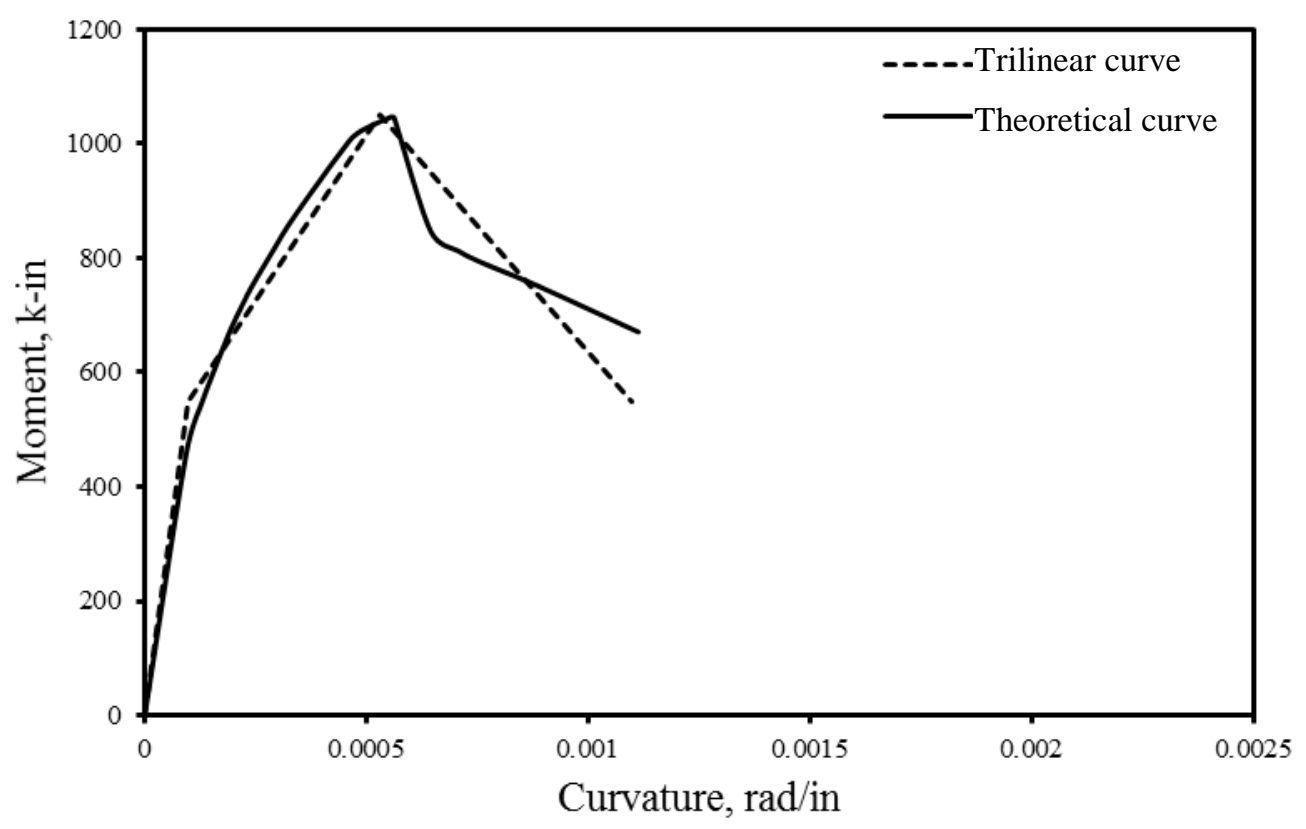

Figure 6.28: Moment-Curvature for Full-scale Column, Axial Load 0.4 $f_{c}^{\prime} A_{g}$ 


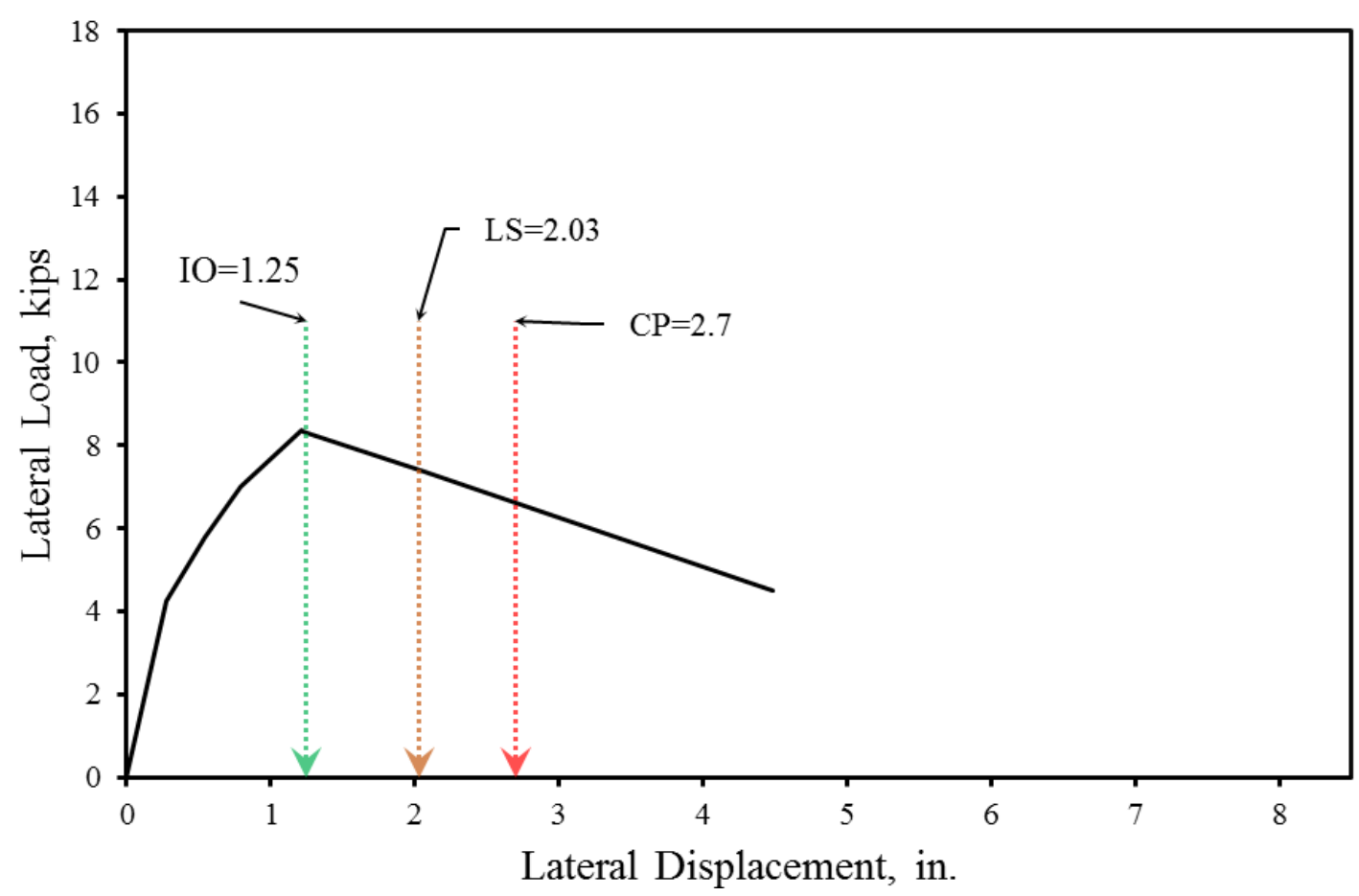

Figure 6.29: Load-Displacement and Acceptance Criteria, Full-scale Column $0.2 f_{c}^{\prime} A_{g}$

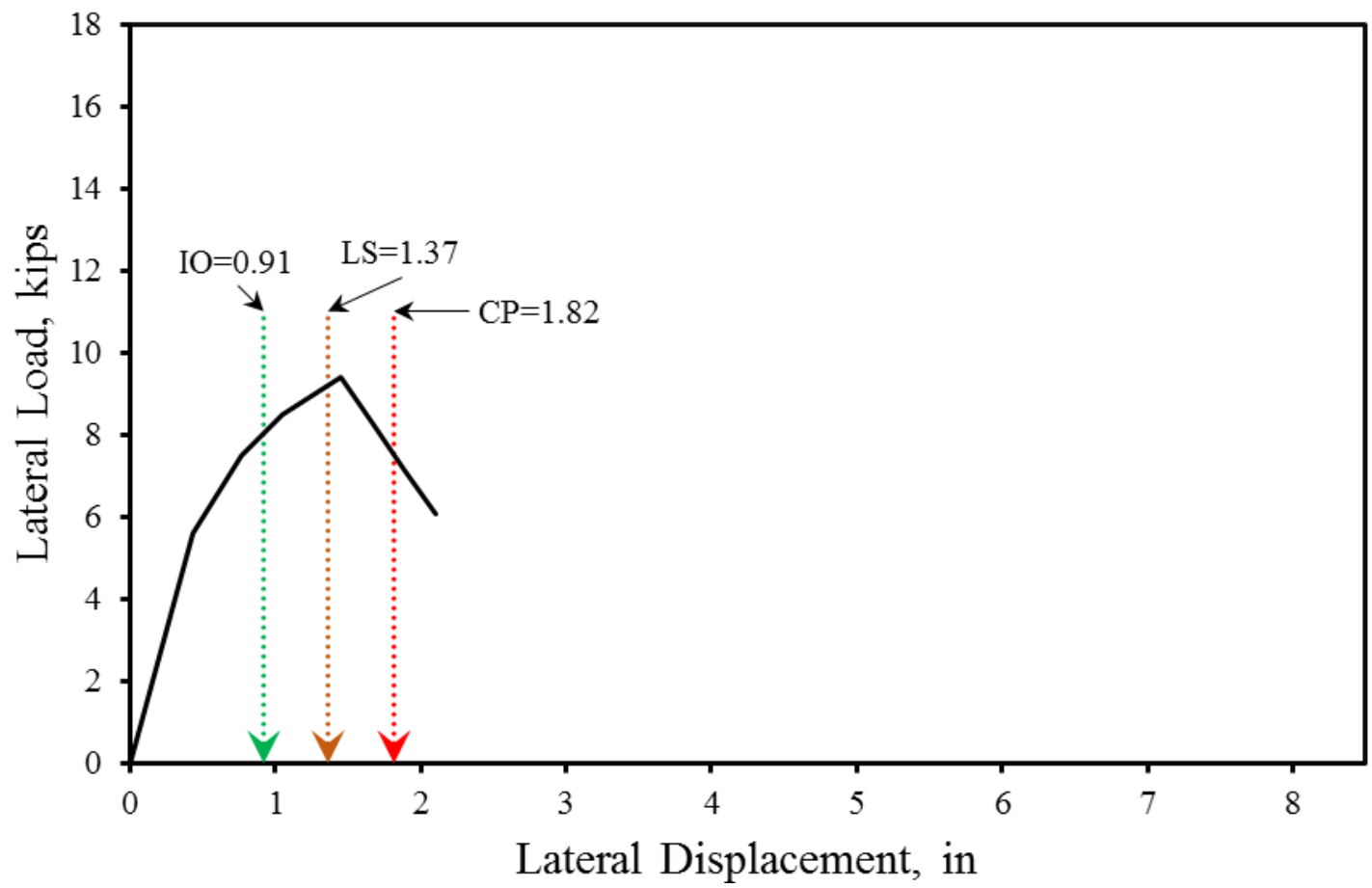

Figure 6.30: Load-Displacement and Acceptance Criteria, Full-Scale Column, $0.4 f_{c}^{\prime} A_{g}$ 
The rotation capacity of the plastic hinge for the columns was calculated based on the moment-curvature and lateral load-displacement relations, and by dividing the lateral displacement by the shear span height of the column. Figures 6.31 and 6.32 illustrate the rotation capacity of the plastic hinge versus normalized moment strength at the plastic hinge region, and the corresponding acceptance criteria for the columns under axial load level $0.2 f_{c}^{\prime} A_{g}$ and $0.4 f_{c}^{\prime} A_{g}$, respectively.

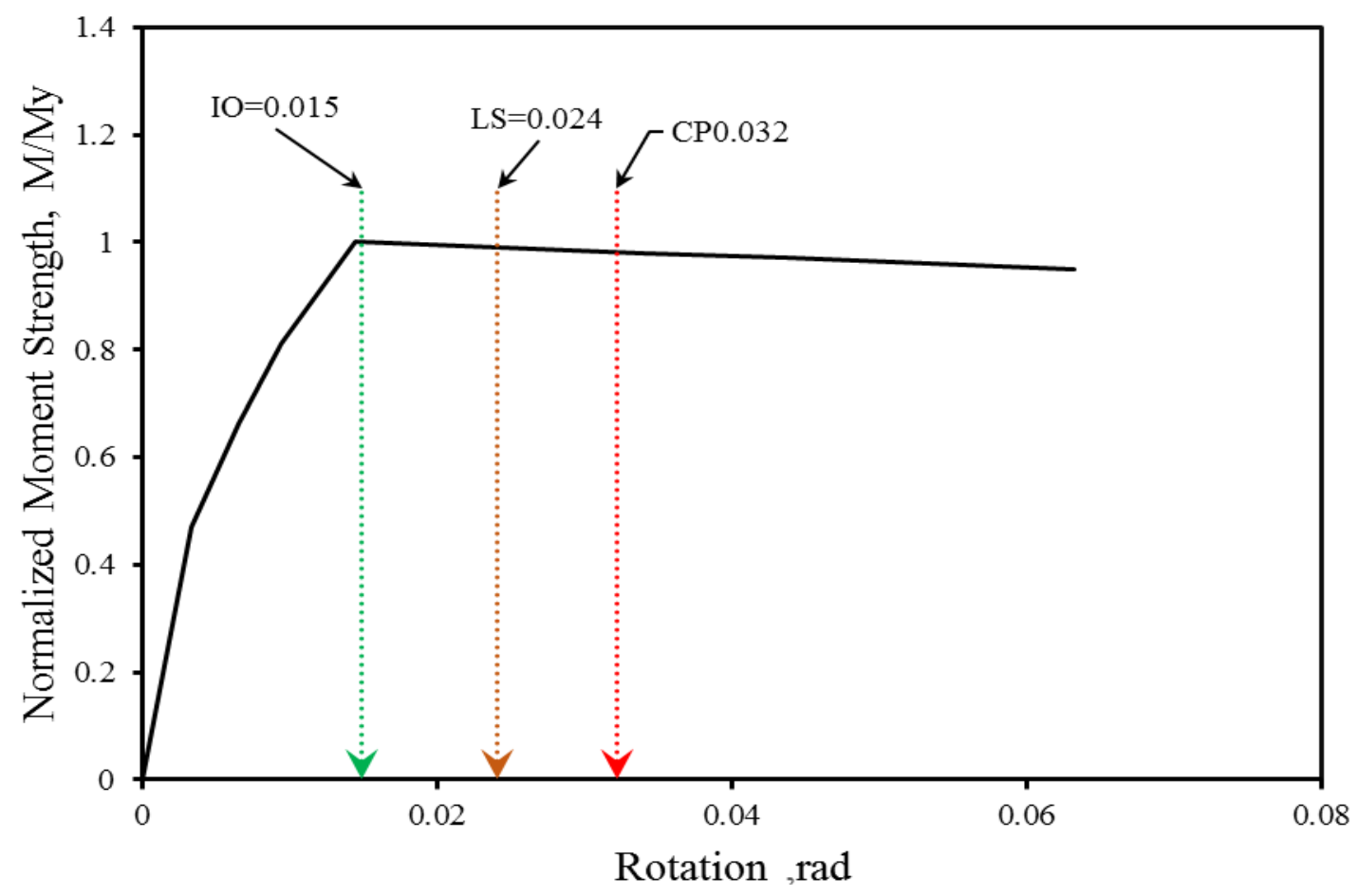

Figure 6.31: Rotation Capacity for Axial Load Level $0.2 f_{c}^{\prime} A_{g}$ 


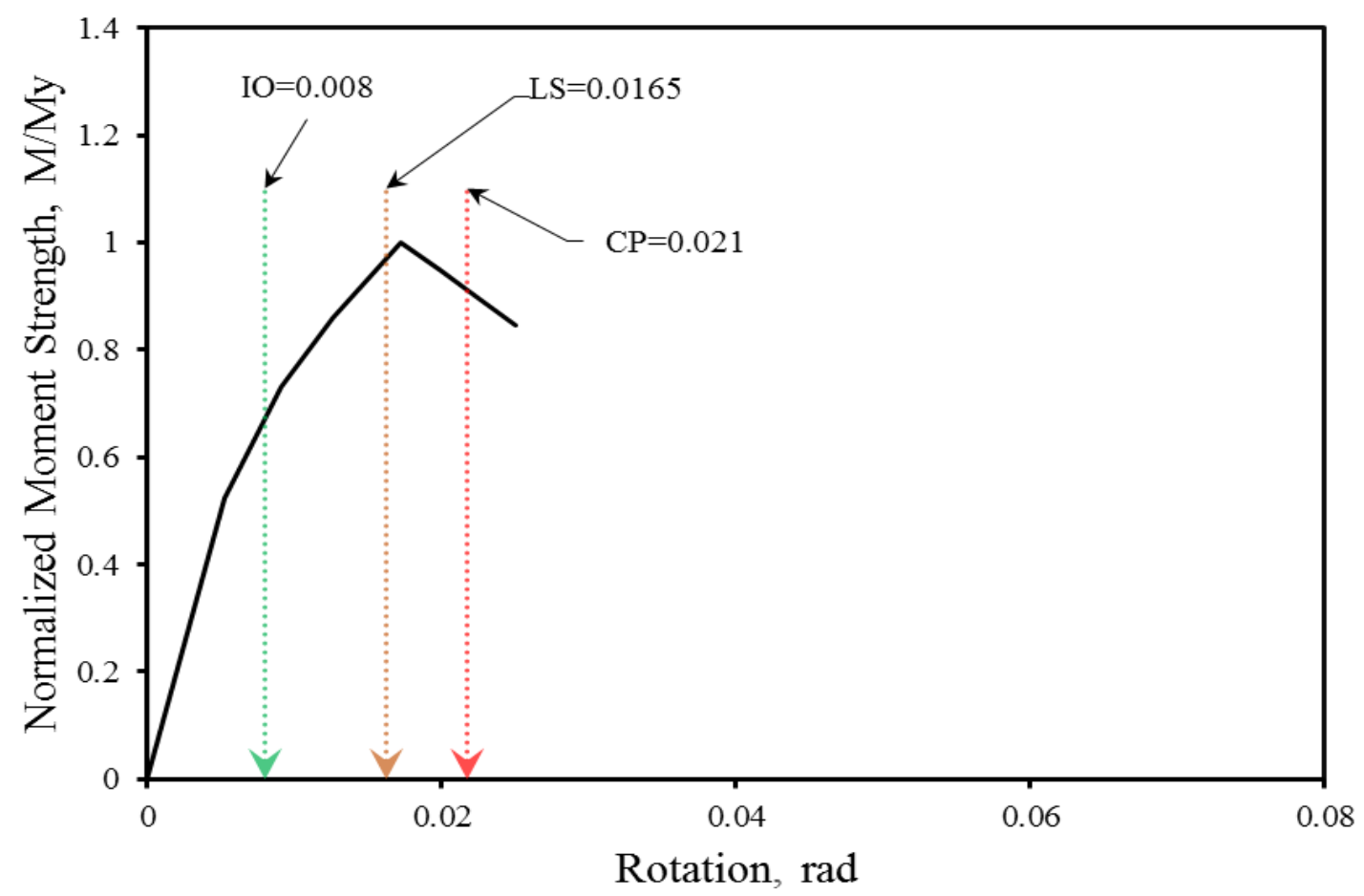

Figure 6.32: Rotation Capacity for Axial Load Level $0.4 f_{c}^{\prime} A_{g}$

\subsubsection{CFRP Retrofit Slender Column}

In order to assess the effect of the CFRP retrofit in improving the performance of the plastic hinge, the same two columns illustrated in the previous section were retrofit with two layers of CFRP in the lateral direction at the plastic hinge regions. The mechanical properties of the CFRP sheet are shown in Chapter 3. The details and configuration of the retrofit specimen are illustrated in Fig. 6.33. In order to reduce the effect of concertation stress on the CFRP sheet, the corners of the cross-section were rounded, with a radius equal to 2 inches. The axial stress-strain model adopted by ACI 440.2R-17, 2017 was used to define the stress-strain behavior of CFRP-confined concrete under axial load. The results of the moment-curvature relation of the CFRP retrofit column with two layers were determined for each axial loading level, $0.2 f_{c}^{\prime} A_{g}$ 
and $0.4 f_{c}^{\prime} A_{g}$ respectively, as shown in Figs. 6.34 and 6.35. The results of the momentcurvature were used to determine the lateral load-displacement relation of both columns, including the effect of the P- $\Delta$, as shown in Figs. 6.36 and 6.37. The acceptance criteria for the retrofit specimens were determined based on the proposed limits, as shown in Figs. 6.36 and 6.37.

The rotation capacity of the plastic hinges, determined with corresponding acceptance criteria, are shown in the Figs. 6.38 and 6.39. Both CP and LS limits improved in terms of displacement ductility and rotation capacity.

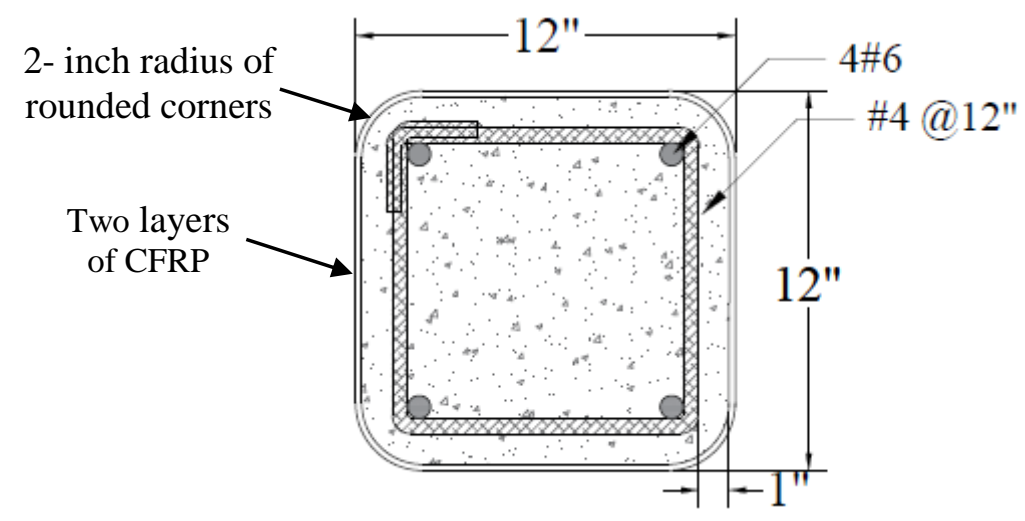

Figure 6.33: Details of CFRP Retrofit 


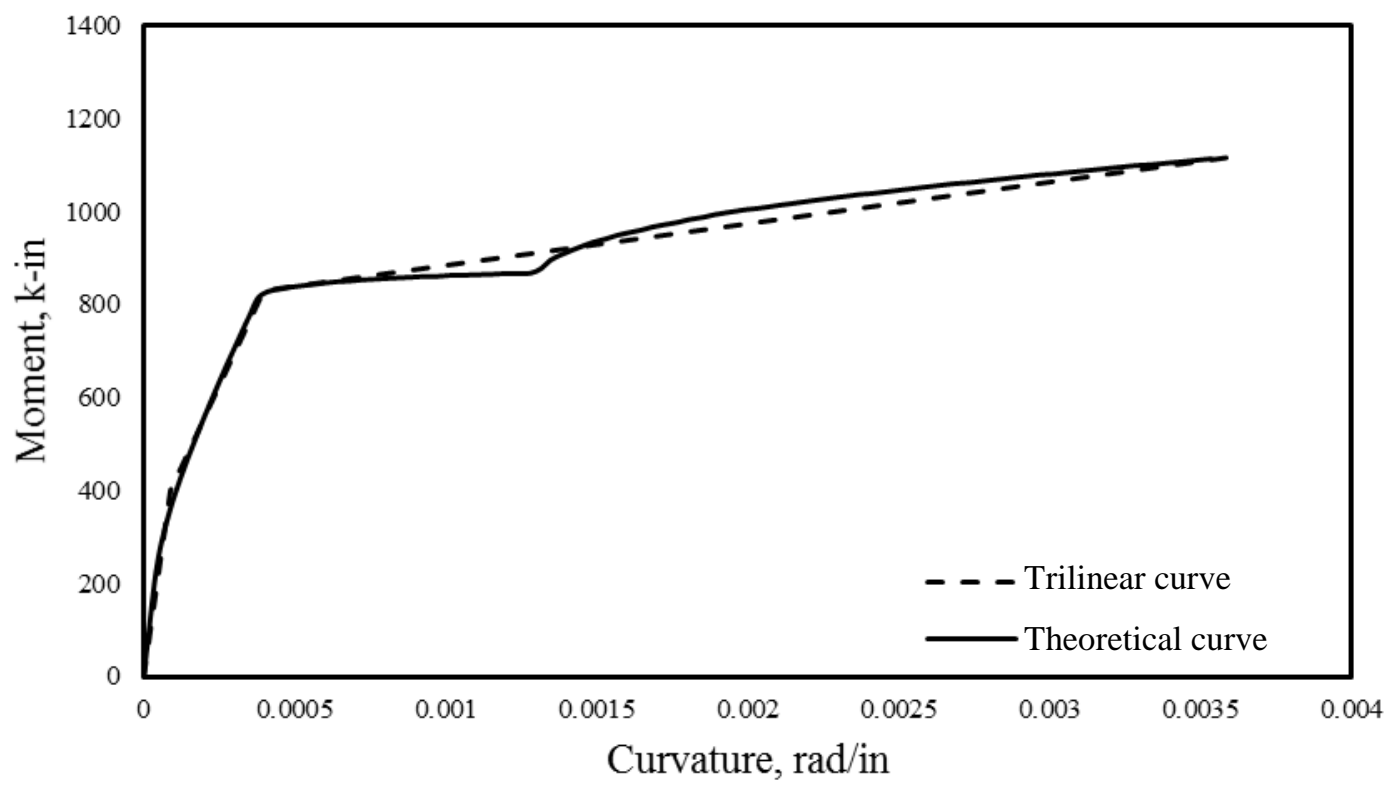

Figure 6.34: Moment-Curvature for Axial Load Level $0.2 f_{c}^{\prime} A_{g}$

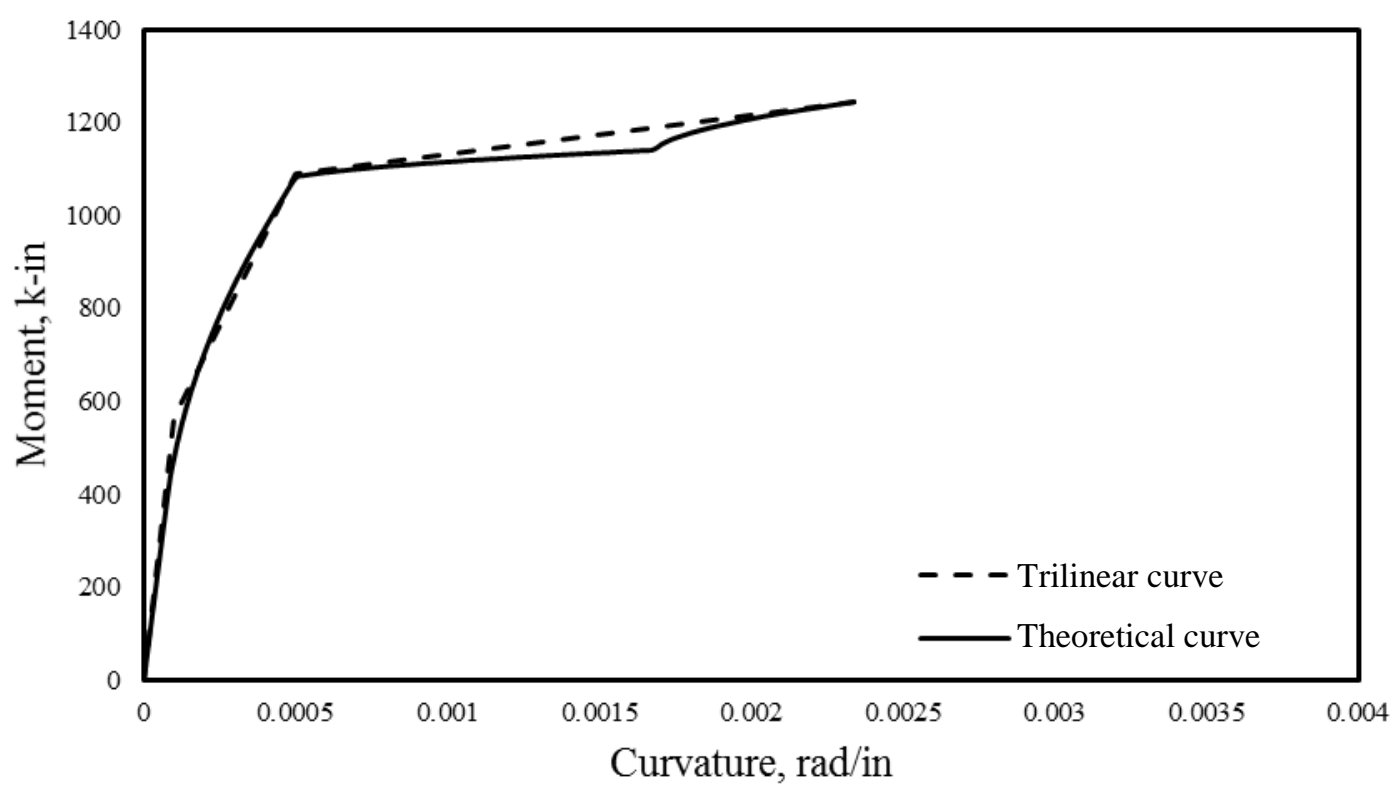

Figure 6.35: Moment-Curvature for Axial Load Level $0.4 f_{c}^{\prime} A_{g}$ 


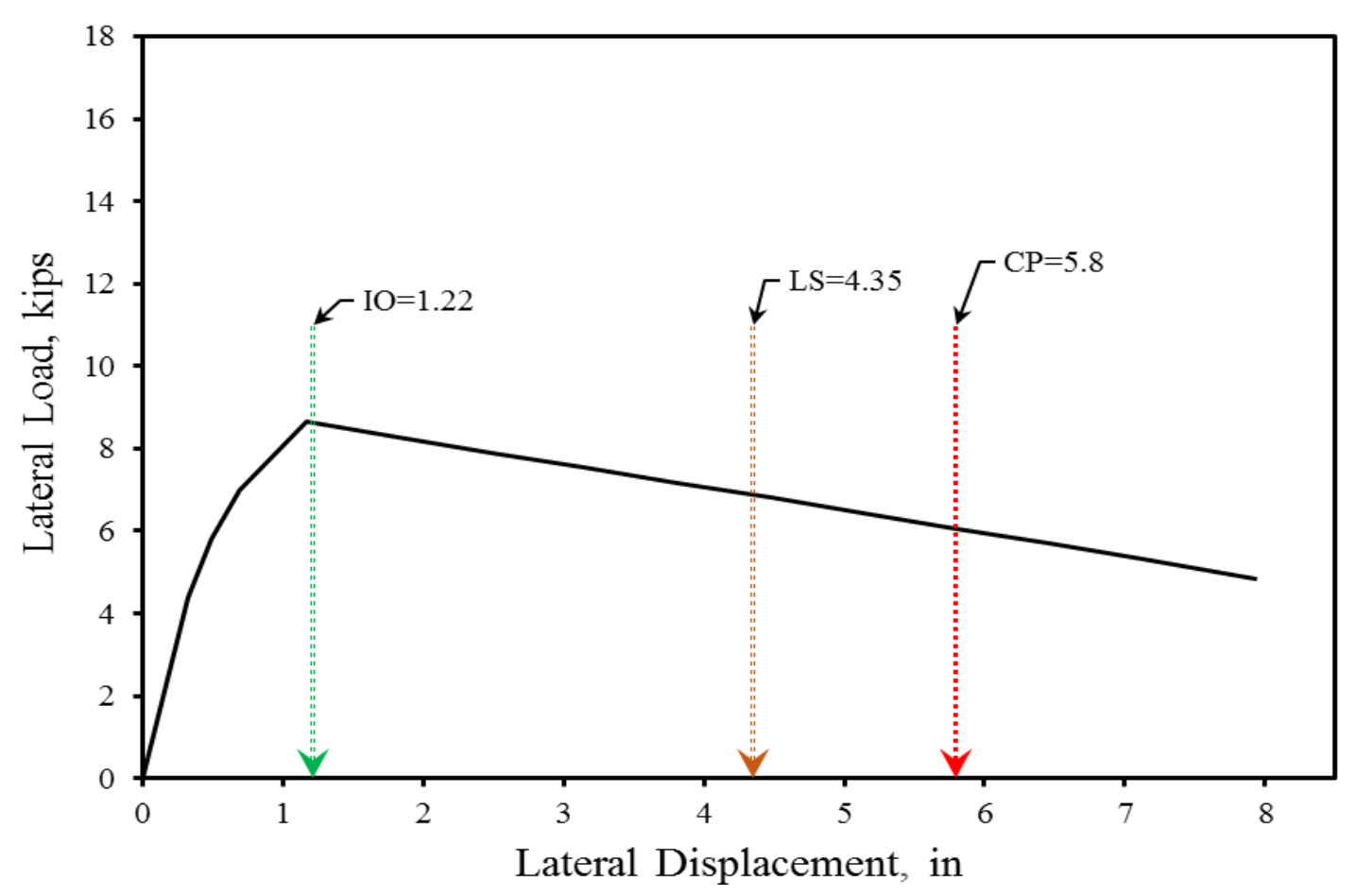

Figure 6.36: Lateral Load-Displacement for Axial Load Level 0.2 $f_{c}^{\prime} A_{g}$

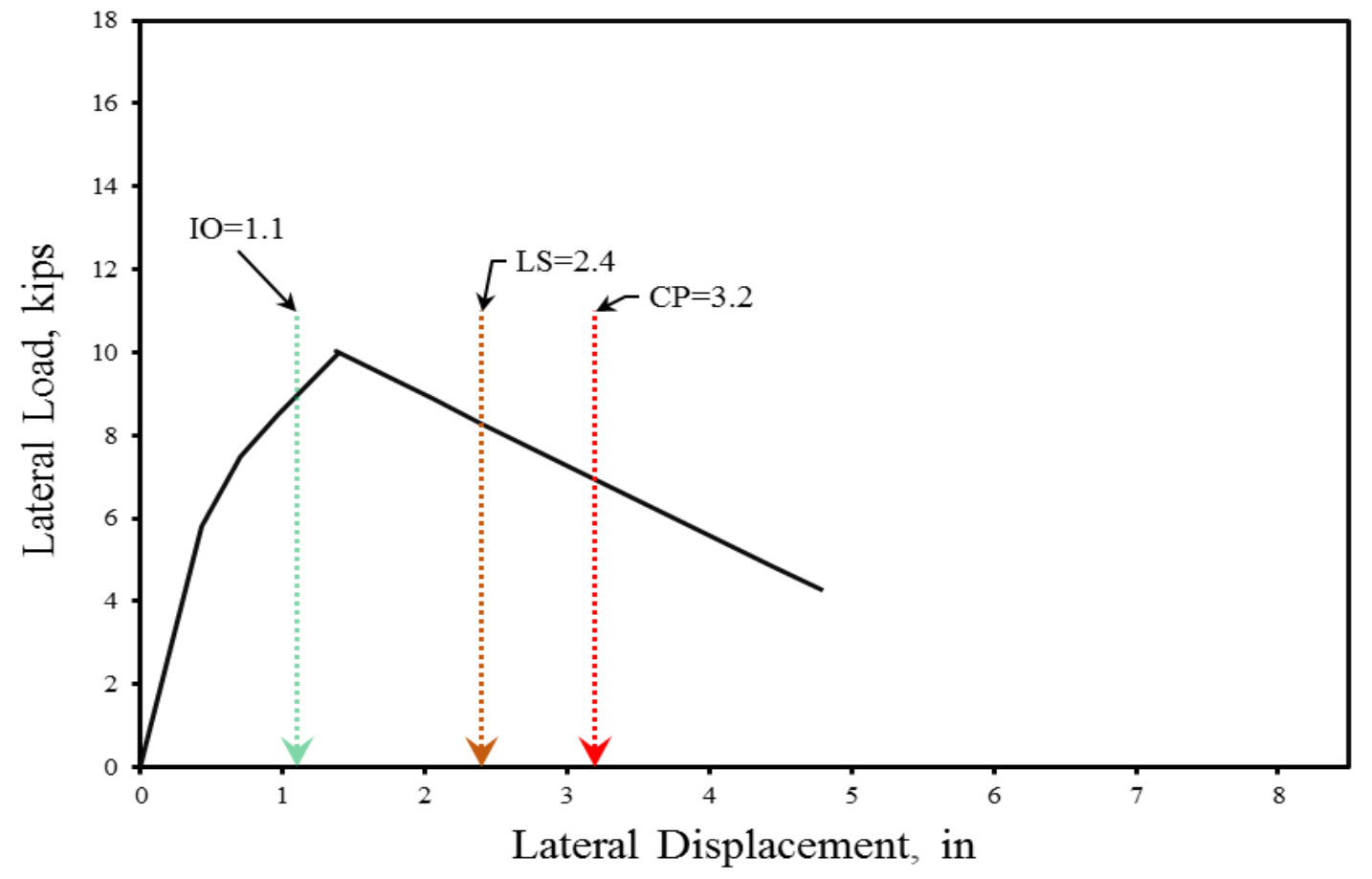

Figure 6.37: Lateral Load-Displacement for Axial Load Level 0.4 $f_{c}^{\prime} A_{g}$ 


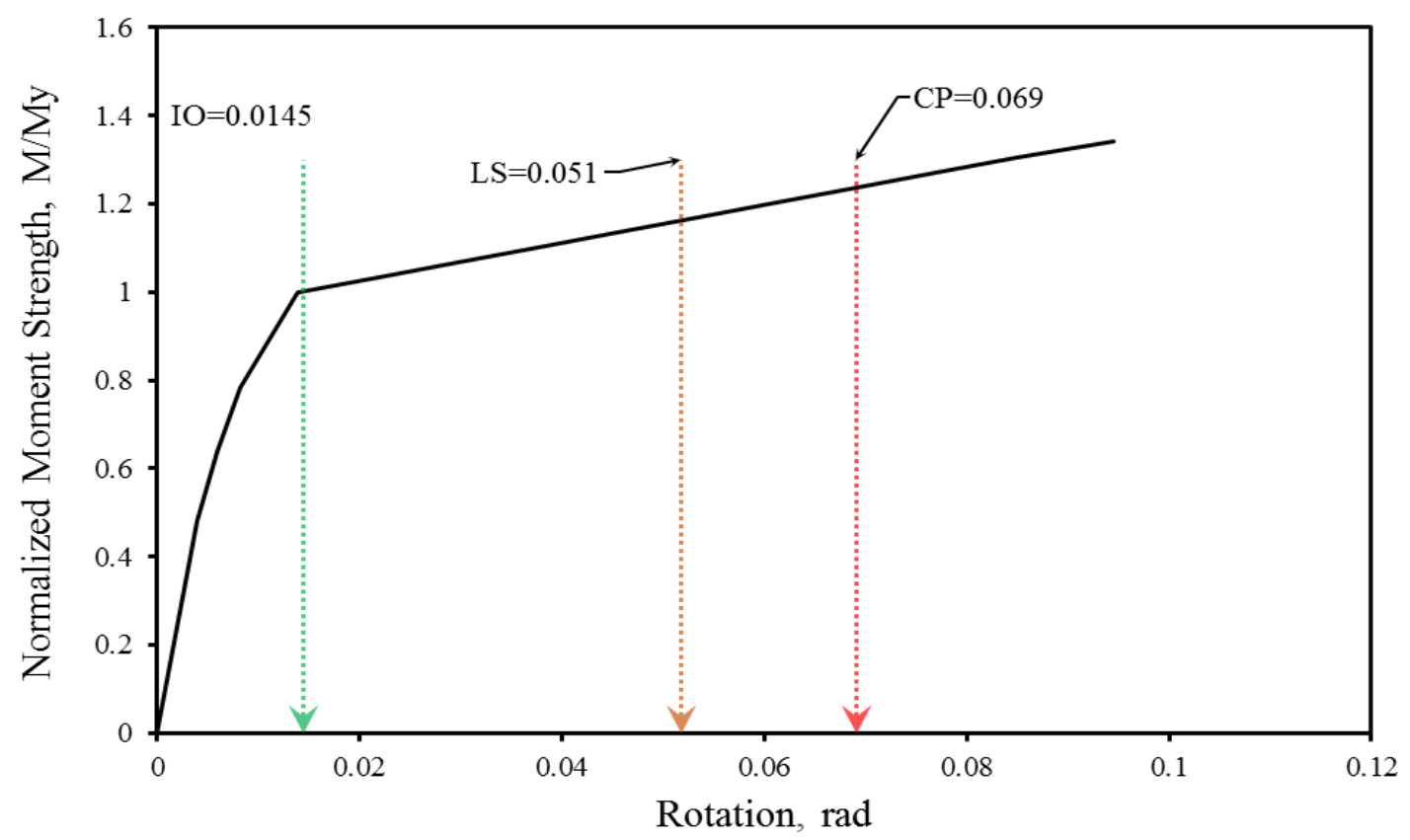

Figure 6.38: Rotation Capacity for Axial Load Level $0.2 f_{c}^{\prime} A_{g}$

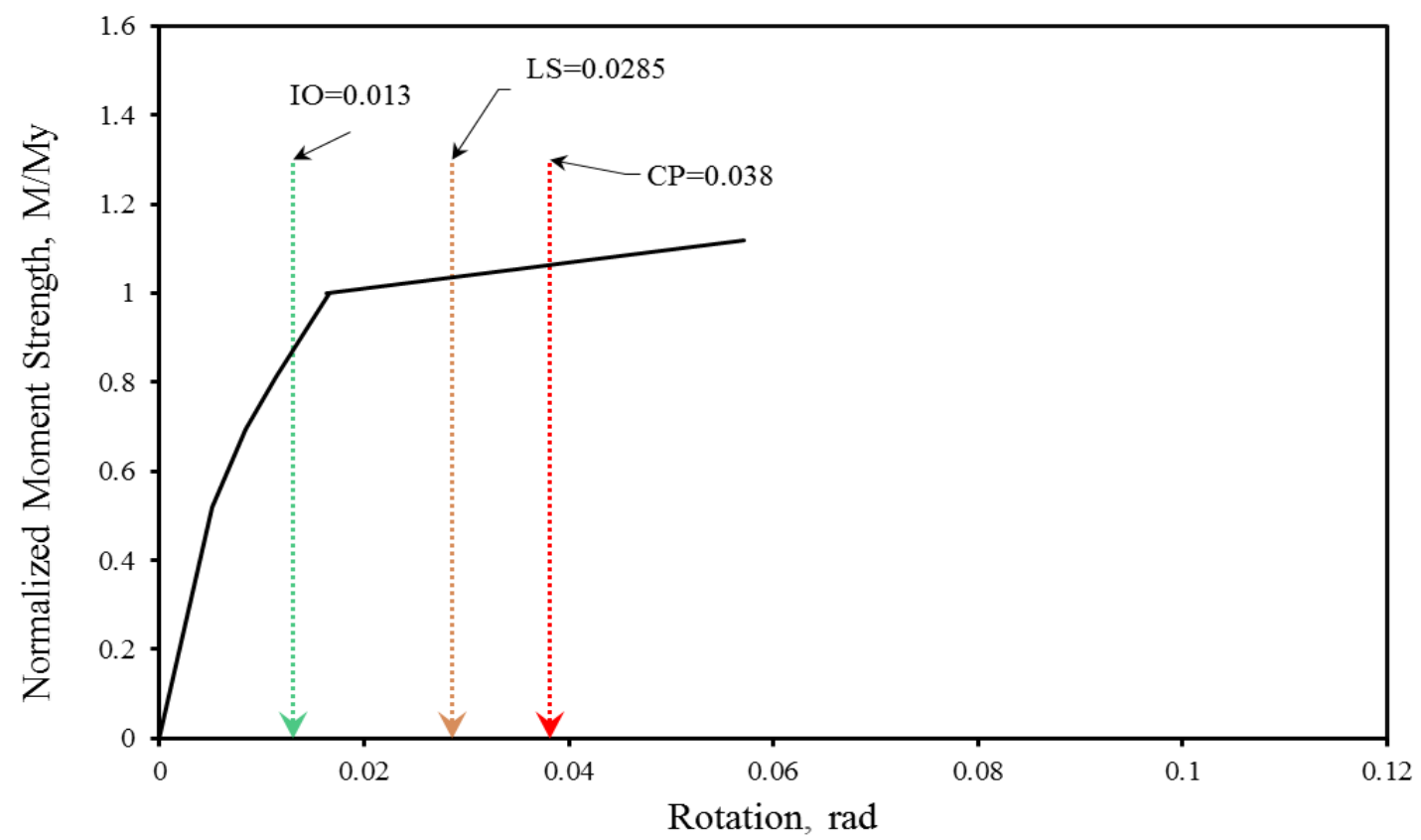

Figure 6.39: Rotation Capacity for Axial Load Level $0.2 f_{c}^{\prime} A_{g}$ 


\subsubsection{Longitudinal CFRP Retrofitting}

In order to increase both the effective stiffness and nominal moment strength of the slender column on the first floor, longitudinal CFRP sheets were placed along the column. Based on the experimental results of specimens Retrofit-C11-0.2, the effective stiffness and nominal moment strength can be improved by using longitudinal CFRP sheet in addition to lateral confinement. Increasing the moment strength led to increased lateral strength of the column and, consequently, shear demand. Therefore, it is important to check the shear strength of the slender column not only at the plastic hinge regions but along the column length.

In this study, the number of the CFRP layers in the longitudinal direction was determined based on the required nominal moment strength, which was larger than the nominal moment strength of the RC beam, to overcome the 'weak column-strong beam' condition. An iteration procedure was used to determine the number of longitudinal CFRP layers required for each column. For brevity, the details of the iterative process are not shown. The results of the procedure indicated the need for four layers in the longitudinal direction and two layers in the lateral direction. The results of the momentcurvature relation of the longitudinal CFRP retrofit column were determined for each axial loading level, $0.2 f_{c}^{\prime} A_{g}$ and $0.4 f_{c}^{\prime} A_{g}$, as shown in Figs. 6.40 and 6.41. In this study, the rupture tensile strain for the longitudinal CFRP sheet was assumed to be 0.00134 , the maximum tensile strain measured during the tensile test. Using the CFRP sheet in strengthening the slender column increased not only the elastic strength, but the inelastic strength up to the CFRP rupture. Based on the moment-curvature relations, the lateral 
load-displacement relation for both columns were determined with the effect of the P- $\Delta$, as shown in Figs. 6.42 and 6.43. The acceptance criteria were determined based on the proposed limits, as shown in Figs. 6.42 and 6.43. Relating the CP limit with the 30\% decay in the lateral strength, the acceptance criterion of the columns was significantly affected because of the rapid drop in lateral strength where the longitudinal CFRP ruptured. The relation between the normalized moment strength and the rotation capacity for the retrofit specimens, including the acceptance criteria limits, are illustrated in Figs. 6.44 and 6.45 .

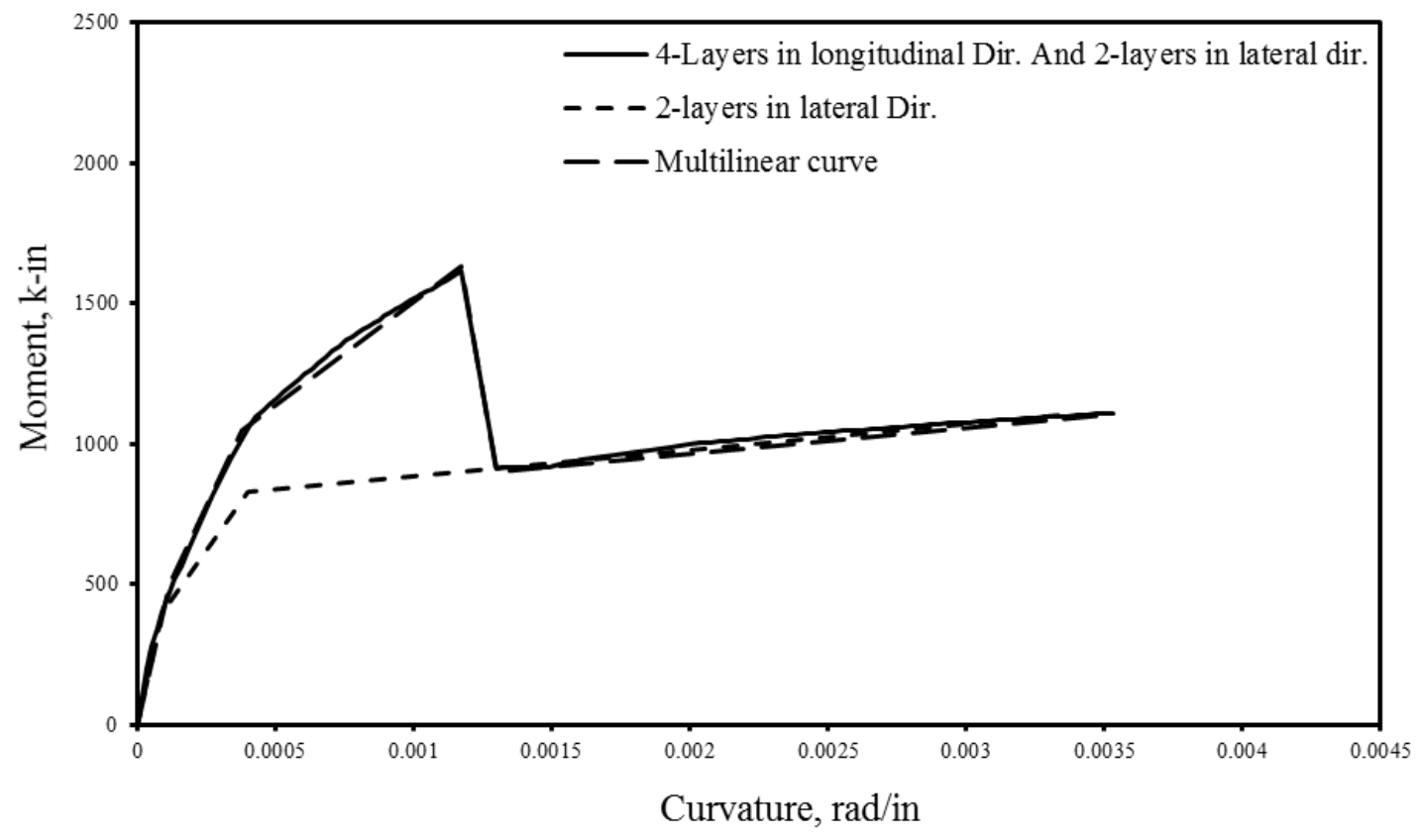

Figure 6.40: Moment-Curvature for Axial Load Level $0.2 f_{c}^{\prime} A_{g}$ 


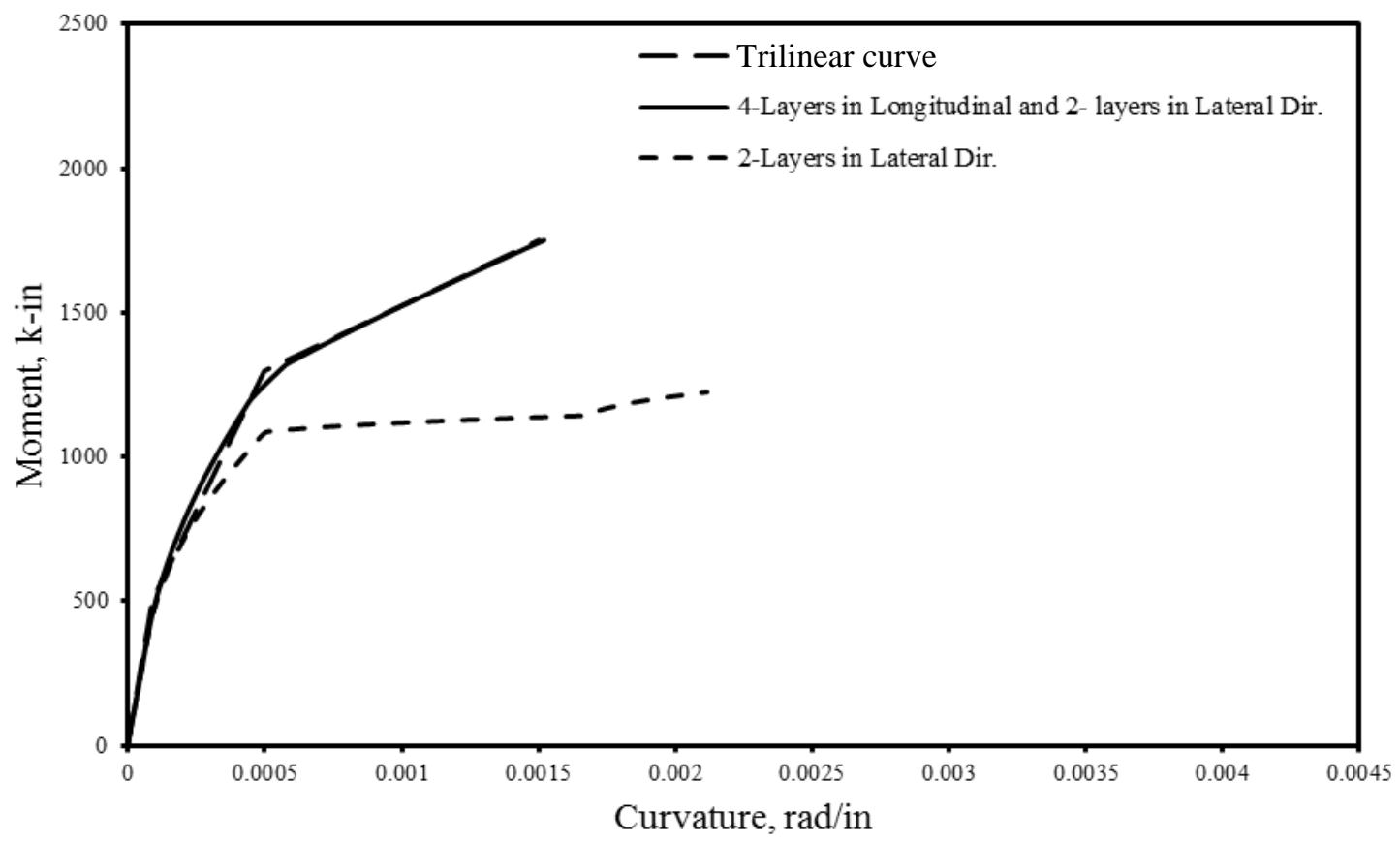

Figure 6.41: Moment-Curvature for Axial Load Level $0.4 f_{c}^{\prime} A_{g}$

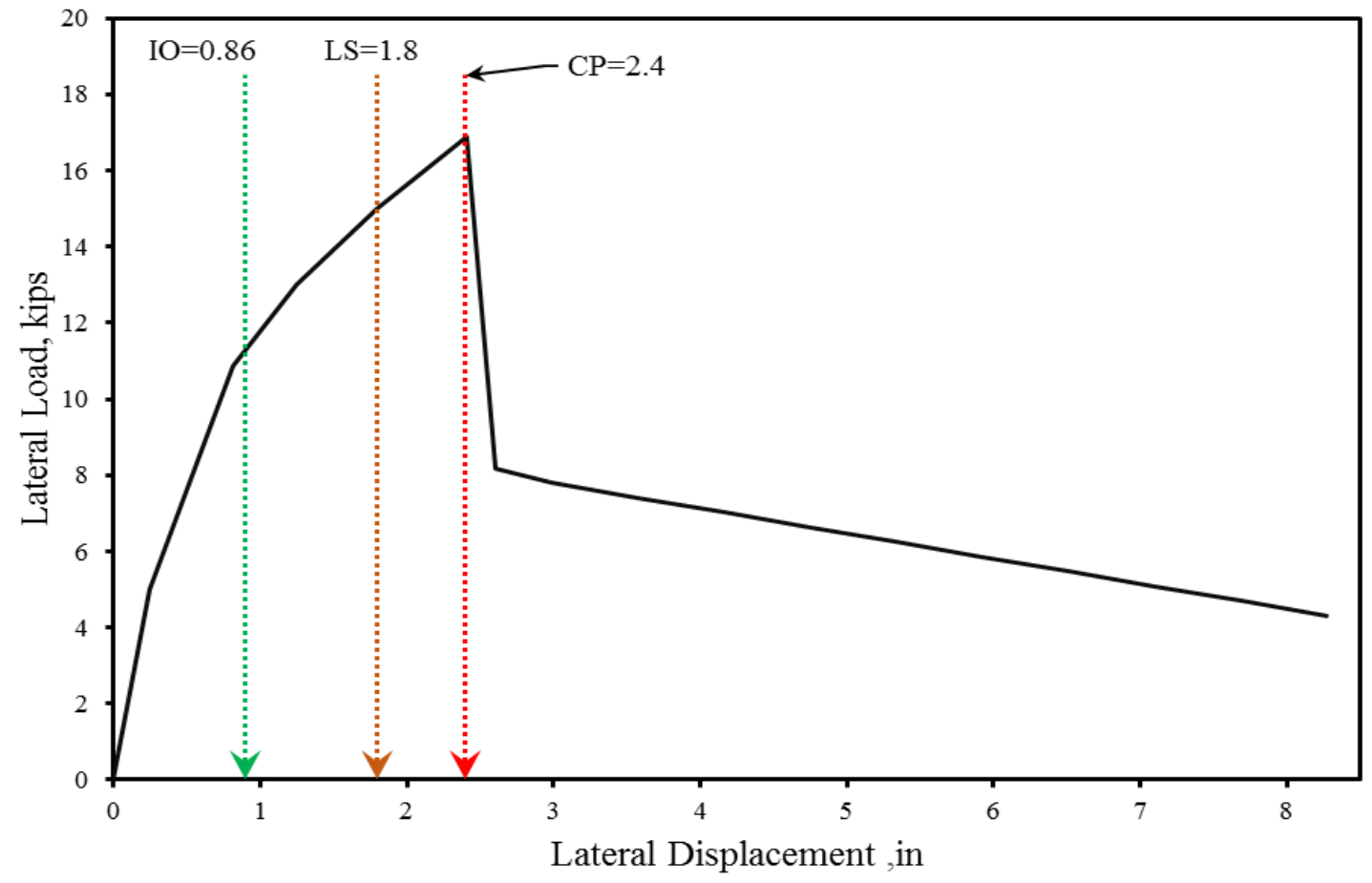

Figure 6.42: Lateral Load-Displacement for Axial Load Level 0.2 $f_{c}^{\prime} A_{g}$ 


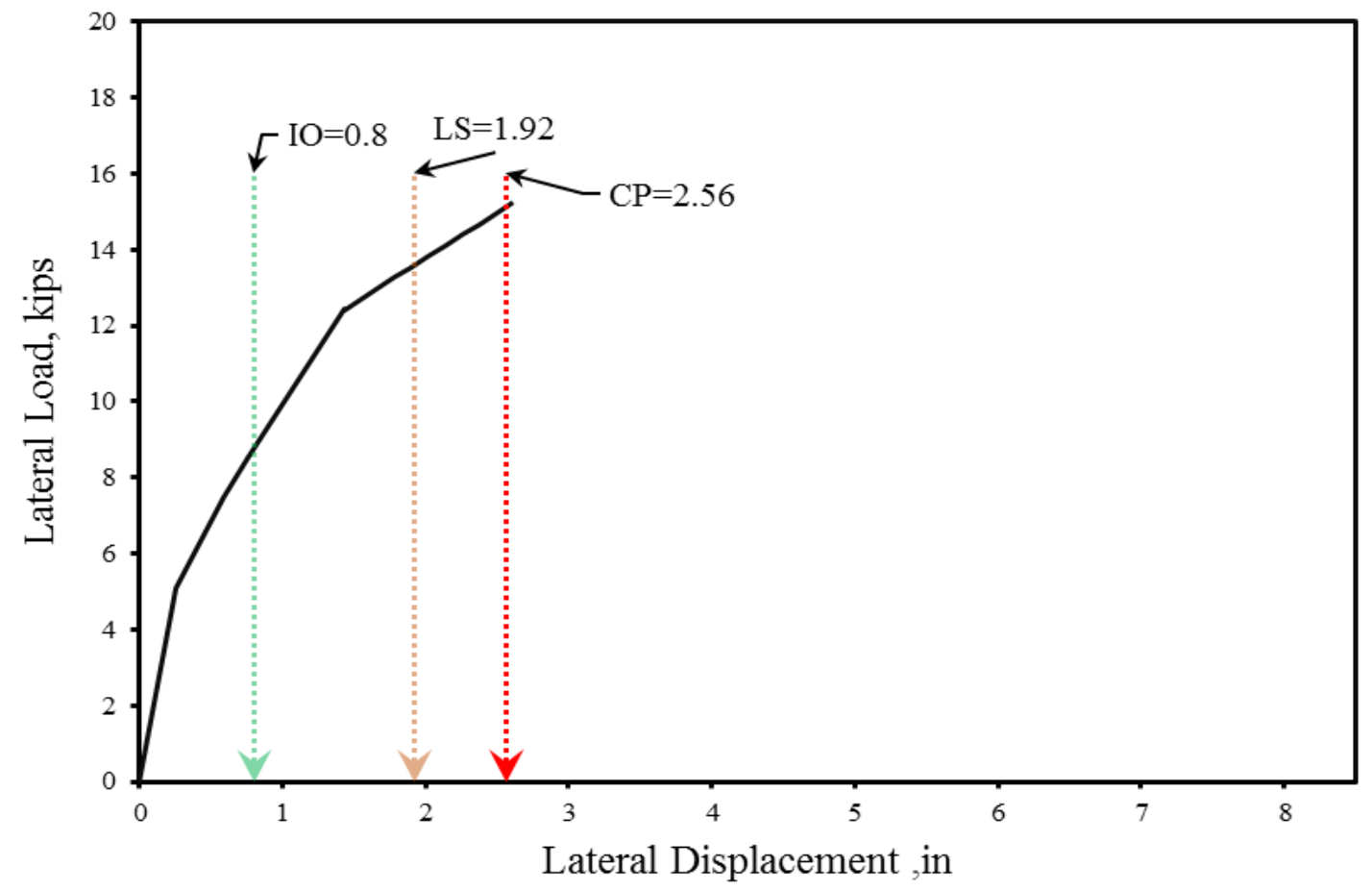

Figure 6.43: Lateral Load-Displacement for Axial Load Level $0.4 f_{c}^{\prime} A_{g}$

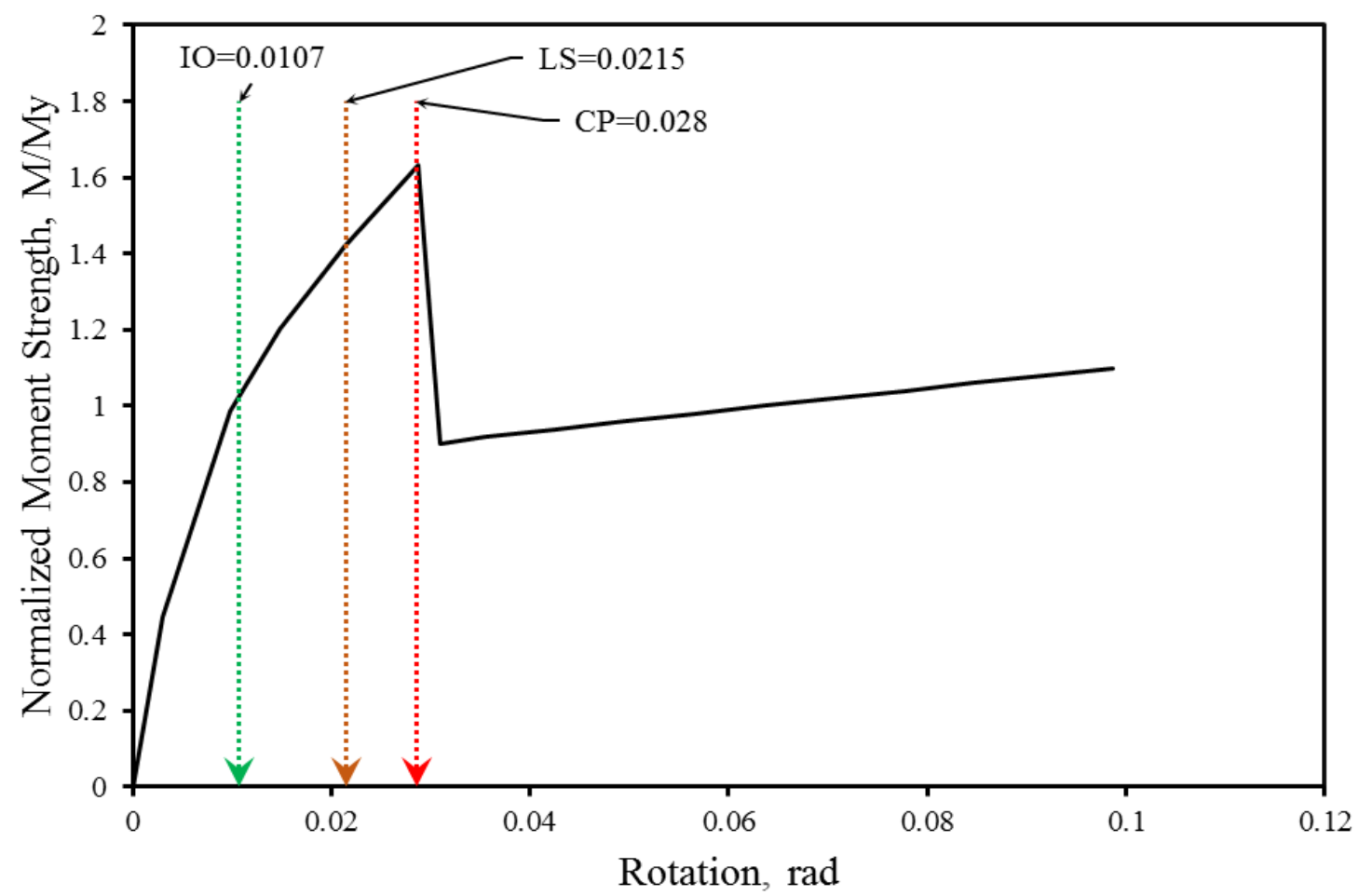

Figure 6.44: Rotation Capacity for Axial Load Level $0.2 f_{c}^{\prime} A_{g}$ 


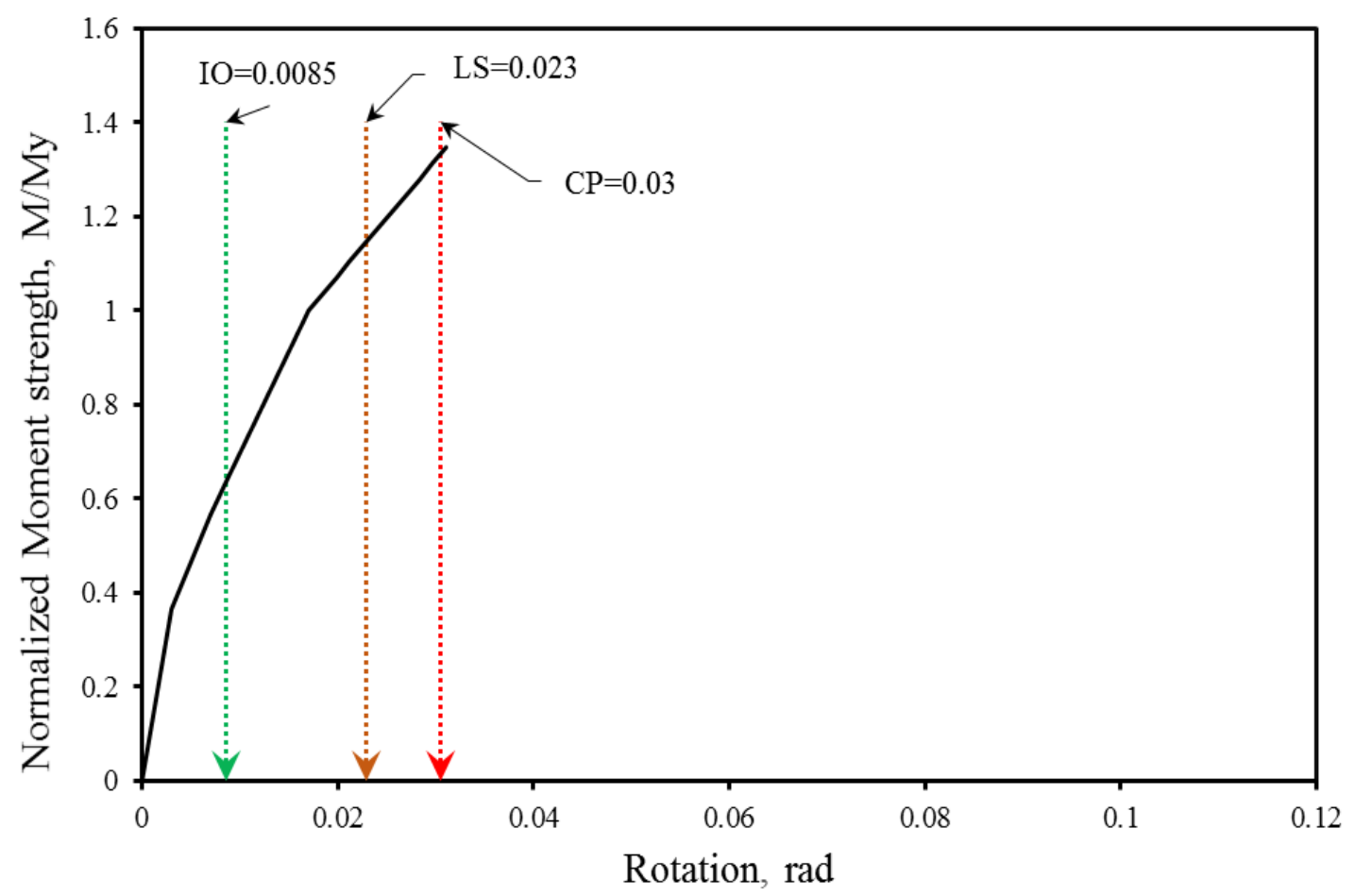

Figure 6.45: Rotation Capacity for Axial Load Level $0.2 f_{c}^{\prime} A_{g}$

\subsubsection{Performance Level of the Buildings}

The performance level of the two- and four-story RC buildings was evaluated by performing a pushover analysis using SAP2000. Only the dead load was considered as the gravity load for the building. The effect of the secondary moment, $\mathrm{P}-\Delta$, was included in the nonlinear analysis of the $\mathrm{RC}$ frame. The plastic hinge rotation for the slender RC columns was defined based on the normalized moment strength-rotation relation. The capacity curve of the buildings represented the relation between the base shear and the roof displacement.

The performance level of the buildings was determined by calculating the lateral displacement demand, or target displacement, using the Coefficient Method Procedure (CMP). As mentioned before, in this study two big cities located in Iraq, Baghdad and Erbil, were selected as a location for the prototypes RC buildings, as shown in Fig. 6.46. 255 
The response acceleration parameters of $2 \%$ probability of exceedance in 50 years for the two sites are listed in Table 6-3 (Srbulov, 2011). The main goal of assessing the performance level of the buildings was to compare the results with current building code (ASCE/SEI41-13, 2013) requirements for the post-earthquake damage. Based on FEMA356 (2000), Basic Safety Object (BSO) is defined as a rehabilitation objective that achieves the LS level for a $10 \%$ probability of exceedance in 50 years, but not exceeding two-thirds of the $2 \%$ probability of exceedance in 50 years, and a CP level for $2 \%$ probability of exceedance in 50 years. Due to lack of information, two-thirds of the $2 \%$ probability of exceedance in 50 years is considered as a limit to identify the BSO requirement. In the following sections, the results of the NSP induced on both the unretrofit and retrofit $\mathrm{RC}$ frames will be discussed.

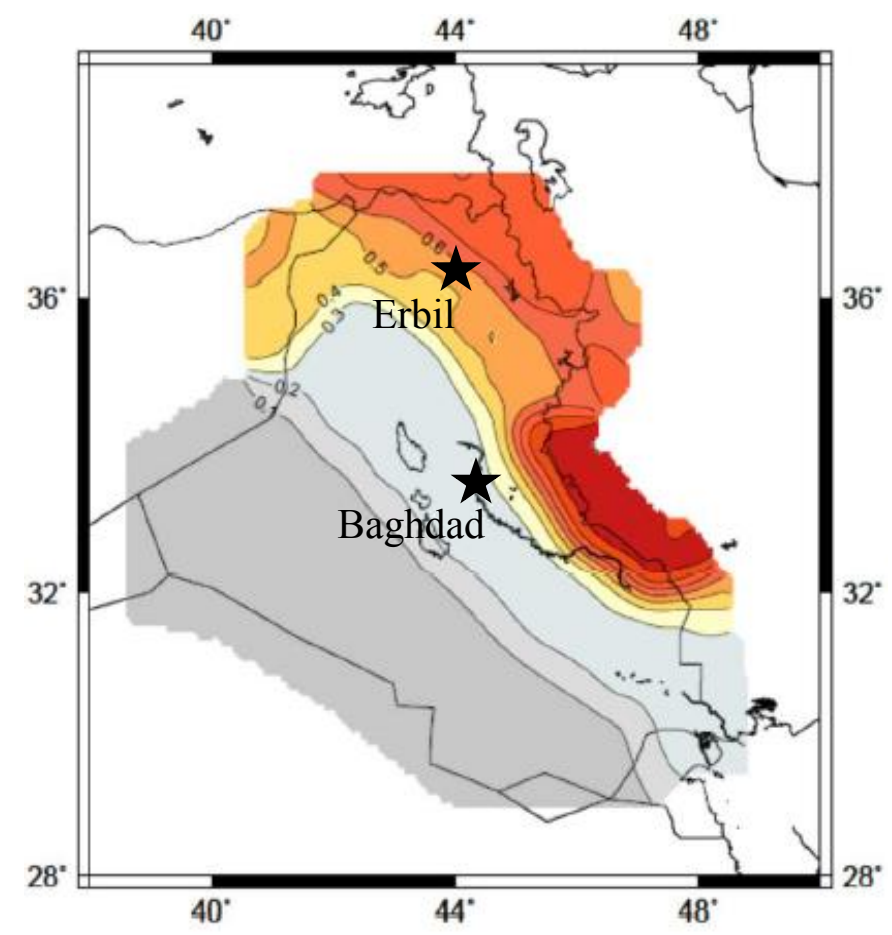

Figure 6.46: Baghdad and Erbil Locations 
Table 6-3: Response Acceleration Parameters of 2\% Probability of Exceedance in 50 years

\begin{tabular}{|c||c||c||c|c||}
\hline \hline \multirow{2}{*}{ City } & \multirow{2}{*}{$\begin{array}{c}\text { Peak Ground } \\
\text { Acceleration } \\
\text { (PGA) }\end{array}$} & Site Class & \multicolumn{2}{|c|}{ Spectral Response Acceleration } \\
\cline { 4 - 5 } & $\begin{array}{c}\text { Short-period, } \mathbf{0 . 2} \\
\text { sec. } \boldsymbol{S}_{\boldsymbol{s}}\end{array}$ & $\begin{array}{c}\text { Long-period, 1.0 } \\
\text { sec. } \boldsymbol{S}_{\mathbf{1}}\end{array}$ \\
\hline \hline Baghdad & $0.2 \mathrm{~g}$. & $\mathrm{D}$ & $0.32 \mathrm{~g}$. & $0.1 \mathrm{~g}$. \\
\hline Erbil & $0.5 \mathrm{~g}$. & $\mathrm{D}$ & $0.7 \mathrm{~g}$. & $0.17 \mathrm{~g}$. \\
\hline \hline
\end{tabular}

\subsubsection{Un-Retrofit Column}

The results of the normalized moment strength versus the rotation capacity were implemented in SAP2000 to define the plastic hinge rotation and the acceptance criteria of the slender columns. By using the results illustrated in Figs. 6.31 and 6.32, the capacity curves for the two- and four-story buildings were determined as shown in Fig. 6.47.

Based on the capacity curves and the response spectra for both cities, Baghdad and Erbil, the target displacements for the two- and four-story buildings in both cities are illustrated in Figs. 6.48 and 6.49.

The performance level of each building was determined based on the limit of the acceptance criteria that the plastic hinge of the RC member reached at the targetdisplacement. Table 6-4 illustrates the performance level for the buildings in Baghdad and Erbil. For both buildings, the performance level was controlled by the plastic hinge developed at both ends of the RC columns in the first floor of the buildings. Moreover, the performance level for the two-story building in both cities is LS. For the four-story 
building, the building collapses due to the large displacement demand required to sustain the four-story building. Therefore, the four-story building is disqualified in both cities.
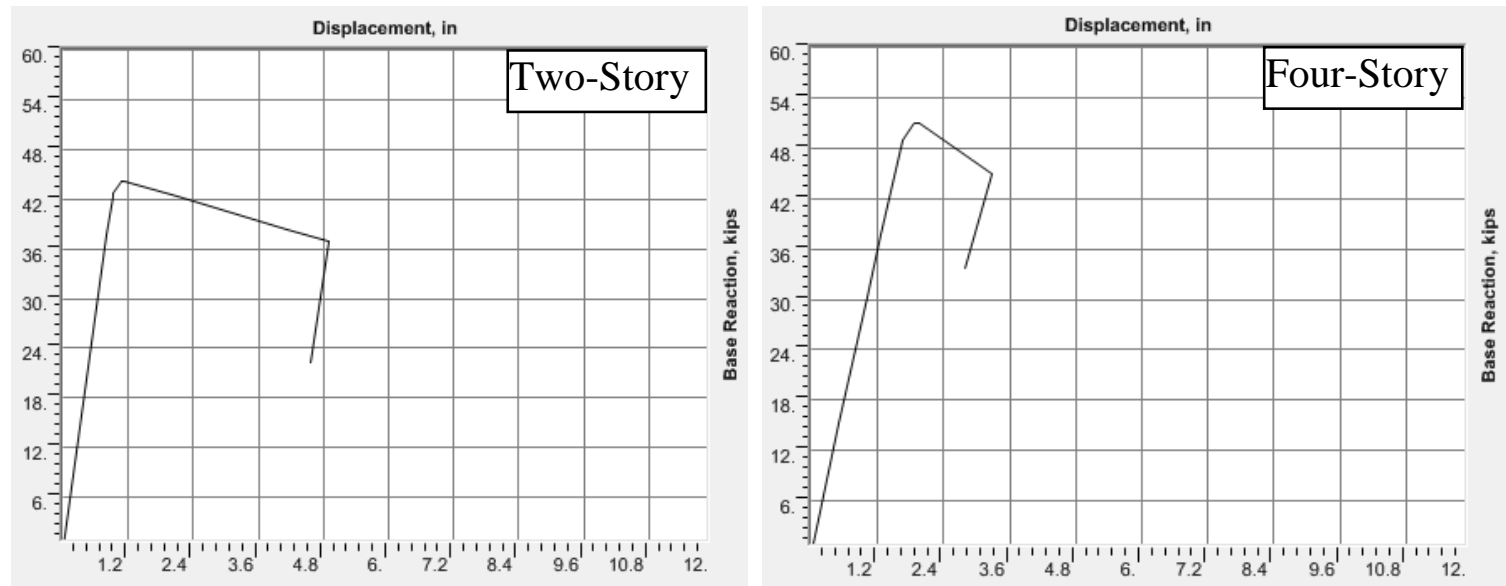

Figure 6.47: Capacity Curve for Un-Retrofit Two and Four-Story Buildings
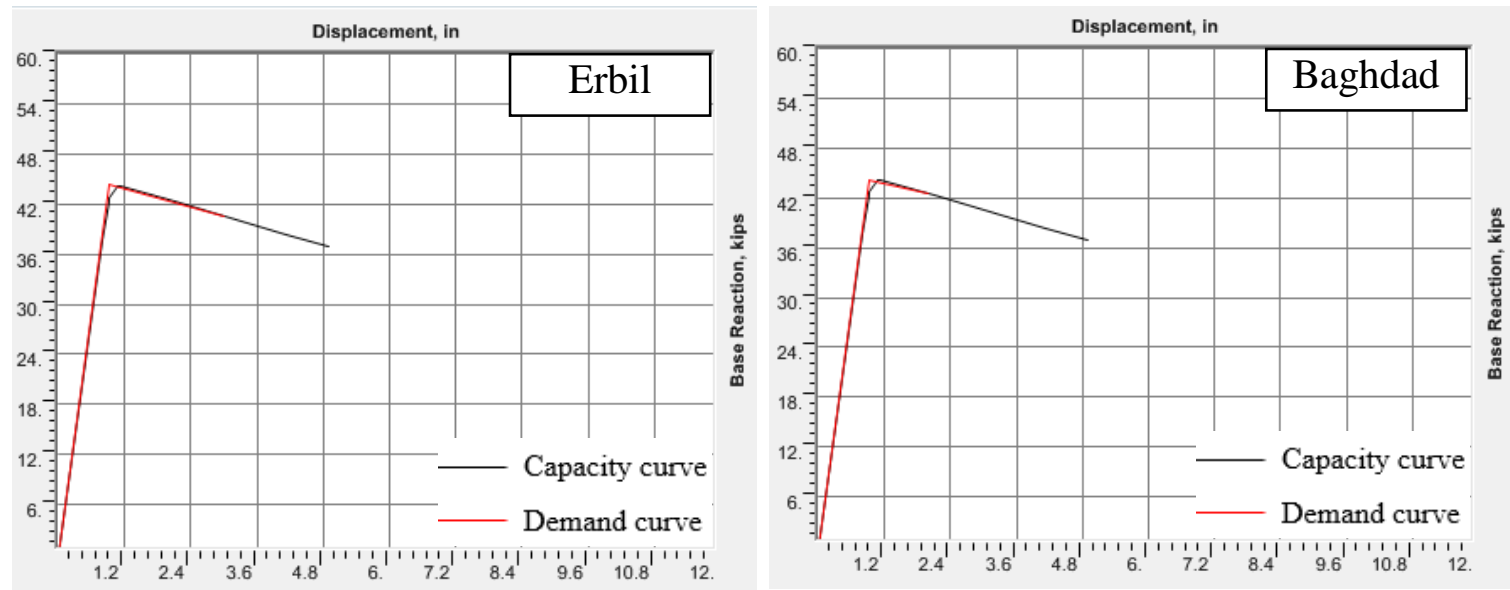

Figure 6.48: Target-Displacement of Two-Story Buildings at Erbil and Baghdad 

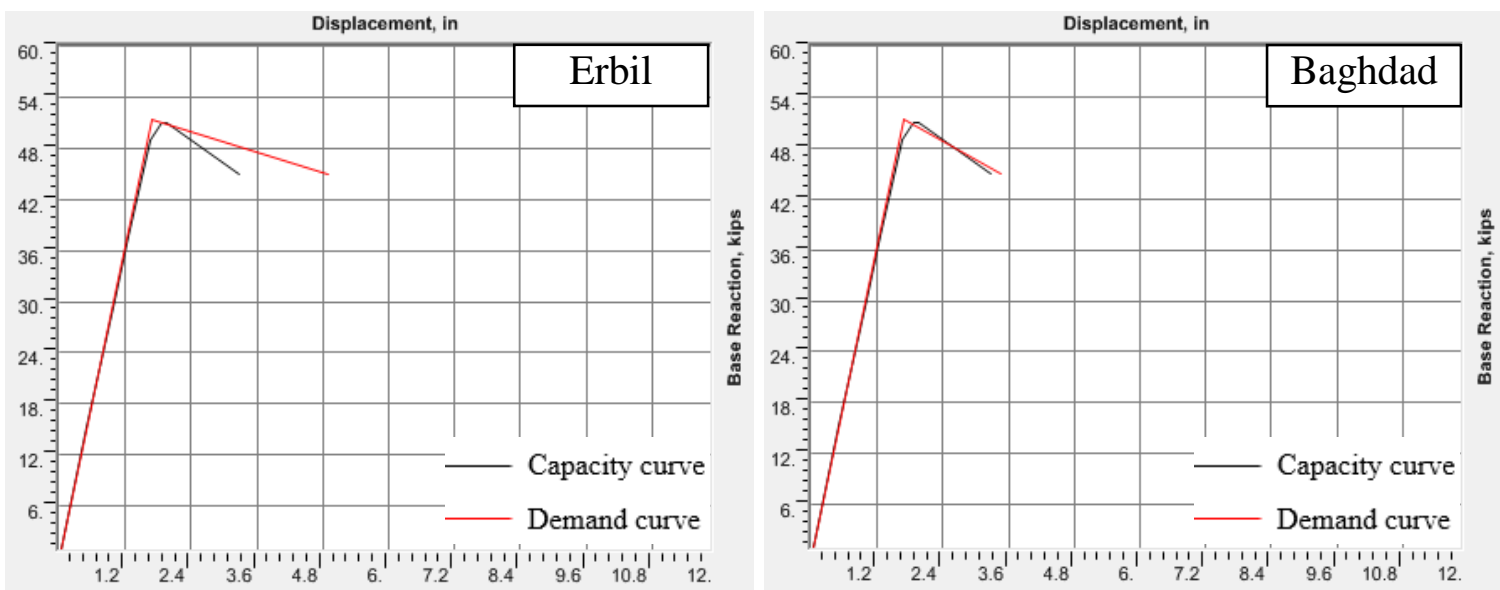

Figure 6.49: Target-Displacement of the Four-Story Buildings in Erbil and Baghdad

Table 6-4: Target-Displacement of Un-Retrofit RC Buildings.

\begin{tabular}{||c|c|c|c|c|c||}
\hline \hline The city & $\begin{array}{c}\text { RC } \\
\text { building }\end{array}$ & $\begin{array}{c}\text { Base } \\
\text { reaction, } \\
\text { kips }\end{array}$ & $\begin{array}{c}\text { Target } \\
\text { displacement } \\
\text { at roof level, } \\
\text { inch }\end{array}$ & $\begin{array}{c}\text { Performance } \\
\text { level of the } \\
\text { first-floor } \\
\text { column }\end{array}$ & $\begin{array}{c}\text { performance level } \\
\text { Overall }\end{array}$ \\
\hline \hline \multirow{3}{*}{ Baghdad } & $\begin{array}{c}\text { Two- } \\
\text { Story }\end{array}$ & 42.5 & 1.89 & LS & LS \\
\cline { 2 - 6 } & $\begin{array}{c}\text { Four- } \\
\text { Story }\end{array}$ & 45.6 & 3.46 & Collapse & Collapse \\
\hline \multirow{2}{*}{ Erbil } & $\begin{array}{l}\text { Two- } \\
\text { Story }\end{array}$ & 40.5 & 2.95 & LS & LS \\
\cline { 2 - 6 } & $\begin{array}{l}\text { Four- } \\
\text { Story }\end{array}$ & 45.6 & 4.89 & Collapse & Collapse \\
\hline
\end{tabular}

The failure mechanism of both buildings at the maximum lateral displacement is shown in Fig. 6.50. It is clear that the existing slender RC columns lead to a soft story failure mechanism, which is a common case of failure with buildings in which the stiffness and resistance of one floor is different from the rest. In addition, concentrated damage in the column's plastic hinge is a result of the weak column-strong beam 
condition. The nominal moment capacity of the T-beam was determined using SAP2000. Two values were obtained for the nominal moment capacity $\mathrm{M}^{+}=1064$ kips.in and $\mathrm{M}^{-}$ $=1706$ kips.in. These values of nominal moment capacity were larger than the first-floor column's moment capacity, 925 kips.in. Therefore, the damage occurred in the column before it occurred in the beams.
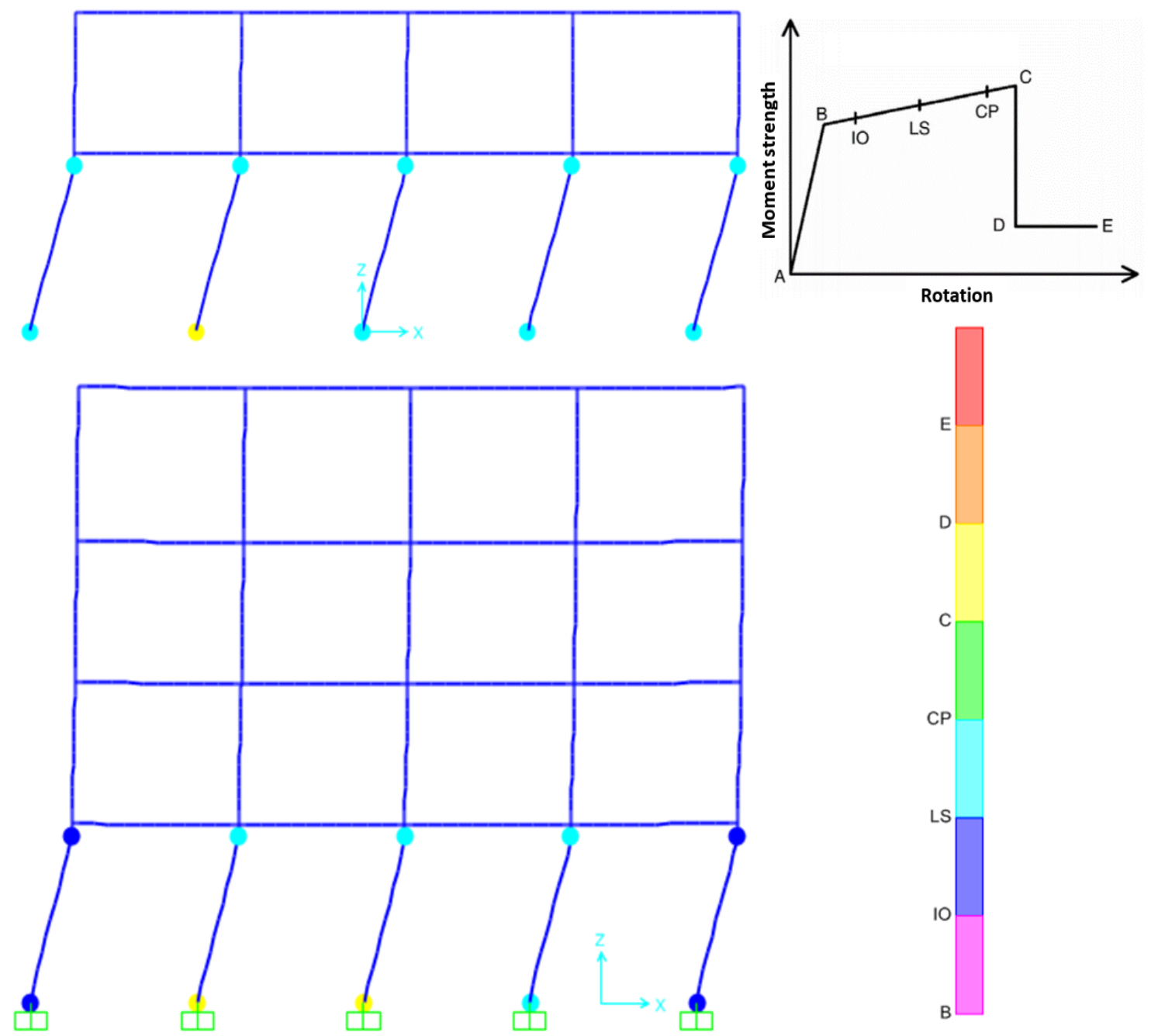

Figure 6.50: Failure Mechanism of Two- and Four-Story Buildings 


\subsubsection{CFRP Retrofit Column}

Using two layers of the CFRP to confine the slender RC column at the plastic hinge region improves the performance level of the column. Based on Figs. 6.38 and 6.39, the capacity curve of the RC columns was determined as shown in Fig. 6.51. Figures 6.52 and 6.53 illustrate the target displacement of the two- and four-story buildings at Erbil and Baghdad. Table 6-5 shows the target displacement values for buildings in each city. The performance level of the two-story building was still within the LS level. However, the performance level of the four-story building was improved to LS level for the building in Baghdad and CP level for Erbil. This improvement in the acceptance criteria makes the building qualify for the requirements of ASCE 41-13.

Using CFRP-confinement for the plastic hinge regions improved the deformation ductility of the plastic hinge region, especially in the inelastic range. This improvement increased the displacement ductility of the slender column, which helped to improve the global displacement ductility and the performance level of the building. However, the nominal moment strength of the column was not enough to overcome the weak columnstrong beam condition. Even so, the soft story failure mechanism of the buildings was not improved, as shown in Fig. 6.54. 

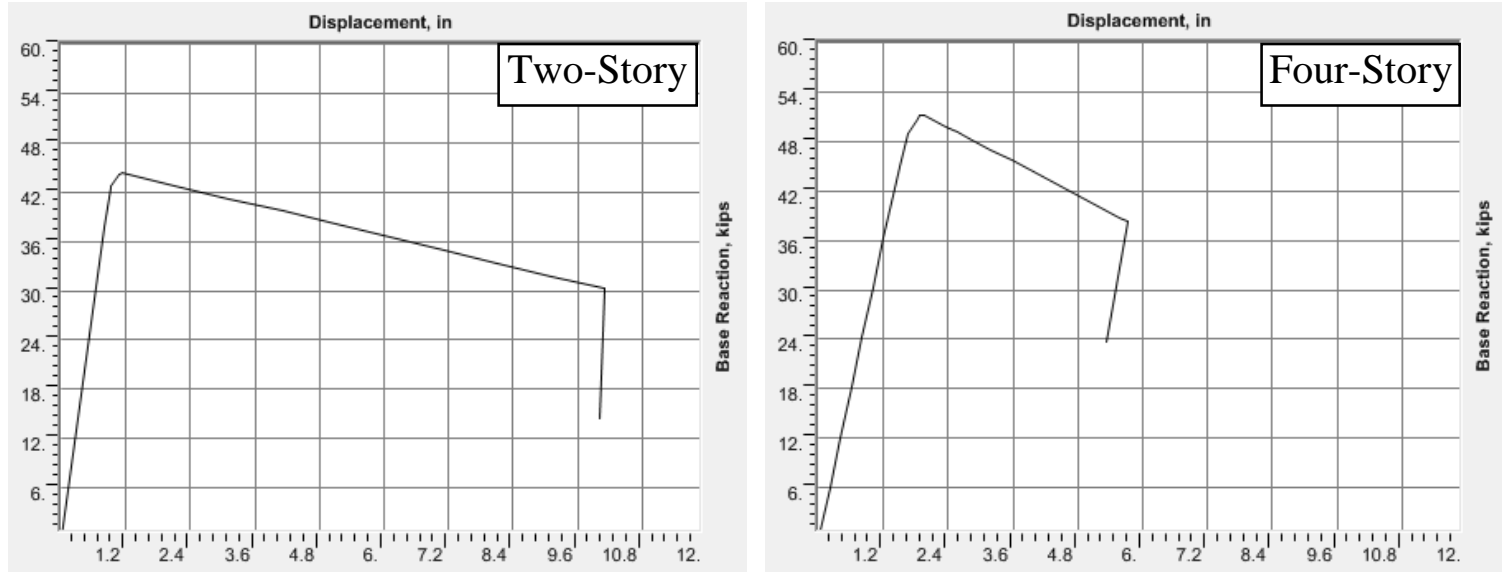

Figure 6.51: Capacity Curve of Two and Four-Story Buildings
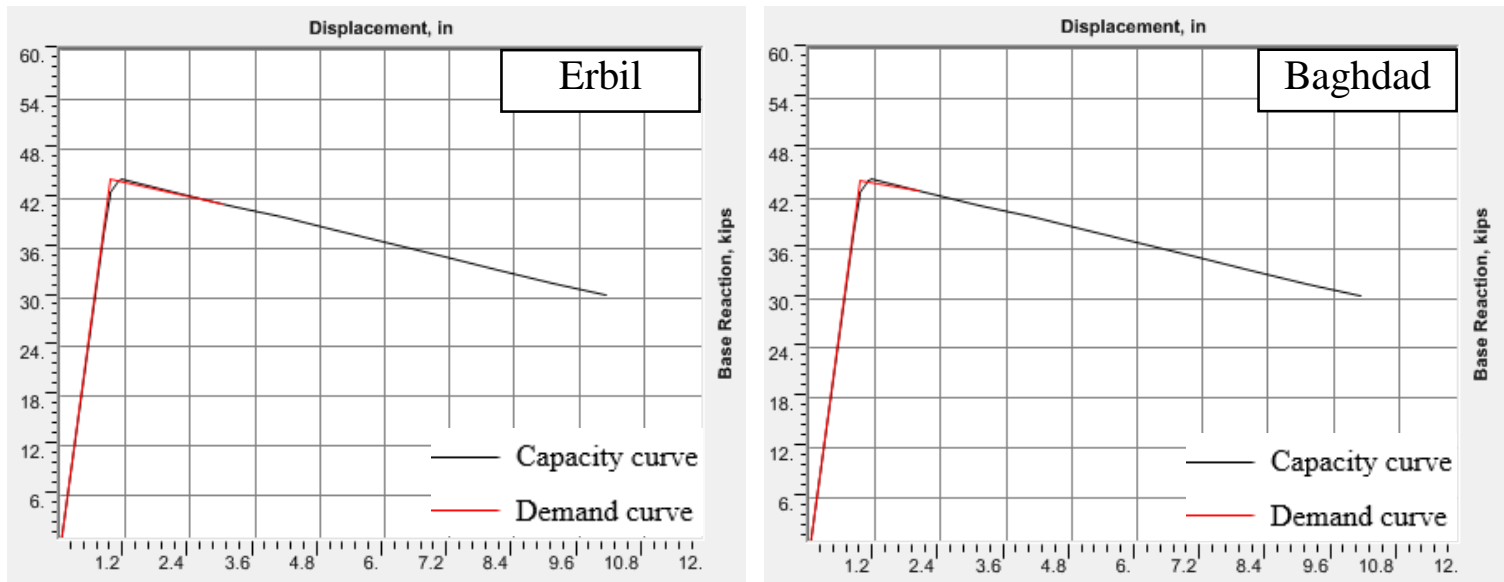

Figure 6.52: Target Displacement of Two-Story Buildings in Erbil and Baghdad 

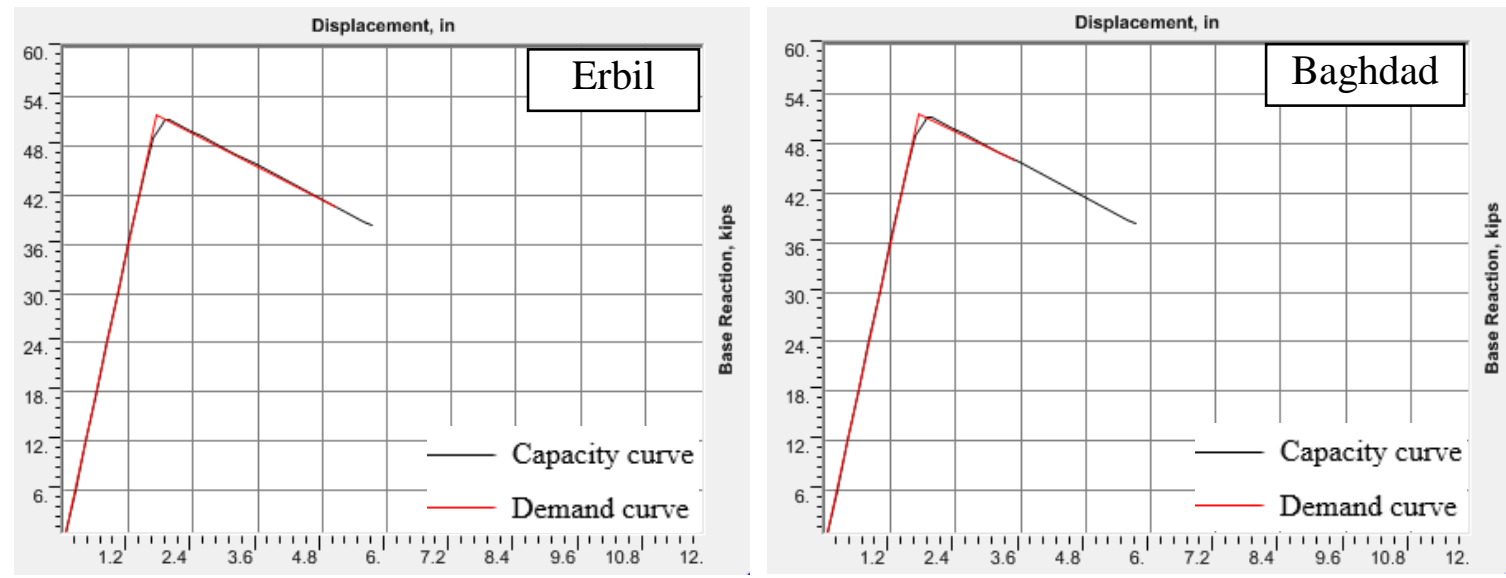

Figure 6.53: Target Displacement of Four-Story Buildings in Erbil and Baghdad

Table 6-5: Displacement Target of Retrofit RC Buildings.

\begin{tabular}{||c|c|c|c|c|c||}
\hline \hline The city & $\begin{array}{c}\text { RC } \\
\text { building }\end{array}$ & $\begin{array}{c}\text { Base } \\
\text { reaction, } \\
\text { kips }\end{array}$ & $\begin{array}{c}\text { Target } \\
\text { displacement } \\
\text { at roof level, } \\
\text { inch }\end{array}$ & $\begin{array}{c}\text { Performance } \\
\text { level of the } \\
\text { first-floor } \\
\text { column }\end{array}$ & $\begin{array}{c}\text { overall } \\
\text { performance } \\
\text { level }\end{array}$ \\
\hline \hline \multirow{3}{*}{ Baghdad } & $\begin{array}{c}\text { Two- } \\
\text { Story }\end{array}$ & 43 & 1.97 & LS & LS \\
\cline { 2 - 6 } & $\begin{array}{c}\text { Four- } \\
\text { Story }\end{array}$ & 46 & 3.48 & LS & LS \\
\hline \multirow{2}{*}{ Erbil } & $\begin{array}{c}\text { Two- } \\
\text { Story }\end{array}$ & 41.5 & 2.99 & LS & LS \\
\cline { 2 - 6 } & $\begin{array}{l}\text { Four- } \\
\text { Story }\end{array}$ & 40.6 & 5.04 & CP & CP \\
\hline \hline
\end{tabular}



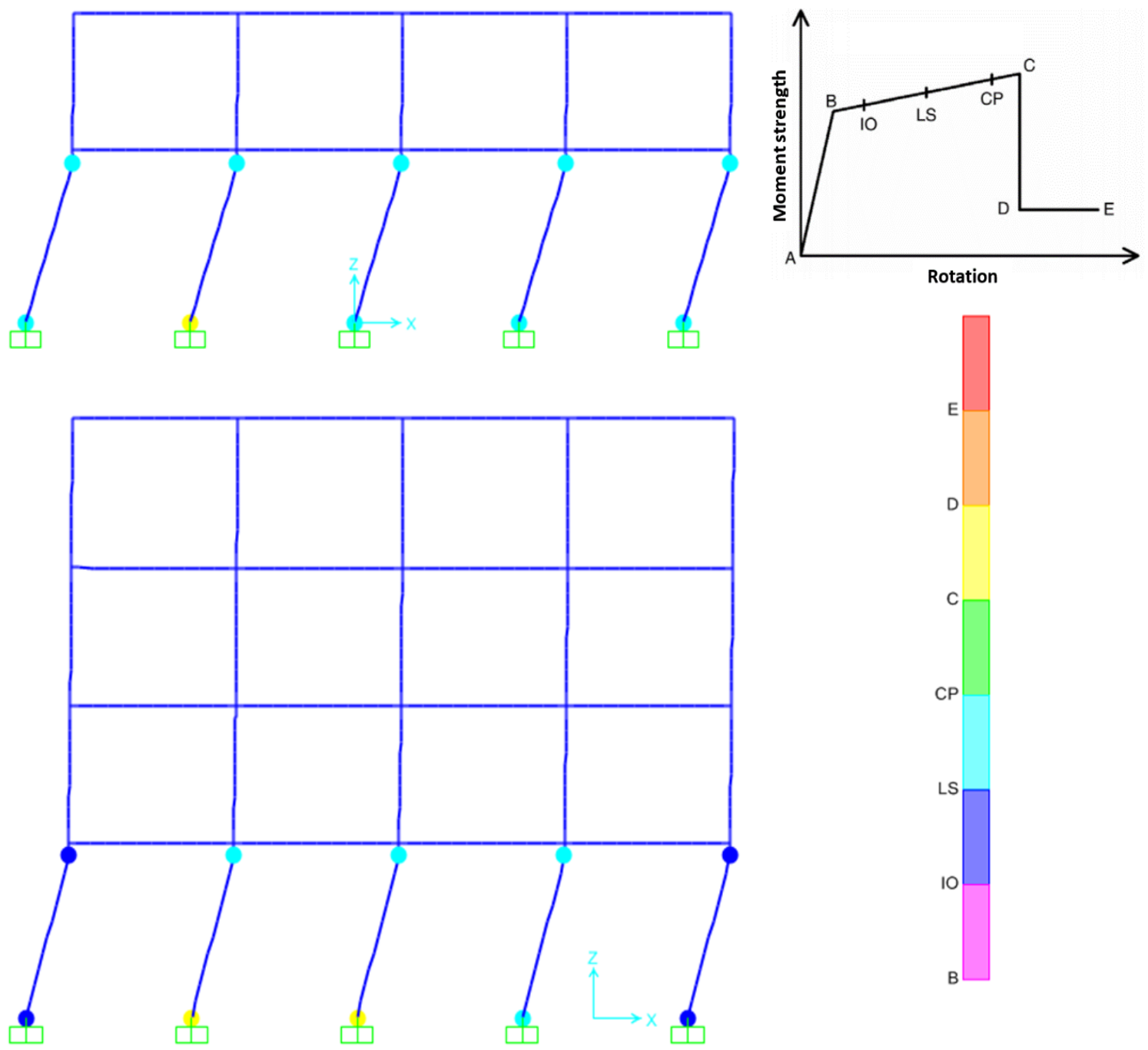

Figure 6.54: Failure Mechanism of the Lateral Retrofit Column

\subsubsection{CFRP Longitudinal Strengthening}

In order to overcome the soft story failure mechanism by increasing both effective stiffness and nominal moment strength of the slender column on the first floor, a longitudinal CFRP sheet was placed along the column. Based on the experimental results of specimen Retroft-C11-0.2, the effective stiffness and the nominal moment strength can be improved by using longitudinal CFRP sheet in addition to the lateral confinement. 
Increasing the moment strength led to an increase in the lateral strength of the column and consequently the shear demand. Therefore, it is important to check the shear strength of the slender column not only at the plastic hinge regions, but along the column length. In this study, the number of the CFRP layers required to overcome the soft story failure mechanism was determined based on the required nominal moment strength, which was larger than the nominal moment strength of the beam. The moment strength of the column was increased up to a value where the plastic deformation starts in beams before column. The results of the iteration procedure revealed that four layers in the longitudinal direction and two layers in the lateral direction was optimal. The capacity curve of the retrofit columns is illustrated in Fig. 6.55. Figures 6.56 and 6.57 illustrate the results of the target-displacement for two- and four-story buildings, respectively. Table 6-6 illustrates the results of the target displacement and acceptance criteria of the buildings and the improvement in the performance level for all buildings.
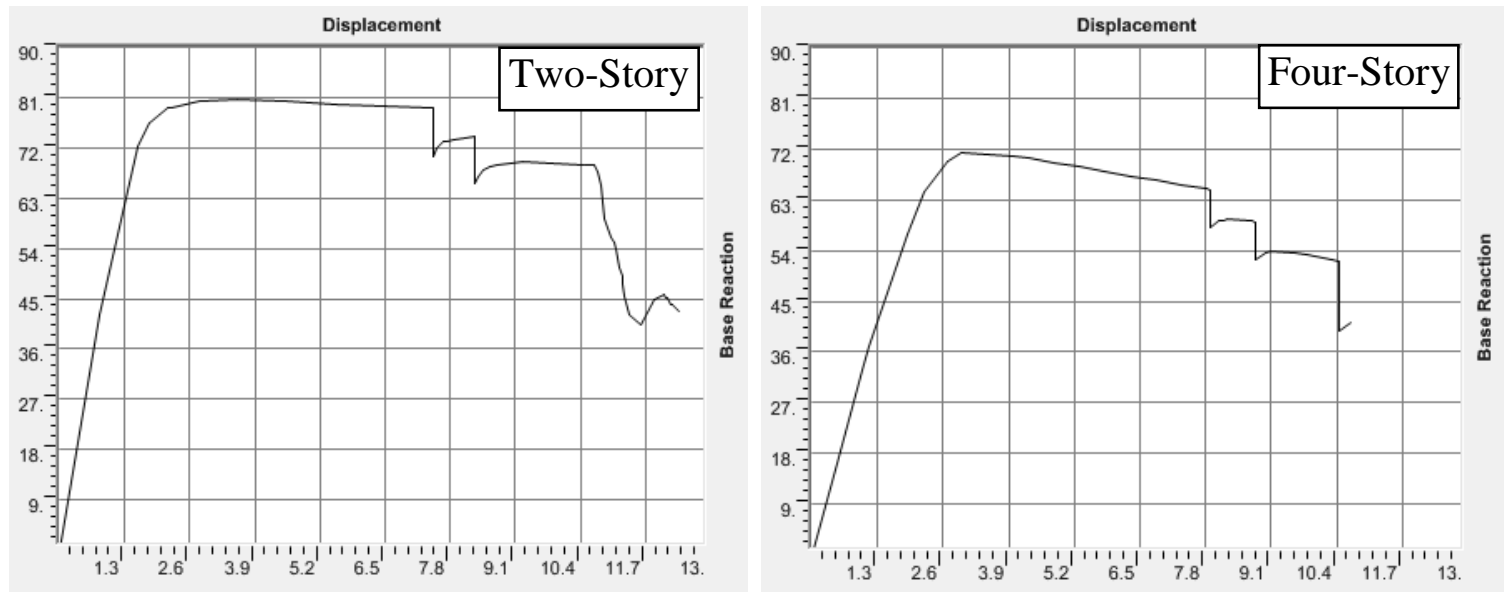

Figure 6.55: Capacity Curve of Two and Four-Story Buildings 

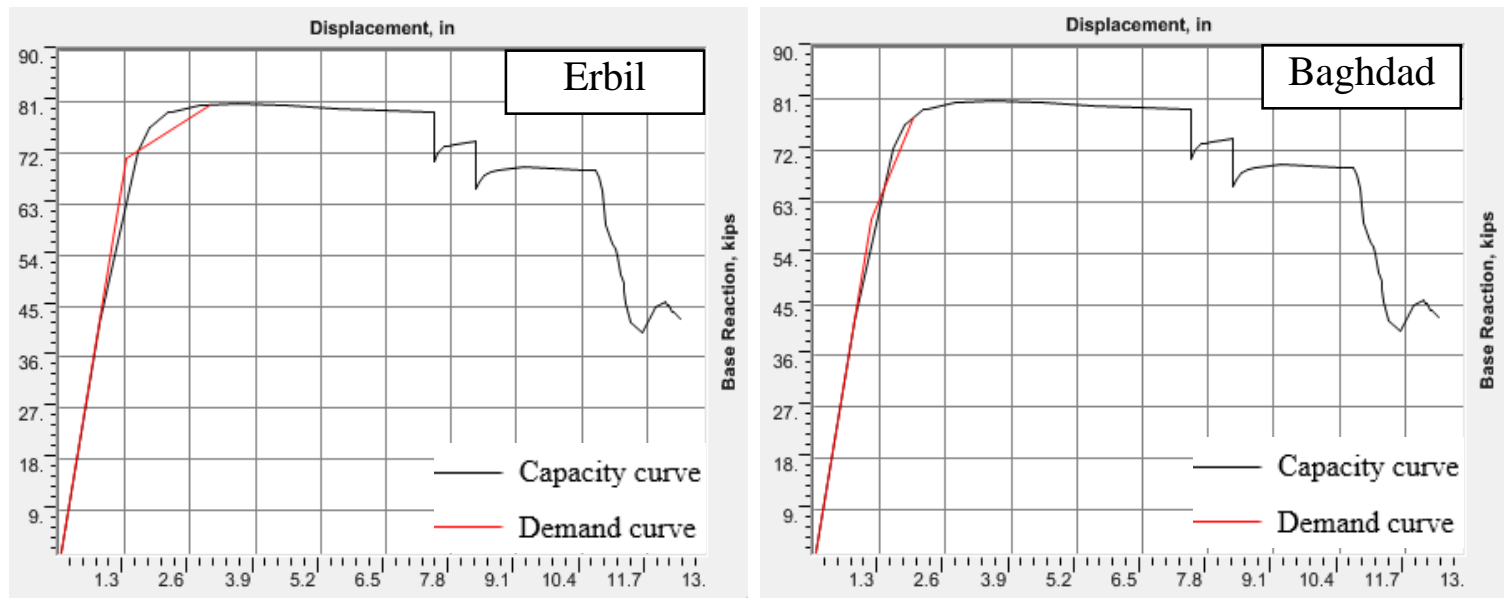

Figure 6.56: Target Displacement of Two-Story Buildings in Erbil and Baghdad
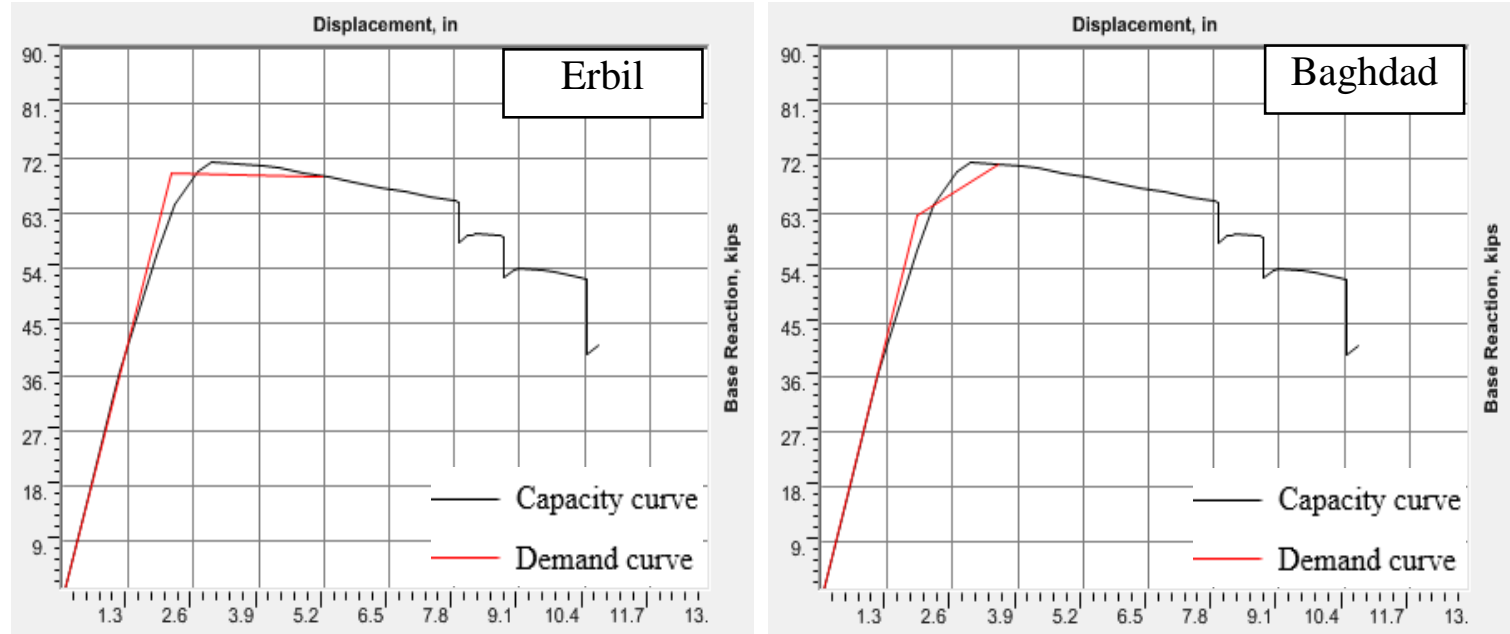

Figure 6.57: Target Displacement of Four-Story Buildings in Erbil and Baghdad 
Table 6-6: Displacement Target of Longitudinal CFRP Strengthening

\begin{tabular}{||c|c|c|c|c|c||}
\hline \hline \multirow{3}{*}{ The city } & $\begin{array}{c}\text { RC } \\
\text { building }\end{array}$ & $\begin{array}{c}\text { Base } \\
\text { reaction, } \\
\text { kips }\end{array}$ & $\begin{array}{c}\text { Target } \\
\text { displacement } \\
\text { at roof level, } \\
\text { inch }\end{array}$ & $\begin{array}{c}\text { Performance } \\
\text { level of the } \\
\text { first-floor } \\
\text { column }\end{array}$ & performance level \\
Overall \\
\hline \hline \multirow{3}{*}{ Baghdad } & $\begin{array}{c}\text { Two- } \\
\text { Story }\end{array}$ & 77.6 & 1.97 & IO & IO \\
\cline { 2 - 6 } & $\begin{array}{c}\text { Four- } \\
\text { Story }\end{array}$ & 71.1 & 3.51 & IO & LS \\
\hline \multirow{2}{*}{ Erbil } & $\begin{array}{c}\text { Two- } \\
\text { Story }\end{array}$ & 80.3 & 2.97 & IO & LS \\
\cline { 2 - 7 } & $\begin{array}{c}\text { Four- } \\
\text { Story }\end{array}$ & 69.0 & 5.17 & LS & LS \\
\hline \hline
\end{tabular}

Using the CFRP sheet in strengthening the slender RC column increased not only the elastic strength, but also the inelastic strength up to the CFRP rupture. However, the rotation capacity of the column and the performance level limits decreased. Increasing the nominal moment strength of the first-floor columns to overcome the weak columnstrong beam condition led to the development of plastic hinges at the beam ends. Even though, the displacement ductility of the RC column in the first-floor is limited, the overall deformation capacity of the building was improved due to the contribution of plastic hinges at the beam ends that increased the deformation capacity of the building without severe damage in the column. The performance level of the first-floor level column was improved in all building as illustrated in the Table 6-6. The failure mechanism of all buildings was improved, and the soft story failures were avoided, as shown in Fig. 6.58 

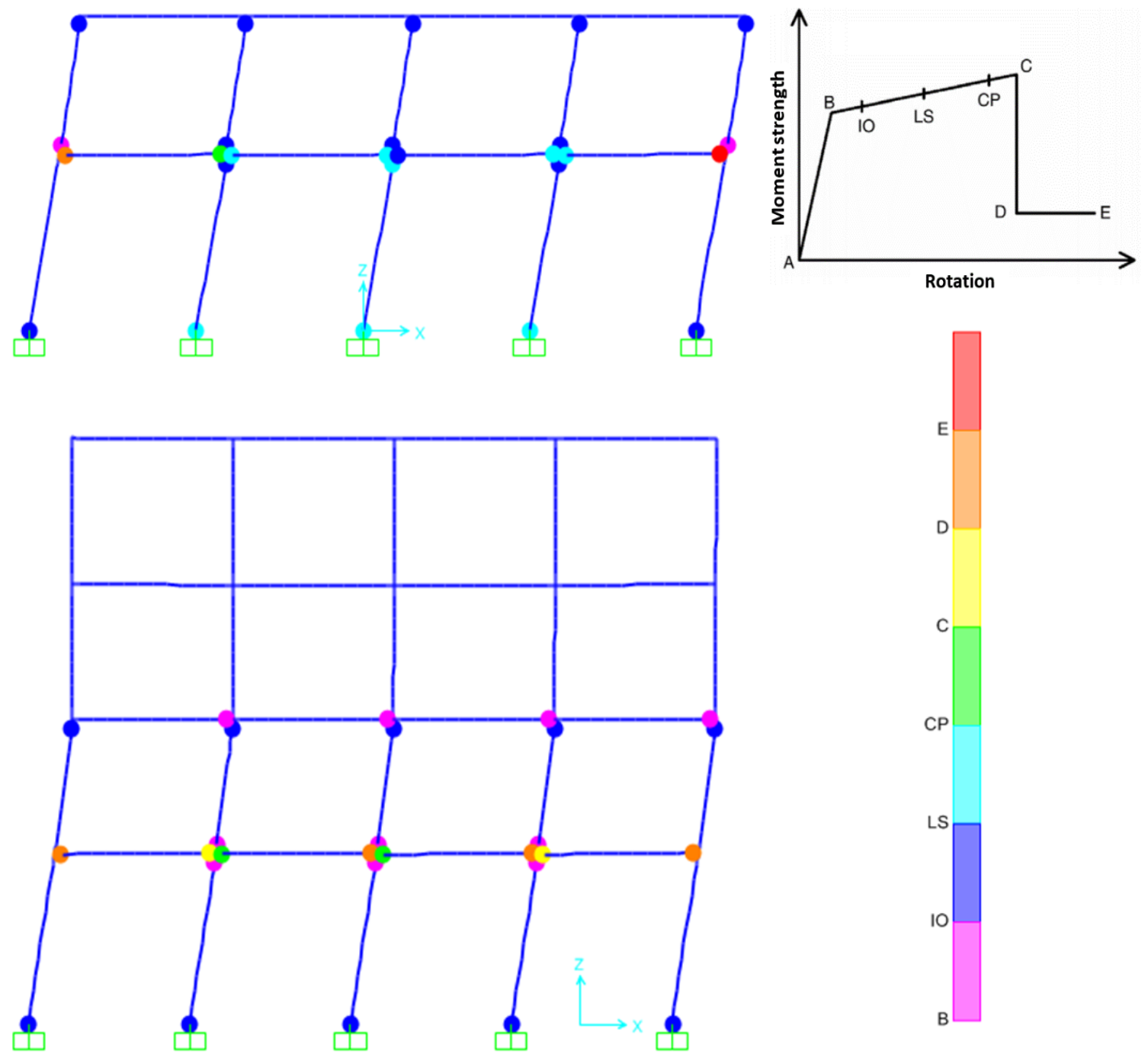

Figure 6.58: Failure Mechanism of the Longitudinal Retrofit Column 


\subsubsection{Comparison between the Un-Retrofit and Retrofit Buildings}

In order to assess the effect of retrofitting the RC building using CFRP, the results will be compared in term of ultimate lateral displacement capacity, and lateral displacement demand. Figure 6.59 and 6.60 illustrates the comparison between the capacity curves of the two and four-story buildings, respectively. It is clear that the effect of the lateral confinement of the slender RC columns helps to improve the ultimate lateral displacement of the buildings by $106 \%$ and $76 \%$ for two and four-story buildings compared with un-retrofit buildings. The effect of the lateral confinement on each of effective elastic stiffness or the ultimate lateral strength of the buildings is not considerable. However, strengthening the first-floor RC columns with four layers of CFRP sheets in the longitudinal direction in addition to the lateral confinement increases the lateral strength by $81 \%$ and $39 \%$ for the two and four-story buildings, respectively. Moreover, the ultimate lateral displacement was improved by $118 \%$ and $219 \%$ for two and four-story respectively compared with un-retrofit buildings. It is important to mention that even though the longitudinal retrofit column at the first-floor provides less ultimate lateral displacement for the columns compared with laterally confined columns, the overall behavior of the building is altered due to transfer of the inelastic deformation to the beams at the column-beam joints by developing plastic hinge regions at the beam ends. Developing the plastic hinges at the beams in addition to the plastic hinges at the columns ends helps to increase the deformation capacity provided by column-beam joints, and as a result the overall lateral displacement of the building is increased. In addition, the participation of the plastic hinges at the beams ends in the elastic 
deformation helps to keep the effective elastic stiffness approximately equal to the effective elastic stiffness of the as-built buildings.

The contribution of the lateral confinement in increasing the lateral displacement for two-story buildings is larger than the four-story building due to the P- $\Delta$ effect that limited the ultimate lateral displacement. However, the contribution of the longitudinal CFRP retrofit on the four-story building in improving the ultimate lateral displacement is larger than the two-story buildings due to developing the plastic hinge in the beams.

Based on the results, there is no need for using the longitudinal CFRP for the two-story building because the lateral confinement provides sufficient ultimate lateral displacement.

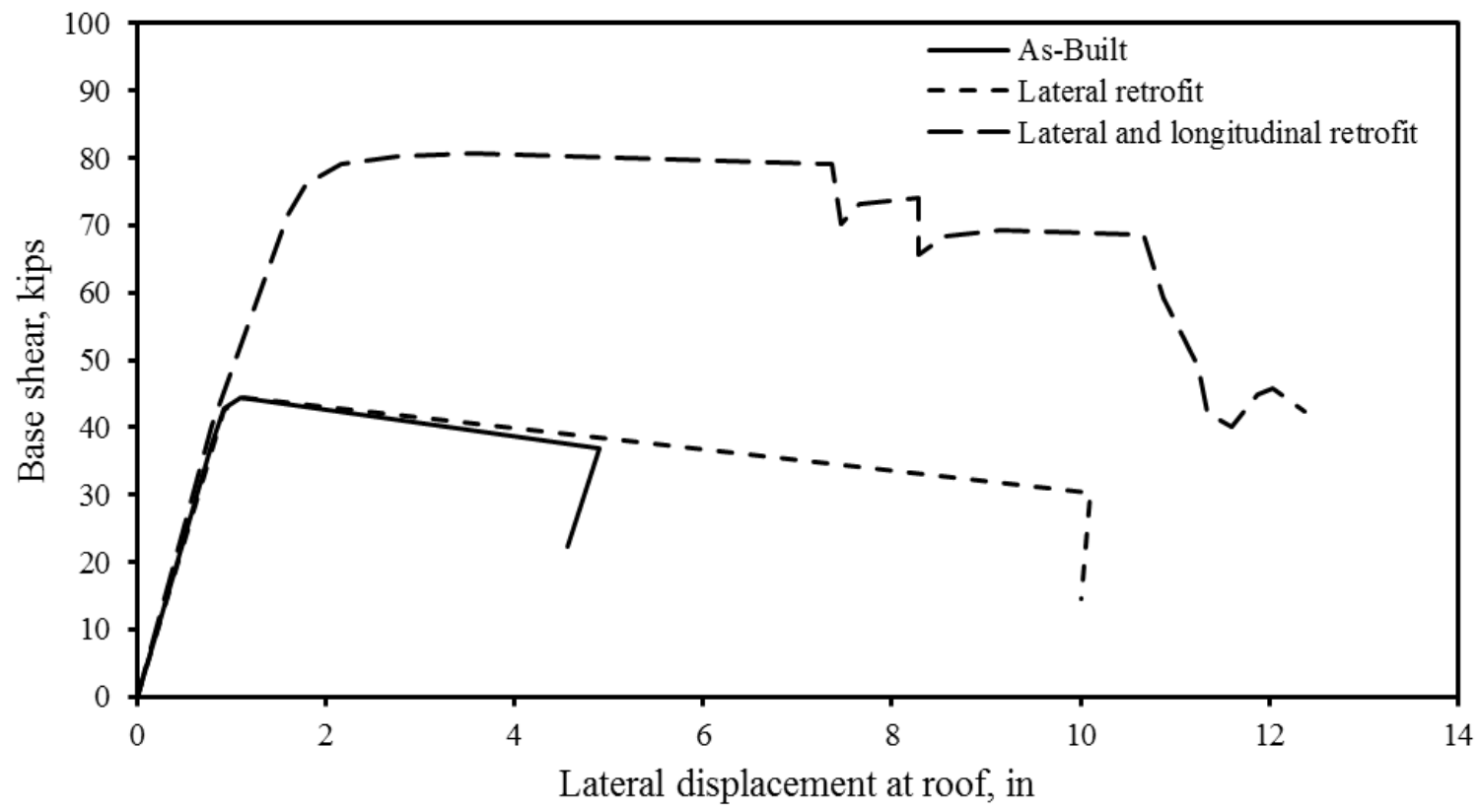

Figure 6.59: Comparison Between Un-Retrofit and Retrofit Two-story Buildings 


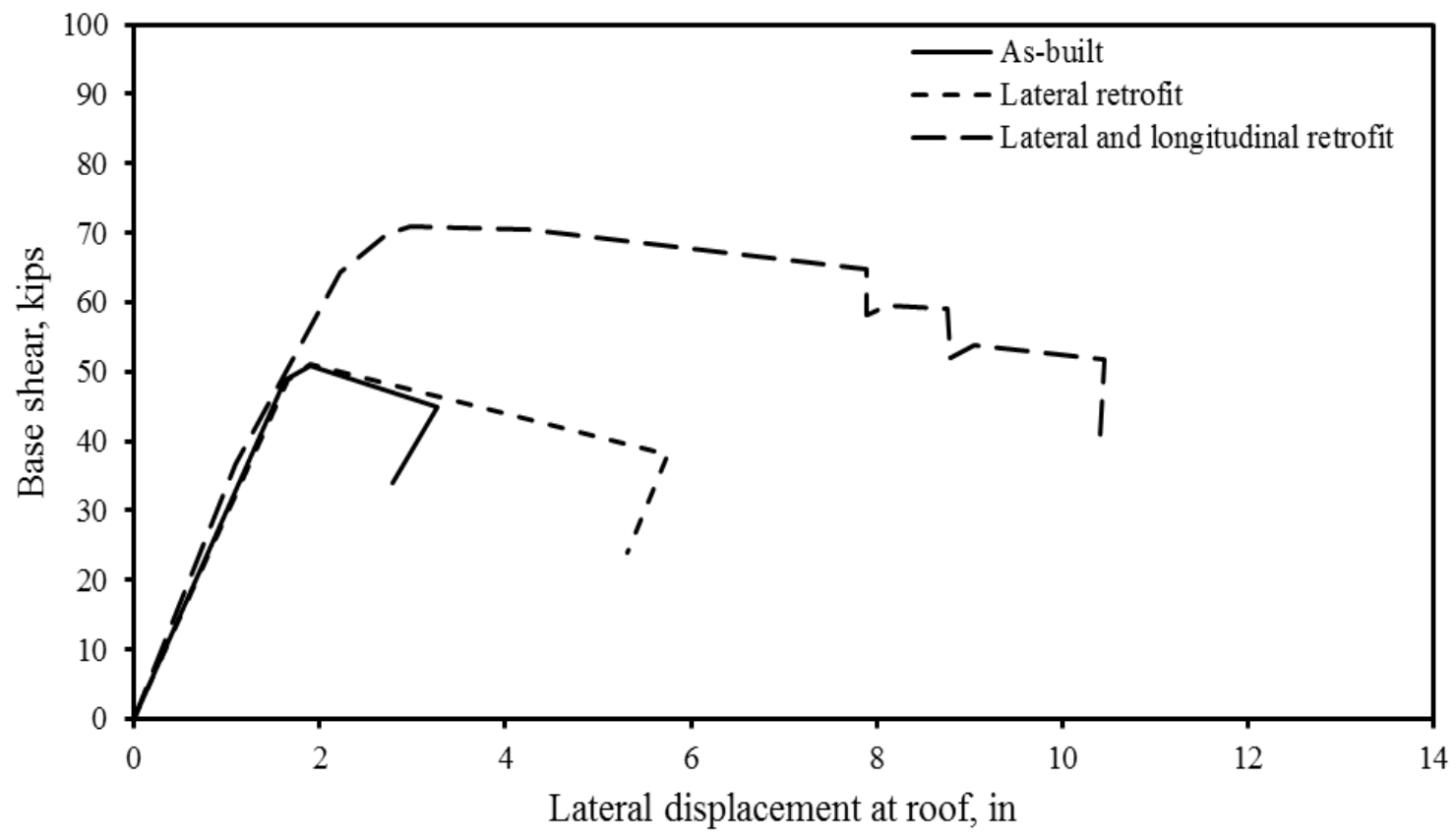

Figure 6.60: Comparison Between Un-Retrofit and Retrofit Four-story Buildings

Table 6-7 shows the ultimate lateral displacement capacity and the lateral displacement demand of the two-story buildings in Baghdad and Erbil. Increasing the intensity of the seismic event increases the lateral displacement demand, therefore, the demand at Erbil is larger than at Baghdad. For the seismic retrofitting system, it is important to keep the natural period close to the as-built building. Increasing the effective elastic stiffness of the building leads to decrease the natural period and as a result, increases the seismic forces, explained elsewhere, (Chopra, 2015). In this study, the displacement demands are approximately equal for the un-retrofit and retrofit buildings due to maintaining the effective elastic stiffness as approximately equal. 
Table 6-7: Target Displacement and Lateral Displacement Capacities

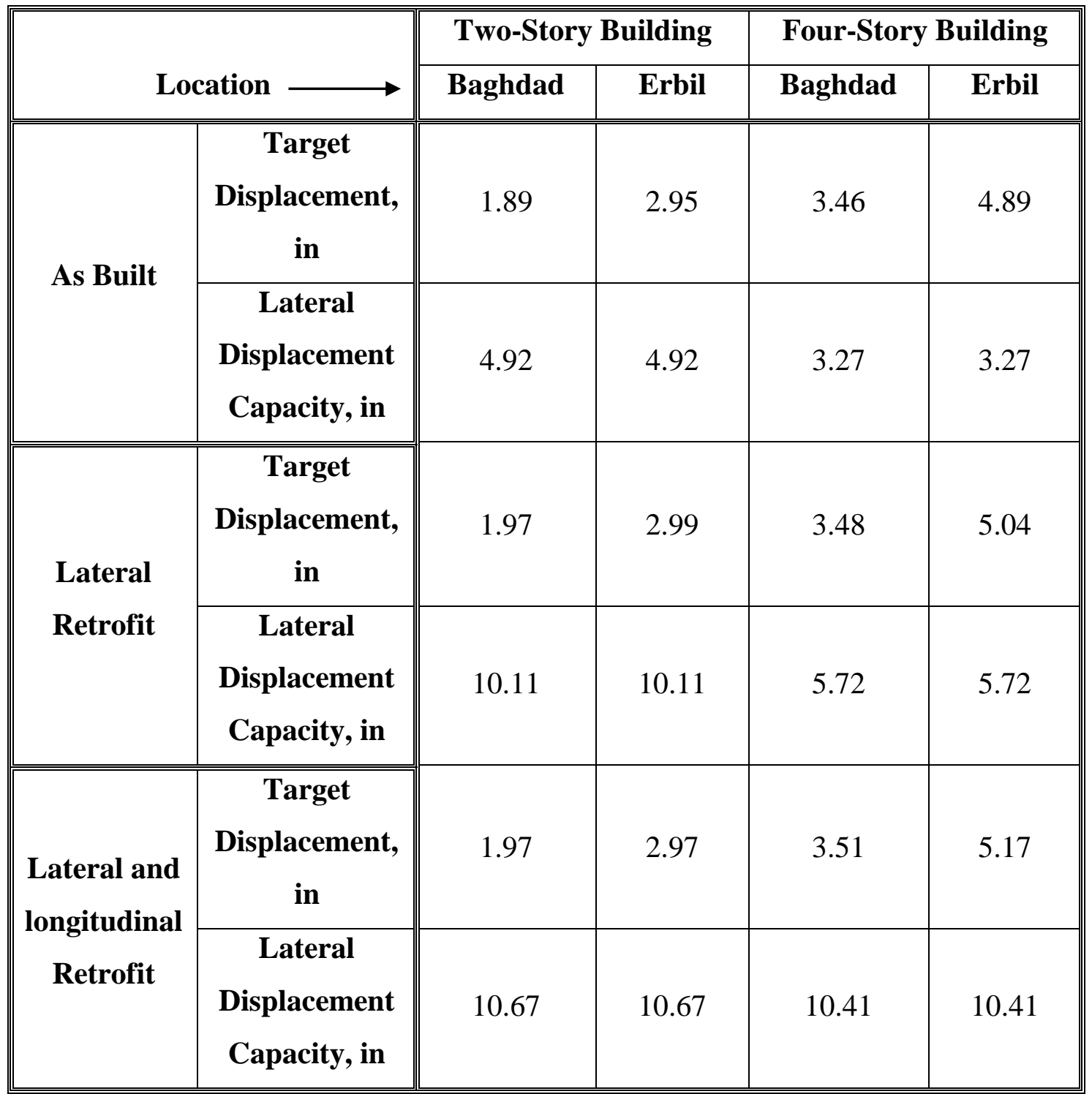




\section{Chapter 7: Conclusions and Recommendations for Future Work}

\subsection{Summary}

In this study, experimental and analytical research were conducted to investigate the seismic behavior of un-retrofit and retrofit older, lightly reinforced RC columns that generally exit in two cities in Iraq, namely Baghdad and Erbil. The behavior of RC slender columns un-retrofit and retrofit with CFRP were determined in terms of effective stiffness, lateral strength, curvature ductility, displacement ductility, and energy dissipation for columns with two levels of axial load. The theoretical results of predicting moment-curvature and lateral load-displacement relations were compared with the experimental results and good agreement was achieved. In this following sections, the conclusions of this study and recommendations for future work are presented.

\subsection{Conclusions}

1. Slender RC columns designed based on older codes, did not perform adequately under cyclic lateral load and an axial load of $0.4 f_{c}^{\prime} A_{g}$. Severe damage due to compressive-flexural failure occurred just after the longitudinal steel yielded, with concrete crushing and steel buckling.

2. Reducing the axial load level to $0.2 f_{c}^{\prime} A_{g}$ improved the displacement ductility of the RC slender columns. Gradual flexural failure occurred with concrete cover spalling followed by steel buckling at the end of the test.

3. CFRP-retrofitting in the lateral direction at the plastic hinge region improved deformation capacity of the plastic hinge region tested under cyclic lateral load. 
Increasing the confinement in the plastic hinge region improved the axial stress-strain behavior of the confined concrete, and prevented concrete cover spalling and steel buckling.

4. With CFRP lateral confinement, the behavior of slender RC columns tested under low and moderate axial load level was improved in terms of displacement ductility, energy dissipation, and failure mechanism, without considerable effect on the effective stiffness and the peak lateral strength.

5. The lateral strain in the lateral CFRP confinement was increased by increasing the lateral displacement up to the end of the test. However, the lateral strain of the CFRP did not return to zero after removing the lateral load, due to the dilation action in the confined concrete.

6. Increasing the axial load level on the slender columns played a significant role in consuming the lateral strength of the columns with increasing lateral displacement, due to the effect of the secondary moment, P- $\Delta$.

7. Using longitudinal CFRP retrofitting with the lateral CFRP confinement increased both the effective stiffness and the lateral strength of the column up to the longitudinal CFRP rupture.

8. Strengthening the weak RC column in the longitudinal direction helped to overcome the strong beam-weak column condition.

9. Using the proposed CFRP anchor provided a stable response during cyclic action and supported the longitudinal CFRP sheet up to rupture. 
10. Defining the acceptance criteria for the un-retrofit RC member based on the ASCE 41-13 (Table 10-8) provided a conservative estimate for the column under low axial load.

11. Using limits on compressive strain of concrete and tensile stress of steel combined with ASCE 41-13 limits to define the acceptance criteria for the experimental tests provided a reasonable estimation for the acceptance criteria of retrofit and un-retrofit RC columns.

\subsection{Recommendations for Future Work}

1. Extend the present investigation to include the effects of the transverse reinforcement ratio, the longitudinal reinforcement ratio, and the secondary moment, $\mathrm{P}-\Delta$, on unretrofit and retrofit slender $\mathrm{RC}$ columns that have a shear span to depth ratio of more than 7 and test these under a constant axial load and lateral cyclic load.

2. Develop more comparable data on slender column behavior in order to generate a relatively high confidence limit for the results submitted in the current study.

3. Extend the investigation of the proposed CFRP anchor in conjunction with thicker longitudinal CFRP sheets, using a proper scaling methodology.

4. Strengthen the slender RC columns in longitudinal direction with different material, e.g., titanium, which can increase stiffness and reduce the P- $\Delta$ effects.

5. Explore more refined methodologies in establishing more reliable acceptance criteria for slender RC columns with light reinforcement.

6. Investigate the effect of including the shear to span ratio on the acceptance criteria for slender RC columns. 
7. Investigate the effect of using high strength concrete and high strength steel reinforcement on slender RC columns. 


\section{References}

ACI 369R-11. 2011. Guide for Seismic Rehabilitation of Existing Concrete Frame Buildings and Commentary.

ACI 440.2R-08. 2008. Guide for the Design and Construction of Externally Bonded FRP Systems for Strengthening Existing Structures.

ACI 440.2R-17. 2017. Guide for the Design and Construction of Externally Bonded FRP Systems for Strengthening Existing Structures.

ACI 374.2R-13. 2013. Guide for Testing Reinforced Concrete Structural Elements under Slowly Applied Simulated Seismic Loads .

ACI 318-14. 2014: Building Code Requirements for Structural Concrete.

Al-Salloum, Yousef A. 2007. "Influence of Edge Sharpness on the Strength of Square Concrete Columns Confined with FRP Composite Laminates." Composites Part B: Engineering 38(5-6):640-50.

Al-Khafaji, H. L. (2016). "Experimental Investigation of CFRP Wrapped Square Nonductile Reinforced Concrete Columns”. M.Sc. Thesis, Portland State University.

Alsinawi, S. A. 2002. "Seismicity, Seismotectonics, Crustal Structure and Attenuation Data on Iraq." The RELEMR Meeting, Antakya, Turkey (v):12-14.

Alvarez, José C., Sergio F. Breña, and Sanjay R. Arwade. 2018. "Nonlinear Backbone Modeling of Concrete Columns Retrofitted with Fiber-Reinforced Polymer or Steel Jackets." ACI Structural Journal 115(1):53-64.

Ameer, A. S., M. L. Sharma, H. R. Wason, and S. A. Alsinawi. 2004. "Seismic Hazard Characterization and Risk Evaluation Using Gumble's Method of Extrems (G1 and G3) and G-R Formula for Iraq." in 13th World Conference on Earthquake Engineering, Vancouver. 2004.

Ameer, A. S., M. L. Sharma, H. R. Wason, and S. A. Alsinawi. 2005. "Probabilistic Seismic Hazard Assessment for Iraq Using Complete Earthquake Catalogue Files." Pure and Applied Geophysics 162(5):951-66.

ASCE/SEI 7-10. 2010. Minimum Design Loads for Buildings and Other Structures. 
ASCE/SEI 41-13. 2013. Seismic Rehabilitation of Existing Buildings.

ATC-6. 1981. Seismic Design Guidelines for Highway Bridges. Applied Tech. Council, Berkeley, Calif.

ATC-40. 1996. Seismic Evaluation and Retrofit of Concrete Buildings. Redwood City, California.

Babazadeh, A., R. Burgueño, and P. F. Silva. 2017. "Model for the Plastic Region in Slender RC Columns with Nonlinear Moment and Stiffness Profiles." Journal of Structural Engineering (United States) 143(9):1-13.

Babazadeh, Ata, Rigoberto Burgueño, and Pedro F. Silva. 2016. "Evaluation of the Critical Plastic Region Length in Slender Reinforced Concrete Bridge Columns." Engineering Structures 125:280-93.

Bae, S. and O. Bayrak. 2005. "Seismic Performance of Full-Scale Reinforced Concrete Columns." Civil, Architectural, and Environemntal Engineering PhD:312.

Bae, Sungiin and Oguzhan Bayrak. 2008a. "Plastic Hinge Length of Reinforced Concrete Columns." ACI Structural Journal 105(3):290-300.

Bae, Sungjin and Oguzhan Bayrak. 2008b. "Seismic Performance of Full-Scale Reinforced Concrete Columns." ACI Structural Journal 105(2):123-33.

Bae, Sungjin, Oguzhan Bayrak, and Eric Williamson. 2004. "What do We Know about the Performance-Based Design of Columns ?" in 13 th World Conference on Earthquake Engineering.

Barrera, A. C., J. L. Bonet, M. L. Romero, and M. A. Fernández. 2012. "Ductility of Slender Reinforced Concrete Columns under Monotonic Flexure and Constant Axial Load." Engineering Structures 40:398-412.

Barrera, A. C., J. L. Bonet, M. L. Romero, and P. F. Miguel. 2011. "Experimental Tests of Slender Reinforced Concrete Columns under Combined Axial Load and Lateral Force." Engineering Structures 33(12):3676-89.

Barros, Joaquim, José Sena-cruz, Salvador Dias, Débora Ferreira, and Adriano Fortes. 2004. "Near Surface Mounted CFRP-Based Technique for the Strengthening of Concrete Structures." Pp. 205-17 In Workshop on R+ D+ I in Technology of Concrete Structures: a tribute to Dr. Ravindra Gettu= Jornada Técnica en Honor a Ravindra Gettu. 
Belarbi, Abdeldjelil D. J., Pedro F. Silva, and Sang-wook Bae. 2008. "Retrofit Using CFRP Composites of RC Bridge Columns under Combined Loads." Proc., 4th Int. Symp. on FRP Composites in Civil Engineering (CICE) 22-24.

Berry, M. P., D. E. Lehman, and L. N. Lowes. 2008. "Lumped-Plasticity Models for Performance Simulation of Bridge Columns.” ACI Structural Journal 105(3).

Binici, Baris. 2008. "Design of FRPs in Circular Bridge Column Retrofits for Ductility Enhancement." Engineering Structures 30(3):766-76.

Biskinis, Dionysis E., George K. Roupakias, and Michael N. Fardis. 2004. "Degradation of Shear Strength of Reinforced Concrete Members with Inelastic Cyclic Displacements." ACI Structural Journal 101(6):773-83.

Biskinis, Dionysis and Michael N. Fardis. 2013. "Models for FRP-Wrapped Rectangular RC Columns with Continuous or Lap-Spliced Bars under Cyclic Lateral Loading." Engineering Structures 57:199-212.

Bournas, D. a., T. C. Triantafillou, K. Zygouris, and F. Stavropoulos. 2009. “TextileReinforced Mortar versus FRP Jacketing in Seismic Retrofitting of RC Columns with Continuous or Lap-Spliced Deformed Bars." Journal of Composites for Construction 13(October):360-71.

Bournas, D. A., T. C. Triantafillou, K. Zygouris, and F. Stavropoulos. 2009. “TextileReinforced Mortar versus FRP Jacketing in Seismic Retrofitting of RC Columns with Continuous or Lap-Spliced Deformed Bars." Journal of Composites for Construction 13(5):360-71.

Bournas, Dionysios A. and Thanasis C. Triantafillou. 2009. "Flexural Strengthening of Reinforced Concrete Columns with near-Surface-Mounted FRP or Stainless Steel." ACI Structural Journal 106(4):495-505.

Brachmann, I., Browning, J., and Matamoros, A. B. 2002. "Drift Capacity Approaches of Rectangular Slender Reinforced Concrete Columns under Cyclic Loading." in SM Report No. 68, University of Kansas Center for Research, Inc. Lawrence, Kansas.

Burgueño, Rigoberto, Ata Babazadeh, Lauren K. Fedak, and Pedro F. Silva. 2016. "Second-Order Effects on Seismic Response of Slender Bridge Columns." ACI Structural Journal 113(4):735-46. 
Caballero-Morrison, K. E., J. L. Bonet, Juan Navarro-Gregori, and J. R. Martí-Vargas. 2012. "Behaviour of Steel-Fibre-Reinforced Normal-Strength Concrete Slender Columns under Cyclic Loading." Engineering Structures 39:162-75.

Chopra, Anil K. 2015. Dynamics of Structures. Theory and Applications to Earthquake Engineering. 4th er. Pearson.

Del Vecchio, Ciro, Marta Del Zoppo, Marco Di Ludovico, Gerardo Mario Verderame, and Andrea Prota. 2017. "Comparison of Available Shear Strength Models for NonConforming Reinforced Concrete Columns." Engineering Structures 148:312-27.

Elsanadedy, Hussein M., Yousef A. Al-Salloum, Saleh H. Alsayed, and Rizwan A. Iqbal. 2012. "Experimental and Numerical Investigation of Size Effects in FRP-Wrapped Concrete Columns." Construction and Building Materials 29:56-72.

Elwood, Kenneth J., Adolfo B. Matamoros, John W. Wallace, Dawn E. Lehman, Jon A. Heintz, Andrew D. Mitchell, Mark A. Moore, Michael T. Valley, Laura N. Lowes, Craig D. Comartin, and Jack P. Moehle. 2007. "Update to ASCE/SEI 41 Concrete Provisions." Earthquake Spectra 23(3):493-523.

Eom, Tae Sung and Hong Gun Park. 2010. "Evaluation of Energy Dissipation of Slender Reinforced Concrete Members and Its Applications." Engineering Structures 32(9):2884-93.

Eshghi, S; and Zanjanizadeh, V. 2008. "Retrofit of Slender Square Reinforced Concrete Columns with Glass Fiber-Reinforced Polymer for Seismic Resistance." Iranian Journal of Scince \& Technology 32(B5):437-50.

Fahmy, M. F. M., A. M. Ismail, and Z. Wu. 2017. "Numerical Study on the Applicability of Design-Oriented Models of FRP-Confined Concrete for Predicting the Cyclic Response of Circular FRP-Jacketed RC Columns." Journal of Composites for Construction 21(5).

Fahmy, Mohamed, Zhishen Wu, and Gang Wu. 2009. "Seismic Performance Assessment of Damage-Controlled FRP-Retrofitted RC Bridge Columns Using Residual Deformations." Journal of Composites for Construction 13(6):498-513.

Faustino, Pedro, Pedro Frade, and Carlos Chastre. 2016. "Lateral Cyclic Behaviour of RC Columns Confined With Carbon Fibres." Structures 5:196-206.

FEMA-440, 2005. "Improvement of Nonlinear Static Seismic Analysis Procedures." FEMA-440, Redwood City 1-392. 
FEMA-356, Prestandard. 2000. "Commentary for the Seismic Rehabilitation of Buildings." Pp. 1-518 in FEMA-356, Federal Emergency Management Agency, Washington, $D C$.

Ferguson, By Phil M. and John E. Breen. 1966. "Investigation of the Long Concrete Column in a Frame Subiect to Lateral Loads." Special Publication 13 : 75-119 (4):75-119.

Fitzwilliam, Jason and Luke A. Bisby. 2010. "Slenderness Effects on Circular CFRP Confined Reinforced Concrete Columns." Journal of Composites for Construction 14(3):280-88.

Ghatte, Hamid Farrokh, Mustafa Comert, Cem Demir, and Alper Ilki. 2016. "Evaluation of FRP Confinement Models for Substandard Rectangular RC Columns Based on Full-Scale Reversed Cyclic Lateral Loading Tests in Strong and Weak Directions." Polymers 8(9):1-24.

Ghee, Ang Beng, M. J. N. Priestley, and T. Paulay. 1989. "Seismic Shear Strength of Circular Reinforced Concrete Columns.” ACI Structural Journal 86(1):45-59.

Ghobarah, A. and K. Elmandoohgalal. 2004. "Seismic Rehabilitation of Short Rectangular Rc Columns.” Journal of Earthquake Engineering 8(1):45-68.

Godat, Ahmed, Francesca Ceroni, Omar Chaallal, and Marisa Pecce. 2017. "Evaluation of FRP-to-Concrete Anchored Joints Designed for FRP Shear-Strengthened RC TBeams." Composite Structures 176:481-95.

Grammatikou, S., D. Biskinis, and M. N. Fardis. 2018. "Effect of Load Cycling, FRP Jackets, and Lap-Splicing of Longitudinal Bars on the Effective Stiffness and Ultimate Deformation of Flexure-Controlled RC Members." Journal of Structural Engineering 144(6):1-19.

Grelle, Stephen V. and Lesley H. Sneed. 2013. "Review of Anchorage Systems for Externally Bonded FRP Laminates." International Journal of Concrete Structures and Materials 7(1):17-33.

Gu, Dong Sheng, Yu Fei Wu, Gang Wu, and Zhi Shen Wu. 2012. "Plastic Hinge Analysis of FRP Confined Circular Concrete Columns." Construction and Building Materials 27(1):223-33. 
Harajli, Mohamed H. 2006. "Axial Stress-Strain Relationship for FRP Confined Circular and Rectangular Concrete Columns." Cement and Concrete Composites 28(10):938-48.

Harajli, Mohamed H. and Farid Dagher. 2008. "Seismic Strengthening of Bond-Critical Regions in Rectangular Reinforced Concrete Columns Using Fiber-Reinforced Polymer Wraps.” ACI Structural Journal 105(1):68-77.

He, Ruili, Stephen Grelle, Lesley H. Sneed, and Abdeldjelil Belarbi. 2013. "Rapid Repair of a Severely Damaged RC Column Having Fractured Bars Using Externally Bonded CFRP.” Composite Structures 101:225-42.

Hines, Eric M., José I. Restrepo, and Frieder Seible. 2004. "Force-Displacement Characterization of Well-Confined Bridge Piers." ACI Structural Journal 101(4):537-48.

Hiotakis, S. 2004. "Repair and Strengthening of Reinforced Concrete Shear Walls for Earthquake Resistance Using Externally Bonded Carbon Fibre Sheets and a Novel Anchor System." Ph.D.Thesis, University of Ottawa.

Hose, Yael, Pedro Silva, and Frieder Seible. 2000. "Development of a Performance Evaluation Database for Concrete Bridge Components and Systems under Simulated Seismic Loads.” Earthquake Spectra 16(2):413-42.

Iacobucci, Richard D., Shamim A. Sheikh, and Oguzhan Bayrak. 2003. "Retrofit of Square Concrete Columns with Carbon Fiber-Reinforced Polymer for Seismic Resistance.” Structural Journal 100.6(October):785-94.

Ilki, Alper, Nahit Kumbasar, and Volkan Koc. 2004. "Low Strength Concrete Members Externally Confined with FRP Sheets." Structural Engineering and Mechanics 18(2):167-94.

Inel, Mehmet and Hayri Baytan Ozmen. 2006. "Effects of Plastic Hinge Properties in Nonlinear Analysis of Reinforced Concrete Buildings." Engineering Structures 28(11):1494-1502.

Jaya, K. P. and Jessy Mathai. 2012. "Strengthening of RC Column Using GFRP and CFRP." 15 WCEE Lisboa 2012. 
Jean, Michael, Charles St-martin, Nathalie Roy, Patrice Rivard, Zabihallah Moradian, Eduardo Carvalho Jr, and Jean Proulx. 2012. "Limit States of Reinforced Concrete Bridge Piers Confined with Carbon Fiber Reinforced Polymer ( CFRP )." in Proceedings of the 15th World Conference on Earthquake Engineering. LISBON, PORTUGAL.

Jiang, Cheng, Yu-Fei Wu, and Gang Wu. 2014. "Plastic Hinge Length of FRP-Confined Square RC Columns." Journal of Composites for Construction 18(4):4014003.

Jiang, T. and J. G. Teng. 2007. "Analysis-Oriented Stress-Strain Models for FRPConfined Concrete.” Engineering Structures 29(11):2968-86.

Kalfat, R., R. Al-Mahaidi, and Scott T. Smith. 2011. "Anchorage Devices Used to Improve the Performance of Reinforced Concrete Beams Retrofitted with FRP Composites: A State of the Art Review." Journal of Composites for Construction 223.

Kassaee, M. Z., M. Ghavami, A. Cheshmehkani, M. Majdi, and E. Motamedi. 2009. "Retrofit of Slender Square Reinforced Concrete Columns with Glass Fiber Reinforced Polymer for Seismic Resistance." Iranian Journal of Science \& Technology, Transaction B, Engineering 6(4):812-15.

Kenneth J. Elwood and Marc O. Eberhard, Robert E.Englekirk. 2009. "Effective Stiffness of Reinforced Concrete Columns." Aci Structural Journal 106(May-June):372-73.

Kenny, Charles. 2009. "Why Do People Die in Earthquakes? The Costs , Benefits and Institutions of Disaster Risk Reduction in Developing Countries." Policy Research Working Paper 4823(January 2009):1-42.

Khalifa, a, T. Alkhrdaji, a Nanni, and S. Lansburg. 1999. "Anchorage of Surface Mounted FRP Reinforcement." Concrete International: Design and Construction, Vol. 21, No.10, Oct 21(10):49-54.

Kosmatka, Steven H. and Michelle L. Wilson. 2011. Design and Control of Concrete Mixtures. Portland Cement Assoc.

Kowalsky, Mervyn J. and M. J.Nigel Priestley. 2000. "Improved Analytical Model for Shear Strength of Circular Reinforced Concrete Columns in Seismic Regions." ACI Structural Journal 97(3):388-96. 
Kwak, Hyo-Gyoung, Sun-Pil Kim, and Ji-Eun Kim. 2004. "Nonlinear Dynamic Analysis of RC Frames Using Cyclic Moment-Curvature Relation.” Structural Engineering and Mechanics 17(3_4):357-78.

L. Lam and J.G. Teng. 2003. "Design-Oriented Stress-Strain Model for FRP Confined Concrete." Construction and Building Materials 17(6-7):471-89.

Lam, L. and Teng, J. G. 2003. "Design-Oriented Stress-Strain Model for FRP-Confined Concrete in Rectangular Columns." Journal of Reinforced Plastics and Composites, Vol. 22, No. 13 22(13):1149-1186pp.

Lam, L. and J. G. Teng. 2009. "Stress-Strain Model for FRP-Confined Concrete under Cyclic Axial Compression." Engineering Structures 31(2):308-21.

Lam, L., J. G. Teng, C. H. Cheung, and Y. Xiao. 2006. "FRP-Confined Concrete under Axial Cyclic Compression." Cement and Concrete Composites 28(10):949-58.

Li, Benben and Kent A. Harries. 2018. "Seismic Performance Assessment of FlexureDominate FRP-Confined RC Columns Using Plastic Rotation Angle." Engineering Structures 172(April):453-71.

Li, Xian, Heng-Lin Lv, Guang-Chang Zhang, Shi-Yu Sha, and Shu-Chun Zhou. 2013. "Seismic Retrofitting of Rectangular Reinforced Concrete Columns Using Fiber Composites for Enhanced Flexural Strength." Journal of Reinforced Plastics and Composites 32(9):619-30.

Liang, Meng, Zhi-Min Wu, Tamon Ueda, Jian-Jun Zheng, and Romuald Akogbe. 2012. "Experiment and Modeling on Axial Behavior of Carbon Fiber Reinforced Polymer Confined Concrete Cylinders with Different Sizes." Journal of Reinforced Plastics and Composites 31(6):389-403.

Liu, Hui, Ming-hua He, Yu-qi Luan, Jia Guo, and Lu-lu Liu. 2013. "A Modified Constitutive Model for FRP Confined Concrete in Circular Sections and Its Implementation with OpenSees Programming." Journal of Zhejiang University SCIENCE A 14(12):856-66.

Lynn, a C., J. P. Moehle, S. a Mahin, and W. T. Holmes. 1996. "Seismic Evaluation of Existing Reinforced Concrete Building Columns." Earthquake Spectra 12(4):71539.

MacGregor, J. G., Breen, John E., Pfrang, E. O. 1970. "Design of Slender Concrete Columns.” ACI Structural Journal 67(1):302-7. 
MacGregor, Sven E. Hage, and James G. 1977. "Stability Analysis and Design of Concrete Frames.” Journal of the Structural Division 103(10):1953-70.

MacGregor, J. G. 1993. "Design of Slender Concrete Columns - Revisited." ACI Structural Journal 90(3):302-7.

Mahdavi, N. and A. A. Tasnimi. 2018. "Modeling and Verification of Response of RC Columns Strengthened in Flexure with Mechanically Fastened FRP." Journal of Vibroengineering 20(4):1774-82.

Mander, J. B., M. J. N. Priestley, and R. Park. 1988. "Observed Stress-Strain Behavior of Confined Concrete.” Journal of Structural Engineering 114(8):1827-49.

Mirmiran, A., Shahawy, M., Samaan, M., Echary, H., Mastrapa, J., and Pico, O. 1998. "Effect of Column Parameters on FRP-Confined Concrete." Journal of Composites for Construction 2(November):175-85.

Monti, By Giorgio and Nicola Nistico. 2001. "Design of FRP Jackets for Upgrade of Circular Bridge Piers." Journal of Composites for Construction 5(May):94-101.

Murray, Justin A. and Mehrdad Sasani. 2013. "Seismic Shear-Axial Failure of Reinforced Concrete Columns vs. System Level Structural Collapse.” Engineering Failure Analysis 32:382-401.

Niemitz, Carl W., Ryan James, and Sergio F. Breña. 2010. "Experimental Behavior of Carbon Fiber-Reinforced Polymer (CFRP) Sheets Attached to Concrete Surfaces Using CFRP Anchors." Journal of Composites for Construction 14(2):185-94.

Ohno, Tomonori and Takashi Nishioka. 1984. "An Experimental Study on Energy Absorption Capacity of Columns in Reinforced Concrete Structures." Doboku Gakkai Ronbunshu 1(350):23-33.

Olivova, K. and J. Bilcik. 2009. "Strengthening of Concrete Columns With CFRP." Slovak Journal of Civil Engineering 1:1-9.

Orton, Sarah Lynn. 2007. "Development of a CFRP System to Provide Continuity in Existing Reinforced Concrete Buildings Vulnerable to Progressive Collapse.” Ph.D. Thesis, The University of Texas at Austin (U.S).

Ouyang, Li Jun, Wan Yang Gao, Bin Zhen, and Zhou Dao Lu. 2017. "Seismic Retrofit of Square Reinforced Concrete Columns Using Basalt and Carbon Fiber-Reinforced Polymer Sheets: A Comparative Study.” Composite Structures 162:294-307. 
Ozbakkaloglu, Togay, Jian C. Lim, and Thomas Vincent. 2013. "FRP-Confined Concrete in Circular Sections: Review and Assessment of Stress-Strain Models." Engineering Structures 49:1068-88.

Ozbakkaloglu, Togay and Murat Saatcioglu. 2009. "Tensile Behavior of FRP Anchors in Concrete." Journal of Composites for Construction 13(April):82-92.

Pam, H. J. and J. C. M. Ho. 2009. "Length of Critical Region for Confinement Steel in Limited Ductility High-Strength Reinforced Concrete Columns." Engineering Structures 31(12):2896-2908.

Park, HG., Eom, TS. 2006. “A Simplified Method for Estimating the Amount of Energy Dissipated by Flexure-Dominated Reinforced Concrete Members for Moderate Cyclic Deformations." Earthq Spectra 2006;22(2):459_90.

Park, R. 1988. "Ductility Evaluation from Laboratory and Analytical Testing." Pp. 60516 in Proceedings of the 9th World Conference on Earthquake Engineering, 2-9 August. Tokyo-Kyoto, Japan.

Park, R. 1989. "Evaluation of Ductility of Structures and Tructural Subassemblages from Laboratory Testing." P. 155-166. in Bulletin of the New Zealand national society for earthquake engineering. Vol. 22.

Park, R. 2001. "Improving the Resistance of Structures to Earthquakes." Bulletin of the New Zealand Society for Earthquake Engineering 34(1):1-39.

Park, R. L., R. Park, and T. Paulay. 1975. Reinforced Concrete Structures. John Wiley \& Sons, Inc., New York, N.Y.

Paulay, T. 1978. "A Consideration of P-Delta Effects in Ductile Reinforced Concrete Frame." Pp. 151-60 in Bulletin of the New Zealand national society for earthquake engineering 11.3.

Paulay, Thomas and MJN Priestley. 1992. Seismic Design of Reinforced Concrete and Masonry Buildings. John Wiley \& Sons, Inc., New York, N.Y.

Paultre, Patrick, Frédéric Légeron, and Daniel Mongeau. 2001. "Influence of Concrete Strength and Transverse Reinforcement Yield Strength on Behavior of HighStrength Concrete Columns.” ACI Structural Journal 98(4):490-501.

Pettinga, Didier and Nigel Priestley. 2007. Accounting for P-Delta Effects in Structures When Using Direct Displacement-Based Design. Pavia, Italy: IUSS Press. 
Pham, Thong M., Le V. Doan, and Muhammad N. S. Hadi. 2013. "Strengthening Square Reinforced Concrete Columns by Circularisation and FRP Confinement." Construction and Building Materials 49:490-99.

Popov, E. 1990. Engineering Mechanics of Solids. Englewood Cliffs, NJ: Prentice Hall, Inc.

Popovics, Sandor. 1973. "A Numerical Approach to the Complete Stress-Strain Curve of Concrete." Cement and Concrete Research 3(5):583-99.

Powell, Graham H. 2008. "Displacement-Based Seismic Design of Structures." Earthquake Spectra 24(2):555-57.

Priestley, M J Nigel. , Verma, Ravindra., Xiao, Yan. and By M. J.Nigel Priestley. 1994. "Seismic Shear Strength of Reinforced Concrete Columns." Journal of Structural Engineering 120(8):2310-29.

Priestley, Michael J. N; Seible, F; and Calvi, G. M. 1996. Seismic Design and Retrofit of Bridges. John Wiley \&Sons, Inc.

Priestley, By M. J.Nigel. 1995. "Seismic Shear Strength of Reinforced Concrete Columns.” Journal of Structural Engineering 120(8):2310-29.

Priestley, M. J. N. 2000. "Performance Based Seismic Design." Pp. 1-22 in 12th World Conference on Earthquake Engineering. Vol. 1. Auckland, New Zeland.

Priestley, M. J. N. and F. Seible. 1995. "Design of Seismic Retrofit Measures for Concrete and Masonry Structures." Construction and Building Materials 9(6):36577.

Priestley, Mjn and R. Park. 1987. "Strength and Ductility of Concrete Bridge Columns under Seismic Loading.” ACI Structural Journal (84):61-76.

Rangan, B.Vijaya. 1989. "Lateral Deflection of Slender Reinforced Concrete Columns under Sustained Load." ACI Structural Journal 86(6):660-63.

Raynor, Dan J., Dawn E. Lehman, and John F. Stanton. 2002. "Bond-Slip Response of Reinforcing Bars Grouted in Ducts." ACI Structural Journal 99(5):568-76.

Realfonzo, R. and A. Napoli. 2009. "Cyclic Behavior of RC Columns Strengthened by FRP and Steel Devices.” Journal of Structural Engineering 135(10):1164-76. 
Rey Castillo, Enrique, Michael Griffith, and Jason Ingham. 2018. "Seismic Behavior of RC Columns Flexurally Strengthened with FRP Sheets and FRP Anchors." Composite Structures 203(July):382-95.

Rocca, Silvia. 2007. "Experimental and Analytical Evaluation of FRP- Confined Large Size Reinforced Concrete Columns." Ph.D Thesis, University of Missouri- Rolla., Rolla, MO, USA.

Rocca, Silvia and Antonio Nanni. 2006. "Large-Size Reinforced Concrete Columns Strengthened With Carbon Frp : Validation of Existing Design Guidelines." Pp. 231-34 in Proc., Composites in Civil Engineering.

Saatcioglu, Murat. 1991. "Deformability of Reinforced Concrete Columns." Pp. 421-52 in Earthquake-Resistant Structures-Inelastic Response and Design, SP-127, American Concrete Institute. Vol. 127. Detroit, MI.

Saatcioglu, Murat and Darek Baingo. 1999. "Circulare High-Strength Concrete Columns under Simulated Seismic Loading.” Journal of Structural Engineering 125(March):272-80.

Saatcioglu, Murat and Salim R. Razvi. 2002. "Displacement-Based Design of Reinforced Concrete Columns for Confinement." ACI Structural Journal 99(1):3-11.

Sadeghian, P. and A. Fam. 2015. "Strengthening Slender Reinforced Concrete Columns Using High-Modulus Bonded Longitudinal Reinforcement for Buckling Control." Journal of Structural Engineering 141(4):1-9.

Sadone, R., Quiertant, M., Mercier, J., \&.Ferrier. 2012. "Experimental Study on RC Columns Retrofitted by FRP and Subjected to Seismic Loading." Pp. 1-9 in 6th International Conference on FRP Composites in Civil Engineering CICE. International Institute for Fiber-Reinforced Polymer (FRP) in Construction (IIFC), Rome.

Saeed, Yasir Matloob. 2016. "Behavior of Prestressed Concrete Beams with CFRP Strands." M.Sc. Thesis, Portland State University.

Salazar, W., B. Lyndon, and G. Mannette. 2013. "Probabilistic Seismic Hazard Assessment for Jamaica." Journal of Civil Engineering and Architecture 7(9(70)):1118-40. 
Saleemuddin, Mohd Zameeruddin Mohd and Keshav K. Sangle. 2017. "Seismic Damage Assessment of Reinforced Concrete Structure Using Non-Linear Static Analyses." KSCE Journal of Civil Engineering 21(4):1319-30.

Sause, Richard, Kent a Harries, Stephanie L. Walkup, Stephen Pessiki, and James M. Ricles. 2005. "Flexural Behavior of Concrete Columns Retrofitted with Carbon Fiber-Reinforced Polymer Jackets.” ACI Structural Journal (101):708-16.

Seible, Frieder, M. J.Nigel Priestley, Gilbert A. Hegemier, and Donato Innamorato. 1997. "Seismic Retrofit of RC Columns with Continuous Carbon Fiber Jackets." Journal of Composites for Construction 1(2):52-62.

Seyhan, Engin C., Caglar Goksu, Ahmet Uzunhasanoglu, and Alper Ilki. 2015. "Seismic Behavior of Substandard RC Columns Retrofitted with Embedded Aramid Fiber Reinforced Polymer (AFRP) Reinforcement.” Polymers 7(12):2535-57.

Sezen, H. and J. P. Moehle. 2004. "Shear Strength Model for Lightly Reinforced Concrete Columns." Journal of Structural Engineering 130(11):1692-1703.

Sezen, Halil and Jack P. Moehle. 2004. "Strength and Deformation Capacity of Reinforced Concrete Columns with Limited Ductility." in Proceedings of the 13th World Conference on Earthquake Engineering.

Sezen, Halil and Eric J. Setzler. 2008. "Reinforcement Slip in Reinforced Concrete Columns.” ACI Structural Journal 105(3):280-89.

Sharifi, Ashkan, Mahmoud Reza Banan, and Mohammad Reza Banan. 2012. "A StrainConsistent Approach for Determination of Bounds of Ductility Damage Index for Different Performance Levels for Seismic Design of RC Frame Members.” Engineering Structures 37:143-51.

Shehata, I. A. E. M., V. Carneiro, and C. D. Shehata. 2001. "Strength of Short Concrete Columns Confined with CFRP Sheets." Materials and Structures 35(245):50-58.

Sheikh, Shamim A. and Yimin Li. 2007. "Design of FRP Confinement for Square Concrete Columns.” Engineering Structures 29(6):1074-83.

Sichko, Alexander and Halil Sezen. 2017. "Review of Methods for Reinforced Concrete Column Retrofit." in Fourth Conference on Smart Monitoring, Assessment and Rehablitaion of Civil Structures. 
Silva, Pedro F. and Arash Sangtarashha. 2012. "P-Delta Effects in Limit State Design of Slender RC Bridge Columns." in 15th World Conference on Earthquake Engineering. Vol. 1. Lisbon, Portugal.

Sozen, M.A., Monteiro, P., Moehle, J.P. and Tang, H. T. 1992. "Effects of Cracking and Age on Stiffness of Reinforced Concrete Walls Resisting in-Plane Shear." Pp. 77785 in 4th Symposium on Current Issues Related to Nuclear Power Plant Structures, Equipment and Piping. Vol. 40. Orlando, Florida.

Srbulov, Milutin. 2011. "Simple Probabilistic Seismic Hazard Assessment." Ingegneria Sismica 28(4):9-14.

T. Nagy-György, M. Moşoarcă, V. Stoian, J. Gergely, D.Dan. 2005. "Retrofit of Reinforced Concrete Shear Walls With CFRP Composites." Pp. 897-902 in Proceedings of the Fib Symposium, Publishing Company of Budapest University of Technology and Economics. Vol. 2. Budapest, Hungary.

Teng, J. G., Y. L. Huang, L. Lam, and L. P. Ye. 2007. "Theoretical Model for FiberReinforced Polymer-Confined Concrete." Journal of Composites for Construction 11(2):201-10.

Teng, J. G., J. Y. Lu, and Q. G. Xiao. 2011. "Numerical Simulation of FRP-Jacketed RC Columns Subjected to Cyclic Loading." Advances in FRP Composites in Civil Engineering - Proceedings of the 5th International Conference on FRP Composites in Civil Engineering, CICE 2010 20(2009):820-23.

Truong, Gia Toai, Jong Chan Kim, and Kyoung Kyu Choi. 2017. "Seismic Performance of Reinforced Concrete Columns Retrofitted by Various Methods." Engineering Structures 134:217-35.

Turgay, T., Z. Polat, H. O. Koksal, B. Doran, and C. Karakoç. 2010. "Compressive Behavior of Large-Scale Square Reinforced Concrete Columns Confined with Carbon Fiber Reinforced Polymer Jackets." Materials and Design 31(1):357-64.

Vrettos, Ioannis, Efstathia Kefala, and Thanasis C. Triantafillou. 2013. "Innovative Flexural Strengthening Of Reinforced Concrete Columns Using Carbon-Fiber Anchors.” ACI Structural Journal (110).

Wang, D. Y., Z. Y. Wang, S. T. Smith, and T. Yu. 2016. "Size Effect on Axial StressStrain Behavior of CFRP-Confined Square Concrete Columns." Construction and Building Materials 118:116-26. 
Wang, Lei Ming and Yu Fei Wu. 2008. "Effect of Corner Radius on the Performance of CFRP-Confined Square Concrete Columns: Test." Engineering Structures 30(2):493-505.

Wang, Yuan-feng and Han-liang Wu. 2010. "Size Effect of Concrete Short Columns Confined with Aramid FRP Jackets." Journal of Composites for Construction 15(August):535-45.

Wang, Zhen Yu, Dai Yu Wang, and Da Gang Lu. 2010. "Behavior of Large-Scale Circular and Square RC Columns Confined with Carbon Fiber-Reinforced Polymer under Uniaxial Compression." Advanced Materials Research 163-167:3686-93.

Wang, Zhenyu and Scott Thomas Smith. 2012. "Size Effect of Square Concrete Columns Confined with CFRP Wraps." in Proceedings of the 3rd Asia-Pacific Conference on FRP in Structures, Hokkaido University. Sapporo, Japan.

Wang, Zhenyu, Daiyu Wang, Scott T. Smith, and Dagang Lu. 2012a. "CFRP-Confined Square RC Columns. I: Experimental Investigation.” Journal of Composites for Construction 16(2):150-60.

Wang, Zhenyu, Daiyu Wang, Scott T. Smith, and Dagang Lu. 2012b. "CFRP-Confined Square RC Columns. II: Cyclic Axial Compression Stress-Strain Model.” Journal of Composites for Construction 16(2):161-70.

Wong, Yuk Lung, T. Paulay, and M. J.Nigel Priestley. 1993. "Response of Circular Reinforced Concrete Columns to Multi-Directional Seismic Attack." ACI Structural Journal 90(2):180-91.

Wu, YF, Tao Liu, and DJ Oehlers. 2006. "Fundamental Principles That Govern Retrofitting of Reinforced Concrete Columns by Steel and FRP Jacketing." Advances in Structural Engineering 9(4):507-34.

Wu, YF, Tao Liu, and Leiming Wang. 2008. "Experimental Investigation on Seismic Retrofitting of Square RC Columns by Carbon FRP Sheet Confinement Combined with Transverse Short Glass FRP Bars in Bored." Journal of Composites for Construction 12(February):53-60.

Wu, Yu-fei and Ying-wu Zhou. 2010. "Unified Strength Model Based on Hoek-Brown Failure Criterion for Circular and Square Concrete Columns Confined by FRP." Composits for Constructio 14(April):175-84. 
Wu, Yu Fei and You Yi Wei. 2010. "Effect of Cross-Sectional Aspect Ratio on the Strength of CFRP-Confined Rectangular Concrete Columns." Engineering Structures 32(1):32-45.

Yalcin, Cem, Osman Kaya, and Mustafa Sinangil. 2008. "Seismic Retrofitting of R/C Columns Having Plain Rebars Using CFRP Sheets for Improved Strength and Ductility." Construction and Building Materials 22(3):295-307.

Yan, Zihan, Chris P. Pantelides, and Lawrence D. Reaveley. 2006. “Fiber-Reinforced Polymer Jacketed and Shape-Modified Compression Members: I - Experimental Behavior." ACI Structural Journal 103(6):885-93.

Yaseen, Abdulhameed Abdullah, David Begg, and Nikos Nanos. 2015. "Seismic Fragility Assessment of Low-Rise Unreinforced Masonry Buildings in the Kurdistan Region of Iraq." International Journal of Structural Analysis \& Design-IJSAD 2(1):2372-4102.

Ying, Ma and Gong Jin-Xin. 2018. "Seismic Failure Modes and Deformation Capacity of Reinforced Concrete Columns under Cyclic Loads.” Periodica Polytechnica Civil Engineering 62(1):80-91.

Yosefani, Anas. 2018. "Flexural Strength, Ductility, and Serviceability of Beams That Contain High-Strength Steel Reinforcement and High-Grade Concrete.” Ph.D. Thesis, Portland State University.

Youssef, Marwan N., Maria Q. Feng, and Ayman S. Mosallam. 2007. "Stress-Strain Model for Concrete Confined by FRP Composites." Composites Part B: Engineering 38(5-6):614-28.

Yu, T., B. Zhang, and J. G. Teng. 2015. "Unified Cyclic Stress-Strain Model for Normal and High Strength Concrete Confined with FRP." Engineering Structures 102:189201.

Yuan, Fang, Yu Fei Wu, and Chun Qing Li. 2017. "Modelling Plastic Hinge of FRPConfined RC Columns.” Engineering Structures 131:651-68.

Yue, Jianguang, Jiang Qian, and Dimitri E. Beskos. 2016. "A Generalized Multi-Level Seismic Damage Model for RC Framed Structures." Soil Dynamics and Earthquake Engineering 80:25-39. 
Zafra, Richelle Gallardo and Kazuhiko Kawashima. 2008. "Analysis of Carbon Fiber Sheet Retrofitted RC Bridge Columns." Pp. 1-8 in 14th World Conference on Earthquake Engineering. Beijing, China.

Zerkane, A. S. H., Saeed, Y. M., \& Rad, F. N. 2019. "Cyclic Loading Behavior of CFRPWrapped Non-Ductile Beam-Column Joints." ACI Special Publication, 331(3), 3454. 